\title{
Investigação geofísica e resistência ao cisalhamento de resíduos sólidos urbanos de diferentes idades
}

Tese apresentada à Escola de Engenharia de São Carlos da Universidade de São Paulo, como parte dos requisitos para obtenção do título de Doutor em Ciências, programa de Pósgraduação em Geotecnia.

Versão corrigida.

Original encontra-se disponível na Unidade que aloja o Programa.

Orientador:

Prof. Dr. Orencio Monje Vilar

São Carlos 
AUTORIZO A REPRODUÇÃO TOTAL OU PARCIAL DESTE TRABALHO, POR QUALQUER MEIO CONVENCIONAL OU ELETRÔNICO, PARA FINS DE ESTUDO E PESQUISA, DESDE QUE CITADA A FONTE.

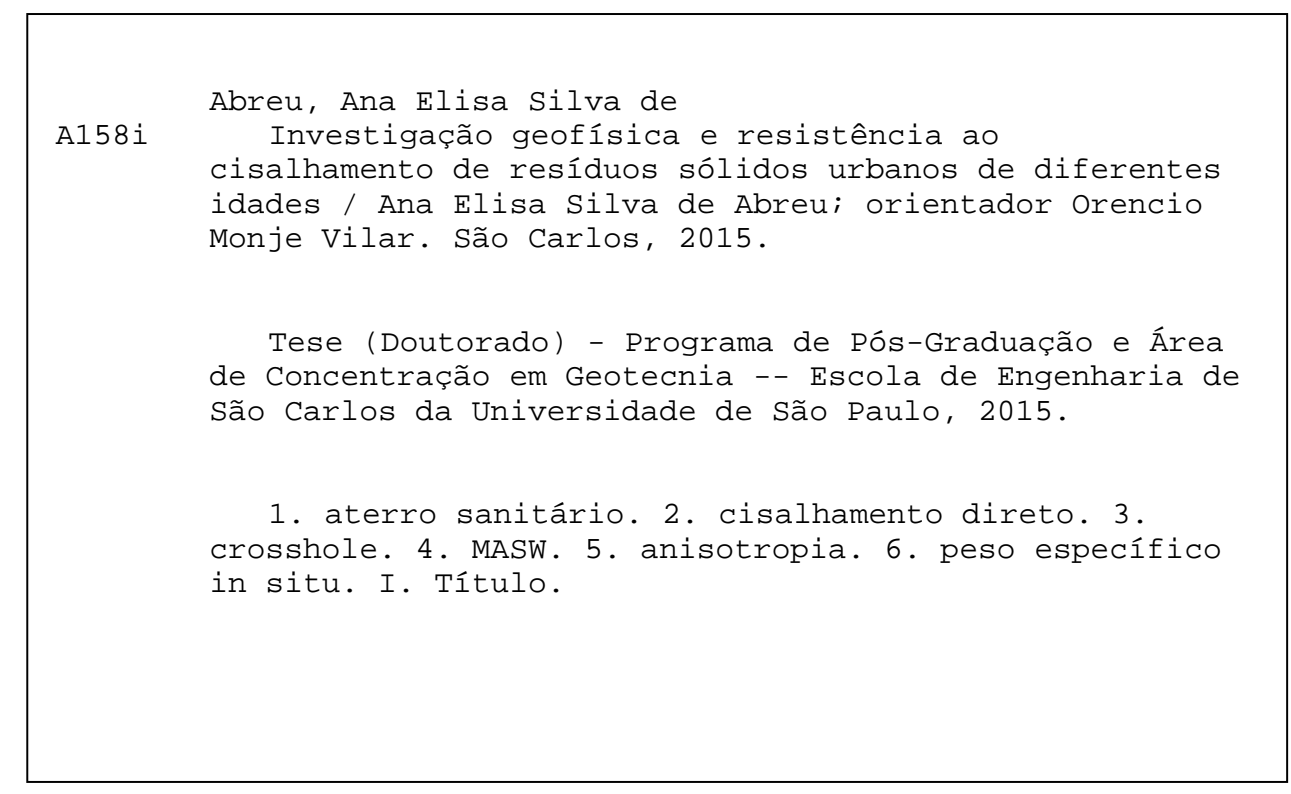




\section{FOLHA DE JULGAMENTO}

Candidata: Engenheira ANA ELISA SILVA DE ABREU.

Título da Tese: "Investigação geofísica e resistência ao cisalhamento de resíduos sólidos urbanos de diferentes idades".

Data da defesa: 08/05/2015

Comissão Julgadora:

Resultado:

Prof. Titular Orencio Monje Vilar (Orientador)

APROVADA

(Escola de Engenharia de São Carlos/EESC)

Prof. Dr. Gustavo Ferreira Simões

(Universidade Federal de Minas Gerais/UFMG)

Profa. Dra. Miriam de Fátima Carvalho

(Universidade Católica do Salvador/UCSAL)

Prof. Dr. Heraldo Luiz Giachetti

(Universidade Estadual Paulista "Júlio de Mesquita Filho"/UNESP - Bauru)

Profa. Dra. Miriam Gonçalves Miguel

(Universidade Estadual de Campinas/UNICAMP)

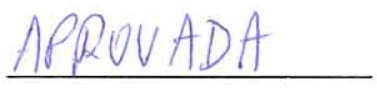

Coordenador do Programa de Pós-Graduação em Geotecnia:

Prof. Dr. Edmundo Rogério Esquivel

Presidente da Comissão de Pós-Graduação:

Prof. Associado Paulo César Lima Segantine 
Dedico ao Luiz Guilherme, ao Felipe e ao Rafael 


\section{AGRADECIMENTOS}

Agradeço ao professor Orencio Monje Vilar, por ter aceitado fazer parte desta empreitada. Aos professores Valdir Schalch e Luiz Antonio Daniel, por terem cedido áreas que estão sob sua responsabilidade para armazenamento das amostras e realização de ensaios.

Ao Alexandre Ferrari, ao Thiago Zanon, ao Wanderley Scudilio Junior, ao Wagner Ribeiro e ao Leonardo Parize, por terem permitido a realização da pesquisa no Aterro Sanitário de São Carlos e por terem fornecido dados técnicos e apoio durante a realização dos trabalhos de campo, guarda e transporte de amostras. Agradeço ao Sr. Alvaro, por ter nos autorizado a retirar uma amostra no Aterro Experimental.

Sou grata à Marjolly, ao Leandro, ao professor Edson Wendland e sua equipe, por terem coletado a amostra no Lixão Desativado de São Carlos.

Aos técnicos Oscar dos Santos Neto, José Luiz Guerra, Benedito Osvaldo de Souza e Clever Valentin, pelas discussões técnicas, sugestões e, principalmente, por terem me ajudado em tantos momentos em que precisamos "colocar a mão na massa". À Maristela, Neiva, Álvaro e Herivelton, pelo apoio com vários assuntos do dia-a-dia.

Também sou grata ao Ademar Maranesi, ao Douglas Alves, ao Rodrigo Souza, ao Marcelo Celestino e ao Sr Armando dos Santos, que me ajudaram nas etapas em que o serviço era mais cansativo. Ao Walter, Manu, Jorge, Marquinhos e Francisco, por terem carregado alguns baldes de brita e de resíduos lá no aterro.

Agradeço ao Camilo, ao Rômulo, ao Bruno, ao Breno, ao Oscar, ao João, ao Chris e ao Roberto, que transportaram a estufa de um lugar para outro. Ao Roberto Cuiabá, que apareceu para me apoiar, quando realmente precisei. À Giovana, ao Oscar, à Mariana e à Marjolly pela disposição para discutirmos aspectos técnicos e, principalmente, pelo companheirismo.

Aos professores Heraldo Giacheti e Miriam Miguel, pelas observações que fizeram no Exame de Qualificação e ao Otávio Gandolfo, pelo entusiasmo em aplicar os métodos geofísicos sísmicos em aterro sanitário.

Agradeço à Tatiana Corrêa, ao Rodrigo Córdoba, à Sônia Almeida, à professora Marisa Crespi, ao professor Jorge Hamada, ao Julio e ao Paulo, do Laboratório de Saneamento, que me ajudaram a decidir quais ensaios físico-químicos e biológicos seriam adequados para caracterização dos resíduos. Ao Gilmar Barreto por ter me explicado uma série de aspectos sobre o funcionamento mecânico de equipamentos de ensaio. À professora Miriam Carvalho, por ter me explicado tantos detalhes do trabalho que desenvolveu na década de 1990 e à Thelma, ao Francisco, ao Cyro e ao Julio, por todas as bibliografias que escanearam e me enviaram por e-mail.

Finalmente, agradeço ao CNPq e à FAPESP, por terem financiado a pesquisa. 


\section{RESUMO}

ABREU, A.E.S. Investigação geofísica e resistência ao cisalhamento de resíduos sólidos urbanos de diferentes idades. 2015. 232 f. Tese (Doutorado) - Escola de Engenharia de São Carlos, Universidade de São Paulo, São Carlos, 2015.

Este trabalho apresenta a caracterização in situ de propriedades de interesse geotécnico de maciços de resíduos sólidos urbanos (RSU) e o estudo das propriedades de resistência ao cisalhamento de RSU com diferentes idades. Foram realizadas investigações por sondagens e com métodos geofísicos sísmicos no Aterro Sanitário de São Carlos (ASSC) e ensaios de cisalhamento direto de grandes dimensões $\left(50 \times 50 \mathrm{~cm}^{2}\right)$ com amostras de diferentes idades de aterramento coletadas no ASSC, no Lixão Desativado de São Carlos e em Aterro Experimental construído nas proximidades do Lixão. As investigações realizadas no ASSC revelaram que as diferentes fases de operação do maciço (aterro controlado e aterro sanitário) produziram dois estratos com diferentes propriedades geotécnicas. A umidade, as velocidades de propagação de ondas sísmicas e o peso específico in situ dos dois estratos são distintos, sendo sempre menores e menos dispersos no estrato mais raso (operado como aterro sanitário) e maiores e mais dispersos no estrato mais profundo (operado como aterro controlado). Realizaram-se tentativas de determinação do peso específico in situ dos RSU com medição dos volumes escavados por substituição de volume. Notou-se que os furos tendiam a diminuir de diâmetro assim que a composição de sondagem era retirada e que o método adotado para avanço dos furos, com trado helicoidal de haste oca, promovia segregação dos componentes atravessados, realizando uma amostragem parcial dos mesmos. Foram calculados valores médios de peso específico in situ para o maciço investigado ( 9 a $15 \mathrm{kN} / \mathrm{m}^{3}$ ) e identificadas as principais limitações da aplicação deste método a aterros sanitários. A aplicação de métodos geofísicos sísmicos foi fundamental para a diferenciação dos dois estratos e permitiu que se calculasse o módulo de cisalhamento máximo $\left(\mathrm{G}_{\mathrm{o}}\right)$ dos resíduos, que variou significativamente de um estrato para outro. Foi possível comparar os resultados obtidos com a aplicação do método crosshole e do método multichannel analysis of surface waves (MASW) no mesmo aterro sanitário. A caracterização das seis amostras utilizadas nos ensaios de cisalhamento direto revelou que, apesar de elas representarem idades distintas de disposição dos resíduos (2 a 25 anos) e condições de aterramento variadas (formas de operação dos depósitos, ambientes de decomposição e condições de confinamento), a maioria delas se encontrava em estágio avançado de degradação (fase metanogênica) e apenas a mais recente ( 2 anos de aterramento) encontrava-se em estágio um pouco menos avançado de 
degradação (início da fase metanogênica). Todas elas exibiram curvas tensão-deslocamento semelhantes, sem pico ou valor de máxima resistência bem caracterizados. Os parâmetros de resistência ao cisalhamento foram obtidos a partir de níveis específicos de deslocamento. Avaliou-se a influência da amostragem, dos procedimentos de preparação das amostras e da composição gravimétrica de cada uma delas sobre os valores calculados para coesão e ângulo de atrito. Para deslocamentos de $100 \mathrm{~mm}$ o resíduo aterrado há dois anos apresentou coesão de $13,7 \mathrm{kPa}$ e ângulo de atrito de $22^{\circ}$. Os resíduos mais degradados, com idades de disposição entre 5 e 25 anos, apresentaram coesão de $4,4 \mathrm{kPa}$ e ângulo de atrito de $30^{\circ}$. Utilizaram-se tensões normais de 50,150 e $250 \mathrm{kPa}$. Realizaram-se ainda ensaios de cisalhamento direto de grandes dimensões em uma das amostras com corpos de prova em duas posições: paralela e perpendicular à direção de compactação. Os resultados confirmaram que os RSU têm comportamento anisotrópico, sendo que os corpos de prova ensaiados com os componentes alinhados preferencialmente na posição vertical (rotacionados) têm comportamento de endurecimento ainda mais pronunciado que aqueles ensaiados com os componentes orientados preferencialmente no plano horizontal.

Palavras-chave: aterro sanitário, cisalhamento direto, crosshole, MASW, anisotropia, peso específico in situ. 


\section{ABSTRACT}

ABREU, A.E.S. Geophysical investigation and shear strength of municipal solid wastes with different landfilling ages. 2015. 232f. Ph.D. Dissertation - Escola de Engenharia de São Carlos, Universidade de São Paulo, São Carlos, 2015.

Field and laboratory tests were combined to characterize some in-place geotechnical properties of the waste body in the São Carlos Sanitary Landfill (SCSL). The investigation was carried out using hollow stem auger soundings and seismic geophysical methods in the field, and large-scale direct shear testing in the laboratory. The field investigation revealed two strata with different geotechnical properties and they could be related to the different operational phases of the landfill (controlled landfill and sanitary landfill). Moisture content, seismic wave velocities and in-place unit weight were systematically lower and less scattered in the upper stratum than in the lower stratum. The upper stratum was operated as a sanitary landfill and the lower stratum was operated as a controlled landfill. The investigations with geophysical seismic methods were essential for identifying the two strata and allowed for the calculation of the Poisson ratio and the small strain shear modulus $\left(G_{0}\right)$ of the waste body. The Poisson ratio showed no sensibility to the waste stratigraphy, but $G_{o}$ values were significantly higher in the lower stratum. Moreover, the results of two different geophysical methods, namely crosshole and multichannel analysis of surface waves (MASW), could be compared. An attempt was made to estimate overboring using a volume substitution method by filling the boreholes with gravel. This aimed at incorporating this aspect in the calculations of the MSW in-place unit weight. Nevertheless, the borings tended to cave in as soon as the augers were removed and this prevented the evaluation of the overboring. Moreover, the hollow stem auger tended to segregate the larger components of the waste and to bring only the smaller ones to the surface. Despite all these difficulties, average values for the MSW inplace unit weight were be calculated $\left(9\right.$ to $15 \mathrm{kN} / \mathrm{m}^{3}$ ). In the laboratory, large-scale direct shear tests $\left(500 \times 500 \mathrm{~mm}^{2}\right)$ were performed to provide an insight on the shear strength response of municipal solid waste (MSW) of different landfilling ages. The test samples were collected from the SCSL, a dumpsite and an experimental landfill. Their landfilling ages ranged from 2 to 25 years. Physico-chemical characterization of the samples revealed that most of them were subjected to the metanogenesis degradation phase, in spite of their different landfilling ages and burial conditions (operational characteristics of the deposits, decomposition environment and confining pressures). Only the newest one (2 years old sample) was subjected to an earlier stage of degradation. In the direct shear tests, all samples 
showed similar stress-strain curves, with continuous strain hardening and no identifiable maximum stress, despite the large displacements. The influence of sampling method, sample preparation and sample gravimetric composition on the calculated shear resistance parameters is discussed. For a $100-\mathrm{mm}$ displacement the shear resistance of the less degraded waste (2 years of landfilling) is best characterized by cohesion $=13.7 \mathrm{kPa}$ and friction angle $=22^{\circ}$. The more degraded wastes ( 5 to 25 years old samples) are best characterized by cohesion $=4.4$ $\mathrm{kPa}$ and friction angle $=30^{\circ}$. The tests were performed with initial normal stresses of 50,150 and $250 \mathrm{kPa}$. Specific large direct shear tests were performed to evaluate anisotropy in the MSW shear response. The test samples had the fibrous materials oriented perpendicular or parallel to the horizontal shear surface. Results confirmed the expected anisotropy by showing a hardening behaviour that was more pronounced when the fibrous materials were oriented perpendicular to the shear plan.

Key-words: sanitary landfill, direct shear testing, crosshole, MASW, anisotropy, in-place MSW unit weight. 


\title{
LISTA DE ABREVIAÇÕES
}

\author{
ABNT $=$ Associação Brasileira de Normas Técnicas \\ ASSC $=$ aterro sanitário de São Carlos \\ ASTM $=$ American Society for Testing and Materials \\ $\mathrm{BMP}=$ Potencial Bioquímico de Metano \\ $\mathrm{C}=$ celulose
}

CEMPRE $=$ Compromisso Empresarial para Reciclagem

$\mathrm{CD}=$ consolidado drenado (tipo de ensaio)

$\mathrm{CH}=$ crosshole (tipo de ensaio geofísico)

$\mathrm{CI}=$ compressão isotrópica (tipo de ensaio)

CLP $=$ controlador lógico programável

$\mathrm{COD}=$ carbono orgânico dissolvido

COT $=$ conteúdo de carbono orgânico total

$\mathrm{CP}=$ corpo de prova

$\mathrm{CSW}=$ ondas superficiais contínuas

$\mathrm{CU}=$ consolidado não-drenado (tipo de ensaio)

$\mathrm{DH}=$ downhole (tipo de ensaio geofísico)

$\mathrm{DQO}=$ demanda química de oxigênio

$\mathrm{DBO}=$ demanda bioquímica de oxigênio

DPSH = ensaio de cravação dinâmica de penetrômetro super pesado

EESC-USP = Escola de Engenharia de São Carlos da Universidade de São Paulo

$\mathrm{EN}=$ norma européia

EUA $=$ Estados Unidos da América

FIPAI = Fundação para o Incremento da Pesquisa e do Aperfeiçoamento Industrial

$\mathrm{H}=$ hemicelulose

HBM = modelos hidro-bio-mecânicos acoplados

IBGE $=$ Instituto Brasileiro de Geografia e Estatística

IDHM = Índice de Desenvolvimento Humano Municipal

IPT $=$ Instituto de Pesquisas Tecnológicas do Estado de São Paulo

$\mathrm{L}=$ lignina

MASW = método de análise de ondas superficiais por multicanais

$\mathrm{MBT}$ = tratamento mecânico e biológico de resíduos sólidos urbanos

$\mathrm{NBR}=$ norma brasileira 
$\mathrm{NM}=$ não mencionado

NTK $=$ nitrogênio total Kjeldahl

PEAD $=$ Polietileno de alta densidade

$\mathrm{PIB}=$ Produto interno bruto

PMSC $=$ Prefeitura Municipal de São Carlos

PNRS = Política Nacional de Resíduos Sólidos

RSU $=$ Resíduo sólido urbano

SASW = análise espectral de ondas superficiais

SDMT = dilatômetro de Marcheti com módulo sísmico

SISNAMA $=$ Sistema Nacional do Meio Ambiente

$\mathrm{SL}=$ suspension logging (tipo de ensaio geofísico)

SNVS = Sistema Nacional de Vigilância Sanitária

SPT $=$ ensaio de penetração dinâmica convencional (standard penetration test)

$\mathrm{STV}=$ sólidos totais voláteis

$\mathrm{TAC}=$ termo de ajustamento de conduta

$\mathrm{TN}=$ tensão normal $(\mathrm{kPa})$

UTM = Universal Transversa de Mercator (sistema de projeção)

$\mathrm{UU}=$ não-consolidado não-drenado (tipo de ensaio) 


\section{LISTA DE SÍMBOLOS}

$\alpha=$ parâmetro de modelagem (equação 3.1) $\left(\mathrm{m}^{4} / \mathrm{kN}\right.$ )

$\alpha_{\mathrm{vs}}=$ coeficiente empírico alpha (usado na equação 3.5)

$\beta=$ parâmetro de modelagem (equação 3.1) $\left(\mathrm{m}^{3} / \mathrm{kN}\right.$ )

$\beta_{\mathrm{vs}}=$ coeficiente empírico beta (usado na equação 3.5)

$\mathrm{B}=$ módulo de elasticidade volumétrico (MPa)

$\mathrm{c}=$ coesão $(\mathrm{kPa})$

$\mathrm{C} \alpha \varepsilon=$ coeficiente de adensamento secundário

$\mathrm{CH}_{4}=$ gás metano

$\mathrm{CO}_{2}=$ gás carbônico

$\Delta \varphi=$ variação do ângulo de atrito (graus)

$\mathrm{D}_{\mathrm{R}}=$ densidade relativa $(\%)$

$\mathrm{e}=$ índice de vazios

$\gamma=$ peso específico do maciço $\left(\mathrm{kN} / \mathrm{m}^{3}\right)$,

$\gamma_{\mathrm{i}}=$ peso específico in situ próximo à superfície $\left(\mathrm{kN} / \mathrm{m}^{3}\right)$,

$\mathrm{G}=$ modulo de cisalhamento (MPa)

$\mathrm{G}_{\mathrm{o}}=$ modulo de cisalhamento máximo $(\mathrm{MPa})$

$\mathrm{h}=$ altura do corpo de prova $(\mathrm{mm})$

$\mathrm{H}_{2} \mathrm{SO}_{4}=$ ácido sulfúrico

$\mathrm{K}=$ módulo volumétrico $(\mathrm{MPa})$

$\mathrm{Ko}=$ coeficiente de empuxo em repouso

$\mathrm{pH}=$ potencial hidrogeniônico do meio

$\phi$ ou $\varphi=$ ângulo de atrito (graus)

$\rho=$ massa específica $\left(\mathrm{g} / \mathrm{cm}^{3}\right)$

$\rho_{\mathrm{s}}=$ massa específica dos sólidos $\left(\mathrm{g} / \mathrm{cm}^{3}\right)$

$\sigma_{\mathrm{v}}=$ tensão normal $(\mathrm{kPa})$

$\mathrm{S}_{\mathrm{R}}=$ grau de saturação (\%)

$\mathrm{N}_{20}=$ resultados do ensaio de cravação dinâmica de penetrômetro super pesado (golpes)

$\mathrm{N}=$ nitrogênio

$\mathrm{N}_{\mathrm{i}}$ = número que expressa os resultados normalizados dos ensaios químicos e bioquímicos

$\mathrm{R}^{2}=$ coeficiente de correlação (\%)

$\tau=$ tensão de cisalhamento $(\mathrm{kPa})$

$v=$ coeficiente de Poisson 
$\mathrm{Vp}=$ velocidade de propagação das ondas compressionais $(\mathrm{m} / \mathrm{s})$

$\mathrm{V}_{\mathrm{R}}=$ velocidade de propagação das ondas superficiais do tipo Rayleigh $(\mathrm{m} / \mathrm{s})$

Vs = velocidade de propagação das ondas cisalhantes $(\mathrm{m} / \mathrm{s})$

$\mathrm{V}_{\mathrm{si}}=$ velocidade de propagação das ondas cisalhantes à superfície $(\mathrm{m} / \mathrm{s})$

$\mathrm{w}=$ umidade gravimétrica (base seca)

$\mathrm{z}=$ profundidade $(\mathrm{m})$

$\zeta=$ ângulo de tensão de tração (graus) 


\section{SUMÁRIO}

1. INTRODUÇÃ

1.1 Definição de Resíduos Sólidos Urbanos ......................................................................... 2

1.2 Definição de Lixão, Aterro Controlado e Aterro Sanitário................................................. 4

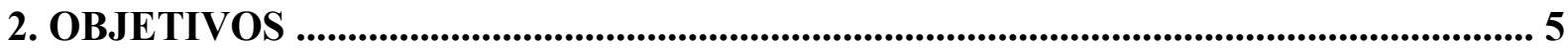

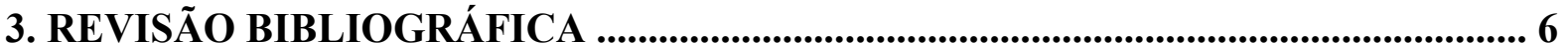

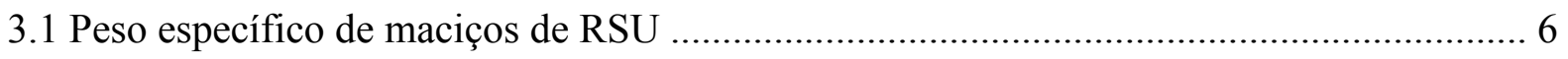

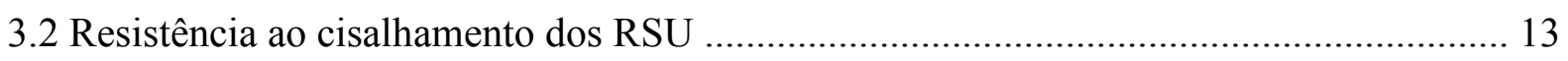

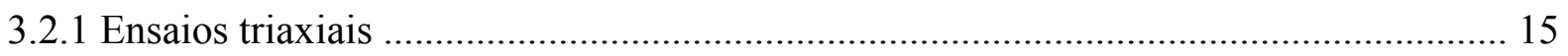

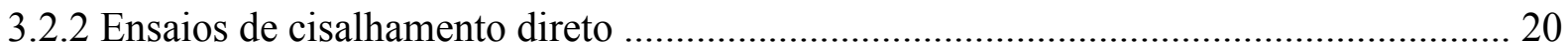

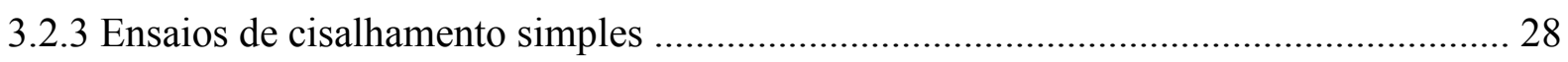

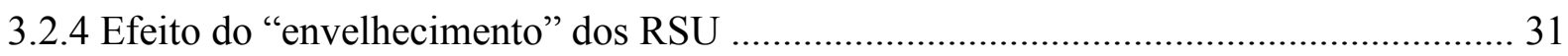

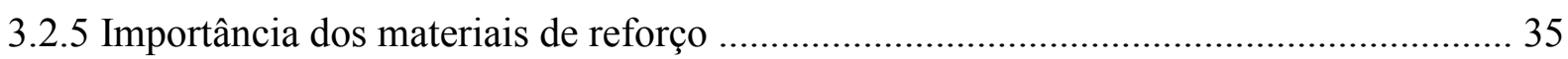

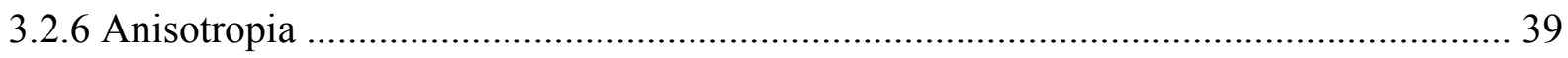

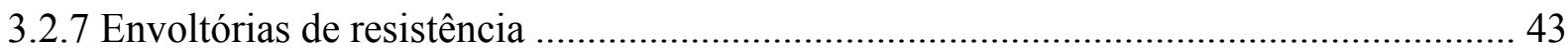

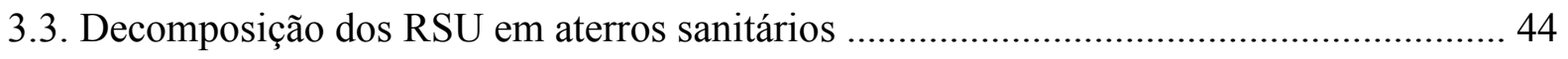

3.3.1 Ensaios para caracterização do estado de decomposição dos RSU .............................. 46

3.3.2 Composição gravimétrica dos resíduos sólidos urbanos ............................................ 48

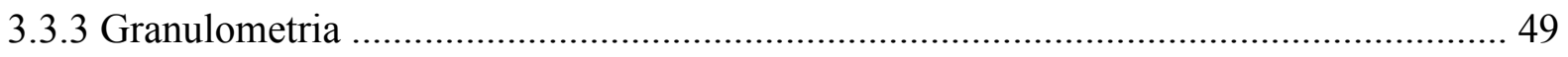

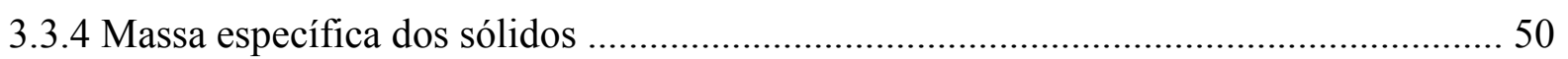

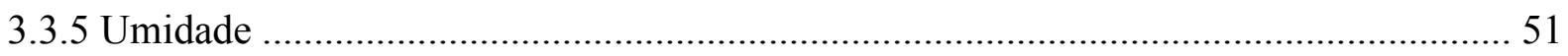

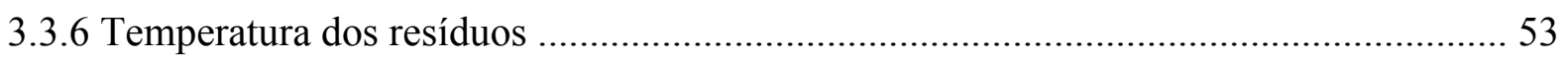

3.3.7 Ensaios para determinação do conteúdo de carbono orgânico ....................................... 55

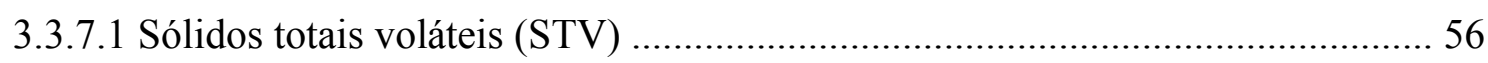

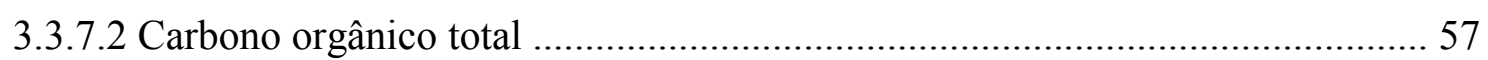

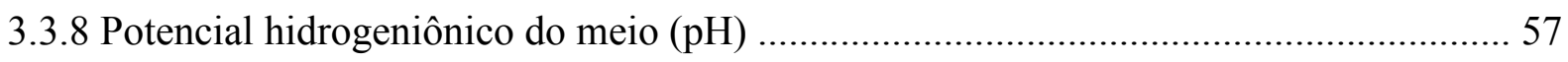

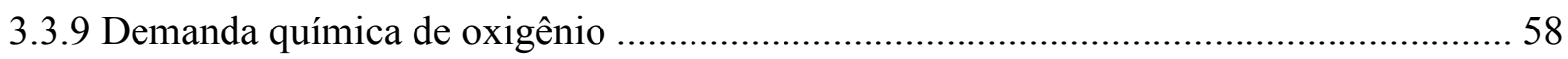

3.3.10 Concentração de celulose e razão de celulose+hemicelulose versus lignina ............... 59

3.3.11 Composição e volume dos gases emitidos pelos RSU ............................................... 60

3.3.12 Ensaio de biodegradação (ou Potencial Bioquímico de Metano) ................................ 61

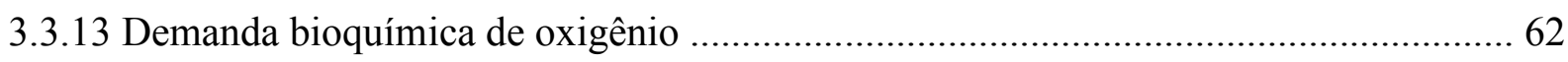

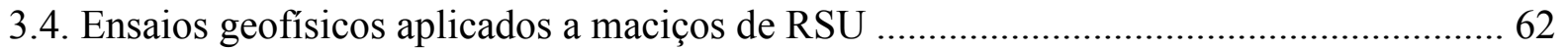

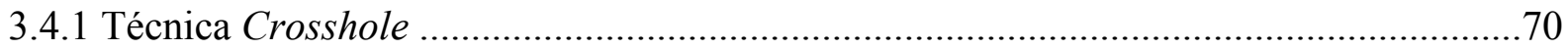

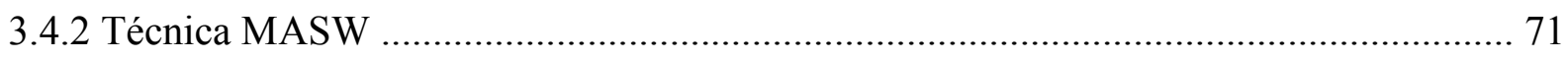




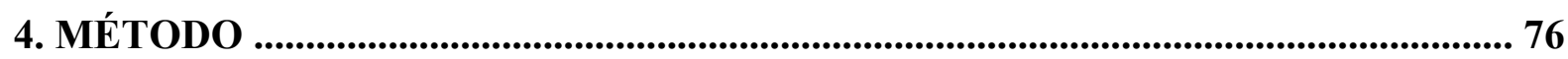

4.1 RSU na cidade de São Carlos de 1979 a 2013 ................................................................ 76

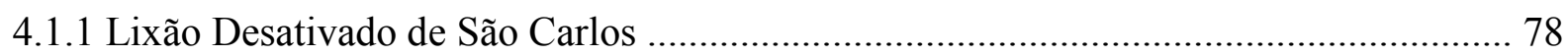

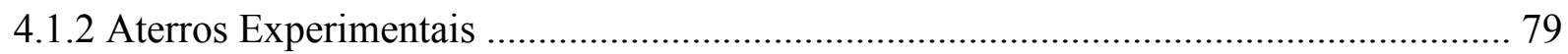

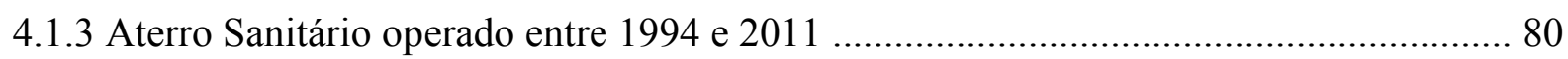

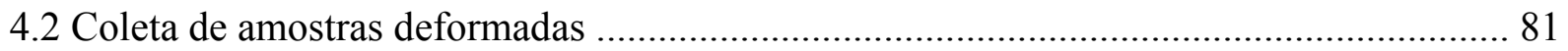

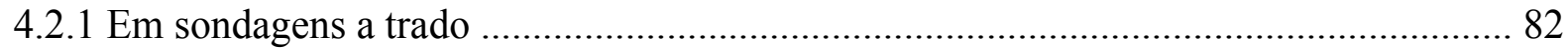

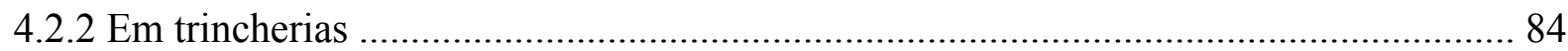

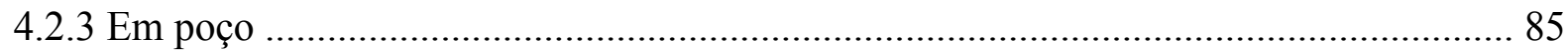

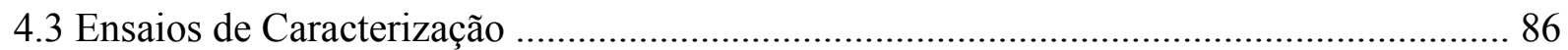

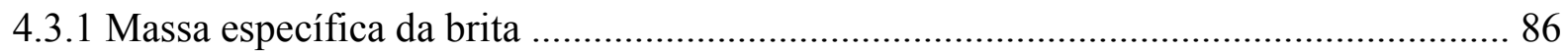

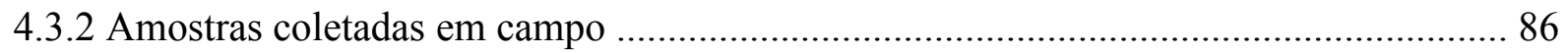

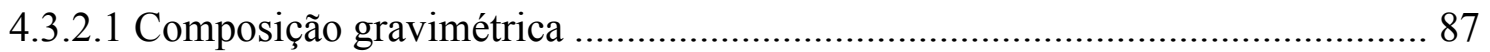

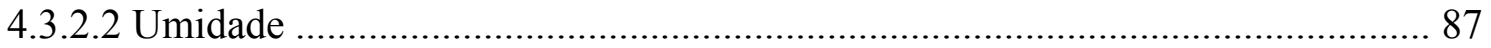

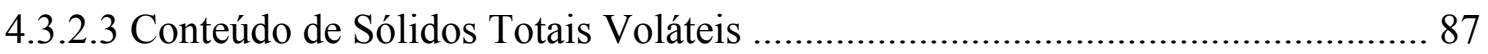

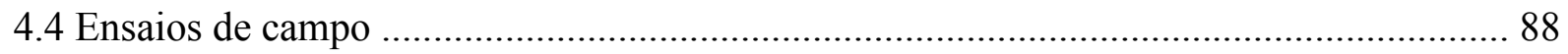

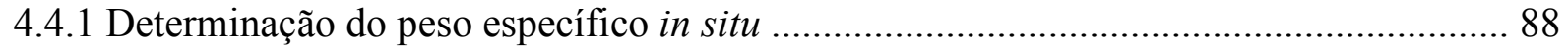

4.4.2 Determinação expedita do peso específico dos RSU à superfície ................................ 92

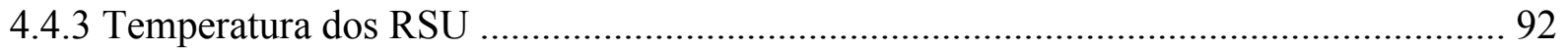

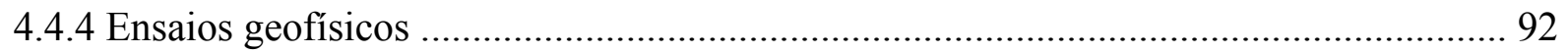

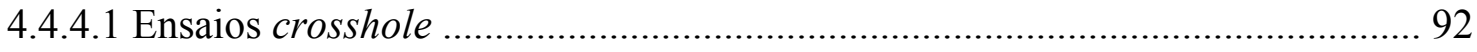

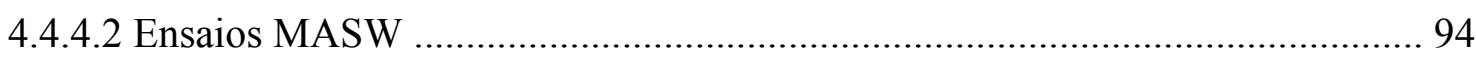

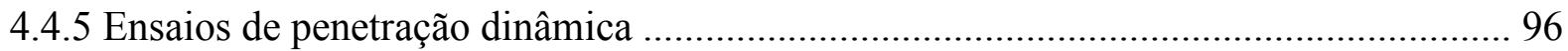

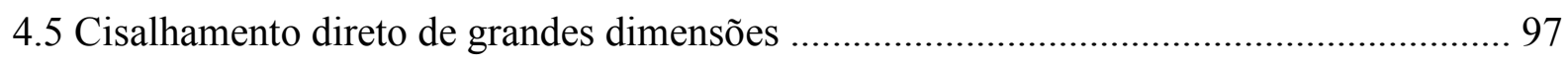

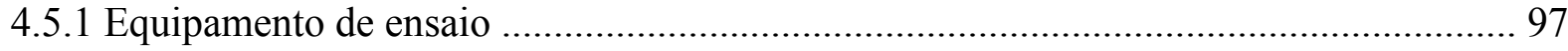

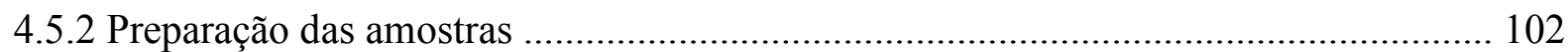

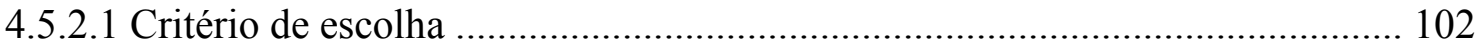

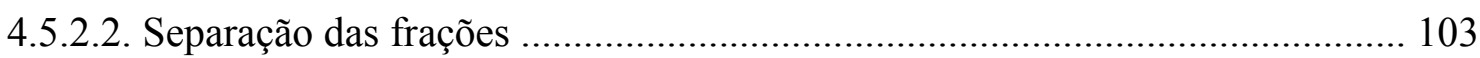

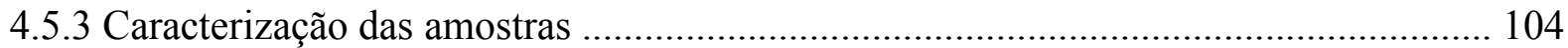

4.5.3.1 Caracterização química e bioquímica ........................................................... 104

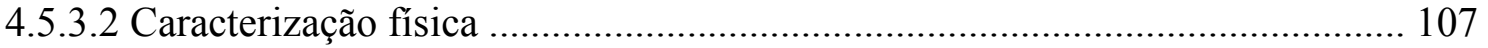

4.5.3.2.1 Composição gravimétrica ................................................................... 107

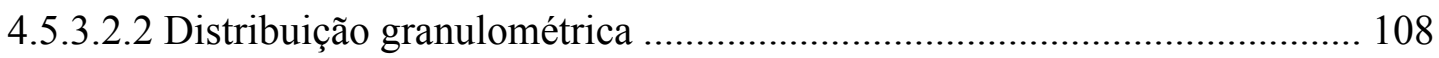

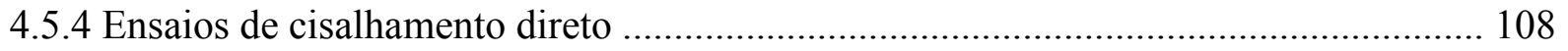

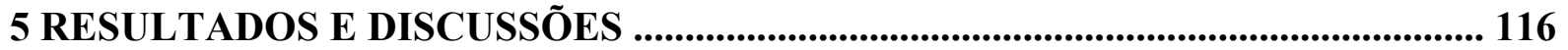

5.1 Caracterização geotécnica do maciço de resíduos ........................................................... 116

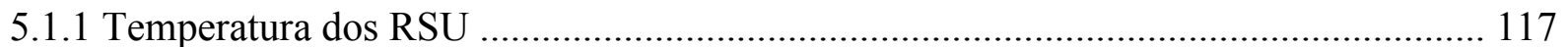




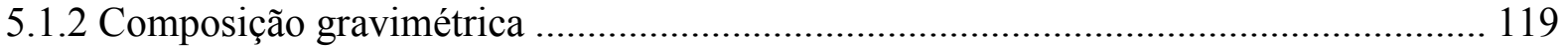

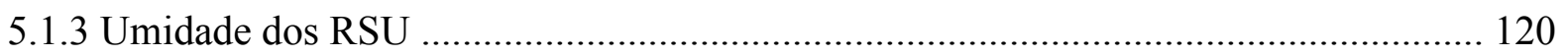

5.1.4 Conteúdo de Sólidos Totais Voláteis ………………............................................ 122

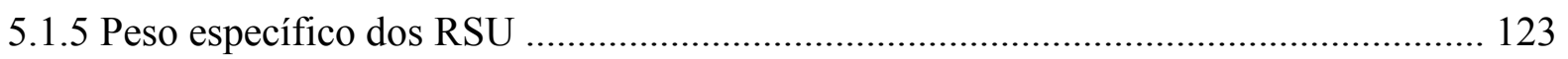

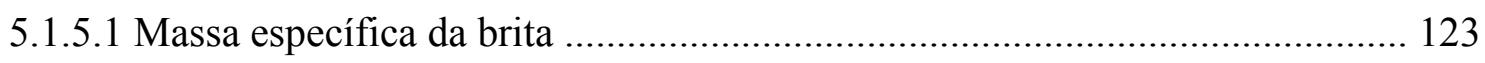

5.1.5.2 Pesos específicos expeditos determinados à superfície .................................... 123

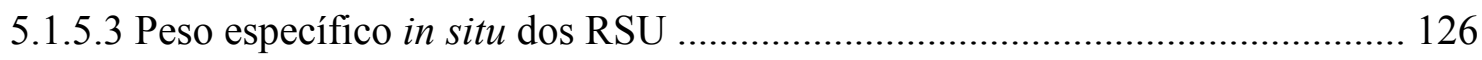

5.1.6 Ensaio de penetração dinâmica ................................................................................ 136

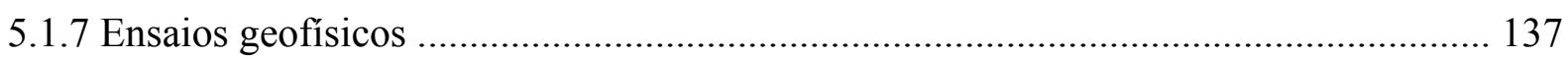

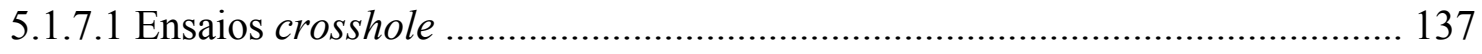

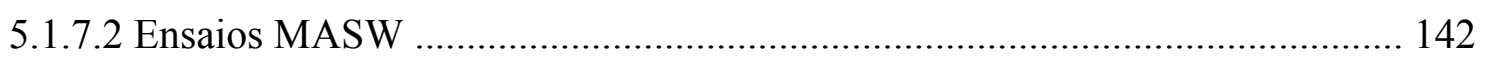

5.1.7.3 Perfil de Vs para o Aterro Sanitário de São Carlos .......................................... 144

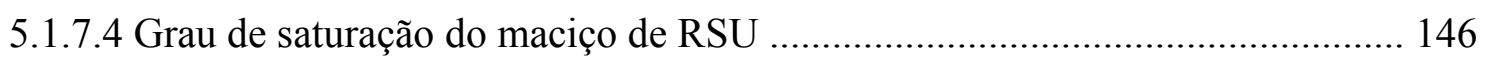

5.1.7.5 Módulo de cisalhamento para pequenas deformações $\left(\mathrm{G}_{\mathrm{o}}\right)$............................ 147

5.2 Cisalhamento direto de grandes dimensões ............................................................ 148

5.2.1 Caracterização das amostras utilizadas nos ensaios .................................................... 148

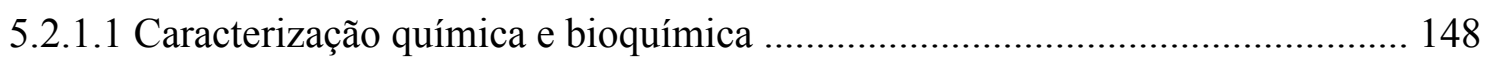

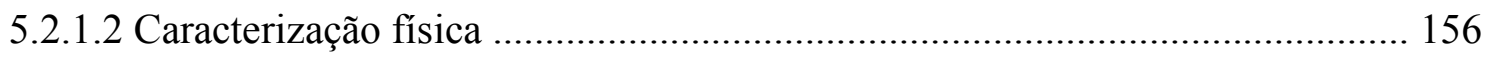

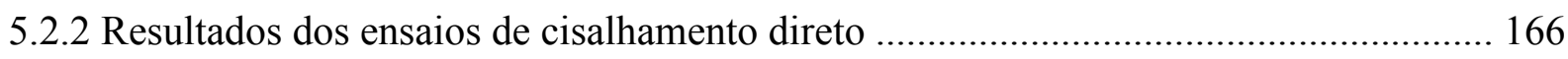

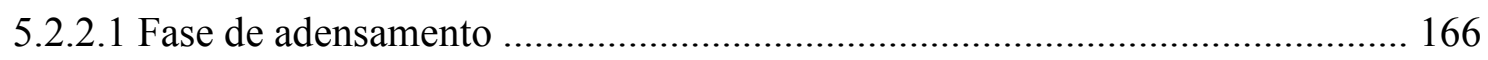

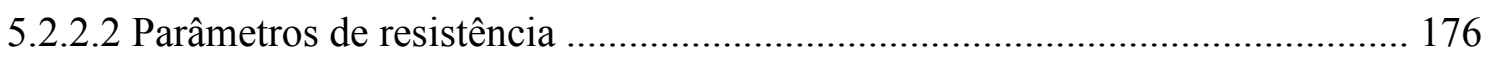

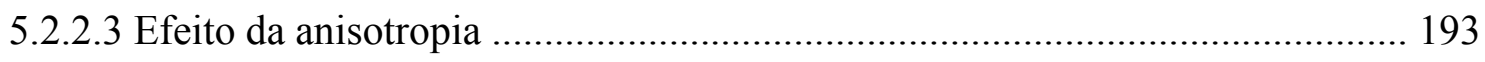

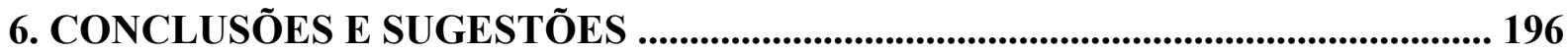

6.1 Caracterização geotécnica do Aterro Sanitário de São Carlos .......................................... 196

6.1.1 Método adotado para a determinação do peso específico dos RSU in situ ................... 197

6.1.2 Aplicação de métodos geofísicos sísmicos a aterros sanitários .................................... 198

6.2 Resistência ao cisalhamento de RSU de diferentes idades .............................................. 198

6.2.1 Caracterização das amostras ensaiadas ................................................................... 198

6.2.2 Parâmetros de resistência ao cisalhamento …………………………………….... 199

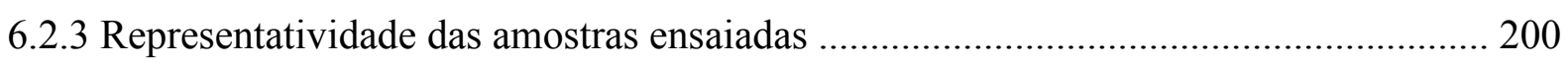

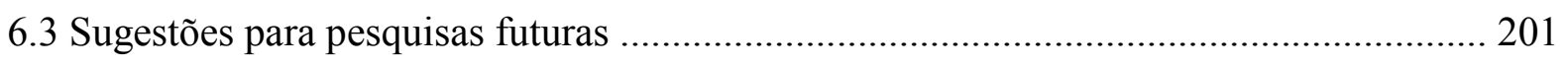

7. REFERÊNCIAS BIBLIOGRÁFICAS ................................................................... 203

APÊNDICE A - Perfis individuais das sondagens ………………………………….... 222

APÊNDICE B - Ensaios MASW - Resultados intermediários …………………………..... 230 


\section{INTRODUÇÃO}

O método mais difundido para destinação final de resíduos sólidos urbanos (RSU) em termos mundiais é a disposição sobre o terreno. Essa disposição ocorreu durante muitos anos de forma desordenada, no que se conhece comumente como lixão. Com o passar dos anos ela evoluiu para empreendimentos que envolvem conceitos de engenharia, os denominados aterros sanitários. A tendência atual, tanto para novos empreendimentos, quanto para a ampliação de aterros existentes, é ocupar a mesma área em planta com um volume maior de resíduos, o que implica construir maciços de resíduos mais altos e com taludes mais íngremes.

As otimizações no aproveitamento do espaço superficial para disposição de RSU envolvem a garantia da estabilidade dos taludes e da operacionalidade dos sistemas de drenagem e de impermeabilização, face às deformações impostas pelo recalque dos RSU ao longo do tempo. Estes dois aspectos estão diretamente relacionados ao comportamento geomecânico dos resíduos, pois envolvem o conhecimento de suas propriedades de resistência e de deformabilidade.

Apesar do grande número de investigações já realizadas sobre o assunto, o entendimento atual sobre o comportamento dos RSU como material geotécnico está longe de poder ser considerado completo. Isto se deve, em parte, ao fato de que os RSU são materiais heterogêneos, formados por partículas de dimensões e formatos diversos. Além disso, sua composição varia de região para região e ao longo do tempo, dependendo dos níveis de desenvolvimento econômico, tecnológico, sanitário e cultural da população e também das práticas de reciclagem, reuso, incineração e pré-tratamento dos resíduos, normalmente instituídas ou fomentadas por políticas públicas.

Outros aspectos que dificultam o entendimento do comportamento geotécnico desses materiais são a dificuldade de se obterem e de se ensaiarem amostras representativas e o fato de que ainda não existem procedimentos de ensaio específicos para esses materiais.

Outrossim, as características geomecânicas dos RSU se alteram após o aterramento, pois os componentes orgânicos sofrem biodegradação, num processo que se prolonga por algumas dezenas de anos. Poucas foram as pesquisas que buscaram investigar especificamente a variação destas propriedades com a "idade" dos resíduos e os resultados disponíveis até o presente sobre este assunto não são conclusivos. 
Esta pesquisa visa ampliar o conhecimento acerca das propriedades geomecânicas dos maciços de RSU no estado de São Paulo e dá continuidade aos trabalhos já realizados na Escola de Engenharia de São Carlos (EESC-USP) sobre este tema.

Para tornar mais claro qual é o objeto de estudo desta pesquisa, apresentam-se a seguir as definições de RSU e das formas de disposição em solos utilizadas costumeiramente no Brasil.

\subsection{Definição de Resíduos Sólidos Urbanos}

Os resíduos sólidos estão definidos em norma (NBR10.004, ABNT, 2004a) como sendo os "resíduos nos estados sólido e semi-sólido, que resultam de atividades de origem industrial, doméstica, hospitalar, comercial, agrícola, de serviços e de varrição. Ficam incluídos nesta definição os lodos provenientes de sistemas de tratamento de água, aqueles gerados em equipamentos e instalações de controle de poluição, bem como determinados líquidos cujas particularidades tornem inviável o seu lançamento na rede pública de esgotos ou corpos de água, ou exijam para isso soluções técnica e economicamente inviáveis em face à melhor tecnologia disponível”.

A Política Nacional de Resíduos Sólidos (PNRS), instituída pela lei federal n. 12.305, de 12 de agosto de 2010, apresenta definição semelhante: resíduos sólidos são os materiais, substâncias, objetos ou bens descartados resultantes de atividades humanas em sociedade, cuja destinação final se procede, se propõe proceder ou se está obrigado a proceder, nos estados sólido ou semissólido, bem como gases contidos em recipientes e líquidos cujas particularidades tornem inviável o seu lançamento na rede pública de esgotos ou em corpos d'água, ou exijam para isso soluções técnica ou economicamente inviáveis em face da melhor tecnologia disponível.

Eles são classificados de acordo com NBR10.004 (ABNT, 2004a) quanto a sua periculosidade: a possibilidade de apresentarem riscos à saúde humana ou ao meio ambiente, se manuseados de forma indevida. As classes definidas são: resíduos perigosos (classe I) e resíduos não perigosos (classe II). Estes últimos dividem-se em Classe IIA, para resíduos nãoinertes, que apresentam biodegradabilidade, combustibilidade ou solubilidade em água, e Classe IIB, para resíduos inertes.

Além disso, os resíduos são classificados quanto à sua origem. Na PNRS consta: 
a) resíduos domiciliares: os originários de atividades domésticas em residências urbanas;

b) resíduos de limpeza urbana: os originários da varrição, limpeza de logradouros e vias públicas e outros serviços de limpeza urbana;

c) resíduos sólidos urbanos: os englobados nas alíneas "a" e "b";

d) resíduos de estabelecimentos comerciais e prestadores de serviços: os gerados nessas atividades, excetuados os referidos nas alíneas "b", "e", "g", "h" e "j";

e) resíduos dos serviços públicos de saneamento básico: os gerados nessas atividades, excetuados os referidos na alínea "c";

f) resíduos industriais: os gerados nos processos produtivos e instalações industriais;

g) resíduos de serviços de saúde: os gerados nos serviços de saúde, conforme definido em regulamento ou em normas estabelecidas pelos órgãos do SISNAMA e do SNVS;

h) resíduos da construção civil: os gerados nas construções, reformas, reparos e demolições de obras de construção civil, incluídos os resultantes da preparação e escavação de terrenos para obras civis;

i) resíduos agrossilvopastoris: os gerados nas atividades agropecuárias e silviculturais, incluídos os relacionados a insumos utilizados nessas atividades;

j) resíduos de serviços de transportes: os originários de portos, aeroportos, terminais alfandegários, rodoviários e ferroviários e passagens de fronteira;

k) resíduos de mineração: os gerados na atividade de pesquisa, extração ou beneficiamento de minérios;

A PNRS define ainda o termo "rejeitos", como sendo os "resíduos sólidos que, depois de esgotadas todas as possibilidades de tratamento e recuperação por processos tecnológicos disponíveis e economicamente viáveis, não apresentem outra possibilidade que não a disposição final ambientalmente adequada" e estabelece que apenas os rejeitos (e não os resíduos sólidos) devem ser encaminhados para aterros.

Os materiais estudados nesta pesquisa são classificados como IIA (resíduos não-inertes) e são provenientes principalmente de domicílios e de limpeza urbana, como definido na PNRS. Secundariamente foram dispostos resíduos de estabelecimentos comerciais (pequenos geradores) e pequenas quantidades de resíduos dos serviços públicos de saneamento básico (lodos de estação de tratamento de esgotos). Nos depósitos mais antigos (tipo lixão) deve-se considerar que resíduos de todas as origens podem estar depositados. 
A PNRS é relativamente recente e o país vive atualmente uma situação de ajuste a esta legislação. Durante décadas os resíduos sólidos urbanos (e não os rejeitos) têm sido encaminhados para disposição final em solo, na forma de lixões, aterros controlados e aterros sanitários. Estes empreendimentos representam diferentes níveis de proteção em relação aos riscos que a destinação final de resíduos em solo pode representar para o meio ambiente e para a saúde humana.

IPT-CEMPRE (1995) definem um lixão como uma forma inadequada de disposição final de resíduos sólidos, que se caracteriza pela simples descarga sobre o solo, sem medidas de proteção ao meio ambiente ou à saúde pública e sem controle quanto aos tipos de resíduos recebidos.

O aterro controlado é definido por esses autores como sendo uma técnica de disposição de RSU no solo, sem causar danos ou riscos à saúde pública e a sua segurança, minimizando os impactos ambientais. Esse método utiliza princípios de engenharia para confinar os resíduos sólidos, cobrindo-os com uma camada de material inerte na conclusão de cada jornada de trabalho e trabalhando-se com uma área de disposição minimizada. Porém, geralmente não dispõe de impermeabilização de base, nem de sistemas de tratamento de lixiviado ou de dispersão dos gases gerados pela decomposição dos resíduos.

O aterro sanitário é definido como um processo utilizado para a disposição de resíduos sólidos no solo fundamentado em critérios de engenharia e em normas operacionais específicas, que permitem o confinamento seguro em termos de controle de poluição ambiental e proteção à saúde pública. No aterro sanitário há o controle sobre a origem e a classificação do resíduo aterrado, há cobertura dos resíduos dispostos, sistema de drenagem de lixiviados e de gases, camadas de impermeabilização de fundo e laterais, captação e tratamento ou destinação adequada de lixiviados e de águas de nascentes, sistema de drenagem de águas superficiais, dentre outras medidas de engenharia que visam proteger o meio ambiente e a saúde pública.

Um aterro sanitário é composto minimamente por uma guarita com balança rodoviária, que controla o acesso dos resíduos ao local, lagoas de armazenamento e/ou tratamento de lixiviados e o maciço de resíduos aterrados. Esta ultima estrutura é o objeto de estudo desta pesquisa. 


\section{OBJETIVOS}

O objetivo geral da pesquisa foi estudar alguns dos parâmetros e propriedades dos RSU necessários ao projeto de aterros sanitários, as formas de determinação dos mesmos e a sua variação ao longo do tempo, devido ao processo de "envelhecimento" (biodegradação). Foram estudados os parâmetros de resistência ao cisalhamento, o módulo de cisalhamento máximo e o peso específico in situ dos RSU.

Os objetivos específicos da pesquisa foram os seguintes:

- determinar o peso específico in situ dos RSU no aterro sanitário de São Carlos (ASSC) e verificar a hipótese de que há correlação entre o peso específico e o aumento da profundidade no maciço de resíduos. O aumento da profundidade englobaria os efeitos do "envelhecimento" dos resíduos e os efeitos do confinamento;

- aplicar métodos geofísicos sísmicos na investigação do maciço de resíduos do ASSC, visando conhecer as potencialidades da aplicação destes métodos a aterros brasileiros e determinar parâmetros de deformabilidade do maciço (módulo de cisalhamento máximo).

- comparar os resultados e potencialidades da aplicação de dois métodos geofísicos sísmicos diferentes no mesmo maciço de resíduos, a saber: método entre furos (crosshole) e método de análise de ondas superficiais por multicanais (multichannel analysis of surface waves, ou simplesmente MASW);

- realizar ensaios de cisalhamento direto em equipamento de grandes dimensões, ensaiando amostras com diferentes idades de aterramento e, supostamente, diferentes estágios de degradação. Pretendeu-se assim verificar a hipótese de que há correlação entre os parâmetros que caracterizam a resistência ao cisalhamento dos RSU e o seu estado de degradação (envelhecimento);

- realizar ensaios de cisalhamento direto em equipamento de grandes dimensões, ensaiando amostras em duas posições diferentes, a fim de se verificar a hipótese de que os RSU apresentam anisotropia de resistência nas direções paralela e perpendicular à compactação. 


\section{REVISÃO BIBLIOGRÁFICA}

\subsection{Peso específico de maciços de RSU}

O peso específico representa a relação entre o peso e o volume unitário da massa de resíduos. Os valores de peso específico disponíveis na literatura técnica variam de $4 \mathrm{kN} / \mathrm{m}^{3}$, para resíduos recém lançados no aterro, sem compactação, a $20 \mathrm{kN} / \mathrm{m}^{3}$ em aterros operados como biorreatores, apresentando no geral grande dispersão. Trata-se de um índice físico essencial para a avaliação da estabilidade e da deformação de maciços de RSU, porém, diferentemente do que ocorre em solos, a sua determinação é dificultada pela grande variabilidade do material e pela ocorrência de componentes de grandes dimensões.

Diversos autores preocuparam-se em entender o comportamento do peso específico dos aterros sanitários, buscando estabelecer uma regra geral, que permitisse uma adequada previsão dos valores de peso específico para projeto e operação dos aterros.

Wiemer (1982), estudando aspectos operacionais de aterros na Alemanha, especialmente o grau de compactação atingido pelos resíduos, afirma que esse é um aspecto determinante para a evolução dos valores de peso específico de um aterro ao longo do tempo. Babu et al. (2014) relatam que o peso específico de RSU recém aterrados pode variar de 4,0 $\mathrm{kN} / \mathrm{m}^{3}$ a $16,0 \mathrm{kN} / \mathrm{m}^{3}$, dependendo apenas do grau de compactação atingido pelas operações de disposição do resíduo.

Entretanto, Fassett et al. (1994, apud Bouazza e Wojnarowicz, 1999) indicaram que abaixo de 10 metros o peso específico de uma camada de aterro inicialmente pouco compactada tende a aproximar-se do peso específico de uma camada bem compactada.

Kavazanjian et al. (1995) apresentaram um perfil típico de peso específico para aterros da região da Califórnia, que foi posteriormente revisado pelos próprios autores (Kavazanjian, 1999, 2001). Nesse perfil revisado os pesos específicos próximos à superfície têm valores entre 10 e $13 \mathrm{kN} / \mathrm{m}^{3}$ e atingem valores entre 13 e $16 \mathrm{kN} / \mathrm{m}^{3}$ a profundidades da ordem de 30 metros. Ressalte-se que essa é uma região de clima seco, onde os aterros têm normalmente pouca umidade.

Kavazanjian (2001) afirma que em aterros com conteúdos elevados de solo de cobertura ou com elevadas umidades o peso específico do maciço em profundidade é tipicamente maior que $15 \mathrm{kN} / \mathrm{m}^{3}$ e que em aterros operados como biorreatores ou com recirculação de lixiviado o peso específico em profundidade aproxima-se ou mesmo excede $20 \mathrm{kN} / \mathrm{m}^{3}$. 
Babu et al. (2014) discutem o efeito da biodegradação sobre o peso específico dos resíduos, afirmando que, com o tempo, os resíduos tornam-se mais finos e mais densos. Segundo esses autores, os resíduos recém-aterrados têm uma quantidade maior de matéria orgânica e, por este motivo, apresentam peso específico mais baixo. Com a biodegradação a matéria orgânica se transforma em componentes não biodegradáveis, que são mais densos. Este processo envolve perda de massa para o meio externo ao maciço de resíduos, acompanhada pelo rearranjo interno das partículas e diminuição de volume.

Burlingame (2007) e Cox et al. (2006) buscaram correlacionar os dados de peso específico com a profundidade por meio de funções lineares, porém ambos obtiveram baixos coeficientes de correlação $(0,35$ e 0,33 , respectivamente).

As informações sobre o peso específico dos resíduos sólidos urbanos foram sistematizadas por Zekkos et al. (2006), que defendem a existência de uma curva característica para a distribuição dos pesos específicos em profundidade para cada aterro sanitário. Os autores propuseram a seguinte equação empírica para essa curva característica:

$$
\gamma=\gamma_{i}+\frac{z}{\alpha+\beta z}
$$

Em que: $\gamma=$ peso específico do maciço $\left(\mathrm{kN} / \mathrm{m}^{3}\right), \gamma_{\mathrm{i}}=$ peso específico in situ próximo à superfície $\left(\mathrm{kN} / \mathrm{m}^{3}\right), \mathrm{z}=$ profundidade (em metros) para a qual o peso específico $(\gamma)$ está sendo estimado; $\alpha\left(\mathrm{m}^{4} / \mathrm{kN}\right)$ e $\beta\left(\mathrm{m}^{3} / \mathrm{kN}\right)=$ parâmetros de modelagem.

O significado físico dos parâmetros $\alpha$ e $\beta$ está ilustrado na Figura 3.1. O parâmetro $\beta$ é uma função da diferença entre o valor do peso específico à superfície e o valor do peso específico em grande profundidade (ou elevada pressão confinante), onde o valor do peso específico tende a se tornar constante. O parâmetro $\alpha$ é uma função da razão de incremento do peso específico com a profundidade nos primeiros metros do maciço, como ilustrado na Figura 3.1.

Na Tabela 3.1 são apresentados os valores sugeridos pelos autores para os parâmetros de modelagem, em função da forma como o aterro sanitário é operado. 


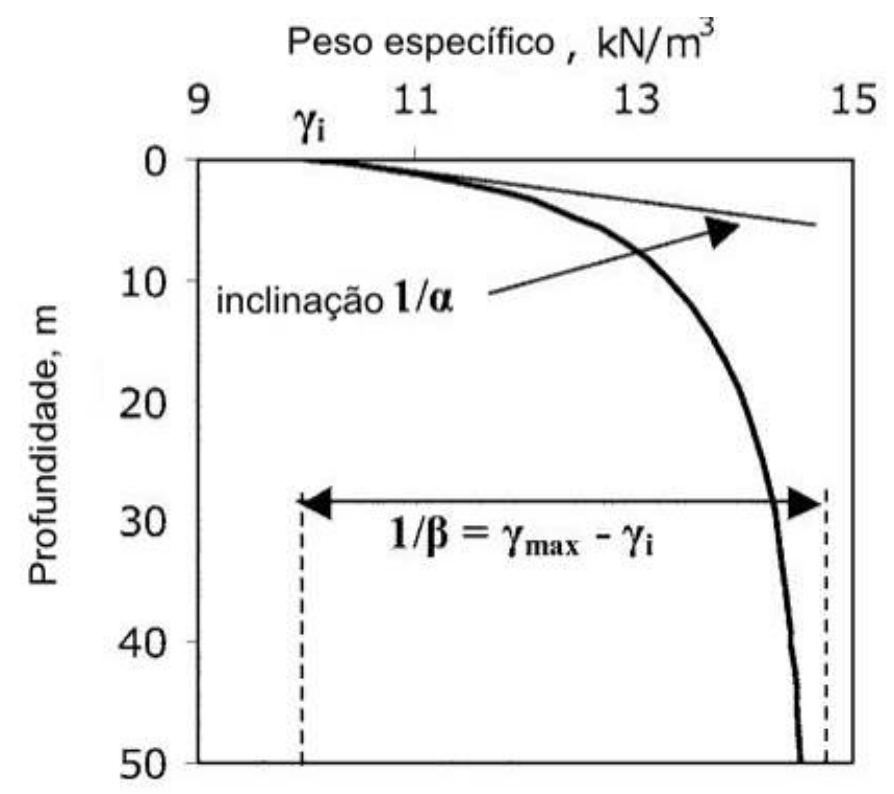

Figura 3.1 - Significado físico dos parâmetros da hipérbole (extraído de Zekkos et al., 2006).

Tabela 3.1 - Parâmetros da equação (3.1) para diferentes esforços de compactação e diferentes quantidades de solo de cobertura (extraído de Zekkos et al., 2006).

\begin{tabular}{lccc}
\hline $\begin{array}{l}\text { Esforço de compactação e } \\
\text { conteúdo de solo de cobertura }\end{array}$ & $\begin{array}{c}\gamma \\
\left(\mathrm{kN} / \mathrm{m}^{3}\right)\end{array}$ & $\begin{array}{c}\beta \\
\left(\mathrm{m}^{3} / \mathrm{kN}\right)\end{array}$ & $\begin{array}{c}\alpha \\
\left(\mathrm{m}^{4} / \mathrm{kN}\right)\end{array}$ \\
\hline Baixo & 5 & 0,1 & 2 \\
Típico & 10 & 0,2 & 3 \\
Alto & 15,5 & 0,9 & 6 \\
\hline
\end{tabular}

Os autores destacam, entretanto, que o modelo tem limitações, pois foi desenvolvido principalmente com dados de aterros "totalmente drenados", que operam com umidades abaixo da capacidade de campo, apesar de considerar aterros de regiões de clima úmido e de regiões de clima seco. Por outro lado, ele incorpora implicitamente os efeitos da degradação dos RSU, pois foi desenvolvido com base em dados de aterros jovens e de aterros antigos. Segundo os autores, os efeitos da degradação sobre o peso específico não estão ainda totalmente entendidos, pois, se, por um lado, a degradação dos resíduos é um processo de perda de massa do sistema (devido à geração de chorume e de gás, que saem do maciço), por outro lado, as pressões confinantes a que os resíduos antigos estão sujeitos fazem com que ocorram recalques e ajustes da estrutura do maciço, o que pode compensar a perda de massa envolvida na degradação.

Com relação a isso, é interessante destacar os resultados de Cartier e Baldit (1983), que instalaram um tubo metálico com comprimento de 17 metros no aterro de Arnouville-LesMantes, na França, e realizaram determinações de densidade dos RSU com um densímetro nuclear a cada 6 meses. Os autores verificaram que não houve variações significativas da densidade entre cada leitura. 
Mais recentemente, diversos autores têm desenvolvido pesquisas no sentido de entender e modelar este balanço entre deformação e perda de massa, que afeta diretamente o comportamento geomecânico dos maciços de RSU (McDougall e Pyrah, 2003; McDougall, 2008). Valendo-se de uma abordagem mais teórica, eles propõem modelos para a previsão das deformações (recalques) que o maciço sofrerá ao longo do tempo, considerando a cinética das reações de degradação dos constituintes individuais dos resíduos e as deformações que ocorrem em sua estrutura, como resposta aos efeitos conjugados da degradação e do confinamento. São os chamados modelos hidro-bio-mecânicos (HBM) acoplados.

Entretanto, Yu et al. (2011) argumentam que a aplicação desses modelos ainda requer muito esforço computacional e a adoção de parâmetros sofisticados, cuja determinação é complicada. Eles defendem que, para a prática corrente de engenharia, sejam adotados modelos teóricos menos sofisticados, como o que propõem em seu artigo. É interessante notar que esse modelo teórico simplificado, proposto por Yu et al. (2011), prevê valores de peso específico muito semelhantes àqueles determinados com o modelo empírico proposto por Zekkos (2005) e Zekkos et al. (2006).

A revisão da literatura técnica sobre o assunto permitiu que se organizassem os procedimentos utilizados para a determinação dos pesos específicos de maciços de RSU em dez métodos, que são listados a seguir, juntamente com a referência aos trabalhos em que estes métodos foram aplicados.

- Método 1 - Dados Operacionais, conforme exposto em Turczynski (1988), entre outros.

- Método 2 - Abertura de valas, aplicado por Landva e Clark (1990), Silveira (2004), entre outros.

- Método 3 - Extração de amostras “indeformadas” (Environmental Services, 1995b, apud Morochnik et al., 1998; Burlingame et al., 2007; Singh et al., 2009; Zhan et al., 2008; Stoltz et al., 2009; Chen et al., 2009, entre outros).

- Método 4 - Determinação do peso específico em furos de sondagem considerando-se seu diâmetro nominal (Carvalho, 1999, entre outros).

- Método 5 - Determinação do peso específico em furos de sondagem com substituição de volume (Kavazanjian et al., 1996; GeoSyntech, 1996b, apud Matasovich e Kavazanjian, 1998; Carvalho, 1999; Zekkos, 2005, entre outros).

- Método 6 - Métodos geofísicos gravimétricos (Gachet et al., 1998; Mantlik et al., 2009). 
- Método 7 - Métodos geofísicos sísmicos, utilizado por Kavazanjian et al. (1996) (ondas superficiais) e por Konstantaki et al. (2015) (sísmica de reflexão e ondas superficiais). Em ambos os casos determinam-se as velocidades de propagação das ondas cisalhantes (Vp) e, utilizando-se correlações com aterros onde se conhecia Vp e o peso específico, calculou-se esta propriedade.

- Método 8 - Cálculo a partir das pressões atuantes para adensamento das argilas da fundação (Burlingame et al., 2007).

-Método 9 - Cálculo a partir das pressões atuantes em células de tensão instaladas no maciço de resíduos ou no sistema de barreiras impermeabilizantes (Gomes e Lopes, 2006; Jang e Kim, 2003; Reinhart et al., 2003).

- Método 10 - Utilização de densímetro nuclear (Cartier e Baldit, 1983; Gachet et al., 1998, Gotteland et al., 1995).

Não existe consenso no meio técnico sobre qual método é mais adequado para a determinação do peso específico em aterros sanitários. As comparações entre diferentes métodos realizadas até o momento apresentaram resultados ora concordantes ora discordantes e estão resumidas na Tabela 3.2 .

Tabela 3.2 - Relatos da execução de comparações entre os métodos para determinação do peso específico em aterros sanitários.

\begin{tabular}{|c|c|c|}
\hline Referência & Métodos & Conclusões \\
\hline Cartier e Baldit (1983) & 4 e 10 & $\begin{array}{l}\text { Densímetro nuclear: resultados satisfatórios, } \\
\text { diferindo menos de } 10 \% \text { dos obtidos em furos de } \\
\text { sondagem. }\end{array}$ \\
\hline Gotteland et al. (1995) & 2 e 10 & Método 2: $18,5 \mathrm{kN} / \mathrm{m}^{3}$. Método 10: $17,4 \mathrm{kN} / \mathrm{m}^{3}$ \\
\hline $\begin{array}{c}\text { GeoSyntech (1996b, apud } \\
\text { Matasovich e Kavazanjian, } \\
\text { 1998) }\end{array}$ & 2 e 5 & Concordância entre os dois métodos. \\
\hline Gachet et al. (1998) & $\begin{array}{l}2,3,4,6 \\
\quad \text { e } 10\end{array}$ & $\begin{array}{l}\text { Métodos } 6 \text { e 10: resultados não confiáveis. } \\
\text { Método 4: resultados normalmente subestimados. } \\
\text { Métodos } 2 \text { e 3: considerados os mais adequados. }\end{array}$ \\
\hline Burlingame et al. (2007) & 3 e 8 & $\begin{array}{l}\text { Concordância entre os dois métodos. Resultados } \\
\text { do método } 3 \text { com grande variabilidade. }\end{array}$ \\
\hline
\end{tabular}

Os métodos 1, 6, 8 e 9 possibilitam a determinação do peso específico médio do maciço de resíduos, o que pode ser interessante para análises de estabilidade estáticas. Os métodos 1 e 2 permitem a execução de ensaios nas camadas superficiais do aterro, não fornecendo 
informações sobre a ocorrência (ou não) de mudanças significativas no peso específico em profundidade. Apenas a aplicação dos métodos 3, 4, 5, 7, 9 e 10 pode fornecer resultados discretos para várias profundidades do maciço de resíduos.

Todos os trabalhos em que foram realizadas determinações do peso específico por um mesmo método evidenciaram grande variabilidade dos resultados, o que reflete a heterogeneidade do meio em apreço e corrobora a necessidade de se utilizarem técnicas de amostragem de grandes volumes e da execução de uma quantidade de determinações com significado estatístico.

$\mathrm{Na}$ Tabela 3.3 são apresentados os resultados das pesquisas que utilizaram sondagens para determinação do peso específico in situ em maciços sanitários. Verifica-se que os métodos de escavação são variados, envolvendo perfurações com diâmetros de 0,10 a 0,90 metros. Na Tabela 3.4 estão resumidas as principais dificuldades ou incertezas identificadas pelos autores nessas determinações.

Tabela 3.3 - Pesquisas que utilizaram sondagens (métodos 3, 4 e 5) para determinação do peso específico in situ de maciços de RSU.

\begin{tabular}{|c|c|c|c|c|c|}
\hline Referência & Local & Método & $\begin{array}{c}\text { Substituição } \\
\text { de volume }\end{array}$ & $\begin{array}{c}\text { Prof. } \\
\text { escavada } \\
(\mathrm{m}) \\
\end{array}$ & $\begin{array}{c}\text { Resultado } \\
\left(\mathrm{kN} / \mathrm{m}^{3}\right)\end{array}$ \\
\hline Wiemer (1982) & $\begin{array}{c}\text { Aterro } \\
\text { Kahlenberg, na } \\
\text { Alemanha } \\
\end{array}$ & $\begin{array}{l}\text { Sondagem rotativa, } \\
\text { diam. } 0,14 \mathrm{~m}\end{array}$ & Não & 25 & 8 a 19 \\
\hline $\begin{array}{c}\text { Oweis e Khera } \\
(1986,1998)\end{array}$ & $\begin{array}{l}\text { Aterro no sul da } \\
\text { Califórnia }\end{array}$ & $\begin{array}{c}\text { Sondagem rotativa, } \\
\text { diâm. } 0,30 \mathrm{~m}\end{array}$ & Não & 28 & 6 a 17 \\
\hline $\begin{array}{l}\text { Environmental } \\
\text { Services Inc. } \\
\text { (1995b, apud } \\
\text { Morochnik et al., } \\
\text { 1998) }\end{array}$ & $\begin{array}{c}\text { OII landfill, } \\
\text { California, EUA }\end{array}$ & NM & NM & NM & 9 a 20 \\
\hline $\begin{array}{c}\text { GeoSyntech } \\
\text { (1996b, apud } \\
\text { Matasovich e } \\
\text { Kavazanjian, } \\
\text { 1998) }\end{array}$ & $\begin{array}{c}\text { OII Landfill, } \\
\text { California, EUA }\end{array}$ & $\begin{array}{c}\text { Trado caçamba, } \\
\text { diâm. } 0,84 \mathrm{~m}\end{array}$ & Com brita & 45 & 12 a 21 \\
\hline $\begin{array}{c}\text { Kavazanjian et al. } \\
\text { (1996); Zornberg } \\
\text { et al. (1999) }\end{array}$ & $\begin{array}{l}\text { Azuza Landfill, } \\
\text { Los Angeles } \\
\text { County, EUA }\end{array}$ & $\mathrm{NM}$ & Com brita & 55 & 10 a 17 \\
\hline $\begin{array}{c}\text { Gachet et al. } \\
\text { (1998) }\end{array}$ & Aterro na França & $\begin{array}{c}\text { Sondagem rotativa, } \\
\text { diâm. } 0,10 \mathrm{~m}\end{array}$ & Não & NM & - \\
\hline
\end{tabular}

(continua) 
(continuação da Tabela 3.3)

\begin{tabular}{|c|c|c|c|c|c|}
\hline Referência & Local & Método & $\begin{array}{l}\text { Substituição } \\
\text { de volume }\end{array}$ & $\begin{array}{l}\text { Prof. } \\
\text { escavada } \\
\text { (m) }\end{array}$ & $\begin{array}{l}\text { Resultado } \\
\left(\mathrm{kN} / \mathrm{m}^{3}\right)\end{array}$ \\
\hline Carvalho (1999) & $\begin{array}{c}\text { Aterro } \\
\text { Bandeirantes - } \\
\text { São Paulo, SP }\end{array}$ & $\begin{array}{l}\text { Trado helicoidal } \\
\text { diâm. } 0,40 \mathrm{~m}\end{array}$ & $\begin{array}{l}\text { Com calda } \\
\text { de bentonita } \\
\text { em um dos } \\
\text { furos }\end{array}$ & 22 & 8,5 a 17,3 \\
\hline $\begin{array}{c}\text { Gomes et al. } \\
(2002)\end{array}$ & $\begin{array}{c}\text { Aterro de Santo } \\
\text { Tirso, Portugal }\end{array}$ & $\begin{array}{l}\text { Sondagem com } \\
\text { diâm. de } 0,20 \mathrm{~m} \text {. }\end{array}$ & Não & 11 & 11,6 \\
\hline Boda (2002) & $\begin{array}{c}\text { Diversos aterros } \\
\text { nos EUA }\end{array}$ & $\begin{array}{l}\text { Trado caçamba, } \\
\text { diâm. de } 0,90 \mathrm{~m} \text {. }\end{array}$ & Não & NM & 5 a 14 \\
\hline $\begin{array}{c}\text { GeoSyntec (2003, } \\
\text { apud Zekkos et al., } \\
2006)\end{array}$ & $\begin{array}{c}\text { Cherry Island } \\
\text { Landfill, } \\
\text { Delaware, EUA }\end{array}$ & NM & Com brita & NM & 8 a 16 \\
\hline $\begin{array}{l}\text { Zekkos, }(2005) \\
\text { Zekkos et al. } \\
(2006)\end{array}$ & $\begin{array}{l}\text { Tri-Cities Landfill, } \\
\text { California, EUA }\end{array}$ & $\begin{array}{l}\text { Trado caçamba, } \\
\text { diâm. } 0,76 \mathrm{~m}\end{array}$ & Com brita & 32 & 11 a 23 \\
\hline Cox et al. (2006) & $\begin{array}{l}\text { Reinham, } \\
\text { Inglaterra }\end{array}$ & NM & NM & NM & 4 a 15 \\
\hline $\begin{array}{l}\text { Burlingame et al. } \\
\qquad(2007)\end{array}$ & $\begin{array}{l}\text { Landfill in } \\
\text { northeastern New } \\
\text { Jersey, EUA }\end{array}$ & $\begin{array}{c}\text { Sonic drilling, } \\
\text { (amostras com } \\
0,102 \mathrm{~m} \text { diâm. em } \\
\text { tubo acrílico, } \\
\text { comprim. de } 1,5 \mathrm{~m} \text { ) }\end{array}$ & Não & 25 & 9,8 a 15,7 \\
\hline $\begin{array}{l}\text { Zhan et al. (2008); } \\
\text { Chen et al. (2009) }\end{array}$ & $\begin{array}{c}\text { Qizhishan } \\
\text { Landfill, China }\end{array}$ & $\begin{array}{l}\text { Sondagens com } \\
\text { revestim. metálico. } \\
\text { diam. } 0,13 \mathrm{a} \\
\text { 0,09m. Amostrador } \\
\text { de parede rígida } \\
\text { diam. } 96 \text { ou } 82 \mathrm{~mm} \text {. }\end{array}$ & Não & 25 a 38 & $\begin{array}{l}3 \text { a } 12 \\
\text { (peso } \\
\text { seco) }\end{array}$ \\
\hline Stoltz et al. (2009) & $\begin{array}{l}\text { Aterro sanitário na } \\
\text { França }\end{array}$ & $\begin{array}{c}\text { Trado caçamba, } \\
\text { diâm. } 0,60 \mathrm{~m}\end{array}$ & Não & 40 & $\begin{array}{c}5,9 \text { a } 9,3 \\
\text { (peso } \\
\text { seco) } \\
\end{array}$ \\
\hline Zalachoris (2010) & $\begin{array}{c}\text { Austin Community } \\
\text { Landfill, Texas, } \\
\text { EUA }\end{array}$ & $\begin{array}{l}\text { Trado cavadeira } \\
\text { manual, diâm. } 4 "\end{array}$ & Com brita & 1,2 & 11,34 \\
\hline $\begin{array}{c}\text { Yu e Batlle (2011), } \\
\text { Yu et al. (2011) }\end{array}$ & $\begin{array}{c}\text { Aterro de Coll } \\
\text { Cardús, Catalunha, } \\
\text { Espanha }\end{array}$ & $\begin{array}{l}\text { Trado caçamba, } \\
\text { diâm. } 0,76 \mathrm{~m}\end{array}$ & Com brita & 30 & 15 a 21 \\
\hline $\begin{array}{l}\text { Gomes e Lopes } \\
\text { (2012) }\end{array}$ & $\begin{array}{l}\text { Aterro de Santo } \\
\text { Tirso, Portugal }\end{array}$ & $\begin{array}{c}\text { Sondagens com } \\
\text { diâm. de } 0,14 \mathrm{e} \\
0,20 \mathrm{~m} .\end{array}$ & Não & 15 & 4 a 18 \\
\hline Wu et al. (2012) & $\begin{array}{l}\text { Aterro ao sul de } \\
\text { Pequim, na China }\end{array}$ & $\begin{array}{l}\text { Trado helicoidal de } \\
\text { haste oca, diâm. } 13 \\
\text { cm }\end{array}$ & Não & 26 & $\begin{array}{c}6,98 \mathrm{a} \\
14,32\end{array}$ \\
\hline
\end{tabular}

$\mathrm{NM}=$ não mencionado 
Tabela 3.4 - Dificuldades relatadas na determinação de pesos específicos in situ, utilizando-se sondagens em aterros sanitários.

\begin{tabular}{|c|c|}
\hline Referência & Dificuldades relatadas \\
\hline $\begin{array}{l}\text { Oweis e Khera }(1986, \\
1998)\end{array}$ & $\begin{array}{l}\text { Considerado pequeno aumento de diâmetro do furo } \\
\text { (sobreescavação), para cálculo do volume perfurado. }\end{array}$ \\
\hline $\begin{array}{l}\text { GeoSyntech (1996b, } \\
\text { apud Matasovich e } \\
\text { Kavazanjian, 1998) }\end{array}$ & $\begin{array}{l}\text { Problemas nos trechos em que percolavam líquidos do aterro } \\
\text { para a perfuração. Adotou-se sobreescavação média de } 16 \% \\
\text { em relação ao diâmetro nominal, ao invés de se considerar } \\
\text { os resultados do teste de substituição de volume. }\end{array}$ \\
\hline Gachet et al. (1998) & $\begin{array}{l}\text { Métodos de perfuração com água geram resultados } \\
\text { claramente menores e não-verdadeiros. Perfuração com } \\
\text { sondagem rotativa, sem água: limitação dos avanços entre } \\
0,8 \text { e } 1,3 \text { metros, para garantir volume amostrado } \\
\text { significativo. Por vezes, as camadas de solo de cobertura } \\
\text { representavam um volume considerável da amostra. }\end{array}$ \\
\hline Carvalho (1999) & $\begin{array}{c}\text { Furos tendiam a fechar entre as operações de retirada e } \\
\text { reinserção do trado, amostras saturadas não eram } \\
\text { recuperadas }\end{array}$ \\
\hline $\begin{array}{l}\text { Burlingame et al. } \\
\qquad(2007)\end{array}$ & $\begin{array}{l}\text { Grande variabilidade dos resultados, devido ao volume } \\
\text { reduzido das amostras }\end{array}$ \\
\hline $\begin{array}{l}\text { Zhan et al. (2008); } \\
\text { Chen et al. (2009) }\end{array}$ & Grande variabilidade dos resultados \\
\hline Yu et al. (2011) & $\begin{array}{l}\text { Impossível perfurar na zona saturada, pois os resíduos } \\
\text { tendiam a migrar para dentro do furo a partir da parede }\end{array}$ \\
\hline
\end{tabular}

\subsection{Resistência ao cisalhamento dos RSU}

A maioria das pesquisas que enfocam a determinação da resistência ao cisalhamento dos RSU considera o critério de ruptura de Mohr-Coulomb. Dispõe-se atualmente de razoável quantidade de determinações de coesão e de ângulo de atrito para RSU, cujos valores mostram grande dispersão: têm sido encontrados valores para o ângulo de atrito entre 10 e $53^{\circ}$ e valores de coesão variando entre 0 e 67 kPa (Kavazanjian, 2006; Bray et al., 2009; Singh et al., 2009).

Alguns aspectos que explicam a grande dispersão destes valores são a natureza heterogênea dos RSU e a ausência de padronização para a obtenção de amostras, para a execução dos ensaios e para a interpretação dos resultados.

A heterogeneidade dos RSU deve-se em princípio a sua composição, que varia significativamente de uma região para outra e que pode variar em uma mesma região ao longo 
do tempo de operação do aterro sanitário. Estas variações estão relacionadas com os níveis de desenvolvimento econômico, tecnológico, sanitário e cultural da população e com as práticas (ou regulamentações e políticas públicas) de reciclagem, incineração e pré-tratamento dos resíduos.

Os parâmetros de resistência dos maciços de RSU podem ser determinados de diversas formas. Uma delas é a retroanálise de escorregamentos (Benvenuto e Cunha, 1991; Kavazanjian et al., 1995; Mitchell, 1996; Eid et al., 2000; Blight, 2008; Stark et al., 2009, entre outros). Nestes casos os valores normalmente apresentam menor dispersão, e alguns autores (Kavazanjian, 2006; Stark et al., 2009) consideram que este é o método mais confiável para a determinação dos parâmetros de resistência dos RSU, pois fornece valores médios de resistência do maciço, abrange grandes volumes e situações in situ. Entretanto, os autores destacam a necessidade de se conhecerem todos os dados para a realização das retroanálises, o que só é possível em poucos casos.

Outra linha de abordagem é a utilização de ensaios de campo e de correlações para a determinação da resistência mecânica dos RSU. Por exemplo, Cartir e Baldit (1993), Coumoulos et al. (1995), Mariano (1999) e Carvalho (1999) realizaram ensaios penetrométricos em aterros sanitários. Carvalho (1999), Varga et al. (2011), entre outros, realizaram ensaios de penetração de cone mecânico e/ou elétrico, inclusive com medida de poropressões. Fucale e Jucá (2002) compararam os resultados de ensaio de penetração tipo SPT em quatro aterros brasileiros, concluindo que os aterros mais antigos apresentam valores de SPT mais baixos (2 a 10 golpes), típicos de resíduos mais degradados, enquanto que no aterro mais recente, melhor drenado e compactado, os valores de SPT são mais elevados (entre 5 e 10 até 4 metros de profundidade e entre 10 e 20 golpes para maiores profundidades, apresentando tendência de crescimento com a profundidade.

As dificuldades para aplicação dessa abordagem vão desde a execução dos ensaios em campo, pois os resíduos têm partículas de grandes dimensões e com elevada resistência individual, que dificultam a penetração das sondas e a execução dos ensaios. Mas o principal fator a ser superado nessa área é o desenvolvimento de correlações específicas para RSU, que possam traduzir os resultados dos ensaios de campo em parâmetros de resistência aplicáveis a análises de estabilidade de taludes.

A terceira possibilidade de abordagem é a realização de ensaios de laboratório para determinação dos parâmetros de resistência dos RSU. Segundo Bray et al. (2009) para esse 
fim têm sido utilizados ensaios de cisalhamento direto, ensaios triaxiais e ensaios de cisalhamento simples de pequenas e grandes dimensões.

\subsubsection{Ensaios triaxiais}

Nos ensaios triaxiais do tipo $\mathrm{CD}$, a relação tensão-deformação comumente se inicia com forma convexa, depois se torna linear e finalmente se torna côncava (exibe curvatura ascendente crescente) sem qualquer sinal de tender a um valor assintótico, muito menos atingir um valor de máxima resistência, mesmo quando o corpo de prova está submetido a grandes deformações (Bray et al., 2009). Portanto, os resíduos exibem comportamento de endurecimento. A Figura 3.2 ilustra a relação tensão-deformação obtida tipicamente nestes ensaios.

Nos ensaios triaxiais do tipo CU, a relação tensão-deformação em termos de tensões totais tem comportamento semelhante, como apresentado na Figura 3.3. Principalmente para as tensões de confinamento mais elevadas os resíduos exibem endurecimento.

Como se pode observar na Figura 3.3, durante o ensaio se desenvolvem elevadas pressões neutras. As trajetórias de tensões efetivas têm forma de "S" e localizam-se à esquerda das trajetórias de tensões totais, como apresentado na Figura 3.4. Elas refletem o fato de que no início do ensaio as pressões na água aumentam rapidamente e em seguida se tornam constantes, permitindo então um aumento da tensão de cisalhamento. Esse comportamento é típico de materiais bastante compressíveis.

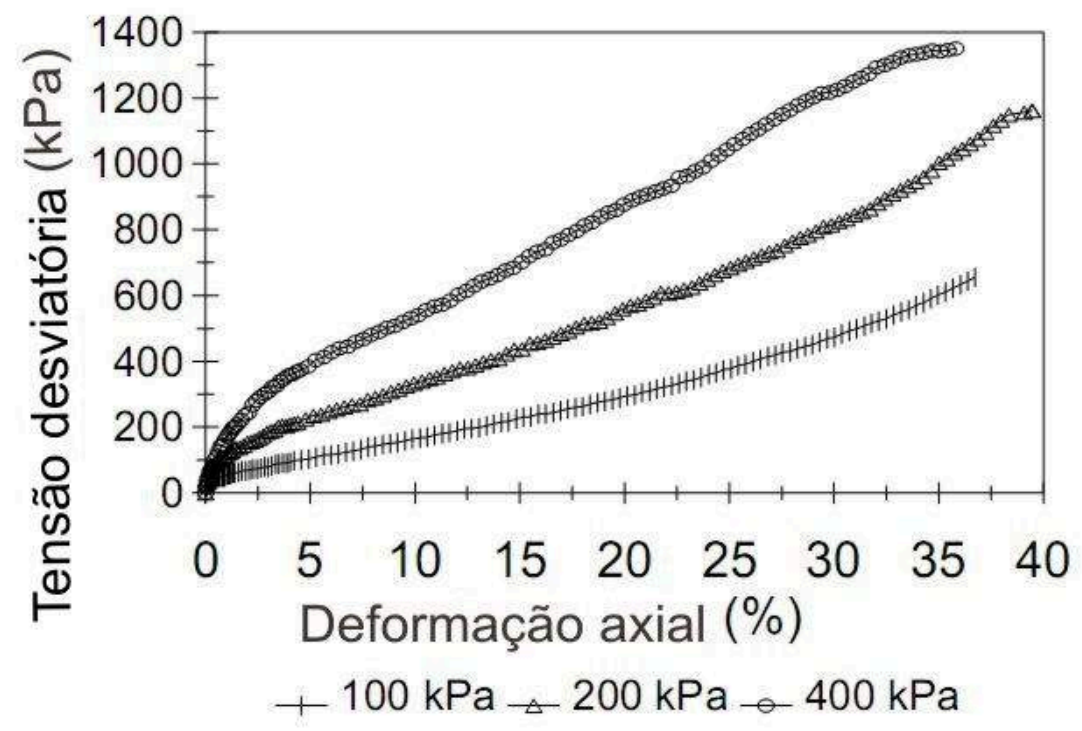

Figura 3.2 - Relações tensão-deformação típicas de ensaios triaxiais do tipo CD realizados com RSU (extraído de Vilar e Carvalho, 2004) 

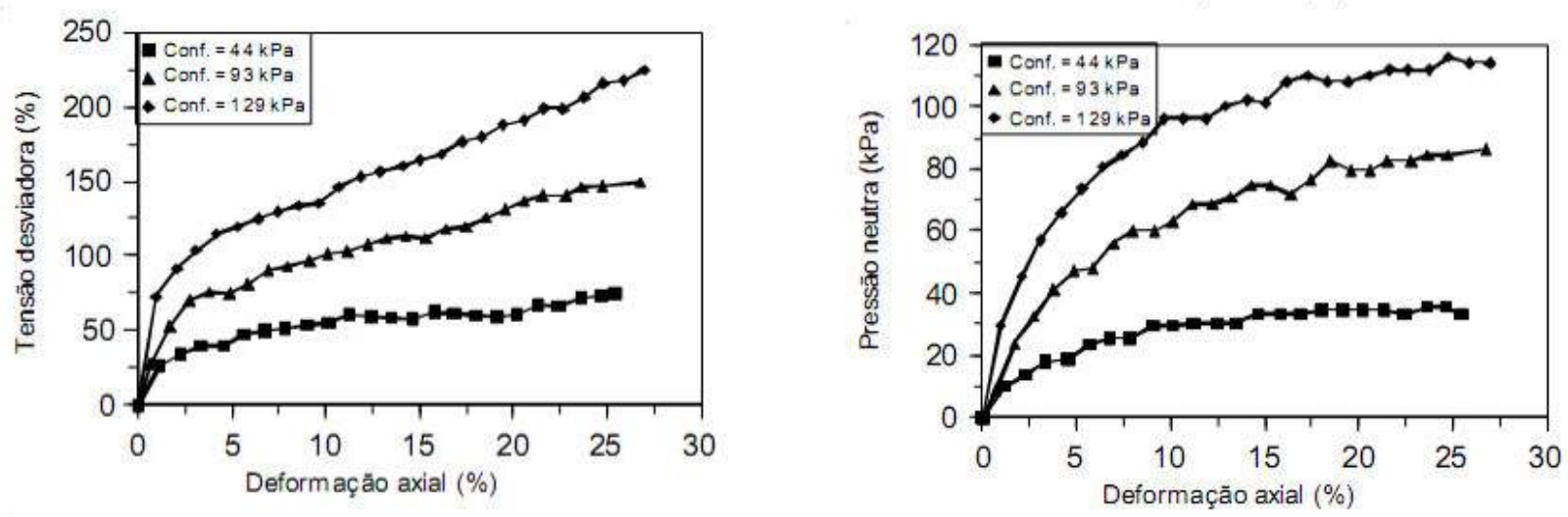

Figura 3.3 - Curvas tensão versus deformação axial e pressão neutra versus deformação axial obtidas de ensaios CU em amostra de RSU novo (extraído de Nascimento et al., 2008).

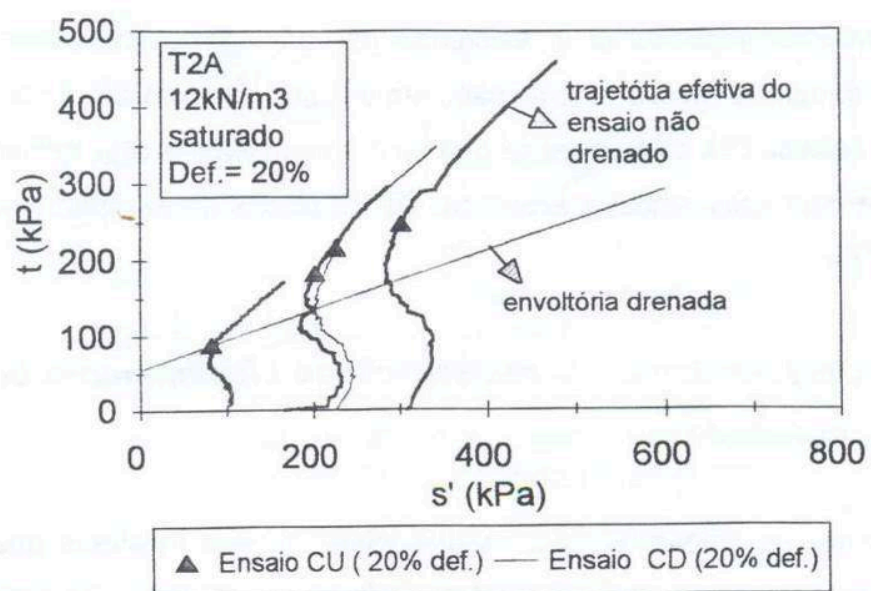

Figura 3.4 - Trajetórias de tensões efetivas de RSU em ensaios triaxiais não drenados, comparadas à envoltória de resistência obtida em ensaios triaxiais drenados (extraído de Carvalho, 1999).

Tanto nos resultados dos ensaios triaxiais drenados, quanto nos resultados dos ensaios não-drenados, não é possível definir claramente uma tensão de máxima resistência ao cisalhamento. Assim sendo, os parâmetros de resistência adotados no critério de MohrCoulomb são dependentes do nível de deformação considerado aceitável em cada obra, sendo comum adotarem-se valores entre 5 e $20 \%$ de deformação específica para cálculo da coesão e do ângulo de atrito.

Diversos grupos de pesquisa realizaram ensaios triaxiais em RSU. A Tabela 3.5 resume essas pesquisas. 
Tabela 3.5 - Pesquisas em RSU que utilizaram ensaios triaxiais

\begin{tabular}{|c|c|c|c|c|c|}
\hline Referência & Origem dos RSU & $\begin{array}{c}\text { Dimensões do corpo } \\
\text { de prova }\end{array}$ & $\begin{array}{l}\text { Tipo de } \\
\text { ensaio }\end{array}$ & $\begin{array}{l}\text { Tensões } \\
\text { confinantes }\end{array}$ & Parâmetros de resistência \\
\hline $\begin{array}{l}\text { Grisolia et al. } \\
\qquad(1995)\end{array}$ & $\begin{array}{l}\text { Composição sintética, média } \\
\text { dos resíduos novos da Itália }\end{array}$ & $\begin{array}{l}\text { Diâmetro de } 250 \mathrm{~mm} \text { e } \\
\text { altura de } 650 \mathrm{~mm}\end{array}$ & $\mathrm{CD}$ & 50,100 e $300 \mathrm{kPa}$ & $\begin{array}{c}\mathrm{c}^{\prime}=4 \text { a } 5 \mathrm{kPa} ; \varphi^{\prime}=20^{\circ} \text { (para } \\
10 \text { a } 15 \% \text { de def. axial) }\end{array}$ \\
\hline $\begin{array}{c}\text { Jessberger e } \\
\text { Kockel (1995) }\end{array}$ & $\begin{array}{l}\text { Resíduos com } 1 \text { a } 3 \text { anos de } \\
\text { aterramento de um aterro na } \\
\text { Alemanha }\end{array}$ & $\begin{array}{l}\text { Diâm. de } 100 \mathrm{~mm} \text { e } \\
\text { alt. de } 200 \mathrm{~mm} \text {. Diâm. } \\
\text { de } 300 \mathrm{~mm} \text { e alt. de } \\
600 \mathrm{~mm}\end{array}$ & $\mathrm{CD}$ & $\begin{array}{c}100,200,300 \mathrm{e} \\
400 \mathrm{kPa}\end{array}$ & NM \\
\hline $\begin{array}{l}\text { Gabr e Valero } \\
\quad(1995)\end{array}$ & $\begin{array}{c}\text { Resíduos com } 15 \text { a } 30 \text { anos } \\
\text { de aterramento, provenientes } \\
\text { do aterro Pioneer Crossing, } \\
\text { na Pensilvânia, EUA }\end{array}$ & $\begin{array}{l}\text { Dois tamanhos: } \\
\text { Diâm. de 70,6mm e } \\
\text { alt. de } 152 \mathrm{~mm} \text {. Diâm. } \\
\text { de } 76 \mathrm{~mm} \text { e alt. de } \\
305 \mathrm{~mm}\end{array}$ & $\mathrm{CU}$ & $\sim 15$ a $170 \mathrm{kPa}$ & $\begin{array}{c}\mathrm{c}^{\prime}=16,8 \mathrm{kPa} ; \varphi^{\prime}=34^{\circ} \text { (para } \\
20 \% \text { de def. axial) }\end{array}$ \\
\hline $\begin{array}{c}\text { Carvalho } \\
\text { (1999); Vilar e } \\
\text { Carvalho } \\
\text { (2004) }\end{array}$ & $\begin{array}{l}\text { Resíduos aterrados há } 15 \\
\text { anos, Aterro Bandeirantes, } \\
\text { São Paulo, SP, Brasil }\end{array}$ & $\begin{array}{l}\text { Diâm. de } 150 \mathrm{~mm} \text { e } \\
\text { alt. de } 300 \mathrm{~mm} \text {. Diâm. } \\
\text { de } 200 \mathrm{~mm} \text { e alt. de } \\
400 \mathrm{~mm} .\end{array}$ & $\mathrm{CD}, \mathrm{CU}$ & $\begin{array}{c}100,200 \text { e } 400 \\
\mathrm{kPa}(\text { ensaios CD), } \\
92 \text { a } 416 \mathrm{kPa} \\
\text { (ensaios CU) }\end{array}$ & $\begin{array}{c}\mathrm{c}^{\prime}=42 \text { a } 60 \mathrm{kPa} ; \varphi^{\prime}=21^{\circ} \text { ou } \\
27^{\circ},(\text { ensaios CD, } 20 \% \text { de } \\
\text { def. axial) }\end{array}$ \\
\hline $\begin{array}{l}\text { Caicedo et al. } \\
\qquad(2002 b)\end{array}$ & $\begin{array}{l}\text { Resíduos aterrados há } 1,5 \\
\text { anos, aterro Dona Juana, } \\
\text { Bogotá, Colômbia }\end{array}$ & $\begin{array}{l}\text { Diâmetro de } 300 \mathrm{~mm} \text { e } \\
\text { altura de } 600 \mathrm{~mm}\end{array}$ & $\mathrm{CU}$ & 50,200 e $350 \mathrm{kPa}$ & $\mathrm{c}^{\prime}=46 \mathrm{kPa} ; \varphi^{\prime}=14^{\circ}$ \\
\hline
\end{tabular}

(continua) 
Zekkos

(2005);

Zekkos et al.

(2012)

Resíduos com 2 a 15 anos de aterramento, do Aterro de

Tri-Cities, Califórnia, EUA
Diâmetro de $300 \mathrm{~mm}$ e

altura de $600-630 \mathrm{~mm}$
CD, Extensão,

Compressão-

descompressão

monotônicos e cíclicos

\begin{tabular}{|c|c|c|c|c|c|}
\hline $\begin{array}{l}\text { Nascimento } \\
\text { (2007); } \\
\text { Nascimento et } \\
\text { al. (2008) }\end{array}$ & $\begin{array}{c}\text { Resíduos novos e com } 4 \text { anos } \\
\text { de aterramento, do Aterro } \\
\text { Metropolitano Centro, } \\
\text { Salvador, Bahia, Brasil }\end{array}$ & $\begin{array}{l}\text { Diâmetro de } 200 \mathrm{~mm} \text { e } \\
\text { altura de } 350-400 \mathrm{~mm}\end{array}$ & $\mathrm{CD}, \mathrm{CU}$ & 50,100 e $200 \mathrm{kPa}$ & $\begin{array}{c}\mathrm{c}^{\prime}=0 \text { e } 25,8 \mathrm{kPa} ; \varphi^{\prime}=19,2 \mathrm{a} \\
39,8^{\circ},(\mathrm{CD}, 20 \% \text { de def. } \\
\text { axial); } \mathrm{c}^{\prime}=0 \mathrm{kPa} ; \varphi^{\prime}=57,7 \mathrm{e} \\
66^{\circ},(\mathrm{CU}, 20 \% \text { de def. } \\
\text { axial })\end{array}$ \\
\hline $\begin{array}{l}\text { Zhan et al. } \\
\quad(2008)\end{array}$ & $\begin{array}{c}\text { Resíduos com } 1,8 \text { a } 11 \text { anos } \\
\text { de aterramento, do Aterro de } \\
\text { Suzhou, na China }\end{array}$ & $\begin{array}{c}\text { Diâmetro de } 77,8 \text { a } \\
98,1 \mathrm{~mm}\end{array}$ & $\mathrm{CD}$ & $\begin{array}{c}50,100,200 \mathrm{e} \\
400 \mathrm{kPa}\end{array}$ & $\begin{aligned} \mathrm{c}^{\prime}= & 0 \text { a } 34 \mathrm{kPa} ; \varphi^{\prime}=14 \text { a } 39^{\circ}, \\
& (20 \% \text { de def. axial })\end{aligned}$ \\
\hline $\begin{array}{l}\text { Singh (2008); } \\
\text { Singh et al. } \\
\quad(2009)\end{array}$ & $\begin{array}{c}\text { Aterro Brock West, } \\
\text { Pickering, Ontario, Canadá }\end{array}$ & $\begin{array}{l}\text { Diâmetro de } 150 \text { ou } \\
\text { 200mm, altura até } \\
450 \mathrm{~mm}\end{array}$ & $\mathrm{CU}$ & 0 a $150 \mathrm{kPa}$ & $\begin{array}{c}\mathrm{c}^{\prime}=0 \mathrm{kPa} ; \varphi^{\prime}=35^{\circ} \text { (limite } \\
\text { inferior); } \mathrm{c}^{\prime}=8,4 \mathrm{kPa} \\
\varphi^{\prime}=47^{\circ} \text { (limite superior); }\end{array}$ \\
\hline $\begin{array}{c}\text { Hossain e } \\
\text { Haque (2009) }\end{array}$ & $\begin{array}{l}\text { Lisímetros em laboratório. } \\
\text { Resíduo proveniente de } \\
\text { Burlingame, Texas, EUA }\end{array}$ & $\begin{array}{l}\text { Diâmetro de } 71 \mathrm{~mm} \text {, } \\
\text { altura } 145 \mathrm{~mm}\end{array}$ & $\mathrm{CD}$ & 69,138 e $207 \mathrm{kPa}$ & $\begin{array}{c}\mathrm{c}^{\prime}=2,4 \mathrm{a} 11,2 \mathrm{kPa} ; \varphi^{\prime}=19 \mathrm{a} \\
27^{\circ},(20 \% \text { de def. axial })\end{array}$ \\
\hline $\begin{array}{l}\text { Shariatmadari } \\
\text { et al. (2009) }\end{array}$ & $\begin{array}{l}\text { Resíduos novos, coletados no } \\
\text { Aterro Metropolitano Centro, } \\
\text { Salvador, Bahia, Brasil }\end{array}$ & $\begin{array}{l}\text { Diâmetro de } 200 \mathrm{~mm} \text { e } \\
\text { altura de } 350 \mathrm{~mm}\end{array}$ & $\begin{array}{c}\mathrm{CD}, \mathrm{CU} \text { e } \\
\text { Compressão } \\
\text { Isotrópica }(\mathrm{CI}) \\
\text { Drenada e } \\
\text { Não-drenada }\end{array}$ & $\begin{array}{l}50,150 \text { e } 300 \mathrm{kPa} \\
\text { (ensaios CD e } \\
\mathrm{CU}), 480 \text { e } 52 \\
\mathrm{kPa}(\text { ensaios } \mathrm{CI})\end{array}$ & $\begin{array}{c}\mathrm{c}^{\prime}=11 \text { a } 26 \mathrm{kPa} ; \varphi^{\prime}=14 \mathrm{a} \\
31^{\mathrm{o}}, \text { (ensaio CU, } 20 \% \text { de } \\
\text { def. axial, diferentes } \\
\text { conteúdos de fibras) }\end{array}$ \\
\hline
\end{tabular}

(continua) 


\begin{tabular}{|c|c|c|c|c|c|}
\hline $\begin{array}{l}\text { Bauer et al. } \\
\text { (2009) }\end{array}$ & $\begin{array}{l}\text { Resíduos pré-tratados, de três } \\
\text { aterros na Alemanha }\end{array}$ & $\begin{array}{c}\text { Diâm. } 475 \mathrm{~mm} \text { e altura } \\
\text { de } 1000 \mathrm{~mm}\end{array}$ & $\begin{array}{l}\text { CD, CU, UU, } \\
\text { isotrópicos e } \\
\text { anisotrópicos }\end{array}$ & Até 300 kPa (?) & $\begin{array}{l}\mathrm{c}^{\prime}=50 \mathrm{kPa} \text { e } \varphi^{\prime}=30^{\circ}(\mathrm{CD}) \\
\mathrm{c}^{\prime}=25 \mathrm{kPa} \text { e } \varphi^{\prime}=28,8^{\circ}(\mathrm{CU}) ; \\
\mathrm{c}=38 \mathrm{kPa} \text { e } \varphi^{\prime}=20,4^{\circ}(\mathrm{UU})\end{array}$ \\
\hline $\begin{array}{l}\text { Reddy et al. } \\
\qquad(2011)\end{array}$ & $\begin{array}{l}\text { Lisímetros em laboratório. } \\
\text { Composição sintética, } \\
\text { baseada na composição média } \\
\text { dos EUA }\end{array}$ & $\begin{array}{c}\text { Diâm. } 50 \mathrm{~mm} \text { e altura } \\
\text { de } 100 \mathrm{~mm}\end{array}$ & $\mathrm{CU}$ & 69,138 e $276 \mathrm{kPa}$ & $\begin{aligned} \mathrm{c}^{\prime}= & 18 \text { a } 56 \mathrm{kPa} ; \varphi^{\prime}=1 \text { a } 11^{\circ}, \\
& (15 \% \text { de def. axial })\end{aligned}$ \\
\hline $\begin{array}{l}\text { Karimpour- } \\
\text { fard et al. } \\
\text { (2011) }\end{array}$ & $\begin{array}{l}\text { Resíduos novos, coletados no } \\
\text { Aterro Metropolitano Centro, } \\
\text { Salvador, Bahia, Brasil }\end{array}$ & $\begin{array}{l}\text { Diâmetro de } 200 \mathrm{~mm} \text { e } \\
\text { altura de } 350 \mathrm{~mm}\end{array}$ & $\mathrm{CD}$ e $\mathrm{CU}$ & 50,150 e $300 \mathrm{kPa}$ & $\begin{array}{c}\mathrm{c}^{\prime}=11 \text { a } 46 \mathrm{kPa} ; \varphi^{\prime}=14 \mathrm{a} \\
20^{\circ},(\text { ensaios } \mathrm{CD}, 20 \% \mathrm{de} \\
\text { def. axial); } \mathrm{c}^{\prime}=17 \text { a } 26 \mathrm{kPa} ; \\
\varphi^{\prime}=14 \text { a } 31^{\circ} \text { (ensaios CU, } \\
\quad 20 \% \text { de def. axial) }\end{array}$ \\
\hline $\begin{array}{c}\text { Bhandari e } \\
\text { Powrie (2013) }\end{array}$ & $\begin{array}{l}\text { Resíduos pré-tratados da } \\
\text { Estação da New Earth } \\
\text { Solutions, em Dorset, } \\
\text { Inglaterra }\end{array}$ & $\begin{array}{l}\text { Diâmetro de } 70 \mathrm{~mm} \\
\text { (equipamento de } \\
\text { ensaio convencional) }\end{array}$ & $\mathrm{CD}$ & $\begin{array}{c}25,50,100 \text { e } 200 \\
\mathrm{kPa}\end{array}$ & $\begin{array}{c}\varphi_{\mathrm{CR}}{ }^{\prime}=36^{\circ} \text { (obtiveram curvas } \\
\text { tensão-deformação com } \\
\text { pico de resistência) }\end{array}$ \\
\hline $\begin{array}{l}\text { Ramaiah et al. } \\
\qquad(2014)\end{array}$ & $\begin{array}{c}\text { Resíduos com } 1,8 \text { a } 11 \text { anos } \\
\text { de aterramento, provenientes } \\
\text { do Aterro de Ghazipur, Delhi, } \\
\text { Índia }\end{array}$ & Diâmetro de $150 \mathrm{~mm}$ & $\mathrm{CU}$ & $\begin{array}{c}25,50 \text { e } 100 \mathrm{kPa} / \\
0,5 \mathrm{~mm} / \mathrm{min} .\end{array}$ & $\begin{array}{c}\mathrm{c}^{\prime}=1,6 \text { a } 4,5 \mathrm{kPa} ; \varphi^{\prime}=46,5 \mathrm{a} \\
57^{\circ},(10 \% \text { de def. axial })\end{array}$ \\
\hline
\end{tabular}




\subsubsection{Ensaios de cisalhamento direto}

Dentre os ensaios utilizados para determinação dos parâmetros de resistência dos RSU o de cisalhamento direto é certamente o mais frequente (Zekkos, 2005). O comportamento típico dos RSU exibido nos ensaios de cisalhamento direto é uma relação tensão-deformação de forma convexa (aproximadamente hiperbólica), que pode tender a um valor assintótico para grandes deformações e algumas vezes exibe uma redução na resistência pós-pico (Bray et al., 2009). A Figura 3.5 ilustra esse comportamento típico.

Como ocorre com os resultados dos ensaios triaxiais, os parâmetros de resistência adotados no critério de Mohr-Coulomb são dependentes do nível de deformação considerado aceitável em cada obra. É comum utilizaram-se entre 5 e 20\% de deslocamento para cálculo da coesão e do ângulo de atrito do material ensaiado.

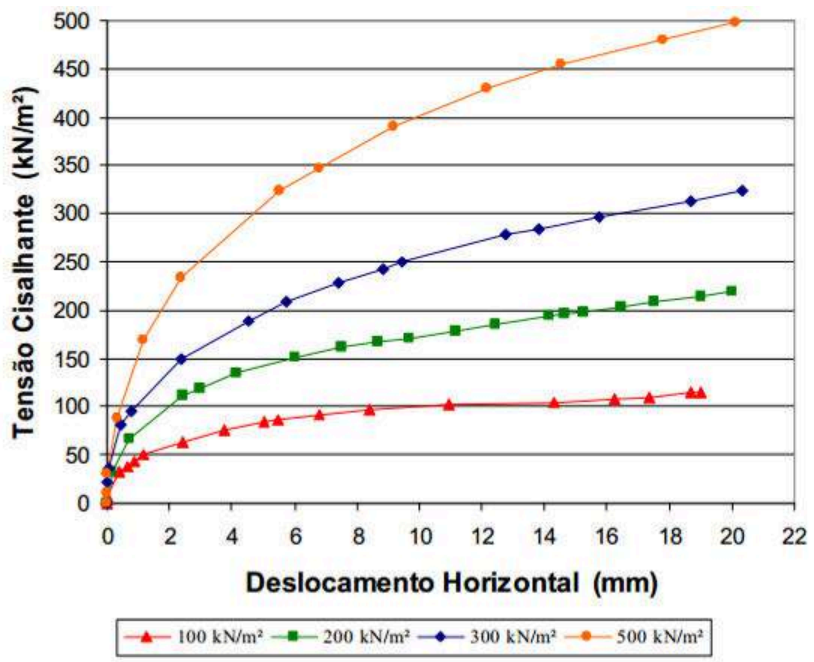

Figura 3.5 - Relações tensão-deformação típicas de ensaios de cisalhamento direto realizados em RSU (extraído de Fucale, 2005)

Destaca-se a possibilidade de se realizarem ensaios de cisalhamento direto in situ, como fizeram Richardson e Reinolds (1991), Houston et al. (1995), Withiam et al. (1995), Gotteland et al. (1995), Mazzucato et al. (1999) e Caicedo et al. (2002a,b). Em dois desses casos procurou-se verificar a representatividade dos ensaios realizados com amostras remoldadas (compactadas a partir dos RSU escavados em aterro sanitário).

Gotteland et al. (1995) ensaiaram amostras indeformadas e amostras remoldadas de um aterro francês, concluindo que as amostras remoldadas apresentavam resistência um pouco superior à amostra indeformada, entretanto o comportamento geral do material não se alterou, conforme ilustrado na Figura 3.6. 
Já Mazzucato et al. (1999) realizaram um procedimento semelhante em um aterro italiano e verificaram que as amostras indeformadas apresentavam resistência um pouco superior às amostras remoldadas. Entretanto, nas amostras indeformadas foram verificadas tensões de cisalhamento pós-pico claramente menores que a de pico, enquanto que nas amostras remoldadas esse feito era pouco perceptível. Esse fato está ilustrado na Figura 3.7.

Caicedo et al. (2002b) também obtiveram tensões de pico em alguns dos ensaios de cisalhamento direto realizados em campo, em amostras de resíduos aterrados há menos de um ano e situadas próximas ao local onde ocorreu a ruptura no aterro Dona Juana, na Colômbia.

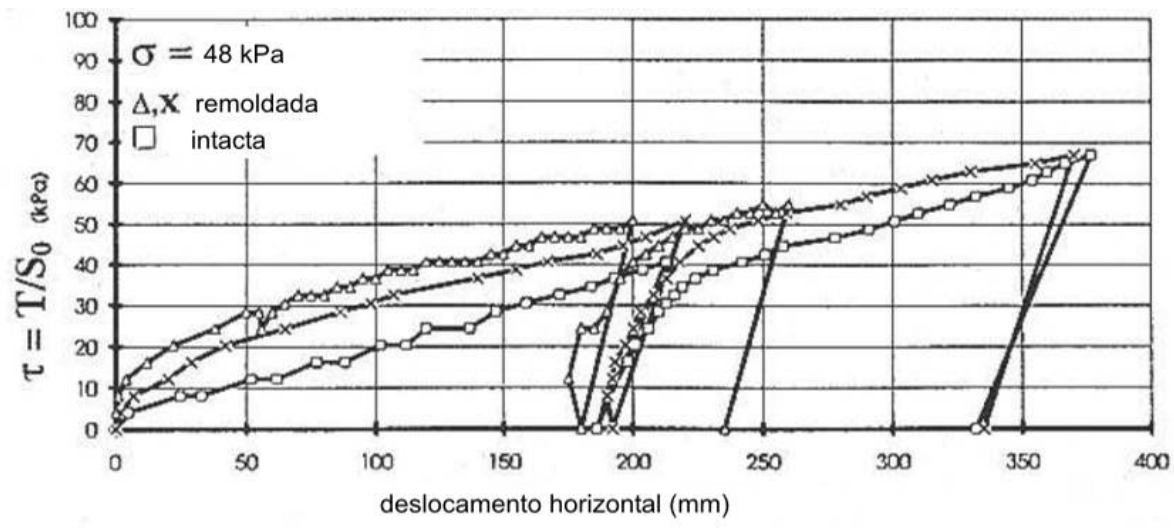

Figura 3.6 - Comparação entre os resultados de ensaios de cisalhamento direto em amostras indeformadas e remoldadas - aterro francês (extraído de Gotteland et al., 1995).

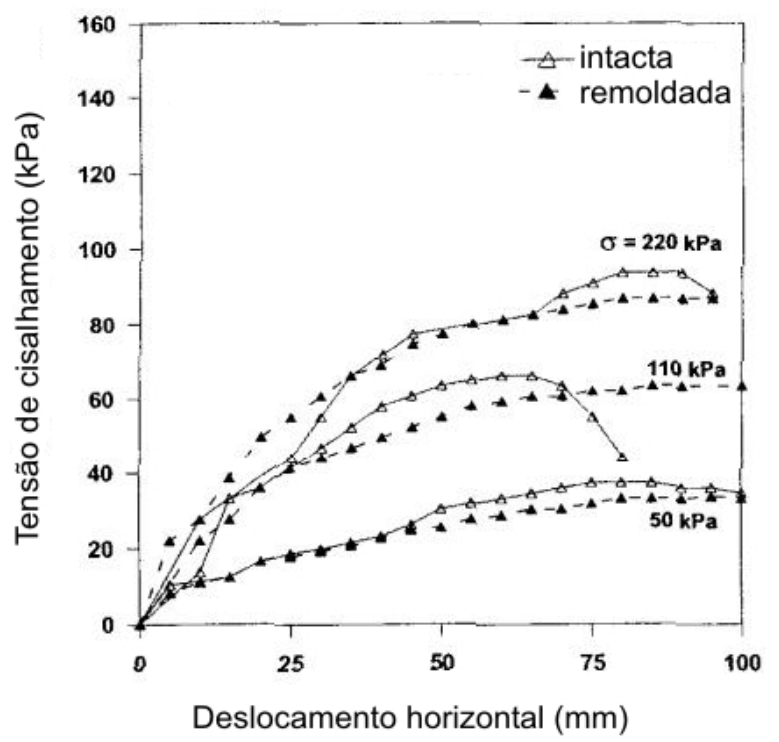

Figura 3.7 - Comparação entre os resultados de ensaios de cisalhamento direto em amostras indeformadas e remoldadas - aterro italiano (extraído de Mazzucato et al., 1999)

A Tabela 3.6 relaciona algumas das pesquisas que realizaram ensaios de cisalhamento direto em RSU, informando as dimensões dos corpos de prova e as características dos resíduos ensaiados, bem como os parâmetros de resistência calculados em cada caso. 
Tabela 3.6 - Ensaios de cisalhamento direto realizados em RSU

\begin{tabular}{|c|c|c|c|c|c|c|}
\hline Referência & Local & $\begin{array}{l}\text { Dimensões da cx de } \\
\text { ensaio }\end{array}$ & "idade" dos RSU & Deslocam. máx. & Sobrecarga & $\begin{array}{l}\text { Parâmetros de } \\
\text { resistência }\end{array}$ \\
\hline $\begin{array}{l}\text { Landva et al. } \\
(1984)\end{array}$ & $\begin{array}{l}\text { Vários aterros do } \\
\text { Canadá }\end{array}$ & $\begin{array}{l}434 \times 287 \mathrm{~mm} \\
(\mathrm{~h}=600 \mathrm{~mm})\end{array}$ & Variadas & $100 \mathrm{~mm}(23 \%)$ & Variadas & $\begin{array}{l}\mathrm{c}=16-23 \mathrm{kPa}, \varphi=24- \\
39^{\circ}\end{array}$ \\
\hline Turczynski (1988) & $\begin{array}{l}\text { Aterros da } \\
\text { Alemanha }\end{array}$ & $\begin{array}{l}2 \mathrm{~m}^{2}=\text { plano } \\
\text { cisalhamento, } \mathrm{h}= \\
400 \mathrm{~mm}\end{array}$ & $\begin{array}{l}\text { Novos, tratados } \\
\text { biologicamente }\end{array}$ & Não menciona & Não menciona & $\begin{array}{l}\mathrm{c}=15 \mathrm{kPa}, \varphi=35^{\circ}(3 \\
\text { anos }) \text { e } \mathrm{c}=10 \mathrm{kPa} \\
\varphi=26^{\circ}(15 \text { anos })\end{array}$ \\
\hline $\begin{array}{l}\text { Landva e Clark } \\
\text { (1990). }\end{array}$ & $\begin{array}{l}\text { Vários aterros do } \\
\text { Canadá }\end{array}$ & $\begin{array}{l}434 \times 287 \mathrm{~mm} \\
(\mathrm{~h}=600 \mathrm{~mm})\end{array}$ & Variadas & Não menciona & Variadas & $\mathrm{c}=0 \mathrm{kPa}, \varphi=27-41^{\circ}$ \\
\hline Siegel et al. (1990) & $\begin{array}{l}\text { Aterro OII, } \\
\text { Califórnia, EUA }\end{array}$ & $\begin{array}{l}130 \text { mm diâmetro, } \\
76 \text { a } 102 \text { mm altura }\end{array}$ & Não menciona & Não menciona & 80 a $600 \mathrm{kPa}$ & $\mathrm{c}=0 \mathrm{kPa}, \varphi=39^{\circ}$ \\
\hline Kolsch (1995) & Não menciona & $\begin{array}{l}2000 \times 1000 \times 1500 \\
\text { mm (comp. x larg x } \\
\text { alt) }\end{array}$ & $\begin{array}{l}\text { Novos, tratados } \\
\text { mecânica e } \\
\text { aerobiamente e } \\
\text { com } 5 \text { anos de } \\
\text { aterrado }\end{array}$ & Não menciona & Não menciona & $\begin{array}{l}\mathrm{c}=15 \mathrm{kPa}, \varphi=15^{\circ} ; \\
\zeta=35^{\circ} \text { (novos) }\end{array}$ \\
\hline $\begin{array}{l}\text { Richardson e } \\
\text { Reinolds (1991) }\end{array}$ & $\begin{array}{l}\text { Aterro no Maine, } \\
\text { EUA }\end{array}$ & 1500 x $1500 \mathrm{~mm}(?)$ & Não menciona & Não menciona & Não menciona & $\begin{array}{l}\mathrm{c}=20-34 \mathrm{kPa}, \varphi=16- \\
26^{\circ}\end{array}$ \\
\hline $\begin{array}{l}\text { Houston et al. } \\
\text { (1995) }\end{array}$ & $\begin{array}{l}\text { Aterro no Arizona, } \\
\text { EUA }\end{array}$ & $\begin{array}{l}1220 \text { x } 1220 \mathrm{~mm} \\
\text { (altura não ficou } \\
\text { clara) }\end{array}$ & Não menciona & $\begin{array}{l}100-110 \mathrm{~mm}(8- \\
9 \%)\end{array}$ & $\begin{array}{l}\text { Aprox. } 15 \text { a } 45 \\
\mathrm{kPa}\end{array}$ & $\begin{array}{l}c=4,4-5,0 \mathrm{kPa} \\
\varphi=33,7-35,7^{\circ}\end{array}$ \\
\hline $\begin{array}{l}\text { Withiam et al. } \\
\text { (1995) }\end{array}$ & $\begin{array}{l}\text { Aterro Dekorte } \\
\text { Park, EUA }\end{array}$ & $\begin{array}{l}1500 \times 1500 \times 1500 \\
\mathrm{~mm}\end{array}$ & Não menciona & Não menciona & 0 a $21 \mathrm{kPa}$ & $\mathrm{c}=10 \mathrm{kPa}, \varphi=30^{\circ}$ \\
\hline $\begin{array}{l}\text { Gabr e Valero } \\
(1995)\end{array}$ & $\begin{array}{l}\text { Aterro na } \\
\text { Pensilvania, EUA }\end{array}$ & $\begin{array}{l}\text { 63,5mm diâm. } x \\
23 \mathrm{~mm} \text { altura }\end{array}$ & 15 a 30 anos & $9 \mathrm{~mm}(14 \%)$ & $\begin{array}{l}69,138 \text { e } 207 \\
\mathrm{kPa}\end{array}$ & $\mathrm{c}=20 \mathrm{kPa}, \varphi=33^{\circ}$ \\
\hline $\begin{array}{l}\text { Gotteland et al. } \\
\text { (1995) }\end{array}$ & $\begin{array}{l}\text { Aterro no sul da } \\
\text { França }\end{array}$ & $\begin{array}{l}1000 \times 1000 \times 700 \\
\mathrm{~mm}\end{array}$ & Não menciona & $350 \mathrm{~mm}(35 \%)$ & Até $100 \mathrm{KPa}$ & $\begin{array}{l}\mathrm{c}=5 \mathrm{kPa}, \varphi=45^{\circ} \\
\text { (aprox.) }\end{array}$ \\
\hline $\begin{array}{l}\text { Collins e Kölsch } \\
\text { (1996, apud } \\
\text { Fucale, 2005) }\end{array}$ & $\begin{array}{l}\text { Resíduos da } \\
\text { Alemanha }\end{array}$ & $\begin{array}{l}2000 \times 1000 \times 1500 \\
\text { mm (comp. x larg x } \\
\text { alt) }\end{array}$ & Frescos e velhos & $20 \mathrm{~mm}(10 \%)$ & $\begin{array}{l}\text { aprox. } 100 \text { a } 300 \\
\mathrm{kPa}\end{array}$ & $\begin{array}{l}\mathrm{c}=15 \mathrm{kPa}, \varphi=29,7- \\
31^{\mathrm{o}} \text { (novo) e } \\
\mathrm{c}=15 \mathrm{kPa}, \varphi=38-40^{\circ} \\
\text { (velho) }\end{array}$ \\
\hline
\end{tabular}

(continua) 
(continuação da Tabela 3.6)

\begin{tabular}{|c|c|c|c|c|c|c|}
\hline Referência & Local & $\begin{array}{l}\text { Dimensões da cx de } \\
\text { ensaio }\end{array}$ & "idade" dos RSU & Deslocam. máx. & Sobrecarga & $\begin{array}{l}\text { Parâmetros de } \\
\text { resistência }\end{array}$ \\
\hline $\begin{array}{l}\text { Taylor (1995, apud } \\
\text { Jones et al. (1997) }\end{array}$ & $\begin{array}{l}\text { Aterro próx. a } \\
\text { Durham, Reino } \\
\text { Unido }\end{array}$ & $300 \times 300 \mathrm{~mm}$ & Novos & $31 \mathrm{~mm}(10 \%)$ & $50 \mathrm{a} 400 \mathrm{kPa}$ & $\mathrm{c}=10,5 \mathrm{kPa}, \varphi=31^{\circ}$ \\
\hline $\begin{array}{l}\text { Kavazanjian et al. } \\
(1999)\end{array}$ & $\begin{array}{l}\text { Aterro OII, } \\
\text { Califórnia, EUA }\end{array}$ & $\begin{array}{l}454 \mathrm{~mm} \text { diâmetro, } \\
460 \mathrm{~mm} \text { altura }\end{array}$ & $\begin{array}{l}\text { Velhos (11 a } 35 \\
\text { anos) }\end{array}$ & $100 \mathrm{~mm}(22 \%)$ & Até $1150 \mathrm{kPa}$ & $\mathrm{c}=43 \mathrm{kPa}, \varphi=31^{\circ}$ \\
\hline Ziehmann (1999) & $\begin{array}{l}\text { Resíduos tratados } \\
\text { da Alemanha }\end{array}$ & $\begin{array}{l}2000 \text { x } 1000 \text { x } 1500 \\
\text { mm (comp. x larg x } \\
\text { alt) }\end{array}$ & Não menciona & Não menciona & $\begin{array}{l}0,100,200 \mathrm{e} \\
300 \mathrm{kPa}\end{array}$ & $\begin{array}{l}c=16,9-35,5 \mathrm{kPa}, \\
\varphi=32,5-36,1^{\circ} ; \\
\zeta=12,9-14,0^{\circ}\end{array}$ \\
\hline $\begin{array}{l}\text { Mazzucato et al. } \\
\text { (1999) }\end{array}$ & $\begin{array}{l}\text { Aterro em } \\
\text { Pescatina, Verona, } \\
\text { Itália }\end{array}$ & $\begin{array}{l}\text { Diam. } 800 \mathrm{~mm} \text {, alt. } \\
220 \mathrm{~mm}\end{array}$ & Não menciona & $100 \mathrm{~mm}(12,5 \%)$ & $\begin{array}{l}50,110 \text { e } 220 \\
\mathrm{kPa}\end{array}$ & $\begin{array}{l}\mathrm{c}=22-24 \mathrm{kPa}, \varphi=17- \\
18^{\mathrm{o}}\end{array}$ \\
\hline $\begin{array}{l}\text { Gotteland et al. } \\
(2000,2001)\end{array}$ & $\begin{array}{l}\text { Aterros de Torcy e } \\
\text { de Montech, } \\
\text { França }\end{array}$ & $\begin{array}{l}1000 \times 1000 \times 650 \\
\mathrm{~mm} \text { (altura) }\end{array}$ & Não menciona & $180 \mathrm{~mm}(18 \%)$ & 50 a $125 \mathrm{kPa}$ & $\begin{array}{l}c=22-55 \mathrm{kPa} \\
\varphi=18,2-26,5^{\circ}\end{array}$ \\
\hline $\begin{array}{l}\text { Pelkey et al. } \\
(2001)\end{array}$ & $\begin{array}{l}\text { Resíduos } \\
\text { sintéticos, } \\
\text { composição do } \\
\text { Canadá }\end{array}$ & $\begin{array}{l}434 \times 287 \mathrm{~mm} \\
(\mathrm{~h}=600 \mathrm{~mm})\end{array}$ & Não menciona & $\begin{array}{l}100 \mathrm{~mm}(23 \%) \\
(\text { ou } 224 \mathrm{~mm}= \\
51 \% ?)\end{array}$ & 27 a $496 \mathrm{kPa}$ & $\begin{array}{l}\mathrm{c}=0 \mathrm{kPa}, \varphi=26,2- \\
29,2^{\circ}\end{array}$ \\
\hline Sadek et al. (2001) & $\begin{array}{l}\text { Beirute, região } \\
\text { costeira, Líbano }\end{array}$ & $600 \times 600 \times 400 \mathrm{~mm}$ & 9 a 24 anos & $50 \mathrm{~mm}(8 \%)$ & 0 a $250 \mathrm{kPa}$ & $\begin{array}{l}\mathrm{c}=1-44 \mathrm{kPa}, \varphi=19- \\
28^{\circ}\end{array}$ \\
\hline $\begin{array}{l}\text { Kavazanjian et } \\
\text { al. }(2001)\end{array}$ & $\begin{array}{l}\text { Aterro tipo } \\
\text { bioreator, nos } \\
\text { EUA }\end{array}$ & 454 mm diâmetro & Não menciona & $100 \mathrm{~mm}(22 \%)$ & $\begin{array}{l}12,6 ; 143,6 \mathrm{e} \\
430 \mathrm{kPa}\end{array}$ & $\mathrm{c}=0 \mathrm{kPa}, \varphi=39^{\circ}$ \\
\hline $\begin{array}{l}\text { Caicedo et al. } \\
(2002 a, b)\end{array}$ & $\begin{array}{l}\text { Aterro Dona } \\
\text { Juana, Bogotá, } \\
\text { Colombia }\end{array}$ & 900 mm diâmetro & $\begin{array}{l}\text { Aterrados há menos } \\
\text { de um ano }\end{array}$ & $\begin{array}{l}55 \text { a } 80 \mathrm{~mm}(6 \text { a } \\
9 \%)\end{array}$ & 6 a $117 \mathrm{kPa}$ & $\mathrm{c}=78 \mathrm{kPa}, \varphi=23^{\circ}$ \\
\hline
\end{tabular}

(continua) 
(continuação da Tabela 3.6)

\begin{tabular}{|c|c|c|c|c|c|c|}
\hline Referência & Local & $\begin{array}{l}\text { Dimensões da cx de } \\
\text { ensaio }\end{array}$ & "idade" dos RSU & Deslocam. máx. & Sobrecarga & $\begin{array}{l}\text { Parâmetros de } \\
\text { resistência }\end{array}$ \\
\hline $\begin{array}{l}\text { Caicedo et al. } \\
(2002 b)\end{array}$ & $\begin{array}{l}\text { Aterro Dona } \\
\text { Juana, Bogotá, } \\
\text { Colombia }\end{array}$ & $\begin{array}{l}300 \mathrm{~mm} \times 300 \mathrm{~mm} . \\
\text { Altura } 200 \mathrm{~mm}\end{array}$ & $\begin{array}{l}\text { Até } 2 \text { anos } \\
\text { (envolvido no } \\
\text { escorregamento) }\end{array}$ & Não menciona & Não menciona & $\mathrm{c}=67 \mathrm{kPa}, \varphi=23^{\circ}$ \\
\hline $\begin{array}{l}\text { De Lamare Neto } \\
(2004)\end{array}$ & $\begin{array}{l}\text { Rio de Janeiro, } \\
\text { Brasil }\end{array}$ & $400 \times 250 \times 100 \mathrm{~mm}$ & 9 meses & $10 \%$ & $\begin{array}{l}25,50,75 \text { e } 100 \\
\mathrm{kPa}\end{array}$ & $\mathrm{c}=6 \mathrm{kPa}, \varphi=42^{\circ}$ \\
\hline Fucale (2005) & $\begin{array}{l}\text { Aterrros Ihlenberg } \\
\text { e Buchen, } \\
\text { Alemanha }\end{array}$ & $\begin{array}{l}100 \times 100 \times 150 \mathrm{~mm} \\
\mathrm{e} 300 \times 300 \times \\
150 \mathrm{~mm}\end{array}$ & $\begin{array}{l}\text { Velhos (12-15 anos } \\
\text { - Ihlenberg) e pré- } \\
\text { tratados } \\
\text { MBA(Buchen) }\end{array}$ & $\begin{array}{l}20 \text { e } 60 \mathrm{~mm} \\
(20 \%)\end{array}$ & $\begin{array}{l}50,100,200 \\
300 \text { e } 500 \mathrm{kPa}\end{array}$ & $\begin{array}{l}c=46,1-50,8 \mathrm{kPa}, \\
\varphi=29,6-24,3^{\circ} ; \\
\zeta=7,0-16,0^{\circ} \text { (velhos) }\end{array}$ \\
\hline $\begin{array}{l}\text { Zekkos (2005); } \\
\text { Bray et al. (2009); } \\
\text { Zekkos et al. } \\
(2010 \text { a) }\end{array}$ & $\begin{array}{l}\text { Aterro Tri Cities, } \\
\text { California, EUA }\end{array}$ & $300 \times 300 \times 180 \mathrm{~mm}$ & $\begin{array}{l}\text { Aterrados há } 15 \\
\text { anos }\end{array}$ & $55 \mathrm{~mm}(18 \%)$ & $\begin{array}{l}2 \mathrm{kPa}, 50 \mathrm{kPa}, \\
150 \mathrm{kPa}, 370 \\
\mathrm{kPa} \text {, and } 700 \\
\mathrm{kPa}\end{array}$ & $\begin{array}{l}\mathrm{c}=15 \mathrm{kPa}, \varphi=41^{\circ} \\
\left(\text { para } \sigma_{\mathrm{n}}=101 \mathrm{kPa}\right)\end{array}$ \\
\hline Harris et al. (2006) & $\begin{array}{l}\text { Aterro Outer Loop } \\
\text { Kentucki, EUA } \\
\text { (bioreator) }\end{array}$ & $\begin{array}{l}300 \times 300 \mathrm{~mm} . \\
\text { Altura }=177,8 \mathrm{~mm}\end{array}$ & $\begin{array}{l}2 \text { anos. Razão } \\
\mathrm{C}+\mathrm{H} / \mathrm{L}=1,17\end{array}$ & $50 \mathrm{~mm}(16 \%)$ & $\begin{array}{l}68,9 \mathrm{kPa} \text { a } 689 \\
\mathrm{kPa}\end{array}$ & $\begin{array}{l}\mathrm{c}=11 \mathrm{kPa}, \varphi=25^{\circ} \\
(\text { para } 30 \mathrm{~mm})\end{array}$ \\
\hline Martins (2006) & $\begin{array}{l}\text { CTRS da BR-040, } \\
\text { Belo Horizonte, } \\
\text { Brasil }\end{array}$ & $\begin{array}{l}700 \times 700 \mathrm{~mm} . \\
\text { Altura de } 500 \mathrm{~mm}\end{array}$ & $\begin{array}{l}\text { Novos e } \\
\text { decompostos }\end{array}$ & $350 \mathrm{~mm}(50 \%)$ & $\begin{array}{l}50,100 \text { e } 200 \\
\mathrm{kPa}\end{array}$ & $\mathrm{c}=8-45 \mathrm{kPa}, \varphi=3-23^{\circ}$ \\
\hline Calle (2007) & $\begin{array}{l}\text { Resíduos pré- } \\
\text { tratados de São } \\
\text { Sebastião - SP e } \\
\text { de Nova } \\
\text { Hamburgo - RJ }\end{array}$ & $\begin{array}{l}60 \text { x } 60 \mathrm{~mm} \text {. Altura } \\
\text { de } 41,6 \mathrm{~mm} \text {, e } 400 \text { x } \\
250 \mathrm{~mm} \text {. Altura de } \\
100 \mathrm{~mm}\end{array}$ & $\begin{array}{l}\text { Novos, pré-tratados } \\
\text { mecânica e } \\
\text { biologicamente }\end{array}$ & $20 \%$ & $\begin{array}{l}50 \text { a } 700 \mathrm{kPa} \\
\text { (peq. dim.); } 50 \mathrm{a} \\
110 \mathrm{kPa}(\mathrm{gr} . \\
\text { dim.) }\end{array}$ & $\mathrm{c}=28 \mathrm{kPa}, \varphi=38^{\circ}$ \\
\hline Bauer et al. (2007) & $\begin{array}{l}\text { Resíduos pré- } \\
\text { tratados típicos da } \\
\text { Alemanha }\end{array}$ & $\begin{array}{l}300 \times 300 \mathrm{~mm} \text { e } 100 \\
\times 100 \mathrm{~mm}\end{array}$ & $\begin{array}{l}\text { Novos, pré-tratados } \\
\text { pelo método MBT }\end{array}$ & $60 \mathrm{~mm}(20 \%)$ & $50 \mathrm{kPa}$ & $\begin{array}{l}\mathrm{c}=13-17 \mathrm{kPa}, \varphi=38- \\
46^{\circ}\end{array}$ \\
\hline
\end{tabular}

(continua) 
(continuação da Tabela 3.6)

\begin{tabular}{|c|c|c|c|c|c|c|}
\hline Referência & Local & $\begin{array}{l}\text { Dimensões da cx de } \\
\text { ensaio }\end{array}$ & "idade" dos RSU & Deslocam. máx. & Sobrecarga & $\begin{array}{l}\text { Parâmetros de } \\
\text { resistência }\end{array}$ \\
\hline $\begin{array}{l}\text { Gabr et al. } \\
(2007 a, b)\end{array}$ & $\begin{array}{l}\text { Resíduos da } \\
\text { Carolina do Norte, } \\
\text { EUA }\end{array}$ & $\begin{array}{l}100 \mathrm{~mm} \text { diâmetro } \mathrm{x} \\
50 \mathrm{~mm} \text { espessura }\end{array}$ & $\begin{array}{l}\text { Razão } \mathrm{C}+\mathrm{H} / \mathrm{L} \\
\text { variando de } 2,52 \text { a } \\
0,25 \text { (decomposto } \\
\text { em lisímetro de } \\
\text { laboratório) }\end{array}$ & $\begin{array}{l}10 \text { a } 12 \mathrm{~mm}(10 \text { a } \\
12 \%)\end{array}$ & $\begin{array}{l}50,100 \text { e } 150 \\
\mathrm{kPa}\end{array}$ & $\mathrm{c}=0 \mathrm{kPa}, \varphi=24-32^{\circ}$ \\
\hline Dixon et al. (2008) & $\begin{array}{l}\text { Composição } \\
\text { sintética }\end{array}$ & $\begin{array}{l}1000 \mathrm{~mm} \times 1000 \\
\mathrm{~mm} \times 800 \mathrm{~mm} \\
\text { (altura) }\end{array}$ & "novos" & $260 \mathrm{~mm}(26 \%)$ & 25 a $100 \mathrm{kPa}$ & $\mathrm{c}=0 \mathrm{kPa}, \varphi=33,9^{\circ}$ \\
\hline Cardim (2008) & $\begin{array}{l}\text { Unidade de } \\
\text { Tratamento de } \\
\text { Lixo, Brasília, } \\
\text { Brasil } \\
\end{array}$ & $\begin{array}{l}1000 \times 1000 \times 1000 \\
\mathrm{~mm}\end{array}$ & Novos & $500 \mathrm{~mm}(50 \%)$ & 15,30 e $50 \mathrm{kPa}$ & $\begin{array}{l}\mathrm{c}=0,0-3,6 \mathrm{kPa}, \\
\varphi=28,1-33,8^{\mathrm{o}}\end{array}$ \\
\hline $\begin{array}{l}\text { Athanasopoulos et } \\
\text { al. (2008) }\end{array}$ & $\begin{array}{l}\text { Aterro Xerolaka, } \\
\text { Patras, Grécia }\end{array}$ & $300 \times 300 \times 180 \mathrm{~mm}$ & $\begin{array}{l}\text { Composições } \\
\text { artificiais, novos }\end{array}$ & $55 \mathrm{~mm}(18 \%)$ & $50 \mathrm{kPa}$ & $\begin{array}{l}\text { Maior resistência } \\
\text { para fibras } \\
\text { orientadas a } 60^{\circ} \mathrm{em} \\
\text { relação à normal }\end{array}$ \\
\hline $\begin{array}{l}\text { Singh (2008); } \\
\text { Singh et al. (2009) }\end{array}$ & $\begin{array}{l}\text { Aterro Brock } \\
\text { West, Ontario, } \\
\text { Canada }\end{array}$ & $\begin{array}{l}1000 \times 1000 \times 1000 \\
\mathrm{~mm}\end{array}$ & $\begin{array}{l}\text { Aterrados há mais } \\
\text { que } 10 \text { anos }\end{array}$ & $280 \mathrm{~mm}(28 \%)$ & $\begin{array}{l}\text { Variável, de } 60 \\
\text { a } 150 \mathrm{kPa}\end{array}$ & $\begin{array}{l}\mathrm{c}=14 \mathrm{kPa} \text { e } \varphi=36^{\circ} \\
\text { ou } \mathrm{c}=0 \mathrm{kPa} \text { e } \varphi=47^{\circ}\end{array}$ \\
\hline Kolsch (2009) & $\begin{array}{l}\text { Vários aterros da } \\
\text { Alemanha }\end{array}$ & $1000 \times 1800 \mathrm{~m}$ & $\begin{array}{l}\text { Novo a } 15 \text { anos de } \\
\text { aterramento. }\end{array}$ & $200 \mathrm{~mm}(20 \%)$ & $\begin{array}{l}\text { Variável, até } \\
300 \mathrm{kPa}\end{array}$ & $\begin{array}{l}\mathrm{c}<10 \mathrm{kPa}, \varphi=25- \\
30^{\circ} ; \zeta=25-35^{\circ}\end{array}$ \\
\hline $\begin{array}{l}\text { Reddy et al. } \\
(2009 a)\end{array}$ & $\begin{array}{l}\text { Aterro Orchard } \\
\text { Hills, Illinois, } \\
\text { EUA (biorreator) }\end{array}$ & $\begin{array}{l}63 \mathrm{~mm} \text { diâmetro } \mathrm{x} \\
49 \mathrm{~mm} \text { espessura }\end{array}$ & $\begin{array}{l}\text { Aterrado há 1,5 } \\
\text { anos }\end{array}$ & $13 \mathrm{~mm}(20 \%)$ & $\begin{array}{l}176,266,538 \mathrm{e} \\
774 \mathrm{kPa}\end{array}$ & $\begin{array}{l}\mathrm{c}=12-64 \mathrm{kPa}, \varphi=31- \\
35^{\circ}\end{array}$ \\
\hline $\begin{array}{l}\text { Reddy et al. } \\
(2009 a)\end{array}$ & $\begin{array}{l}\text { Aterro Orchard } \\
\text { Hills, Illinois, } \\
\text { EUA (biorreator) }\end{array}$ & $\begin{array}{l}63 \mathrm{~mm} \text { diâmetro } \mathrm{x} \\
49 \mathrm{~mm} \text { espessura }\end{array}$ & Novos & $13 \mathrm{~mm}(20 \%)$ & $\begin{array}{l}176,266,538 \mathrm{e} \\
774 \mathrm{kPa}\end{array}$ & $\begin{array}{l}\mathrm{c}=31-64 \mathrm{kPa}, \varphi=26- \\
30^{\circ}\end{array}$ \\
\hline Stoltz et al. (2009) & $\begin{array}{l}\text { Aterro sanitário na } \\
\text { França }\end{array}$ & $\begin{array}{l}300 \mathrm{~mm} \times 300 \mathrm{~mm} \times \\
180 \mathrm{~mm} \text { altura }\end{array}$ & Aterrado há 5 anos. & $35 \mathrm{~mm}(11 \%)$ & 50 a $350 \mathrm{kPa}$ & $\begin{array}{l}\mathrm{c}=0-36 \mathrm{kPa}, \varphi=28- \\
39^{\circ}\end{array}$ \\
\hline
\end{tabular}

(continua) 
(continuação da Tabela 3.6)

\begin{tabular}{|c|c|c|c|c|c|c|}
\hline Referência & Local & $\begin{array}{l}\text { Dimensões da cx de } \\
\text { ensaio }\end{array}$ & "idade" dos RSU & Deslocam. máx. & Sobrecarga & $\begin{array}{l}\text { Parâmetros de } \\
\text { resistência }\end{array}$ \\
\hline $\begin{array}{l}\text { Shariatmadari et } \\
\text { al. (2011) }\end{array}$ & $\begin{array}{l}\text { Aterro Kahrizak } \\
\text { Center, Teerã, Irã }\end{array}$ & $300 \times 300 \times 150 \mathrm{~mm}$ & Novos & $45 \mathrm{~mm}(15 \%)$ & $\begin{array}{l}20,50,100 \mathrm{e} \\
200 \mathrm{kPa}\end{array}$ & $\begin{array}{l}\mathrm{c}=10-21 \mathrm{kPa}, \varphi=7- \\
28^{\circ}\end{array}$ \\
\hline Reddy et al. (2011) & $\begin{array}{l}\text { Composição média } \\
\text { dos EUA }\end{array}$ & $\begin{array}{l}\text { Diâm. } 63 \mathrm{~mm} \text { e } \\
\text { altura } 34 \mathrm{~mm}\end{array}$ & $\begin{array}{l}\text { Degradados em } \\
\text { lisímetros e novos }\end{array}$ & $13 \mathrm{~mm}(20 \%)$ & $\begin{array}{l}32,87,179,271 \\
\text { e } 364 \mathrm{kPa}\end{array}$ & $\begin{array}{l}\mathrm{c}=1 \mathrm{kPa} \text { e } \varphi=35^{\circ} \\
\text { (novos); } \mathrm{c}=40 \mathrm{kPa} \text { e } \\
\varphi=28^{\circ} \text { (mais } \\
\text { degradados). }\end{array}$ \\
\hline Varga et al. (2011) & $\begin{array}{l}\text { Aterro Sanitário } \\
\text { Pusztazámor, na } \\
\text { Turquia }\end{array}$ & $\begin{array}{l}500 \times 500 \mathrm{~mm} . \\
\text { Altura de } 400 \mathrm{~mm}\end{array}$ & $\begin{array}{l}\text { Cconteúdo de } \\
\text { matéria orgânica de } \\
63 \% \text { a } 15 \%\end{array}$ & Não menciona & 0 a $200 \mathrm{kPa}$ & $\begin{array}{l}c=3,4-26,2 \mathrm{kPa}, \\
\varphi=19,8-36,0^{\circ}\end{array}$ \\
\hline Motta (2011) & $\begin{array}{l}\text { CTR Igarassu } \\
\text { (Pernambuco, BR) }\end{array}$ & $\begin{array}{l}600 \times 600 \mathrm{~mm} . \\
\text { Altura de } 600 \mathrm{~mm}\end{array}$ & $\begin{array}{l}\text { Fresco e misturado } \\
\text { com lodo de esgoto }\end{array}$ & $120 \mathrm{~mm}(20 \%)$ & 25 a $100 \mathrm{kPa}$ & $\begin{array}{l}\mathrm{c}=34 \mathrm{kPa}, \varphi=28^{\circ} \\
\text { (sem mistura) }\end{array}$ \\
\hline $\begin{array}{l}\text { Bareither et al. } \\
\text { (2012) }\end{array}$ & $\begin{array}{l}\text { Aterro em } \\
\text { Wisconsin e RSU } \\
\text { da Carolina do } \\
\text { Norte, EUA }\end{array}$ & $\begin{array}{l}\text { Diâm. } 280 \mathrm{~mm} \text { e } \\
\text { altura } 340 \mathrm{~mm}\end{array}$ & $\begin{array}{l}\text { Fresco e } \\
\text { envelhecido em } \\
\text { lisímetros }\end{array}$ & $62 \mathrm{~mm}(22 \%)$ & 12 a $90 \mathrm{kPa}$ & $\mathrm{c}=20 \mathrm{kPa}, \varphi=37^{\circ}$ \\
\hline
\end{tabular}

$\zeta=$ ângulo de tensão de tração, considerado no modelo proposto por Kolsch (1995). NM = não mencionado. 
Como exposto na Tabela 3.6, os equipamentos de cisalhamento direto utilizados têm dimensões bastante diversificadas. Um grupo limitado de pesquisadores utilizou equipamentos de pequenas dimensões (menores que $300 \mathrm{~mm}$ x $300 \mathrm{~mm}$ no plano de ensaio). Pesquisas em equipamentos de grandes dimensões são mais frequentes, destacando-se a utilização de equipamentos com dimensões métricas (Kolsch, 1995; Gotteland et al., 1995, 2000 e 2001, Ziehmann, 1999, dentre outros).

Entretanto, como os constituintes dos RSU incluem partículas com grandes dimensões, mesmo quando se utilizam equipamentos de grande porte para os ensaios há a necessidade de separar ou tratar os constituintes cujas dimensões são excessivas em relação às dimensões da caixa de ensaios. Não há um critério estabelecido com relação à dimensão máxima de partícula a ser incluída nos corpos de provas. Alguns grupos de pesquisa adotaram o critério da norma ASTM D3080 (ASTM, 2011), que estabelece que as partículas ensaiadas podem ter dimensão de até 1/12 do lado (ou diâmetro) da caixa de ensaio (Fucale, 2005; Reddy et al., 2009a,b, 2011).

Em outros casos, utilizaram-se partículas com até $1 / 5$ ou 1/6 do comprimento do lado da caixa, como é usual em mecânica dos solos. Athanasopoulos (2011) propõe que, para as partículas volumosas e duras, tais como pedaços de madeira, vidro e pedras, sejam respeitadas as dimensões de até 1/6 do lado da caixa de ensaio, enquanto que para os constituintes moles, tais como filmes plásticos e papéis, possam ser ensaiadas partículas com até $1 / 4$ do comprimento do lado da caixa, como foi o caso na pesquisa realizada por Zekkos (2005). Finalmente, alguns grupos de pesquisa realizaram ensaios com partículas que tinham comprimento de até metade do comprimento da caixa de ensaio (Dixon et al., 2008; Kolsch, 2009).

Para adequar o material constituinte dos RSU às restrições dimensionais do ensaio foram adotados critérios diferenciados nas várias pesquisas (Athanasopoulos, 2008):

- escalpelamento dos componentes com dimensões maiores que as especificadas para ensaio, excluindo-os da amostra;

- corte dos constituintes maiores, de tal forma que eles pudessem ser incorporados à amostra, ainda que suas dimensões originais não estivessem preservadas;

- trituração dos constituintes maiores, incorporando-os à amostra com dimensões e formas alteradas.

Com relação aos sistemas de carregamento dos diversos equipamentos de ensaio, para a aplicação das tensões normais são normalmente utilizados sistemas hidráulicos. O 
equipamento de grandes dimensões utilizado por De Lamare Neto (2004) e por Calle (2007) é uma exceção, pois realiza a aplicação da carga vertical por um sistema de pesos e alavancas. A duração da fase de adensamento nos ensaios é bastante diversificada. A título de exemplo, podemos citar que Bareither et al. (2012) mantiveram o carregamento vertical por 60 minutos antes de iniciar o cisalhamento. Jones et al. (1997) mantiveram o carregamento normal de um dia para o outro, Sadek et al. (2001) referem-se a 24 horas e Fucale (2005) manteve os carregamentos normais por períodos que variaram entre 48 e 72 horas, antes de cisalhar. Dixon et al. (2008) aplicavam uma pré-carga de $75 \mathrm{kPa}$ até estabilização dos recalques, descarregavam e depois aplicavam a tensão normal do ensaio por 15 minutos antes de começar a cisalhar. A maioria das pesquisas trabalhou com tensões confinantes de até 500 $\mathrm{kPa}$.

Para a realização do estágio de cisalhamento propriamente dito (aplicação do deslocamento horizontal) são utilizados sistemas hidráulicos ou fusos acoplados a motores. As velocidades de deslocamento aplicadas variaram de 0,024 a $10 \mathrm{~mm} / \mathrm{min}$.

Definindo-se deslocamento relativo máximo como a razão entre o comprimento máximo cisalhado no ensaio e o comprimento da caixa de ensaio, verifica-se que alguns equipamentos atingem menos que 10\% de deslocamento relativo máximo (Sadek et al., 2001; Caicedo et al., 2002a, b; Houston et al., 1995), enquanto outros são capazes de atingir grandes deslocamentos relativos máximos (até 50\%), como no caso das pesquisas realizadas por Martins (2006) e Cardim (2008).

Todos estes aspectos apenas evidenciam as dificuldades e a ausência de padronização ao se realizar ensaios com RSU para a determinação de seus parâmetros de resistência.

\subsubsection{Ensaios de cisalhamento simples}

Quanto aos ensaios de cisalhamento simples, a Tabela 3.7 resume as pesquisas realizadas com RSU. A relação tensão de cisalhamento-distorção obtida tipicamente nestes ensaios tem forma convexa, que pode tender a um valor assintótico para grandes deformações e algumas vezes exibe uma redução na resistência pós-pico, como ocorreu nos ensaios reportados por Pelkey et al. (2001), ou pode não apresentar um valor de resistência máxima, como ocorreu nos ensaios realizados por Kavazanjian et al. (1999), Harris et al. (2006) e Yuan et al. (2011). A Figura 3.8 ilustra esse comportamento típico. 
Tabela 3.7 - Ensaios de cisalhamento simples realizados em RSU

\begin{tabular}{|c|c|c|c|c|}
\hline Referência & Origem dos RSU & $\begin{array}{l}\text { Dimensões } \\
\text { do CP }\end{array}$ & $\begin{array}{l}\text { Tensões } \\
\text { normais }\end{array}$ & Parâmetros de resistência \\
\hline $\begin{array}{l}\text { Kavazanjian } \\
\text { et al. (1999) }\end{array}$ & $\begin{array}{l}\text { Aterro OII, } \\
\text { Califórnia, EUA, } \\
\text { resíduos aterrados } \\
\text { há vários anos }\end{array}$ & $\begin{array}{l}\text { Diâmetro de } \\
\text { 460mm }\end{array}$ & NM & $\begin{array}{c}\mathrm{c}^{\prime}=0 \mathrm{kPa} ; \varphi^{\prime}=30^{\circ} \\
\text { (interpret. cisalham. direto, } \\
10 \% \text { de distorção); } \mathrm{c}^{\prime}=16 \\
\text { a } 30 \mathrm{kPa} ; \varphi^{\prime}=33 \text { a } 59^{\circ} \\
\text { (interpret. máx. } \\
\text { obliquidade, } 10 \% \text { de } \\
\text { distorção) }\end{array}$ \\
\hline $\begin{array}{l}\text { Pelkey et al. } \\
\qquad(2001)\end{array}$ & $\begin{array}{c}\text { Canadá, } \\
\text { composição } \\
\text { sintética, produzida } \\
\text { com resíduos novos }\end{array}$ & $\begin{array}{c}434 \times 287 \\
\mathrm{~mm} \\
(\mathrm{~h}= \\
300 \mathrm{~mm})\end{array}$ & $\begin{array}{c}59 \text { a } 532 \\
\mathrm{kPa}\end{array}$ & $\begin{array}{c}\mathrm{c}^{\prime}=0 \mathrm{kPa} ; \varphi^{\prime}=29,4^{\circ} \\
\text { (interpret. cisalham. } \\
\text { direto) }\end{array}$ \\
\hline \multirow{2}{*}{$\begin{array}{l}\text { Harris et al. } \\
\quad(2006)\end{array}$} & $\begin{array}{l}\text { Aterro no estado de } \\
\text { Nova Iorque, EUA, } \\
\text { resíduos com mais } \\
\text { de } 10 \text { anos de } \\
\text { aterramento }\end{array}$ & \multirow{2}{*}{$\begin{array}{l}\text { Diâmetro de } \\
152 \mathrm{~mm} \text { e } \\
\text { alt. de } \\
50 \mathrm{~mm}\end{array}$} & \multirow{2}{*}{$\begin{array}{l}69 \text { a } 690 \\
\text { kPa } \\
\text { (ensaios } \\
\text { drenados e } \\
\text { não- } \\
\text { drenados) }\end{array}$} & $\begin{array}{c}\mathrm{c}^{\prime}=9,3 \mathrm{kPa} ; \varphi^{\prime}=28^{\circ} \\
\text { (interpret. máx. } \\
\text { obliquidade, } 30 \% \text { de } \\
\text { distorção) }\end{array}$ \\
\hline & $\begin{array}{l}\text { Aterro no estado de } \\
\text { Kentucky, EUA, } \\
\text { resíduos com } 2 \\
\text { anos de } \\
\text { aterramento }\end{array}$ & & & $\begin{array}{c}\mathrm{c}^{\prime}=11,6 \mathrm{kPa} ; \varphi^{\prime}=23,5^{\circ} \\
\text { (interpret. máx. } \\
\text { obliquidade, } 30 \% \text { de } \\
\text { distorção) }\end{array}$ \\
\hline $\begin{array}{l}\text { Finno et al. } \\
\text { (2007) }\end{array}$ & $\begin{array}{l}\text { Aterro de Tri- } \\
\text { Cities, Califórnia, } \\
\text { EUA (amostras } \\
\text { ensaiadas por } \\
\text { Zekkos, 2005) }\end{array}$ & $\begin{array}{l}\text { Retangulare } \\
\text { s, com } \\
375 \mathrm{~mm} \text { de } \\
\text { largura e } \\
500 \mathrm{~mm} \text { de } \\
\text { altura }\end{array}$ & $75 \mathrm{kPa}$ & NM \\
\hline $\begin{array}{l}\text { Yuan et al. } \\
\text { (2011) }\end{array}$ & $\begin{array}{l}\text { Resíduos com } 2 \text { a } \\
15 \text { anos de } \\
\text { aterramento, } \\
\text { provenientes do } \\
\text { Aterro de Tri- } \\
\text { Cities, Califórnia, } \\
\text { EUA }\end{array}$ & $\begin{array}{l}\text { Diâmetro de } \\
\text { 460mm }\end{array}$ & $75 \mathrm{kPa}$ & $\begin{array}{c}\mathrm{c}^{\prime}=0 \mathrm{kPa} ; \varphi^{\prime}=38 \text { a } 47^{\circ} \text { ou } \\
\mathrm{c}^{\prime}=15 \mathrm{kPa} ; \varphi^{\prime}=30 \mathrm{a} 41^{\circ} \\
\text { (interpret. cisalham. } \\
\text { direto) }\end{array}$ \\
\hline
\end{tabular}

$\mathrm{NM}=$ não mencionado 


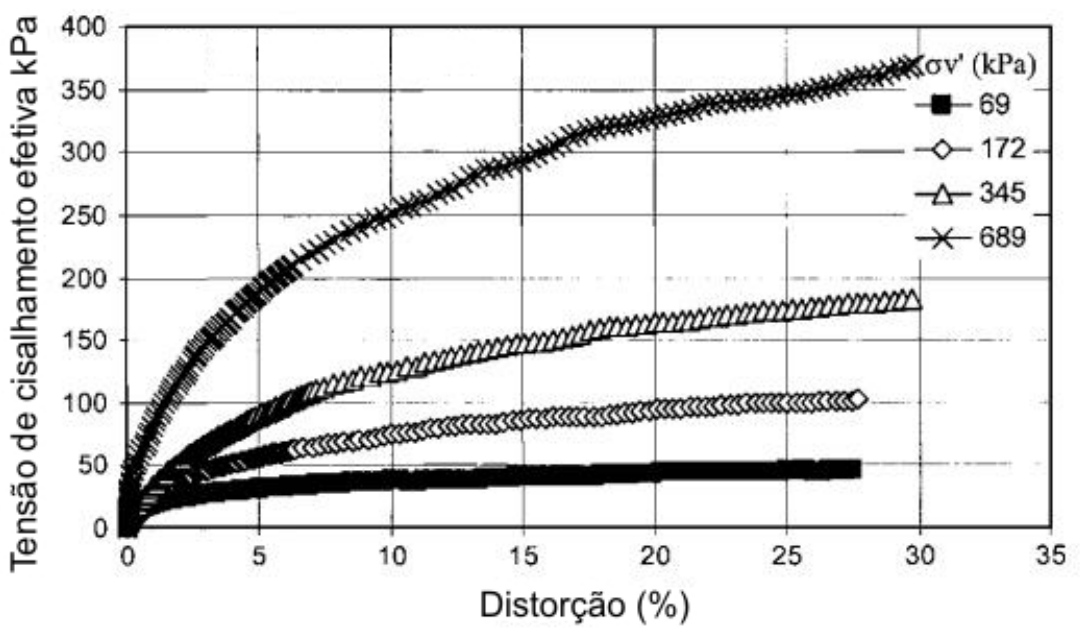

Figura 3.8 - Resultados típicos de RSU em ensaios de cisalhamento simples (extraído de Harris et al., 2006)

A interpretação dos resultados do ensaio de cisalhamento simples envolve a adoção de hipóteses sobre a posição do plano de ruptura, além da definição de uma distorção a ser considerada como aceitável para a obra em questão. Uma das possibilidades é a de se assumir que a ruptura ocorre em um plano horizontal, exatamente como se dá no ensaio de cisalhamento direto. No caso dos ensaios conduzidos com RSU este plano é também paralelo ao plano de compactação das amostras dentro da caixa de ensaios e resulta em valores mínimos para os parâmetros de resistência. Outra opção é considerar que a ruptura ocorre no plano em que atuam as tensões principais. Este plano não é conhecido a priori e o cálculo de sua posição exige que se conheça o valor do coeficiente de empuxo em repouso do material (Ko). Alguns grupos de pesquisa apresentaram interpretações baseadas nesta hipótese, assumindo diferentes valores de Ko. A Figura 3.9, apresentada por Kavazanjian et al. (1999), ilustra as diferenças entre os parâmetros de resistência obtidos considerando-se estas duas hipóteses para interpretação dos resultados dos ensaios. Neste caso assumiu-se Ko igual a 0,6.

Por outro lado, o trabalho de Finno et al. (2007) demonstrou que uma hipótese básica considerada nos dois tipos de interpretações apresentadas acima não é válida. Nos dois casos assume-se que a distribuição das tensões é uniforme ao longo do corpo de prova. Essa parece ser uma afirmação verdadeira para solos, porém Finno et al. (2007) constaram que isso não ocorre nos ensaios com RSU, principalmente para distorções maiores que $2 \%$. 


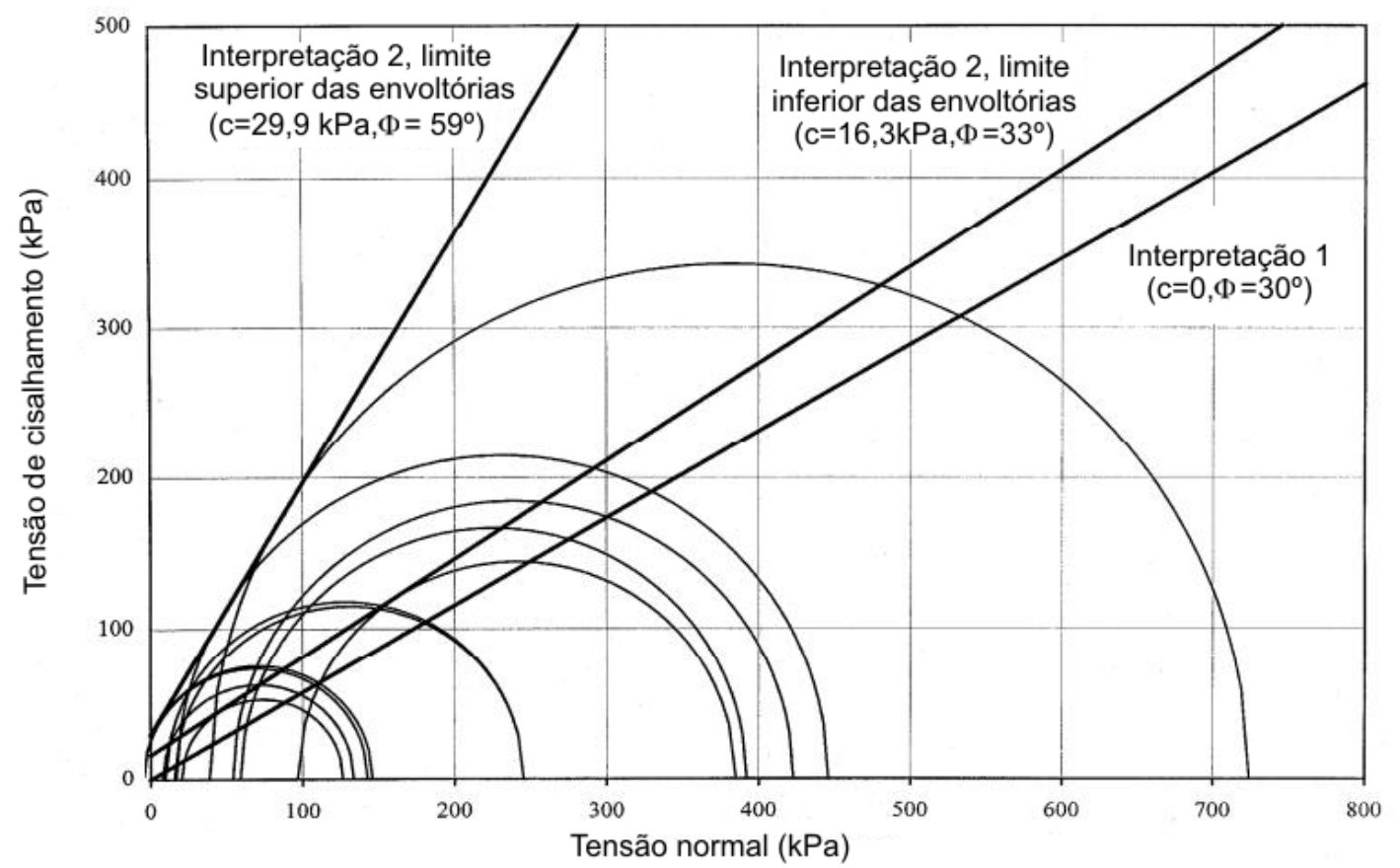

Figura 3.9 - envoltórias comparadas. (extraído de Kavazanjian et al., 1999)

\subsubsection{Efeito do "envelhecimento" dos RSU}

Como afirmam Bray et al. (2009) e Stoltz et al. (2009) há uma lacuna no conhecimento sobre os RSU com relação aos efeitos que a degradação tem sobre as propriedades geomecânicas dos RSU.

As pesquisas realizadas até hoje para investigação deste tema apresentam resultados contraditórios. Turczynski (1988), Kaimoto e Cepollina (1996), Caicedo et al. (2002b), Gabr et al. (2007a,b), Varga et al. (2011), Hossain e Haque (2009) e Reddy et al. (2009a) verificaram que ocorre diminuição da resistência mecânica com o envelhecimento dos resíduos. Zhan et al. (2008) concluíram o contrário, trabalhando com sobrecargas superiores a $50 \mathrm{kPa}$. Reddy et al. (2011) concluíram que o ângulo de atrito diminui e a coesão aumenta com a progressão da biodegradação, de tal forma que, para tensões confinantes menores que 240 $\mathrm{kPa}$ os resíduos mais degradados são mais resistentes e para tensões maiores que $240 \mathrm{kPa}$ ocorre o inverso.

Por outro lado, Zekkos (2005), Machado et al. (2006) e Nascimento (2007) concluíram que não há diferenças significativas nos parâmetros que caracterizam a resistência de resíduos de diferentes idades. 
Deve-se ressaltar que a idade dos resíduos, definida simplesmente como o tempo decorrido desde o seu aterramento, não traduz por si só informações suficientes para avaliação do estado de degradação dos mesmos.

O avanço do processo de biodegradação depende de uma série de fatores ambientais, econômicos e operacionais, que variam de aterro sanitário para aterro sanitário e o fato de um resíduo ter sido disposto há dez anos em um determinado aterro (por exemplo, em uma região árida, com pequena disponibilidade de água) não implica que ele está mais degradado que outro, depositado há dois anos em outro local (por exemplo, em uma região tropical, sem camada de cobertura, e, portanto, com abundância de água para a ocorrência dos processos de decomposição).

No item 3.3 são apresentadas as fases do processo de decomposição dos resíduos sólidos urbanos e os ensaios comumente utilizados para avaliação do estado de degradação dos resíduos, destacando-se quais foram os ensaios utilizados nas pesquisas que buscaram avaliar o efeito do "envelhecimento" sobre a resistência dos resíduos sólidos urbanos.

Além disso, em muitas das pesquisas que se propuseram a estudar o assunto, por exemplo, em Turkzynski (1988) e em Martins (2006), os resíduos ditos envelhecidos eram na realidade misturas de componentes pouco biodegradáveis novos, tais como plásticos, vidros, etc., e resíduos pré-tratados por sistemas aeróbios, por exemplo, aqueles resultantes de processos de compostagem. Como hipótese básica nessas pesquisas assume-se que o conjunto formado pela junção desses materiais teria o mesmo comportamento resistente que os resíduos com longo tempo de aterramento propriamente ditos.

Outro aspecto a ser considerado quando se analisa o envelhecimento dos maciços de RSU é o fato de que com o passar do tempo a proporção relativa do solo que compõe as camadas de cobertura aumenta. Isso ocorre porque as camadas de cobertura são normalmente formadas por materiais não degradáveis, enquanto que muitos dos constituintes dos resíduos são degradáveis, e o processo de degradação gera substâncias que deixam o maciço na forma de líquidos ou de gases. Além disso, com a evolução dos recalques e mudanças na estrutura física do aterro, as camadas de cobertura vão progressivamente sendo incorporadas às camadas de resíduos, havendo mistura entre os materiais.

A importância dos solos de cobertura na determinação do comportamento geotécnico dos RSU já é reconhecida há muitos anos. Kavazanjian et al. (1999), por exemplo, analisam a resistência das amostras ensaiadas em função da quantidade de partículas com dimensões 
menores que $20 \mathrm{~mm}$, pois os autores acreditam que até essa dimensão as partículas refletem em grande parte o comportamento dos solos de cobertura utilizados no aterro sanitário.

Hossain e Haque (2009) analisaram esse aspecto, submetendo amostras de resíduos em diversas fases de degradação, geradas em lisímetros operados em laboratório, a ensaios triaxiais drenados. Parte dos lisímetros recebeu inicialmente apenas resíduos e a outra parte recebeu resíduos e camadas de cobertura. A Figura 3.10 ilustra os resultados obtidos pelos autores. Para todas as fases de degradação, conforme aumenta a proporção em peso das camadas de cobertura, aumenta também a resistência do material. Nesse caso foram utilizadas camadas de cobertura arenosas.

Reddy et al. (2011) também estudaram a variação da resistência de resíduos degradados em lisímetros em laboratório, e concluíram que a coesão do material aumenta com a degradação, enquanto que o ângulo de atrito sofre descréscimo, como indicado na Figura 3.11. As amostras continham originalmente $40 \%$ em peso de solos locais, argilosos (classificados como CL) e arenosos (areias finas, classificadas como SP), que são os materiais comumente utilizados como camada de cobertura na região. Os autores atribuem o aumento da coesão dos resíduos à natureza argilosa do solo de cobertura, cuja porcentagem relativa tende a aumentar, conforme progride a biodegradação dos resíduos.

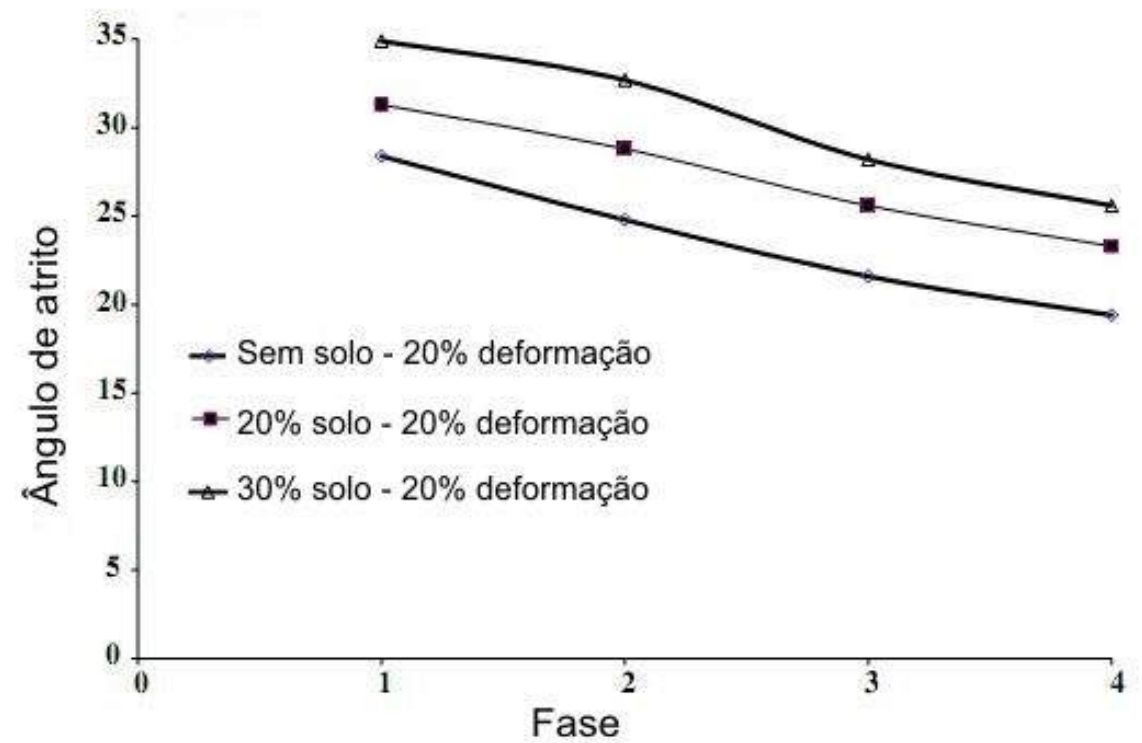

Figura 3.10 - Aumento do valor do ângulo de atrito com o aumento da quantidade de solo de cobertura, em todas as fases do processo de decomposição dos RSU. Fase 1 = anaeróbia ácida, Fase 2 = geração acelerada de metano, Fase3 = produção desacelerada de metano e Fase 4 = estabilização completa (extraído de Hossain e Haque, 2009). 


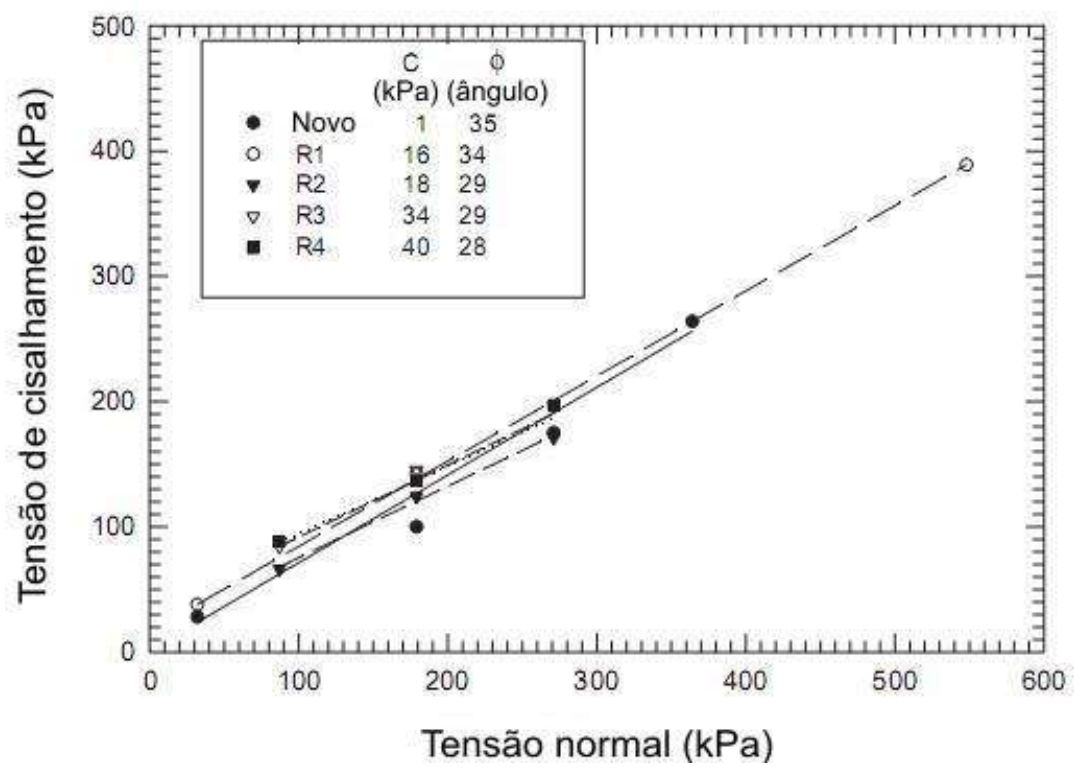

Figura 3.11 - Resultados dos ensaios de cisalhamento direto para os resíduos ensaiados em diferentes fases do processo de decomposição (extraído de Reddy et al., 2011)

Bareither et al. (2012) realizaram ensaios de cisalhamento direto sobre resíduos em diferentes estados de decomposição e com duas origens diferentes. Os resíduos foram degradados em lisímetros e o estágio de degradação foi controlado com ensaios físicoquímcios. Em um dos casos não há evidência clara de alteração dos parâmetros de resistência, enquanto que no outro o ângulo e atrito aumenta e a coesão diminui com o avanço da degradação. Ao compararem seus resultados a diversos outros relatados na literatura os autores aventam que talvez não exista uma relação única entre a resistência dos RSU e seu estado de degradação. Parece-lhes que os parâmetros de resistência são mais dependentes da composição inicial dos resíduos e de como esta composição vai se alterando ao longo da "vida" dos resíduos após aterramento, do que do estado de decomposição em si.

Deve-se ainda lembrar que, na prática, coexistem em um maciço de RSU materiais em diferentes estágios de degradação. De um lado, sempre há o aterramento de novos resíduos. Por outro lado, como as camadas de cobertura intermediárias tendem a constituir selos mais ou menos eficientes e isolar as células de resíduos, em um mesmo aterro podem existir partes mais degradadas, ao lado de outras menos degradadas.

Em vista disso, Hossain et al. (2003) advogam que não devem ser adotados valores globais para o maciço de resíduos como um todo, para caracterizar suas propriedades em estudos geotécnicos. Um modelo mais realista deveria adotar parâmetros diferenciados para as várias camadas do aterro, de acordo com seu estado de decomposição. 


\subsubsection{Importância dos materiais de reforço}

O comportamento de resistência dos RSU, como apresentado nas Figuras 3.2 e 3.5, assemelha-se ao de solos reforçados com fibras (Kolsch, 1990, apud Kolsch, 1993; Oweis, 1993; Manassero et al., 1996; entre outros). Em vista disso, diversas pesquisas procuraram estudar quais são os mecanismos que explicam esse "reforço".

Kolsch (1990, apud Kolsch, 1993) concluiu, a partir dos resultados de ensaios de cisalhamento direto, que esse efeito de reforço era devido à mobilização de tensões de tração em alguns dos componentes do RSU, principalmente os plásticos, os tecidos e outros materiais fibrosos. Nos seus ensaios esse efeito só era verificado para tensões normais acima de $200 \mathrm{kPa}$, o que foi atribuído ao fato de não haver ancoragem entre os materiais de reforço e a matriz básica dos RSU para tensões menores que essa.

Da idéia de que o resíduo se comporta como um solo reforçado decorre o conceito de que existe na composição dos resíduos um conjunto de materiais que forma a "matriz básica" (denominação adotada por Fucale, 2005; Nascimento, 2007, entre outros), ou um material "tipo-solo" (denominação "soil-like material”, adotada por Kavazanjian et al., 1999; Zekkos, 2005 e outros), ou uma "fração pastosa" (denominação adotada por Machado et al., 2002, 2006). Esse conjunto de componentes teria comportamento semelhante ao dos solos nãoreforçados, se ensaiado individualmente.

Entretanto, a definição do que seria esse material "tipo-solo" ainda não está clara. Zekkos et al. (2010b) defendem que esse material corresponde aos componentes do resíduo com dimensões inferiores a $20 \mathrm{~mm}$. Os resultados das pesquisas realizadas por De Lamare Neto (2004), por Zekkos (2005) e por Stoltz et al. (2009) contradizem essa afirmação.

De Lamare Neto (2004) ensaiou resíduos sólidos urbanos pré-tratados, provenientes do município do Rio de Janeiro, RJ. Em equipamento de cisalhamento direto de grandes dimensões foram realizados ensaios com partículas de até $19 \mathrm{~mm}$ e em equipamento de dimensões convencionais foram ensaiados os resíduos com até 9mm. Em ambos os casos os resíduos apresentaram comportamento semelhante ao de solos reforçados com fibras.

Zekkos (2005) realizou ensaios de cisalhamento direto de grandes dimensões em amostras de RSU com $100 \%$ de partículas inferiores a $20 \mathrm{~mm}$ e em amostras com apenas $62,1 \%$ de partículas menores que 20mm. Ambos os tipos de amostras apresentaram comportamento semelhante. 
Stoltz et al. (2009) realizaram ensaios de cisalhamento direto de grandes dimensões sobre amostras com 47,4\% em peso de partículas menores que $20 \mathrm{~mm}$, e sobre amostras compostas apenas por partículas menores que 20mm. Em ambos os casos os resíduos apresentaram um comportamento de endurecimento, sendo que as amostras compostas apenas por partículas menores que $20 \mathrm{~mm}$ apresentavam-se mais resistentes que as outras.

Nascimento (2007) realizou ensaios triaxiais do tipo CD em amostras de RSU saturadas, compostas apenas por partículas menores que $20 \mathrm{~mm}$ e das quais os componentes fibrosos foram eliminados por catação. $\mathrm{O}$ autor verificou que esse material apresenta, principalmente para as tensões de confinamento maiores $(200 \mathrm{kPa})$, uma tendência ao amolecimento, com a configuração de uma resistência de pico e de uma resistência residual.

Esse conjunto de resultados sugere que a natureza das partículas seja mais importante do que a sua dimensão para determinação da sua contribuição com relação ao "reforço" dos RSU.

Outra linha de pesquisadores advoga que os componentes dos RSU com dimensões inferiores a 8mm correspondem aos materiais "tipo-solo". Os resultados das pesquisas de Fucale (2005) e de Bauer et al. (2007) corroboram essa afirmação.

Nos ensaios de cisalhamento direto realizados por Fucale (2005) sobre a matriz básica, a tensão cisalhante cresce com o aumento do deslocamento horizontal, atingindo um valor máximo, e em seguida reduz até alcançar a resistência pós-pico, que se mantém aproximadamente constante até o final do ensaio. Este tipo de comportamento de pico não é constatado quando o material é composto não apenas pela matriz básica, mas também pela matriz fibrosa, como é o caso das amostras da matriz composta e composta reforçada. A resistência na matriz composta sofre um aumento com o deslocamento horizontal, sem atingir um pico, mas demonstrando uma leve tendência à estabilização nas tensões de 50 e $100 \mathrm{kPa}$. No caso da matriz composta reforçada, a tensão cisalhante também cresce com os deslocamentos, porém, com exceção da tensão normal de $50 \mathrm{kPa}$, não indica uma constância dos valores, mas sim uma tendência de aumento até mesmo para a condição final do ensaio, onde ocorreram $20 \%$ de deslocamento horizontal do material.

Bauer et al. (2007) ensaiaram resíduos pré-tratados pelo método MBT, com partículas de até $60 \mathrm{~mm}$, e ensaiaram a matriz básica desses resíduos em equipamentos de cisalhamento direto, variando a umidade das amostras. Para estes autores a matriz básica era composta pelas partículas com até $8 \mathrm{~mm}$. Eles relatam que a matriz básica apresentou resistência de pico 
e resistência residual, caracterizando-se como um material "tipo-solo", enquanto que o resíduo pré-tratado apresentou comportamento característico de RSU.

Outro aspecto a respeito do qual os resultados das diversas pesquisas são controversos é o efeito que a adição dos elementos de reforço tem sobre a resistência mecânica dos RSU, expressa segundo o critério de Mohr-Coulomb.

Por exemplo, Calle (2007) realizou ensaios de cisalhamento direto com a fração dos resíduos passante na malha de $0,2 \mathrm{~mm}$. As amostras foram ensaiadas no estado fofo, inicialmente sem plásticos, e depois com a adição de $0,05 \%$ e $0,15 \%$ de plásticos moles, dispostos em duas camadas horizontais. O autor verificou que o ângulo de atrito do material não era alterado pela adição de plástico, enquanto que a coesão era fortemente dependente dessa adição. No geral, as amostras com maior quantidade de plástico apresentavam-se mais resistentes. A Figura 3.12 ilustra os resultados obtidos pelo autor.
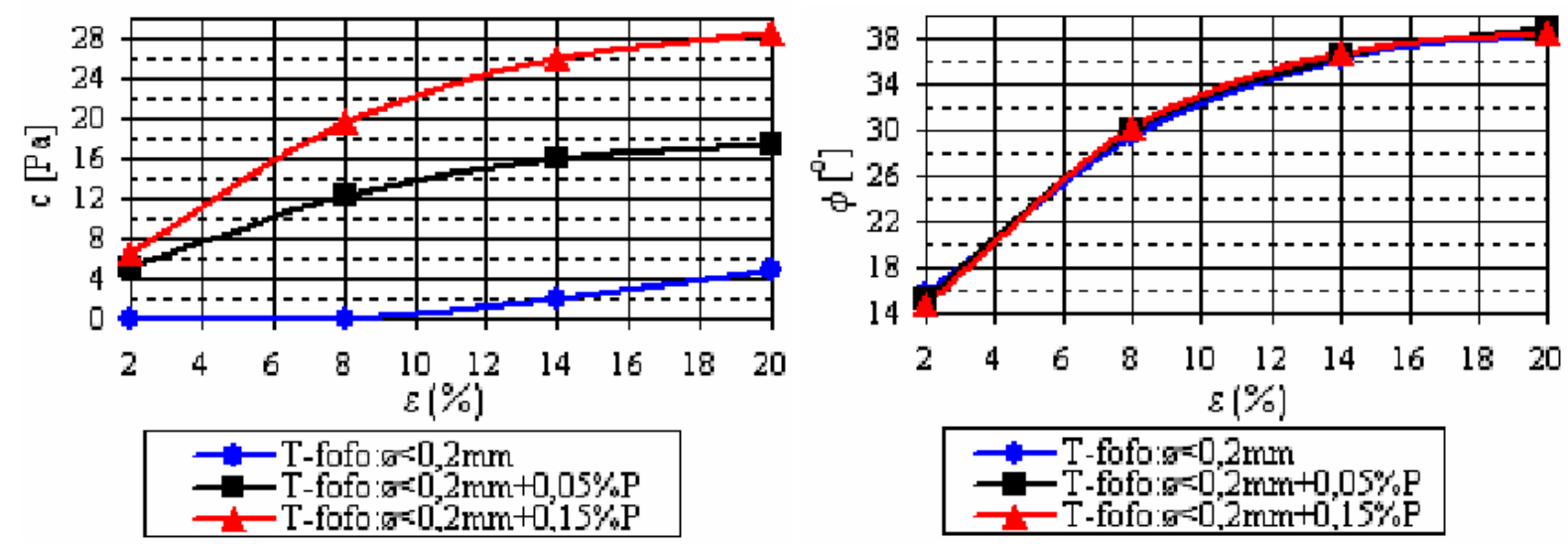

Figura 3.12 - Variação dos parâmetros de resistência em função do conteúdo de plástico na amostra de resíduo triturado ensaiada (extraído de Calle, 2007).

Os resultados obtidos por Fucale (2005) indicam que o aumento do conteúdo de fibras aumenta a resistência do material, mas não indefinidamente. No caso da amostra denominada de matriz composta 1 (matriz reforçante/matriz básica=20\%), que possuía o dobro da quantidade de fibras em relação à amostra denominada matriz composta 2 (matriz reforçante/matriz básica $=10 \%$ ), a resistência foi inferior em todas as tensões normais de ensaio. Para explicar esse resultado, a autora argumenta que grande parte dos elementos de reforço na matriz composta 1 tenha deslizado entre si, ao invés de ser tracionado. 
Shariatmadari et al. (2011) realizaram ensaios de cisalhamento direto sobre resíduos novos com diferentes conteúdos de fibras e observaram que o aumento deste conteúdo diminuiu sistematicamente a resistência do material. Reiterando as conclusões apresentadas anteriormente por Landva e Clark (1990), na situação extrema em que a amostra é composta exclusivamente por plásticos foram registradas as menores resistências, como apresentado na Figura 3.13 a seguir.

Por outro lado, Karimpour-fard et al. (2011) verificaram que a resistência dos RSU aumentou sistematicamente com o aumento do conteúdo de fibras. Os autores estudaram resíduos novos em ensaios triaxiais $\mathrm{CD}$ e $\mathrm{CU}$, com conteúdos de fibras variando de 0 a $25 \%$ e seus resultados estão apresentados na Figura 3.14.

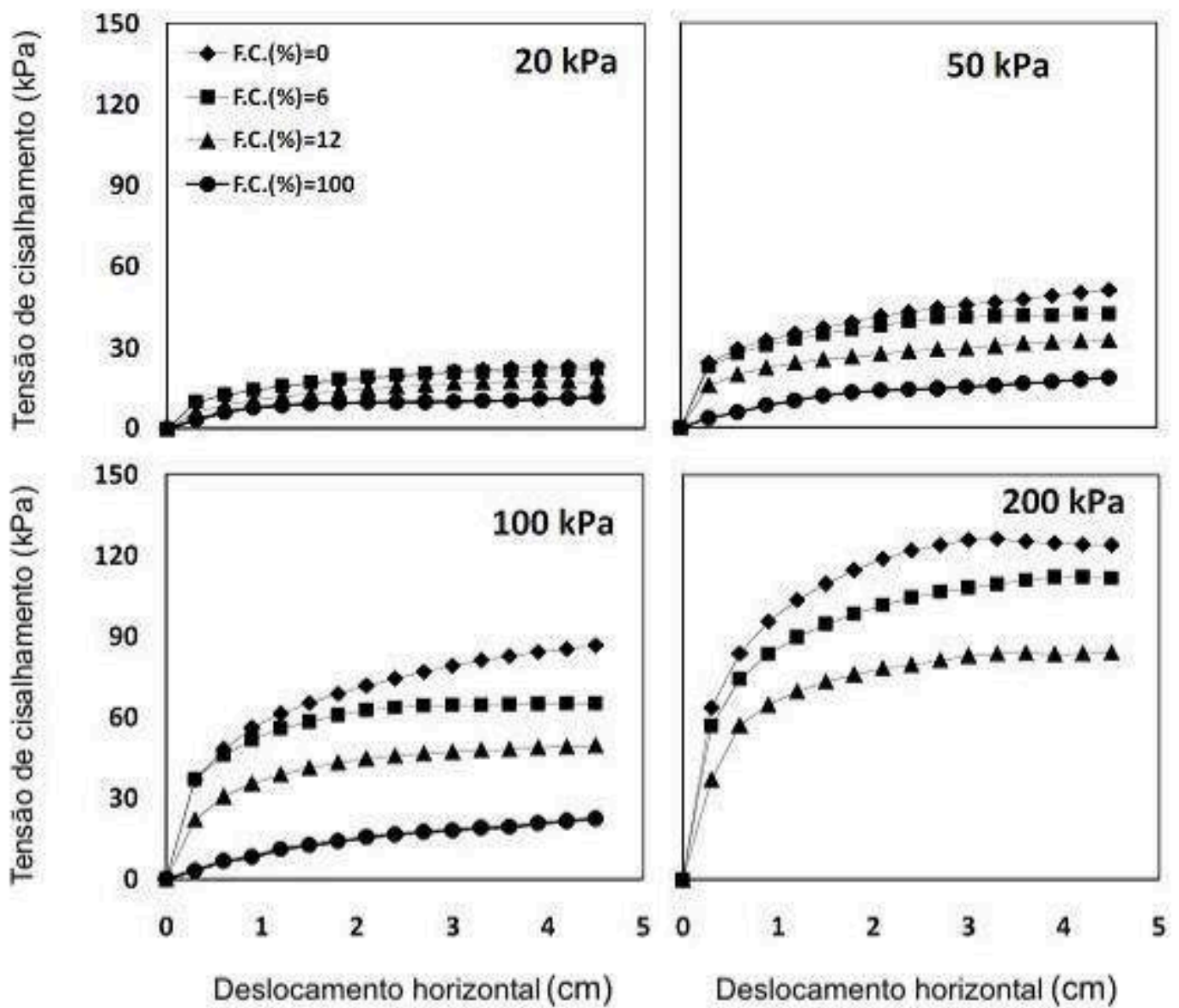

Figura 3.13 - Resultados do ensaio de cisalhamento direto para diferentes conteúdos de fibra na amostra (F.C. $=$ fiber content) (extraído de Shariatmadari et al., 2011). 

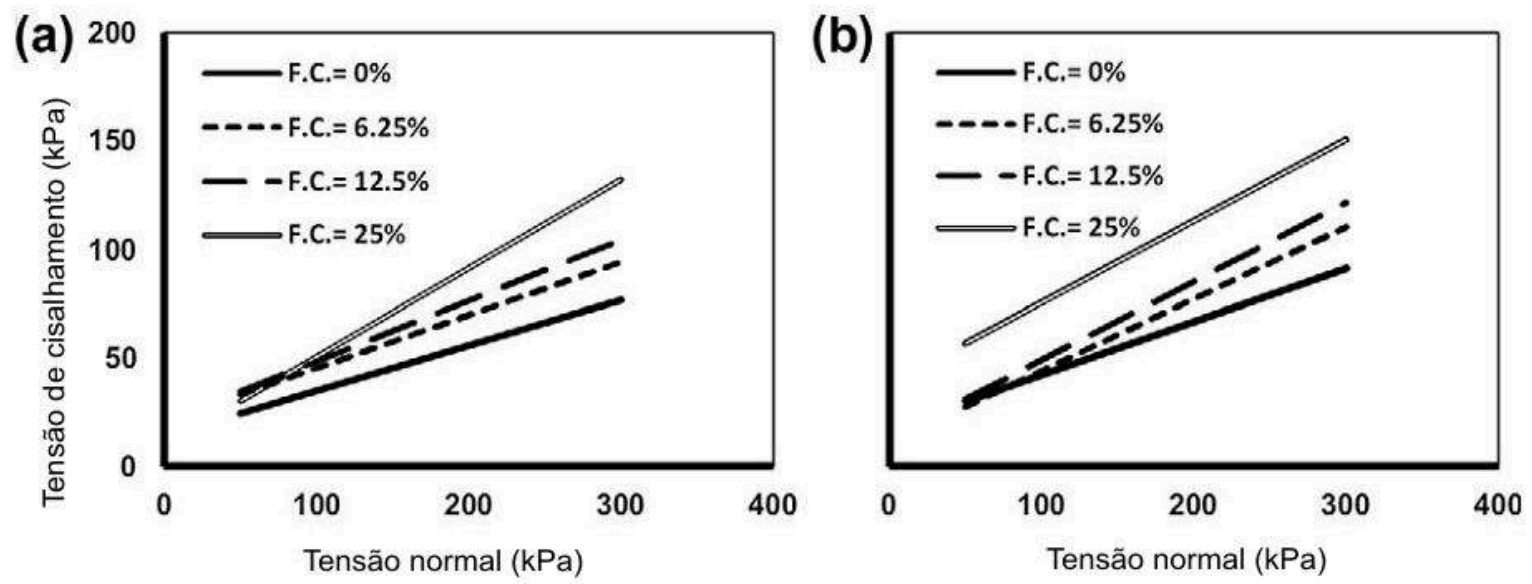

Figura 3.14 - Envoltórias de resistência para RSU com diferentes conteúdos de fibras (F.C. = fiber content) em ensaios triaxiais (a) em condições não-drenadas e (b) em condições drenadas (extraído de Karimpour-fard et al., 2011).

Com relação a essas controvérsias, deve-se lembrar que a composição dos RSU é muito variável de um local para outro e os resultados obtidos são específicos para o material ensaiado, sendo que, na maioria das vezes, não podem ser extrapolados para outras localidades.

Outrossim, as condições e os tipos de ensaio realizados em cada uma das pesquisas são diferentes e isso deve ser considerado no momento de se compararem os resultados obtidos em cada uma delas. Esse aspecto também é discutido no item seguinte.

\subsubsection{Anisotropia}

Nas paredes de escavações realizadas em aterros sanitários diversos pesquisadores observaram que o material exposto apresentava uma espécie de estratificação, com alguns dos componentes dos resíduos, especialmente os plásticos, os tecidos e as madeiras, com seus eixos maiores orientados preferencialmente na horizontal, de forma similar a uma estratificação (Cowland et al., 1993, Kavazanjian, 2006).

Zekkos et al. (2011) apresentaram as imagens obtidas com a filmagem das paredes das perfurações de grande diâmetro realizadas no aterro OII na California, que evidenciam que os RSU estavam estruturados em camadas horizontais.

Essas observações fazem com que seja esperado um comportamento anisotrópico dos RSU em relação a suas propriedades mecânicas, o que vem sendo confirmado pelos resultados das pesquisas que enfocaram esse aspecto da mecânica dos RSU. 
Zekkos (2005) e Zekkos et al. (2010a) realizaram ensaios de cisalhamento direto sobre amostras com as fibras orientadas paralelamente ao plano de corte e perpendicularmente a ele. A Figura 3.15 ilustra os resultados obtidos pelos autores. Para amostras com a mesma composição, mesma umidade e peso específico, as amostras com fibras paralelas ao plano de cisalhamento exibiram maior resistência para os deslocamentos iniciais, mas, conforme progrediram os deslocamentos, foram sempre as amostras com fibras orientadas perpendicularmente ao plano de cisalhamento que exibiram maiores resistências. Além disso, a forma das curvas é diferente nas duas situações: para as amostras com fibras paralelas ao plano de cisalhamento o comportamento é de ruptura "por deformação excessiva", enquanto que nas amostras com fibras perpendiculares ao plano de ensaio o comportamento é de endurecimento.

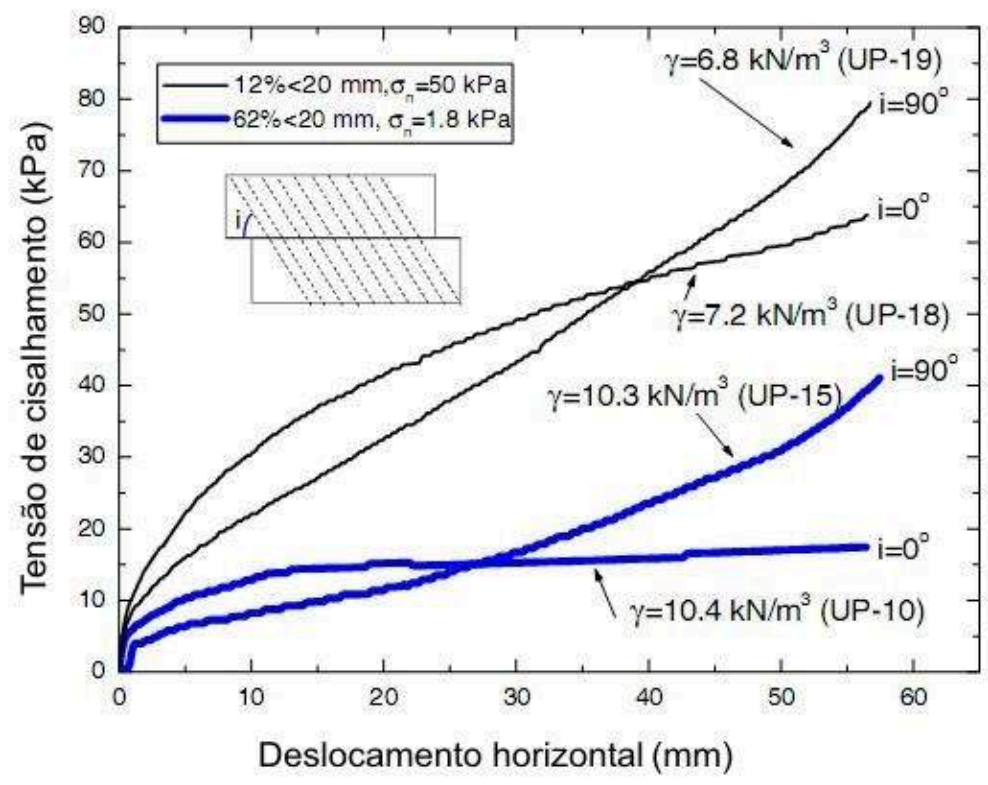

Figura 3.15 - Efeito do conteúdo de material fibroso e de sua orientação em relação à superfície de cisalhamento, em ensaios de cisalhamento direto (extraído de Zekkos et al., 2010a).

Athanasopoulos et al. (2008) estudaram o efeito que diferentes materiais de reforço têm sobre composições artificiais de RSU. Eles realizaram ensaios de cisalhamento direto sobre amostras de partículas de RSU com até $20 \mathrm{~mm}$, reforçadas por pedaços de sacolas plásticas, de madeira e de papel, cortados a partir de materiais novos, não aterrados. Os autores variaram a orientação dos reforços, que foram intercalados ao RSU em camadas distintas. A Figura 3.16 apresenta uma das amostras, preparada com orientação de $60^{\circ}$ em relação ao plano de cisalhamento. Foram estudados reforços colocados a $0^{\circ}, 30^{\circ}, 60^{\circ}$ e $90^{\circ}$ com relação ao plano de ensaio. 


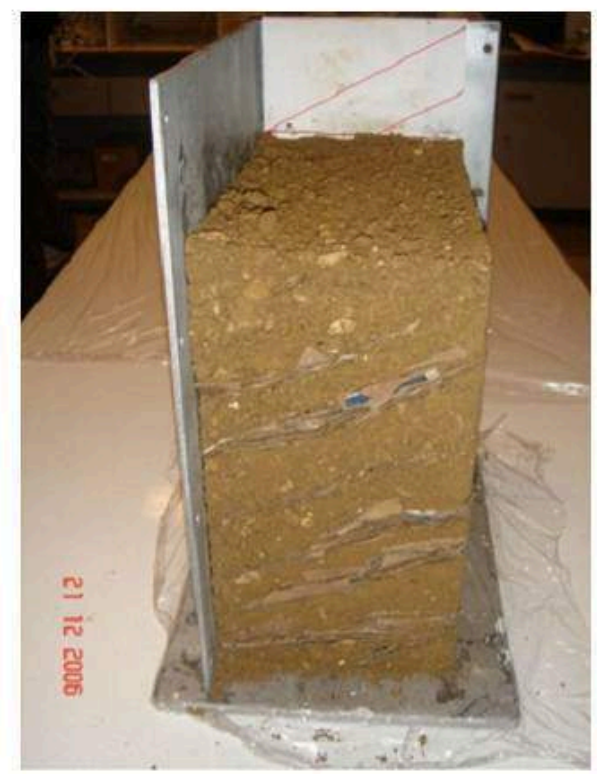

Figura 3.16 - Aspecto do corpo de prova no molde (extraído de Athanosopoulos et al., 2008).

A Figura 3.17 apresenta os resultados obtidos pelos autores. De forma semelhante aos resultados obtidos por Zekkos (2005) e Zekkos et al. (2010a) os ensaios realizados com os reforços a $0^{\circ}$ apresentam a menor resistência. $O$ formato da curva também sofre alteração, passando de um comportamento de ruptura "por excesso de deformação" para um comportamento de endurecimento. Os autores verificaram que a máxima resistência ocorre para reforços inclinados $60^{\circ}$ em relação ao plano de cisalhamento do ensaio.

Shariatmadari et al. (2009) destacam a importância desse comportamento anisotrópico na interpretação de ensaios triaxiais não drenados realizados sobre RSU. No gráfico da Figura 3.18, apresentada a seguir, os autores apresentam a relação entre as deformações axiais e radiais, nas fases de adensamento dos ensaios triaxiais realizados na pesquisa, evidenciando que o comportamento das amostras era marcadamente anisotrópico. O gráfico apresentado na Figura 3.18 exemplifica como a interpretação dos resultados dos ensaios CU pode ser afetada pelo fato de se considerar ou não o comportamento dos resíduos como anisotrópico.

Zekkos (2005), Athanasopoulos et al. (2008) e Shariatmadari et al. (2011) atribuem à anisotropia as diferenças de comportamento que os RSU exibem em ensaios triaxiais e em ensaios de cisalhamento direto. Como apresentado no item 3.1, nos ensaios triaxiais o RSU exibe endurecimento, enquanto que nos ensaios de cisalhamento direto o material tende a apresentar ruptura do tipo plástico, ou "por deformação excessiva", pelo menos para os níveis de deformação (ou deslocamento) a que os equipamentos em geral conseguem submeter as amostras. Os autores atribuem essa diferença de comportamento ao fato de o ensaio de 
cisalhamento direto romper o material na direção paralela à dos plásticos, enquanto que nos ensaios triaxiais a resistência é mobilizada em um ângulo oblíquo a essa direção. Segundo Zekkos (2005) os ensaios de cisalhamento direto permitem a determinação de uma resistência mínima do material, pois a superfície de ruptura é paralela à direção de maior fraqueza do mesmo.

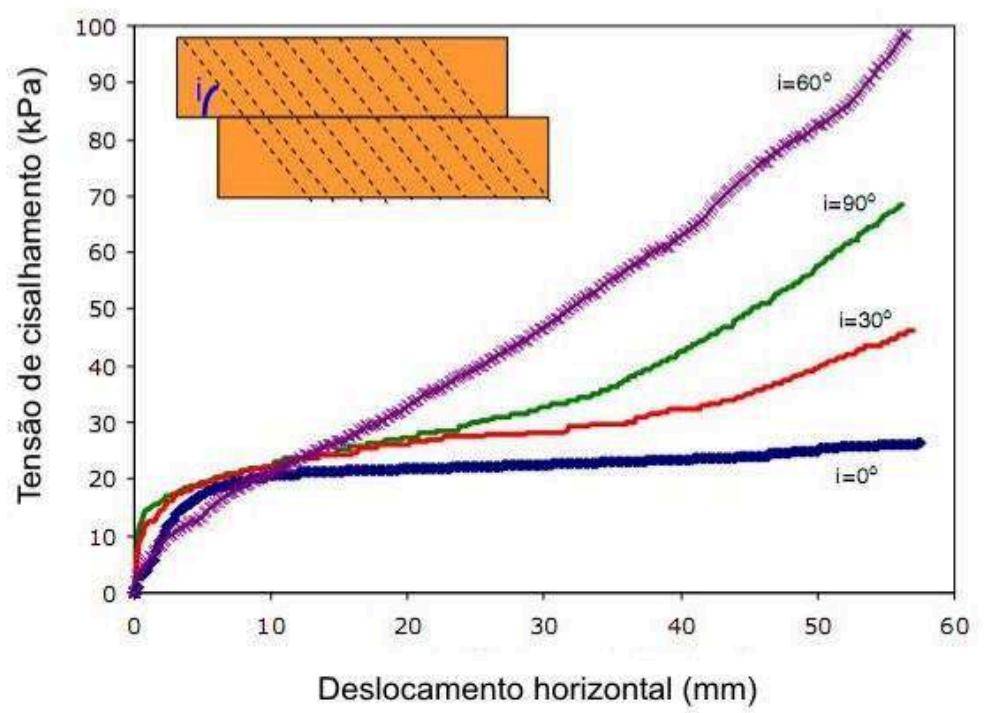

Figura 3.17 - Efeito do conteúdo de material fibroso e de sua orientação em relação à superfície de cisalhamento, em ensaios de cisalhamento direto (extraído de Athanasopoulos et al., 2008)

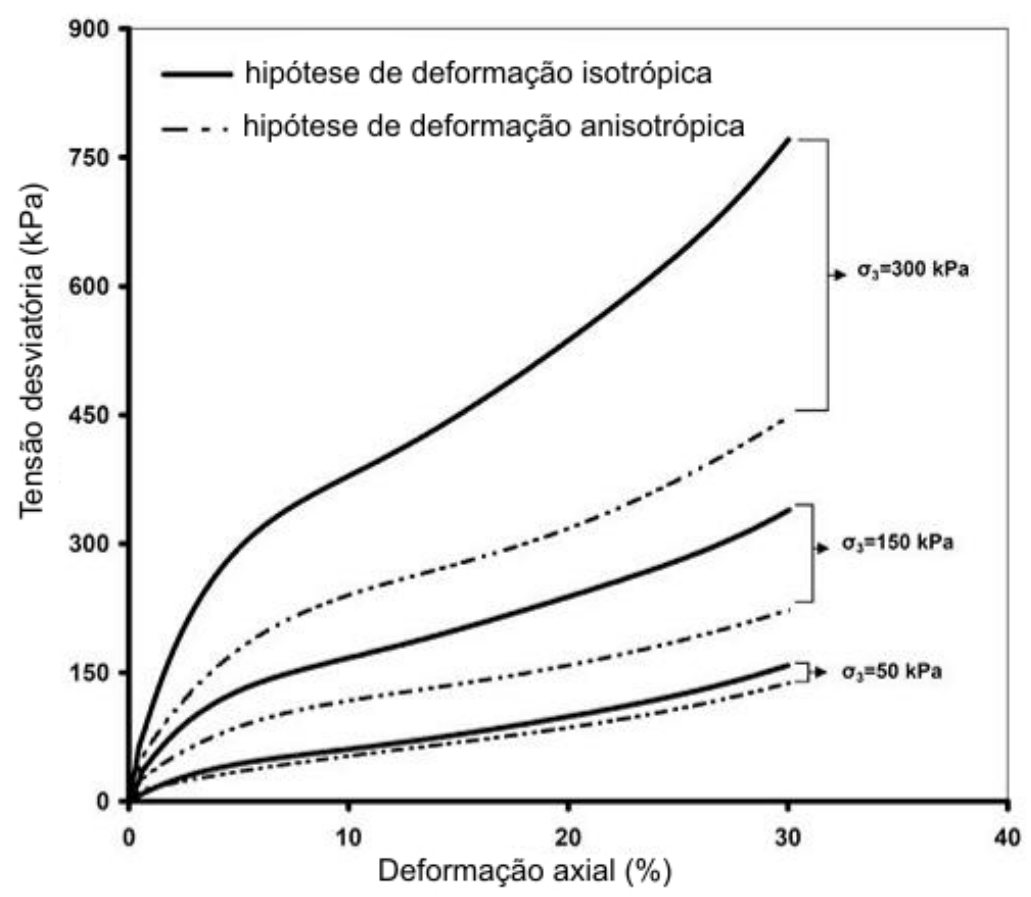

Figura 3.18 - Diferentes tensões desviatórias calculadas na interpretação de ensaios triaxiais em RSU, considerando-se deformação isotrópica ou anisotrópica (extraído de Shariatmadari et al., 2009). 
Abbiss (2001) realizou determinações do módulo cisalhante horizontal e vertical para pequenas deformações (métodos geofísicos) em um aterro sanitário da Inglaterra e constatou que a rigidez na direção horizontal é cerca de quatro vezes maior que na direção vertical.

\subsubsection{Envoltórias de resistência}

Apesar de todas as dificuldades e controvérsias que a determinação de parâmetros de resistência para maciços de RSU envolvem, diversos autores propuseram envoltórias de resistência para caracterizar o comportamento destes materiais. A Tabela 3.8 apresenta algumas destas envoltórias, bem como a forma como elas foram obtidas (retroanálises, revisão da literatura sobre o assunto, ensaios de laboratório ou uma combinação delas). A Tabela 3.9 apresenta os resultados de retroanálises desenvolvidas para casos de rupturas ocorridas no Brasil e que foram divulgadas na literatura técnica. Da observação destas duas tabelas depreende-se que, apesar do grande número de pesquisas já realizadas sobre o assunto, ainda não há realmente consenso sobre quais são os valores adequados para representar a resistência dos RSU. No geral, as envoltórias propostas na literatura internacional representam um material mais resistente que aquelas propostas na literatura nacional, principalmente para tensões de confinamento mais elevadas.

Tabela 3.8 - Algumas das envoltórias de resistência propostas para RSU

\begin{tabular}{ccccc}
\hline Referência & $\begin{array}{c}\text { Coesão } \\
(\mathrm{kPa})\end{array}$ & $\begin{array}{c}\text { Ângulo de } \\
\text { Atrito (graus) }\end{array}$ & $\begin{array}{c}\text { Tensões } \\
\text { normais }(\mathrm{kPa})\end{array}$ & Dados \\
\hline $\begin{array}{c}\text { Kavazanjian et al. } \\
(1995)\end{array}$ & 24 & 0 & $0-30$ & $\begin{array}{c}\text { Revisão da literatura e } \\
\text { análise de taludes estáveis }\end{array}$ \\
\cline { 2 - 5 } & 0 & 33 & $30-350$ & $\begin{array}{c}\text { Revisão da literatura e } \\
\text { análise de taludes estáveis }\end{array}$ \\
\hline $\begin{array}{c}\text { Kavazanjian et al. } \\
(1999)\end{array}$ & 43 & 31 & $0-1800$ & $\begin{array}{c}\text { Ensaios de cisalhamento } \\
\text { simples }\end{array}$ \\
\hline $\begin{array}{c}\text { Eid et al. (2000) } \\
\text { Kavazanjian (2008) }\end{array}$ & 0 & 35 & $0-400$ & $\begin{array}{c}\text { Revisão da literatura e } \\
\text { retroanálise de rupturas. }\end{array}$ \\
\hline Stark et al. (2009) & 6 & 30 & $0-600$ & $\begin{array}{c}\text { Revisão da literatura } \\
\text { Revisão da literatura e } \\
\text { retroanálise de 7 rupturas } \\
\text { no mundo todo. }\end{array}$ \\
\hline Zekkos et al. (2010a) & 15 & $36\left(\Delta \varphi=5^{\circ}\right)^{*}$ & 0 a 1000 & $\begin{array}{c}\text { Ensaios de cisalhamento } \\
\text { direto }\end{array}$ \\
\hline
\end{tabular}

(*) Ângulo de atrito definido para pressão atmosférica. Sofre redução, conforme aumenta a tensão normal 
Tabela 3.9 - Resultados de retroanálises de rupturas no Brasil

\begin{tabular}{|c|c|c|c|c|}
\hline Referência & $\begin{array}{c}\text { Coesão } \\
(\mathrm{kPa})\end{array}$ & $\begin{array}{c}\text { Ângulo de } \\
\text { Atrito (graus) }\end{array}$ & Característica assumida & Dados \\
\hline $\begin{array}{l}\text { Benvenuto e } \\
\text { Cunha (1991) }\end{array}$ & 13,5 & 22 & $\begin{array}{l}\text { Elevadas pressões } \\
\text { neutras, resíduo antigo }\end{array}$ & $\begin{array}{l}\text { Retroanálise de } \\
\text { ruptura no Aterro } \\
\text { Bandeirantes, em } \\
\text { São Paulo }\end{array}$ \\
\hline \multirow{3}{*}{$\begin{array}{c}\text { Kaimoto e } \\
\text { Cepolina (1996) }\end{array}$} & 13,5 & 22 & $\begin{array}{l}\text { Elevadas pressões } \\
\text { neutras, resíduo antigo }\end{array}$ & \multirow{3}{*}{$\begin{array}{c}\text { Monitoramento da } \\
\text { operação do Aterro } \\
\text { Bandeirantes, em } \\
\text { São Paulo }\end{array}$} \\
\hline & 16 & 22 & $\begin{array}{l}\text { Resíduos dispostos há } \\
\text { mais que } 2 \text { anos, } \\
\text { maciço com drenagem }\end{array}$ & \\
\hline & 16 & 28 & $\begin{array}{l}\text { Resíduos dispostos há } \\
\text { menos que } 2 \text { anos, } \\
\text { maciço com drenagem }\end{array}$ & \\
\hline $\begin{array}{c}\text { Ecourbis } \\
\text { Ambiental SA }\end{array}$ & 19 & 28 & Resíduo antigo & \multirow{2}{*}{$\begin{array}{c}\text { Retroanálise de } \\
\text { ruptura do Aterro } \\
\text { Sítio São João, em } \\
\text { São Paulo }\end{array}$} \\
\hline $\begin{array}{c}\text { (2007, apud } \\
\text { Campi e } \\
\text { Boscov, 2011) }\end{array}$ & 13,5 & 22 & Resíduo recente & \\
\hline
\end{tabular}

\subsection{Decomposição dos RSU em aterros sanitários}

A degradação dos RSU em aterros sanitários é um processo longo, que depende da velocidade de degradação dos diferentes substratos, e sequencial, em razão dos metabolismos distintos que se sucedem e se superpõem. Há diversos modelos propostos na literatura para demonstrar as diferentes etapas que conduzem à estabilização dos resíduos (Borges de Castilho et al., 2003).

Barlaz et al. (1989, apud Hossain et al., 2003) e Christensen e Kjeldsen (1995, apud Kjeldsen et al., 2002) dividem os processos que se sucedem na decomposição dos RSU em quatro fases: fase aeróbia (fase 1), fase anaeróbia ácida (fase 2), fase de produção acelerada de metano (fase 3) e fase de produção desacelerada de metano (fase 4).

A fase 1 inicia-se logo após a cobertura dos resíduos em um aterro sanitário e corresponde ao consumo do oxigênio aprisionado no interior da célula confinada para degradação dos RSU. O principal gás formado nesta fase é o $\mathrm{CO}_{2}$. Sua duração é 
relativamente curta, em média um mês em aterros com espessuras superiores a 3 metros, segundo Borges de Castilho et al. (2003).

Com a diminuição da quantidade de oxigênio começam a predominar os organismos anaeróbios facultativos, iniciando-se a fase 2 (anaeróbia ácida). Esta fase é caracterizada pela geração e pelo acúmulo de diversos tipos de ácidos (por exemplo, ácidos acético, butírico e propiônico), o que torna o $\mathrm{pH}$ do meio baixo e praticamente não há decomposição da matéria orgânica.

Com a extinção total do oxigênio disponível no meio e a evolução do processo de degradação, estabelecem-se as condições para a proliferação dos organismos estritamente anaeróbios, denominados bactérias metanogênicas. É a fase 3 do processo de decomposição dos RSU, onde os ácidos carbônicos acumulados anteriormente são transformados em $\mathrm{CH}_{4} \mathrm{e}$ $\mathrm{CO}_{2}$ e o pH aumenta. Nesta fase a taxa de produção do gás metano é máxima. Na fase 4 a taxa de produção de gases pelo processo anaeróbio de degradação dos RSU decai, mantendo-se as condições de $\mathrm{pH}$ do meio.

O processo de degradação dos RSU depende de uma série de fatores, a saber:

- composição inicial dos RSU;

- condições de disposição do resíduo (eficiência da compactação, utilização de cobertura diária, entre outros);

- disponibilidade de água no maciço de resíduos (relacionado com a existência e com a eficiência dos sistemas de drenagem do maciço, com o clima da região; com a existência e com a eficiência dos sistemas de cobertura, com a composição inicial do resíduo, com a forma de operação do aterro, por exemplo, com recirculação de líquidos lixiviados, etc.)

- disponibilidade de oxigênio no maciço de resíduos.

Os processos biológicos (biodegradação), hidráulicos (condutividade, caminhos preferenciais de percolação, grau de saturação) e físicos (densidade, porosidade) estão intimamente relacionados em um maciço de RSU, e são determinantes para a evolução da composição dos RSU ao longo do tempo.

A caracterização do estado de decomposição dos resíduos não pode ser realizada exclusivamente com a informação sobre o tempo decorrido entre sua disposição no aterro e o tempo presente, pois, como mencionado no item 3.2.4, aterros situados em diferentes regiões geográficas, operados de formas diversas ou que recebem RSU com composição ou umidade 
inicial variadas podem apresentar diferenças significativas na evolução dos processos de biodegradação.

É necessário realizar ensaios de caracterização para que se possa definir quão avançado está o processo de degradação em um maciço de RSU. Os ensaios comumente utilizados para tal fim são descritos a seguir.

\subsubsection{Ensaios para caracterização do estado de decomposição dos RSU}

As caracterizações do estado de decomposição dos RSU por meio de ensaios físicoquímicos (e não apenas pelo tempo de aterramento dos resíduos) são realizadas por diversos motivos. Por exemplo, Attal et al. (1992), Akunna et al. (2009) e Britto (2006) visavam a estimativa do potencial de geração de gás metano pela decomposição dos resíduos em aterros sanitários; Reinhart e Al-Yousfi (1996) e Barlaz et al. (2010) pretendiam avaliar a eficiência da operação de aterros como biorreatores para aceleração do processo de decomposição dos resíduos; Zekkos (2005), Fucale (2005), Machado et al. (2006), Nascimento (2007), Singh (2008), Hossain e Haque (2009) e Bareither et al. (2012) visavam correlacionar as propriedades geotécnicas dos RSU com seu estado de degradação.

A Tabela 3.10 resume os ensaios mencionados nestas pesquisas, indicando o substrato sobre o qual o ensaio é realizado.

Deve-se ressaltar que esta relação não é exaustiva, pois existem outros ensaios aplicados na avaliação do estado de biodegradação dos resíduos sólidos urbanos para outros fins. Por exemplo, na Europa são abundantes as pesquisas sobre ensaios para avaliação do estado de degradação do RSU por meios aeróbios, pois os RSU são tratados mecânica e biologicamente, antes de serem aterrados. Os trabalhos de Laine-Ylijoki et al. (2004) e Godley et al. (2004) são exemplos de pesquisas nessa linha.

As fases de degradação dos RSU em aterros sanitários têm bons marcadores, definidos principalmente pela composição dos gases e pelas características químicas do lixiviado resultante do processo de decomposição. Entretanto, poucos são os marcadores relacionados a amostras no estado sólido, como as que foram estudadas nessa pesquisa.

Outro aspecto considerado para a realização da revisão bibliográfica foi o fato de que alguns dos ensaios comumente empregados para determinação das fases de degradação dos resíduos exigem que se acompanhe a evolução de determinado parâmetro ao longo do tempo, por exemplo, a concentração de gás metano, o que só é possível se a amostragem é 
continuada, como aquelas realizadas, por exemplo, nas pesquisas de Mehta et al. (2002), Hossain et al. (2003), Gabr et al. (2007a,b), El-Fadel e Al-Rashed (1998), Singh (2008) e Hossain e Haque (2009).

Tabela 3.10 - Ensaios físicos, químicos e bioquímicos para determinação do estado de degradação dos RSU e substrato sobre o qual o ensaio é realizado.

\begin{tabular}{cccc}
\hline Ensaio & Substrato sólido & Substrato líquido (*) & Substrato gasoso \\
\hline Sólidos totais voláteis & $\mathrm{X}$ & \\
$\mathrm{pH}$ & & $\mathrm{X}$ & \\
Granulometria & $\mathrm{X}$ & & \\
Umidade & $\mathrm{X}$ & $\mathrm{X}$ & $\mathrm{X}$ \\
Composição & $\mathrm{X}$ & $\mathrm{X}$ & \\
gravimétrica & $\mathrm{X}$ & $\mathrm{X}$ & \\
Temperatura & & & \\
DQO & & & \\
DBO & $\mathrm{X}$ & & $\mathrm{X}$ \\
Concentração de & $\mathrm{X}$ & & $\mathrm{X}$ \\
celulose & $\mathrm{X}$ & & \\
Razão C+H/L & $(* *)$ & $\mathrm{X}$ & \\
Potencial bioquímico de & & & \\
metano & & & \\
Massa específica dos & & & \\
sólidos & & & \\
Volume de gases & Composição dos gases &
\end{tabular}

(*) líquidos lixiviados do aterro ou solução lixiviada ou solubilizada a partir da amostra de RSU.

(**) $\mathrm{C}+\mathrm{H} / \mathrm{L}=$ razão entre o conteúdo de celulose + hemicelulose, dividido pelo conteúdo de lignina.

A amostragem envolvida nessa pesquisa é do tipo "one- time event" (ou evento único no tempo), análoga ao que foi realizado nas pesquisas de Attal et al. (1992), Carvalho (1999), Zekkos (2005), Harris et al. (2006) e Machado et al. (2006).

Em outras palavras, alguns dos ensaios mais tradicionais para determinação do estado de degradação do RSU não são adequados para a pesquisa em questão, que visa quantificar o estado de degradação de RSU em amostras sólidas, extraídas em um único evento.

A seguir são apresentados os ensaios mais utilizados na determinação do estado de degradação dos RSU de interesse para essa pesquisa. 


\subsubsection{Composição gravimétrica}

A fase sólida dos RSU pode ser caracterizada por meio da separação manual de seus constituintes em grupos de substâncias similares e determinação da massa destes vários grupos. Esta caracterização é denominada composição gravimétrica dos RSU e pode ser realizada sobre base úmida (referida à massa úmida da amostra inicial) ou sobre base seca (referida à massa seca da amostra inicial).

Como o processo de degradação dos RSU envolve transformações físicas, químicas e biológicas com transferência de massa do estado sólido para os estados líquido e gasoso, a composição gravimétrica dos RSU vai se alterando com o passar dos anos após o aterramento. No geral ocorre a diminuição no tamanho das partículas, mudança na forma dos materiais compressíveis e deterioração dos materiais biodegradáveis.

Fricke et al. (1999, apud Dixon e Langer, 2006) estudaram o potencial de biodegradação dos vários componentes de RSU e concluíram que madeira, couro, restos orgânicos, papéis e papelão apresentam potencial de biodegradação superior a $75 \%$ de seu peso seco, enquanto que plásticos rígidos apresentam apenas $23 \%$ e plásticos flexíveis, metais e substâncias minerais não se degradam. Sendo assim, a porcentagem de materiais biodegradáveis tende a diminuir com o tempo na composição gravimétrica dos resíduos, enquanto que a porcentagem dos materiais pouco ou não biodegradáveis aumenta relativamente. Desta forma, a quantificação da composição gravimétrica dos RSU pode ser um indicativo do seu "envelhecimento".

Deve-se lembrar, entretanto, que existe uma variação significativa na porcentagem dos principais componentes do resíduos sólido urbano de uma região para outra e que pode ocorrer variação da composição dos resíduos de uma mesma região durante o tempo de operação de um aterro sanitário. Estas variações estão relacionadas com os níveis de desenvolvimento econômico, tecnológico, sanitário e cultural da população (Cartier e Baldit, 1983) e com as práticas (ou regulamentações e políticas públicas) de reciclagem, incineração, pré-tratamento dos resíduos, bem como com os hábitos de desperdícios da sociedade (Cowland e Koor, 1995, apud Carvalho, 1999).

Por exemplo, nos estudos sobre resistência relatados por Zhan et al. (2008) para o aterro da cidade de Suzhou, na China, as diferenças de comportamento geotécnico verificadas para as amostras mais recentes e mais antigas são atribuídas em grande parte à sua composição inicial. Naquele caso os resíduos mais recentes (0 a 5 anos) eram compostos por maior 
quantidade de plásticos e de materiais fibrosos, enquanto que os resíduos mais antigos (5 a 12 anos) apresentavam originalmente uma elevada quantidade de cinzas. Esta diferença de composição explicava o fato de resíduos mais recentes ( 0 a 5 anos) apresentarem maior coesão, enquanto que os mais antigos apresentavam comportamento tipicamente granular.

Entretanto, se fossem considerados apenas os resultados para as amostras aterradas há 5 anos ou menos, para as quais a composição da amostra inicial poderia ser considerada uniforme, as características de resistência mecânicas dos resíduos aumentaram com a idade de deposição, em função principalmente do processo de degradação.

A determinação da composição gravimétrica dos resíduos de várias idades deve ser acompanhada pela análise crítica das transformações nos padrões de consumo da sociedade e pela legislação pertinente ao assunto na área geradora dos resíduos em questão.

\subsubsection{Granulometria}

Os RSU são compostos por materiais de dimensões bastante diversificadas. Há desde peças centimétricas, tais como garrafas plásticas, pedaços de mobília, fraldas, etc., até materiais milimétricos, como restos orgânicos e similares. Uma possibilidade para a caracterização da granulometria dos resíduos é a realização de uma análise de peneiramento e o traçado da curva de distribuição do tamanho dos grãos, como se faz rotineiramente em mecânica dos solos.

Ao longo do tempo o percentual de materiais com granulação mais fina tende a aumentar como resultado da degradação do material orgânico. A Figura 3.19 mostra as curvas do tamanho das partículas para RSU com diferentes idades e a faixa de variação típica da granulometria de RSU sugerida por Jessberger (1994). A grande faixa de variação da distribuição do tamanho das partículas é o resultado da composição muito heterogênea dos resíduos. Esta variação da distribuição granulométrica dos RSU ao longo do tempo pôde também ser observada nos estudos desenvolvidos por Carvalho (1999), Zhan et al. (2008), Gomes e Lopes (2012), entre outros. 

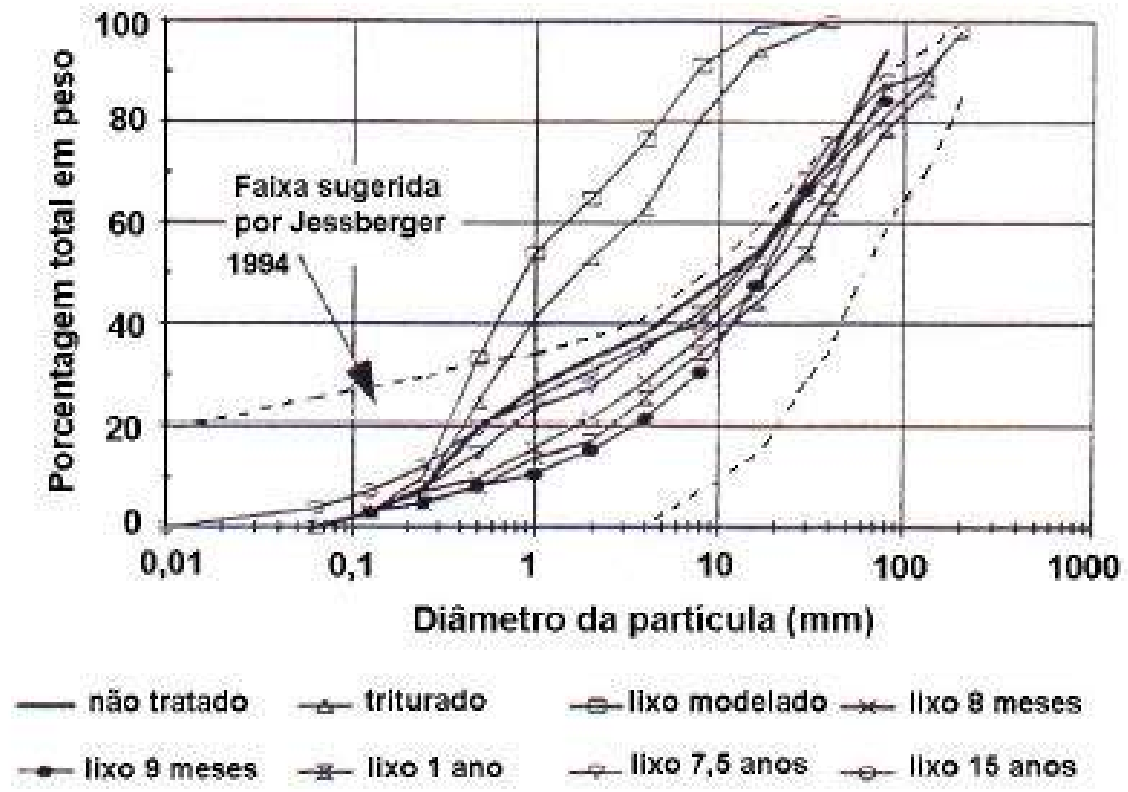

Figura 3.19 - Distribuição Granulométrica do RSU para diferentes idades (extraído de Manassero et al, 1996)

\subsubsection{Massa específica dos sólidos}

O processo de biodegradação transforma progressivamente a composição dos resíduos aterrados, mantendo no maciço apenas os componentes lentamente biodegradáveis e os não degradáveis e perdendo parte da massa aterrada para o meio externo, na forma de gases e de líquidos. Além disso, com o progresso da operação do aterro ocorre a incorporação de componentes minerais ao volume aterrado, principalmente dos materiais constituintes das camadas de cobertura

Recentemente alguns autores têm sugerido que a massa específica dos sólidos $\left(\rho_{\mathrm{s}}\right)$ pode ser usada como um indicador do estado de degradação dos resíduos, pois ela reflete as alterações na composição dos resíduos sólidos ao longo da vida útil do aterro. Gomes e Lopes (2012), Yesiller et al. (2014) e Reddy et al. (2011) observaram uma tendência de aumento dessa propriedade com o aumento do tempo de aterramento.

A determinação da massa específica dos sólidos para RSU não é normatizada. A maioria dos autores utilizaram os procedimentos usuais para determinação de $\rho_{\mathrm{s}}$ em solos, aumentando as dimensões do recipiente de vidro utilizado no ensaio, a quantidade de material ensaiado e o diâmetro máximo das partículas, para que as características dos resíduos pudessem ser melhor representadas. A Tabela 3.11 apresenta alguns dos resultados para a determinação desta propriedade. 
Tabela 3.11 - Determinações da massa específica dos sólidos em RSU

\begin{tabular}{lcc}
\hline Referência & Tempo de aterramento dos resíduos & Resultados $\left(\mathrm{g} / \mathrm{cm}^{3}\right)$ \\
\hline Carvalho (1999) & 15 anos & 2,29 a 2,56 \\
\hline Gabr e Valero (1995) & 15 a 30 anos & 2,00 \\
\hline \multirow{2}{*}{ Nascimento (2007) } & 1 ano & 1,77 \\
\hline \multirow{2}{*}{ Reddy et al. (2009a,b) } & 4 anos & 2,07 \\
\cline { 2 - 3 } & Fresco (não aterrado) & $0,85 \pm 0,13$ \\
\hline & Fresco (não aterrado) & $0,97 \pm 0,06$ \\
\cline { 2 - 3 } & RSU na fase anaeróbia ácida (fase 2) & 1,09 \\
\cline { 2 - 3 } & $\begin{array}{c}\text { RSU na fase anaeróbia metanogênica } \\
\text { acelerada (fase 3) }\end{array}$ & 2,05 \\
\cline { 2 - 3 } Reddy et al. (2011) $(*)$ & $\begin{array}{c}\text { RSU na fase anaeróbia metanogênica } \\
\text { desacelerada (fase 4) }\end{array}$ & 2,26 \\
\cline { 2 - 3 } & $\begin{array}{c}\text { RSU na fase de estabilização } \\
\text { metanogênica (posterior à fase 4) }\end{array}$ & 2,47 \\
\hline Gomes e Lopes (2012) & 2 a 10 anos & $1,87-2,32$ \\
\hline
\end{tabular}

(*) Decomposição realizada em lisímetro.

\subsubsection{Umidade}

A umidade é a medida do conteúdo gravimétrico de água, com relação à massa inicial da amostra, e pode ser medida em base úmida ou em base seca. Nos aterros sanitários o teor de umidade pode variar significativamente entre um ponto e outro, tornando-se relevante a obtenção do perfil de umidade com a profundidade. A água presente no maciço de resíduos provém de diversas fontes:

- do próprio resíduo aterrado, sendo seu conteúdo normalmente mais elevado, quando há maior quantidade de matéria orgânica nos resíduos. A compressão progressiva dos resíduos, devido ao aterramento, e as reações químicas do processo de biodegradação promovem a progressiva liberação da água que compõe os resíduos aterrados.

- de líquidos infiltrados, que podem ser as águas superficiais infiltradas pela superfície ou pelos taludes laterais expostos do aterro ou as águas subterrâneas infiltradas pelos taludes laterais e pela base do aterro, no caso de empreendimentos que não dispõem de barreiras impermeabilizantes. 
- líquidos (água, lixiviados ou esgotos) introduzidos no maciço de resíduos, tanto no sistema de co-disposição, quanto no sistema de biorreatores.

A presença de água é um parâmetro decisivo para o desenvolvimento do processo de biodegradação dos resíduos. A umidade dos resíduos no maciço sanitário fornece indicações sobre as condições do meio e permite que se analise se as mesmas são favoráveis ou não à biodegradação. A umidade ótima para a degradação de compostos orgânicos segundo Rodriguez et al. (2001, apud Imhoff et al., 2007) é de 65\% (base úmida). Para a operação de aterros como biorreatores a umidade deve ser mantida acima da capacidade de campo dos RSU (Warith e Sharma, 1998; Imhoff et al., 2007). Rocha e Azevedo (2008) determinaram a capacidade de campo para RSU novos (não aterrados) e antigos (10 a 15 anos de aterramento), obtidos no aterro controlado de Ponte Nova, em Minas Gerais. Os resultados variaram de 59 a $65 \%$ (base seca) para os resíduos novos e de 29 a 33\% para os resíduos antigos.

Tchobanoglous et al. (1993) afirmam que a umidade dos aterros sanitários nos Estados Unidos (operados de forma convencional) variava entre 15 e $40 \%$, sendo que $25 \%$ poderia ser considerado como um valor típico. A Tabela 3.12 fornece alguns dos valores de umidade obtidos em pesquisas realizadas em aterros com diferentes distribuições geográficas.

Tabela 3.12 - Umidades dos RSU determinadas em diferentes pesquisas

\begin{tabular}{ccc}
\hline Referência & Origem dos RSU & Umidades \\
\hline Coumoulus et al. (1995) & $\begin{array}{c}\text { Aterro Ano Liossia, em Atenas, } \\
\text { Grécia }\end{array}$ & 10 a 180\% (base seca) \\
\hline $\begin{array}{c}\text { Matasovich e } \\
\text { Kavazanjian (1998) }\end{array}$ & Aterro OII, Califórnia, EUA & 15 a 41\% \\
\hline Zornberg et al. (1999) & Aterro Azuza, Califórnia, EUA & 7 a 52\% (base seca) \\
\hline Carvalho (1999) & $\begin{array}{c}\text { Aterro Sanitário Bandeirantes, } \\
\text { São Paulo, SP, Brasil }\end{array}$ & 45 a 110\% (base seca) \\
\hline Santos (1997) & $\begin{array}{c}\text { Aterro da Muribeca (Célula 1, } \\
\text { mais antiga) }\end{array}$ & 28,2 e 108,0\% (base seca) \\
\hline Mariano (1999) & $\begin{array}{c}\text { Aterro da Muribeca (Célula 1, } \\
\text { mais antiga) }\end{array}$ & 19,5 e 149,0\% (base seca) \\
\cline { 2 - 4 } & $\begin{array}{c}\text { Aterro da Muribeca (Célula 2, } \\
\text { mais nova) }\end{array}$ & 15,1 e 116,4\% (base seca) \\
\hline Melo (2003) & $\begin{array}{c}\text { Aterro da Muribeca (Célula 2, } \\
\text { mais nova) }\end{array}$ & 18 a 61\% (base seca) \\
\hline Nascimento (2007) & $\begin{array}{c}\text { Aterro Metropolitano Centro, } \\
\text { Salvador, BA, Brasil }\end{array}$ & 63 a 137\% (base seca) \\
\hline Zekkos (2005) & Aterro Tri-Cities, Califórnia, EUA & 12 a 25\% (base seca) \\
\hline Stoltz et al. (2009) & Aterro sanitário na França & 50 a 129\% \\
\hline
\end{tabular}




\subsubsection{Temperatura dos resíduos}

O calor é um dos produtos do processo de biodegradação, juntamente com a geração de chorume e de gás. Assim sendo, a temperatura no interior do maciço de resíduos é um dos indicadores das reações bioquímicas que estão ocorrendo no processo de degradação da matéria orgânica.

As reações aeróbias que ocorrem no início do processo de degradação são altamente exotérmicas e são responsáveis pelo aumento da temperatura verificado ao longo dos primeiros anos no processo de decomposição (Robinson, 1986, apud El-Fadel, 1999; Hanson et al., 2010). Diversos autores afirmam que a velocidade de decomposição mais elevada durante a fase aeróbia ocorre em temperaturas entre 52 e $60^{\circ} \mathrm{C}$ (Richard e Walker, 1998, apud Agostini et al., 2012). Em temperaturas menores que estas a velocidade de decomposição diminui e em temperaturas maiores ela cessa, não havendo atividade microbiana em temperaturas acima de $70-75^{\circ} \mathrm{C}$.

No estágio de decomposição anaeróbia as reações estão associadas a menores liberações de energia, porém verifica-se que ocorre aumento da temperatura do maciço de resíduos também nesta fase do processo de degradação (El-Fadel, 1999; Hanson et al., 2010). Quando o estado de degradação dos resíduos é mais avançado a temperatura do maciço de resíduos começa a cair lentamente, em um processo que se prolonga por décadas (Hanson et al., 2010). Segundo Wilson et al. (2008, apud Agostini et al., 2012), a decomposição anaeróbia é bastante sensível ao aumento da temperatura, diminuindo rapidamente de velocidade para temperaturas acima de $55^{\circ} \mathrm{C}$.

As temperaturas registradas em aterros sanitários variam em geral entre 40 e $65^{\circ} \mathrm{C}$ para aterros com alturas entre 20 e 60 metros e o intervalo de temperaturas considerado ideal para a produção de biogás a partir da decomposição de RSU em aterros sanitários é entre 34 e $45^{\circ} \mathrm{C}$ (diversos autores citados por Hanson et al., 2010). Diminuição significativa na produção de biogás é esperada para temperaturas abaixo de $20^{\circ} \mathrm{C}$ e acima de $75^{\circ} \mathrm{C}$ (Tchobanoglous et al., 1993).

A distribuição de temperaturas não é homogênea no maciço de resíduos e depende de diversos fatores, a saber: calor da reação, calor específico da água e dos resíduos, calor de neutralização, perdas de calor para o ar externo e para o solo, radiação solar e metabolismo aeróbio (principalmente) (Rees, 1980, apud El-Fadel, 1999). Hanson et al. (2010) concluíram 
que a temperatura dos resíduos no momento da disposição é outro fator que influencia a distribuição da temperatura no maciço.

No geral, nos primeiros 10 metros mais próximos à superfície a temperatura do maciço de resíduos sofre influência da sazonalidade do clima local (a depender da presença e do tipo de camada de cobertura, bem como do clima e velocidade dos ventos na região). Abaixo desta profundidade ela não é influenciada pelos fatores climáticos, refletindo apenas a evolução dos processos de biodegradação e as características de porosidade, peso específico, composição, umidade, etc., do maciço de resíduos. $\mathrm{Na}$ maioria dos casos verifica-se aumento da temperatura até aproximadamente $1 / 3$ da profundidade total do aterro e posterior decréscimo das temperaturas nas maiores profundidades, mais próximas da base do aterro (Coumoulos et al., 1995; Mariano, 1999; Hanson et al., 2010).

Hanson et al. (2010) propuseram um modelo das variações de temperatura típicas de um aterro sanitário, apresentado na Figura 3.20.

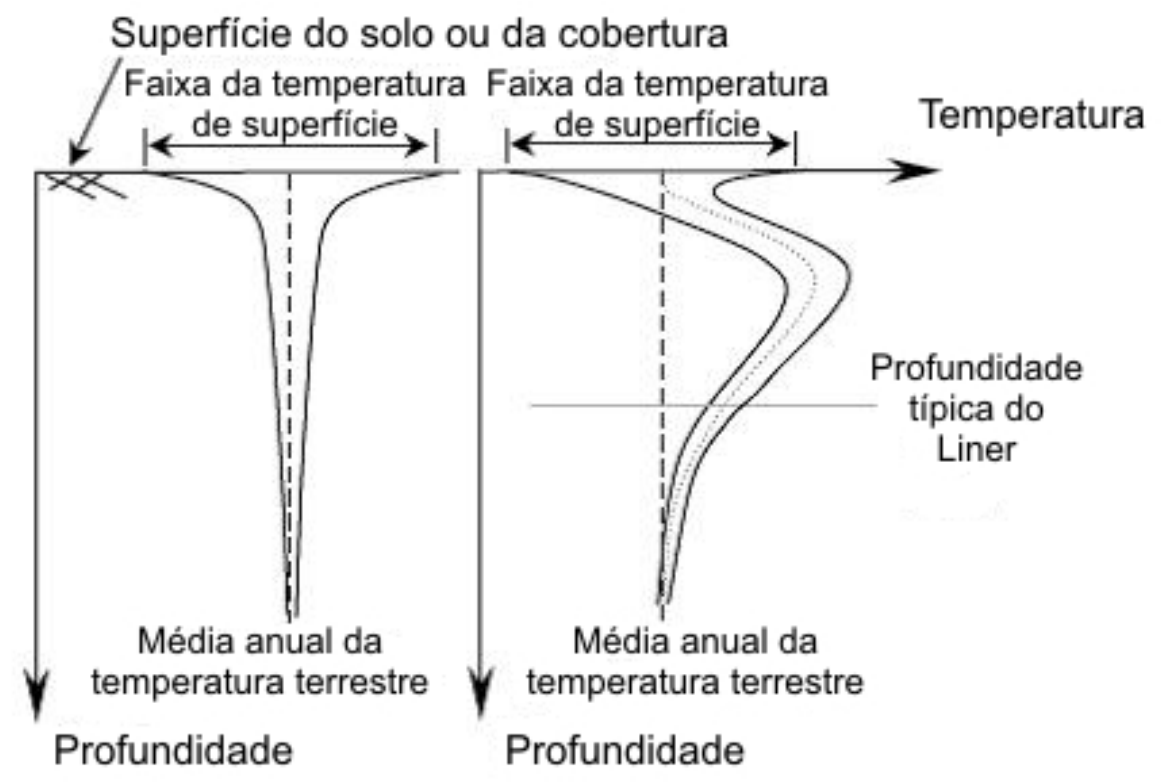

Figura 3.20 - Envoltórias de temperatura típicas para solos e para aterros sanitários. (extraído de Hanson et al., 2010)

Mariano (1999), em pesquisa realizada no aterro da Muribeca, no Recife, concluiu, com base nas determinações de temperatura (ver Figura 3.21) e outros ensaios, que os resíduos da célula 1 apresentavam-se nos estágios avançados do processo de biodegradação, enquanto que os resíduos da célula 2 apresentavam-se menos degradados. 


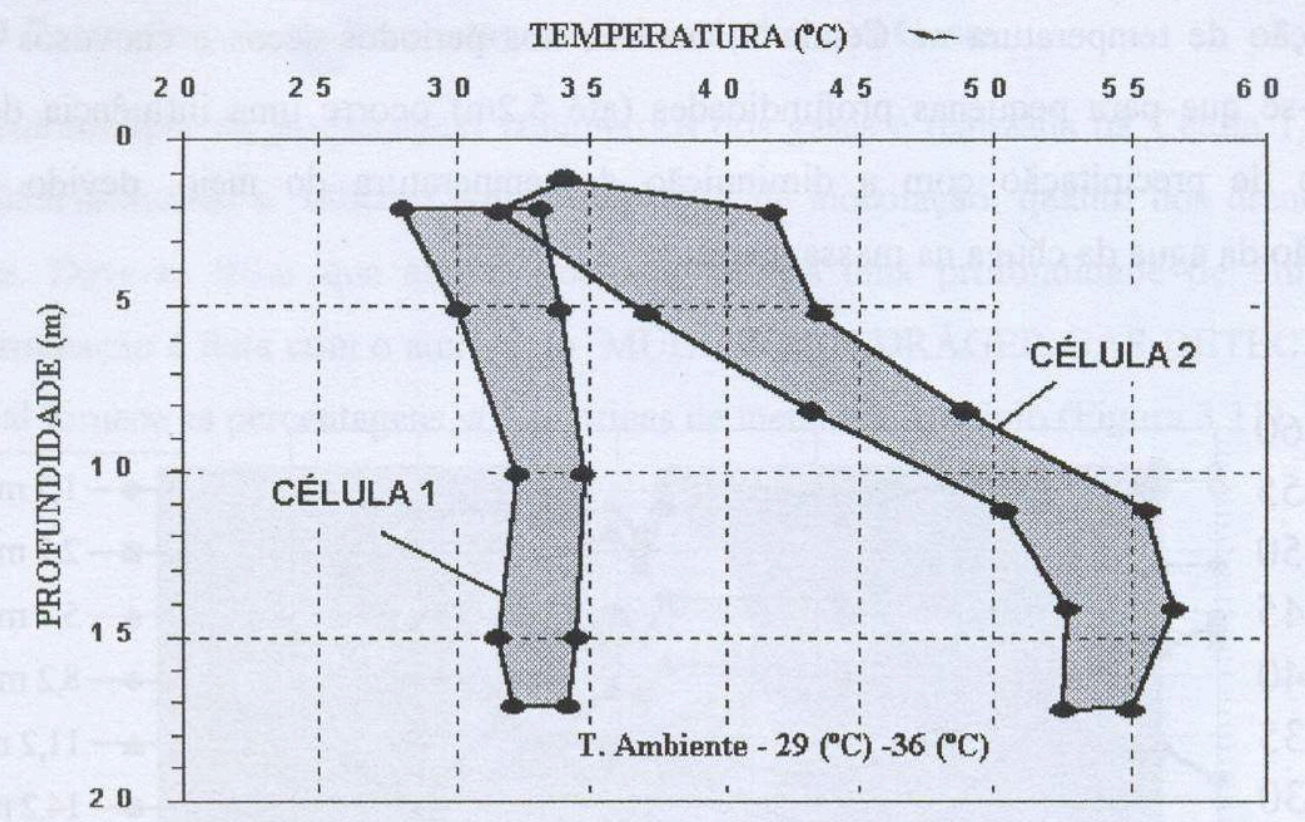

Figura 3.21 - Faixas de variação da temperatura nas Células 1 e 2 do Aterro da Muribeca, em Recife (extraído de Mariano, 1999).

3.3.7 Ensaios para determinação do conteúdo de carbono orgânico

O carbono pode estar presente nos materiais sólidos sob várias formas: como carbono elementar (carvão, grafita e fuligem); como carbono orgânico (resultante da decomposição de plantas e animais, inclusive derivados de petróleo) ou como carbono inorgânico (solos ou rochas ricos em carbono, por exemplo carbonatos e dolomitos e fertilizantes). O conteúdo de carbono orgânico total (COT, em inglês: total organic carbon $=$ TOC) nos RSU diminui com a progressão de sua biodegradação, pois é o carbono orgânico que participa das reações envolvidas na biodegradação.

Há diversos métodos para a determinação do conteúdo de carbono orgânico total de um material sólido. O princípio básico da maioria desses métodos é a destruição total da matéria orgânica na amostra, o que pode ser obtido por tratamento químico, ou por aquecimentos a elevadas temperaturas. Schumacher (2002) e Jensen et al. (2003) apresentam revisões extensas sobre o assunto, considerando diversos tipos de materiais: solos, sedimentos, esgotos, água e resíduos orgânicos.

No estudo dos processos de degradação dos resíduos sólidos os ensaios mais utilizados são a determinação dos sólidos totais voláteis (STV) e a determinação do carbono orgânico total (COT), apresentados a seguir. 


\subsubsection{Sólidos totais voláteis (STV)}

O ensaio para determinação dos STV corresponde à destruição de todos os sólidos voláteis contidos na amostra por meio de aquecimento a temperaturas da ordem de 440$600^{\circ} \mathrm{C}$.

O ensaio determina a quantidade de sólidos totais voláteis, e apenas parte destes sólidos correspondem a carbono orgânico. Em RSU os sólidos voláteis incluem tanto materiais degradáveis, tais como celulose e hemicelulose, quanto materiais recalcitrantes, tais como lignina, plásticos e outros (Mehta et al., 2002).

Apesar disso, a utilização deste ensaio é muito comum. Sua principal vantagem é o fato de envolver um procedimento extremamente simples, se comparado aos demais ensaios (Kelly et al., 2006).

Um alto percentual de STV indica a presença de muita matéria orgânica ainda não degradada (resíduo novo) e baixos valores indicam que o resíduo já passou por um acentuado processo de degradação.

As principais desvantagens apresentadas pelo ensaio são:

- não é normatizado e apresenta relativa dispersão nos resultados (Kelly et al., 2006)

- os resultados são afetados pela presença de plásticos na amostra (Attal et al., 1992;

Kelly et al., 2006).

- os resultados são significativamente afetados pela presença de solo de cobertura na amostra (Mehta et al., 2002).

Para transformar o valor dos STV em Conteúdo de Carbono Orgânico Total (TOC) é preciso aplicar um fator de correção, que leve em consideração a possibilidade de existirem na amostra outros tipos de carbono, além do orgânico (Schumacher, 2002).

As normas da Comissão Européia determinam que os resíduos só podem ser aterrados se forem inertes. Der acordo com Laine-Ylijoki et al. (2004), na Alemanha as legislações fixam o limite de STV inferior e 5\% para que os resíduos sejam considerados como inertes. $\mathrm{Na}$ prática esse limite só é atingido por processos de incineração. O pré-tratamento aeróbio dos resíduos costuma produzir rejeitos com STV de 25 a 35\%, dependendo de sua composição inicial. 


\subsubsection{Carbono orgânico total}

O procedimento mais utilizado para determinação do conteúdo de carbono orgânico total (COT) é aquele constante da norma EN 13137:2001, adotada pela Comunidade Européia. Para sólidos, o método envolve combustão a seco, a altas temperaturas $\left(900^{\circ} \mathrm{C}\right)$, e posterior detecção de $\mathrm{CO}_{2}$ por espectrometria de infravermelho.

Nesta revisão bibliográfica não foram localizadas pesquisas que tenham utilizado este ensaio para caracterização do estado de degradação dos resíduos, entretanto Kolsch (2009) afirma que na Alemanha e na Europa em geral este teste deve ser realizado, juntamente com ensaios de respiração, potencial bioquímico de metano (BMP), STV, umidade e granulometria para caracterização do estado de degradação biológica dos resíduos e para que se possa decidir se o mesmo está apto para ser encaminhado a aterros sanitários ou não.

As normas da Comissão Européia determinam que os resíduos só podem ser aterrados se forem inertes. De acordo com Laine-Ylijoki et al. (2004), na Alemanha as legislações fixam o limite de COT sobre amostras sólidas variando de 1 a 18\%, dependendo do processo de pré-tratamento empregado, para que os resíduos sejam considerados como inertes.

Outra opção seria a determinação do conteúdo de carbono em um extrato solubilizado ou sobre um lixiviado neutro gerado a partir dos resíduos. A maioria dos trabalhos que realiza a determinação do conteúdo de carbono em solução trabalha diretamente com o lixiviado de aterros sanitários. Como a realização dessa determinação a partir de uma amostra sólida envolve procedimentos de lixiviação ou de solubilização, o procedimento adotado para geração da fase líquida afeta os resultados.

Soyez (2001, apud Laine-Ylijoki et al., 2004) relata que para extrações realizadas com pH neutro sobre RSU pré-tratados os valores de carbono orgânico dissolvido (COD) variaram entre 1500 e $3000 \mathrm{mg} / \mathrm{l}$. Com resíduos submetidos a tratamentos mecânicos e biológicos normalmente foram atingidos valores de $300 \mathrm{mg} / \mathrm{l}$. Para que sejam atingidos os valores de 100 $\mathrm{mg} / 1$ (prescritos pela legislação alemã) seriam necessários pré-tratamentos mais intensivos e de mais longo prazo sobre os resíduos.

\subsubsection{Potencial hidrogeniônico do meio $(\mathrm{pH})$}

A concentração em íons $\mathrm{OH}^{-}$no meio tem grande influência sobre o crescimento dos microorganismos. Na digestão anaeróbia de RSU em aterros sanitários observam-se duas 
etapas sucessivas: a primeira se caracteriza por diminuição do $\mathrm{pH}$ em patamares próximos de 5,0 (fase 2 do processo de degradação) e a segunda, por aumento do pH e sua estabilização em valores próximos da neutralidade (fases 3 e 4 do processo de degradação). Segundo Zehnder (1978, apud Mehta et al., 2002) pH de 6,8 a 7,4 (neutro) é o ideal para o crescimento de bactérias metanotróficas. Mehta et al. (2002) comentam que parece haver uma tendência a se obterem valores de $\mathrm{pH}$ pouco acima desta faixa ideal em resíduos que já se encontram bastante degradados.

Os procedimentos adotados para a determinação do $\mathrm{pH}$ dos resíduos são variados, principalmente com relação à forma como é realizada a solubilização dos componentes do RSU para obtenção da solução aquosa para realização do ensaio. Em outros casos ocorre a determinação do $\mathrm{pH}$ do lixiviado gerado pela massa de resíduos. Apesar das divergências quanto ao método empregado na determinação, praticamente todas as pesquisas que visam a caracterização do estado de degradação dos resíduos realizam a determinação do $\mathrm{pH}$ do meio.

\subsubsection{Demanda química de oxigênio}

A demanda química de oxigênio (DQO) corresponde à medida volumétrica da quantidade de oxigênio consumido para a oxidação dos componentes orgânicos e inorgânicos oxidáveis existentes em uma solução aquosa produzida com o resíduo (ou no lixiviado). Altos valores de DQO caracterizam em um resíduo fresco, que ainda se encontra na fase acidogênica (correspondente à fase 2), e baixos valores de DQO caracterizam um resíduo que já se encontra na fase metanogênica (Ehrig, 1983, apud Souto, 2009). Os valores citados como típicos para o lixiviado de aterros sanitários na fase acidogênica (fase 2) são DQO entre 6.000 e $60.000 \mathrm{mg}$ de $\mathrm{O}_{2} / 1$. Na fase metanogênica os valores típicos são entre 500 e $4.500 \mathrm{mg}$ de $\mathrm{O}_{2} / 1$.

A relação entre a demanda bioquímica de oxigênio (DBO) e a DQO em amostras de lixiviado é, segundo diversos autores, um bom indicador da fase do processo de degradação em que se encontram os resíduos. Os ácidos produzidos na fase 2 do processo de degradação dos RSU em aterros sanitários são biodegradáveis e isto explica o fato de as maiores concentrações de DBO e de DQO serem determinadas durante esta fase do processo. A razão DBO/DQO na fase 2 do processo de degradação dos RSU é superior a 0,4 (segundo Ehrig, 1988, apud Barlaz, 2006) ou 0,7 (segundo Robinson, 1995, apud Barlaz, 2006). Na fase 3 do

processo de decomposição a presença dos ácidos orgânicos diminui e ocorre um 
correspondente decréscimo da DBO e da DQO do lixiviado. Na fase 4 a razão DBO/DQO no lixiviado é baixa, como resultado da pequena presença de matéria orgânica degradável no resíduo, em contraste com a ocorrência de compostos orgânicos recalcitrantes, que são consumidos no ensaio DQO.

Estes valores estão razoavelmente bem estabelecidos para o lixiviado, mas para RSU há divergências em relação ao procedimento adotado para a obtenção de extratos líquidos e em relação a que parcela da amostra adotar para a realização dos ensaios. Esse assunto é abordado, por exemplo, por Cossu et al. (2012), que testaram diferentes processos de obtenção de extrato solubilizado a partir de resíduos no estado sólido e compararam os valores de $\mathrm{DBO}_{5} / \mathrm{DQO}$ com aqueles obtidos por ensaios respirométricos, concluindo que a relação $\mathrm{DBO}_{5} / \mathrm{DQO}$ é um bom indicador do estado de degradação dos resíduos, considerandose os procedimentos de solubilização testados na pesquisa.

3.3.10 Concentração de celulose e razão de celulose+hemicelulose versus lignina

A celulose (C) e a hemicelulose (H) são os principais componentes orgânicos biodegradáveis dos RSU (Hilger e Barlaz, 2001, apud Hossain et al., 2003; Barlaz, 2006). A lignina (L) é o outro componente orgânico mais abundante nos RSU, porém é lentamente degradável em condições metanogênicas.

As principais fontes de celulose e hemicelulose em aterros sanitários são os papéis de todos os tipos (papelão, jornais, papel de escritório, revistas), seguidos por madeiras, restos de jardim (podas) e restos de comidas (Barlaz, 2006).

As concentrações de celulose e de hemicelulose e a concentração relativa destes dois componentes em relação à concentração de lignina sofrem alterações ao longo do processo de degradação dos RSU, pois, a partir da fase de produção acelerada de metano (fase 3 do processo de degradação) a celulose e a hemicelulose passam a ser transformadas em gases por reações de hidrólise, enquanto que a lignina não é alterada. $\mathrm{Na}$ fase 4 a taxa de degradação destes dois compostos aumenta ainda mais. Assim sendo, é possível monitorar a evolução do processo de degradação dos RSU ou avaliar em que fase deste processo os resíduos se encontram, acompanhando-se a evolução da concentração de celulose ou a evolução da razão de celulose + hemicelulose por lignina $(\mathrm{C}+\mathrm{H} / \mathrm{L})$ nos resíduos ao longo do tempo.

Valores típicos de $\mathrm{C}+\mathrm{H} / \mathrm{L}$ para resíduos sólidos frescos variam de 2,5 a 4 (Harris et al, 2006). Bookter e Ham (1982) relatam valores em torno de 0,2 para amostras com 20 a 30 
anos de aterramento e Wang et al. (1994, apud Harris et al, 2006) relatam valores de 0,01 a 0,16 para amostras com 7 a 21 anos de aterramento. Barlaz (2006) destaca que as diferenças entre os resultados encontrados nessas duas pesquisas podem estar relacionadas aos métodos utilizados, sendo que o método utilizado por Wang et al. (1994 apud Barlaz, 2006) fornece valores de concentração de celulose sistematicamente menores que aquele utilizado por Bookter e Ham (1982).

$\mathrm{Na}$ maioria das pesquisas que utilizaram esse parâmetro para quantificar o estado de degradação de resíduos, a tendência foi de redução sistemática dos valores, conforme aumentava o tempo de aterramento dos mesmos (inclusive em Gabr et al., 2007, Hossain e Haque, 2009 e Bareither et al, 2012). Entretanto, em um dos aterros pesquisados por Bookter e Ham (1982) não foi possível identificar uma tendência clara no comportamento desse parâmetro, quer para redução, quer para aumento ou estabilização.

Barlaz (2006) argumenta que a utilização da razão de celulose + hemicelulose por lignina $(\mathrm{C}+\mathrm{H} / \mathrm{L})$ ou da razão de celulose por lignina $(\mathrm{C} / \mathrm{L})$ é mais adequada que a utilização da concentração de celulose (C) de forma isolada, pois a aplicação de camadas de solo de cobertura aos aterros faz com que estes materiais sejam incluídos nas amostras em diferentes proporções, o que altera significativamente as concentrações absolutas dos componentes orgânicos, mas não afeta as razões entre suas concentrações.

Pelo mesmo motivo Mehta et al. (2002) argumentam que os resultados da determinação da razão celulose + hemicelulose versus lignina são mais significativos que os valores de STV.

Kelly et al. (2006), por outro lado, argumentam que a determinação do conteúdo de lignina sofre interferência do conteúdo de plásticos na amostra e que este é variável, sendo portanto recomendável que estes materiais sejam removidos da amostra para realização dos ensaios ou que se utilize do conteúdo de celulose de forma isolada para avaliação da evolução do processo de degradação.

\subsubsection{Composição e volume dos gases emitidos}

Os gases que compõem as emissões de aterros sanitários compreendem principalmente metano e dióxido de carbono. Secundariamente ocorrem gás sulfídrico, oxigênio, hidrogênio, mercaptanas, propano, butano e outros compostos. As variações observadas na concentração 
dos gases de aterro sanitário são atribuídas às diferenças de composição dos resíduos e ao estágio dos processos de decomposição destes.

O monitoramento dos volumes e da composição dos gases emitidos pelos RSU durante o processo de degradação permite avaliar o progresso do processo de biodegradação quando as medidas são contínuas ou quando se podem comparar medidas realizadas sucessivamente em um mesmo local, como ocorre em lisímetros ou aterros monitorados por longo prazo.

Para a realização de medidas isoladas, como se pretende nesta pesquisa, ainda não existem valores de referência, que possam indicar qual é o estado de degradação dos resíduos com apenas uma leitura.

\subsubsection{Ensaio de biodegradação (ou Potencial Bioquímico de Metano)}

O ensaio de biodegradação é um ensaio biológico que determina a quantidade de metano (ou biogás) gerada em condições anaeróbias por certa quantidade em peso de um substrato. Como regra geral, as amostras mais degradadas produzirão menores volumes de biogás que as amostras menos degradadas.

Cossu et al. (2012) reconhecem que este é um dos ensaios mais utilizados atualmente para a determinação do estado de degradação dos RSU. Como ocorre com praticamente todos os ensaios aplicados na área de RSU, ainda não há um procedimento largamente aceito para a execução do ensaio, apesar de existirem alguns procedimentos (diferentes entre si) normatizados (Angelidaki et al., 2009). Além disso, nas pesquisas é comum que se adotem procedimentos modificados a partir daqueles normatizados, o que tem complicado a comparação dos resultados em termos quantitativos.

Como destacam Angelidaki et al. (2009) os resultados são sensíveis a vários fatores, a saber: tamanho das partículas após moagem, características do inóculo utilizado (tipo, atividade, quantidade), disponibilidade de nutrientes no meio de ensaio, qualidade e representatividade das amostras de branco, processo de mistura entre substrato, inóculo e nutrientes adotado durante o ensaio, porcentagem de dissolução da amostra em água para formação do substrato e pH do meio no início do ensaio.

Kelly et al. (2006) argumentam que o ensaio BMP é mais caro e resulta em maior dispersão dos resultados do que as determinações da concentração de celulose e dos STV, e que estes dois últimos métodos apresentam melhor correlação com a idade dos resíduos 
aterrados na pesquisa realizada pelos autores. Eles recomendam que o ensaio BMP não seja utilizado isoladamente para este fim.

Este é um ensaio essencial em projetos de sistemas que pretendam explorar economicamente o biogás gerado em aterros sanitários.

\subsubsection{Demanda bioquímica de oxigênio}

A demanda bioquímica de oxigênio (DBO) mede a quantidade volumétrica de oxigênio consumido por seres vivos para decomposição da matéria orgânica presente em uma solução aquosa produzida com o resíduo (ou no lixiviado), em condições similares à da natureza, durante um determinado período de tempo. Normalmente adotam-se cinco dias e o ensaio é identificado como $\mathrm{DBO}_{5}$.

Barlaz (2006) e Cossu et al. (2012) discutem sua aplicação para caracterização do estágio de decomposição dos resíduos em aterros sanitários, por meio da medição da razão DBO/DBQ determinados sobre o lixiviado, como exposto no item 3.3.9.

\subsection{Ensaios geofísicos aplicados a maciços de RSU}

A obtenção de amostras indeformadas com dimensões representativas tem sido uma das principais dificuldades encontradas no estudo de RSU. Neste contexto os métodos geofísicos sísmicos surgem como uma alternativa atraente, pois permitem que se ensaiem grandes volumes de material in situ.

Eles têm sido aplicados com finalidades diversas. A mais frequente tem sido a determinação de propriedades de interesse à análise de estabilidade dos maciços de resíduos frente a solicitações dinâmicas, notadamente em áreas sujeitas a atividades sísmicas mais intensas. Neste caso podem ser citados os trabalhos de Sharma et al. (1990), Singh e Murphy (1990), Houston et al. (1995), Kavazanjian et al. (1995, 1996), Zalachoris (2010), entre outros.

Outra aplicação relativamente comum é na investigação inicial de maciços cujo histórico de operações não é conhecido, como nos trabalhos efetuados por Kavazanjian et al. (1996), Bouazza et al. (2003), Cossu et al. (2005), Sahadewa et al. (2011), Carpenter et al. (2013) e Konstantaki et al. (2015). 
Há ainda a utilização das técnicas geofísicas sísmicas para a determinação de parâmetros de rigidez do maciço visando o cálculo das deformações imediatas esperadas em maciços que sofrerão ampliações ou sobre os quais se pretende implantar outros tipos de uso. Os trabalhos de Del Greco et al. (2007), de Pereira et al. (2002), de Van Elk et al. (2007) e de Abbiss (2001) são exemplos deste tipo de aplicação. No Brasil destaca-se o trabalho de Carvalho (1999) na investigação do Aterro Sanitário Bandeirantes.

Nos ensaios geofísicos sísmicos uma fonte transmite ondas ao terreno e instrumentos denominados geofones captam a chegada destas ondas em outro ponto da área de interesse para investigação. Estas ondas são de dois tipos: ondas de corpo e ondas superficiais. Os tempos de chegada das ondas são obtidos a partir dos registros sísmicos captados pelos geofones e as distâncias entre os dois pontos são conhecidas ou calculadas, de tal forma que se consiga determinar as velocidades de propagação das ondas sísmicas no meio investigado. Estas velocidades são dependentes das propriedades físicas do meio atravessado, principalmente de seus módulos volumétrico (B) e de cisalhamento (G) e de sua massa específica $(\rho)$.

As ondas de corpo são de dois tipos: compressionais, normalmente identificadas pela letra "P", e cisalhantes, normalmente identificadas pela letra "S". Sua propagação impõe ao maciço níveis de deformação específica da ordem de $0,01 \%$. Para estes níveis de deformação os parâmetros de rigidez podem ser calculados com base na teoria da elasticidade. O módulo de cisalhamento em especial é um dos parâmetros de rigidez de maior interesse para a realização de análises de estabilidade dinâmica. Ele expressa a relação tensão-deformação para solicitações de cisalhamento e sofre degradação (diminuição) com o aumento da deformação. Quando calculado para pequenas deformações ele é denominado módulo de cisalhamento máximo e anotado como $\mathrm{G}_{\mathrm{o}}$. A Figura 3.22 ilustra esta situação.

Considerando-se o meio como isotrópico e homogêneo, o módulo de cisalhamento máximo pode ser calculado a partir da medida da velocidade da onda cisalhante (Vs) com ensaios geofísicos sísmicos, utilizando-se a expressão (3.2): 


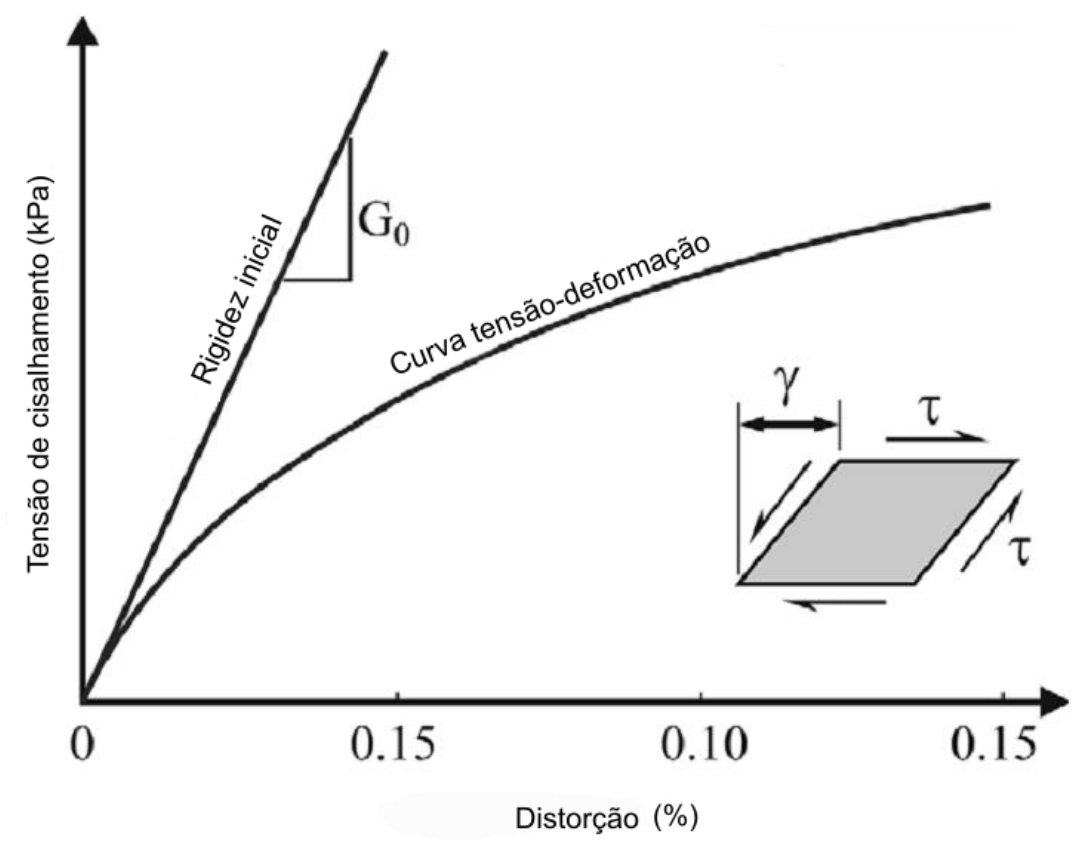

Figura 3.22 - Definição de módulo de cisalhamento (Extraído de Jamiolkowski, 2012).

$\mathrm{G}_{\mathrm{o}}=\rho \times \mathrm{Vs}^{2}$

Onde Vs = velocidade de propagação da onda $S, G_{0}=$ modulo de cisalhamento máximo e $\rho=$ massa específica do meio atravessado.

Se a velocidade de propagação de ondas $\mathrm{P}(\mathrm{Vp})$ e a velocidade de propagação de ondas S (Vs) forem conhecidas para um mesmo local é possível calcular ainda um outro parâmetro de interesse para caracterização das propriedades geotécnicas do maciço: o coeficiente de Poisson (v). Novamente, é utilizada a formulação da teoria da elasticidade, que resulta na equação (3.3).

$$
v=\frac{(V p / V s)^{2}-2}{2 \times\left(V p / V_{S}\right)^{2}-2}
$$

Em que: $v=$ coeficiente de Poisson, $\mathrm{Vp}=$ velocidade de propagação das ondas compressionais e Vs = velocidade de propagação das ondas cisalhantes.

Zekkos et al (2008) constataram que a maioria dos ensaios de laboratório e de campo realizados em RSU indicam que valores de coeficiente de Poisson variando de 0,05 a 0,35 são razoáveis para maciços de RSU. De acordo com Kavazanjian (2003) para aterros sanitários os valores de coeficiente de Poisson só estão acima de 0,4 em aterros operados como 
biorreatores ou em aterros sem impermeabilização de fundo e que se situam abaixo do nível d'água.

O outro grupo de ondas sísmicas utilizadas nos ensaios geofísicos são as ondas superficiais. Elas são de dois tipos: ondas Rayleigh, também denominadas ondas R, e ondas Love, também denominadas ondas L. Estas ondas se formam pela interação das ondas de corpo com a superfície livre (contato com a atmosfera). As ondas Rayleigh estão sempre presentes, enquanto as ondas Love podem ou não estar presentes, pois dependem da existência de uma camada superficial de baixa velocidade sobre um substrato de velocidade superior, formando-se devido ao aprisionamento de energia e às múltiplas reflexões.

Segundo Lopes et al. (2008), alguns fatores contribuem para que as ondas Rayleigh tenham interesse geotécnico: o fato de estarem sempre presentes, de se propagarem até à superfície, de transportarem $2 / 3$ do total da energia transmitida, de se propagarem com uma frente de onda cilíndrica e de se atenuarem mais lentamente com a distância que as ondas de corpo.

Com base na teoria da elasticidade é possível conhecer a relação entre as velocidades de propagação de ondas em função do coeficiente de Poisson. Na Figura 3.23 estão apresentadas as relações entre as velocidades de propagação de ondas de compressão $(\mathrm{P})$, cisalhantes $(\mathrm{S})$ e superficiais do tipo Rayleigh (R) num semi-espaço elástico para valores de coeficiente de Poisson variando de 0 a 0,5 .

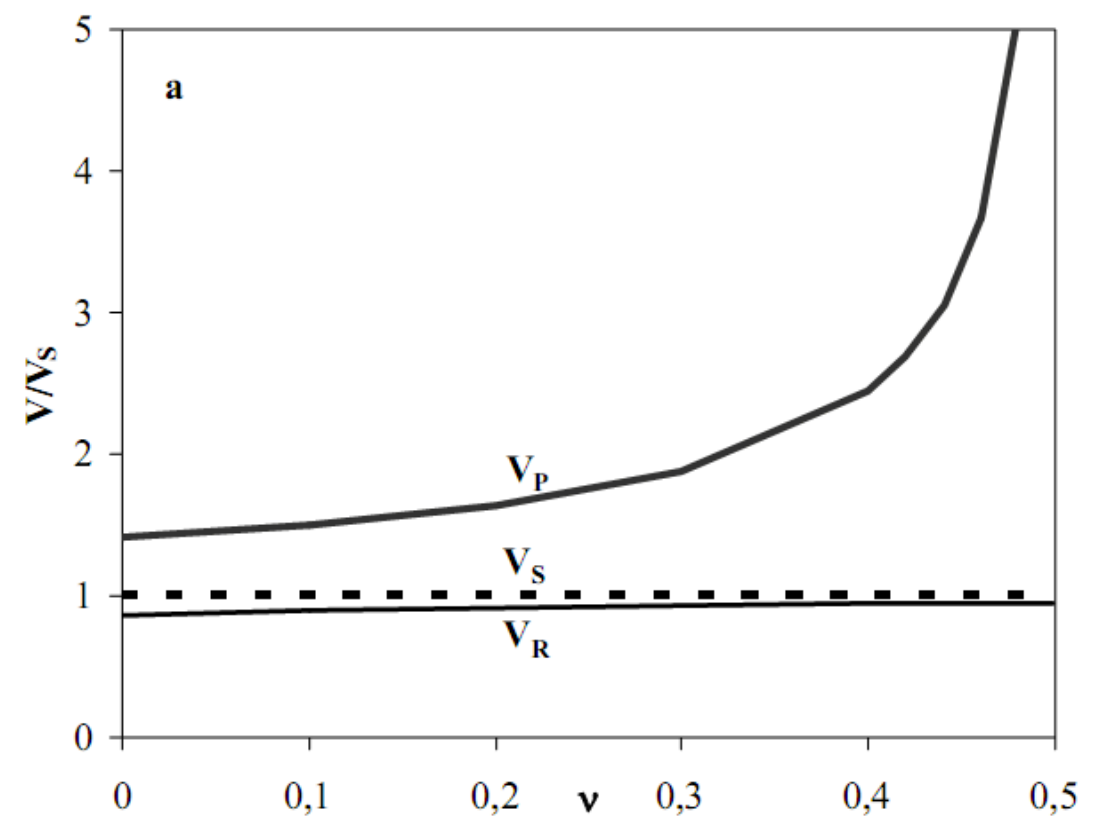

Figura 3.23 - Relações entre as velocidades de propagação de ondas $\mathrm{S}, \mathrm{P}$ e R, em função do coeficiente de Poisson ( $\mathrm{V}=\mathrm{Vp}$, Vs ou $\mathrm{V}_{\mathrm{R}}$ ) (extraído de Lopes et al., 2008). 
Da análise da Figura 3.23 verifica-se que as ondas $\mathrm{S}$ e $\mathrm{R}$ apresentam velocidades de propagação muito próximas, especialmente quando o coeficiente de Poisson assume valores maiores que 0,3. Por este motivo, para muitas aplicações práticas de engenharia, é comum considerar a velocidade de propagação da onda $\mathrm{R}$ igual a da onda $\mathrm{S}$. Este tem sido o caso em muitas das aplicações de métodos geofísicos a maciços sanitários ligadas à engenharia de sismos, quando é importante conhecer o perfil vertical de velocidades de propagação de ondas cisalhantes (Vs) para o cálculo dos deslocamentos horizontais esperados à superfície, para cada solicitação sísmica.

Zekkos et al. (2008) apresentam uma síntese destes estudos e afirmam que, para os 30 metros mais superficiais dos aterros sanitários as velocidades da onda $\mathrm{S}$ variam entre 50 e 200 $\mathrm{m} / \mathrm{s}$, mostrando-se no geral crescentes com a profundidade. Uma "crosta" de material mais rígido está presente normalmente à superfície e logo abaixo dela. Os autores reconhecem que esta faixa de valores é bastante ampla, porém afirmam que os perfis de Vs para cada aterro costumam exibir menor variabilidade, e ressaltam a importância de se realizarem levantamento sísmicos específicos em cada caso de estudo.

Kavazanjian et al. (1996), com base em investigações realizadas em vários aterros da região da Califórnia, propuseram uma curva típica de variação de Vs com a profundidade, que poderia ser adotada para os aterros desta região, na ausência de investigações específicas. A Figura 3.24 apresenta esta proposição.

Choudhury e Savoikar (2009) analisaram os resultados de diversos perfis de Vs disponíveis na literatura e propuseram a equação (3.4) para o cálculo dos valores médios de Vs em aterros sanitários, em função da profundidade.

$$
V S=\frac{111+9,82 z^{0,77}}{1+0,0012 z^{0,77}}
$$

Em que: Vs $=$ velocidade de propagação da onda $S$ na profundidade de interesse $(\mathrm{m} / \mathrm{s})$ e $z=$ profundidade de interesse $(\mathrm{m})$.

Zekkos et al (2014) analisaram os resultados de ensaios de laboratório e perfis de Vs determinados em campo e propuseram a equação (3.5) para a definição do intervalo de valores mais prováveis de Vs em aterros sanitários, para profundidades até 30 metros. 


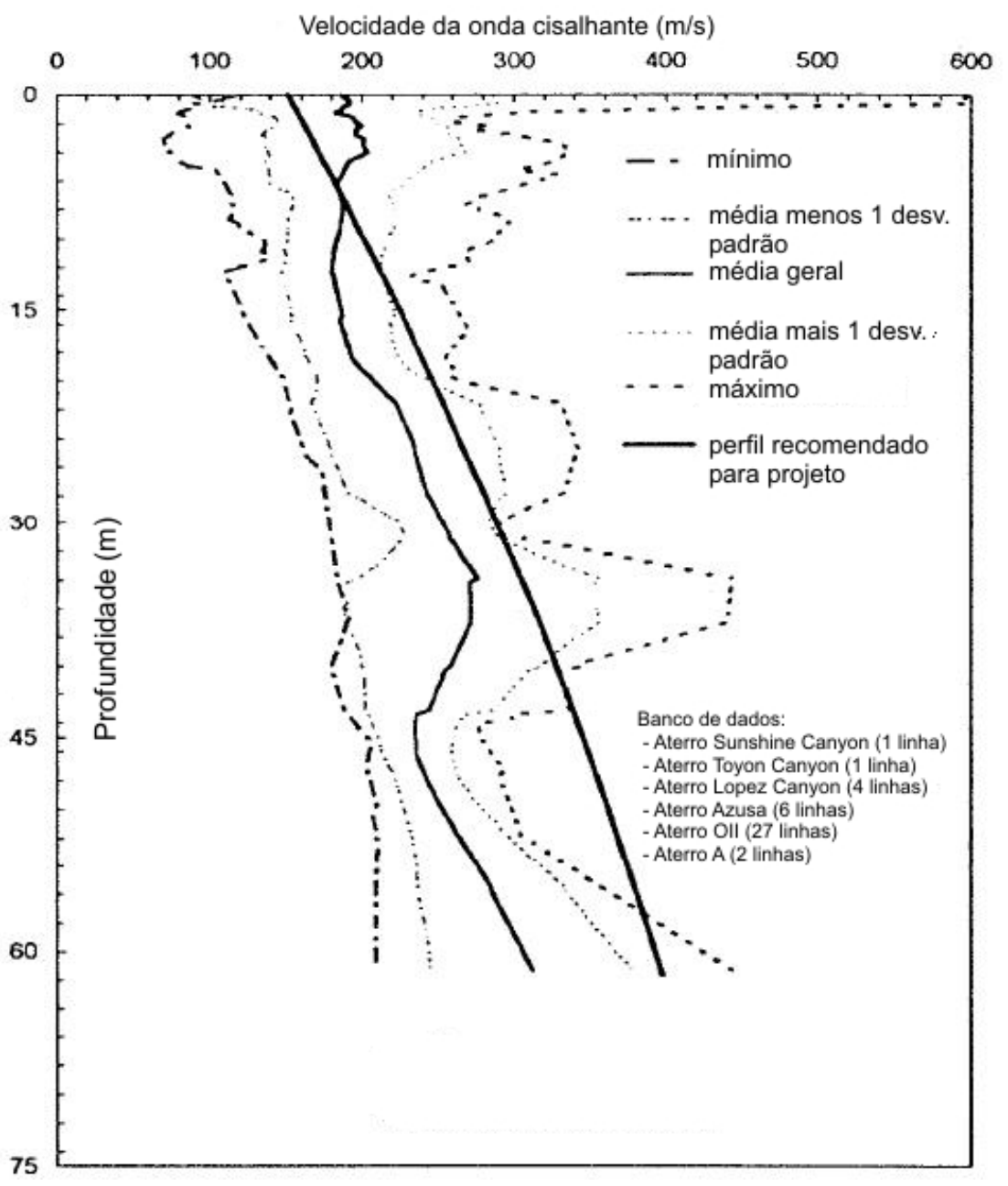

Figura 3.24 - Envoltória das velocidades de propagação das ondas S em aterros sanitários da Califórnia proposta por Kavazanjian et al. (1996).

$$
V_{s}=V_{s i}+\frac{z}{\alpha_{V_{s}}+\beta_{V_{s}} \times z}
$$

Em que: Vs = velocidade de propagação da onda $\mathrm{S}$ na profundidade de interesse, $\mathrm{V}_{\mathrm{si}}=$ velocidade de propagação da onda $\mathrm{S}$ à superfície, $\mathrm{z}=$ profundidade de interesse, $\alpha_{\mathrm{vs}}=$ coeficiente empírico alpha e $\beta_{\mathrm{vs}}=$ coeficiente empírico beta.

Os autores propõem que $V_{\text {si }}$ varie entre 48 e $159 \mathrm{~m} / \mathrm{s}$, com valor médio de $89 \mathrm{~m} / \mathrm{s}, \alpha_{v s}$ varie entre 0,04 e 0,19 , com valor médio de 0,08 e $\beta_{\mathrm{vs}}$ varie entre 0,003 e $0,012 \mathrm{~m} / \mathrm{s}$, com valor médio de 0,006 .

O grau de saturação de um maciço composto por materiais não consolidados pode influenciar as velocidades de propagação das ondas sísmicas. No caso da onda $\mathrm{S}$, a sua velocidade de propagação está relacionada com a rigidez do esqueleto sólido e com a massa específica do material (ver equação (3.2)). De acordo com Stokoe et al. (2004), em solos 
arenosos, onde o efeito do aumento da rigidez devidos aos efeitos de capilaridade é menos sensível, Vs é afetada apenas pelo aumento na massa específica resultante da saturação do maciço. Em solos argilosos, onde os efeitos das forças capilares sobre o módulo de cisalhamento são mais sensíveis, o grau de saturação do maciço afeta Vs tanto por força das variações do módulo, quanto por força das variações da massa específica. Nestes casos, quanto menor for o grau de saturação, maior será a rigidez do material e maior será a velocidade de propagação das ondas $\mathrm{S}$.

O grau de saturação também tem influência sobre as velocidades de propagação das ondas P. Como apresentado em (3.6), a velocidade de propagação das ondas compressionais é controlada pelos módulos volumétrico e cisalhante. Isto implica que tanto a matriz sólida, quanto o fluido presente em seus poros, influenciam diretamente a velocidade destas ondas.

$$
V p=\sqrt{\frac{K+(4 / 3) G}{\rho}}
$$

Em que: $\mathrm{Vp}=$ velocidade de propagação da onda $\mathrm{P}, \mathrm{G}=$ modulo de cisalhamento, $\mathrm{K}=$ módulo volumétrico e $\rho=$ densidade do meio atravessado.

Para graus de saturação inferiores a 99\% a velocidade das ondas P é controlada pela matriz sólida, como ocorre para as ondas S (Stokoe et al., 2004). Nestas condições, a maior influência do conteúdo de água sobre a velocidade de Vp advém de efeitos de capilaridade que impactam a rigidez da matriz sólida do meio. Entretanto, se o grau de saturação atinge $100 \%$, Vp passa a ser dominada pela incompressibilidade relativa do fluido presente neste meio. Nesta situação, o valor de Vp é afetado pelo índice de vazios ou porosidade do material, pelo módulo volumétrico dos grãos que compõem o esqueleto sólido e pelo módulo volumétrico do fluido (Stokoe et al., 2004). O módulo volumétrico da fase fluida é muito sensível à quantidade de ar que está dissolvida nele. Por este motivo, quando o grau de saturação em solos encontra-se entre 99,5 e 100\%, o valor de Vp torna-se muito sensível ao grau de saturação. A Figura 3.25 apresenta resultados de laboratório que ilustram essa sensibilidade do valor de Vp ao grau de saturação em meio porosos. Por outro lado, quando se determinam velocidades de ondas compressionais iguais (ou superiores) a $1.500 \mathrm{~m} / \mathrm{s}$ nestes meios, pode-se afirmar que os mesmos estão saturados por um fluido incompressível, por exemplo, água. 


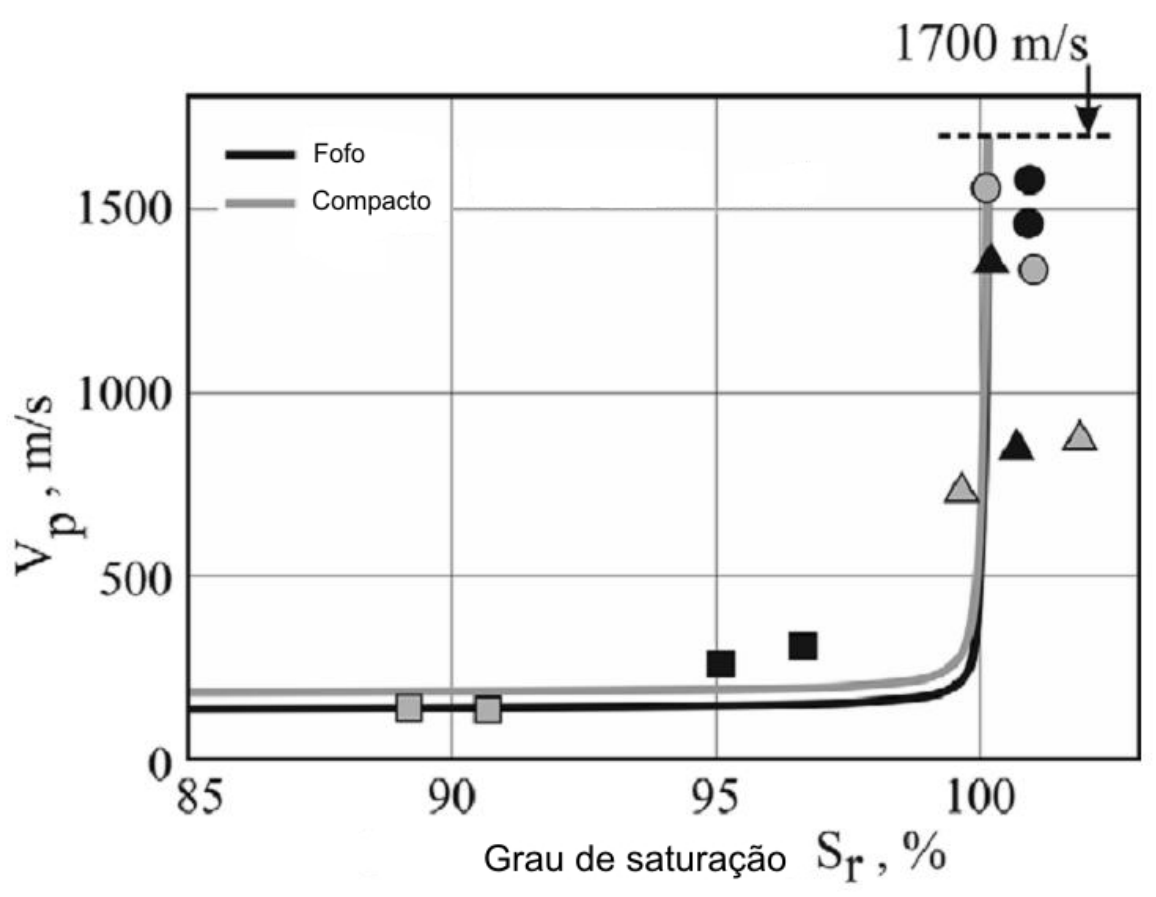

\begin{tabular}{cccc} 
& $\begin{array}{c}\mathrm{D}_{\mathrm{R}} \\
\%\end{array}$ & $\begin{array}{l}\text { Método de } \\
\text { saturação }\end{array}$ & $\begin{array}{c}\mathrm{S}_{\mathrm{r}} \\
\%\end{array}$ \\
\hline $\mathbf{\square}$ & $90.2-93.5$ & Atmosfera & $89.2-90.7$ \\
\hline$\square$ & $15.3-25.9$ & Atmosfera & $95.1-96.7$ \\
\hline $\boldsymbol{\Delta}$ & $96.7-97.7$ & Vácuo & 100 \\
\hline$\triangle$ & $25.4-29.9$ & Vácuo & 100 \\
\hline $\boldsymbol{0}$ & $96.2-99.7$ & Vácuo $+\mathrm{CO}_{2}$ & 100 \\
\hline 0 & $24.6-31.2$ & Vácuo $+\mathrm{CO}_{2}$ & 100 \\
\hline
\end{tabular}

Figura 3.25 - Velocidade de propagação das ondas compressionais versus grau de saturação, segundo Takahashi et al. (2001) (Extraído de Jamiolkowski, 2012).

Esta característica das ondas P tem sido aplicada a maciços de RSU na tentativa de se mapear áreas saturadas com líquidos. Cossu et al. $(2001,2005)$ aplicaram técnicas sísmicas, juntamente com técnicas eletrorresistivas e eletromagnéticas, para investigação dos limites e da distribuição de líquidos e de gases em aterros sanitários na Itália. Del Greco et al. (2007) também afirmam que a determinação das velocidades de ondas $\mathrm{P}$ revelou a estratigrafia dos resíduos e locais com concentrações de lixiviado em outro aterro italiano.

Os métodos geofísicos sísmicos incluem técnicas intrusivas e técnicas não intrusivas. Os métodos intrusivos são denominados downhole, uphole, crosshole, bottom hole, suspension logging e ensaio de penetração do cone sísmico. Os ensaios não intrusivos incluem a sísmica de refração, a sísmica de reflexão, a análise espectral de ondas superficiais (em inglês: $S A S W$ ), 
as ondas superficiais contínuas (em inglês: $C S W$ ), a análise de ondas superficiais por multicanais (em inglês: $M A S W$ ) e as tomografias sísmicas em geral.

No caso de aterros sanitários, as técnicas não intrusivas representam uma grande vantagem, tanto do ponto de vista operacional, pois alguns equipamentos de perfuração encontram dificuldades para avançar na massa de resíduos (Bouazza et al., 1996, referindo-se ao cone mecânico), quanto do ponto de vista de saúde e segurança dos operadores, devido à não-exposição dos mesmos aos resíduos desaterrados durante as perfurações (Bouazza e Kavazanjian, 2000).

Entretanto, como será explicado com maiores detalhes no item 3.4.2, estes ensaios não fornecem a medida direta das velocidades de propagação de ondas sísmicas no aterro. Sua interpretação envolve a adoção de um modelo da estratigrafia do meio investigado, para comparação com os resultados obtidos no ensaio e existem sempre vários modelos para explicar um mesmo resultado.

Na presente pesquisa serão aplicados os métodos crosshole e MASW. Por esse motivo apresentam-se a seguir detalhes de como esses dois métodos são aplicados.

\subsubsection{Técnica Crosshole}

Os ensaios tipo crosshole são realizados em pelo menos dois furos de sondagem, paralelos e próximos entre si. Tipicamente são utilizados três furos alinhados, distantes 3 metros um do outro, como preconizado pela norma ASTM 4428/4428M (ASTM, 2007). No interior dos furos são instalados tubos de PVC rígido, dentro dos quais são colocados os geofones e as fontes geradoras de ondas sísmicas. O espaço entre o tubo de PVC e a parede do furo é totalmente preenchido por um material que garanta a continuidade do meio e que tenha aproximadamente o mesmo peso específico do maciço investigado. Para a realização do ensaio, os geofones são colocados em dois dos furos (no caso em que se usam três furos) a uma profundidade conhecida e no outro furo, à mesma profundidade, é colocada a fonte de ondas sísmicas (ondas S e P separadamente). A utilização de três, em lugar de dois furos apenas, é recomendada, pois elimina a necessidade de se garantir sincronia absoluta entre o início dos registros sismográficos e o momento exato em que se dispara a fonte de ondas. A Figura 3.26 ilustra o esquema geral do ensaio.

Com esse arranjo é possível realizar a medida da velocidade de propagação das ondas $\mathrm{S}$ e das ondas $\mathrm{P}$ em uma trajetória direta entre os furos, sem a necessidade de se utilizar um 
modelo matemático para calcular a provável trajetória das ondas. De posse das velocidades de propagação de ondas, do peso específico do meio e utilizando-se os conceitos da teoria da elasticidade pode-se calcular o módulo de cisalhamento e o coeficiente de Poisson do material situado entre os furos, utilizando-se as equações (3.2) e (3.3).

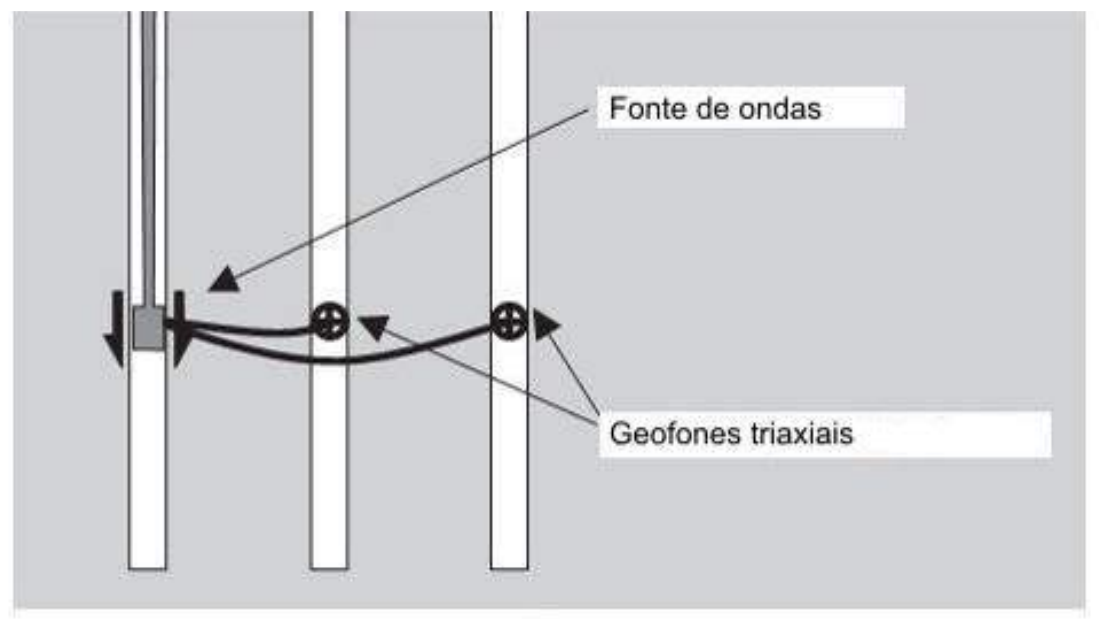

Figura 3.26 - Arranjo geral para o ensaio tipo crosshole (extraído de Clayton, 2011).

\subsubsection{Técnica MASW}

Os ensaios com ondas superficiais só passaram a ser utilizados pela engenharia a partir da década de 80, quando se desenvolveram métodos mais acurados de análise dos dados. $\mathrm{O}$ MASW, ou multichannel analysis of surface waves, é um destes ensaios. Trata-se de uma técnica não-intrusiva, ou seja, tanto a fonte de ondas sísmicas, quanto os geofones são colocados na superfície do terreno, não havendo a necessidade de se executarem perfurações no maciço. O arranjo adotado está ilustrado na Figura 3.27. São utilizados geofones para baixas frequências, adequados para medir as velocidades de propagação das ondas Rayleigh. A fonte de ondas é normalmente estacionária e composta por uma fonte de ondas compressionais, por exemplo, um golpe de marreta sobre uma placa metálica. Também podem ser utilizadas fontes estacionárias vibratórias, nas quais se controla a frequência de vibração.

A característica dessas ondas que interessa para investigação do subsolo é o fato de que sua profundidade de penetração no terreno é proporcional à sua frequência (Figura 3.28). Em terrenos não homogêneos, cada frequência de onda terá uma velocidade diferente de chegada ao mesmo geofone, gerando a chamada curva de dispersão. Esse gráfico, que relaciona as frequências de onda com as velocidades de chegada, é considerado uma impressão digital do terreno não homogêneo. Ele é calculado a partir de transformações matemáticas aplicadas aos 
registros de campo (sismogramas) (Figura 3.29(a)), gerando o domínio frequência-número de ondas (f-K) e a definição da curva de dispersão (Figura 3.29(b)). Da interpretação dos máximos de energia nesta curva calcula-se a curva de dispersão aparente.

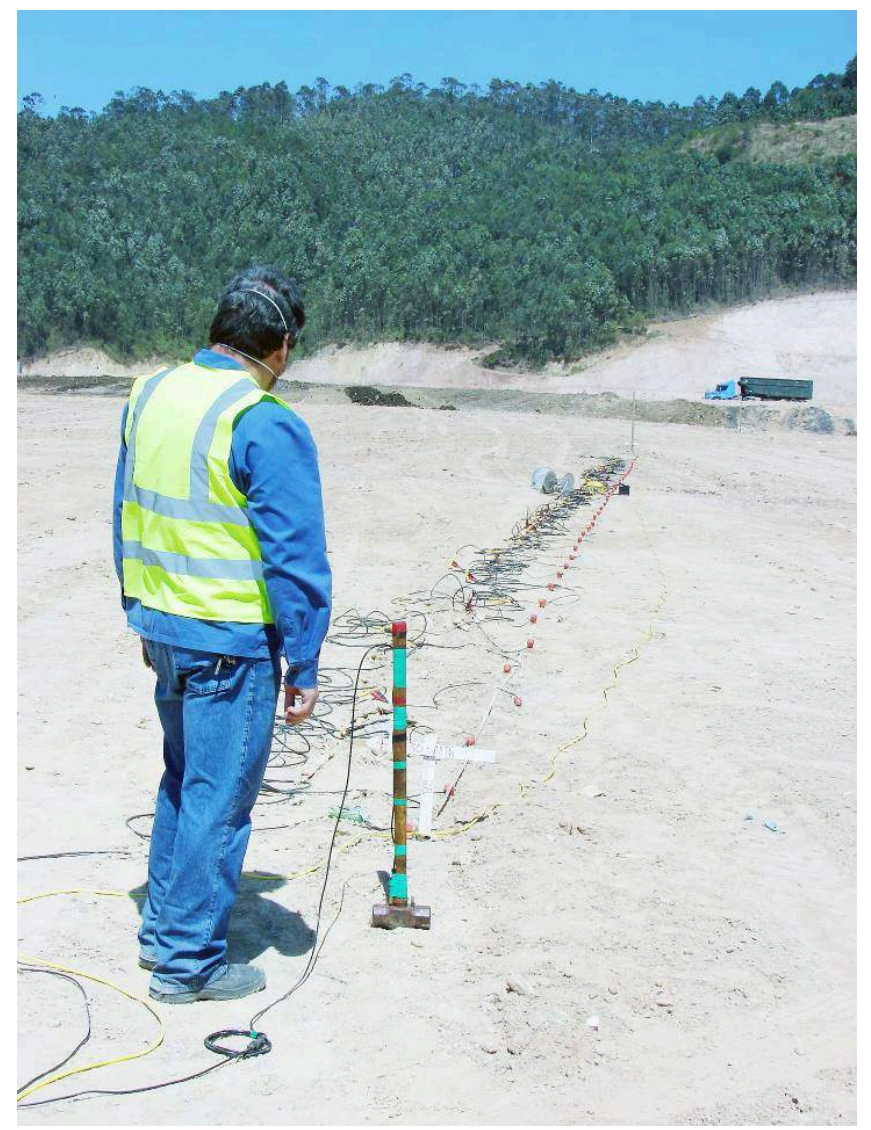

Figura 3.27 - Arranjo do método MASW (uma fonte e 24 geofones em linha).

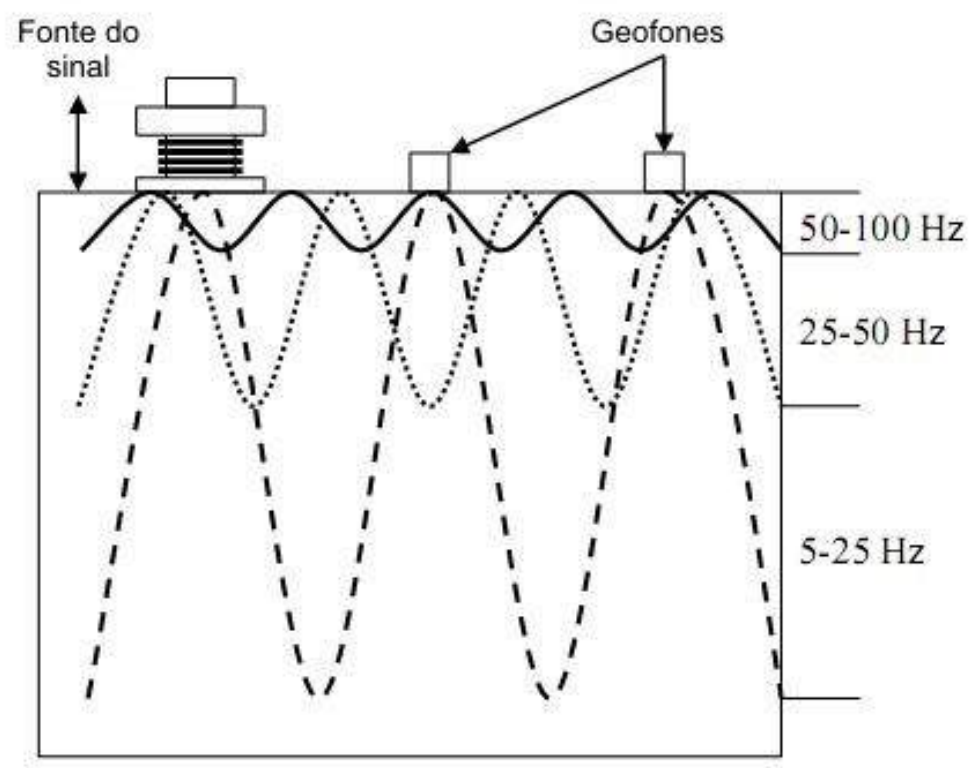

Figura 3.28 - Profundidade de penetração da investigação em ensaios com ondas superficiais (extraído de Bouazza e Kavazanjian, 2000) 


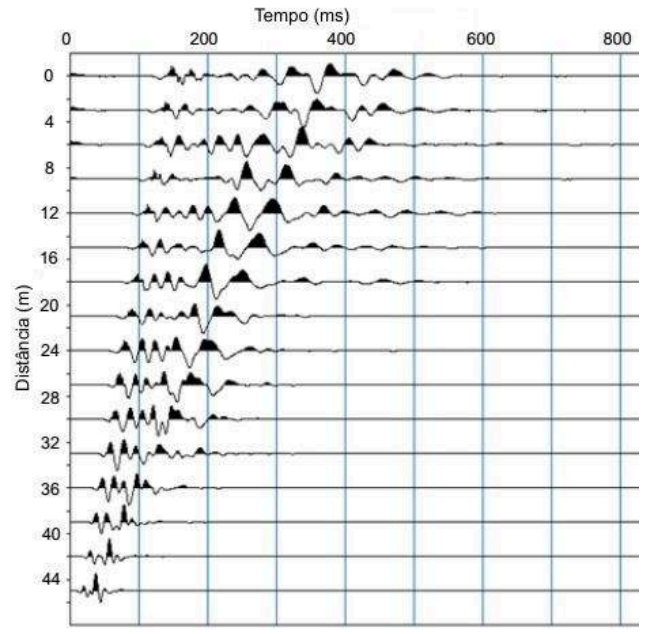

(a)

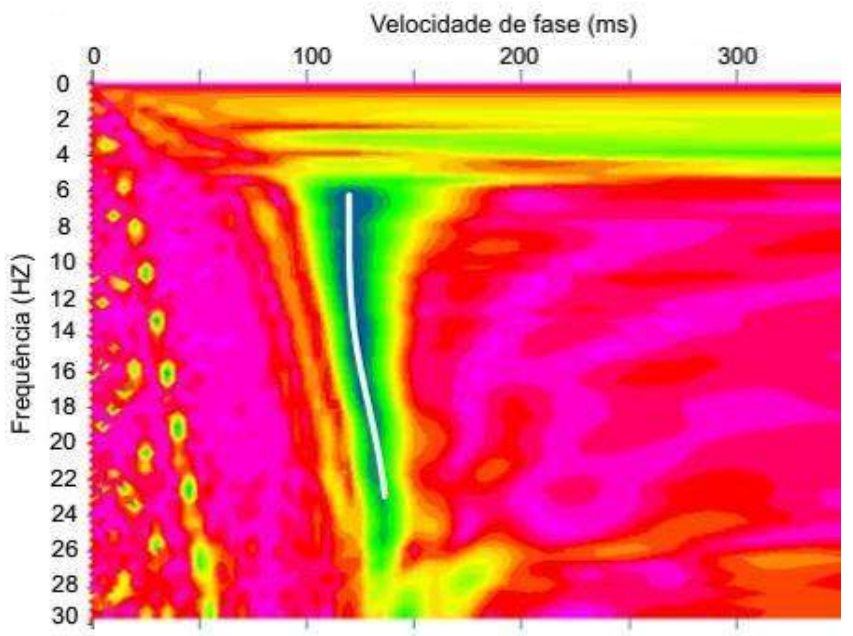

(b)

Figura 3.29 - Etapas do processamento dos dados de campo: (a) sismograma e (b) curva de dispersão completa - a linha branca indica os pontos de máxima energia, para construção da curva de dispersão aparente (extraído de Sahadewa et al., 2011).

O que se faz em seguida é a interpretação os dados, em um processo denominado inversão. A inversão consiste em calcular matematicamente qual é o modelo de terreno que pode gerar uma curva de dispersão igual àquela determinada no ensaio de campo e que, ao final do processo, corresponde ao perfil de velocidades de propagação de ondas interpretado para o maciço investigado. A Figura 3.30 ilustra as etapas conceituais da aplicação do método como um todo.

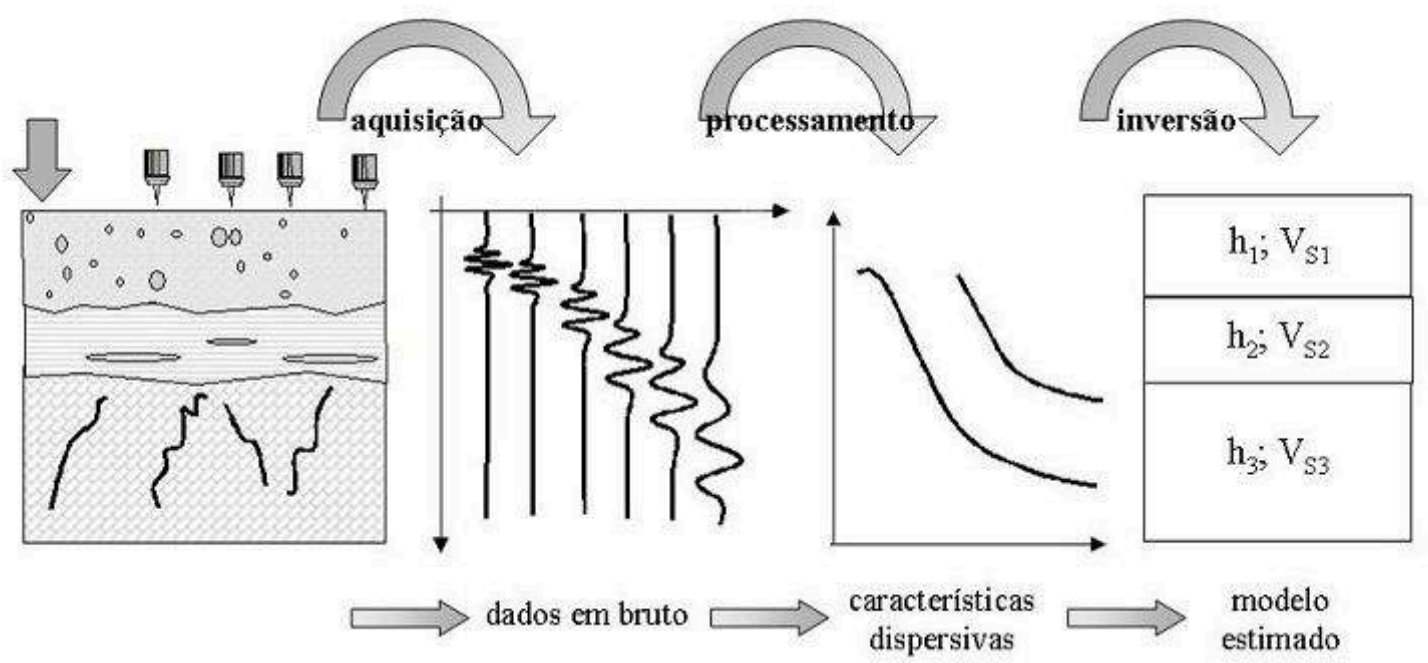

Figura 3.30 - Esquema das etapas principais para aplicação dos métodos das ondas superficiais com o respectivo resultado (Strobbia, 2003, extraído de Lopes et al., 2008). 
A necessidade de se realizar a inversão é apontada como uma desvantagem da aplicação deste método a aterros sanitários, pois neste processo assume-se um modelo de terreno em camadas horizontais, o que não é necessariamente verdade (Konstantaki et al., 2015).

Como exposto anteriormente, como as velocidades de propagação das ondas Rayleigh são muito próximas das velocidades de propagação das ondas $S$, esses valores são utilizados para determinação de um perfil vertical de Vs, que é atribuído ao centro do arranjo de geofones. Juntamente com o peso específico do material, essas velocidades podem ser aplicadas às formulações da teoria da elasticidade na determinação do módulo de cisalhamento máximo do maciço.

De acordo com Kavazanjian (2003) um aspecto importante da investigação pelo método das ondas superficiais é o fato de que o "volume representativo" que está sendo ensaiado aumenta proporcionalmente ao aumento da profundidade de investigação. Em princípio, a velocidade média de propagação de onda calculada por essa técnica pode ser considerada como aplicável a uma fatia bidimensional que contém o plano que passa pelos dois geofones e tem a largura de um comprimento de onda, ou seja, é aproximadamente duas vezes mais larga que a profundidade investigada. Em outras palavras, quanto mais profunda for a investigação, maior é o volume ensaiado. Essa é uma propriedade interessante se o objetivo é obter o comportamento médio do maciço. Porém, isso é algo desvantajoso se o que se pretende é localizar regiões do maciço com rigidez anômala.

Zekkos et al. (2014) destacam que Vs e $G_{0}$ são dependentes da frequência das solicitações impostas ao meio. Isto se verificou para o caso de RSU em duas pesquisas independentes: Zekkos et al. (2008) realizaram ensaios triaxiais cíclicos com amostras de RSU e constataram que $G_{0}$ aumenta com um fator 1,1 para cada aumento logarítmico do número de ciclos, quando se alteram as frequências de solicitação numa faixa que varia de 0,01 a $10 \mathrm{~Hz}$. Lee (2007) realizou ensaios em colunas ressonantes com amostras de RSU e constatou o mesmo fator de aumento de $\mathrm{G}_{\mathrm{o}}$ para frequências variando de 0,03 a $260 \mathrm{~Hz}$. Isto é importante quando se realizam comparações entre os módulos de cisalhamento calculados com base em diferentes métodos geofísicos, pois os ensaios entre furos, por exemplo o ensaio crosshole, costumam trabalhar com frequências de 100 a $300 \mathrm{~Hz}$, enquanto os métodos que utilizam ondas superficiais, por exemplo o MASW, costumam trabalhar com frequências na faixa de 3 a $50 \mathrm{~Hz}$ (Zekkos et al., 2014).

Stokoe et al. (2011) também advogam que diferenças na rigidez dos RSU em função das frequências de solicitação podem ser responsáveis pelas incongruências verificadas nos 
valores de $G_{0}$ determinados a partir de ensaios downhole e de ensaios realizados com fontes estacionárias contínuas, que operam com frequências bem menores, no maciço de resíduos do Aterro Sanitário de Austin, no Texas. Os autores ressaltam, entretanto, que este assunto ainda deve ser melhor estudado. 


\section{MÉTODO}

\subsection{RSU na cidade de São Carlos de 1979 a 2013}

A cidade de São Carlos está localizada na porção central do estado de São Paulo, na região sudeste do Brasil. Segundo dados do último senso realizado pelo IBGE em 2010 sua população era de 221.950 habitantes, com taxa de urbanização de aproximadamente 95\% e taxa de alfabetização de $89,4 \%$. O índice de desenvolvimento humano municipal (IDHM) neste ano era 0,805. Em 2012 o PIB per capita do município era de R\$25.493,00. As principais atividades econômicas desenvolvidas no município eram: setor de serviços $(67,5 \%)$, setor industrial $(30,0 \%)$ e setor agropecuário $(2,5 \%)$.

A altitude média do município é de 856 metros acima do nível do mar e o clima, segundo a classificação de Koppen, é Cwa (subtropical), com inverno seco, temperatura média mínima de $18^{\circ} \mathrm{C}$, e verão quente e chuvoso, temperatura média máxima de $23^{\circ} \mathrm{C}$. A precipitação média anual é $1.300 \mathrm{~mm} /$ ano.

Em 2009 o município produzia 160 toneladas de resíduos diariamente (FIPAI, 2009), sendo que toda a área urbana era atingida pelo serviço de coleta. Além disso, o município possui uma série de ações criadas no sentido de gerenciar adequadamente os resíduos, inclusive com a implantação de programas de tratamento, coleta seletiva e destinação adequada dos resíduos. Nestas iniciativas estão incluídos compostagem, coleta seletiva e destinação adequada de resíduos de construção civil, com a operação de aterros específicos e de uma usina de reciclagem para este tipo de resíduo (atualmente inativa).

O programa municipal de coleta seletiva existe desde 2002. Em 2009 ele abrangia 80\% da área urbana e coletava mensalmente cerca de 100 toneladas de resíduos, o que corresponde a $3.000 \mathrm{~kg}$ por dia (FIPAI, 2009). Matos (2006) realizou uma caracterização dos resíduos plásticos presentes nos resíduos sólidos domiciliares da cidade e constatou que, apesar de haver coleta seletiva implantada, a quantidade de plásticos enviada para o aterro sanitário ainda era elevada $(10,47 \%$ da massa de resíduos sólidos domésticos) e encontrava-se no mesmo nível de outras cidades brasileiras.

A composição gravimétrica dos RSU de São Carlos foi investigada em três ocasiões. Na pesquisa de doutoramento de Gomes (1989), na pesquisa de mestrado conduzida por Frésca (2007) e no levantamento realizado por São Carlos Ambiental (2003). 
Gomes (1989) e Frésca (2007) realizaram o estudo das rotas dos caminhões de coleta e as características dos setores atingidos por esses caminhões, para planejamento de uma amostragem que fosse representativa dos resíduos coletados em toda a cidade. As amostras analisadas foram obtidas por quarteamento e homogeneização de amostras maiores, coletadas em diversos caminhões. Gomes (1989) realizou oito caracterizações em épocas distintas do ano e Frésca (2007) realizou 15 caracterizações ao longo do ano.

Os valores médios da composição gravimétrica dos resíduos produzidos pela cidade relatados por esses autores são apresentados na Tabela 4.1. Verifica-se que os orgânicos correspondiam à maior fração em ambos os levantamentos, perfazendo 56-59\% do total de resíduos em peso. A porcentagem de papéis e de metais mostrou uma significativa redução entre 1989 e 2007, devido à implantação de políticas governamentais de estímulo à reciclagem (Frésca, 2007).

São Carlos Ambiental (2013) realizou a caracterização gravimétrica dos resíduos trazidos ao aterro em janeiro de 2013. De cada caminhão coletor foi retirada uma amostra com massa variando de 55 a $100 \mathrm{~kg}$, de tal forma que todos os setores de coleta estivessem representados na amostragem. Os valores médios determinados naquela ocasião constam da Tabela 4.1. Foi constatada redução do conteúdo de orgânicos e aumento do conteúdo de plásticos e de papel, concluindo-se que quantidades significativas de materiais potencialmente recicláveis estavam sendo encaminhados ao aterro naquela época.

Tabela 4.1 - Composição gravimétrica dos RSU coletados na cidade de São Carlos.

\begin{tabular}{lccc}
\hline \multirow{2}{*}{ Categoria } & \multicolumn{3}{c}{ Composição gravimétrica (\% da massa úmida) } \\
\cline { 2 - 4 } & Gomes, 1989 & Frésca, 2007 & $\begin{array}{c}\text { São Carlos } \\
\text { Ambiental, 2013 }\end{array}$ \\
\hline Orgânicos & 56,70 & 59,08 & 37,6 \\
Papel & 21,30 & 6,44 & 15,3 \\
Plásticos & 8,50 & 10,47 & 13,1 \\
Metais & 5,40 & 1,31 & 2,4 \\
Vidro & 1,40 & 1,67 & 3,8 \\
TetraPak & - & 0,94 & - \\
Outros & 6,70 & 20,09 & 7,9 \\
\hline
\end{tabular}

A disposição final desses resíduos foi realizada em um lixão entre 1979 e 1994 e a partir de então em aterros sanitários. Nos anos iniciais de operação do primeiro aterro sanitário ocorreram interrupções esporádicas na disposição, por problemas técnicos ou por problemas relacionados a licenças ambientais, e, nessas ocasiões, os resíduos voltaram a ser dispostos no lixão, que só foi completamente desativado em 1996. 
Entre 1994 e 2011 foi utilizado um aterro sanitário situado a nordeste do perímetro urbano e desde julho de 2013 está sendo utilizado um novo aterro sanitário situado a sudoeste da área urbana. Entre janeiro de 2012 e julho de 2013 os resíduos foram encaminhados para disposição final em aterro sanitário situado em outro município.

Em 1988 foram construídos dois aterros experimentais nas proximidades do lixão, então ainda em operação, para realização de pesquisas pela equipe do Departamento de Hidráulica e Saneamento da Universidade de São Paulo.

Para a presente pesquisa foram coletadas amostras no Lixão Desativado de São Carlos, em um dos aterros experimentais e no aterro sanitário operado entre 1994 e 2011 . Essas três áreas de disposição final de resíduos são detalhadas a seguir. Na Figura 4.1 é apresentada sua localização.

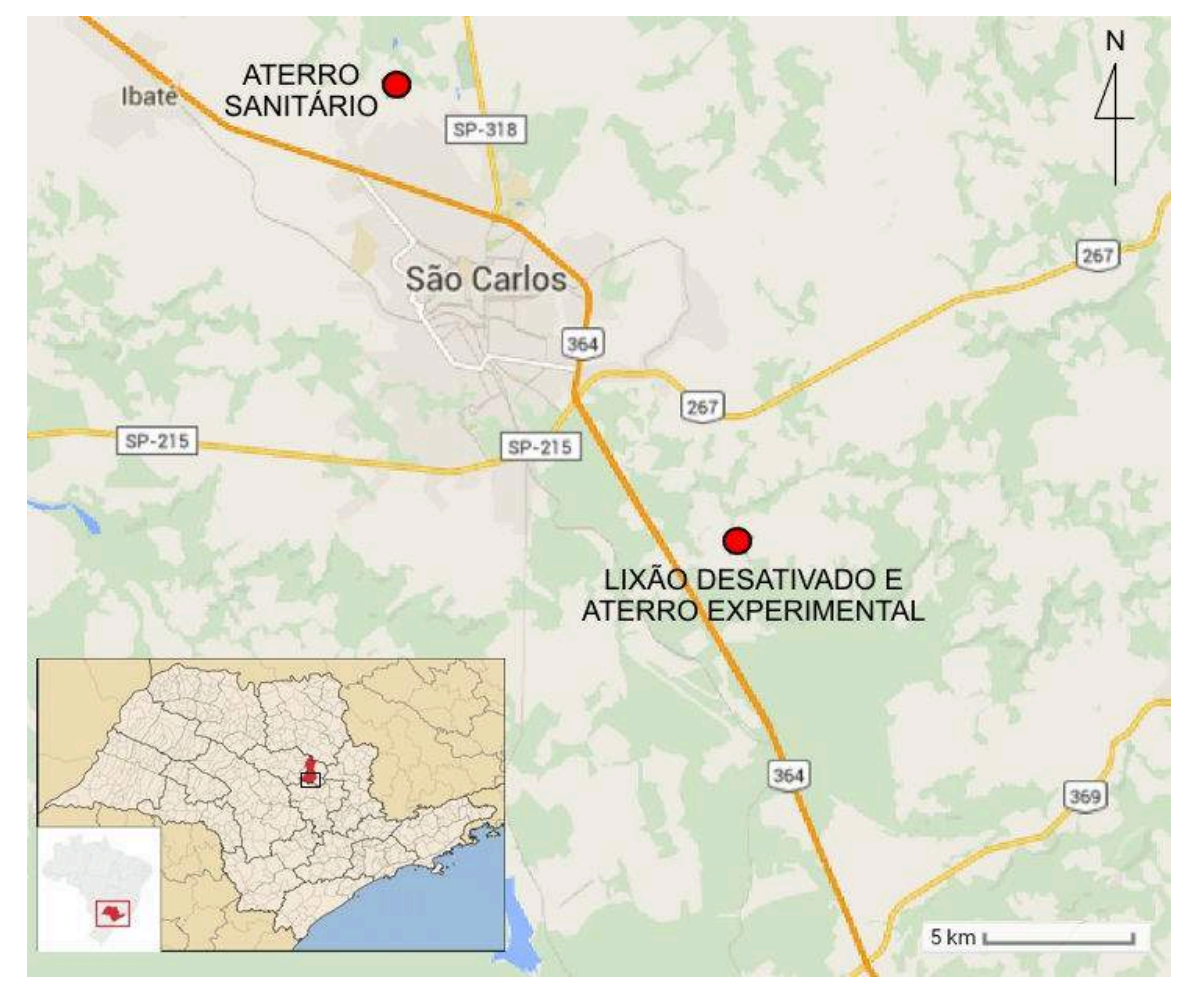

Figura 4.1 - Localização dos locais de coleta de amostras no município de São Carlos - SP.

\subsubsection{Lixão Desativado de São Carlos}

Entre 1979 e 1996 os RSU coletados na cidade de São Carlos foram dispostos em um lixão, localizado a sudeste do perímetro urbano, entre as coordenadas UTM 209678 - 210361 Leste e 7555344 - 7554535 Norte. Este lixão está situado em áreas de uma fazenda particular, denominada Santa Madalena e também é conhecido por esse nome. O acesso é feito pela antiga estrada São Carlos-Analândia, a aproximadamente $2 \mathrm{~km}$ de distância da rodovia 
Washington Luiz, km 221. Apesar de estar situado em terreno particular, a responsabilidade pela operação do lixão sempre coube à prefeitura municipal.

O lixão ocupou um fundo de vale onde anteriormente existia uma vossoroca de grandes dimensões. Menezes (1995) acompanhou em 1994 e 1995 a disposição de resíduos neste local e constatou o despejo indiscriminado de RSU, resíduos de construção e demolição, resíduos de serviços de saúde e resíduos industriais de curtume e de fábrica de papelão.

Gadotti (1997) recuperou o histórico de operação do depósito, tendo constatado que a disposição se iniciou pela cabeceira da voçoroca (1980 a 1982). A seguir os resíduos passaram a ser depositados horizontalmente, cobrindo o fundo da voçoroca (1982 a 1987). Em 1988 foi assinado um termo de ajustamento de conduta (TAC) e alguns procedimentos mínimos para prevenção da poluição foram adotados: o depósito recebeu uma cobertura argilosa compactada, antes da disposição de novas camadas e passou-se a realizar a cobertura diária dos resíduos com solo. A operação nestes moldes ocorreu até 1996. Entretanto, não foram localizados registros da execução de estruturas de drenagem de líquidos ou de gases durante a fase de operação do lixão, bem como de camadas de impermeabilização das laterais da massa de resíduos.

Diversas pesquisas foram desenvolvidas nessa área, visando o entendimento do fluxo da água subterrânea, da migração da contaminação do lençol freático, da caracterização do maciço de resíduos e seus contaminantes (Menezes, 1995, Gadotti, 1997, Velozo, 2006, Shinzato, 2014, entre outros).

\subsubsection{Aterros Experimentais}

Em 1988, como parte de um amplo projeto de estudos sobre a degradação de RSU e sua disposição em aterros sanitários, foram construídos dois aterros experimentais em área próxima ao lixão. Esses aterros foram aproveitados nas pesquisas realizadas por Gomes (1989), Leite (1991) e Schalch (1992), dentre outros.

Os maciços de resíduos destes aterros tinham a forma de um tronco de pirâmide invertido, área de $30 \times 30 \mathrm{~m}^{2}$ (aterro 1) e $26 \times 26 \mathrm{~m}^{2}$ (aterro 2) e profundidades de 5 e 4 metros respectivamente. Para contenção lateral dos resíduos foram construídos diques em solo e a sua profundidade foi determinada pelo fato de se ter atingido rocha no fundo da escavação. $\mathrm{O}$ tratamento da base constituiu-se de uma camada de areia com 5 centímetros de espessura, uma manta plástica tipo Hypalon de $1,5 \mathrm{~mm}$ de espessura, outra camada de areia de 5 
centímetros e um camada de argila compactada de 20 centímetros. As paredes laterais também foram recobertas pela manta plástica.

Em ambos os aterros havia uma linha de drenagem de fundo, situada na metade do aterro e constituída por canaletas meia-cana e brita. Essa linha de drenagem se interligava, no meio do aterro, a um dreno vertical de gás, constituído por um tubo de PVC de 4 polegadas, perfurado, envolvido por um cinturão de brita com diâmetro de 1 metro.

Segundo Gomes (1989), o enchimento dos aterros experimentais com resíduos demorou três meses e foi realizado em camadas, formando-se rampas com a inclinação de 1:3. O tratoresteira compactou cada célula aproximadamente cinco vezes (no sentido de baixo para cima), procedimento que era usual à época para disposição final dos resíduos da cidade, e em seguida foi colocada uma camada de solo, também compactado, para a cobertura das células. Foram aterrados apenas resíduos sólidos urbanos, incluindo resíduos de varrição e de capina.

Como cobertura final dos aterros experimentais foi colocada manta plástica sobre a camada de cobertura dos resíduos e sobre essa manta foi executada uma camada de solo argiloso compactado, com posterior plantio de grama e construção de canaletas para drenagem da água superficial.

\subsubsection{Aterro Sanitário operado entre 1994 e 2011}

Entre 1994 e 2011 os RSU da cidade de São Carlos foram dispostos em um aterro sanitário particular, localizado a nordeste do perímetro urbano e com centro situado nas coordenadas UTM 198318 Leste e 7569824 Norte. Esse empreendimento tem altura máxima de 30 metros acima do terreno circundante e está localizado em área que pertencia originalmente à Fazenda Guaporé, sendo também conhecido por esse nome. $\mathrm{O}$ acesso é feito por estrada vicinal, a partir da rodovia Washington Luiz, km 243.

O maciço de resíduos compõe um volume único, que sofreu três grandes ampliações ao longo de sua história, conforme ilustrado nas Figuras 4.2 e 4.3. O trecho mais antigo foi formado entre 1994 e 1997 e localiza-se na parte nordeste do empreendimento. A primeira ampliação ocorreu em 1998 e estendeu-se até 2004, formando a parte sudeste do maciço que existe atualmente. Em seguida ocorreram mais duas ampliações para oeste. A primeira delas ocorreu entre 2005 e 2007 e a segunda entre 2008 e 2011. Ao final destas duas últimas etapas de ampliação o maciço de resíduos mais antigo, construído entre 1994 e 2004, foi coberto por uma (ou mais) camada de resíduos novos, como esquematizado na Figura 4.2. 


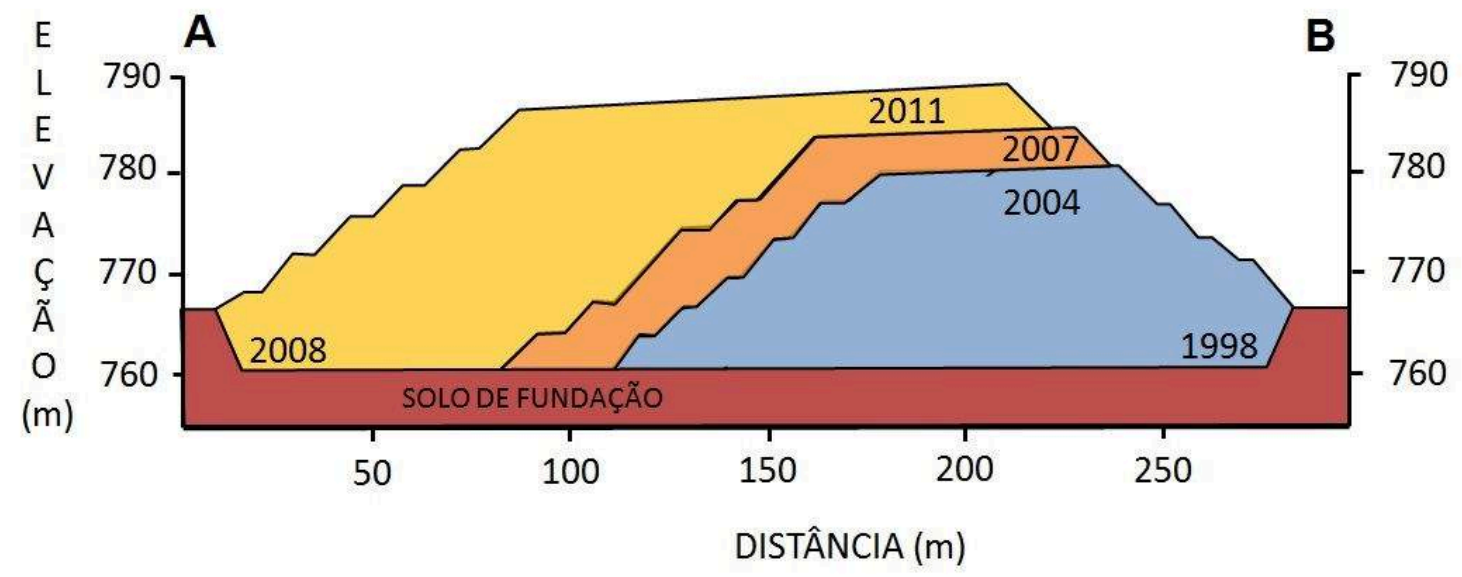

Figura 4.2 - Corte esquemático do maciço de resíduos do Aterro Sanitário de São Carlos.

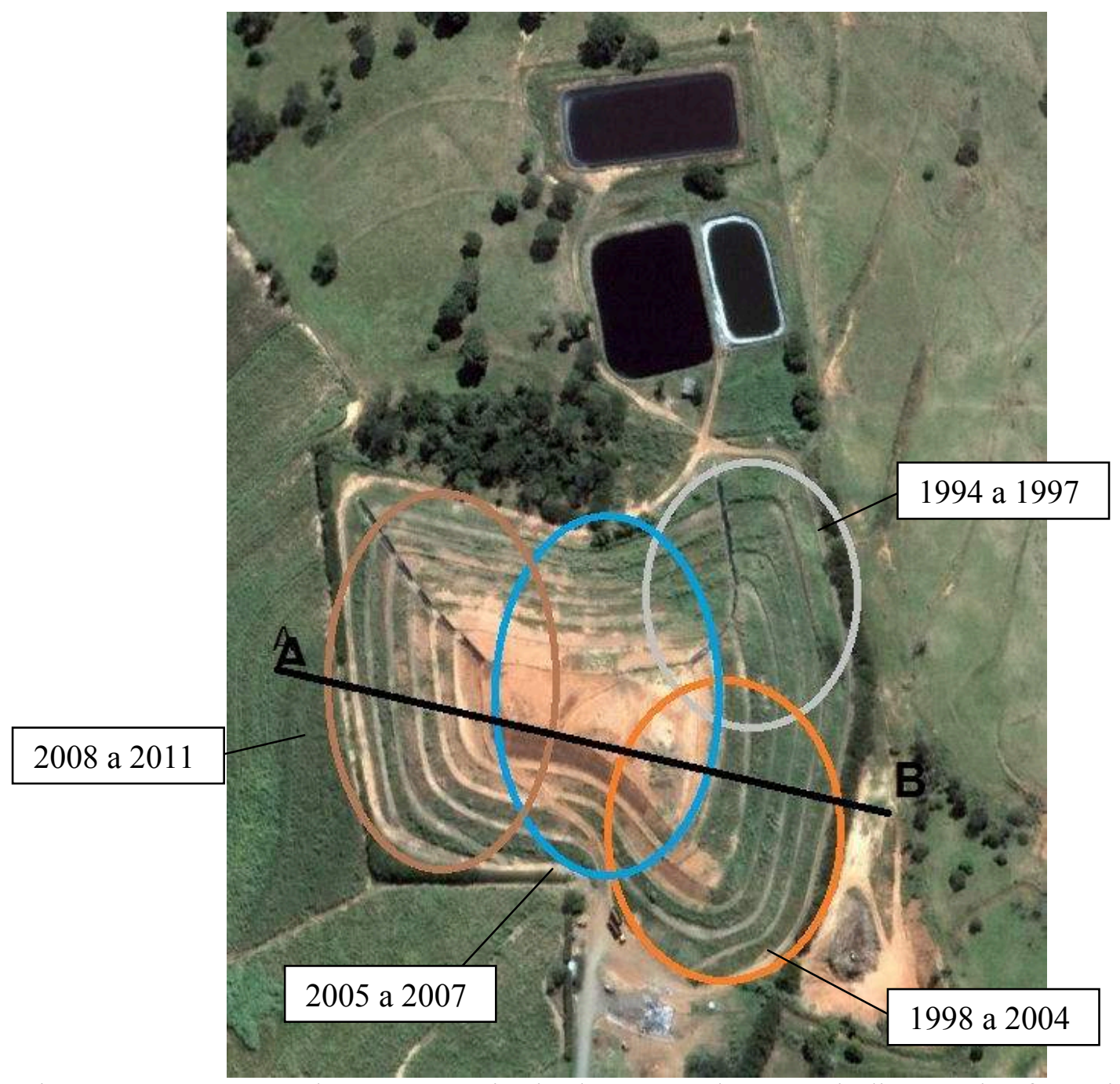

Figura 4.3 - Imagem do Aterro Sanitário de São Carlos, com indicação das fases de operação (Imagem aérea obtida em 04 de janeiro de 2012. Disponível em GoogleEarth, acessado em 15-03-2013). 
$\mathrm{Na}$ parte mais antiga do maciço de resíduos, cuja construção se iniciou na década de 1990, foi executada uma camada de impermeabilização de fundo e laterais composta por solo argiloso compactado. Essa parte mais antiga do maciço foi executada com as tecnologias consideradas adequadas à época, o que se denominava "aterro controlado". Eram executadas camadas de cobertura dos resíduos aterrados, porém não ocorria a implantação extensiva de sistemas de drenagem de gás e de líquidos percolados.

Em 2005 foi assinado um TAC, de tal forma que, quando da realização da segunda grande ampliação em 2005, se executou impermeabilização de fundo e laterais, inclusive para separação lateral dos novos resíduos em relação ao maciço de resíduos existente, com camadas de argila compactada e geomembrana (PEAD 2mm). À época já eram executados drenos de líquidos percolados e de gases no maciço de resíduos de forma sistemática. Não se pôde precisar em que ano esses elementos de drenagem começaram a ser implantados de forma mais intensiva e em que quantidade, mas a partir desta data pode-se afirmar que o empreendimento já era operado como um aterro sanitário.

De acordo com PMSC (2007, apud Ferreira, 2010) o aterro recebia os resíduos sólidos de origem domiciliar recolhidos pela coleta regular no município, assim como resíduos de construção civil em volumes de até 50 litros e resíduos comerciais em volumes de até 100 litros. Também eram dispostos no aterro alguns resíduos especiais, tais como animais de pequeno porte e resíduos volumosos, tais como restos de móveis e colchões, e ainda os resíduos provenientes dos serviços de varrição, poda e capina. Além disso, havia codisposição de lodo de Estação de Tratamento de Esgoto.

Várias pesquisas foram executadas no empreendimento, visando à caracterização dos líquidos lixiviados (Ferreira, 2010), do estado de degradação dos resíduos aterrados (Almeida, 2007), à quantificação das emissões gasosas (Berto Neto, 2009), entre outras.

\subsection{Coleta de amostras deformadas}

\subsubsection{Em sondagens a trado}

Em julho de 2012 foram realizadas seis perfurações no maciço de RSU do Aterro Sanitário de São Carlos utilizando-se uma perfuratriz do tipo trado de haste oca (hollow steam auger). As perfurações atingiram profundidades máximas entre 16,8 e 24,8 metros e diâmetros de $35,5 \mathrm{~cm}$ (furos 1, 2 e 3) e $29 \mathrm{~cm}$ (furos 4, 5 e 6). Elas distaram no máximo 10 
metros entre si e foram realizadas na parte mais antiga do maciço de resíduos, conforme ilustrado na Figura 4.4.

Todo o material escavado foi descrito com relação à sua composição (RSU, lodo, solo de cobertura), cor (marrom escuro, cinza, "colorido" ou preto) e aspecto geral de umidade (seco, pouco, úmido, muito úmido). Os intervalos onde a saída de gás era visível foram anotados.

Nestas perfurações foram coletadas 31 amostras deformadas ditas "grandes" (pesos úmidos entre 80 e $900 \mathrm{~kg}$ ), que foram designadas por “AX-Y”, sendo X o furo de sondagem e Y o número da amostra.

Nos dois primeiros furos as amostras foram coletadas em intervalos de 3 metros, separados por 2 metros não amostrados. A partir do terceiro furo, quando, em função do histórico de operação do aterro e dos resultados das duas primeiras sondagens, a "estratigrafia" do maciço já era conhecida, os intervalos de amostragem foram readequados.

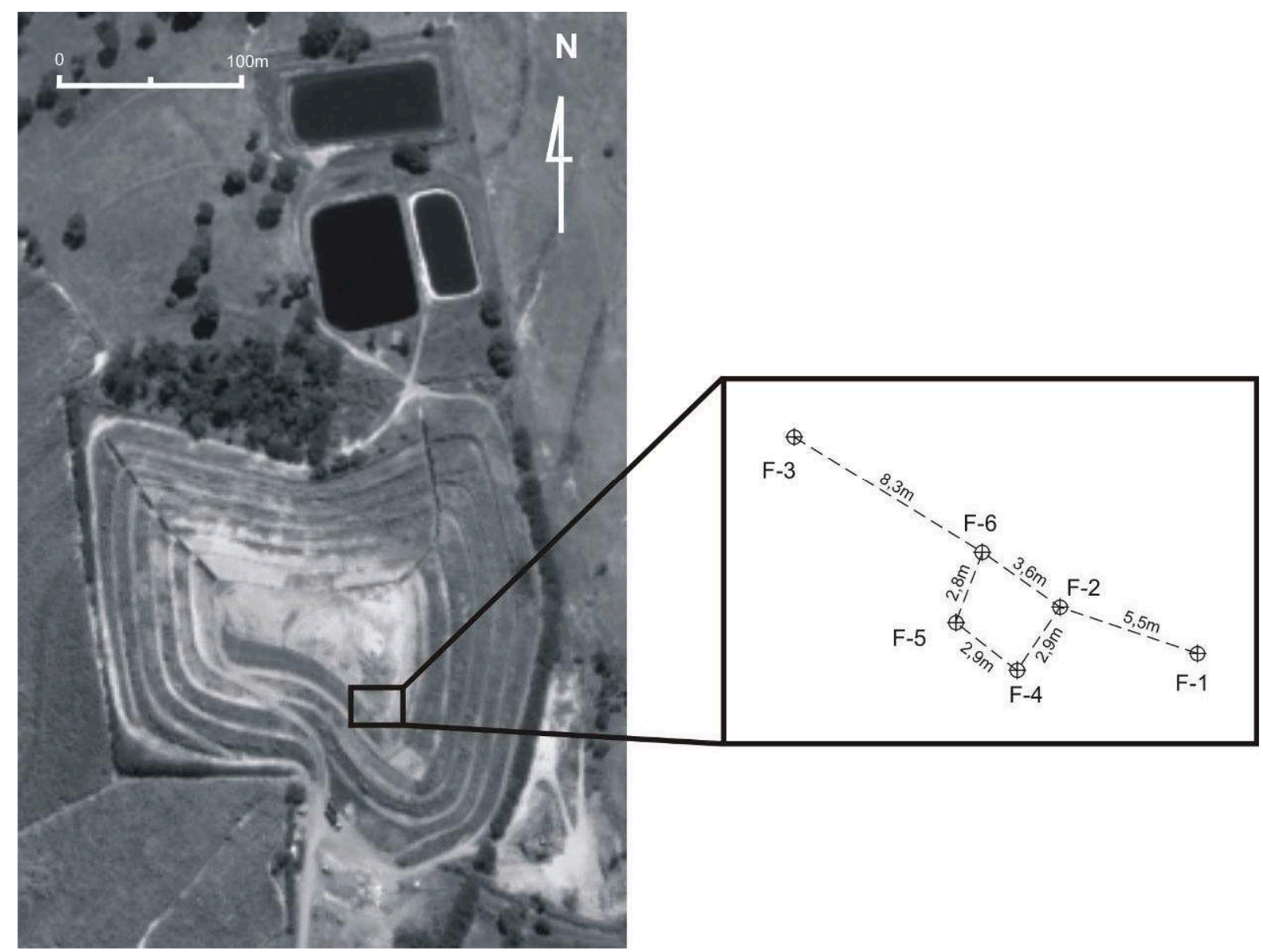

Figura 4.4 - Planta de localização das sondagens no Aterro Sanitário de São Carlos (Imagem aérea obtida em 04 de janeiro de 2012. Disponível em GoogleEarth, acessado em 15-032013). 
Nos furos 3, 4 e 5 buscou-se amostrar "camadas" de resíduos com mesma idade e que incluíssem a menor quantidade possível de solo de cobertura. No furo 6 a prioridade foi amostrar intervalos diferentes dos demais furos. A correlação entre as amostras está apresentada na Figura 4.5.

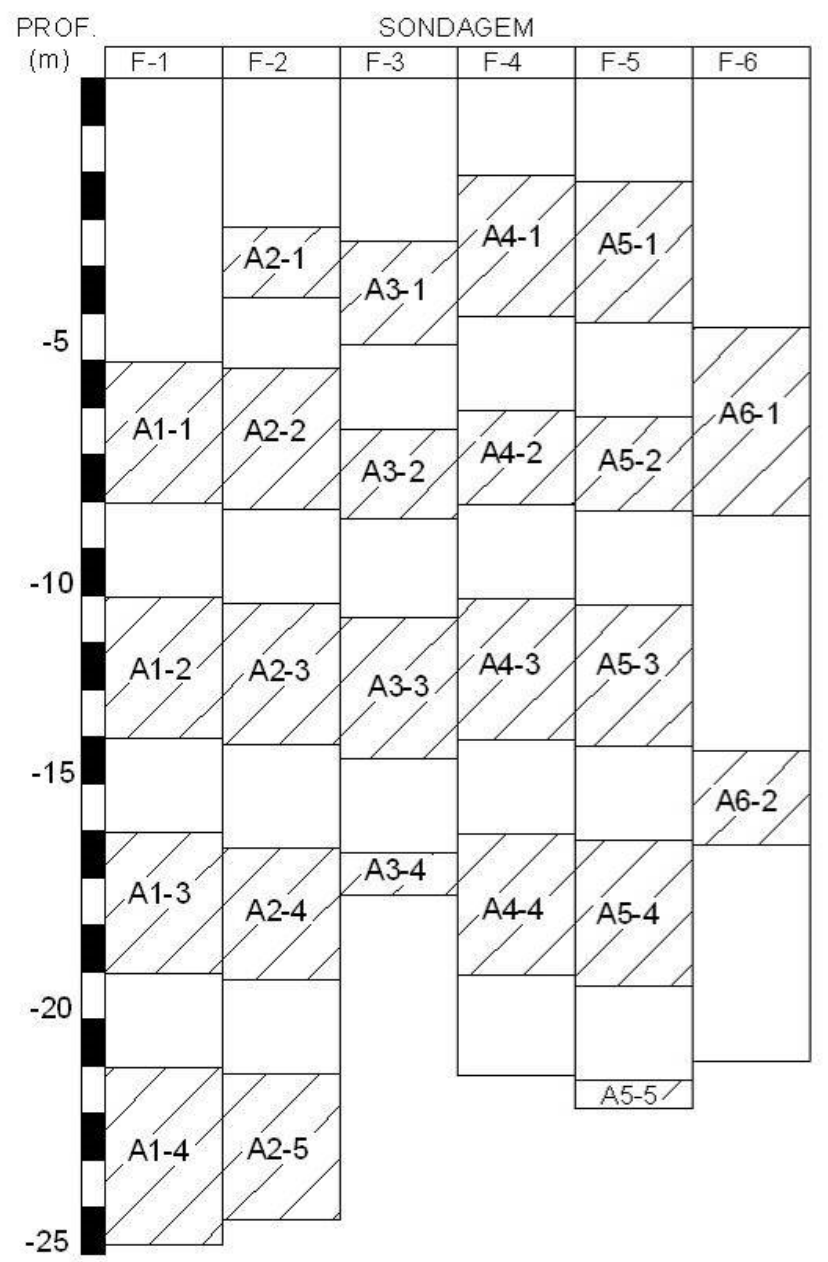

Figura 4.5 - Correlação entre as amostras coletadas no Aterro Sanitário de São Carlos.

Além dessas, foram coletadas 26 amostras denominadas "pequenas" (peso úmido entre 2 e $20 \mathrm{~kg}$ ) para registro das características do material situado entre os intervalos de amostragem maiores.

\subsubsection{Em trincherias}

Em junho de 2013 foi escavada uma trincheira no Aterro Sanitário de São Carlos, para retirada de amostra de resíduos aterrados em 2011. A trincheira foi executada com retroescavadeira e estava localizada cerca de cinco metros para oeste do furo de sondagem F5. A camada de cobertura do aterro era composta por cerca de 40 centímetros de material 
arenoso pouco argiloso misturado com entulhos diversos, seguida por cerca de 50 centímetros de material arenoso pouco argiloso. Ambas tinham a mesma coloração marrom. A partir de cerca de 0,9 metros de profundidade ocorriam os resíduos sólidos urbanos. A amostra foi coletada entre as profundidades de 1,0 e 1,3m. Os resíduos escavados foram colocados sobre uma lona plástica e os componentes maiores que 20 centímetros foram separados manualmente, pesados e devolvidos para o aterro. Foi necessário abrir (rasgar) manualmente os sacos plásticos utilizados para o acondicionamento dos RSU para coleta, pois os mesmos encontravam-se na maioria das vezes ainda fechados. Os materiais menores que 20 centímetros foram ensacados, pesados e transportados para o laboratório.

Em outubro de 2013 foi aberta uma trincheira no platô do Aterro Experimental, visando a coleta de resíduos aterrados em 1988. A trincheira foi escavada com uma retroescavadeira. Atravessou-se inicialmente uma camada de 30 centímetros de argila pouco arenosa, vermelha, sob a qual foi identificada a manta de Hypalon colocada no Aterro Experimental à época da sua construção para evitar a infiltração de águas superficiais. Sob a manta existia uma camada de 40 centímetros de argila arenosa, vermelho-amarelada e, a partir de 0,7 metros de profundidade, resíduos sólidos urbanos decompostos. A amostra foi coletada entre as profundidades de 1,0 e 1,5m. Os resíduos escavados foram colocados sobre uma lona plástica e os componentes maiores que 20 centímetros foram separados manualmente, pesados e devolvidos para a trincheira, que foi em seguida fechada com terra. Em geral, não foi necessário rasgar os sacos plásticos que acondicionavam os resíduos, pois estes já se encontravam abertos ou deteriorados. Os materiais menores que 20 centímetros foram ensacados, pesados e transportados para o laboratório.

\subsubsection{Em poço}

Shinzato (2014) realizou em julho de 2011 a escavação de um poço circular (diâmetro de 1,5 metro) na região central do maciço de resíduos que compõe o Lixão Desativado de São Carlos. A escavação atravessou 30 centímetros de camada de cobertura arenosa pouco argilosa, atingindo os resíduos em seguida. Todos os materiais escavados entre de 0,7 e 1,5 metros de profundidade foram ensacados e encaminhados ao laboratório, onde este material foi pesado e colocado sobre uma lona para separação manual dos componentes maiores que $20 \mathrm{~cm}$. Não foi necessário rasgar os sacos plásticos que acondicionavam os resíduos, pois estes já se encontravam abertos ou deteriorados. Os componentes maiores que 20 centímetros 
foram pesados e encaminhados para o aterro sanitário que se encontrava em atividade na cidade à época. Os componentes menores que 20 centímetros foram homogeneizados e ensacados novamente, para armazenagem. O primeiro nível d'água suspenso foi detectado por Shinzato (2014) a 3,5 metros de profundidade neste local.

\subsection{Ensaios de Caracterização}

\subsubsection{Massa específica da brita}

Nos ensaios de determinação do peso específico in situ dos RSU, descritos adiante, foi utilizada brita 1 fabricada a partir de basaltos da região de São Carlos. A massa específica desse material não é uma grandeza conhecida com rigor, pois não se sabe qual o estado de compacidade que a brita atinge ao se assentar no interior do furo de sondagem. $\mathrm{O}$ que se denominou "calibração" da brita foi a determinação de um intervalo de valores dentro do qual se acredita que esteja situada a massa específica da brita assentada no interior do furo de sondagem. Para tanto foram realizados ensaios que simulassem as situações consideradas a priori como extremas (estado solto e compactado por vibração) e situações semelhantes ao lançamento que ocorreria em campo.

Para simulação do lançamento do material em estado fofo utilizou-se o procedimento B1 descrito na norma NBR 12.004 (ABNT, 1990).

Para simular a situação de campo, a brita foi lançada de diferentes alturas, por dentro de um tubo de PVC de $7,1 \mathrm{~cm}$ de diâmetro. Na extremidade inferior do tubo estava colocado um balde com volume conhecido. Com o lançamento da brita o balde enchia-se e era pesado, permitindo a determinação da massa específica da brita lançada de diferentes alturas. Este procedimento foi realizado para as alturas de 3,0 e 7,0 metros e foi repetido 10 vezes para cada uma delas.

\subsubsection{Amostras coletadas em campo}

As amostras grandes coletadas por sondagem no Aterro Sanitário foram caracterizadas por sua composição gravimétrica, sua umidade e seu conteúdo de sólidos totais voláteis (STV). Para as amostras pequenas foi realizada apenas a determinação da umidade. As 
amostras coletadas em trincheiras e em poço foram caracterizadas quanto à sua composição gravimétrica e sua umidade.

\subsubsection{Composição gravimétrica}

De cada uma das 31 amostras grandes coletadas no Aterro Sanitário de São Carlos, assim como das duas amostras coletadas em trincheiras e da amostra coletada em poço, após homogeneização, foram separados por quarteamentos sucessivos, entre 45 e $65 \mathrm{~kg}$ para a determinação da composição gravimétrica. Essa fração da amostra, ainda úmida, foi colocada sobre uma peneira de abertura $19 \mathrm{~mm}$. O material passante foi classificado como "menor que $19 \mathrm{~mm}$ " e corresponde aos componentes "tipo solo" presentes na amostra. O material retido na peneira foi separado manualmente nas seguintes categorias: plásticos moles, plásticos duros, madeira, tecidos, metais, pedras (e cerâmicos), borracha, papel, vidro e outros (inclui principalmente isopor, espuma e materiais que não puderam ser identificados). Após a separação as frações foram secadas em estufa a $70^{\circ} \mathrm{C}$ e calcularam-se as porcentagens em peso seco de seus componentes.

\subsubsection{Umidade}

As umidades foram determinadas por secagem em estufa a $60^{\circ} \mathrm{C}$ até constância de peso em pesagens realizadas com intervalo de no mínimo 12 horas. Os resultados são apresentados sobre base seca.

As frações separadas para determinação da composição gravimétrica também foram secadas em estufa para determinação das umidades parciais de cada classe de componentes.

As amostras pequenas foram secadas em estufa para determinação das umidades globais.

\subsubsection{Conteúdo de Sólidos Totais Voláteis}

Para cada uma das 31 amostras grandes coletadas no Aterro Sanitário de São Carlos foram tomadas $350 \mathrm{~g}$ da categoria de materiais menores que $19 \mathrm{~mm}$, que já haviam sido secados em estufa para determinação da umidade. 
Essa porção foi destorroada em almofariz e teve os plásticos duros e moles, as pedras, os vidros e os metais removidos manualmente. Em seguida, de cada amostra foram tomadas pelo menos três alíquotas com pesos entre 25 e $50 \mathrm{~g}$ para execução do ensaio em si. As alíquotas foram aquecidas em estufa a $70^{\circ} \mathrm{C}$ por uma hora, pesadas, e, aquecidas em mufla a $600^{\circ} \mathrm{C}$ por duas horas, sendo então novamente pesadas. $\mathrm{O}$ valor dos sólidos totais voláteis (STV) foi calculado como sendo a porcentagem de massa perdida entre as duas etapas de aquecimento, em relação à massa remanescente após o aquecimento a $600^{\circ} \mathrm{C}$.

\subsection{Ensaios de campo}

\subsubsection{Determinação do peso específico in situ}

Em todas as sondagens a trado executadas no Aterro Sanitário de São Carlos foram realizadas determinações do peso específico dos RSU. O trado de haste oca é constituído por uma série de segmentos que vão sendo progressivamente emendados, conforme progride a perfuração do furo de sondagem. A execução dos furos pode ser dividida em duas grandes fases: a de avanço, ou perfuração propriamente dita, e a de retirada do conjunto de trados.

$\mathrm{Na}$ extremidade inferior do conjunto de trados existe uma coroa, que é a ferramenta responsável pelo corte do material durante a fase de avanço (Figura 4.6). O trado em si é helicoidal e tem a função de transportar o material escavado para a superfície e de manter o furo aberto, atuando de certa forma como um revestimento capaz de sustentar as paredes do furo, caso elas tendam a se fechar (Figura 4.7). A escavação é realizada a seco, sem a adição de água ou de qualquer outro fluido de perfuração. Para que não suba material pelo centro do trado (haste oca) uma peça cilíndrica com sapata cortante avança por rotação no interior da haste (Figura 4.8), acompanhando a descida da coroa.

A profundidade da escavação era anotada considerando-se o comprimento total da composição de sondagem, que corresponde à soma dos comprimentos de todos os segmentos de hélice mais a altura da coroa de perfuração que estavavam colocados dentro do furo de sondagem. Apenas no final da perfuração (fase de avanço do furo) e antes de se iniciar a retiradas dos segmentos de hélice é que se realizou uma medida do comprimento total do furo, com trena, por dentro da haste oca do trado.

Para a determinação do peso específico dos RSU realizou-se a pesagem do material extraído do furo durante a fase de avanço. Essa informação, somada ao diâmetro nominal do 
furo e ao comprimento perfurado foi suficiente para o cálculo do peso específico do maciço de RSU em cada trecho perfurado.

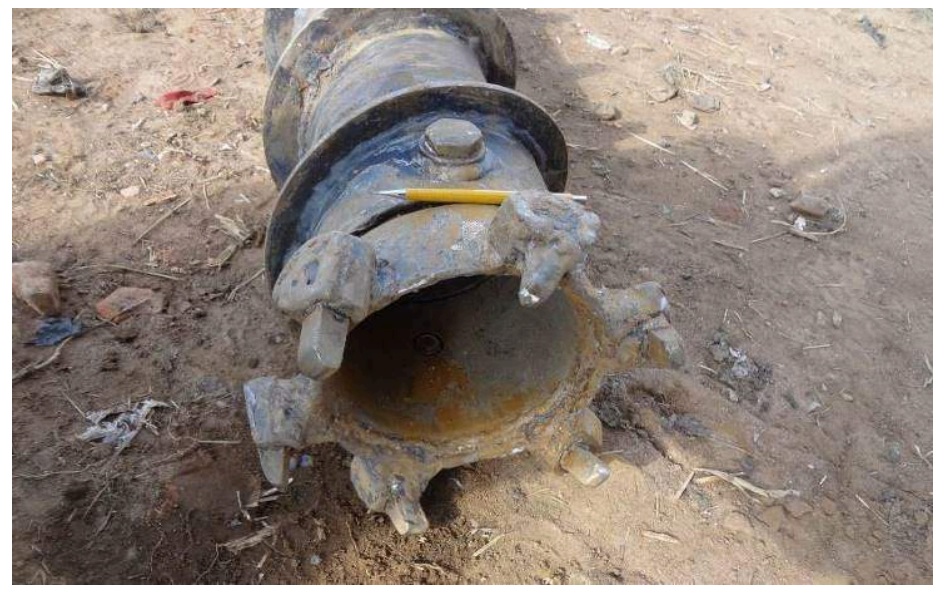

Figura 4.6 - Detalhe da coroa dentada que realiza a escavação do furo de sondagem, engatada na extremidade inferior do conjunto de trados de haste oca.

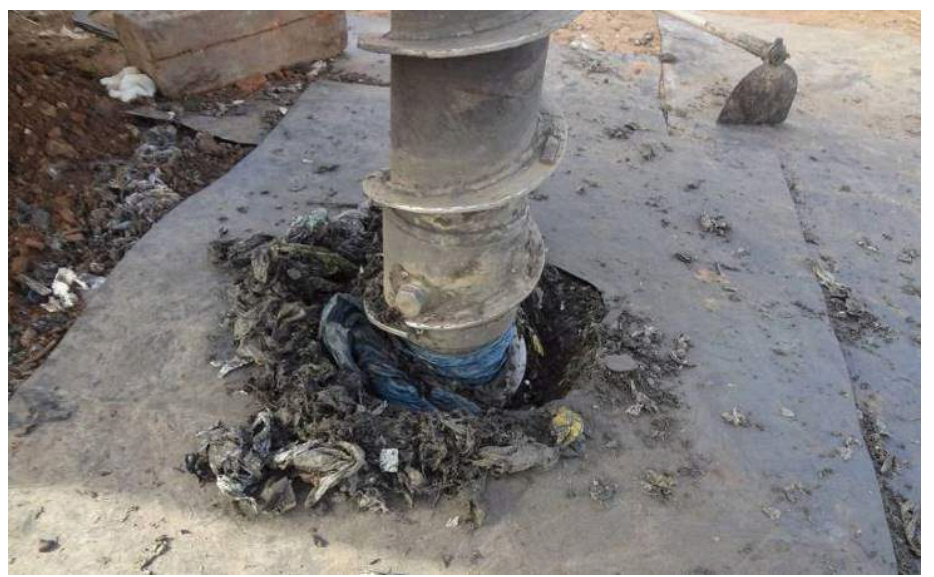

Figura 4.7 - Resíduos chegando à superfície, trazidos pela composição de trados helicoidais.

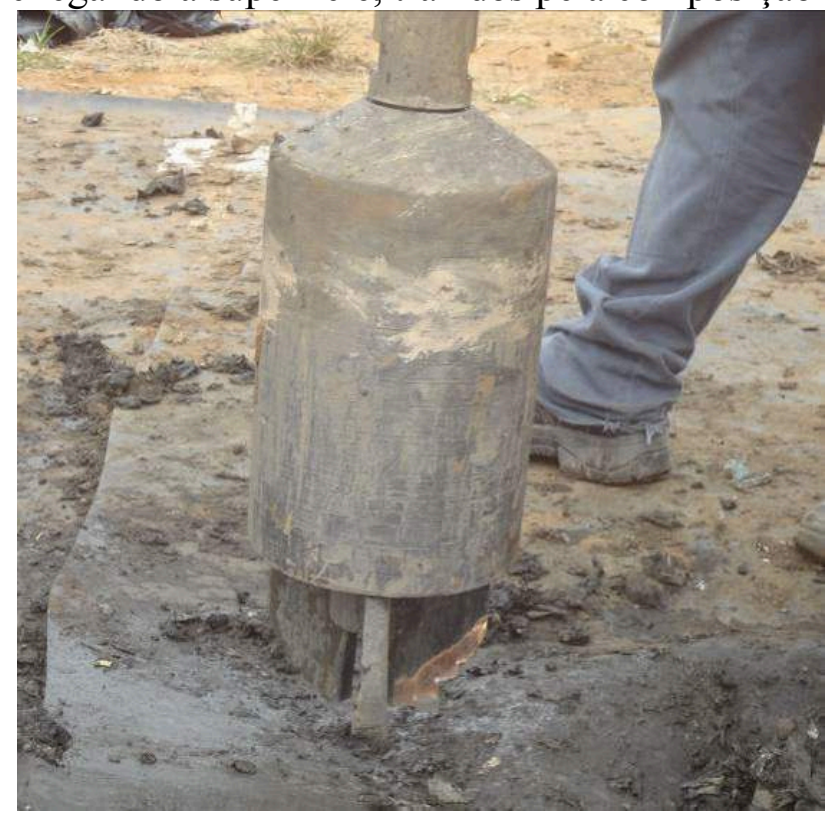

Figura 4.8 - Detalhe da sapata cortante que realiza a escavação do furo no interior da haste oca e impede que o material suba por dentro do trado. 
Nos furos 1 a 4 foram pesados e amostrados os materiais extraídos das perfurações em intervalos de cerca de 3 metros de extensão, intercalados por um trecho de cerca de dois metros, em que o material não foi pesado. Nos furos 5 e 6 todo o material retirado do furo foi pesado, apesar de só terem sido amostrados trechos intercalados. Na Tabela 4.2 é apresentado um resumo dos intervalos pesados e amostrados nessa fase da pesquisa.

Tabela 4.2 - Ensaios de determinação do peso específico in situ

\begin{tabular}{|c|c|c|}
\hline Sondagem & Trecho ensaiado (m) & Nome da amostra \\
\hline \multirow{4}{*}{ F-1 } & 6,0 a 9,0 & A1-1 \\
\hline & 11,0 a 14,0 & A $1-2$ \\
\hline & 16,0 a 19,0 & A $1-3$ \\
\hline & 21,0 a 24,8 & A1-4 \\
\hline \multirow{5}{*}{ F-2 } & 3,0 a 4,5 & A2-1 \\
\hline & 6,0 a 9,0 & A2-2 \\
\hline & 11,0 a 14,0 & A2-3 \\
\hline & 16,2 a 19,0 & A2-4 \\
\hline & 21,0 a 24,1 & $\mathrm{~A} 2-5$ \\
\hline \multirow{4}{*}{ F-3 } & 3,0 a 5,2 & A3-1 \\
\hline & 7,0 a 8,9 & A3-2 \\
\hline & 11,0 a 14,0 & A3-3 \\
\hline & 16,0 a 16,9 & A3-4 \\
\hline \multirow{4}{*}{ F-4 } & 2,0 a 5,0 & A4-1 \\
\hline & 7,0 a 9,0 & A4-2 \\
\hline & 11,0 a 14,0 & A4-3 \\
\hline & 16,0 a 19,0 & A4-4 \\
\hline \multirow{9}{*}{ F-5 } & 2,0 a 5,0 & A5-1 \\
\hline & 5,0 a 7,0 & - \\
\hline & 7,0 a 9,0 & A5-2 \\
\hline & 9,0 a 11,0 & - \\
\hline & 11,0 a 14,1 & A5-3 \\
\hline & 14,1 a 16,0 & - \\
\hline & 16,0 a 19,1 & A5-4 \\
\hline & 19,1 a 21,1 & - \\
\hline & 21,1 a 21,7 & A5-5 \\
\hline \multirow{5}{*}{ F-6 } & 2,0 a 5,0 & - \\
\hline & 5,0 a 9,0 & A6-1 \\
\hline & 9,0 a 14,0 & - \\
\hline & 14,0 a 16,0 & A6-2 \\
\hline & 16,0 a 20,9 & - \\
\hline
\end{tabular}


Na segunda fase de execução dos furos (durante a retirada das hastes) foi inserida brita "pré-calibrada" dentro da cavidade escavada, visando à determinação do volume real escavado por um método de substituição de volume. A brita foi lançada por dentro da haste oca, em incrementos proporcionais aos segmentos de haste que eram sacados do furo. Os dados computados em campo nessa operação foram a massa de brita inserida e a altura ocupada pela brita dentro do furo em cada incremento. A altura pôde ser medida com uma trena colocada por dentro da haste oca do trado, desde a superfície até a base da perfuração, com precisão de $0,01 \mathrm{~m}$ (Figura 4.9). Esse procedimento foi executado ao longo de todo o furo, praticamente até a superfície. Os metros finais do furo foram obturados com calda de bentonita.

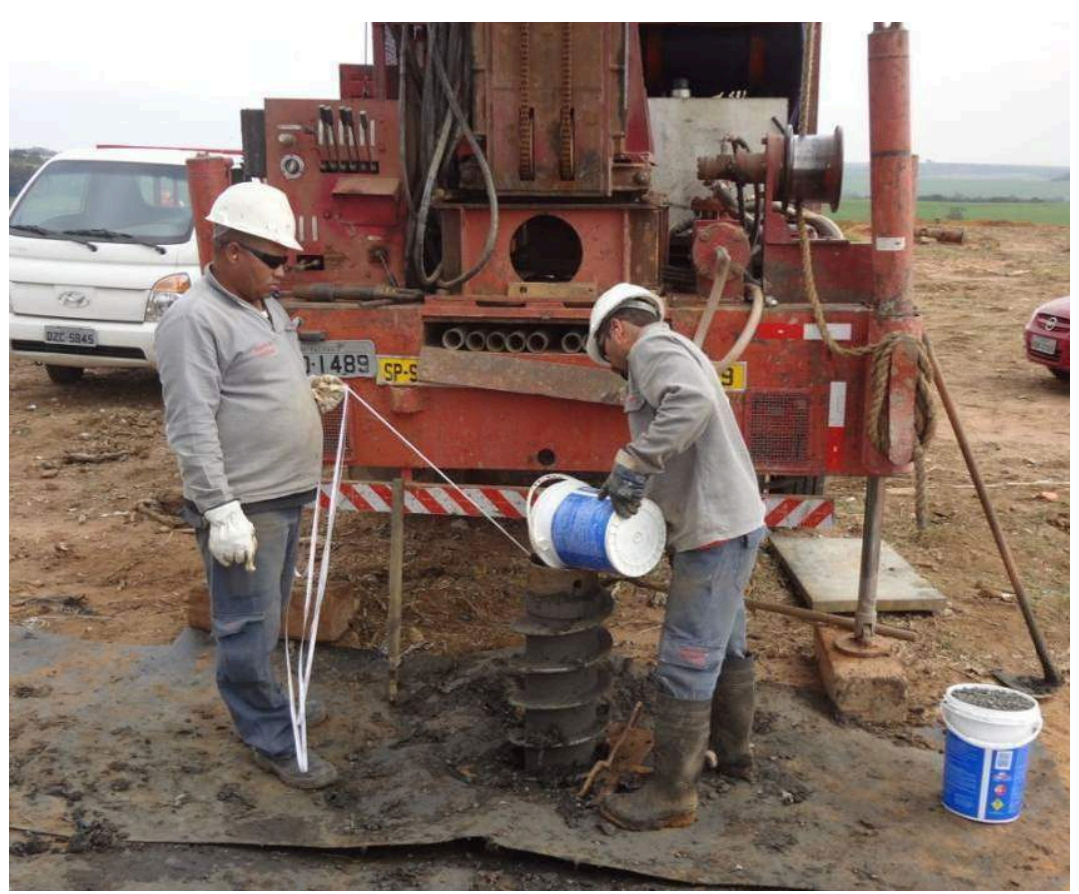

Figura 4.9 - Colocação da brita no furo de sondagem e medida da profundidade com trena, durante a operação de retirada dos segmentos de trado de dentro do furo de sondagem.

A brita é dita "pré-calibrada", pois sua massa específica foi determinada como exposto no item 4.3.1. Conhecendo-se a massa específica da brita em $\mathrm{kg} / \mathrm{m}^{3}$ e a massa de brita inserida em um determinado intervalo (em quilos), era possível determinar o volume do intervalo. Como a altura do intervalo era conhecida, era possível determinar a área do mesmo e seu diâmetro. O diâmetro assim determinado foi sempre chamado de diâmetro "aparente". 


\subsubsection{Determinação expedita do peso específico dos RSU à superfície}

Para os furos 2 a 6, nos intervalos em que se realizaram amostragens dos resíduos, foi também adotado um procedimento expedito de campo para estimativa do peso específico das amostras. Parte do material escavado foi pesado em baldes cujo volume havia sido prédeterminado, de tal forma que se pudesse calcular o peso específico dos materiais escavados em duas situações: simplesmente colocados dentro do balde e colocados dentro do balde e adensados por sucessivas batidas do balde no chão. Para cada amostra foram realizadas três destas determinações expeditas de peso específico solto e adensado à superfície.

\subsubsection{Temperatura dos RSU}

Durante a execução das sondagens, na fase de avanço do trado, as temperaturas dos RSU foram medidas com termômetro de mercúrio assim que os resíduos transportados pela hélice atingiam a superfície.

\subsubsection{Ensaios geofísicos}

Foram executados ensaios geofísicos sísmicos do tipo crosshole (entre-furos) e investigações com a técnica multi-channel analysis of surface waves (análise de ondas superficiais por multi-canais, MASW). Estes ensaios foram executados em outubro de 2012, por pessoal e com equipamentos do Instituto de Pesquisas Tecnológicas do Estado de São Paulo - IPT.

\subsubsection{Ensaios crosshole}

Durante os trabalhos de investigação do maciço de resíduos por sondagens a trado os furos F-2, F-4, F-5 e F-6 foram preparados para execução dos ensaios crosshole. Para tal foram instalados tubos de PVC de 4 polegadas, Classe 15, dentro do trado oco e o espaço entre o tubo e as paredes da perfuração foi preenchido com brita "pré-calibrada", conforme os segmentos do trado eram sacados da perfuração. Nos tubos assim preparados foram executados quatro ensaios crosshole. Nos dois primeiros ensaios, executados simultaneamente, a fonte foi colocada no furo 2 e os geofones foram colocados nos furos 5 e 
6. No terceiro e quarto ensaios, executados simultaneamente, a fonte foi colocada no furo $5 \mathrm{e}$

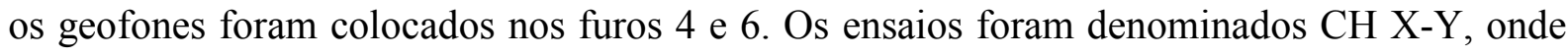
$\mathrm{X}$ é o furo onde a fonte foi posicionada e $\mathrm{Y}$ é o furo onde o geofone foi posicionado. A distância entre os centros dos tubos de PVC instalados nos furos de sondagem foi medida na superfície com uma trena. Na Figura 4.10 é apresentado o esquema de posicionamento da fonte e dos geofones para estes ensaios. A Tabela 4.3 resume suas características técnicas.
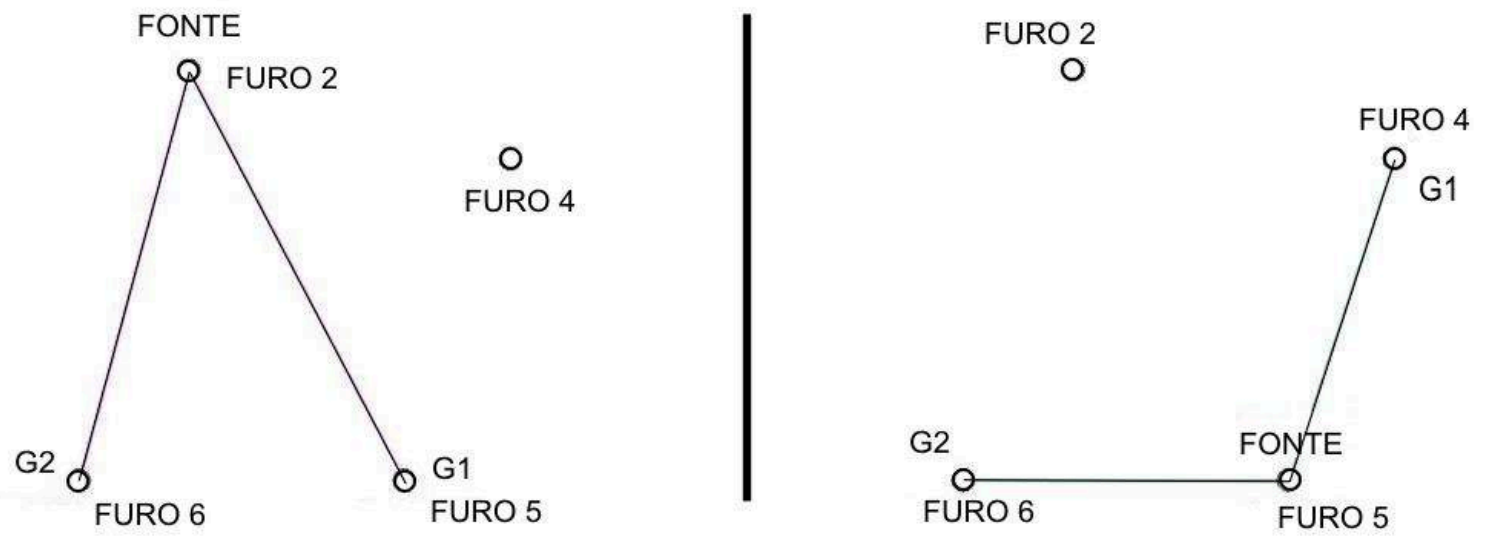

Figura 4.10 - Esquema adotado para a execução dos ensaios tipo crosshole.

Tabela 4.3 - Características dos ensaios crosshole

\begin{tabular}{ccccc}
\hline Ensaio & $\begin{array}{c}\text { Furo onde a } \\
\text { fonte foi } \\
\text { colocada }\end{array}$ & $\begin{array}{c}\text { Furo onde o } \\
\text { geofone foi } \\
\text { colocado }\end{array}$ & $\begin{array}{c}\text { Distância entre os } \\
\text { centros dos furos } \\
(\mathrm{m})\end{array}$ & $\begin{array}{c}\text { Máxima profundidade } \\
\text { ensaiada }\end{array}$ \\
\hline CH 2-5 & 2 & 5 & 3,99 & $\mathrm{~V}_{\mathrm{P}} ; \mathrm{V}_{\mathrm{S}}: 20 \mathrm{~m}$ \\
CH 2-6 & 2 & 6 & 3,65 & $\mathrm{~V}_{\mathrm{P}} ; \mathrm{V}_{\mathrm{S}}: 20 \mathrm{~m}$ \\
CH 5-4 & 5 & 4 & 2,91 & $\mathrm{~V}_{\mathrm{P}}: 20 \mathrm{~m} ; \mathrm{V}_{\mathrm{S}}: 16 \mathrm{~m}$ \\
CH 5-6 & 5 & 6 & 2,83 & $\mathrm{~V}_{\mathrm{P}}: 20 \mathrm{~m} ; \mathrm{V}_{\mathrm{S}}: 16 \mathrm{~m}$ \\
\hline
\end{tabular}

Os equipamentos utilizados na realização desses ensaios foram os seguintes:

- sismógrafo digital modelo SmartSeis (12 canais), marca Geometrics (EUA);

- dois conjuntos de geofones do tipo bobina móvel, frequência natural de $8 \mathrm{~Hz}$, triaxiais (uma componente vertical e duas horizontais), constituídos de corpo cilíndrico de PVC, com fixação na parede por meio de um sistema pneumático; - fonte mecânica da Bison, modelo 1465-1 (EUA), constituída de um martelo com um corpo fixo e um batedor corrediço, com fixação às paredes do tubo por meio de sapatas ativadas hidraulicamente, para geração de ondas de cisalhamento (onda S); 
- fonte do tipo canhão de ar comprimido (air gun), desenvolvida no IPT, para geração de ondas de compressão (onda P).

Para a execução de cada um dos ensaios o procedimento foi o de, numa primeira etapa, com o furo seco, realizar medidas do tempo de chegada da onda S, utilizando a fonte mecânica da Bison. Este dispositivo de impacto permite a geração de ondas transversais com polaridade invertida para facilitar sua identificação. Em seguida, com o furo preenchido com água, foram efetuadas as medidas do tempo de chegada das ondas longitudinais (ondas P), utilizando como fonte de ondas o air gun.

Os ensaios foram realizados até 20 metros de profundidade, exceto para o caso da determinação da velocidade de propagação das ondas S nos ensaios CH5-4 e CH5-6, que só puderam ser executados até a profundidade de 16 metros, pois a partir de 17 metros havia líquidos lixiviados no tubo de PVC onde a fonte estava inserida.

\subsubsection{Ensaios MASW}

Os ensaios MASW foram executados em arranjos lineares, com 48 geofones cada um. O espaçamento entre os geofones foi de um metro. A Figura 4.11 apresenta a localização dos três ensaios no platô do maciço de resíduos (linhas L-1, L-2 e L-3). Os ensaios foram executados na região mais antiga do maciço e as linhas cruzavam os furos de sondagem no seu trecho inicial. A máxima profundidade investigada foi de 17,3 metros.

Deve-se ressaltar que, apesar de as linhas dos ensaios MASW terem sido executadas próximas à locação dos ensaios crosshole (Figura 4.12), os volumes de material investigados pelos dois métodos são diferentes. Enquanto no método crosshole a investigação envolve apenas as camadas que ocorrem entre os dois furos, numa mesma profundidade, no método MASW o volume amostrado é muito maior e aumenta com a profundidade de investigação. Como os ensaios MASW atingiram profundidades de investigação de 17,3m pode-se considerar que o volume ensaiado em cada uma das linhas corresponde a um prisma com face horizontal de 34,6 metros por 48,0 metros, sendo que a linha de geofones está situada no centro desta face. A profundidade do prisma corresponde à profundidade de investigação $(17,3 \mathrm{~m})$. Considerando-se este volume ensaiado pode-se dizer que as linhas L-1 e L-2 investigaram um maciço com a mesma estratigrafia daquele investigado nos ensaios crosshole, enquanto a linha L-3 investigou um maciço com estratigrafia um pouco diferente, 


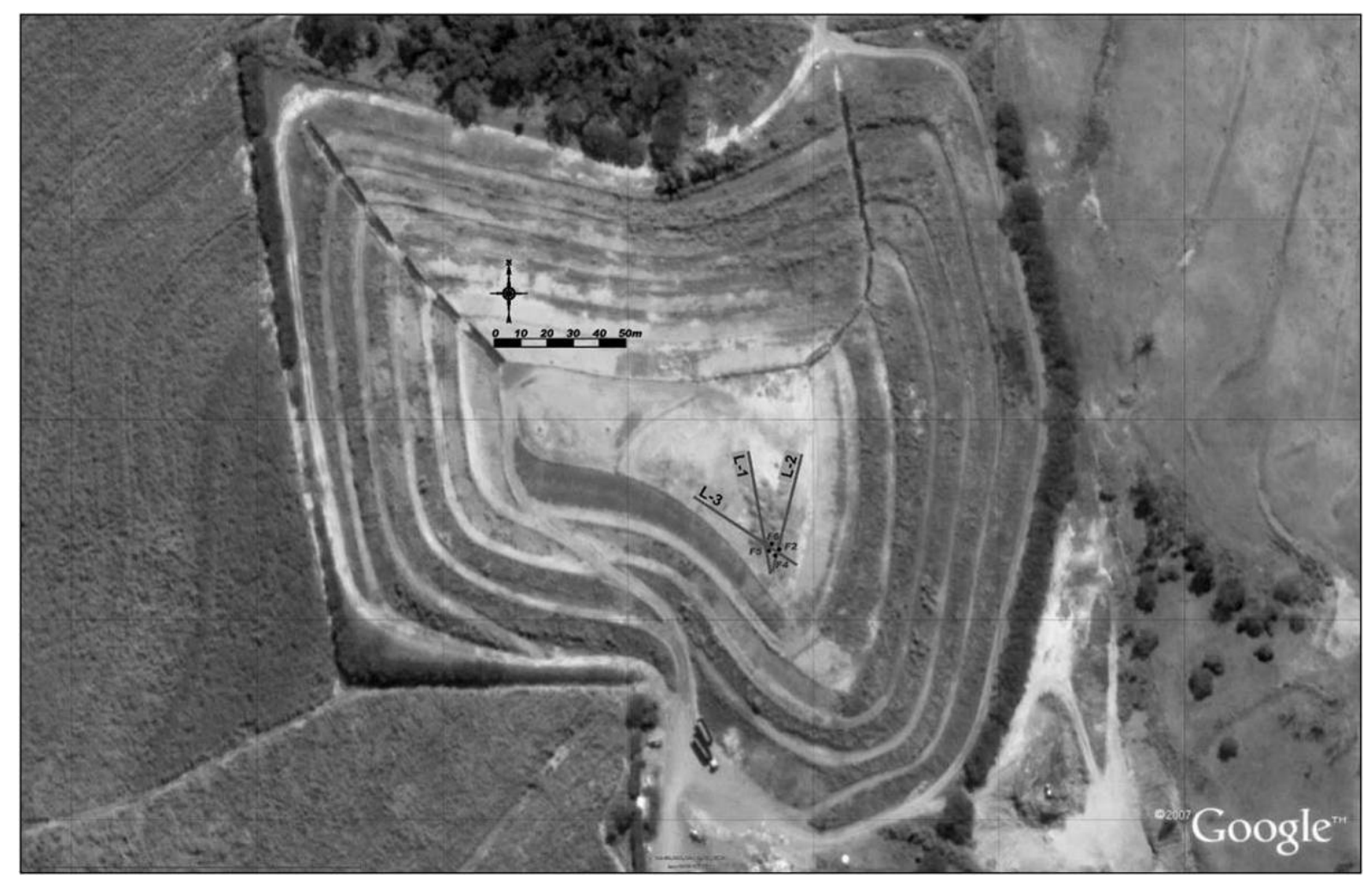

Figura 4.11 - Localização dos ensaios MASW (linhas L1 a L3) e dos furos F2, F4, F5 e F6, utilizados nos ensaios crosshole no Aterro Sanitário de São Carlos. (base: imagem aérea obtida em 04 de janeiro de 2012. Fonte: GoogleEarth, acessado em 15-03-2013).

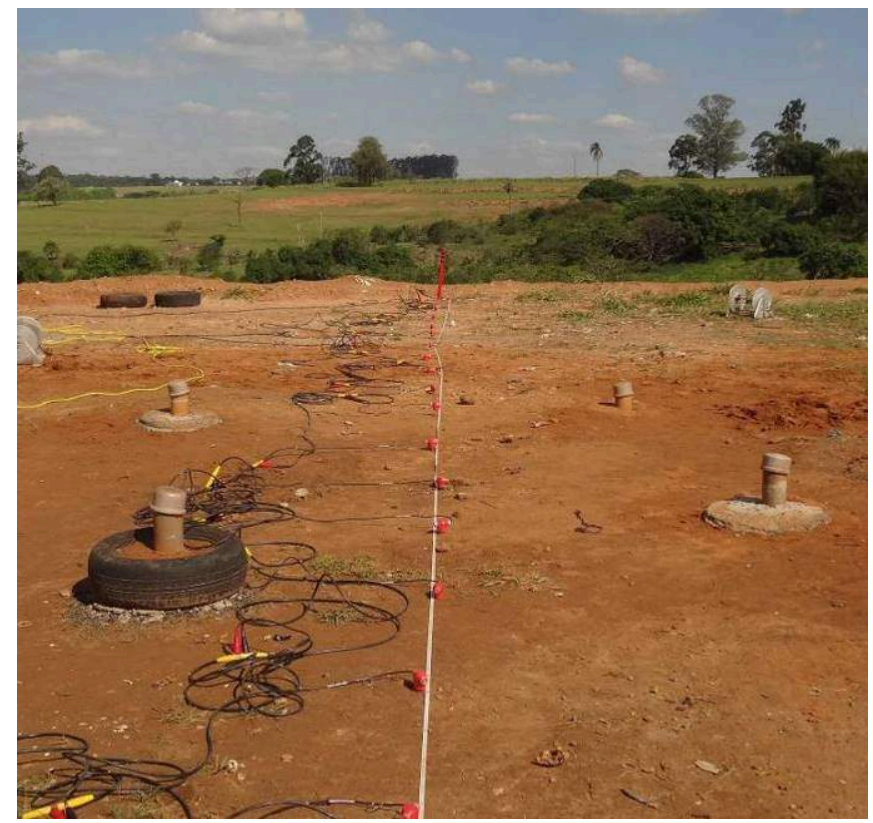

Figura 4.12 - Detalhe da execução da L3 do ensaio MASW, que passa entre os furos utilizados nos ensaios crosshole. 
pois estendeu-se parcialmente sobre a área da primeira ampliação lateral que o maciço de resíduos sofreu a partir de 2003.

Os equipamentos utilizados nesses ensaios foram os seguintes:

- sismógrafo modelo Goede (Geometrics Inc., EUA) de 48 canais;

- geofones de componente vertical e frequência de 4,5Hz;

- fonte de ondas sísmicas utilizando o impacto de uma marreta de $5 \mathrm{~kg}$ contra uma placa metálica posicionada na superfície do terreno.

Os sismogramas foram registrados com uma janela de gravação igual a 1000ms. Em cada linha de aquisição foram adquiridos registros com pontos de tiros correspondentes a cinco "offsets" mínimos diferentes: $4 \mathrm{~m}, 6 \mathrm{~m}, 8 \mathrm{~m}, 10 \mathrm{~m}$ e $12 \mathrm{metros}$. As curvas de dispersão foram calculadas considerando-se a média das curvas obtidas para os cinco "offsets" mínimos utilizados.

Os sismogramas adquiridos em campo (domínio tempo-distância) foram transportados para o domínio frequência-número de onda (f-K) por meio da aplicação sucessiva de duas transformadas de Fourier. Deste domínio f-K, que mostra as propriedades dispersivas das ondas Rayleigh, foi obtida a curva de dispersão (velocidade de fase em função da frequência), resultado da identificação dos máximos de energia para cada frequência. Utilizando processos matemáticos de inversão da curva de dispersão, pôde ser obtido um perfil $1 \mathrm{D}$ da variação de velocidade da onda cisalhante com a profundidade (perfil de Vs), informação essa que foi atribuída ao centro do arranjo de geofones. Todo esse processamento foi realizado pela equipe do Instituto de Pesquisas Tecnológicas do Estado de São Paulo - IPT, com a utilização do software SeisImager/SW, v.3, 2009, elaborado pela Geometrics Inc.

\subsubsection{Ensaios de penetração dinâmica}

Em dezembro de 2013 foram realizados ensaios de cravação dinâmica de penetrômetro super pesado, conhecido usualmente como DPSH (dynamic proving super heavy), na área do Aterro Sanitário que já havia sido investigada por meio de ensaios geofísicos do tipo crosshole. Com a realização desses ensaios pretendia-se verificar se as diferenças de comportamento mecânico do maciço de resíduos constatadas nos ensaios geofísicos poderiam ser identificadas também com investigações mecânicas. Dentre estas, as investigações com sondagens utilizando o ensaio de penetração dinâmica convencional (em inglês: standard penetration test, ou SPT) são as mais frequentes no Brasil, porém sabe-se que a execução 
deste tipo de ensaio em aterros sanitários é difícil. Em vista disso, optou-se por realizar o ensaio de cravação do penetrômetro do tipo DPSH, que utiliza a mesma energia de cravação do ensaio SPT, porém trabalha com uma ponteira fechada, de dimensões padronizadas internacionalmente. Com este ensaio não há possibilidade de recuperação de amostras, porém a cravação pode ser executada de forma contínua e esperava-se que o fato de a ponteira ser fechada pudesse facilitar a penetração no maciço de resíduos. Medem-se os golpes necessários para penetração do amostrador em intervalos de 20 centímetros de comprimento. Os resultados são expressos como $\mathrm{N}_{20}$.

Foram executadas duas sondagens, denominadas D1 e D2 e localizadas entre os furos dos ensaios crosshole. A Figura 4.13 apresenta sua localização.

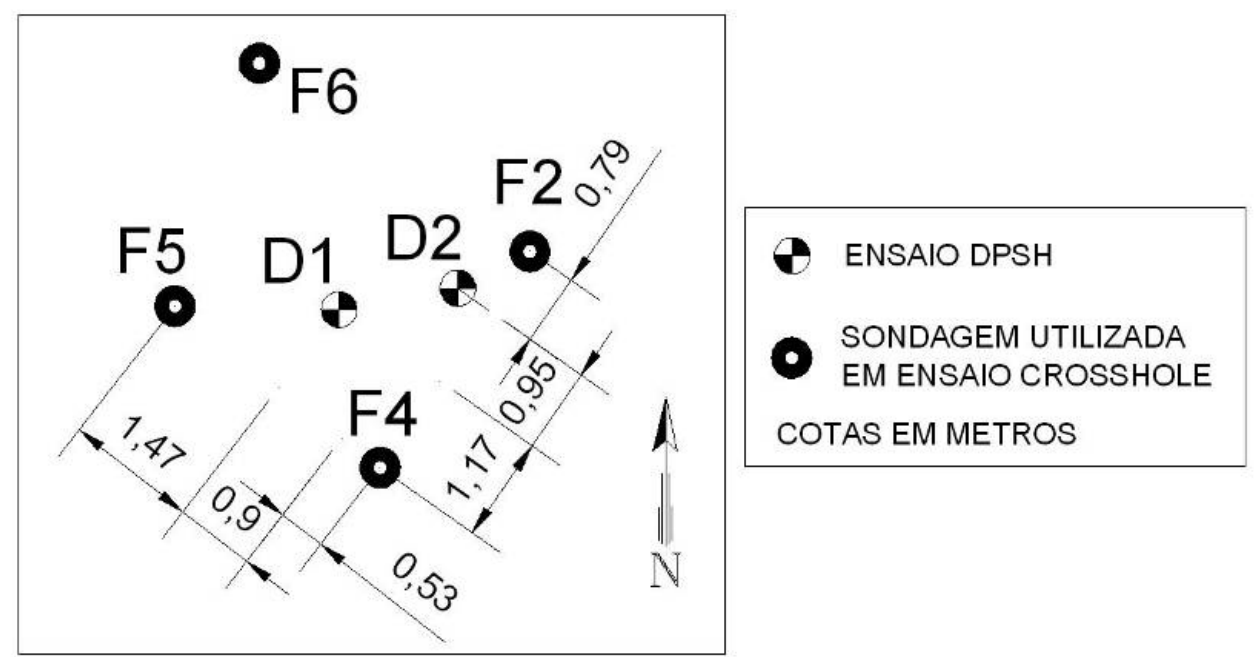

Figura 4.13 - Planta de localização dos ensaios DPSH realizados no Aterro Sanitário de São Carlos.

4.5 Cisalhamento direto de grandes dimensões

\subsubsection{Equipamento de ensaio}

Foi construído um equipamento de cisalhamento direto de grandes dimensões (caixa de ensaio com 50 x 50 x 50 centímetros). A Figura 4.14 apresenta o equipamento ao final de um dos ensaios. 


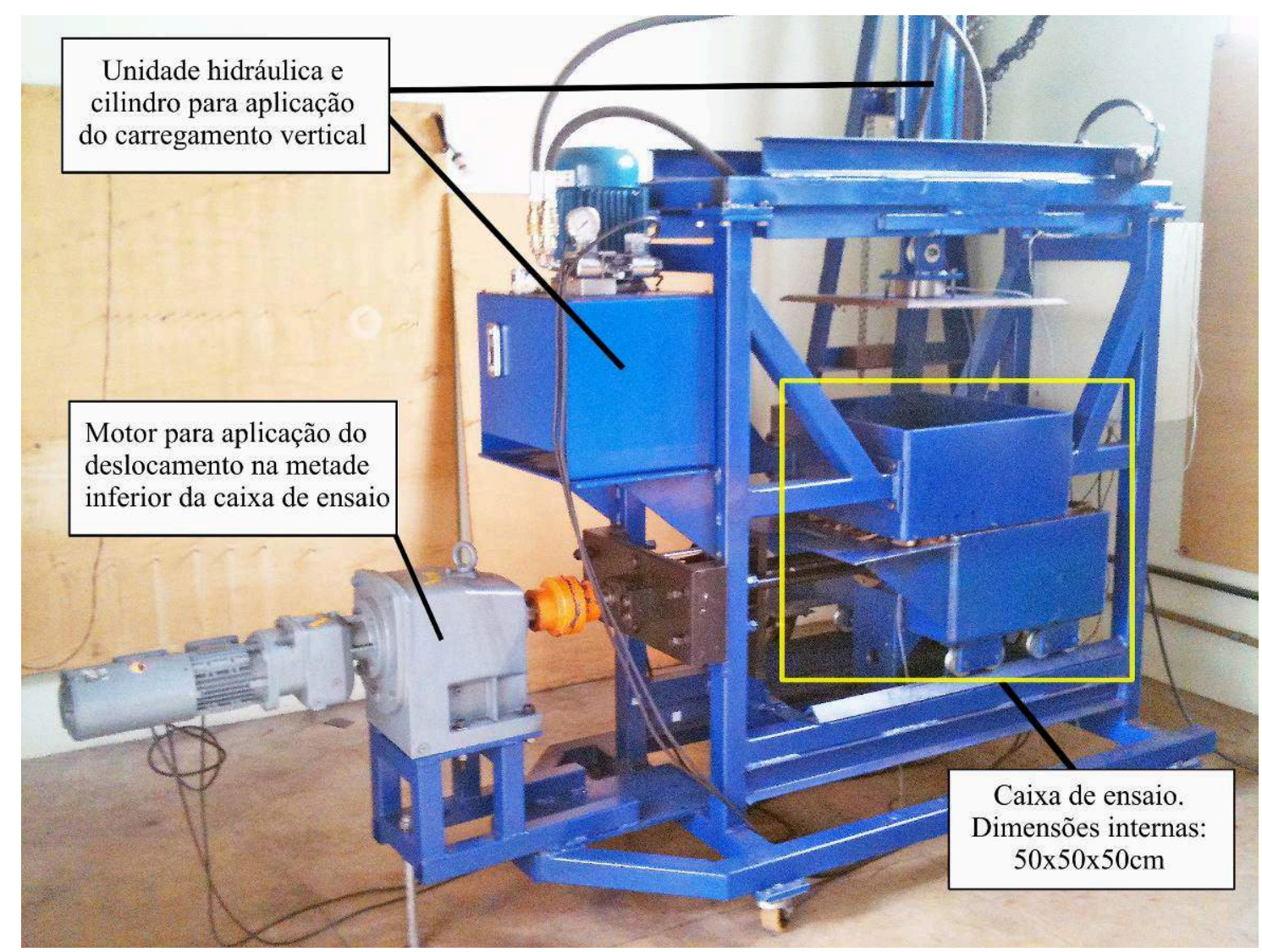

Figura 4.14 - Foto do equipamento de cisalhamento direto de grandes dimensões.

A metade superior da caixa de ensaio está solidarizada ao pórtico metálico, o que impede deslocamentos horizontais e verticais da mesma. A metade inferior da caixa de ensaio está livre para se movimentar na vertical e na horizontal. Ela se desloca do lado do motor para o lado do quadro de controle (esquerda para a direita na Figura 4.14) e está apoiada sobre oito roldanas, dispostas duas a duas, em quatro trens. As roldanas possuem canal de rolamento em V e deslizam sobre dois trilhos (perfis metálicos tipo cantoneiras) soldados ao pórtico.

As duas metades da caixa de ensaios têm a mesma altura. Entre ambas há um espaço de $8 \mathrm{~mm}$, para evitar o atrito entre as bordas e a consequente interferência nos resultados dos ensaios. Esse espaço era preenchido com esponjas durante as fases de moldagem e de adensamento do corpo de prova, de tal forma a não permitir que parte dos resíduos se colocasse entre as caixas. Para moldagem da última camada de resíduos podia ser utilizado um colarinho, com altura de 15 centímetros.

A aplicação das cargas horizontais é realizada por um fuso, conectado a um motor elétrico e a um redutor. O ensaio é realizado com deslocamento controlado e as velocidades de ensaio podem variar de 0,2 a $2 \mathrm{~mm}$ por minuto. A velocidade de ensaio era ajustada por meio de um inversor, que controlava a velocidade de giro do motor elétrico e mostrou-se 
constante e homogênea durante toda a pesquisa. Ainda assim, na fase de cisalhamento dos ensaios realizava-se também o controle da velocidade de avanço da parte inferior da caixa de ensaio com um relógio comparador (Figura 4.15).

Todos os ensaios desta pesquisa foram realizados com velocidade horizontal de $1 \mathrm{~mm}$ por minuto. Os materiais ensaiados apresentaram sempre um recalque imediato significativo, seguido de uma fase de compressão secundária, não sendo possível a aplicação de critérios clássicos para a definição da velocidade de ensaio. Nas pesquisas realizadas por outros autores estão relatadas velocidades variando entre 0,024 e $10 \mathrm{~mm} / \mathrm{min}$. Adotou-se velocidade de $1 \mathrm{~mm} / \mathrm{min}$, por ter sido utilizada nos ensaios relatados por Zekkos et al. (2010a), com os quais se desejava realizar uma comparação mais direta dos resultados.

A caixa inferior é dotada de uma aba metálica, que visa evitar que o material do corpo de prova deixe a caixa de ensaio e caia no chão ou sobre o sistema de aplicação da força horizontal (Figura 4.15). Esta aba está soldada à lateral da caixa, pelo lado externo, e é suportada por duas mãos francesas e está colocada 1 centímetro mais baixa que o plano de cisalhamento.

A aplicação das cargas verticais é realizada com um cilindro hidráulico, previsto para aplicação de força de até 15 toneladas, o que resultaria em tensões de $500 \mathrm{kPa}$. A carga é transferida para amostra por uma tampa metálica (chapa com 1" de espessura), chanfrada nas extremidades e com dimensões um pouco inferiores à dimensão interna da caixa (folga de 0,5 cm em cada lado), de tal forma que pudessem acontecer recalques diferenciais do corpo de prova, sem que a tampa ficasse "travada" nas paredes da caixa de ensaio.

Apesar de os sistemas de aplicação de carga horizontal e vertical estarem dimensionados para aplicar carregamentos de até $500 \mathrm{kPa}$, a máxima tensão normal que se conseguiu aplicar nos ensaios foi de $250 \mathrm{kPa}$, devido a constantes falhas no sistema de reação horizontal.

As tensões aplicadas à amostra são registradas por duas células de carga com capacidade para realizar leituras até 15 toneladas. Na Figura 4.15 vê-se a célula de carga horizontal. Os dados são coletados a cada 0,06 minuto por um controlador lógico programável (CLP) e armazenados em arquivos de formato de texto. Foi desenvolvido um programa para controle do ensaio e armazenamento dos dados durante sua execução. Ao final de cada ensaio é gerado um arquivo em formato xls com as leituras das cargas vertical e horizontal, os deslocamentos verticais e o tempo decorrido desde o seu início. 


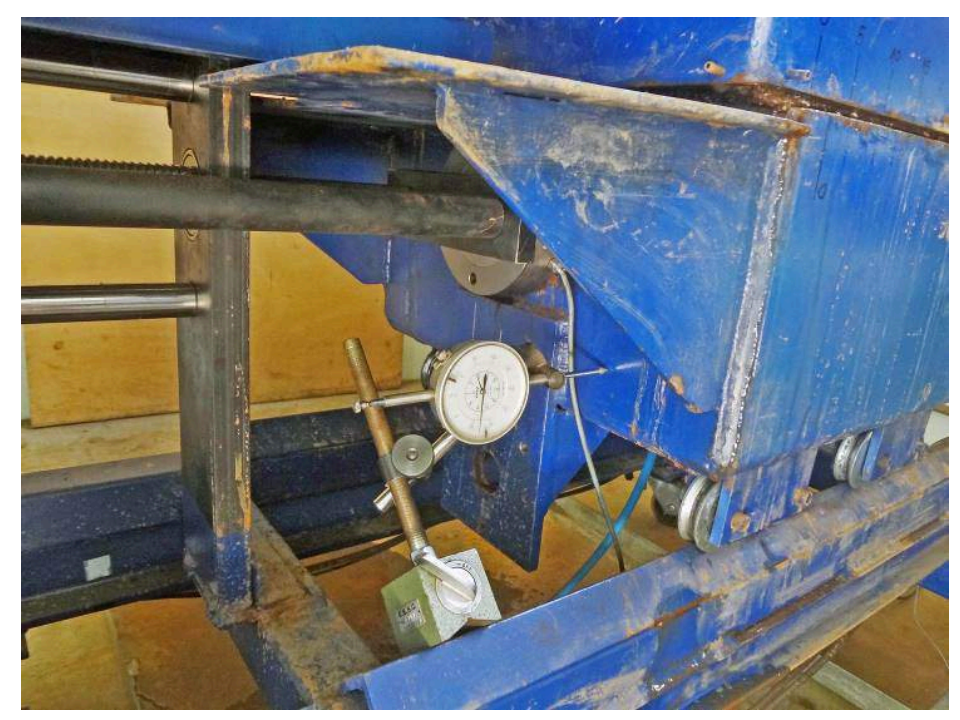

Figura 4.15 - Detalhe do relógio comparador utilizado para aferição da velocidade de avanço da metade inferior da caixa de ensaio, do sistema de aplicação da carga horizontal, da célula de carga e da aba que protege este sistema contra a queda de material do corpo de prova.

Os deslocamentos verticais são registrados por um encoder com precisão de centésimo de milímetro, que monitora os deslocamentos por meio de uma barra metálica solidarizada ao pistão de aplicação da carga vertical, conforme ilustrado na Figura 4.16. Eles também foram controlados com um relógio comparador colocado sobre a tampa da caixa de ensaio, na região próxima ao ponto de aplicação da carga vertical. Como os recalques na fase de adensamento eram maiores que o curso do relógio comparador $(50 \mathrm{~mm})$, também se controlava o afundamento total em três posições opostas da caixa de ensaios, com uma régua milimetrada (Figura 4.16). Verificou-se que os registros do encoder e do relógio comparador foram sempre iguais para os recalques ocorridos após alguns minutos. Quanto aos recalques imediatos, o encoder fornecia normalmente valores inferiores ao do sistema relógio comparador + medida direta na caixa. Para efeito de cálculo do adensamento das amostras foram utilizados os registros do encoder, com os recalques imediatos corrigidos de acordo com as leituras do outro sistema. 

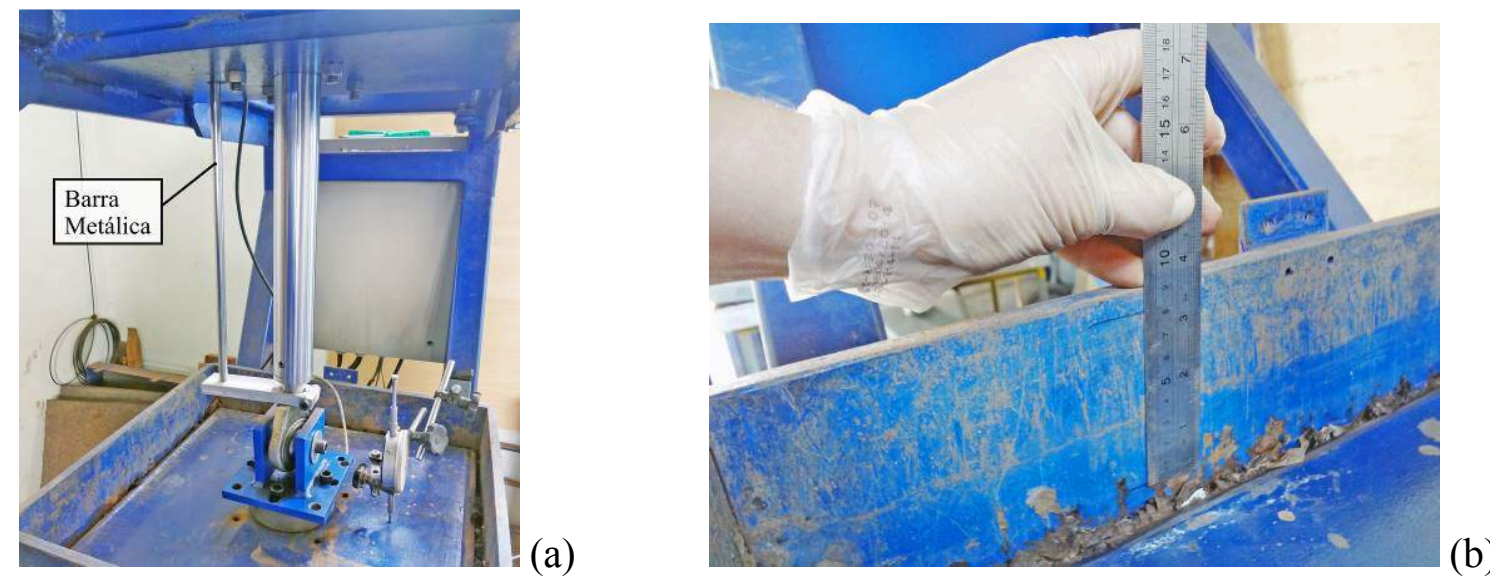

Figura 4.16 - (a) detalhe da barra metálica solidarizada ao pistão de aplicação da carga vertical (b) registro dos afundamentos diretamente na parede da caixa de ensaio.

$\mathrm{Na}$ fase de cisalhamento dos ensaios verificou-se o progressivo desnivelamento da tampa que aplica a força normal. Ela encostava na parede da caixa de ensaio, na direção de movimento da metade inferior, quando se registravam deslocamentos horizontais entre 20 e $30 \mathrm{~mm}$. Após encostar na lateral da caixa ela ficava progressivamente mais alta do lado em que se encontra o quadro elétrico e mais baixa do lado do motor (Figura 4.17). O máximo desnivelamento da tampa medido nos ensaios realizados foi de 8,7 graus.

Nesta fase dos ensaios os registros de deslocamentos verticais feitos pelo encoder e pelo relógio comparador são bem diferentes. Isso se deve ao fato de que no momento em que se posiciona o relógio comparador, antes de começar o ensaio, não é possível saber onde se localizará a linha da tampa que não subirá, nem descerá por desnivelamento. Para essa fase dos ensaios foram considerados apenas os deslocamentos verticais registrados pelo encoder.
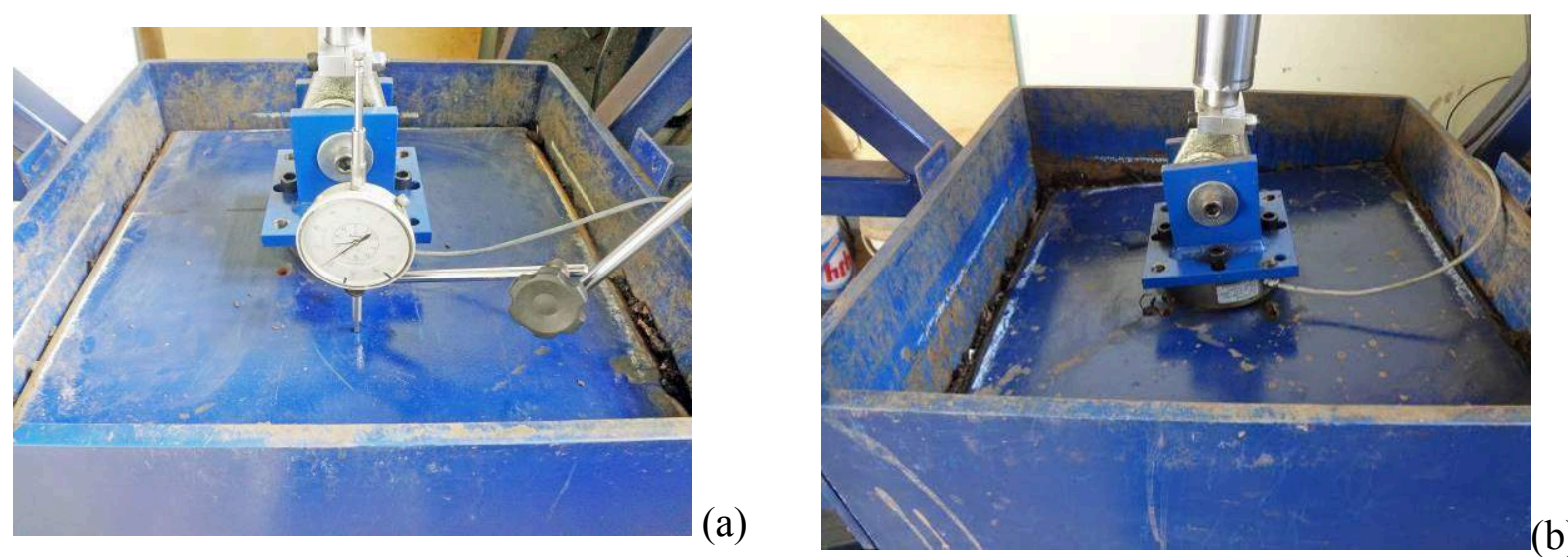

Figura 4.17 - Aspecto da tampa que aplica o carregamento vertical sobre o corpo-de-prova no início do ensaio (a) e no final (b). 
Pretendia-se inicialmente que os ensaios pudessem ser conduzidos com deslocamentos de até $250 \mathrm{~mm}$, porém, dificuldades com o sistema de aplicação de carga horizontal obrigaram à realização de alterações no sistema, que tem atualmente capacidade de impor até 160 milímetros de deslocamento à caixa inferior de ensaio. Entretanto, devido ao forte desnivelamento apresentado pela tampa da caixa de ensaio para grandes deslocamentos horizontais, julgou-se adequado considerar apenas os resultados para deslocamentos horizontais de até $125 \mathrm{~mm}$, descartando-se as tensões e deslocamentos verticais registrados para maiores deslocamentos horizontais. Isso corresponde a um deslocamento relativo de $25 \%$, compatível com aqueles utilizados em pesquisas com RSU.

\subsubsection{Preparação das amostras}

\subsubsection{Critério de escolha}

As amostras a serem ensaiadas deveriam ter idades de aterramento diferentes. Isto motivou a coleta das amostras no Aterro Experimental, construído em 1988, e no Lixão Desativado de São Carlos, de onde se extraíram resíduos aterrados em 1995.

Quanto aos resíduos amostrados no aterro sanitário de São Carlos, os seguintes critérios foram adotados:

- Amostras aterradas em anos diferentes;

- Amostras que tivessem características de RSU típico, e para as quais não houvessem evidências óbvias de contaminação por materiais mais novos, arrancados da parede durante a subida até a superfície;

- Preferencialmente amostras que fossem grandes o suficiente para serem ensaiadas individualmente, sem que houvesse a necessidade de mistura com outras amostras.

Para representar os resíduos aterrados entre 1999 e 2001 foi escolhida a amostra A2-4 e para representar os resíduos aterrados em 2003/2004 foi escolhida a amostra A3-3, porque ambas eram amostras grandes, que permitiriam a execução dos ensaios com folga de material.

Para a camada de resíduos aterrados em 2007 foi necessário misturar as amostras A3-2, A4-2 e A5-2, pois a massa de cada uma delas não era suficiente para a realização dos ensaios. As proporções em porcentagem de massa dessa mistura foram de $21 \%$ : 43\% : 36\% na sequencia A3-2 : A4-2 : A5-2. 
Com relação aos resíduos aterrados em 2011, verificou-se que, mesmo se todas as amostras coletadas nas sondagens a trado fossem misturadas, não haveria material suficiente para a realização dos ensaios previstos. Dessa forma, optou-se pela abertura de uma trincheira (item 4.2.2) para coleta de uma amostra específica para os ensaios de cisalhamento direto.

A Tabela 4.4 resume as características das seis amostras selecionadas.

Tabela 4.4 - Idade de aterramento, tipo, local e forma de coleta das amostras selecionadas para ensaio.

\begin{tabular}{cccccc}
\hline Amostra & Local de coleta & $\begin{array}{c}\text { Forma de } \\
\text { coleta }\end{array}$ & $\begin{array}{c}\text { Profundidade } \\
(\mathrm{m})\end{array}$ & $\begin{array}{c}\text { Idade de } \\
\text { aterramento (anos) }\end{array}$ & $\begin{array}{c}\text { Tipo de } \\
\text { amostra }\end{array}$ \\
\hline A1988 & $\begin{array}{c}\text { Aterro } \\
\text { experimental }\end{array}$ & Trincheira & 1,0 a 1,5 & 25 & simples \\
A1995 & Lixão desativado & Poço & 0,7 a 1,5 & 16 & simples \\
A2001 & Aterro sanitário & Sondagem & 16,2 a 19,0 & 11 & simples \\
A2004 & Aterro sanitário & Sondagem & 11,0 a 14,0 & 8 & simples \\
A2007 & Aterro sanitário & Sondagem & 7,0 a 9,0 & 5 & composta \\
A2011 & Aterro sanitário & Trincheira & 1,0 e 1,3 & 2 & simples \\
\hline
\end{tabular}

\subsubsection{Separação das frações}

Como o corpo de prova dos ensaios de cisalhamento direto tem dimensões de 500 x 500 x $500 \mathrm{~mm}$, apenas os componentes das amostras menores que $85 \mathrm{~mm}$ podem ser utilizados para moldagem dos corpos de prova. Dessa forma respeitam-se as recomendações de que as partículas ensaiadas tenham dimensões de até 1/6 do comprimento do lado da caixa de ensaio. Isto implica que o material a ser ensaiado corresponde na realidade apenas a uma fração do material coletado em campo. Os materiais maiores que 20 centímetros já haviam sido pesados e descartados na etapa de coleta e de homogeneização das amostras em campo, para facilitar o transporte das mesmas. O material restante, com peso úmido variando entre $297 \mathrm{~kg}$ (amostra A2011) e 985kg (amostra A1995) foi quarteado, de tal forma que a amostra pudesse ser reduzida. Em seguida, realizou-se a separação manual dos componentes maiores que $85 \mathrm{~mm}$, que foram excluídos da amostra (escalpelamento). Todos os componentes menores que $85 \mathrm{~mm}$ foram mantidos e compuseram as amostras utilizadas nos ensaios de cisalhamento direto. A Tabela 4.5 apresenta o peso das amostras reduzidas, o peso do material escalpelado e o peso das amostras disponíveis para ensaio. 
Tabela 4.5 - Peso úmido das amostras reduzidas e das mesmas após o escalpelamento dos componentes maiores que $85 \mathrm{~mm}$.

\begin{tabular}{ccccccccc}
\hline Descrição & Unid. & \multicolumn{7}{c}{ Amostra } \\
\cline { 3 - 8 } & A1988 & A1995 & A2001 & A2004 & A2007 & A2011 \\
\hline Amostra reduzida & $\mathrm{kg}$ & 259 & 331 & 319 & 320 & 249 & 264 \\
$\begin{array}{c}\text { Descartes (materiais } \\
\text { maiores que 85 mm) }\end{array}$ & $\mathrm{kg}$ & 36 & 79 & 85 & 80 & 59 & 83 \\
$\begin{array}{c}\text { Preparado para ensaios de } \\
\text { cisalhamento direto }\end{array}$ & $\mathrm{kg}$ & 223 & 252 & 235 & 240 & 190 & 181 \\
\hline
\end{tabular}

\subsubsection{Caracterização das amostras}

\subsubsection{Caracterização química e bioquímica}

Como a avaliação da resistência mecânica dos RSU em função do seu estado de degradação foi um dos objetivos dessa pesquisa, foram executados ensaios químicos e bioquímicos de caracterização. Pretendia-se assim identificar parâmetros que pudessem indicar o estado de degradação do resíduo e correlacionar essa propriedade com sua resistência mecânica.

O fluxograma apresentado na Figura 4.18 resume a sequencia de parcelamentos da amostra e os ensaios que foram executados sobre cada fração extraída da mesma.

Após a extração de amostras para determinação da composição gravimétrica e da umidade e após a remoção dos componentes maiores que $85 \mathrm{~mm}$, quarteou-se uma parte de cada uma das seis amostras separadas para ensaio de cisalhamento, peneirou-se na malha $19 \mathrm{~mm}$ e o material passante foi secado em estufa a $60^{\circ} \mathrm{C}$. Após secagem, esse material foi novamente homogeneizado, quarteado e separado em duas frações de 1,5kg cada uma.

Uma das frações foi preparada para ensaios de determinação dos STV. Para tal o material foi destorroado em almofariz e teve os plásticos duros e moles, as pedras, os vidros e os metais removidos manualmente. Em seguida, de cada amostra foram tomadas pelo menos três alíquotas com pesos entre 100 e $150 \mathrm{~g}$ para execução do ensaio em si. As alíquotas foram aquecidas em estufa a $70^{\circ} \mathrm{C}$ por uma hora, pesadas, aquecidas em mufla a $440^{\circ} \mathrm{C}$ por duas horas, pesadas e novamente aquecidas a $600^{\circ} \mathrm{C}$ por duas horas, para então se realizar a última pesagem. O valor dos sólidos totais voláteis (STV) foi calculado como sendo a porcentagem 
de massa perdida entre duas etapas de aquecimento, em relação à massa remanescente após o aquecimento, conforme equação (4.1). Os resultados correspondem à média de pelo menos três determinações para cada amostra e são expressos em porcentagem.

$$
\mathrm{STV}=\frac{\text { peso inicial }\left(70^{\circ} \mathrm{C}\right)-\text { peso final }\left(440 \text { ou } 600^{\circ} \mathrm{C}\right)}{\text { peso final }\left(440 \text { ou } 600^{\circ} \mathrm{C}\right)}
$$

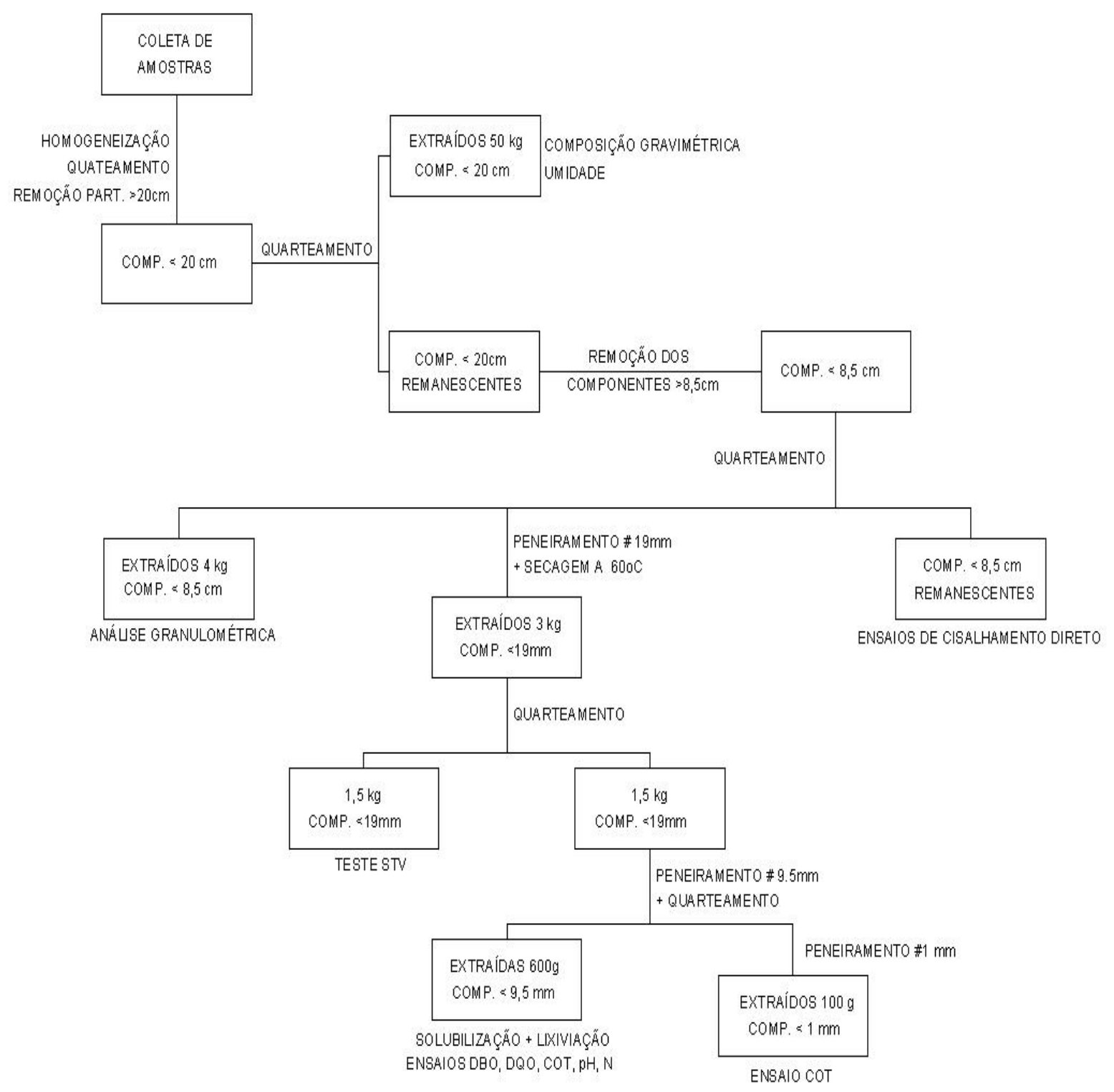

Figura 4.18 - Fluxograma das etapas para formação das sub-amostras para realização dos ensaios de caracterização. 
A outra fração de $1,5 \mathrm{~kg}$ foi passada por uma peneira com abertura de 9,5mm. Da fração passante foram tomados $600 \mathrm{~g}$ para solubilização. A solubilização foi realizada de acordo com a norma NBR 10.006 (ABNT, 2004b), e a lixiviação segundo procedimento descrito por Gomes (1989) para o ensaio de demanda química de oxigênio (DQO).

Sobre o extrato solubilizado foram executados os ensaios de determinação da quantidade de carbono orgânico total (COT), demanda bioquímica de oxigênio $\left(\mathrm{DBO}_{5}\right)$, DQO, nitrogênio total Kjeldahl (NTK), nitrogênio amoniacal total e concentração hidrogeniônica $(\mathrm{pH})$. Todos eles foram executados de acordo com a 22 $2^{\mathrm{a}}$ Edição do "Standard Methods for Water and Wastewater Analysis" no Laboratório de Saneamento do Departamento de Hidráulica e Saneamento da Escola de Engenharia de São Carlos.

Também foi realizado ensaio de determinação da DQO sobre extrato lixiviado. O procedimento de lixiviação e de ensaio foi o mesmo adotado por Almeida (2007). Para a realização do ensaio realizou-se a catação manual dos inertes (plásticos em geral, metais, pedras e cerâmicos, vidros) em uma fração dos resíduos passante na peneira de $9,5 \mathrm{~mm}$ e secos em estufa. Tomou-se $1 \mathrm{~g}$ dos resíduos assim preparados, adicionou-se $5 \mathrm{ml}$ de água destilada e $20 \mathrm{ml}$ de ácido sulfúrico e esperou-se até que a reação esfriasse. Em seguida a mistura foi colocada em um balão volumétrico de $250 \mathrm{ml}$ e o volume foi completado com água destilada. A amostra foi então filtrada e $2 \mathrm{ml}$ da mesma foram misturados com 3,5 $\mathrm{ml}$ do reagente 1 e 1,5 $\mathrm{ml}$ do reagente 2 (Reagente 1: ácido sulfúrico, dicromato de potássio e sulfato mercúrico; Reagente 2: ácido sulfúrico e sulfato de prata).

O branco foi preparado com $20 \mathrm{~mL}$ de $\mathrm{H}_{2} \mathrm{SO}_{4}$ diluído a $250 \mathrm{ml}$ com água destilada. As soluções resultantes foram levadas para um bloco digestor a $150^{\circ} \mathrm{C}$, onde permaneceram durante 2 horas. Deixou-se esfriar por 1 hora. As medidas de absorbância foram realizadas num Espectrofotômetro DR/2000 - Hach - 220 V - DR/2000 Direct Reading Spectrophotometer Prog 955 (Prog USP), empregando $\lambda$ máximo $=620 \mathrm{~nm}$.

$\mathrm{Na}$ realidade esse ensaio foi proposto inicialmente por Gomes (1989), porém o método para determinação da DQO foi atualizado desde então, de tal forma que, do procedimento proposto originalmente, a parte de extração da solução lixiviada foi mantida e a parte que envolve a determinação da DQO propriamente dita foi modificada.

Parte do material menor que $9,5 \mathrm{~mm}$ foi ainda passado na peneira de $1,0 \mathrm{~mm}$ e $30 \mathrm{~g}$ do material com dimensões inferiores a 1,0mm foram separadas para os ensaios de determinação do conteúdo de COT sobre amostra sólida. Esses ensaios foram realizados no Laboratório de Química Ambiental do Instituto de Química da USP São Carlos, e envolveram a combustão a 
seco da amostra, a altas temperaturas $\left(900^{\circ} \mathrm{C}\right)$, e posterior detecção de $\mathrm{CO}_{2}$ por espectrometria de infravermelho em um equipamento da marca Shimadzu, modelo TOC- $\mathrm{V}_{\mathrm{CPH}}$, com módulo analisador de amostras sólidas modelo SSM-5000A, para amostra com $100 \mathrm{mg}$ de massa. A sensibilidade do equipamento é de $0,001 \mu \mathrm{g} / \mathrm{kg}$. Para cada amostra foram realizadas três determinações.

\subsubsection{Caracterização física}

\subsection{Composição gravimétrica}

As amostras ensaiadas foram homogeneizadas e quarteadas, para separação de massas entre 39 e 54 kg (peso úmido) para a determinação da composição gravimétrica. Essa fração da amostra, ainda úmida, foi colocada sobre uma peneira de abertura 19,1 mm. O material passante foi classificado como "menor que 19mm" e corresponde aos componentes "tipo solo" presentes na amostra. O material retido na peneira foi separado manualmente nas seguintes categorias: plásticos moles, plásticos duros, madeira, tecidos, metais, pedras (e cerâmicos), borracha, papel, vidro e outros (inclui principalmente isopor, espuma e materiais que não puderam ser identificados). Todas as frações foram secadas em estufa a $60^{\circ} \mathrm{C}$ até constância de massa e as porcentagens foram calculadas com base na massa seca.

Com relação aos componentes "tipo solo", verificou-se por inspeção visual que a composição dessa fração era variada e julgou-se apropriado realizar um detalhamento da sua composição. De cada amostra a ser ensaiada foi tomada uma sub-amostra de $2 \mathrm{~kg}$ (massa seca), que foi peneirada na malha $4,76 \mathrm{~mm}$. Os componentes retidos foram destorroados e novamente peneirados. Aqueles que ainda ficaram retidos foram separados manualmente em duas categorias: a) plásticos moles e tecidos e b) outros materiais.

Além disso observou-se que em algumas das amostras os plásticos moles maiores que $19 \mathrm{~mm}$ encontravam-se bastante impregnados por solo e isso influenciava significativamente os pesos determinados para essa fração. Em vista disso, de cada amostra foi tomada uma subamostra de $2 \mathrm{~kg}$ (massa seca), que foi destorroada, peneirada na malha 4,76mm e os componentes que não passaram nesta malha foram separados manualmente, considerando-se as mesmas duas categorias: a) plásticos moles e tecidos e b) outros materiais. 


\subsection{Distribuição granulométrica}

Realizou-se a separação dos componentes de cada amostra em dois grupos: menores e maiores que $19 \mathrm{~mm}$. Essa separação foi realizada manualmente, sendo a amostra úmida colocada sobre uma peneira de abertura 19,1 $\mathrm{mm}$. Em seguida, cada grupo foi quarteado e frações representativas, determinadas de acordo com a NBR 7181 (ABNT, 1984), foram secadas em estufa a $60^{\circ} \mathrm{C}$. A determinação da granulometria das amostras foi realizada com peneiramento por via seca, utilizando-se as peneiras de abertura 0,$075 ; 0,149 ; 0,297 ; 0,42$; 0,$59 ; 1,19 ; 2,00 ; 4,76 ; 9,52 ; 19,1 ; 25,4 ; 50$ e $75 \mathrm{~mm}$.

\subsubsection{Ensaios de cisalhamento direto}

Os ensaios realizados procuraram atingir dois grandes objetivos: verificar se ocorre alteração nos parâmetros de resistência dos RSU conforme eles "envelhecem" e se eles se caracterizam como materiais anisotrópicos. Para a caracterização da anisotropia foi adotada um abordagem analítica, fixando-se o peso específico e a umidade do corpo de prova e variando a direção do "acamamento" em relação à direção de aplicação das cargas normal e cisalhante. Para o estudo do efeito do envelhecimento sobre os parâmetros de resistência adotou-se uma abordagem sintética, em que tanto os efeitos relacionados à composição das amostras, quanto os efeitos relacionados à condição de aterramento pudessem ser representados. Desta forma, as condições de preparo dos corpos de prova foram definidas com base nas características médias dos estratos identificados no ASSC. Nas amostras coletadas e pequena profundidade utilizaram-se as características de umidade e peso específico do estrato superior do aterro, enquanto que para as amostras coletadas a profundidades maiores utilizaram-se a umidade e o peso específico médios do estrato inferior. A Tabela 4.6 resume os ensaios de cisalhamento direto realizados nessa pesquisa. A moldagem dos diversos corpos de prova de uma mesma amostra envolveu reúso de material.

Nos ensaios que objetivavam caracterizar a resistência dos resíduos aterrados a pequenas profundidades pretendia-se que os corpos de prova fossem moldados com peso específico de $9 \mathrm{kN} / \mathrm{m}^{3}$ e umidade de $43 \%$. Nos ensaios que objetivavam caracterizar a resistência dos resíduos aterrados em profundidades maiores pretendia-se que os corpos de prova fossem moldados com peso específico de $15 \mathrm{kN} / \mathrm{m}^{3}$ e umidade de $53 \%$. 
Os corpos de prova de todas as amostras foram compactados em quatro camadas de 10 centímetros, e uma quinta camada foi executada com altura variável, a depender das características de moldagem de cada amostra.

Os corpos de prova ensaiados com as camadas na posição horizontal, identificados como $0^{\circ}$ na Tabela 4.6, foram moldados diretamente na caixa de ensaios, utilizando-se o cilindro de aplicação da carga vertical e a tampa para compactação estática.

Tabela 4.6 - Ensaios de cisalhamento direto realizados nesta pesquisa.

\begin{tabular}{|c|c|c|c|c|c|}
\hline Amostra & $\begin{array}{l}\text { Corpo de } \\
\text { Prova }\end{array}$ & $\begin{array}{c}\text { Tensao } \\
\text { normal } \\
(\mathrm{kPa})\end{array}$ & $\begin{array}{l}\text { Posição das } \\
\text { camadas }\end{array}$ & $\begin{array}{l}\text { Umidade } \\
(\%)\end{array}$ & $\begin{array}{l}\text { Peso Específico } \\
\qquad\left(\mathrm{kN} / \mathrm{m}^{3}\right)\end{array}$ \\
\hline \multicolumn{6}{|c|}{ Amostras rasas } \\
\hline A1988 & $\mathrm{CP} 3$ & 50 & $0^{\circ}$ & 44,5 & 9,1 \\
\hline (aterro & $\mathrm{CP} 1$ & 150 & $0^{\circ}$ & 43,0 & 9,1 \\
\hline experimental) & $\mathrm{CP} 4$ & 250 & $0^{\circ}$ & 45,5 & 9,1 \\
\hline \multirow{4}{*}{$\begin{array}{l}\text { A1995 } \\
\text { (lixão) }\end{array}$} & $\mathrm{CP} 2$ & 25 & $0^{\circ}$ & 45,0 & 9,2 \\
\hline & $\mathrm{CP} 1$ & 50 & $0^{\circ}$ & 43,3 & 9,6 \\
\hline & $\mathrm{CP} 3$ & 150 & $0^{\circ}$ & 42,6 & 9,1 \\
\hline & CP6 & 250 & $0^{\circ}$ & 41,6 & 9,3 \\
\hline A2011 & $\mathrm{CP} 1$ & 50 & $0^{\circ}$ & 45,0 & 8,1 \\
\hline \multirow[t]{2}{*}{ (aterro sanit.) } & $\mathrm{CP} 5$ & 150 & $0^{\circ}$ & 39,0 & 9,0 \\
\hline & CP6 & 250 & $0^{\circ}$ & 42,5 & 9,0 \\
\hline A2007 & $\mathrm{CP} 1$ & 50 & $0^{\circ}$ & 43,0 & 9,7 \\
\hline \multirow[t]{2}{*}{ (aterro sanit.) } & $\mathrm{CP} 2$ & 150 & $0^{\circ}$ & 45,0 & 10,3 \\
\hline & $\mathrm{CP} 3$ & 250 & $0^{\circ}$ & 43,0 & 11,0 \\
\hline \multicolumn{6}{|c|}{ Amostras profundas } \\
\hline A2004 & $\mathrm{CP} 1$ & 50 & $0^{\circ}$ & 52,0 & 13,8 \\
\hline \multirow[t]{3}{*}{ (aterro sanit.) } & $\mathrm{CP} 3$ & 150 & $0^{\circ}$ & 53,0 & 14,1 \\
\hline & $\mathrm{CP} 5$ & 150 & $0^{\circ}$ & 49,0 & 14,5 \\
\hline & $\mathrm{CP} 4$ & 250 & $0^{\circ}$ & 49,0 & 14,8 \\
\hline A2001 & $\mathrm{CP} 2$ & 50 & $0^{\circ}$ & 49,0 & 15,1 \\
\hline \multirow[t]{2}{*}{ (aterro sanit.) } & $\mathrm{CP} 1$ & 150 & $0^{\circ}$ & 52,0 & 15,2 \\
\hline & $\mathrm{CP} 3$ & 250 & $0^{\circ}$ & 52,3 & 14,9 \\
\hline \multicolumn{6}{|c|}{ Anisotropia } \\
\hline A1995 & $\mathrm{CP} 7$ & 50 & $0^{\circ}$ & 40,9 & 12,0 \\
\hline \multirow[t]{5}{*}{ (lixão) } & $\mathrm{CP} 8$ & 150 & $0^{\circ}$ & 42,4 & 12,0 \\
\hline & CP13 & 50 & $90^{\circ}-\mathrm{X}$ & 44,0 & 12,0 \\
\hline & CP12 & 150 & $90^{\circ}-X$ & 39,1 & 12,0 \\
\hline & CP9 & 50 & $90^{\circ}-\mathrm{Y}$ & 41,5 & 12,0 \\
\hline & CP11 & 165 & $90^{\circ}-\mathrm{Y}$ & 44,0 & 12,0 \\
\hline
\end{tabular}


Para moldagem dos corpos de prova das amostras A1988 e A1995 com peso específico de $9 \mathrm{kN} / \mathrm{m}^{3}$ não foi necessária compactação. Os corpos de prova da amostra A2007 não puderam ser moldados com peso específico de $9,0 \mathrm{kN} / \mathrm{m}^{3}$, pois ao ser colocado na caixa de ensaio o material ficava naturalmente com peso específico maior do que esse (entre 9,7 e 11,0 $\mathrm{kN} / \mathrm{m}^{3}$, conforme consta da Tabela 4.6). Na moldagem dos corpos de prova das amostras A2001 e A2004 com umidade entorno de 53\% as amostras perdiam grande quantidade de água quando se aplicava o carregamento estático para obtenção do peso específico de 15 $\mathrm{kN} / \mathrm{m}^{3}$. Adotou-se como regra manter a aplicação do carregamento vertical por 10 minutos em cada camada, e então subir o cilindro, escarificar a superfície recém-compactada e colocar o material para moldagem da nova camada.

As amostras A2004 e A2011 apresentaram comportamento resiliente, ou seja, restituíam parte do deslocamento vertical obtido com a aplicação da carga estática assim que esta era removida (Figura 4.19). Isto explica porque os corpos de prova da amostra A2004 foram moldados com pesos específicos entre 13,8 e $14,5 \mathrm{kN} / \mathrm{m}^{3}$, ao invés de $15 \mathrm{kN} / \mathrm{m}^{3}$. No caso da amostra A2011, quando se recolhia o cilindro vertical, o corpo de prova expandia e o peso específico da amostra acabava ficando entorno de $6-7 \mathrm{kN} / \mathrm{m}^{3}$. Para que fosse possível moldar o corpo de prova com peso específico de $9 \mathrm{kN} / \mathrm{m}^{3}$ o cilindro vertical não foi mais recuado após a aplicação do carregamento estático para moldagem da última camada.

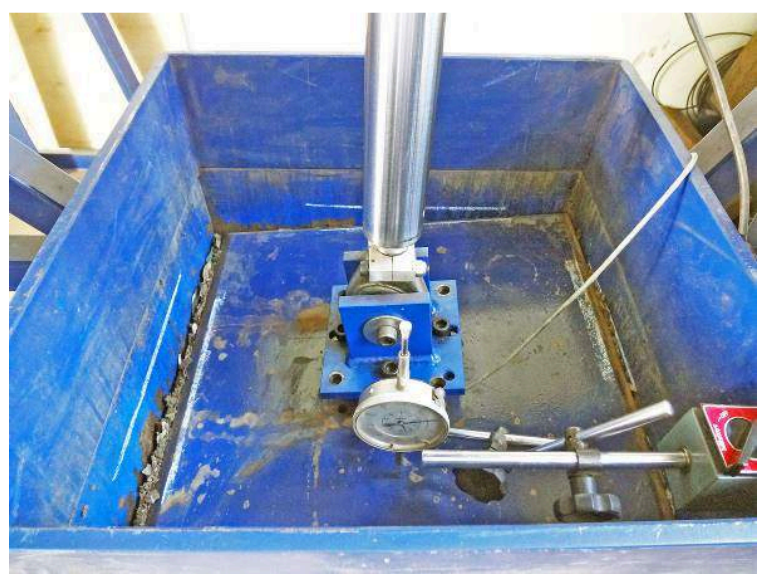

(a)

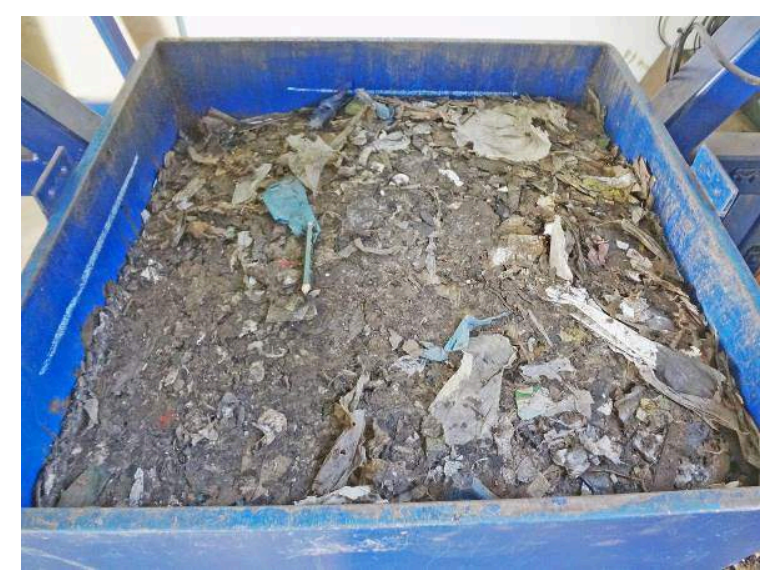

(b)

Figura 4.19 - (a) final do ensaio de cisalhamento realizado com a amostra A2011 - observar que a amostra está "descolada" da parede da caixa de ensaio no lado esquerdo (b) com a remoção do carregamento vertical a amostra expande, encostando novamente na parede lateral da caixa de ensaio e ultrapassando parcialmente a marca de giz da parede do fundo. 
Os corpos de prova ensaiados com as camadas na posição vertical, identificados como $90^{\circ}$ na Tabela 4.6, foram confeccionados em um molde metálico externo, que depois era fechado, transportado para dentro da caixa de ensaios e removido (Figura 4.20). Nestes casos utilizou-se um peso metálico caindo sobre uma base metálica cilíndrica (compactação dinâmica) para obtenção do peso específico de $12 \mathrm{kN} / \mathrm{m}^{3}$.

Além disso, nos ensaios com rotação da camada verificou-se que o corpo de prova cedia lateralmente no momento em que o molde metálico era retirado de dentro da caixa de ensaio. Isto se deve ao fato de que o molde foi confeccionado com dimensões um pouco menores que a caixa, para que entrasse com folga. Para diminuir o espaço disponível nas laterais da amostra e minimizar esse efeito de acomodação foram instaladas placas de isopor entre o molde e a parede da caixa de ensaio e, após a retirada do molde metálico, colocavam-se outras placas de isopor nos lados em que isso fosse possível. Com a adoção de todas estas medidas a acomodação do corpo de prova diminuiu, porém ainda podia ser percebida pela abertura de trincas paralelas ao acamamento e pela diminuição da altura do corpo de prova. A Figura 4.21 ilustra essa situação.

Para os ensaios de verificação da anisotropia dos RSU as amostras foram rotacionadas em relação a dois eixos diferentes. Com isso, as "camadas" de orientação preferencial dos componentes da amostra rotacionada estavam sempre posicionadas na vertical, porém em um dos casos o eixo era perpendicular a essas camadas e no outro o eixo Y era perpendicular as mesmas, como ilustrado na Figura 4.22. O eixo perpendicular ao plano de "acamamento" foi utilizado como índice para identificar a posição da amostra na caixa de ensaios.

Nos primeiros testes, a fase de adensamento foi mantida por período mais longo, de até 9 horas. Verificou-se que com quatro horas de adensamento as amostras já haviam ultrapassado a fase de compressão primária e decidiu-se que esse seria o tempo mínimo de adensamento do corpo de prova em cada ensaio.

Em muitos corpos de prova os recalques na fase de adensamento foram tão expressivos, que, após alguns minutos, sua altura era inferior a 37 centímetros. Nestes casos o adensamento foi interrompido e foi acrescentada nova camada de resíduos à amostra, para então se reiniciar o processo. Ocorriam então novos recalques imediatos. Esse procedimento foi repetido conforme necessário, para que se ensaiassem corpos de prova com altura mínima de 37 centímetros. 

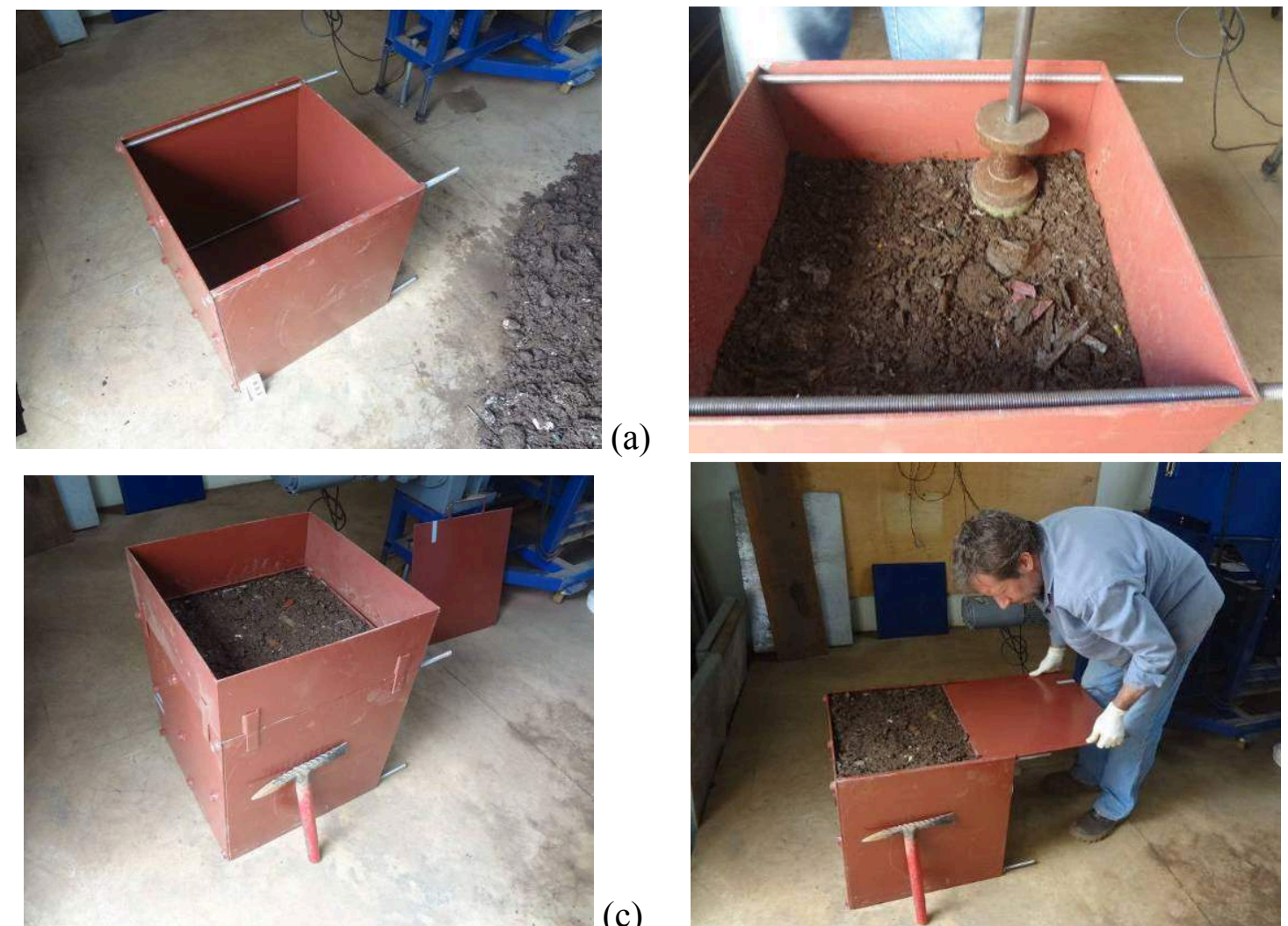

(a)

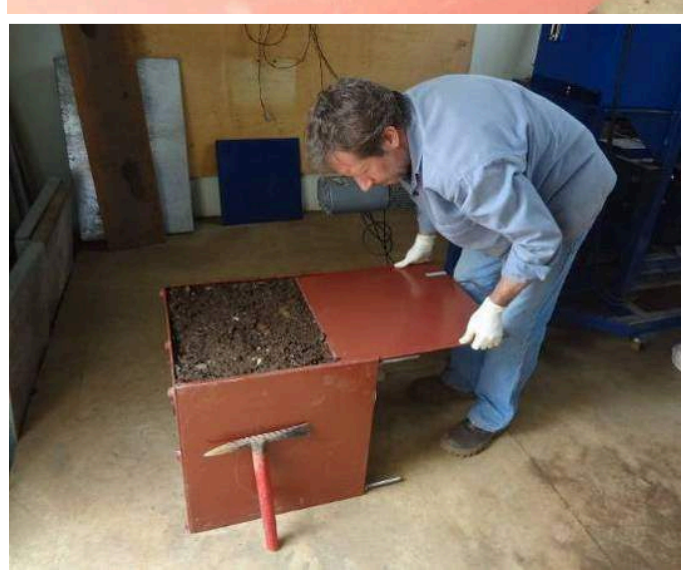

(b)

(c)
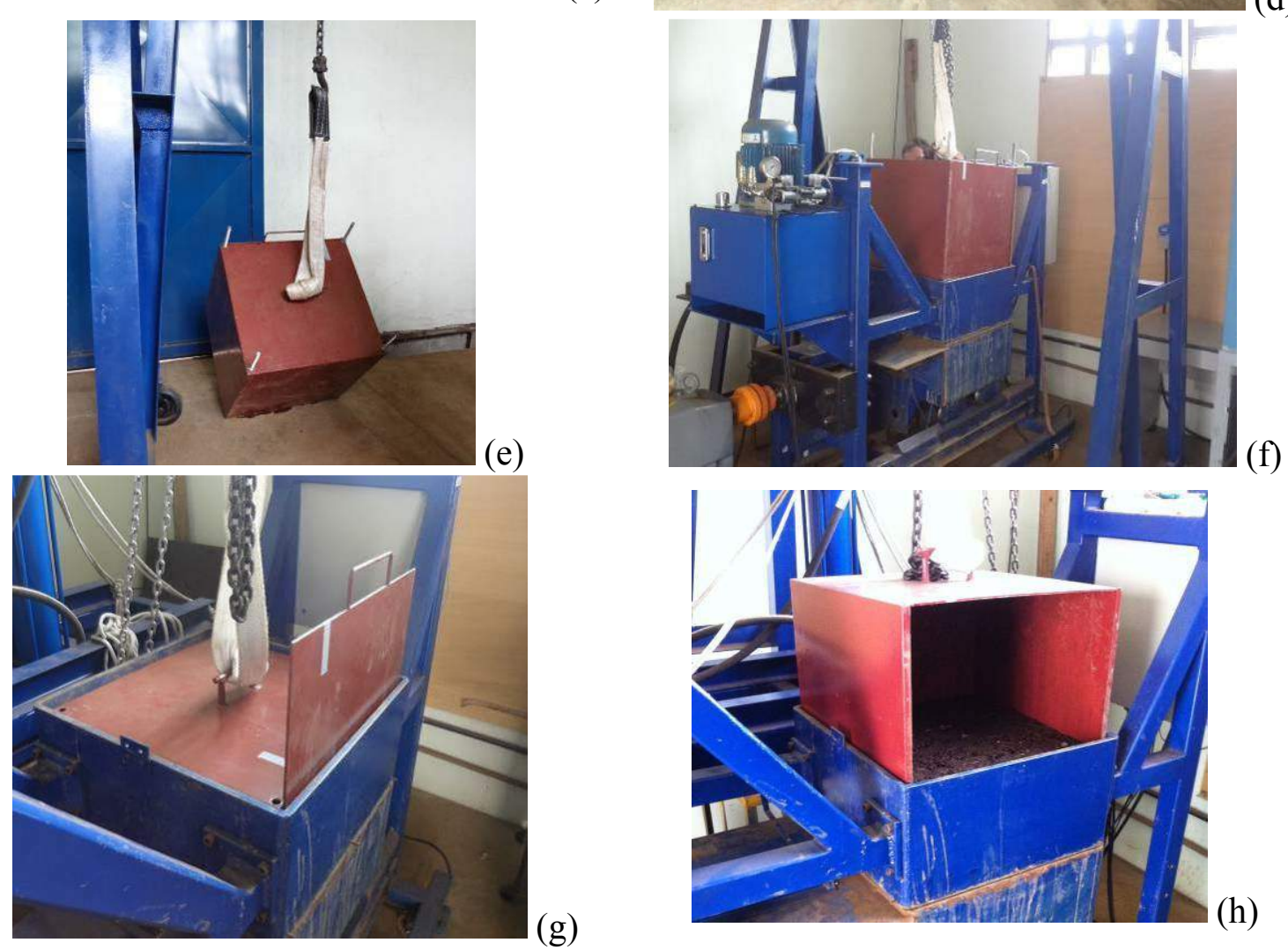

Figura 4.20 - (a) molde metálico vazio (b) moldagem do corpo-de-prova (c) aspecto do molde com colarinho (d) colocação da tampa (e) rotação das camadas (f) colocação do corpo de prova na caixa de ensaio $(\mathrm{g})$ retirada da tampa $(\mathrm{h})$ retirada do molde metálico. 


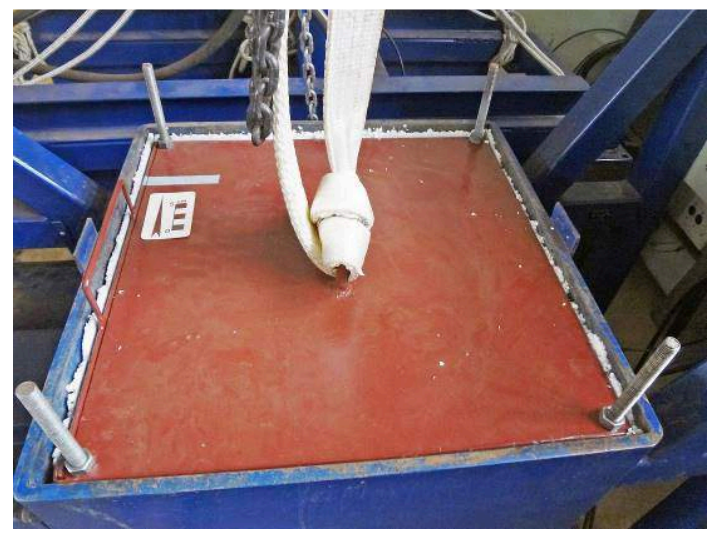

(a)

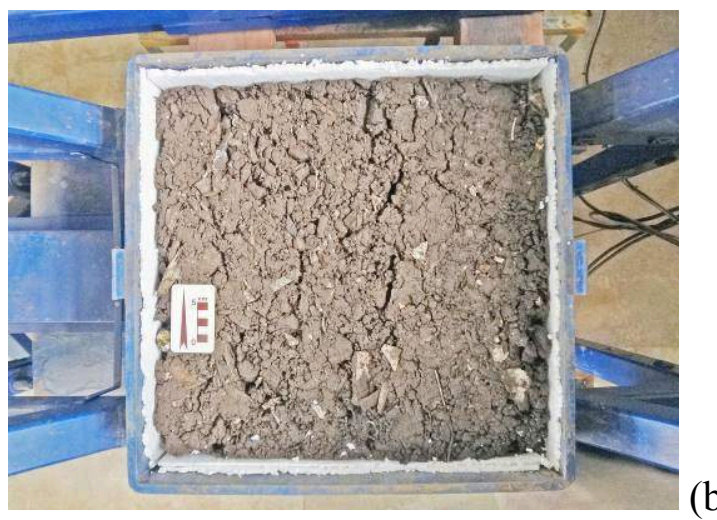

(b)

Figura 4.21 - (a) Colocação de placas de isopor entre o molde metálico e a caixa de ensaio e (b) aspecto do corpo de prova, após a remoção do molde.
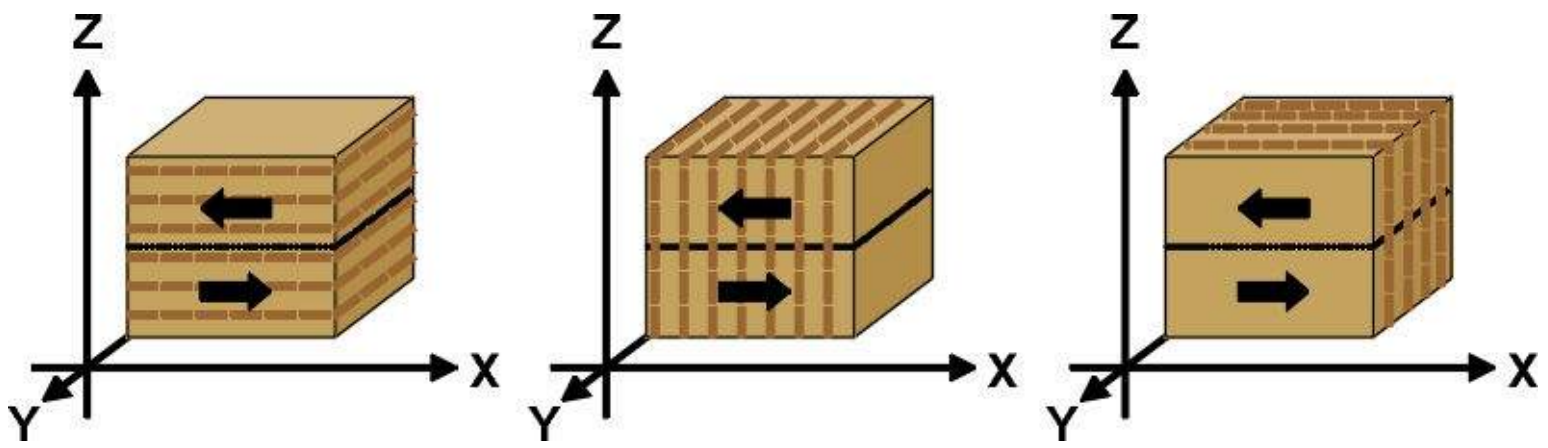

Figura 4.22 - Posição relativa das "camadas" de orientação preferencial dos componentes da amostra na caixa de ensaio. À esquerda: $0^{\circ}$, no centro: $90^{\circ} \mathrm{X}$ e à direita: $90^{\circ} \mathrm{Y}$.

Esse fato também motivou a alteração do plano de ensaios para verificação da anisotropia. Pretendia-se executar os ensaios para verificação da anisotropia com corpos de prova preparados com peso específico de $9 \mathrm{kN} / \mathrm{m}^{3}$, entretanto, para os corpos de prova ensaiados com rotação das camadas não haveria a possibilidade de se acrescentar mais material, caso o corpo de prova ficasse com altura inferior a $37 \mathrm{~cm}$ no final da fase de adensamento. Decidiu-se moldar os corpos de prova para esses ensaios com peso específico de $12 \mathrm{kN} / \mathrm{m}^{3}$, como constou da Tabela 4.6, contando com uma redução dos deslocamentos verticais durante a fase de adensamento. Também se verificavam recalques imediatos quando o carregamento vertical era retomado, após ter ficado desligado durante a noite.

Outra dificuldade para a execução dos ensaios foi a obtenção das umidades pretendidas para moldagem dos corpos de prova. Como as amostras eram grandes, era difícil atingir e manter as umidades desejadas. Como exposto anteriormente, as amostras ensaiadas com umidade entorno de $52 \%$ perdiam água durante a própria moldagem. A drenagem dos corpos 
de prova ocorria pelo fundo da caixa de ensaio, pelo plano de cisalhamento e pela parte superior.

A ocorrência de drenagem do CP pelo fundo era planejada: havia uma chapa perfurada no fundo da caixa de ensaio e, sob a chapa, ranhuras em desnível conduziam os líquidos percolados para um orifício central, ao qual estava conectada uma mangueira. A ocorrência de drenagem pelo plano de cisalhamento e pela parte superior do corpo de prova não era planejada, especialmente não nos volumes em que ela ocorreu. Na parte superior, a água era expelida pelas laterais da tampa e pelos buracos dos parafusos que a seguravam, na região central (Figura 4.23). Conforme a tampa sofria desnivelamentos, a água que havia sido expulsa migrava para as laterais e escorria pela parede da caixa de ensaio. Quando muita água se acumulava sobre a tampa era necessário recolher esse volume com uma esponja. Para coletar a água que saia pelo fundo, pelas laterais e pela parte superior da caixa de ensaios foi instalada uma bandeja metálica sob o equipamento, que era periodicamente substituída (Figura 4.23). Media-se o volume de água expulso pela amostra em uma proveta graduada.
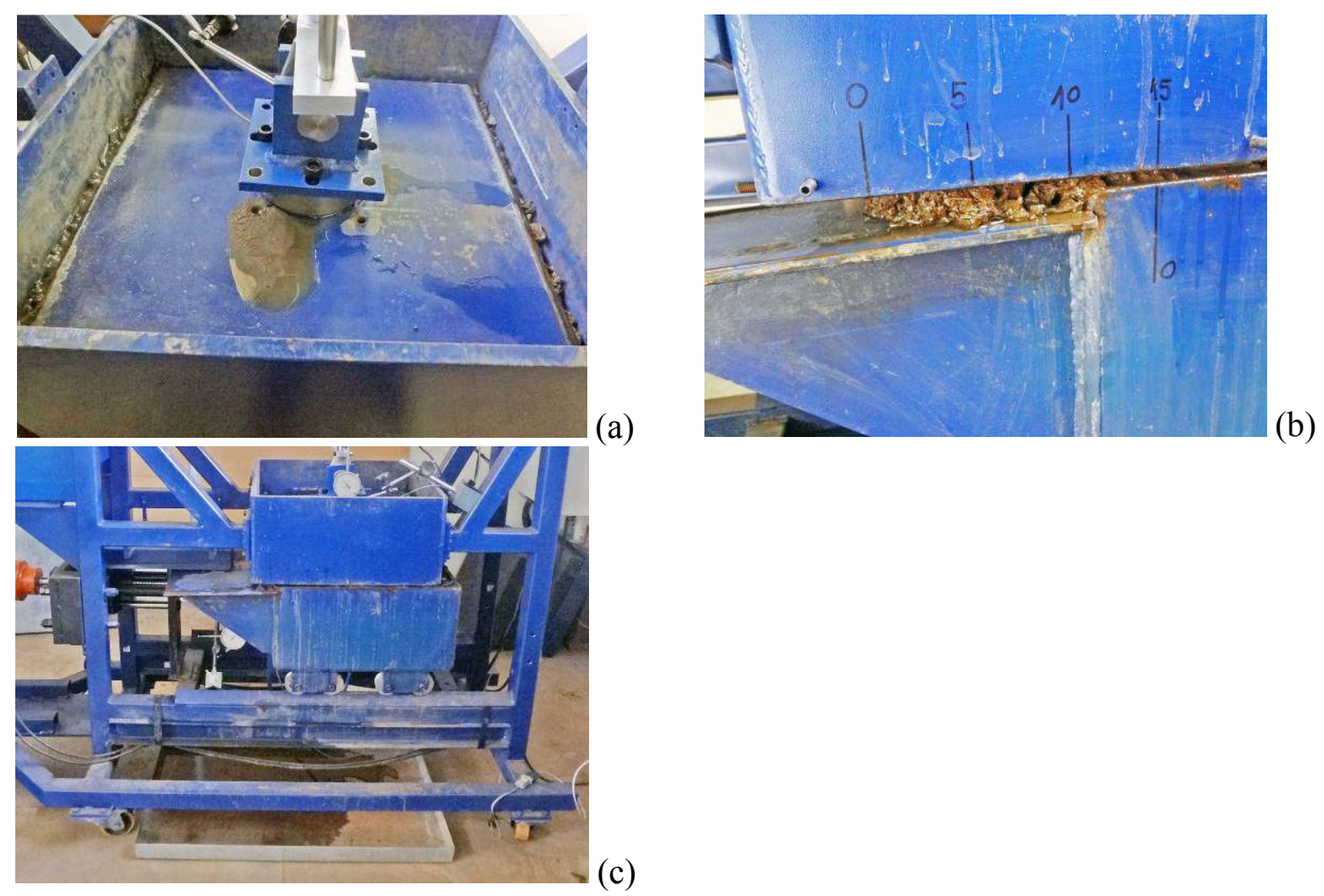

b)

Figura 4.23 - (a) drenagem de água da amostra pelos orifícios e laterais da tampa de aplicação da carga vertical (b) drenagem de água da amostra pelo plano de cisalhamento e (c) bandeja colocada sob o equipamento de ensaio para captação da água que saía do corpo de prova. 
A umidade das amostras no momento da moldagem era determinada com a separação de parte do material em uma bandeja quando a terceira camada de RSU estava sendo moldada. As bandejas utilizadas para determinação da umidade eram metálicas, com dimensões de 40 x 60 x 5,5 centímetros e, quando cheias, acomodavam entre 4 e $6 \mathrm{~kg}$ de RSU úmido em cada determinação.

Ao desmontar o corpo de prova eram coletadas duas bandejas para determinação da umidade: uma na profundidade do plano de cisalhamento e outra na base do corpo de prova. Verificou-se que durante o ensaio ocorria uma redistribuição de umidade no corpo de prova, mesmo nas amostras que não liberavam água durante qualquer uma das fases. Ao final do cisalhamento a parte basal do corpo de prova (últimos 5 a 10 centímetros) estava sempre mais úmida que as partes superiores. 


\section{RESULTADOS E DISCUSSÕES}

\subsection{Caracterização geotécnica do maciço de resíduos}

$\mathrm{Na}$ área do Aterro Sanitário de São Carlos (ASSC) investigada com sondagens a trado, a camada de cobertura do platô final do aterro é composta por solo arenoso de cor marrom e tem espessura de 0,8 a 1,2m. A camada mais superficial de resíduos foi aterrada em novembro de 2011. Até 2,5 metros de profundidade o material apresentava pouca descoloração e estava relativamente seco. De 2,5 a 6,6 metros de profundidade os resíduos encontravam-se úmidos e com cor preta.

Nos furos 2, 3 e 4 foi identificada uma camada de $0,4 \mathrm{~m}$ de espessura de solo de cobertura iniciando-se à profundidade de 6,6 metros. No furo 2 esse solo de cobertura era marrom e arenoso e nos furos 3 e 4 ele era preto, arenoso e estava misturado a poucas partículas de resíduos. Nos furos 1, 5 e 6 esta camada não foi identificada.

A segunda camada de resíduos tinha 4 metros de espessura e havia sido aterrada em 2007. O material encontrava-se pouco a muito úmido e com cor preta. A camada de solo de cobertura que separava essa camada da seguinte não pôde ser distinguida no material escavado, mas a velocidade de avanço do equipamento de perfuração sofria forte diminuição à profundidade de cerca de 12 metros, que corresponde aproximadamente à cota de topo da terceira camada de resíduos (aterrados em 2003-2004).

Daí em diante não foi possível discernir as camadas de resíduos entre si, ou em relação às camadas de solo de cobertura. $\mathrm{O}$ material recuperado apresentava diferentes graus de umidade (pouco úmido, úmido ou muito úmido) e diferentes concentrações de gás. $\mathrm{Na}$ realidade, o conteúdo e a composição dos gases que saíram dos furos não foram analisados, mas em alguns trechos era possível enxergar saída de um vapor branco, associado (ou não) a um cheiro forte e nauseante (atribuído à presença de amônia). A cor dos resíduos era usualmente preta e, em alguns poucos casos, cinza. De acordo com o histórico de operação do aterro as camadas mais profundas atingidas pelas sondagens corresponderiam a resíduos aterrados em 1999.

A Figura 5.1 apresenta um perfil esquemático das camadas atravessadas pelas sondagens. No Anexo A são apresentados os perfis individuais das sondagens.

A descrição visual dos materiais extraídos dos furos de sondagem indicou que correspondiam a RSU. Não foram escavados materiais que pudessem ser associados a 
resíduos de construção civil. Na sondagem 1, entre 7,0 e 10,0 m, 15,2 e 15,5m e 18,5 e 18,7m de profundidade, na sondagem 2 entre 21,0 e 22,0 $\mathrm{m}$ e na sondagem 3 entre 14,0 e 14,8m de profundidade, foi escavado material de consistência muito mole, semelhante a lodo de estação de tratamento de esgoto.

Para as três camadas superiores, mais recentes, a época de aterramento dos resíduos também pôde ser determinada pelas datas de validade que ainda puderam ser lidas em algumas das embalagens coletadas, além do histórico de operação do aterro.

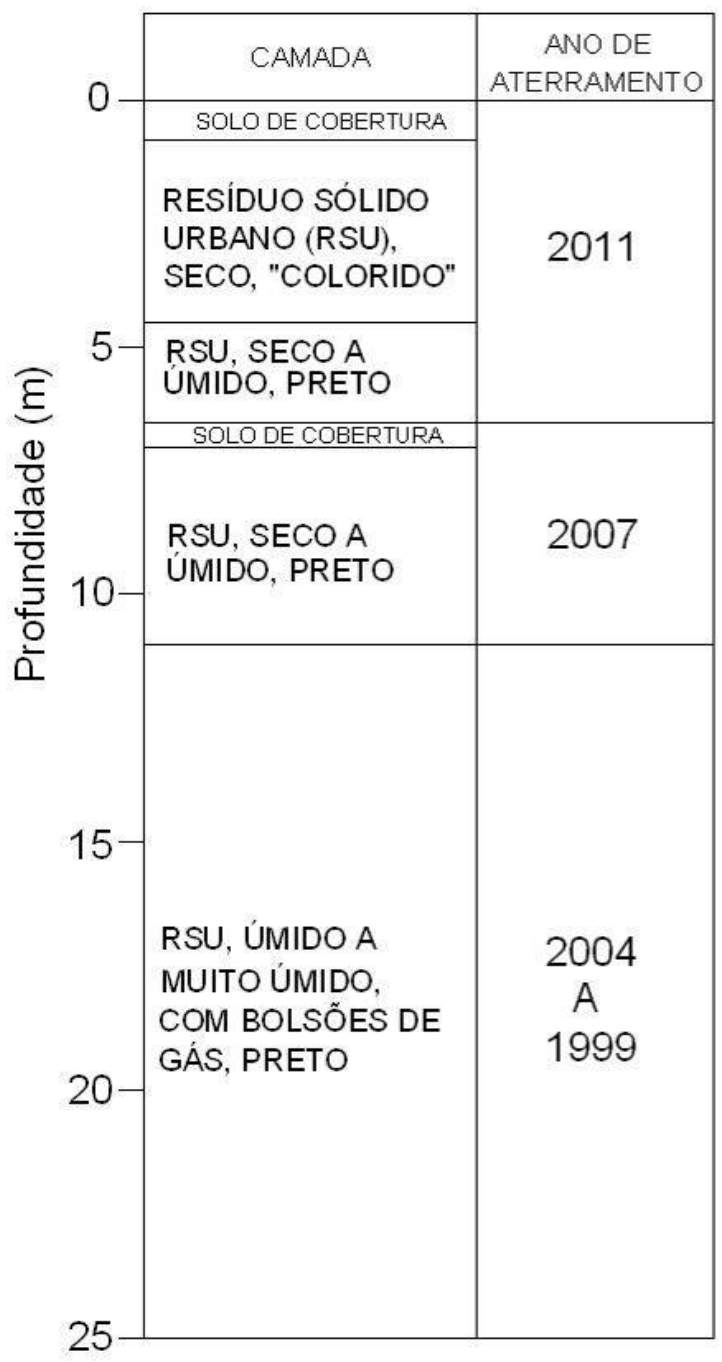

Figura 5.1 - Camadas atravessadas pelas sondagens no Aterro Sanitário de São Carlos

\subsubsection{Temperatura dos RSU}

As temperaturas dos RSU variaram de 32 a $50^{\circ} \mathrm{C}$, conforme ilustrado na Figura 5.2, para temperaturas ambientes entre 11 e $30^{\circ} \mathrm{C}$. Entre 2 e 10 metros de profundidade elas tenderam a aumentar e mostraram-se menos dispersas. O valor médio da temperatura para este trecho foi 
de $39^{\circ} \mathrm{C}$, a amplitude foi de $13^{\circ} \mathrm{C}$ e o desvio padrão foi de $3^{\circ} \mathrm{C}$. A partir dos 10 metros de profundidade a dispersão dos resultados foi maior, sem apresentar uma tendência clara de aumento ou diminuição. $\mathrm{O}$ valor médio da temperatura para esse intervalo foi de $42^{\circ} \mathrm{C}$, a amplitude foi de $15^{\circ} \mathrm{C}$ e o desvio padrão foi de $4^{\circ} \mathrm{C}$. Esses valores situam-se dentro da faixa de temperaturas comumente registradas em aterros sanitários com alturas entre 20 e 60 metros (Hanson et al., 2010) e indicam que os resíduos ainda estão sendo degradados, provavelmente em condições metanogênicas (anaeróbias).

Para efeito de comparação, Mariano (1999), estudando o Aterro da Muribeca, em Pernambuco, mediu temperaturas entre 28 e $34^{\circ} \mathrm{C}$ na Célula 1 , em que os resíduos eram mais antigos, e temperaturas entre $28^{\circ} \mathrm{C}$ e $56^{\circ} \mathrm{C}$ na Célula 2, de resíduos mais novos. Shinzato (2014) mediu temperaturas de $20^{\circ} \mathrm{C}$ entre 0,5 e $2,5 \mathrm{~m}$ de profundidade e $21^{\circ} \mathrm{C}$ entre 2,5 e $7,0 \mathrm{~m}$ metros no Lixão Desativado de São Carlos.

Gomes e Lopes (2012) estudando um aterro em Portugal registraram temperaturas entre 40 e $45^{\circ} \mathrm{C} \operatorname{logo}$ após a disposição dos RSU, atingindo um máximo entre 50 e $53^{\circ} \mathrm{C}$ nos $1,4-2$ anos seguintes e decaindo gradualmente, até atingir $25-30^{\circ} \mathrm{C}$ nos resíduos mais antigos (10 anos de aterramento).

Zekkos (2005) determinou temperaturas entre 31 e $45^{\circ} \mathrm{C}$ para os resíduos do Aterro de Tri-Cities, na Califórnia (EUA), estudados em sua pesquisa em profundidades entre 6 e 35 metros.

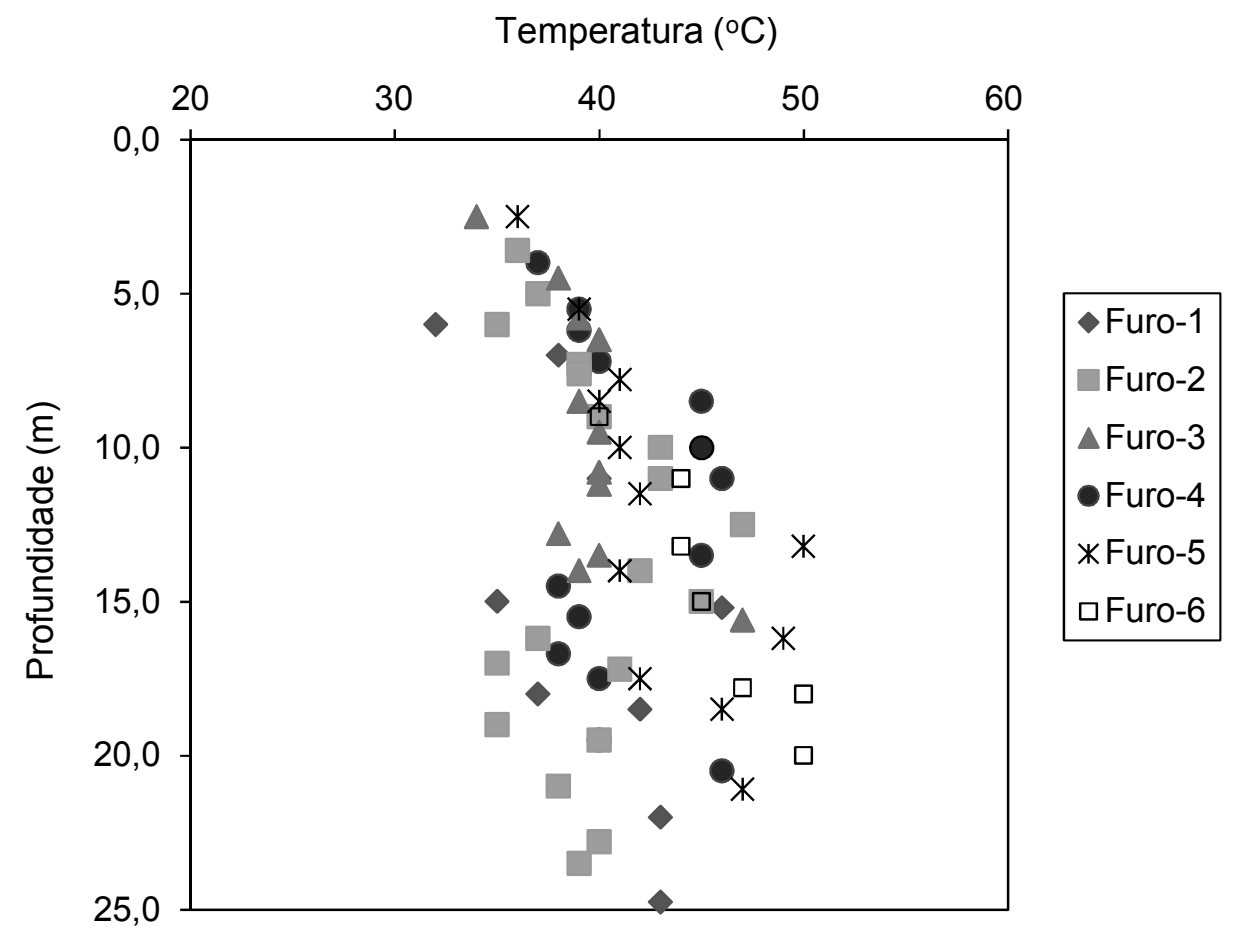

Figura 5.2 - Temperatura dos RSU no Aterro Sanitário de São Carlos 


\subsubsection{Composição gravimétrica}

A composição gravimétrica média (base seca) das amostras coletadas nas sondagens a trado foi $51,0 \%$ de material menor que $19 \mathrm{~mm}, 23,1 \%$ plástico mole, $7,5 \%$ plástico duro, 2,3\% madeira, $4,5 \%$ tecidos, $2,9 \%$ metais, $4,8 \%$ pedras, $0,5 \%$ borracha, $0,6 \%$ papel, $0,3 \%$ vidro e $0,3 \%$ outros. Estas porcentagens incluem os pesos correspondentes aos componentes maiores que 20 centímetros, escalpelados em campo. No geral as composições foram semelhantes, como apresentado na Figura 5.3. Apenas as amostras A1-1 e A1-2 apresentaram conteúdo de materiais menores que $19 \mathrm{~mm}$ inferior às demais (24 e 36\%, respectivamente) e as amostras A2-5 e A3-4 apresentaram conteúdo superior às demais (68 e 69\%, respectivamente).

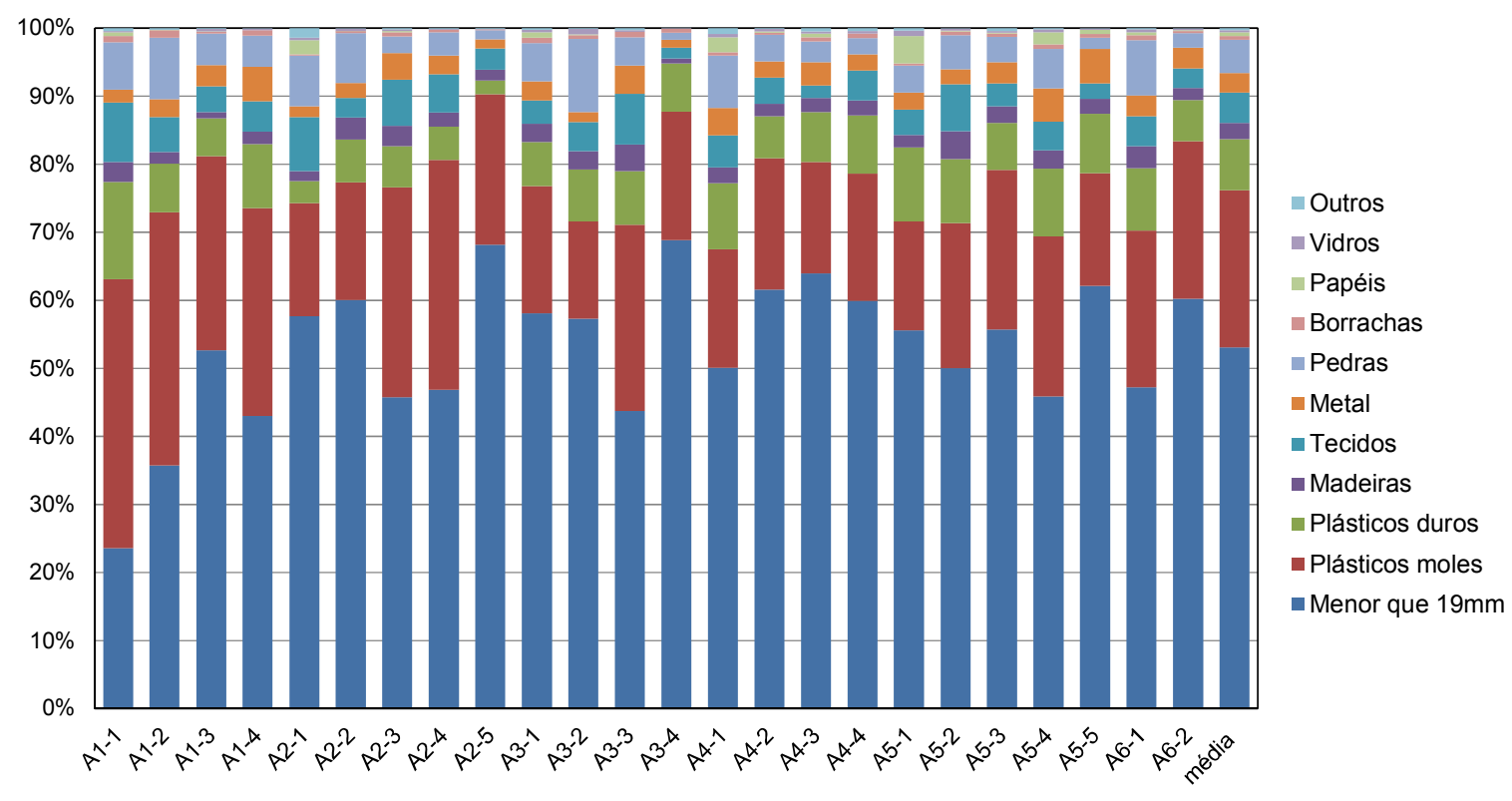

Figura 5.3 - Composição gravimétrica dos resíduos coletados por sondagens no Aterro Sanitário de São Carlos (base seca).

Analisando-se as composições médias das amostras por ano de aterramento (amostras retiradas da mesma profundidade), verifica-se que a fração plásticos moles foi maior nos resíduos aterrados anteriormente a 2004 do que nos resíduos aterrados mais recentemente. A Figura 5.4 ilustra essa comparação. Para as demais frações as composições foram semelhantes entre si, não havendo uma tendência contínua de aumento ou de diminuição. Esse resultado diverge daquele encontrado por Gomes e Lopes (2012) para os resíduos do Aterro de Santo Tirso, em Portugal, onde de verificou uma clara diminuição da porcentagem relativa de tecidos e de plásticos e um aumento da porcentagem de componentes minerais e nãoidentificáveis com o aumento do tempo de aterramento dos resíduos. 


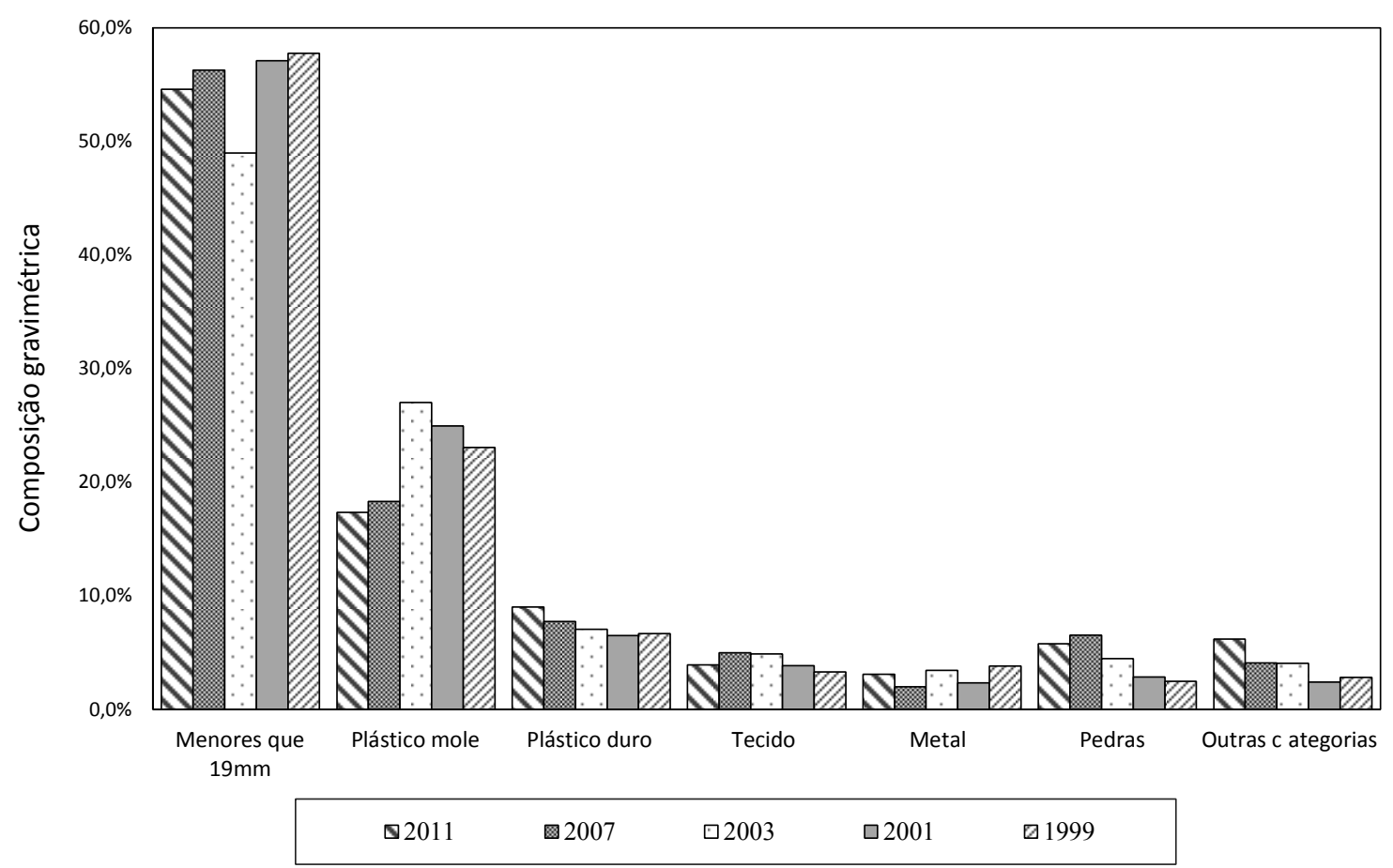

Figura 5.4 - Variação da composição gravimétrica dos resíduos, conforme o ano de aterramento (base seca).

\subsubsection{Umidade dos RSU}

A Figura 5.5 mostra os resultados obtidos para as umidades globais das amostras grandes e pequenas, expressos em base seca. A menor umidade determinada foi de $30,4 \%$ e a maior foi de $94,4 \%$. Considerando-se apenas as amostras grandes o valor máximo passa a ser de $66,9 \%$.

Não se observou uma clara correlação com a profundidade ou com o tempo de aterramento, porém para as amostras grandes coletadas na porção superior (profundidades menores que 11 metros) os valores apresentaram menor dispersão, com média de 43\%, amplitude de $23 \%$ e desvio padrão de $7 \%$, se comparados aos valores obtidos para as amostras grandes situadas na porção inferior (profundidades maiores que 11 metros), para as quais a média foi $53 \%$, a amplitude foi $64 \%$ e o desvio padrão foi $15 \%$.

Quanto à umidade dos diferentes componentes dos resíduos sólidos urbanos, os valores médios obtidos nessa pesquisa são apresentados na Tabela 5.1 . 


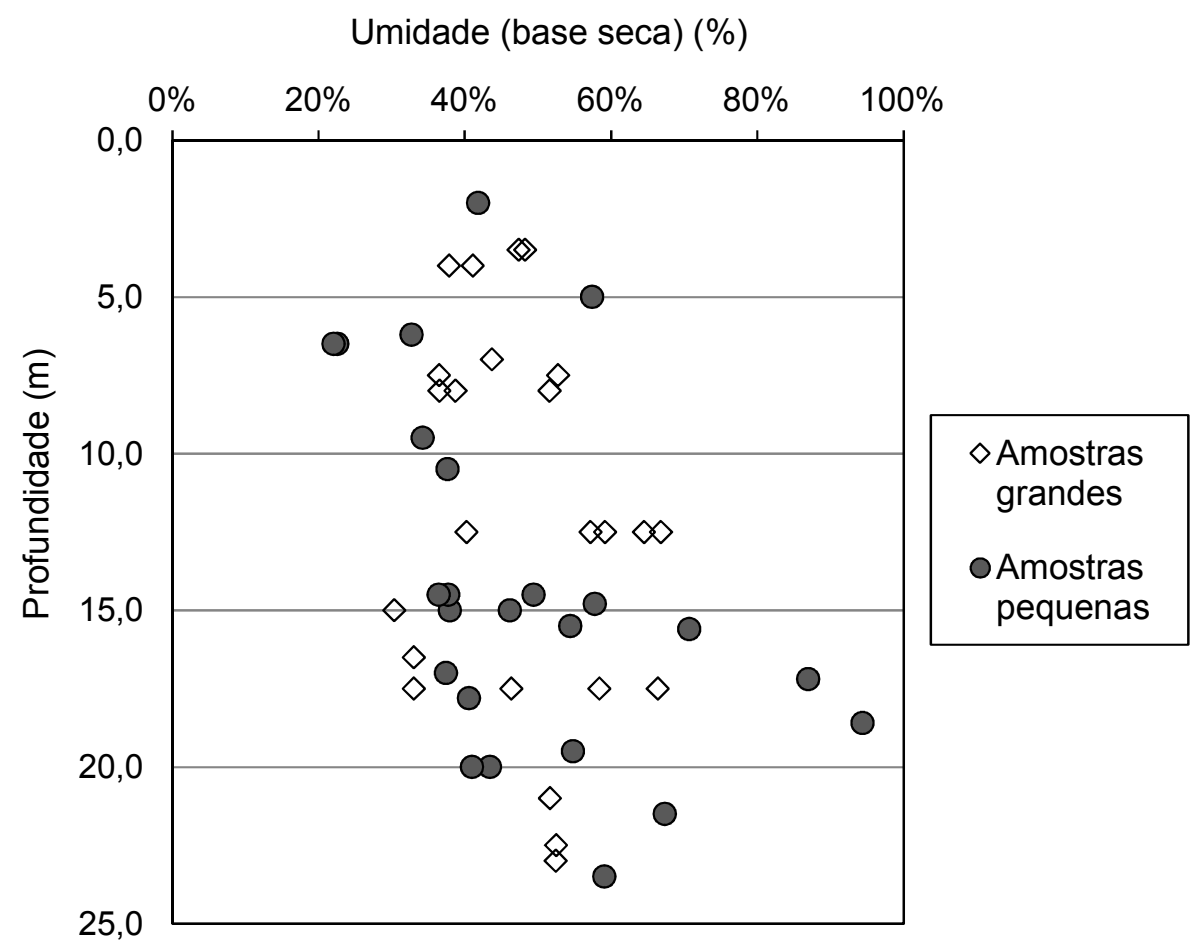

Figura 5.5 - Umidades do RSU no Aterro Sanitário de São Carlos

Tabela 5.1 - Teor de umidade médio das frações.

\begin{tabular}{lc}
\hline Fração & $\begin{array}{c}\text { Umidade }(\%, \\
\text { base seca) }\end{array}$ \\
\hline Menores que 19mm & 41,8 \\
Plástico mole & 49,8 \\
Plástico duro & 33,2 \\
Madeira & 68,4 \\
Tecido & 66,2 \\
Metal & 23,3 \\
Pedras & 9,2 \\
Borracha & 25,2 \\
Papel & 99,3 \\
Vidro & 13,2 \\
Outros & 57,8 \\
\hline
\end{tabular}

Estes resultados mostram grande dispersão, porém pesquisas realizadas em outros aterros sanitários no Brasil (Carvalho, 1999; Mariano, 1999; Santos, 1997, entre outros) e no exterior (Coumoulos et al., 1995; Stolz et al., 2009) também obtiveram valores dispersos para esta propriedade. As umidades determinadas para o ASSC estão acima dos valores médios identificados nos aterros operados de forma convencional nos Estados Unidos (15 a 40\%, 
segundo Tchobanoglous et al., 1993). Se considerados os valores de capacidade de campo obtidos por Rocha e Azevedo (2008) para resíduos antigos, o ASSC opera provavelmente acima da sua capacidade de campo.

\subsubsection{Conteúdo de Sólidos Totais Voláteis}

Os valores encontrados para as amostras coletadas por sondagens no aterro sanitário mostraram-se novamente dispersos, com tendência de diminuição com a profundidade, como ilustrado na Figura 5.6. Para esse parâmetro a dispersão foi maior nas camadas de aterramento mais recente (2011, 2007 e 2004-2003), situadas a menos que 15 metros de profundidade, do que para as camadas mais antigas (2001 e anos anteriores), situadas abaixo de 15 metros. Os valores máximo e mínimo encontrados foram de $9 \%$ e $23 \%$, e a média foi de $16 \%$. Entre 0 e 15 metros a amplitude foi de $14 \%$ e o desvio padrão foi de 4\%. Entre 15 e 25 metros a amplitude foi de $11 \%$ e o desvio padrão foi de $3 \%$.

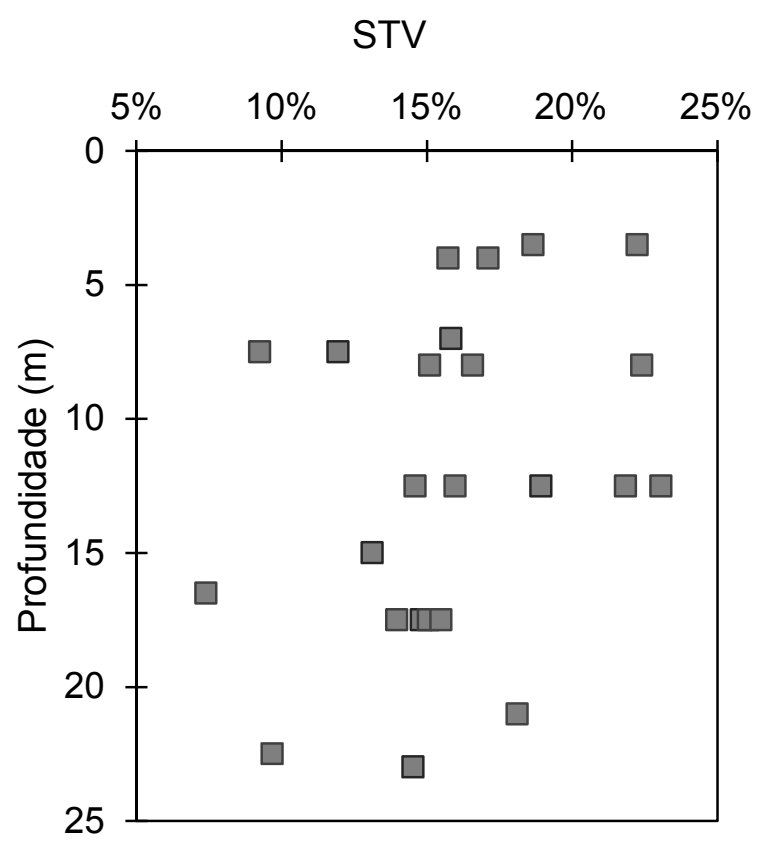

Figura 5.6 - Conteúdo de STV das amostras coletadas por sondagem no Aterro Sanitário de São Carlos.

Mariano (1999), estudando o Aterro da Muribeca, mediu valores de STV entre 5 e 56\% na Célula 1, em que os resíduos eram mais antigos, e entre 6 e 43\% na Célula 2, com resíduos mais novos. Santos (1997), trabalhando também na Célula 1 desse aterro, determinou valores de STV entre 9 e 13 para resíduos aterrados há cerca de dez anos, e entre 23 e 43\%, para resíduos aterrados há menos que dois anos. Melo (2003), trabalhando também na Célula 4 do 
Aterro da Muribeca, determinou valores de STV variando de 6 a 18\% para resíduos aterrados há 5 e 16 anos. Esses valores também são semelhantes aos dessa pesquisa. Os três pesquisadores calcinaram as amostras a $550^{\circ} \mathrm{C}$.

Entretanto, esses resultados divergem daqueles obtidos por Gomes e Lopes (2012) para amostras coletadas no Aterro de Santo Tirso, em Portugal. Essas autoras determinaram valores de STV entre 33 e 78\%, em amostras com idades de aterramento variando de poucos meses a 10 anos e identificaram uma clara tendência de diminuição dos valores de STV com o aumento da idade dos resíduos. As amostras foram calcinadas a $550^{\circ} \mathrm{C}$.

Nascimento (2007) determinou valores de STV médios de 23,2\% para resíduos com 4 anos de aterramento e de 56,8\% para resíduos novos, coletados no Aterro Metropolitano Centro, em Salvador.

\subsubsection{Peso específico dos RSU}

\subsubsection{Massa específica da brita}

Os resultados obtidos para a massa específica da brita utilizada nestes ensaios estão apresentados na Tabela 5.2. Para o cálculo do volume ocupado pela brita dentro dos furos de sondagem considerou-se que sua massa específica estaria situada entre $1.400 \mathrm{~kg} / \mathrm{m}^{3}$ e 1.808 $\mathrm{kg} / \mathrm{m}^{3}$.

Tabela 5.2 - Resultados dos ensaios de "calibração" da massa específica da brita

\begin{tabular}{lc}
\hline Procedimento de ensaio & $\begin{array}{c}\text { Massa específica } \\
\left(\mathrm{kg} / \mathrm{m}^{3}\right)\end{array}$ \\
\hline NBR 12.004 (ABNT,1990) (estado fofo) & 1.400 \\
Lançamento de 3,0 metros de altura & 1.808 \\
Lançamento de 7,0 metros de altura & 1.704 \\
\hline
\end{tabular}

5.1.5.2 Pesos específicos expeditos determinados à superfície

Os pesos específicos soltos determinados pelo método expedito variaram de 3,6 a 15,7 $\mathrm{kN} / \mathrm{m}^{3}$ e os pesos socados variaram de 5,0 a $16,6 \mathrm{kN} / \mathrm{m}^{3}$. A tendência geral, como se percebe na Figura 5.7, é de aumento com a profundidade, entretanto, observa-se grande dispersão dos resultados (desvio padrão de $3,2 \mathrm{kN} / \mathrm{m}^{3}$ em ambos os casos). Pode-se novamente separar um horizonte superior, acima de 10-12 metros, onde a média e a dispersão dos resultados são 
menores (desvio padrão de $1,4 \mathrm{kN} / \mathrm{m}^{3}$ para o peso expedito solto e de $1,5 \mathrm{kN} / \mathrm{m}^{3}$ para o peso expedito socado). Para as amostras coletadas abaixo de 10 metros de profundidade o desvio padrão dos pesos expeditos soltos foi de $3,3 \mathrm{kN} / \mathrm{m}^{3}$ e o desvio padrão para os pesos expeditos socados foi de $2,5 \mathrm{kN} / \mathrm{m}^{3}$.

O peso específico determinado por estes métodos expeditos está em princípio relacionado à composição e à umidade das amostras. Entretanto, como indicam as figuras 5.8 e 5.10, os pesos específicos solto e socado não exibem uma boa correlação com estas duas propriedades, se analisados separadamente. Como esta determinação foi realizada à superfície, ela não reflete os efeitos do confinamento ou a compacidade dos RSU in situ. Entretanto, na Figura 5.7 parece haver correlação dos resultados de peso específico com a profundidade, enquanto que na Figura 5.9, que apresenta os resultados de peso específico seco, essa correlação não existe. É possível que a composição das amostras se altere progressivamente com a profundidade e isto esteja refletido nos resultados do ensaio, porém não possa ser avaliado de forma individualizada, considerando-se os parâmetros adotados para descrição da composição das amostras nesta pesquisa.

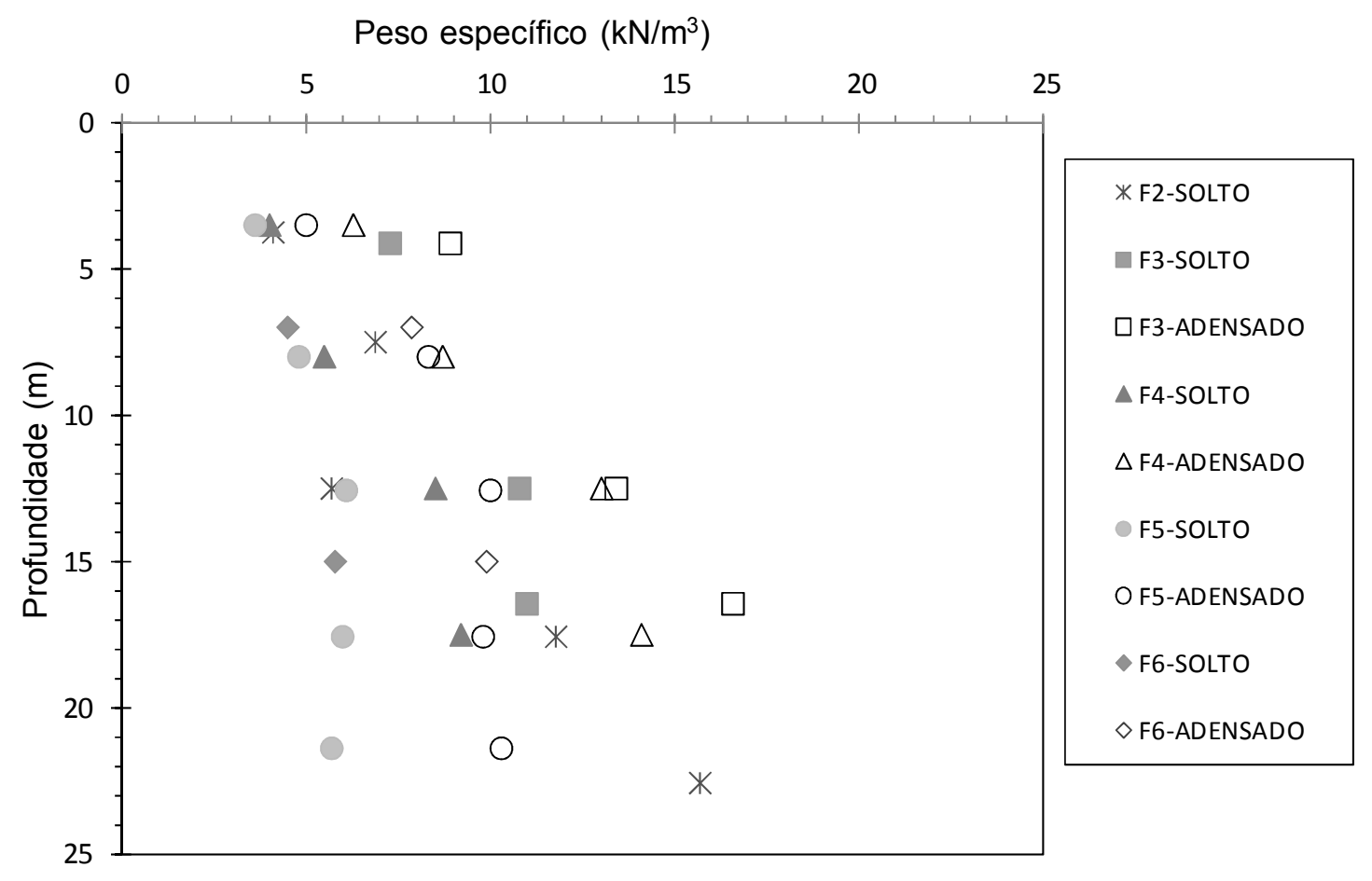

Figura 5.7 - Peso específico expedito das amostras coletadas por sondagem no Aterro Sanitário de São Carlos. 


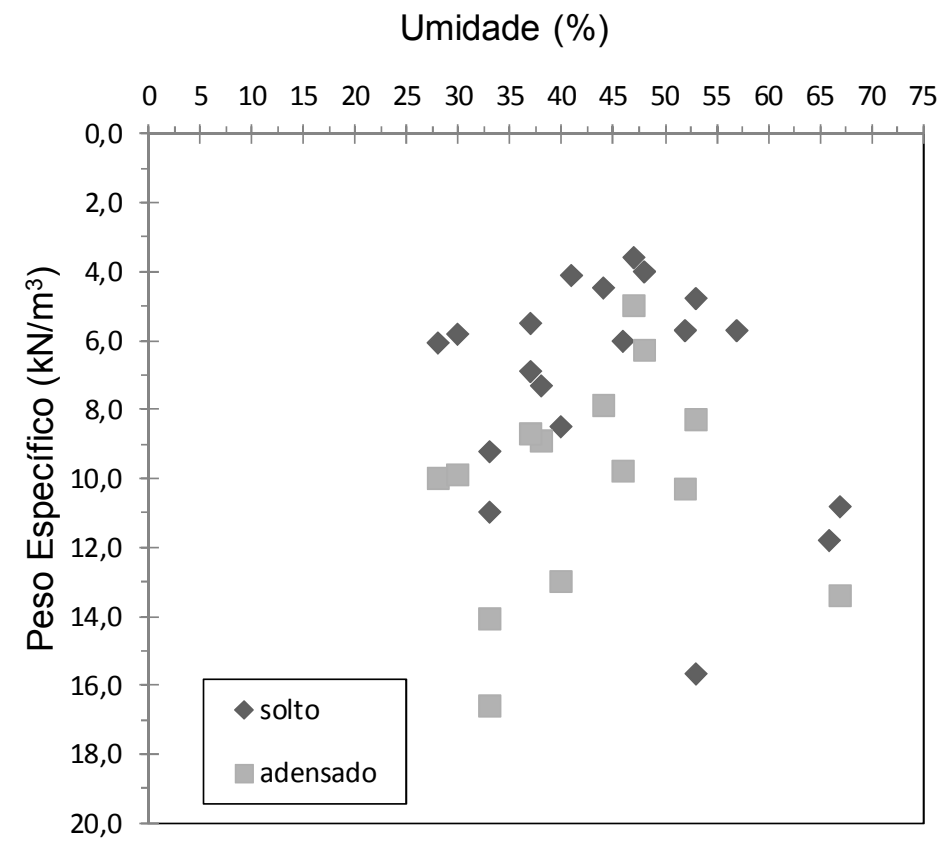

Figura 5.8 - Correlação entre o peso específico determinado por processo expedito e a umidade das amostras coletadas por sondagem no Aterro Sanitário de São Carlos.

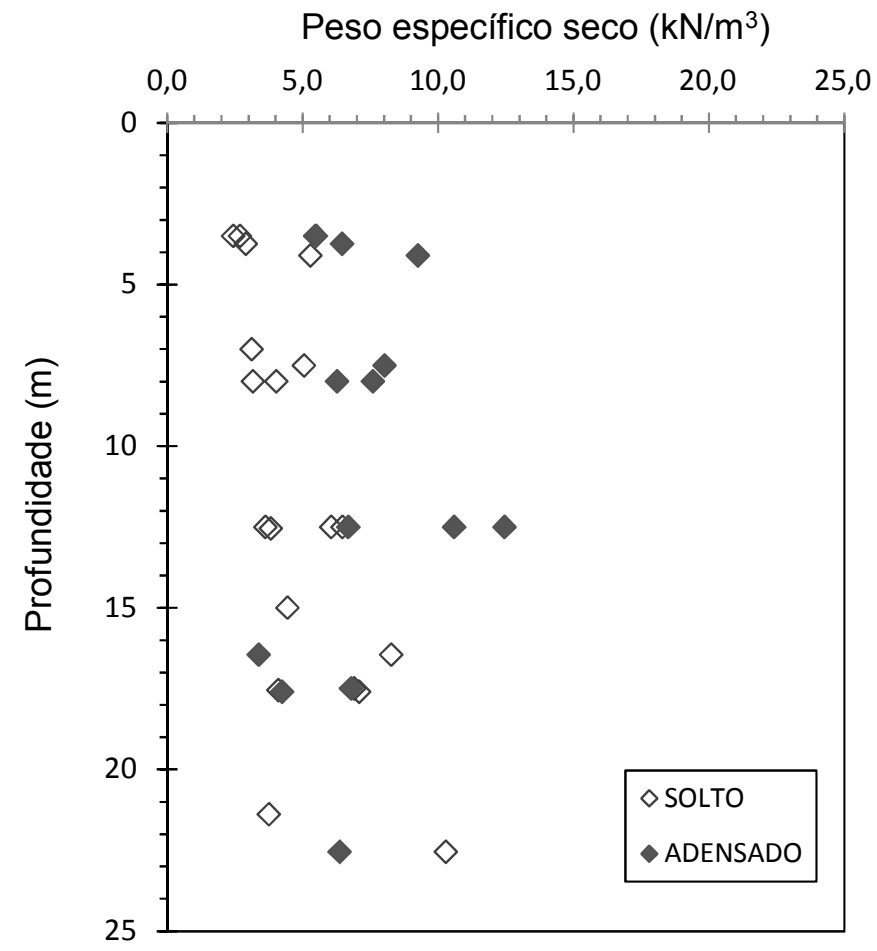

Figura 5.9 - Peso específico seco expedito das amostras coletadas por sondagem no Aterro Sanitário de São Carlos. 
Fração menor que 19mm (\%)

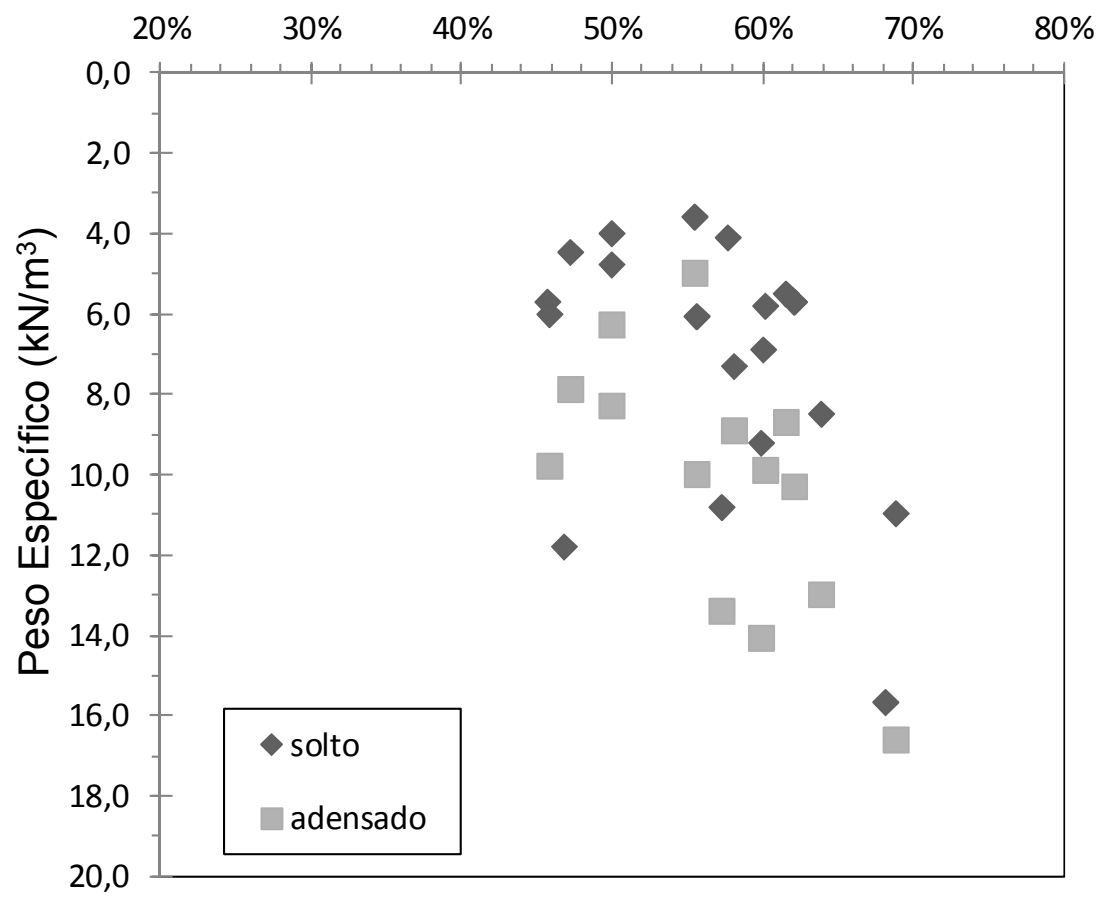

Figura 5.10 - Correlação entre o peso específico determinado por processo expedito e a composição das amostras coletadas por sondagem no Aterro Sanitário de São Carlos.

\subsubsection{Peso específico in situ dos RSU}

$\mathrm{Na}$ Tabela 5.3 são apresentadas as massas das amostras coletadas com sondagens a trado no ASSC. O diâmetro nominal externo do equipamento de perfuração corresponde ao diâmetro do círculo que tangencia as faces externas dos bits da coroa de perfuração e que é alguns centímetros maior que o diâmetro externo das hélices do trado helicoidal. Os furos 1, 2 e 3 foram executados com diâmetro nominal de 35,5 centímetros, enquanto que os furos 4, 5 e 6 foram executados com diâmetro nominal de 29,0 centímetros.

Considerando-se as massas apresentadas na Tabela 5.3 e o diâmetro nominal do equipamento de perfuração, o peso específico in situ dos RSU variou de 6 a $24 \mathrm{kN} / \mathrm{m}^{3}$. A tendência geral é de crescimento com a profundidade, como apresentado na Figura 5.11, porém, os resultados exibem grande dispersão, principalmente a profundidades maiores que 11 metros. A amplitude dos resultados é de $18 \mathrm{kN} / \mathrm{m}^{3}$ e o desvio padrão é de $5 \mathrm{kN} / \mathrm{m}^{3}$. 
Tabela 5.3 - Massa dos resíduos escavados e intervalos considerados para a determinação do peso específico in situ dos RSU.

\begin{tabular}{|c|c|c|c|}
\hline Sondagem & $\begin{array}{l}\text { Diâmetro nominal } \\
\text { da perfuração (m) }\end{array}$ & Trecho ensaiado (m) & $\begin{array}{c}\text { Massa dos resíduos } \\
\text { no intervalo }(\mathrm{kg})\end{array}$ \\
\hline \multirow{4}{*}{ F-1 } & \multirow{4}{*}{0,355} & 6,0 a 9,0 & 320,5 \\
\hline & & 11,0 a 14,0 & 447,9 \\
\hline & & 16,0 a 19,0 & 632,7 \\
\hline & & 21,0 a 24,8 & 909,1 \\
\hline \multirow{5}{*}{$\mathrm{F}-2$} & \multirow{5}{*}{0,355} & 3,0 a 4,5 & 105,4 \\
\hline & & 6,0 a 9,0 & 387,8 \\
\hline & & 11,0 a 14,0 & 394,8 \\
\hline & & 16,2 a 19,0 & 527,8 \\
\hline & & 21,0 a 24,1 & 712,1 \\
\hline \multirow{4}{*}{ F-3 } & \multirow{4}{*}{0,355} & 3,0 a 5,2 & 198,8 \\
\hline & & 7,0 a 8,9 & 210,4 \\
\hline & & 11,0 a 14,0 & 497,3 \\
\hline & & 16,0 a 16,9 & 150,9 \\
\hline \multirow{4}{*}{ F-4 } & \multirow{4}{*}{0,290} & 2,0 a 5,0 & 171,0 \\
\hline & & 7,0 a 9,0 & 144,4 \\
\hline & & 11,0 a 14,0 & 243,5 \\
\hline & & 16,0 a 19,0 & 291,4 \\
\hline \multirow{9}{*}{ F-5 } & \multirow{9}{*}{0,290} & 2,0 a 5,0 & 119,2 \\
\hline & & 5,0 a 7,0 & 139,1 \\
\hline & & 7,0 a 9,0 & 166,6 \\
\hline & & 9,0 a 11,0 & 113,6 \\
\hline & & 11,0 a 14,1 & 278,1 \\
\hline & & 14,1 a 16,0 & 309,4 \\
\hline & & 16,0 a 19,1 & 231,4 \\
\hline & & 19,1 a 21,1 & 149,4 \\
\hline & & 21,1 a 21,7 & 82,5 \\
\hline \multirow{5}{*}{ F-6 } & \multirow{5}{*}{0,290} & 2,0 a 5,0 & 175,2 \\
\hline & & 5,0 a 9,0 & 293,6 \\
\hline & & 9,0 a 14,0 & 364,3 \\
\hline & & 14,0 a 16,0 & 79,4 \\
\hline & & 16,0 a 20,9 & 448,1 \\
\hline
\end{tabular}




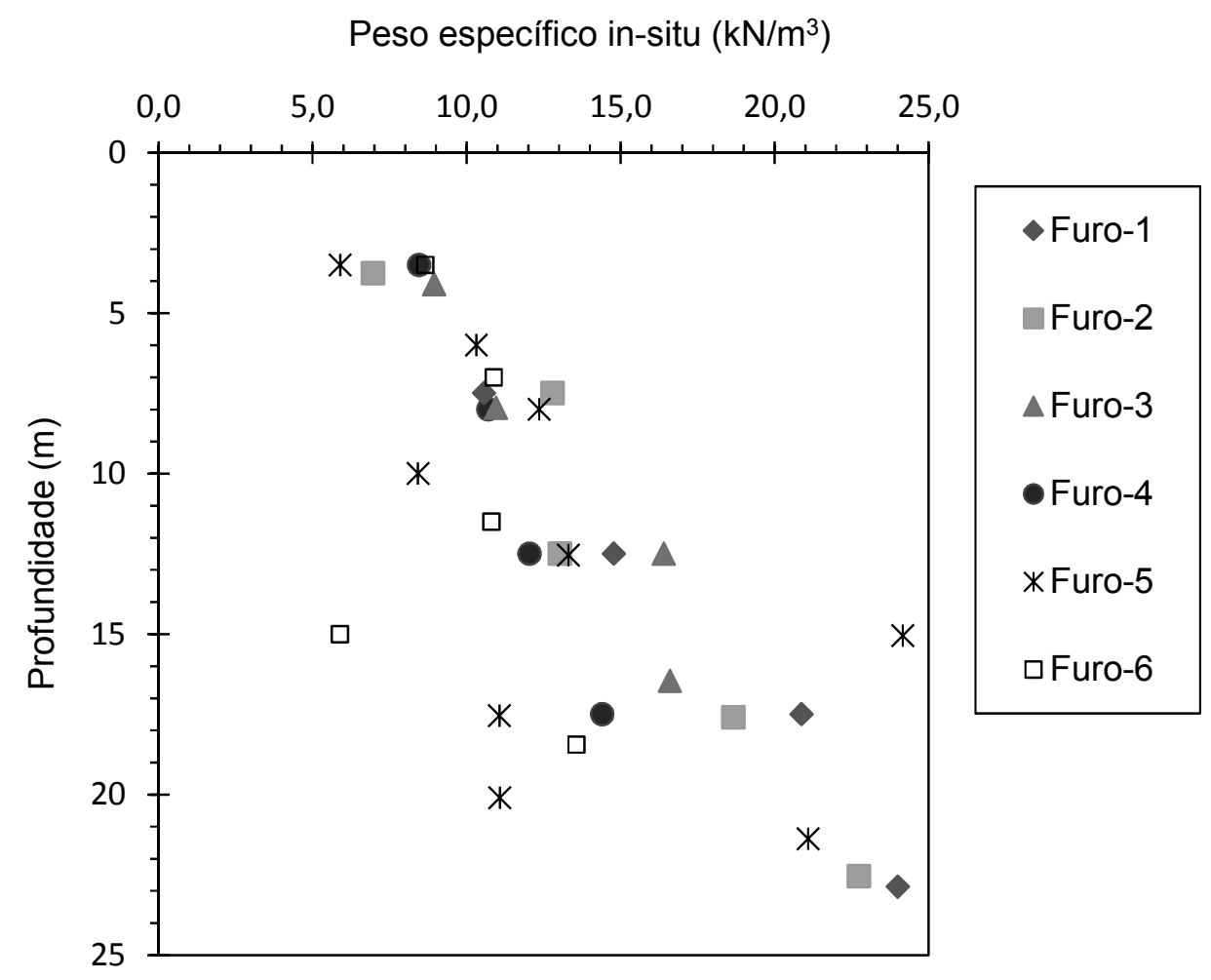

Figura 5.11 - Peso específico in situ dos RSU no Aterro Sanitário de São Carlos.

Entretanto, verificou-se que existe um aspecto relacionado ao método de perfuração que compromete a confiabilidade desses resultados. Como os RSU são materiais relativamente moles, com componentes resistentes à tração, tais como plásticos e tecidos, durante a operação de avanço do furo a composição de sondagem é capaz de sobreescavar o material atravessado. Acredita-se que esta sobreescavação possa ocorrer tanto nas paredes laterais do furo de sondagem, quanto no fundo do furo. Esse "sobre-avanço" ou sobreescavação do fundo do furo de sondagem não foi quantificado para cada intervalo de amostragem. Apenas no final da perfuração se realizou uma medida do comprimento total do furo por dentro da haste oca do trado. A Tabela 5.4 apresenta o comprimento total da composição de sondagem, que corresponde à soma dos comprimentos de todos os segmentos de hélice mais a altura da coroa de perfuração que estavam colocados dentro do furo de sondagem, e o comprimento total do furo, medido com trena (precisão centimétrica), ao término da etapa de avanço da perfuração.

Essa diferença é pequena se considerarmos o comprimento total do furo (máximo de $1,4 \%$ no furo 5 ), porém ela se torna muito significativa quando se consideram intervalos discretos com poucos metros de comprimento. Por exemplo, para intervalos com comprimento de 3 metros uma diferença de $0,3 \mathrm{~m}$ representa $10 \%$. A profundidade que define os intervalos de amostragem foi sempre definida por medidas realizadas na composição de 
sondagem, e não por medidas realizadas diretamente no fundo no furo, retirando-se a sapata cortante para a realização de medidas diretas por centro da haste oca no início e no fim de cada intervalo de amostragem.

Tabela 5.4 - "Sobre-avanço" medido nos furos de sondagem

\begin{tabular}{cccc}
\hline Furo de sondagem & $\begin{array}{c}\text { Comprimento da } \\
\text { composição }(\mathrm{m})\end{array}$ & $\begin{array}{c}\text { Comprimento do furo } \\
(\mathrm{m})\end{array}$ & Diferença(m) \\
\hline Furo 1 & 24,50 & 24,70 & $+0,20$ \\
Furo 2 & 24,00 & 24,10 & $+0,10$ \\
Furo 3 & 16,80 & 16,90 & $+0,10$ \\
Furo 4 & 21,00 & 21,20 & $+0,20$ \\
Furo 5 & 21,40 & 21,70 & $+0,30$ \\
Furo 6 & 20,90 & 20,90 & 0,0 \\
\hline
\end{tabular}

Da forma como se procedeu em campo, não foram obtidas medidas precisas da profundidade do furo para cada intervalo de amostragem. Além disso, os erros de medida provavelmente não foram sistemáticos. Isso se reflete na alternância de valores de peso específico muito elevados, seguidos de valores muito baixos, como se verificou para os furos 5 e 6, onde todo o material extraído da perfuração foi pesado (ver Figura 5.11).

Dessa forma, concluiu-se que o método empregado para perfuração não é adequado para a determinação do peso específico em intervalos discretos, alternados e de pequena extensão, mas permite o cálculo de valores médios caso todo o material extraído da perfuração seja pesado e caso sejam considerados intervalos de amostragem mais extensos.

Considerando-se o diâmetro nominal dos furos de sondagem, para o furo 5 o peso específico médio entre 2 e 11 metros de profundidade foi $9 \mathrm{kN} / \mathrm{m}^{3}$ e entre 11 e 21,7 metros de profundidade, $15 \mathrm{kN} / \mathrm{m}^{3}$. Para o furo 6 , entre 2 e 9 metros de profundidade o peso específico médio do maciço de RSU foi de $10 \mathrm{kN} / \mathrm{m}^{3}$ e entre 9 e 20,9 metros de profundidade, $11 \mathrm{kN} / \mathrm{m}^{3}$. Os resíduos coletados no furo 6 estavam menos úmidos que os resíduos coletados no furo 5, o que deve explicar a diferença nos valores médios de peso específico observada nos dois furos para as profundidades maiores.

Nestes dois furos pesou-se também o material que saia da perfuração durante a operação de retirada da haste do furo de sondagem (segunda etapa da execução das sondagens). No furo 5 foram pesados $98 \mathrm{~kg}$, o que corresponde a $6,7 \%$ do total retirado durante o avanço do furo. No furo 6 foram pesados $168 \mathrm{~kg}$, ou seja, 12,3\% do total retirado durante o avanço do furo. Não se pode precisar se este material foi removido das paredes durante a operação de subida 
da composição de sondagem ou se ele foi escavado durante o avanço do furo e, neste caso, se a remoção ocorreu de forma distribuída ou concentrada, por exemplo, do último intervalo de perfuração. Esses valores não foram considerados no cálculo dos pesos específicos, mas podem influenciar os resultados de forma significativa, se a remoção tiver ocorrido durante a fase de avanço do furo.

Diversos autores (Carvalho, 1999, Gachet et al., 1998, Zekkos et al, 2006) afirmam que a determinação do peso específico de RSU in situ em profundidade está sujeita a incertezas, principalmente quanto ao volume da cavidade que foi efetivamente escavada. Essa discussão não se refere simplesmente ao que foi exposto acima e que é mais específico para os casos de sondagens realizadas com trados de haste oca, para o qual se usa uma coroa dentada na ponta do trado. Ela contempla todos os tipos de equipamentos de sondagem ou amostragem que atuam em maciços de RSU (trados caçamba, trados helicoidas, sondagens rotativas, entre outros) e está relacionada com o fato de que os resíduos possuem componentes resistentes à tração, que podem ser "arrancados" do maciço, causando uma "sobreescavação". Uma das formas proposta por alguns desses grupos de pesquisa para a superação dessa dificuldade é a execução de ensaios com substituição de volume. Isso foi o que se pretendeu realizar nessa pesquisa, pela inserção de brita "pré-calibrada" na perfuração, no momento em que a haste do trado era sacada.

O volume escavado, determinado por esse método, corresponde a um intervalo de valores prováveis, pois não se sabe ao certo qual é a massa específica que a brita tem dentro do furo de sondagem. Trabalhou-se com valores máximos e mínimos $\left(1.400\right.$ e $\left.1.808 \mathrm{~kg} / \mathrm{m}^{3}\right)$, determinados experimentalmente como apresentado no item 5.1.5.1. Por outro lado é possível conhecer com precisão a altura da brita dentro do furo de sondagem, pois a mesma é medida de forma direta com uma trena a partir da superfície. Nas Figuras 5.12 a 5.17 são apresentados os resultados dos diâmetros "aparentes" calculados para as seis sondagens executadas no ASSC.

Comparando-se os valores médios do diâmetro "aparente" aos diâmetros nominais da perfuração é possível estimar os comprimentos em que houve tendência de diminuição do diâmetro da perfuração. A Tabela 5.5 apresenta estes dados. No geral, em $84 \%$ do comprimento ensaiado os resultados sugerem que houve diminuição do diâmetro do furo. Em $9 \%$ ele parece ter se mantido, enquanto que em $7 \%$ ele parece ter sido alargado. 


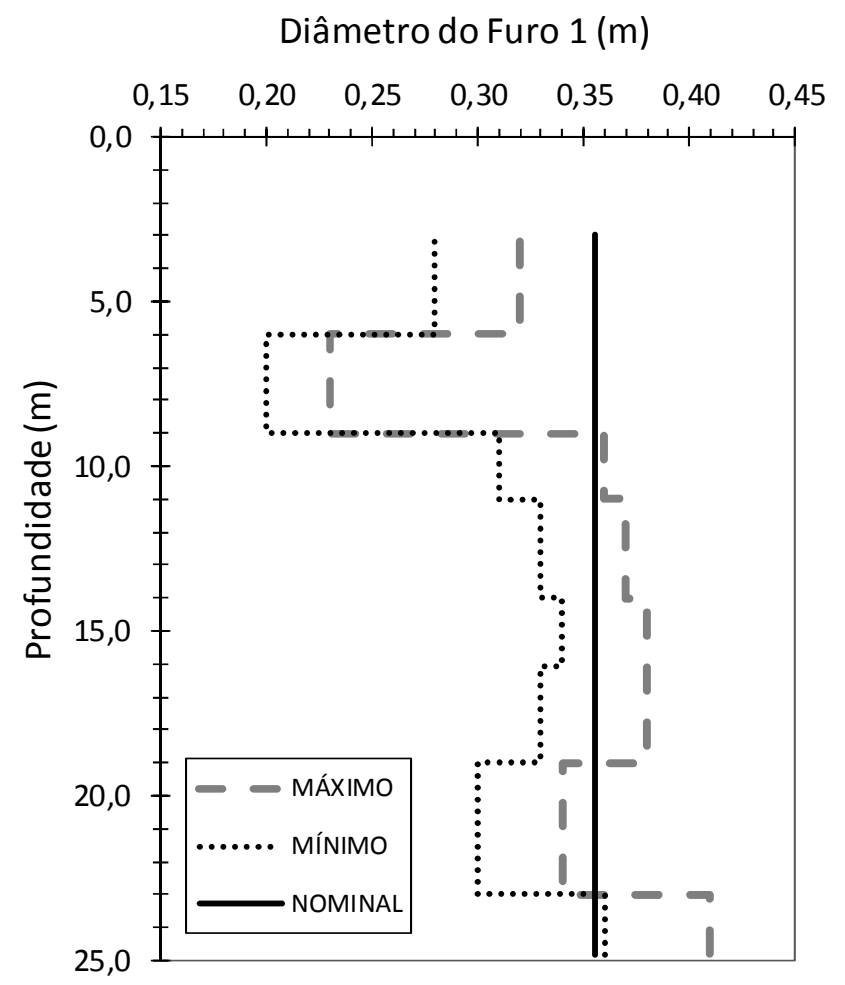

Figura 5.12 - Diâmetros nominal e "aparente" do furo de sondagem 1.

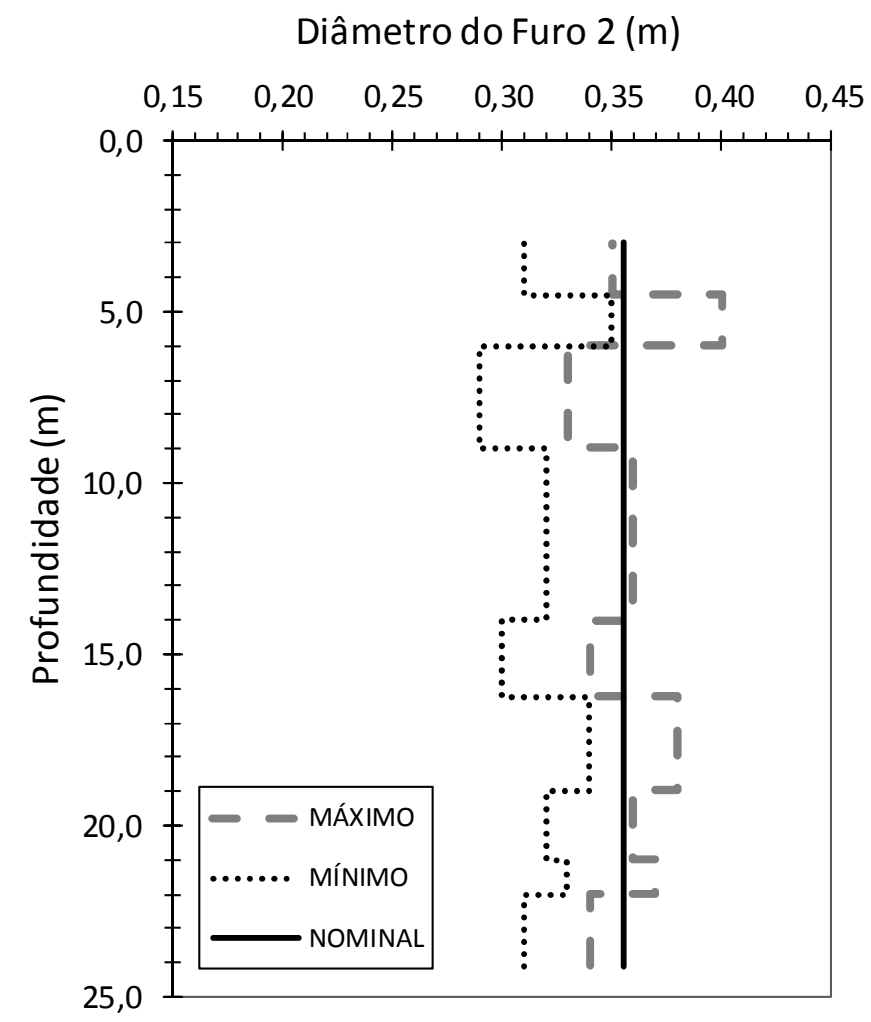

Figura 5.13 - Diâmetros nominal e "aparente" do furo de sondagem 2. 


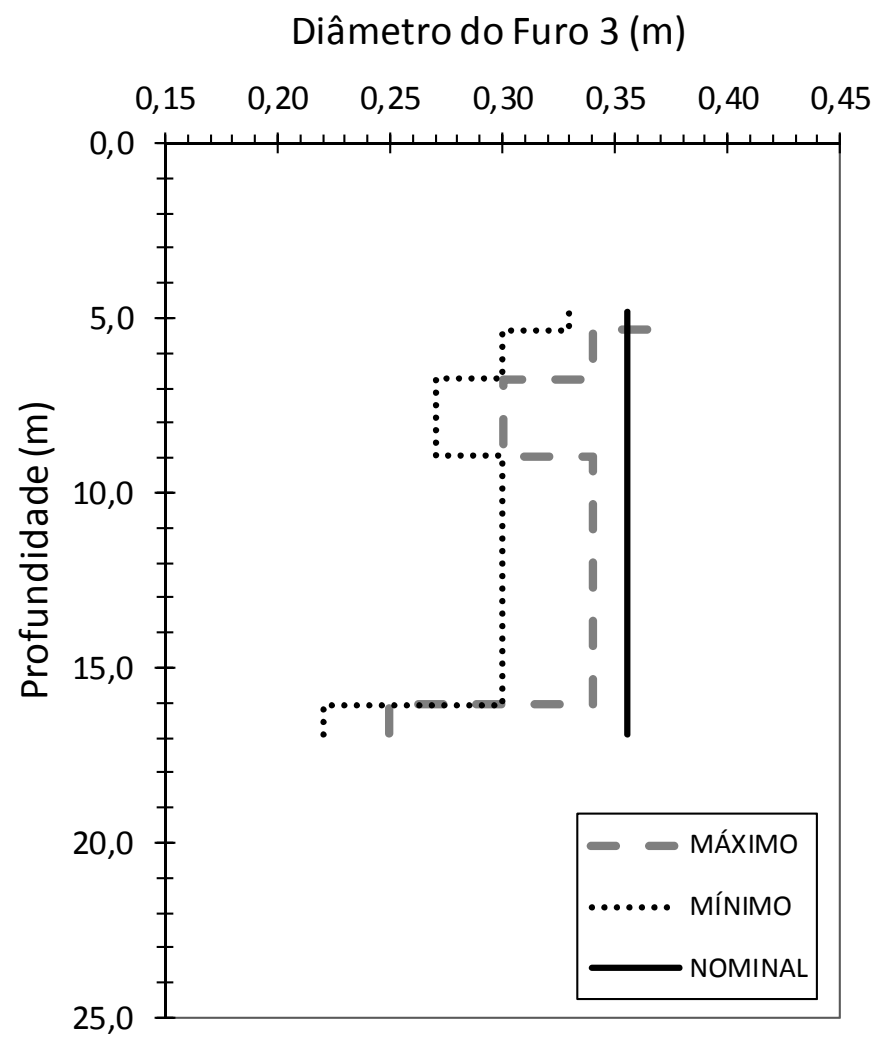

Figura 5.14 - Diâmetros nominal e "aparente" do furo de sondagem 3.

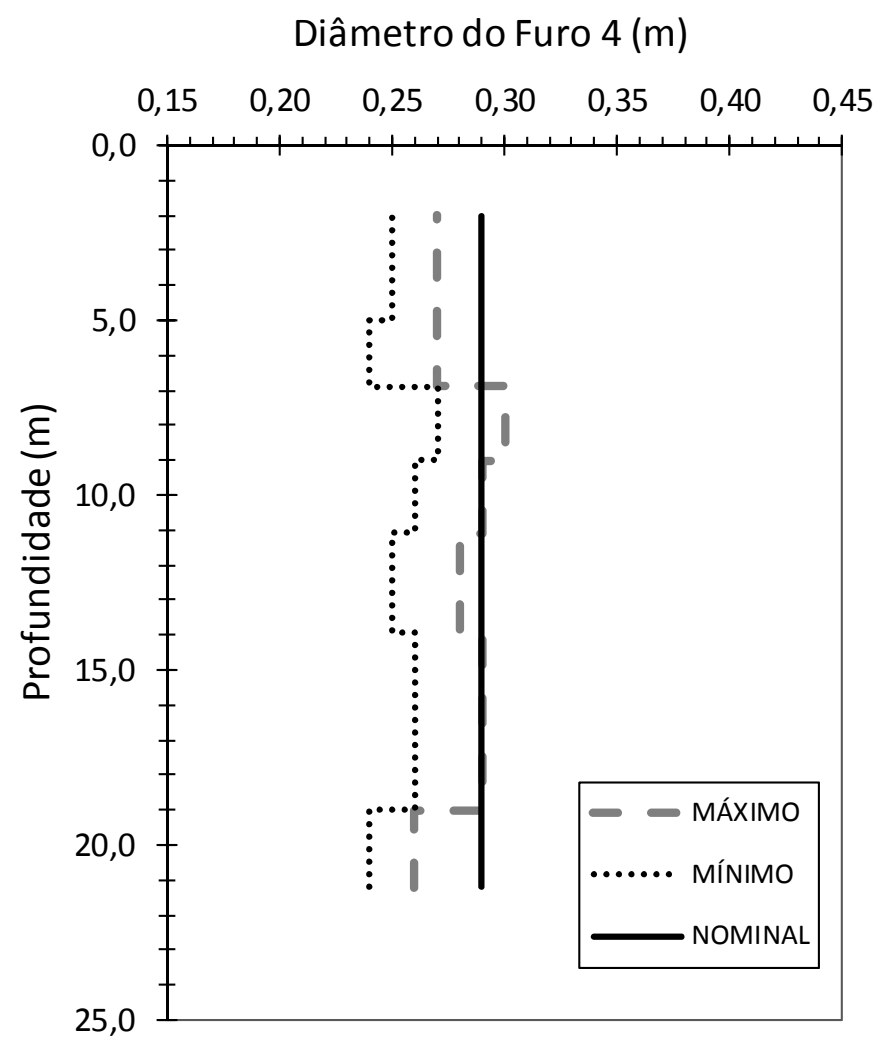

Figura 5.15 - Diâmetros nominal e "aparente" do furo de sondagem 4. 


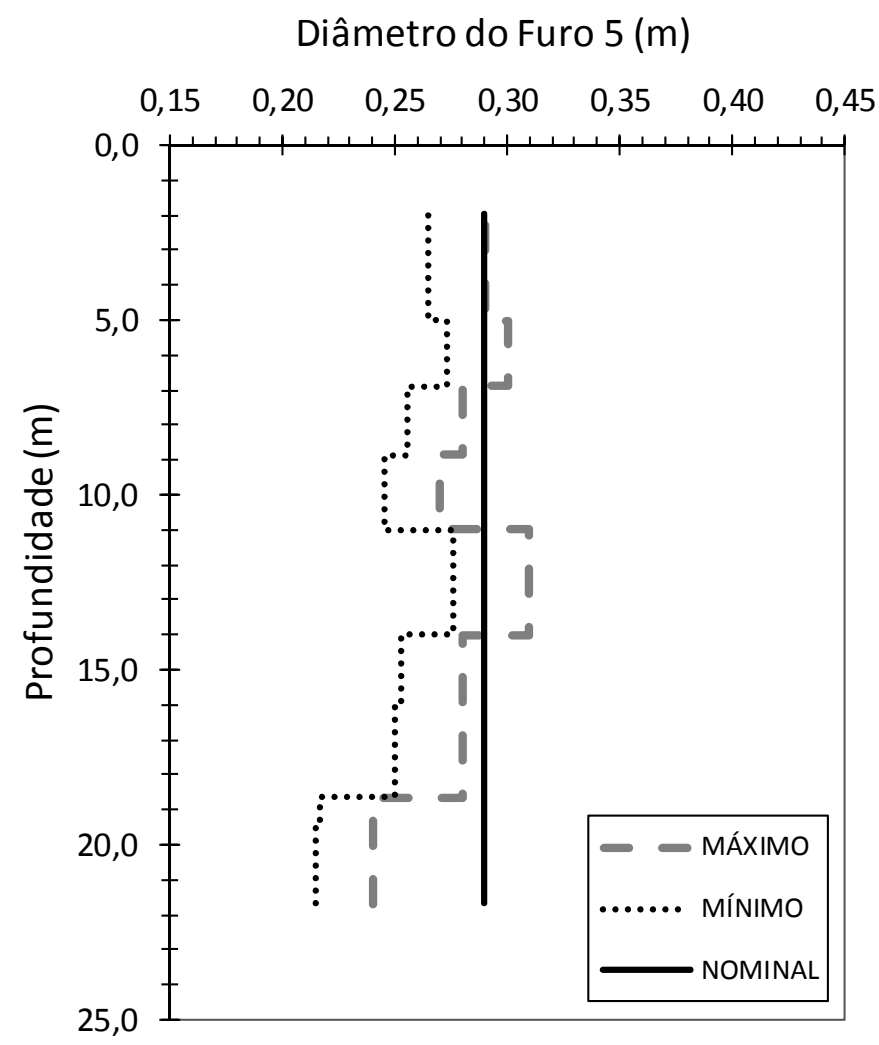

Figura 5.16 - Diâmetros nominal e "aparente" do furo de sondagem 5.

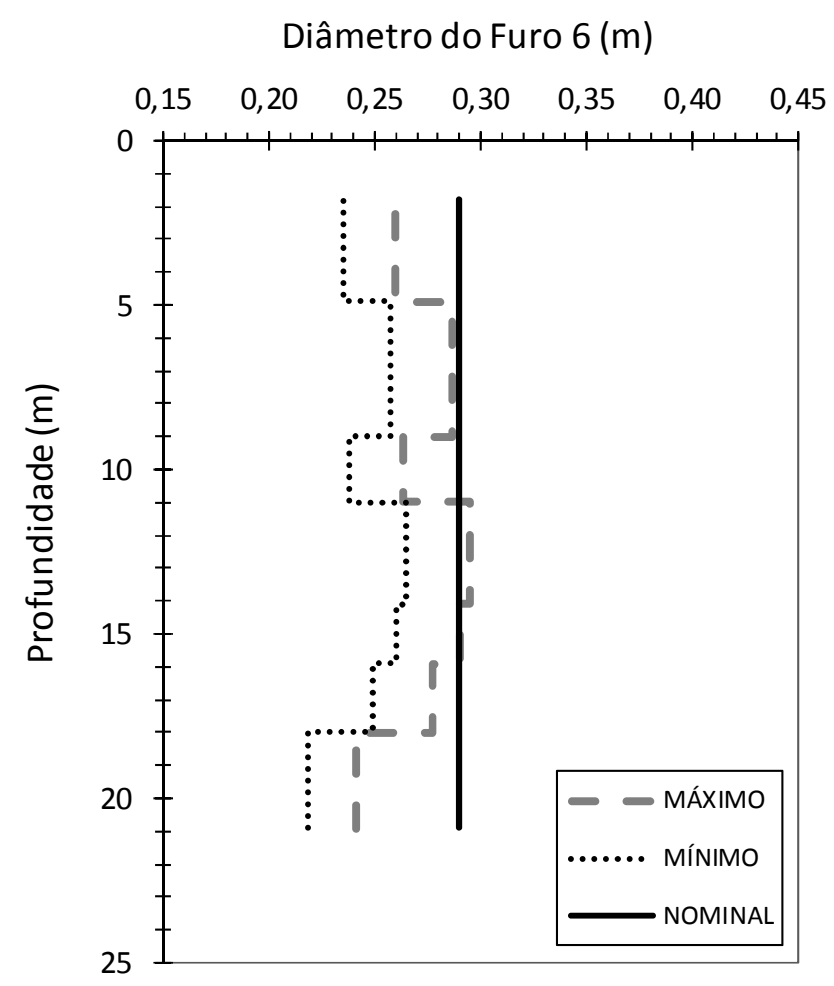

Figura 5.17 - Diâmetros nominal e "aparente" do furo de sondagem 6. 
Tabela 5.5 - Comparação entre os diâmetros "aparente" e nominal, expressa em comprimento de sondagem.

\begin{tabular}{ccccc}
\hline \multirow{2}{*}{ Sondagem } & \multicolumn{4}{c}{ Comprimento $(\mathrm{m})$} \\
\cline { 2 - 5 } & Ensaiado & Maior & Menor & Igual \\
\hline Furo 1 & 21,8 & 3,9 & 15,0 & 2,9 \\
Furo 2 & 21,1 & 4,3 & 16,9 & 0,0 \\
Furo 3 & 12,1 & 0,0 & 12,1 & 0,0 \\
Furo 4 & 19,2 & 0,0 & 17,1 & 2,1 \\
Furo 5 & 19,8 & 0,0 & 14,9 & 4,9 \\
Furo 6 & 19,1 & 0,0 & 19,1 & 0,0 \\
Total & 113,0 & 8,1 & 95,0 & 9,9 \\
\hline
\end{tabular}

Constatou-se que o diâmetro calculado pelo método de substituição de volume resultava menor do que o diâmetro nominal do furo, com poucas exceções. Apesar de o intervalo de tempo entre a remoção do trado e a inserção da brita ser pequeno (cerca de 15 minutos), ele era suficiente para que as paredes do furo convergissem e tendessem a reduzir seu diâmetro.

No furo 1 chama a atenção o intervalo entre 6 e 9 metros de profundidade, para o qual o diâmetro do furo se reduz muito mais do que no restante do furo. Este intervalo reflete o comportamento da camada de RSU co-disposto com lodo de estação de tratamento de esgotos, que foi atravessada por esta sondagem entre 7 e 10 metros de profundidade. $\mathrm{Na}$ Figura 5.18 vê-se a consistência deste material ao chegar à superfície durante o avanço do furo.

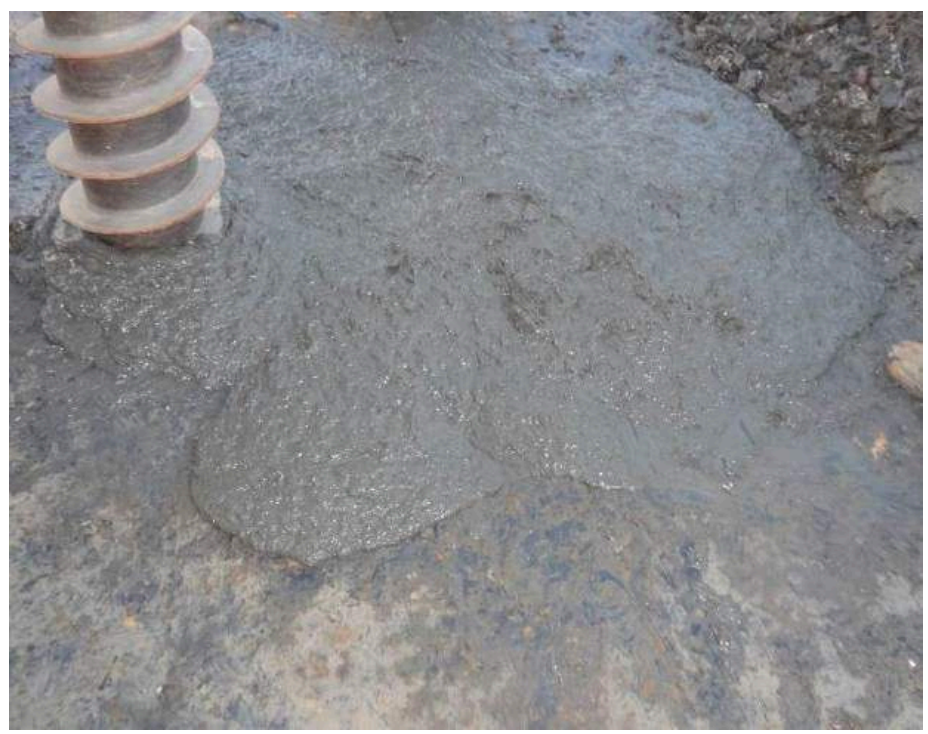

Figura 5.18 - Aspecto de trecho de RSU co-disposto com lodo de estação de tratamento de esgotos assim que chega à superfície - furo 1, entre 7,0 e 10,0 metros de profundidade. 
$\mathrm{Na}$ Tabela 5.6 são apresentados os pesos específicos médios para os furos 5 e 6 , calculados com os diâmetros "aparentes" e nominal, para efeito de comparação.

Tabela 5.6 - Peso específico in-situ médio calculado para os RSU nas sondagens 5 e 6 , considerando os diâmetros "aparentes" e nominal dos furos de sondagem.

\begin{tabular}{ccccc}
\hline \multirow{2}{*}{ Sondagem } & $\begin{array}{c}\text { Intervalo de } \\
\text { profundidade } \\
(\mathrm{m})\end{array}$ & $\begin{array}{c}\text { Considerando diâmetro } \\
\text { "aparente " máximo }\end{array}$ & $\begin{array}{c}\text { Considerando diâmetro } \\
\text { "aparente " mínimo }\end{array}$ & $\begin{array}{c}\text { Considerando } \\
\text { diâmetro } \\
\text { nominal }\end{array}$ \\
\hline \multirow{2}{*}{5} & $2,0-21,7$ & 13 & 16 & 12 \\
& $2,0-11,0$ & 9 & 11 & 9 \\
& $11,0-21,7$ & 16 & 20 & 15 \\
\hline \multirow{2}{*}{6} & $2,0-20,9$ & 12 & 15 & 11 \\
& $2,0-9,0$ & 11 & 14 & 10 \\
\hline
\end{tabular}

Dificuldades na aplicação do método de substituição de volume já haviam sido relatadas por outros pesquisadores. Por exemplo, Carvalho (1999) verificou grande redução do diâmetro da perfuração ao realizar a substituição de volume com calda de bentonita algumas horas depois de aberto o furo. Yu et al. (2011) tentaram aplicar o método de substituição de volume no aterro de Colls Cardú, na Espanha, utilizando uma perfuratriz do tipo bucket-auger (trado concha) de grande diâmetro e brita para preenchimento da cavidade, porém os autores obtiveram sucesso parcial apenas. Depois que o nível de líquidos lixiviados foi atingido em uma das duas perfurações o ensaio não pôde mais ser executado. GeoSyntech (1996b, apud Matasovich e Kavazanjian, 1998) também relata dificuldades na utilização desse método no Aterro OII na Califórnia, principalmente em intervalos onde havia líquidos percolando para dentro da perfuração com uma velocidade relativamente elevada.

Por outro lado, alguns autores relatam a aplicação do método de substituição de volume em aterros sanitários com sucesso, a saber: Zornberg et al. (1999), Zekkos et al. (2006) e Matasovich e Kavazanjian (1998). Yu et al. (2011) relatam que não se verificou sobreescavação do furo no trecho não saturado do maciço de Coll Cardú, enquanto Matasovich e Kavazanjian (1998) consideraram sobreescavação uniforme de 16\% no Aterro OII.

A umidade dos RSU no Aterro Sanitário de São Carlos é mais elevada que a umidade da maioria dos aterros em que os ensaios de determinação do peso específico in situ por 
substituição de volume foram executados. Por exemplo, no Aterro de Azuza a umidade dos RSU variou de 7 a 52\% (Zornberg et al., 1999) e no Aterro de Cherry Island ela variou de 20 a 50\% (GeoSynthec, 2003, apud Zekkos et al., 2006). No Aterro de Coll Cardú (Yu et al, 2011) a umidade das partículas menores que $15 \mathrm{~mm}$ variou de 18,5 a $27,9 \%$. No Aterro de TriCities a umidade das partículas com menos que 20mm era de 12 a 25\% (Zekkos et al., 2006) e no Aterro OII ela variou de 15 a 41\%, para as partículas de mesma dimensão (Matasovich e Kavazanjian, 1998). Por outro lado, Carvalho (1999) determinou umidades entre 46 e $110 \%$ no Aterro Bandeirantes. Não está claro se nos estudos relatados para os aterros de Cherry Island, OII e Coll Cardú os valores de umidade informados foram calculados com base seca ou com base úmida.

Acredita-se que em maciços de RSU mais úmidos, como é o caso do Aterro Sanitário de São Carlos e do Aterro Bandeirantes, o método de substituição de volume não seja capaz de detectar eventuais sobreescavações nas paredes que ocorram durante a fase de avanço do furo, pois o mesmo tende a fechar, assim que o trado (ou o revestimento) é retirado da escavação.

\subsubsection{Ensaio de penetração dinâmica}

A Figura 5.19 exibe os resultados dos ensaios de penetração dinâmica. Verifica-se que as sondagens atingiram pequenas profundidades (5,8 e 8,0 metros), não sendo capazes de atravessar a camada superior de resíduos identificada nos ensaios geofísicos como tendo espessura de 11 metros. Nas duas investigações ocorreram desvios da composição de sondagem em relação à vertical, o que impedia a continuidade da cravação da ponteira. $\mathrm{Na}$ primeira sondagem foi possível recuperar toda a composição e verificou-se que a última haste havia entortado. Na segunda sondagem parte das hastes e a ponteira não puderam ser recuperados. Os resultados do ensaio de penetração em si $\left(\mathrm{N}_{20}\right)$ foram bastante dispersos (Figura 5.19), de forma semelhante ao que ocorre no ensaio SPT, quando executado em aterros sanitários. 


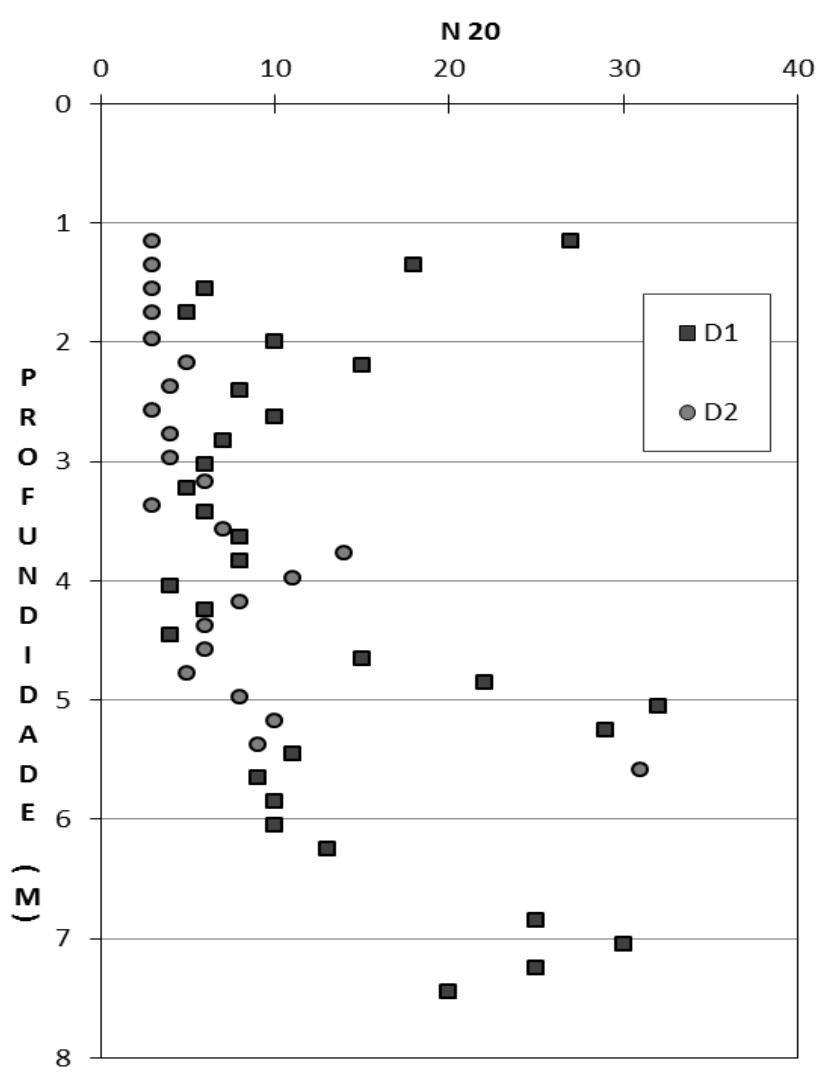

Figura 5.19 - Resultados do ensaio de penetração com DPSH.

\subsubsection{Ensaios geofísicos}

\subsubsection{Ensaios crosshole}

Os resultados desses ensaios são apresentados nas Tabelas 5.7 e 5.8 e na Figura 5.20 para as velocidades de propagação das ondas S (cisalhantes) e P (compressionais).

Pode-se dividir o maciço de resíduos em dois pacotes: o pacote superior, situado em profundidades até 11 metros e que corresponde aos resíduos aterrados em 2007 e em 2011, e o pacote inferior, situado em profundidades maiores que 11 metros e que corresponde aos resíduos aterrados em 2004 e anteriormente.

No pacote superior as velocidades de propagação das ondas $\mathrm{S}$ variaram de 92 a $168 \mathrm{~m} / \mathrm{s}$ (amplitude de $76 \mathrm{~m} / \mathrm{s}$ ), com média de $125 \mathrm{~m} / \mathrm{s}$ e desvio padrão de $19 \mathrm{~m} / \mathrm{s}$, e no pacote inferior essas velocidades estiveram compreendidas entre 126 e $214 \mathrm{~m} / \mathrm{s}$ (amplitude de $88 \mathrm{~m} / \mathrm{s}$ ), com média de $165 \mathrm{~m} / \mathrm{s}$ e desvio padrão de $24 \mathrm{~m} / \mathrm{s}$. 
Tabela 5.7 - Velocidades de onda P determinadas nos ensaios crosshole

\begin{tabular}{ccccc}
\hline Profundidade $(\mathrm{m})$ & $\mathrm{CH} 2-5$ & $\mathrm{CH} 2-6$ & $\mathrm{CH} 5-4$ & $\mathrm{CH} 5-6$ \\
\hline 1 & 279 & 268 & 227 & 272 \\
2 & 197 & 209 & 260 & 240 \\
3 & 275 & 223 & 237 & 198 \\
4 & 279 & 270 & 214 & 236 \\
5 & 287 & 242 & 219 & 238 \\
6 & 289 & 297 & 240 & 228 \\
7 & 281 & 263 & 251 & 270 \\
8 & 285 & 243 & 233 & 214 \\
9 & 293 & 285 & 262 & 207 \\
10 & 281 & 309 & 294 & 267 \\
11 & 314 & 315 & 316 & 311 \\
12 & 333 & 372 & 245 & 322 \\
13 & 411 & 392 & 388 & 308 \\
14 & 438 & 451 & 346 & 318 \\
15 & 403 & 354 & 297 & 286 \\
16 & 317 & 361 & 355 & 272 \\
17 & 335 & 376 & 383 & 301 \\
18 & 293 & 372 & 422 & 292 \\
19 & 376 & 415 & 388 & 304 \\
20 & 347 & 358 & 334 & 292 \\
\hline
\end{tabular}

Tabela 5.8 - Velocidades de onda $\mathrm{S}$ determinadas nos ensaios crosshole

\begin{tabular}{ccccc}
\hline Profundidade $(\mathrm{m})$ & Furos 2-5 & Furos 2-6 & Furos 5-4 & Furos 5-6 \\
\hline 1 & 151 & 131 & 99 & 153 \\
2 & 115 & 92 & 102 & 120 \\
3 & 136 & 99 & 98 & 111 \\
4 & 145 & 114 & 111 & 119 \\
5 & 143 & 98 & 119 & 121 \\
6 & 144 & 125 & 135 & 126 \\
7 & 143 & 109 & 125 & 142 \\
8 & 130 & 97 & 116 & 104 \\
9 & 155 & 120 & 131 & 101 \\
10 & 144 & 122 & 138 & 116 \\
11 & 155 & 126 & 168 & 142 \\
12 & 167 & 153 & 176 & 180 \\
13 & 186 & 164 & 214 & 162 \\
14 & 212 & 187 & 171 & 166 \\
15 & 193 & 151 & 141 & 167 \\
16 & 148 & 138 & 148 & 141 \\
17 & 189 & 143 & - & - \\
18 & 126 & 163 & - & - \\
19 & 205 & 155 & - & - \\
20 & 130 & 142 & - & - \\
\hline & & & &
\end{tabular}



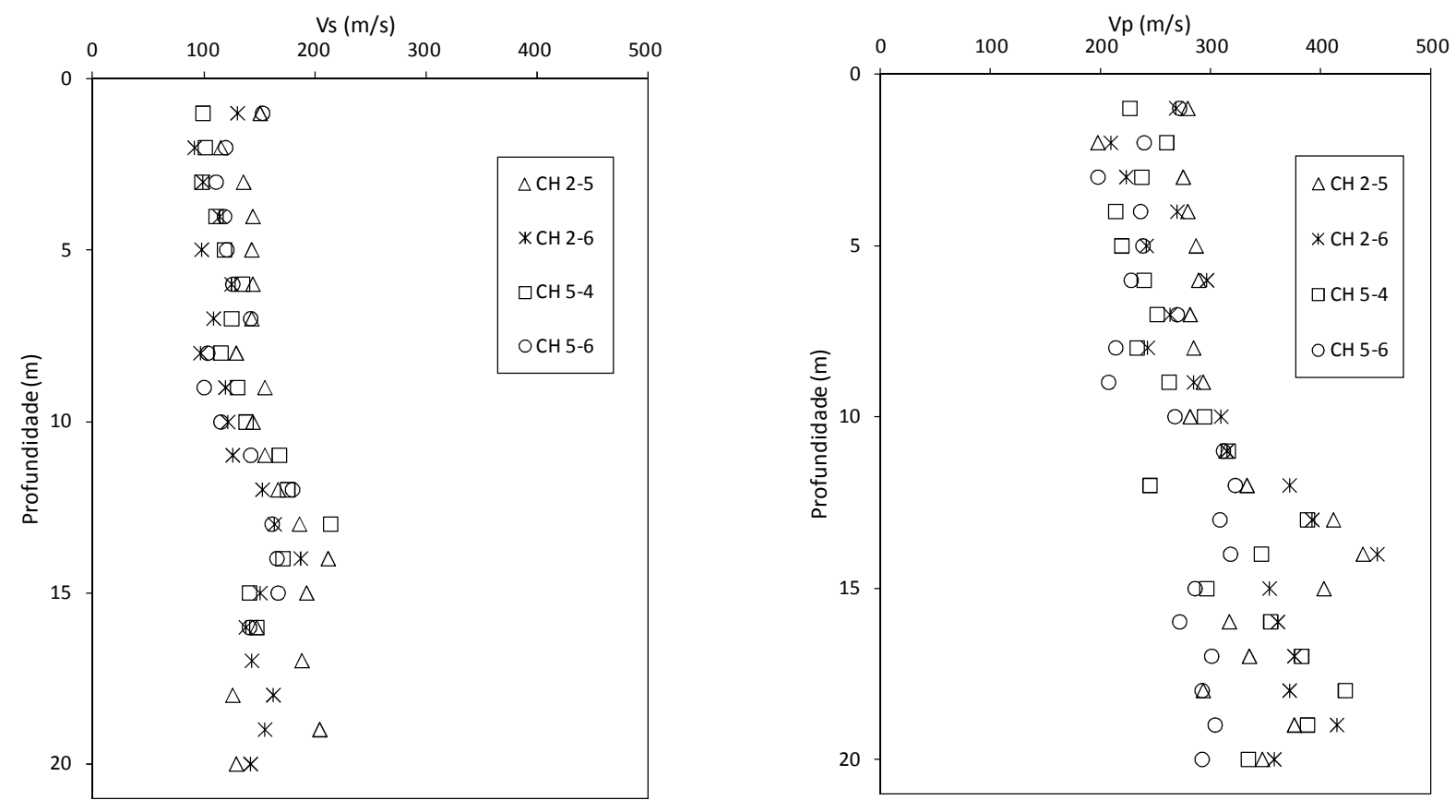

Figura 5.20 - Resultados dos ensaios crosshole (ondas S e P)

Para as ondas $\mathrm{P}$, no pacote superior as velocidades variaram de 197 a $316 \mathrm{~m} / \mathrm{s}$ (amplitude de $119 \mathrm{~m} / \mathrm{s}$ ), com média de $260 \mathrm{~m} / \mathrm{s}$ e desvio padrão de $34 \mathrm{~m} / \mathrm{s}$, enquanto que no pacote inferior as velocidades de propagação das ondas $P$ foram de 245 a $451 \mathrm{~m} / \mathrm{s}$ (amplitude de $206 \mathrm{~m} / \mathrm{s}$ ), com média de $349 \mathrm{~m} / \mathrm{s}$ e desvio padrão de $50 \mathrm{~m} / \mathrm{s}$.

Em ambos os casos verifica-se um aumento das velocidades do pacote superior para o pacote inferior, bem como um aumento da dispersão dos resultados. Essas tendências também foram observadas para o peso específico e para as medidas de temperatura do maciço de RSU nesse aterro sanitário.

As velocidades de propagação de ondas $\mathrm{P}$ medidas nesta pesquisa estão de acordo com os resultados apresentados por Carvalho (1999) e Houston et al. (1995), mas são muito inferiores aos valores relatados por Sharma et al. (1990), como consta da Figura 5.21.

As velocidades de propagação de ondas $\mathrm{S}$ medidas nesta pesquisa estão de acordo com os resultados apresentados por Carvalho (1999) e Castelli e Maugeri (2014), porém são inferiores aos demais resultados, como apresentado na Figura 5.22. 


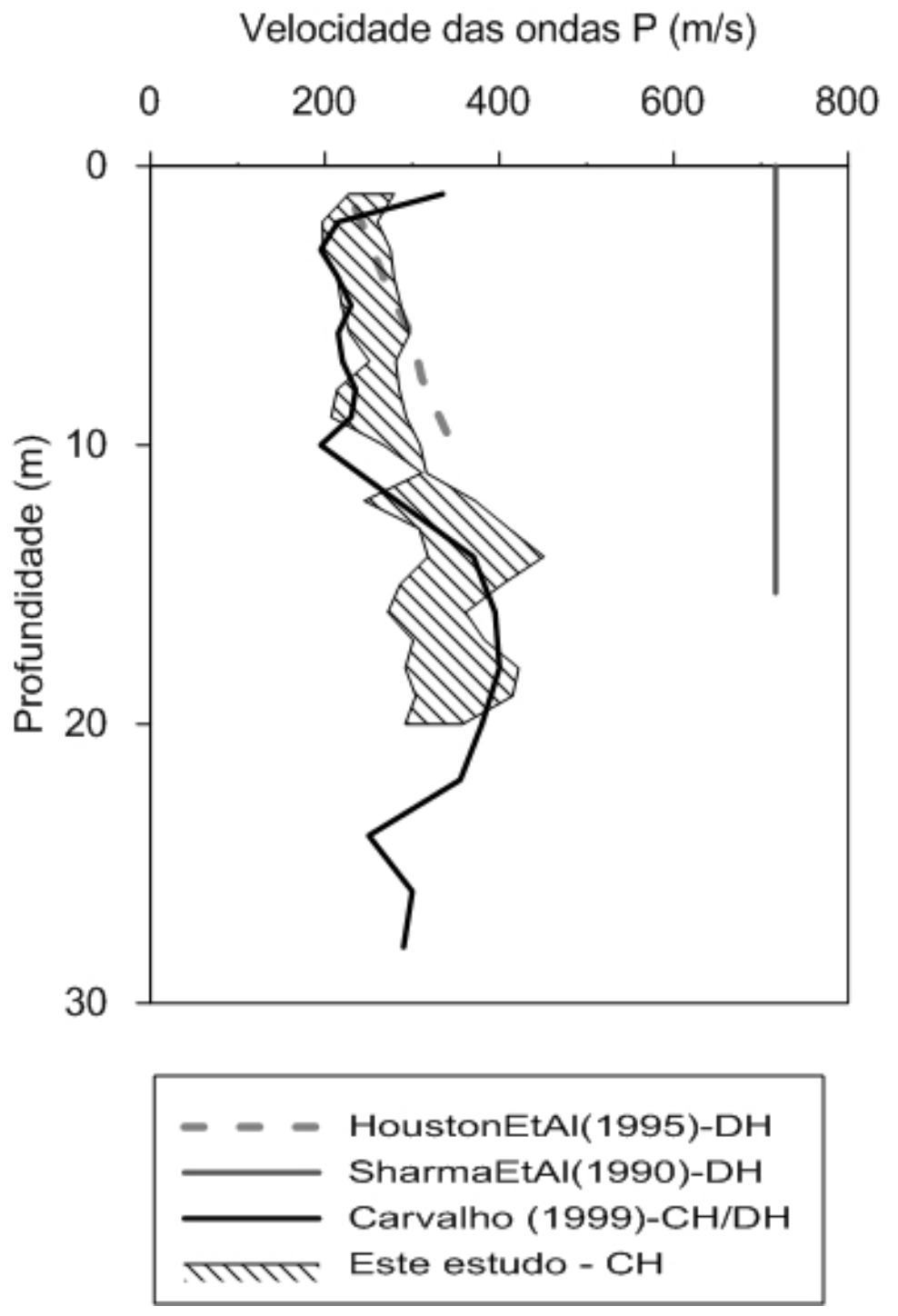

Figura 5.21 - Comparação entre os valores de velocidade de propagação de ondas compressionais $(\mathrm{Vp})$ obtidos nessa pesquisa e aqueles constantes da literatura. 


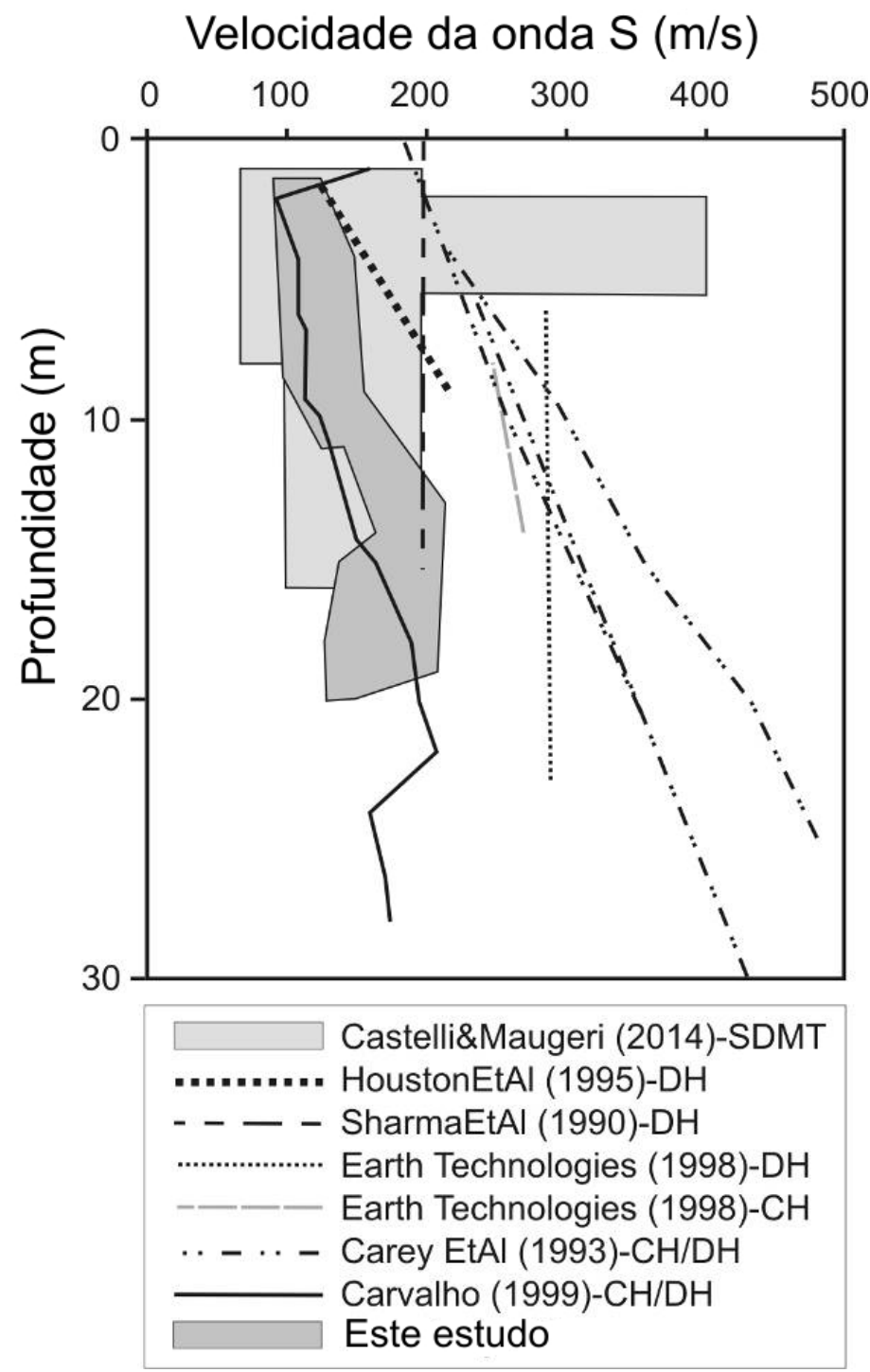

Figura 5.22 - Comparação entre os valores de velocidade de propagação de ondas cisalhantes (Vs) obtidos nos ensaios crosshole e aqueles constantes da literatura (ensaios intrusivos). $\mathrm{DH}=$ downhole, $\mathrm{SDMT}=$ dilatômetro de Marcheti com módulo sísmico, $\mathrm{CH}=$ crosshole.

A partir das velocidades de propagação das ondas S e P e considerando-se a teoria da elasticidade, pode-se calcular o coeficiente de Poisson ( $v$ ) do maciço de RSU para pequenas deformações. Os valores máximo e mínimo calculados foram de 0,24 e 0,42 e o valor médio para o maciço como um todo foi 0,35 . Neste caso não há diferenças significativas entre o pacote superior e o inferior. A Figura 5.23 apresenta a comparação desses valores com aqueles constantes em outros trabalhos sobre o assunto, mostrando a semelhança dos resultados, apesar de que os valores obtidos nessa pesquisa mostrarem, em geral, menor amplitude. 


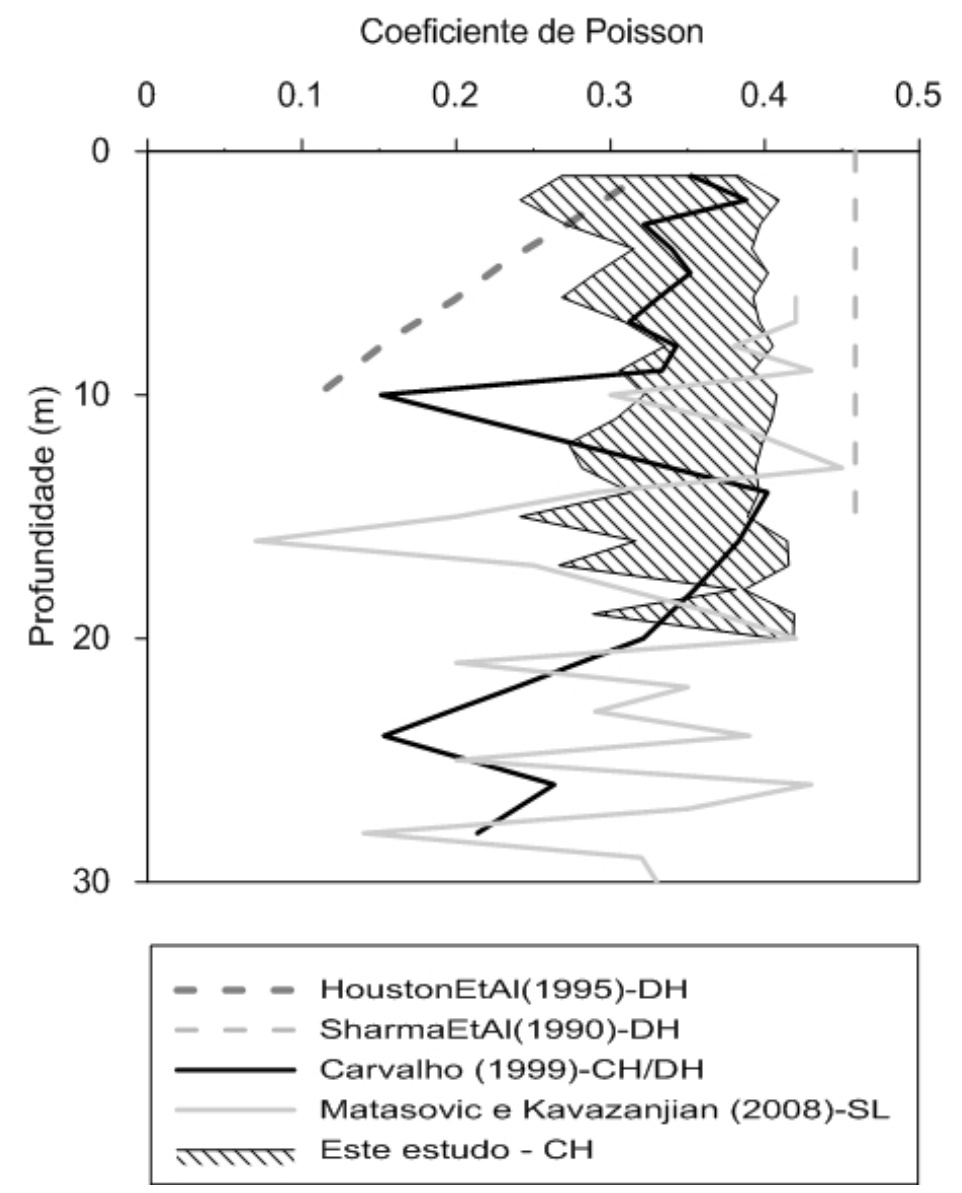

Figura 5.23 - Comparação entre os valores de coeficiente de Poisson obtidos nessa pesquisa e aqueles constantes da literatura. $\mathrm{CH}=$ crosshole; $\mathrm{DH}=$ downhole; $\mathrm{SL}=$ suspension logging.

\subsubsection{Ensaios MASW}

$\mathrm{Na}$ Tabela 5.9 são apresentados os valores de velocidade de propagação da onda cisalhante calculados para cada linha dos ensaios MASW. O valor mínimo foi de $77 \mathrm{~m} / \mathrm{s}$ e o valor máximo foi de $151 \mathrm{~m} / \mathrm{s}$ (amplitude de $74 \mathrm{~m} / \mathrm{s}$ ). No Anexo B são apresentados os sismogramas e as curvas de dispersão para estes ensaios. Como ilustrado na Figura 5.24, os perfis mostram tendência geral de aumento das velocidades de propagação com a profundidade, mas resultaram em velocidades menores que aquelas determinadas pelo método crosshole. Não se percebe nestes perfis uma separação clara entre um estrato superior e um estrato inferior, como ocorre nos resultados do ensaio crosshole.

O fato de o método MASW resultar em velocidades de propagação das ondas S menores que o método crosshole pode ser explicado pelo fato de que os dois métodos trabalham com frequências de ondas diferentes. Nesta pesquisa o método crosshole utilizou frequências entre 30 e $94 \mathrm{~Hz}$, enquanto o método MASW utilizou ondas com frequências entre 5 e $18 \mathrm{~Hz}$. 
Assim, era de se esperar que o método intrusivo resultasse em valores de Vs maiores que os do método MASW, como sugerido por Zekkos et al. (2014).

Tabela 5.9 - Perfis de velocidade de propagação de ondas S (Vs) desenvolvidos a partir dos dados coletados nos ensaios MASW.

\begin{tabular}{cccccc}
\hline LINHA 1 & \multicolumn{3}{c}{ LINHA 2 } & \multicolumn{3}{c}{ LINHA 3 } \\
\hline Prof. $(\mathrm{m})$ & Vs $(\mathrm{m} / \mathrm{s})$ & Prof. $(\mathrm{m})$ & Vs $(\mathrm{m} / \mathrm{s})$ & Prof. $(\mathrm{m})$ & Vs $(\mathrm{m} / \mathrm{s})$ \\
\hline 0 & 91 & 0 & 82 & 0 & 88 \\
0,9 & 80 & 0,9 & 79 & 0,9 & 81 \\
2 & 77 & 2 & 90 & 2 & 79 \\
3,3 & 91 & 3,3 & 100 & 3,3 & 91 \\
4,7 & 94 & 4,7 & 104 & 4,7 & 92 \\
6,4 & 107 & 6,4 & 107 & 6,4 & 105 \\
8,2 & 107 & 8,2 & 104 & 8,2 & 106 \\
10,2 & 130 & 10,2 & 128 & 10,2 & 130 \\
12,4 & 135 & 12,4 & 133 & 12,4 & 134 \\
14,7 & 150 & 14,7 & 151 & 14,7 & 149 \\
17,3 & 150 & 17,3 & 151 & 17,3 & 149 \\
\hline
\end{tabular}

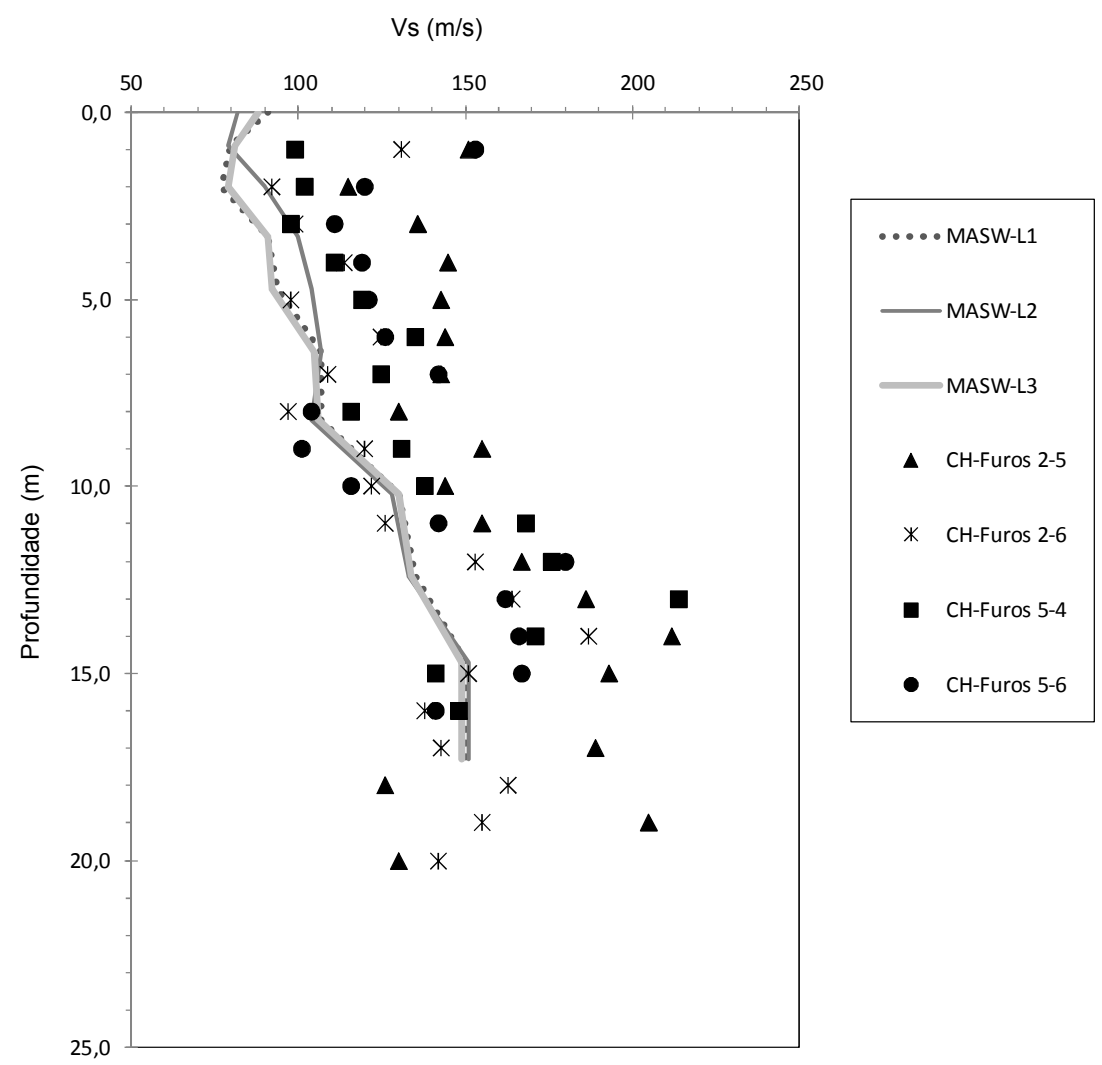

Figura 5.24 - Comparação entre os resultados dos ensaios MASW e crosshole executados no Aterro Sanitário de São Carlos. 
Nas Figuras 5.25 e 5.26 são apresentados os resultados dos ensaios MASW realizados nessa pesquisa e aqueles de outras pesquisas realizadas em aterros sanitários. Verifica-se que os valores de velocidades de propagação de ondas $\mathrm{S}$ determinados pelo método MASW em São Carlos são inferiores àqueles propostos por Kavazanjian et al. (1996), mas estão de acordo com os valores relatados por outros pesquisadores, tais como Zalachoris (2010), Lin et al. (2004), Pereira et al. (2002) e Rix et al. (1998).

\subsubsection{Perfil de Vs para o Aterro Sanitário de São Carlos}

Nos resultados do ensaio crosshole pode-se identificar dois estratos, enquanto que no método MASW a velocidade Vs aumenta continuamente e os resultados não sugerem a divisão do maciço em estratos. Com relação a isso, deve-se considerar que no método crosshole a investigação envolve apenas as camadas que ocorrem entre os dois furos, numa mesma profundidade, enquanto no método MASW o volume amostrado é muito maior e aumenta com a profundidade de investigação. $\mathrm{O}$ método crosshole fornece maior detalhe, mas investiga um volume menor, enquanto o método MASW fornece um resultado mais geral sobre as condições de subsuperfície.

Para o ajuste de uma equação que correlacione os valores de Vs com a profundidade no ASSC, os resultados obtidos para o primeiro metro de profundidade foram desconsiderados, pois estão provavelmente influenciados pela passagem de máquinas para execução das camadas de cobertura do aterro sanitário, quando do seu encerramento em 2011. Esse feito de aumento de Vs nas camadas mais superficiais foi constatado também em outros aterros, como sintetizado por Zekkos et al. (2014).

Essa equação tem o formato proposto por Zekkos et al. (2014) (Eq. (3.5)) e os coeficientes são $\mathrm{V}_{\mathrm{si}}=81 \mathrm{~m} / \mathrm{s}, \alpha_{\mathrm{vs}}=0,08$ e $\beta_{\mathrm{vs}}=0,005$, com $\mathrm{R}^{2}=99 \%$. Este ajuste é apresentado na figura 5.27, juntamente com as curvas para valores médios propostas por Choudhury e Savoikar (2009) e por Zekkos et al. (2014). 


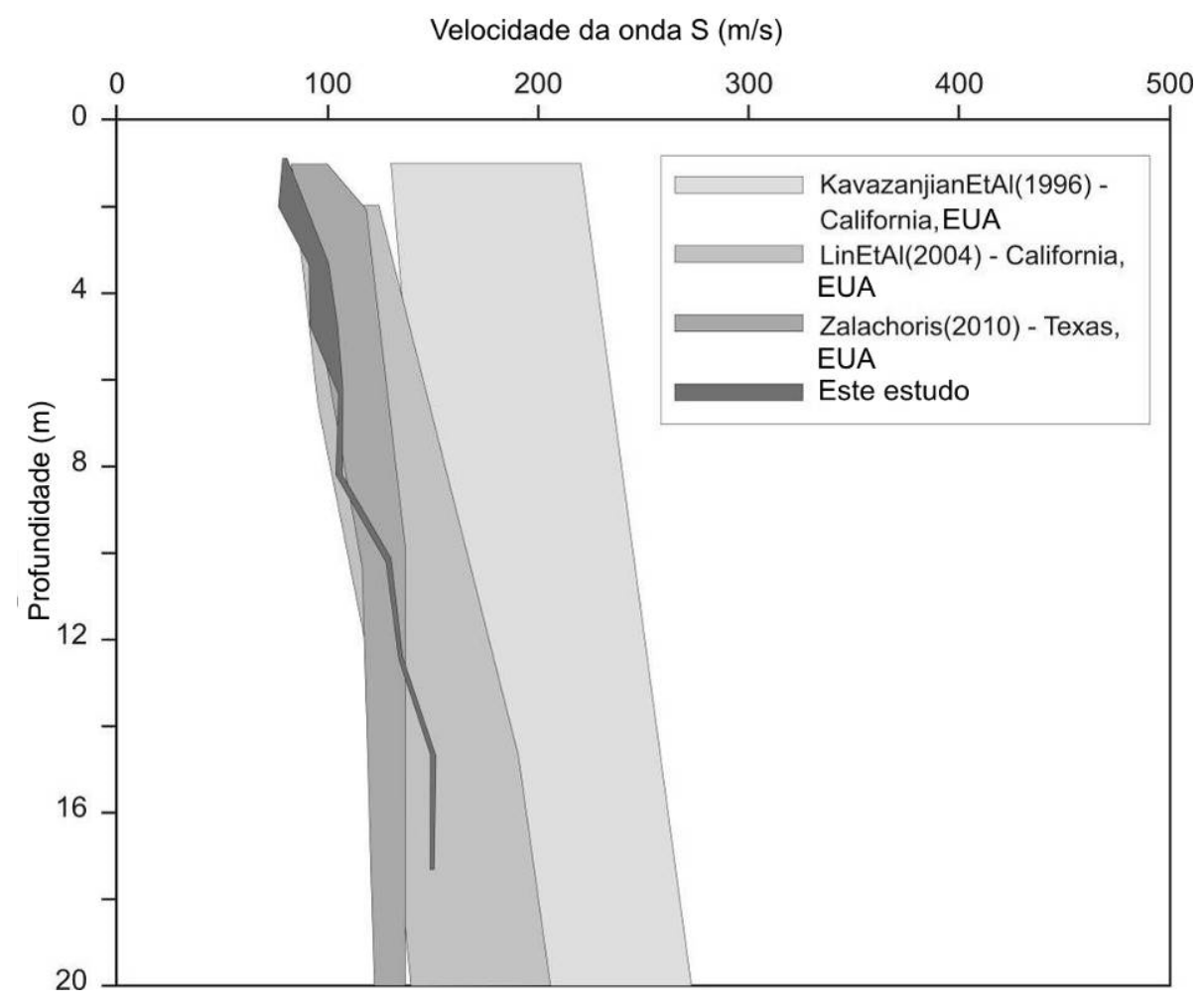

Figura 5.25 - Comparação entre os resultados dos ensaios MASW obtidos nessa pesquisa e aqueles obtidos por métodos não-intrusivos em aterros da região da California e Texas (EUA).

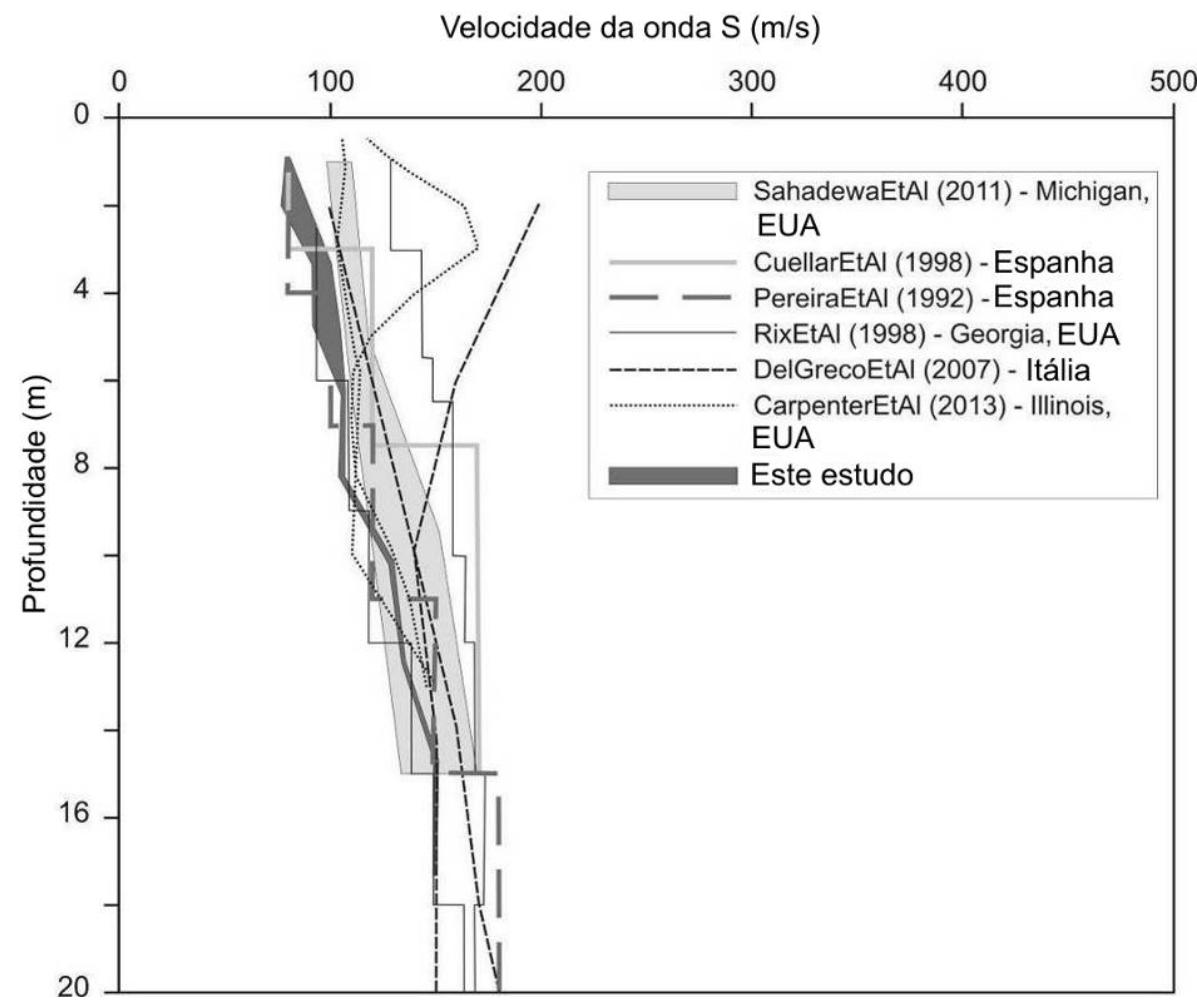

Figura 5.26 - Comparação entre os resultados dos ensaios MASW obtidos nessa pesquisa e aqueles obtidos por métodos não-intrusivos em aterros de outras regiões. 


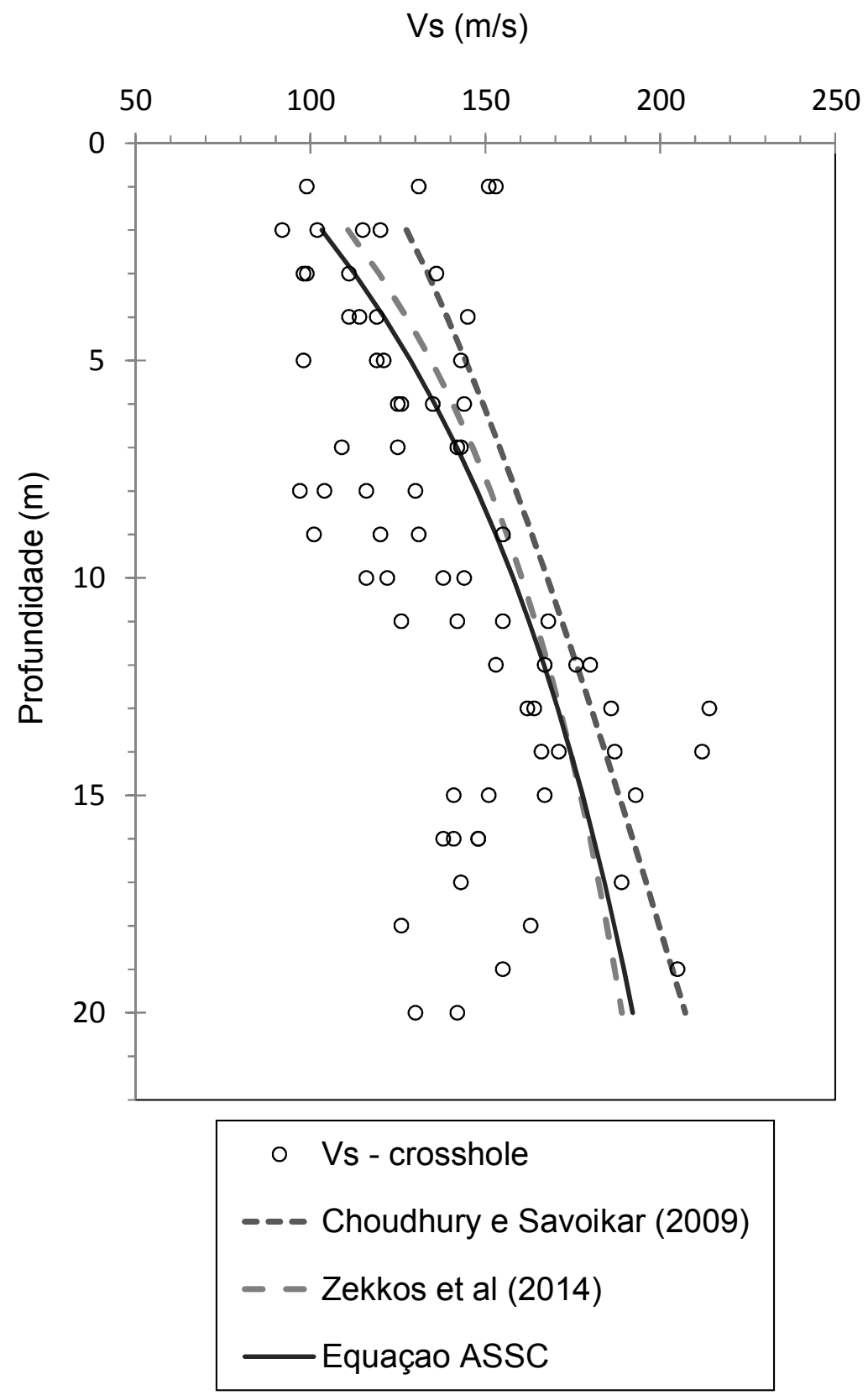

Figura 5.27 - Valores médios de Vs (crosshole) para o Aterro Sanitário de São Carlos (ASSC).

\subsubsection{Grau de saturação do maciço de RSU}

As velocidades de onda $\mathrm{P}$ determinadas no ASSC atingem valor máximo de $451 \mathrm{~m} / \mathrm{s}$, o que indica que o maciço de resíduos não estava saturado por um fluido incompressível quando os ensaios foram realizados.

Cabem aqui algumas considerações. A primeira delas diz respeito ao método utilizado nesta pesquisa para preparação dos furos para o ensaio crosshole. $\mathrm{O}$ espaço anelar entre o 
tubo de PVC e a parede do furo foi preenchido com brita ao longo de toda a profundidade de investigação. A preparação dos furos ocorreu em julho de 2011 e os ensaios geofísicos foram executados em outubro do mesmo ano. Como a brita é um material drenante, ela interligou as várias camadas que atravessou, possibilitando a migração de gás para camadas mais rasas e a descida de líquidos para as camadas mais profundas. Não havia interligação direta com as águas superficiais ou com a atmosfera, pois os metros finais de todos os furos foram preenchidos por bentonita, que funciona como selante.

Assim sendo, se alguma das camadas estava saturada por fluido incompressível no momento da perfuração dos furos, pode ter acontecido uma redistribuição desta fase líquida ao longo destes três meses, de tal forma que, quando se realizaram os ensaios geofísicos, o maciço não se encontrava mais saturado.

Além disso, deve-se considerar que a biodegradação dos RSU produz biogás. Este biogás pode estar dissolvido na fase líquida em quantidades tais, que tornem este fluido compressível, o que também resultaria em valores de $\mathrm{Vp}$ menores que $1.500 \mathrm{~m} / \mathrm{s}$.

\subsubsection{Módulo de cisalhamento para pequenas deformações $\left(\mathrm{G}_{\mathrm{o}}\right)$}

Quando se dispõe de valores de velocidade de propagação de ondas cisalhantes (Vs) e da massa específica de um mesmo material pode-se calcular, considerando-se a teoria da elasticidade, o módulo de cisalhamento do material para pequenas deformações $\left(G_{\text {máx }}\right.$ ou $\left.G_{0}\right)$.

Os valores de módulo de cisalhamento determinados nessa pesquisa para os primeiros onze metros de profundidade do maciço (resíduos mais recentes) variaram entre 8 e 29 Mpa, considerando-se peso específico de $9-10 \mathrm{kN} / \mathrm{m}^{3}$. Para o maciço de resíduos mais antigos, em profundidades situadas entre 11 e 20 metros, os valores de $G_{o}$ variaram entre 18 e $51 \mathrm{MPa}$, considerando-se peso específico de $11 \mathrm{kN} / \mathrm{m}^{3}$, e entre 24 e $70 \mathrm{MPa}$, considerando-se peso específico de $15 \mathrm{kN} / \mathrm{m}^{3}$.

Os valores determinados para o estrato superior de resíduos estão de acordo com aqueles relatados por Abbiss (2001), Zekkos et al. (2008) e Yuan et al. (2011).

Zekkos et al. (2008) e Yuan et al. (2011) trabalharam com amostras reconstituídas a partir de resíduos escavados do aterro de Tri-Cities, na Califórnia, EUA, com três diferentes proporções de materiais mais finos que 20mm: $35 \%$, 65\% e 100\%. O peso específico das amostras ensaiadas por esses autores variou entre 6 e $14,5 \mathrm{kN} / \mathrm{m}^{3}$. Essas amostras tinham umidades de 7,5 a $25 \%$ e correspondiam a resíduos pouco degradados. O confinamento 
aplicado sobre as amostras foi de $75 \mathrm{kPa}$, que, segundo os autores, para o aterro de Tri-Cities corresponde a profundidades entre 9 e 13 metros. Zekkos et al. (2008) realizaram ensaios triaxiais com instrumentação direta das deformações e determinaram valores de $G_{0}$ entre 5 e 30 Mpa. Yuan et al. (2011) realizaram ensaios de cisalhamento simples, instrumentados com geofones, para determinação da velocidade de propagação das ondas $\mathrm{S}$ na amostra compactada e encontraram valores entre 4 e $29 \mathrm{MPa}$.

Abbiss (2001) investigou profundidades rasas (até 3,5 metros) do Aterro de Calvert, na Inglaterra, com o método de refração para determinação do coeficiente de Poisson dos resíduos e com ondas Rayleigh para determinação das velocidades de propagação das ondas cisalhantes. A massa específica dos resíduos foi determinada pelo método da trincheira. De posse desses dados o autor calculou $\mathrm{G}_{0}$, que resultou 4,4 Mpa.

5.2 Cisalhamento direto de grandes dimensões

\subsubsection{Caracterização das amostras utilizadas nos ensaios}

\subsubsection{Caracterização química e bioquímica}

Durante o processo de solubilização foram observadas diferenças no comportamento das diversas amostras. Após seis dias de contato com a água e previamente à filtragem, o aspecto das soluções geradas pelas amostras A1988, A1995, A2001, A2003 e A2007 era semelhante, com as partículas sólidas quase todas decantadas, enquanto que na amostra A2011 a solução era mais turva, havia material em suspensão e ocorreu o crescimento de um fungo na superfície da solução. A Figura 5.28 ilustra essa situação.

$\mathrm{Na}$ Tabela 5.10 são apresentados os resultados dos ensaios químicos e bioquímicos realizados sobre o extrato solubilizado obtido a partir das amostras ensaiadas nessa pesquisa. Nas Figuras 5.29 a 5.31 esses resultados são apresentados em função do ano de aterramento das amostras. Eles indicam que a amostra A2011 tem características químicas e bioquímicas claramente diferentes das demais e sugerem que elas possam ser separadas em dois grandes grupos: grupo 1, composto apenas pela amostra A2011, e grupo 2, composto pelas amostras (A1988, A1995, A2001, A2004 e A2007). O fato de a amostra A2011 apresentar valores de

$\mathrm{DBO}_{5}, \mathrm{DQO}_{\text {(solubilizada) }}$ e $\mathrm{COT}_{\text {(solubilizado) }}$ maiores que as demais, indica que ela se encontra menos degradada. 
Tabela 5.10 - Resultados dos ensaios químicos e bioquímicos realizados sobre o extrato solubilizado.

\begin{tabular}{cccccccc}
\hline \multirow{2}{*}{ Parâmetro } & \multirow{2}{*}{ Unidade } & \multicolumn{7}{c}{ Amostra } \\
\cline { 3 - 7 } & & $\mathrm{A} 1988$ & $\mathrm{~A} 1995$ & $\mathrm{~A} 2001$ & $\mathrm{~A} 2004$ & $\mathrm{~A} 2007$ & $\mathrm{~A} 2011$ \\
\hline $\mathrm{DBO}_{5}$ & $\mathrm{mgO}_{2} / 1$ & 100 & 52 & 51 & 49 & 45 & 8956 \\
$\mathrm{DQO}$ & $\mathrm{mgO}_{2} / 1$ & 461 & 284 & 328 & 356 & 212 & 15580 \\
Nitrogênio & $\mathrm{mgN}^{2}$ & 37 & 10 & 6 & 12 & 10 & 239 \\
amoniacal & $\mathrm{NH}_{3} / 1$ & & & & & & \\
Nitrogênio & $\mathrm{mgN} / 1$ & 43 & 24 & 46 & 47 & 39 & 437 \\
total & $\mathrm{mgC} / 1$ & 197,7 & 218,4 & 145,6 & 154,1 & 104,1 & 5275 \\
$\mathrm{COT}$ & - & 8,1 & 7,8 & 8,0 & 8,0 & 8,0 & 6,0 \\
$\mathrm{pH}$ & - & & & & & & \\
\hline
\end{tabular}
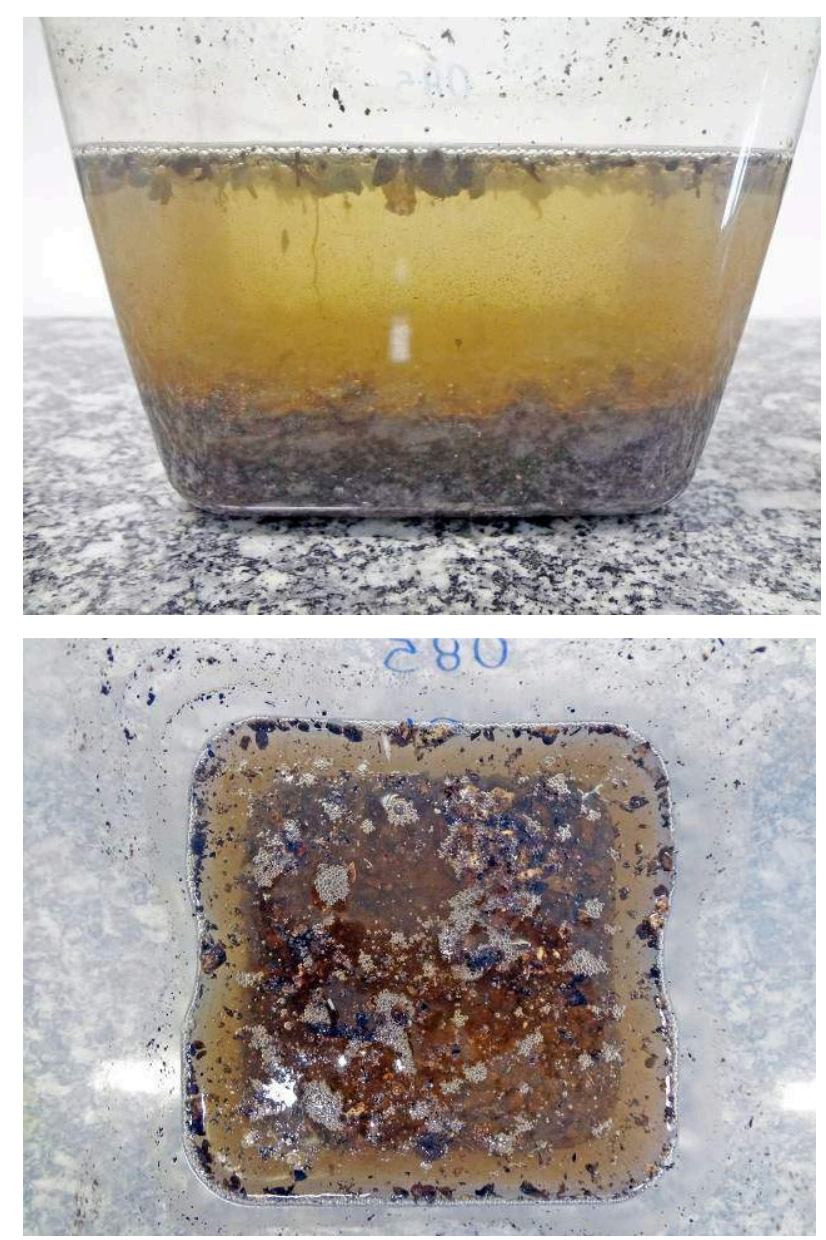

(a)
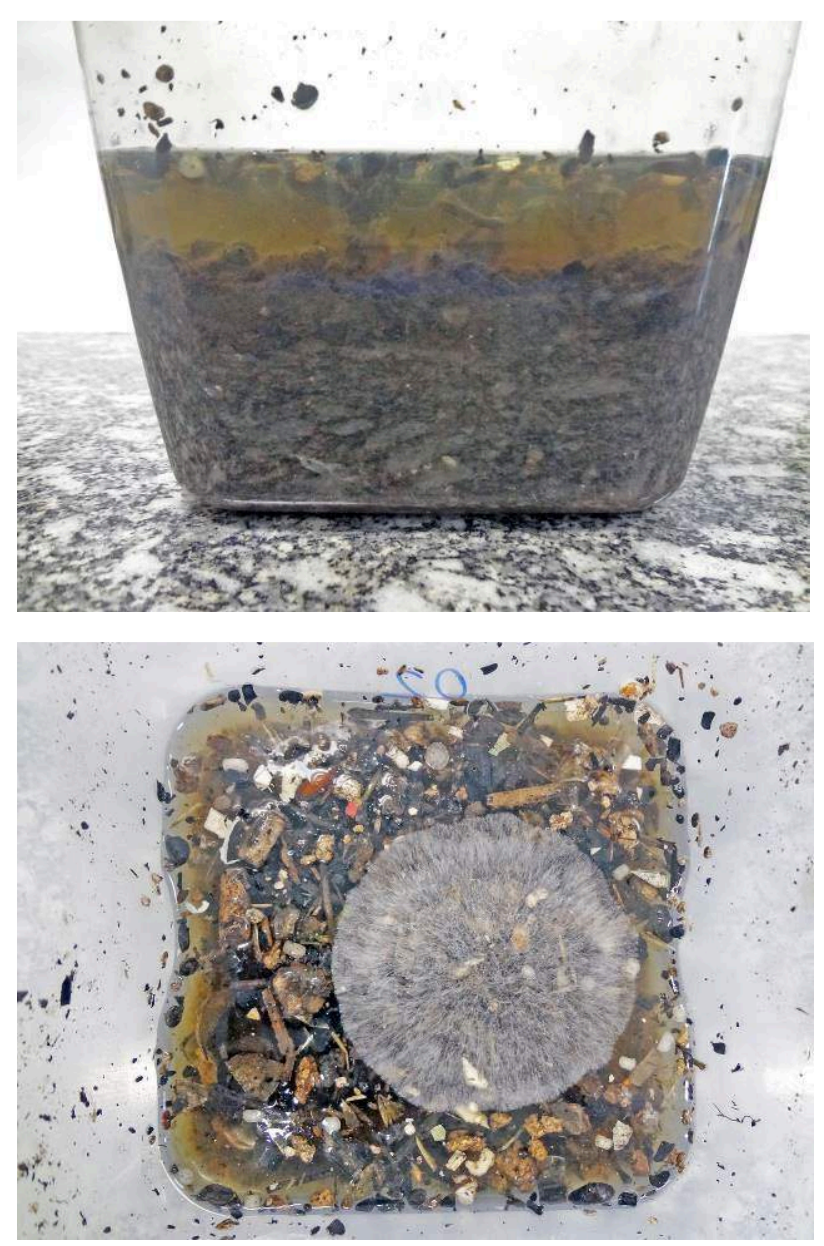

(b)

Figura 5.28 - Aspecto das soluções geradas pelas amostras A1995 (a) e A2011(a) após seis dias em contato com a água, durante o processo de solubilização. 


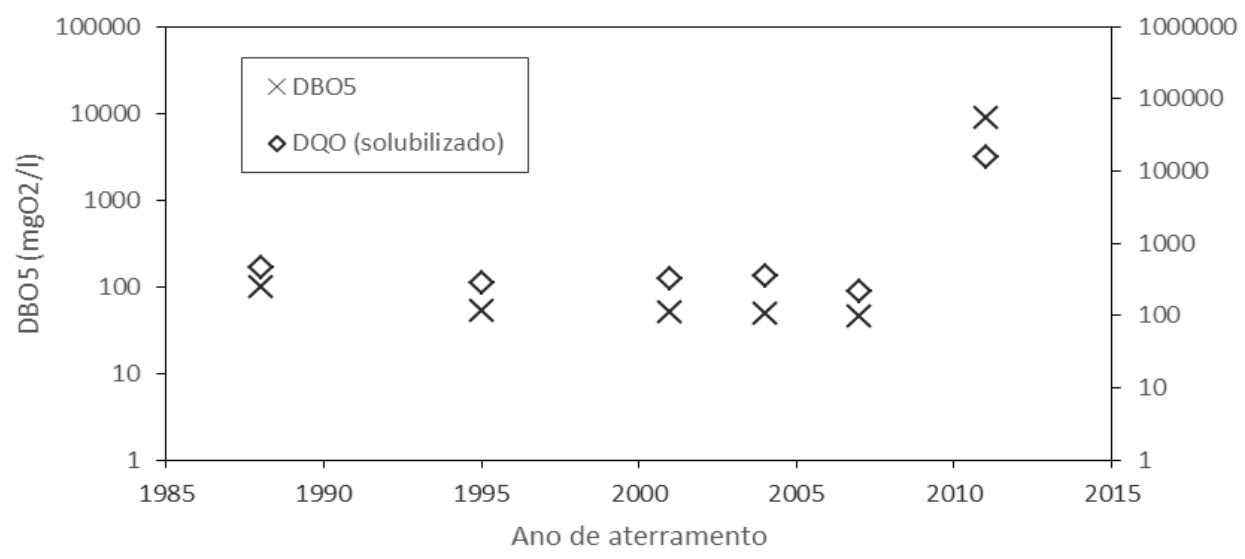

Figura 5.29 - Relação entre o ano de aterramento da amostra e os parâmetros $\mathrm{DBO}_{5}$ e $\mathrm{DQO}_{\text {(solubilizado). }}$

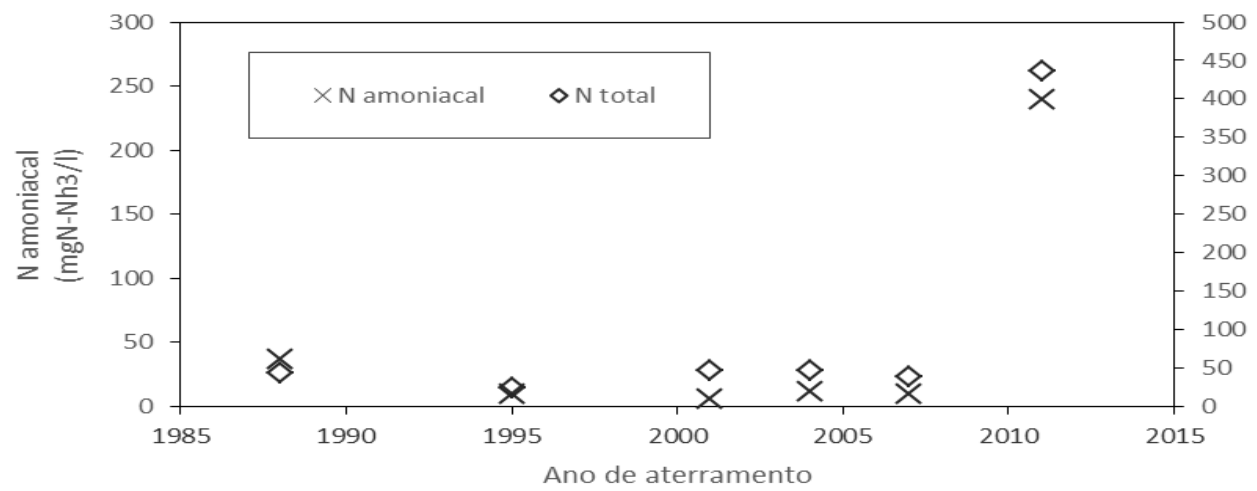

Figura 5.30 - Relação entre o ano de aterramento da amostra e os parâmetros nitrogênio total e amoniacal.

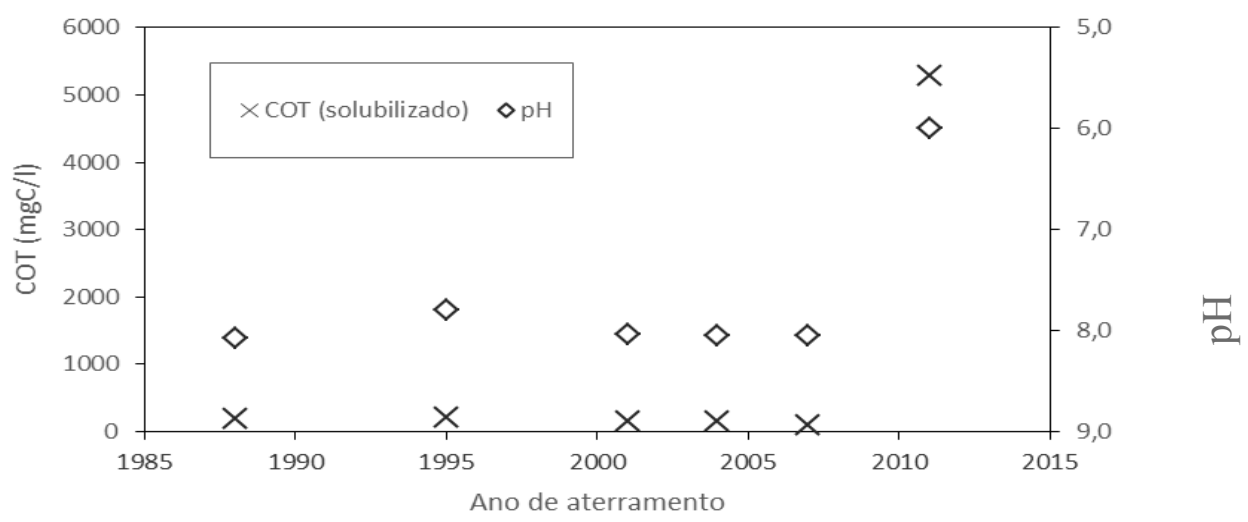

Figura 5.31 - Relação entre o ano de aterramento da amostra e os parâmetros $\operatorname{COT}_{(\text {solubilizado) }}$ e $\mathrm{pH}$.

Considerando-se que o $\mathrm{pH}$ determinado sobre o extrato solubilizado pode ser utilizado como um indicador do $\mathrm{pH}$ que ocorre na fase líquida presente no local de aterramento das 
amostras, e se conjuntamente analisarmos as temperaturas registradas nos locais de disposição

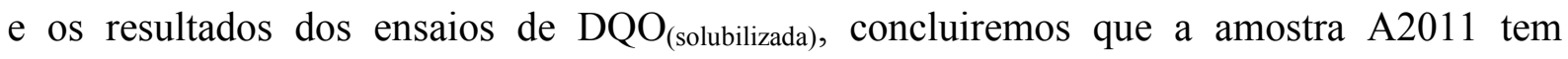
características de um resíduo submetido às fases iniciais de metanogênese (início da fase 3), na parte superior do aterro sanitário, enquanto que as demais amostras têm características de resíduos submetidos a condições de metanogênese bem estabelecidas (fases 3 ou 4 do processo de biodegradação), tanto nas regiões mais profundas do aterro sanitário, quanto nos locais de disposição mais antigos.

Os parâmetros $\mathrm{N}$ amoniacal e $\mathrm{N}$ total não são considerados indicadores do estado de degradação das amostras, mas foram analisados, pois poderiam revelar a presença de nitrogênio em quantidades inibidoras do processo de biodegradação e explicar resultados anômalos. Verificou-se, entretanto, que as concentrações de $\mathrm{N}$ amoniacal e $\mathrm{N}$ total seguem a mesma tendência das concentrações dos demais elementos, não havendo evidência de inibição do processo de biodegradação pela presença desses elementos químicos.

Considerando-se apenas os resultados das amostras do grupo 2, não foi possível estabelecer, uma ordem de estado de degradação das mesmas. Verificou-se que as amostras coletadas no aterro sanitário (A2001, A2004 e A2007) apresentaram comportamento bastante semelhante em todos os ensaios, enquanto que as amostras coletadas no lixão desativado (A1995) e no aterro experimental (A1988) apresentaram resultados ora maiores, ora menores que as outras três.

A relação $\mathrm{DBO}_{5} / \mathrm{DQO}$ calculada com base nestes resultados é apresentada na Tabela 5.11 e ilustrada na Figura 5.32. Diversos autores propõem que esta relação seja utilizada como um indicador do estado de degradação das amostras de RSU, variando, entretanto, a forma de obtenção do extrato sobre o qual os ensaios devem ser realizados. No geral admite-se que em amostras com razão $\mathrm{DBO}_{5} / \mathrm{DQO}$ acima de 0,4 ainda há bastante matéria orgânica a ser degradada. Novamente as amostras mais antigas puderam ser agrupadas e a amostra A2011 ficou isolada das demais, apresentando um valor mais elevado e corroborando os resultados apresentados anteriormente. No grupo 2, as amostras A1988 e A2007 seriam as menos degradadas.

Na Tabela 5.12 e na Figura 5.33 são apresentados os resultados dos ensaios de DQO realizados sobre extratos lixiviados a partir das amostras. A amostra A2011 apresentou novamente o maior resultado, discrepante dos demais. As amostras A1988, A1995, A2004 e A2007 exibiram resultados semelhantes, enquanto que a amostra A2001 teve valor um pouco inferior. Em princípio, quanto maior o resultado deste ensaio, menos degradada está a 
amostra. Entretanto, neste caso, tomando-se os valores de referência utilizados para lixiviado, todas as amostras (inclusive a amostra A2011) apresentaram valores típicos de resíduos em avançado estado de degradação (fase metanogênica).

Tabela 5.11 - Relação $\mathrm{DBO}_{5} / \mathrm{DQO}$ calculada para as amostras.

\begin{tabular}{ccccccc}
\hline \multirow{2}{*}{$\begin{array}{c}\text { Parâmetro } \\
\text { (adimensional) }\end{array}$} & A1988 & A1995 & A2001 & A2004 & A2007 & A2011 \\
\cline { 2 - 7 } & 0,217 & 0,183 & 0,156 & 0,138 & 0,212 & 0,575 \\
\hline $\mathrm{DBO}_{5} / \mathrm{DQO}$ & 0,2210 &
\end{tabular}

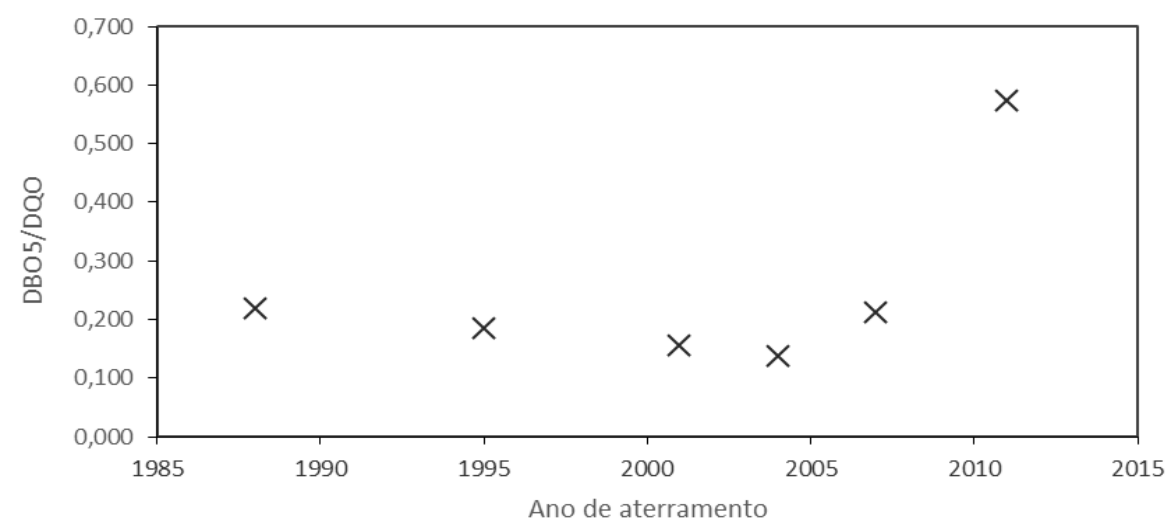

Figura 5.32 - Relação entre o ano de aterramento da amostra e a razão $\mathrm{DBO}_{5} / \mathrm{DQO}$.

Tabela 5.12 - Resultados dos ensaios de DQO realizados sobre o extrato lixiviado.

\begin{tabular}{|c|c|c|c|c|c|c|c|}
\hline \multirow{2}{*}{ Parâmetro } & \multirow{2}{*}{ Unidade } & \multicolumn{6}{|c|}{ Amostra } \\
\hline & & A1988 & A1995 & A2001 & A2004 & A2007 & A2011 \\
\hline $\begin{array}{c}\text { DQO } \\
\text { (lixiviado) }\end{array}$ & $\mathrm{mgO}_{2} / 1$ & 234 & 263 & 163 & 236 & 223 & 708 \\
\hline
\end{tabular}

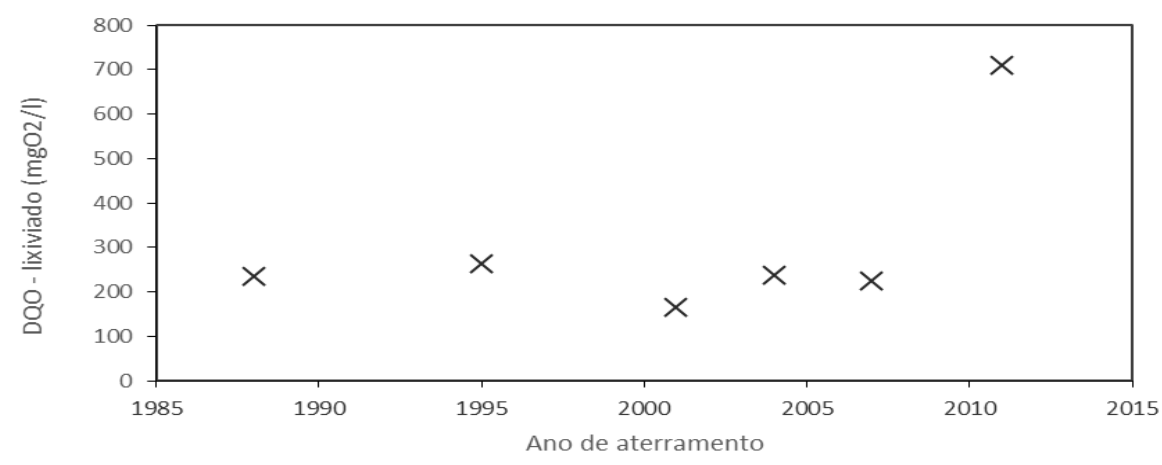

Figura 5.33 - Relação entre o ano de aterramento da amostra e o parâmetros $\mathrm{DQO}_{\text {(lixiviado). }}$

Os resultados dos ensaios de determinação dos STV para diferentes temperaturas de calcinação são apresentados na Tabela 5.13. As máximas diferenças observadas entre os 
resultados do ensaio de STV para ambas as temperaturas foram de 1 a $4 \%$. Como essa diferença é pequena, doravante serão discutidos apenas os resultados do ensaio para calcinação a $600^{\circ} \mathrm{C}$. Os resultados das determinações do COT sobre amostra sólida constam da Tabela 5.14. A Figura 5.34 ilustra a relação desses dois parâmetros com o ano de aterramento.

Os resultados dos ensaios de STV variaram de 11 a $26 \%$ para as amostras aterradas entre 1988 e 2007 e para a amostra de 2011 o resultado foi de $80 \%$. Também neste caso a amostra A2011 mostra-se menos degradada que as demais. Nas amostras do grupo 2, aquelas coletadas em 1988 e 1995 apresentam valores de 26 e 29\%, enquanto que as amostras coletadas no aterro sanitário (A2001, A2004 e A2007) apresentam resultados mais baixos, entre 11 e $16 \%$.

Tabela 5.13 - Valores de STV obtidos com aquecimento a 70,440 e $600^{\circ} \mathrm{C}$

\begin{tabular}{cccc}
\hline Amostra & $\begin{array}{c}\mathrm{STV}_{(4400 \mathrm{C})} \\
(\%)\end{array}$ & $\begin{array}{c}\mathrm{STV}_{(600 \mathrm{C})} \\
(\%)\end{array}$ & $\begin{array}{c}\text { Diferença } \\
(\%)\end{array}$ \\
\hline $\mathrm{A} 1988$ & 25 & 26 & +1 \\
$\mathrm{~A} 1995$ & 25 & 29 & +4 \\
$\mathrm{~A} 2001$ & 10 & 11 & +1 \\
$\mathrm{~A} 2004$ & 14 & 16 & +2 \\
$\mathrm{~A} 2007$ & 13 & 15 & +2 \\
$\mathrm{~A} 2011$ & 77 & 80 & +3 \\
\hline
\end{tabular}

Tabela 5.14 - Conteúdo de COT nas amostras ensaiadas nesta pesquisa.

\begin{tabular}{cc} 
Amostra & COT $_{\text {(amostra sólida) }}(\%)$ \\
\hline A1988 & 7,6 \\
A1995 & 9,5 \\
A2001 & 3,3 \\
A2004 & 5,4 \\
A2007 & 3,8 \\
A2011 & 19,3 \\
\hline
\end{tabular}




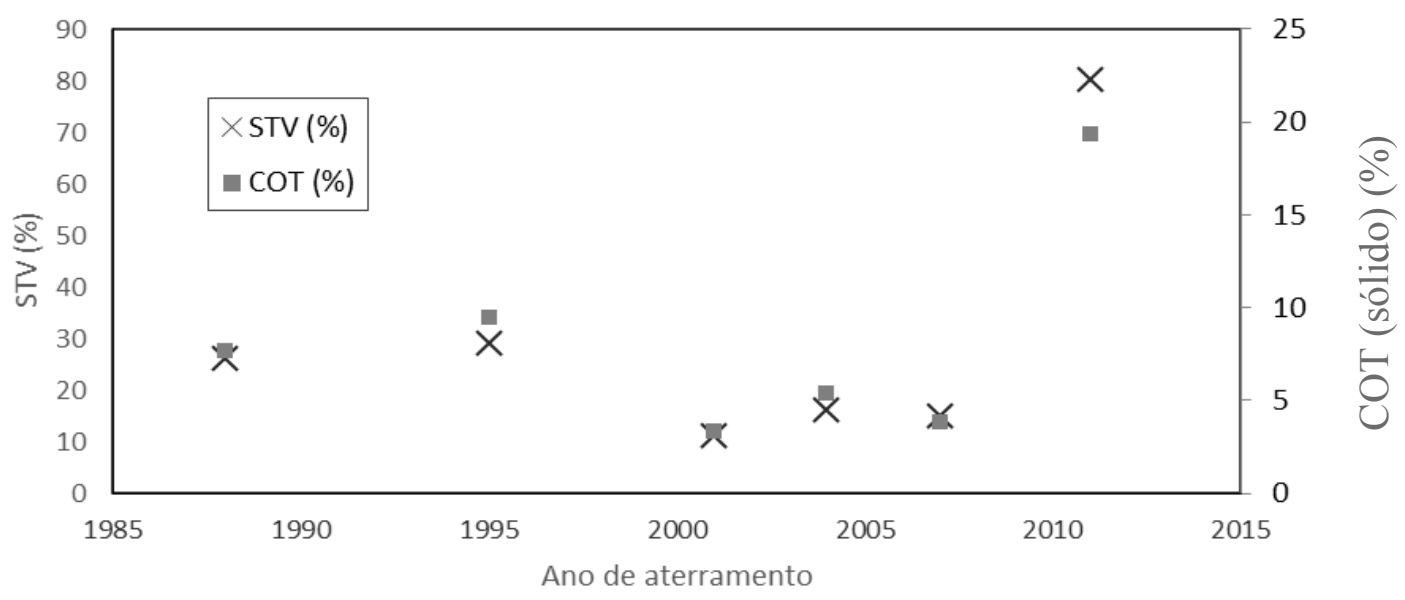

Figura 5.34 - Relação entre o ano de aterramento da amostra e os parâmetros STV e $\mathrm{COT}_{\text {(amostra sólida) }}$.

No ensaio de determinação do COT sobre amostra sólida a amostra de 2011 apresentou resultado de 19,3\%, enquanto que as demais apresentaram resultados variando entre 3,3 e 9,5\%. Aqui também as amostras coletadas no aterro sanitário apresentaram os menores resultados (3,3 a 5,4\%) e as amostras A1988 e A1995 apresentaram valores um pouco mais elevados, de 7,6 e 9,5\%, respectivamente.

Os resultados de ambos os ensaios apresentaram a mesma tendência, o que pode ser consequência do fato de ambos basearem-se em técnicas semelhantes, envolvendo o aquecimento do material em estado sólido a elevadas temperaturas. Nos dois casos, considerase que ocorre um decréscimo do conteúdo de STV ou COT das amostras mais recentes para as mais antigas. Assim sendo, a amostra A2011 é a menos degradada, dentre as seis amostras estudadas, o que corrobora os resultados dos ensaios realizados sobre os extratos solubilizado e lixiviado. As amostras A1988 e A1995 estariam em um patamar intermediário de degradação e as amostras A2001, A2004 e A2007 estariam no estágio mais avançado de degradação.

Para facilitar a comparação entre os resultados dos ensaios para as amostras do grupo 2 foi realizada a normalização desses valores, tomando-se como padrão os valores encontrados para a amostra A2007, que apresenta os menores valores com mais frequência. $\mathrm{O}$ número Ni, que expressa essa normalização, foi calculado da seguinte forma:

$$
\mathrm{Ni}=\frac{\text { resultado da amostra } \mathrm{i}}{\text { resultado da amostra } \mathrm{A} 2007}
$$


A Figura 5.35 apresenta os resultados dessa normalização. Verifica-se que as tendências não são uniformes, não permitindo que se correlacione diretamente o tempo de aterramento e o estado de degradação das amostras. É difícil discernir qual das amostras desse grupo está mais degradada em relação às demais, mas os resultados sugerem que as amostras A1988 e A1995 têm um comportamento diferente das demais, estando aparentemente um pouco menos degradadas que as amostras A2001, A2004 e A2007.

As amostras A1988 e A1995, apesar de serem as mais antigas, estiveram sujeitas a ambientes com menor disponibilidade de água durante todo o período em que estiveram aterradas, pois ambas estavam aterradas em condições rasas (até 1,5 metros de profundidade). A amostra A1995 estava situada acima do primeiro nível d'água suspenso detectado por Shinzato (2014) a 3,5 metros de profundidade no Lixão Desativado de São Carlos e a amostra A1988 estava aterrada sob duas camadas de cobertura compostas por solos argilosos, intercaladas a uma manta de Hypalon, que devem ter funcionado como proteção (ainda que falível) contra a entrada de água no maciço de resíduos do Aterro Experimental ao longo dos anos.
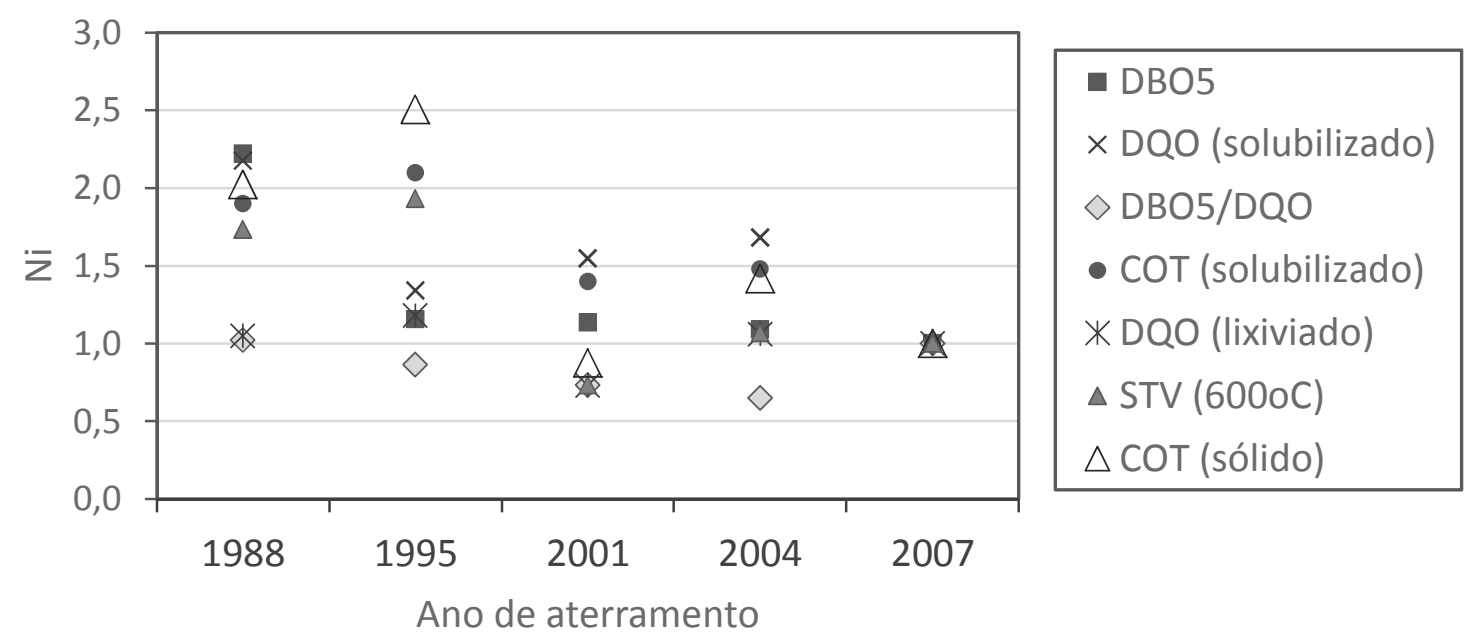

Figura 5.35 - Resultados normalizados dos ensaios de caracterização das amostra do Grupo 2 (mais degradadas).

Em vista dos resultados dos ensaios químicos e bioquímicos realizados, pôde-se concluir que a amostra A2011 encontra-se claramente menos degradada que as demais. Quanto às outras amostras, os ensaios realizados sobre os extratos solubilizado e lixiviado não apresentam uma tendência clara quanto ao estado de degradação de uma em relação à outra. Porém, os resultados dos ensaios realizados sobre as amostras sólidas indicam, para este grupo, que as amostras A2001, A2004 e A2007 encontram-se no estágio mais avançado de 
degradação, enquanto as amostras A1988 e A1995 encontram-se relativamente menos degradadas.

A antiguidade do aterramento não foi proporcional ao estado de degradação das amostras em estudo. Para isso podem ter colaborado tanto as características iniciais das amostras, quanto as condições em que elas estiveram aterradas nos locais de disposição e as condições em que ficaram armazenadas após a coleta. De qualquer forma, para a interpretação dos resultados dos ensaios de cisalhamento em função do estado de degradação das amostras, que era um dos objetivos principais desta pesquisa, deve-se considerar que as amostras do grupo 2 representam resíduos bastante degradados, que ocorrem nas condições de disposição final estudadas nesta pesquisa após cinco anos de aterramento. Os resultados dos ensaios de $\mathrm{DQO}$, relação $\mathrm{DQO} / \mathrm{DBO}_{5}$, temperatura e $\mathrm{pH}$ sugerem que estas amostras encontravam-se nas fases 3 ou 4 de degradação (fase metanogênica). A amostra A2011 representa resíduos menos degradados, em estágio inicial de metanogênese (início da fase 3), que vigoravam nos primeiros metros de profundidade do maciço de RSU do aterro sanitário de São Carlos após dois anos de aterramento.

\subsubsection{Caracterização física}

Devido à remoção dos componentes maiores que $85 \mathrm{~mm}$, o material efetivamente ensaiado corresponde a uma fração em peso da amostra toda, como apresentado na Tabela 5.15 .

Tabela 5.15 - Porcentagem em peso úmido das frações escalpeladas durante o processo de preparação das amostras para ensaio.

\begin{tabular}{ccccccc}
\hline Descrição & \multicolumn{7}{c}{ Amostra } \\
\cline { 2 - 7 } & A1988 & A1995 & A2001 & A2004 & A2007 & A2011 \\
\hline Coletado & 100 & 100 & 100 & 100 & 100 & 100 \\
\hline $\begin{array}{c}\text { Descartes de campo } \\
\text { (componentes maiores que }\end{array}$ & 34 & 25 & 2 & 2 & 6 & 31 \\
$\begin{array}{c}\text { 20cm) } \\
\text { Descartes de laboratório } \\
\text { (componentes menores que } \\
\text { 20cm e maiores que 8,5cm) } \\
\text { Componentes utilizados nos } \\
\text { ensaios de cisalhamento direto }\end{array}$ & 57 & 57 & 72 & 74 & 72 & 47 \\
\hline
\end{tabular}


Esses dados sugerem que a forma como as amostras são coletadas influi em sua composição. As amostras A1988, A1995 e A2011 foram coletadas em trincheiras abertas com retroescavadeiras nos locais de deposição. Já as amostras A2001, A2004 e A2007 foram recuperadas em sondagens a trado. $\mathrm{Na}$ Tabela 5.15 verifica-se que em todas as amostras coletadas por sondagem, os componentes maiores que $20 \mathrm{~cm}$ correspondem a uma porcentagem pequena do peso total da amostra, enquanto que nas amostras coletadas em trincheiras esses componentes têm maior porcentagem em peso. Quando se calculam as porcentagens de material utilizadas nos ensaios, em relação ao peso total da amostra, verificase que nas amostras coletadas por sondagem os materiais ensaiados correspondem a $72-74 \%$ do peso total da amostra, enquanto que nas amostras coletadas em trincheiras essa porcentagem cai para $47-57 \%$.

$\mathrm{Na}$ realidade o que ocorre é que a amostragem por sondagem, utilizando-se trado helicoidal, não é capaz de remover os componentes de maiores dimensões, portanto a proporção dos componentes menores que $19 \mathrm{~mm}$ já é naturalmente maior nestas amostras. A amostragem realizada desta forma não é tão representativa da composição do maciço, como aquela realizada por trincheiras.

Com relação aos componentes passantes na peneira de $19 \mathrm{~mm}$, verificou-se por inspeção visual que a composição dessa fração era variada. As amostras A1988 e A1995 assemelhavam-se a areias com poucos componentes rígidos maiores, representados por plásticos duros, metais, vidros e pedregulhos. As amostras A2001, A2004 e A2007 eram parecidas entre si e apresentavam uma matriz arenosa com componentes rígidos (plásticos duros, metais, vidros e pedregulhos) e muitos plásticos moles. Na amostra A2011 a fração menor que $19 \mathrm{~mm}$ era composta principalmente por gravetos, folhas e papel. A Figura 5.36 ilustra essas três composições típicas e a Tabela 5.16 apresenta a proporção em peso seco entre os principais componentes desta fração nas seis amostras ensaiadas.

Acredita-se que o "enriquecimento" desta fração com plásticos moles que ocorre nas amostras A2001, A2004 e A2007 seja causado pela operação do trado helicoidal, que rasga os sacos plásticos maiores presentes no maciço de resíduos e os transforma em fragmentos menores. Quando se coletam amostras em trincheiras verifica-se que os sacos plásticos são componentes para os quais predominam dimensões decimétricas. 

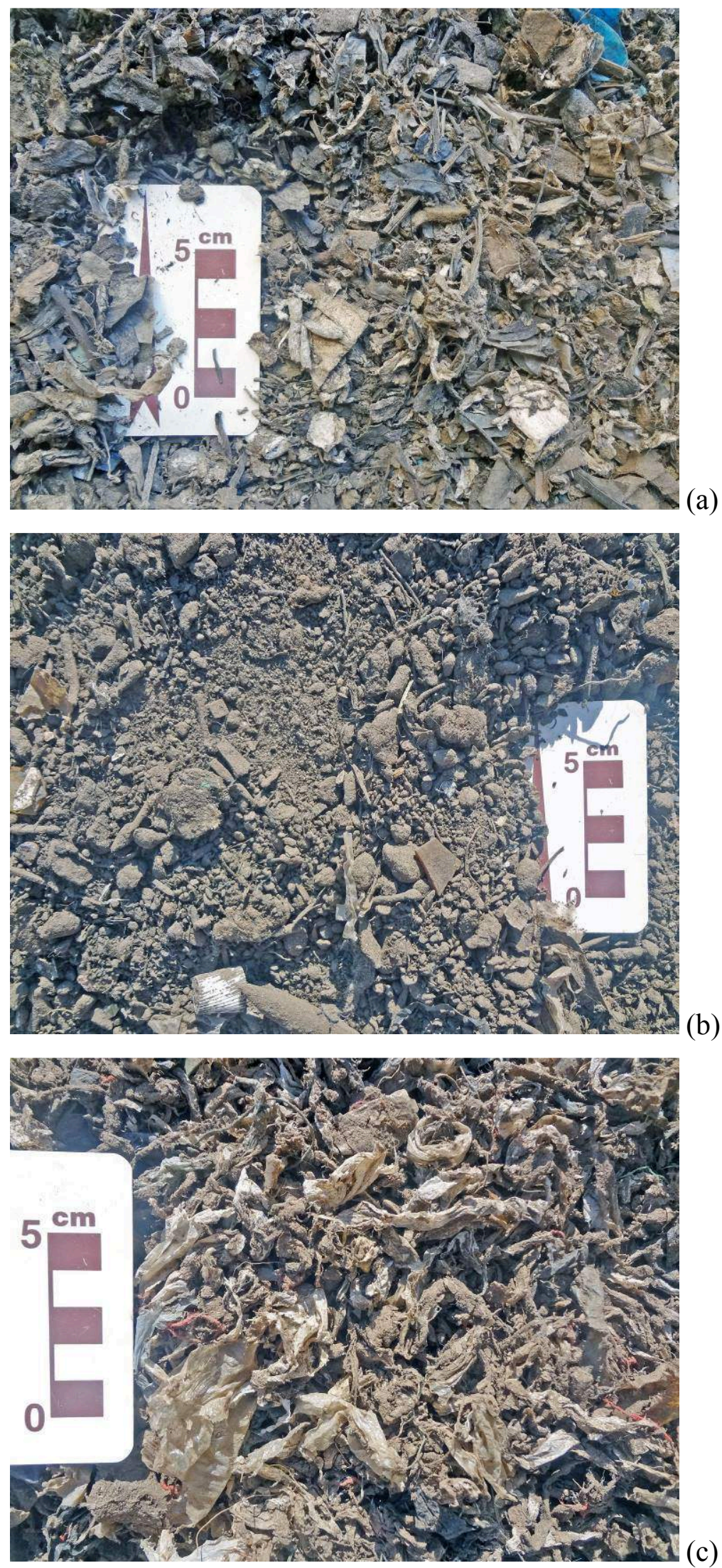

Figura 5.36 - Aspecto dos componentes menores que 19mm (a) A2011 (b) A1988 (c) A2001. 
A Tabela 5.17 apresenta os resultados do detalhamento da composição da classe "plásticos moles" por meio de destorroamento, peneiramento e catação manual. Verifica-se que na amostra A2011 os plásticos estão menos "impregnados" do que nas demais amostras. Esses resultados evidenciam a dificuldade de se compararem resultados de pesquisas com resíduos sólidos urbanos, pois os procedimentos para caracterização das amostras não são normatizados.

Nas seis amostras ensaiadas nesta pesquisa o fato de se realizar esse detalhamento implicou um aumento da porcentagem em peso seco da fração menor que $19 \mathrm{~mm}$ e uma diminuição da porcentagem de plásticos moles, na mesma proporção. As diferenças foram de 0,2\% na amostra A1988, 2,0\% na amostra A1995, 7,7\% na amostra A2001, 2,7\% na A2004, 5,3\% na A2007 e 0,5\% na amostra A2011. Quando se realizam pesquisas com resíduos novos ou com amostras ditas sintéticas (compostas a partir de materiais ainda não aterrados) essa impregnação dos plásticos com materiais tipo-solo não corre. Nas comparações apresentadas ao longo desta pesquisa será utilizada sempre a composição gravimétrica das amostras considerando-se esse detalhamento.

Tabela 5.16 - Porcentagem em peso seco dos componentes principais da fração menor que $19 \mathrm{~mm}$.

\begin{tabular}{ccccccc}
\hline \multirow{2}{*}{ Descrição } & \multicolumn{7}{c}{ Amostra } \\
\cline { 2 - 7 } & A1988 & A1995 & A2001 & A2004 & A2007 & A2011 \\
\hline Menor que 4,76mm & 70,3 & 72,5 & 80,8 & 74,4 & 75,2 & 64,9 \\
Plásticos moles, tecidos & 0,1 & 0,4 & 11,3 & 17,5 & 5,5 & 1,0 \\
Pedras, metais, plásticos rígidos & 29,6 & 27,1 & 8,0 & 8,1 & 19,3 & $34,1\left(^{*}\right)$ \\
\hline
\end{tabular}

(*)Inclui papéis.

Tabela 5.17 - Detalhamento da proporção entre os componentes da classe "plásticos moles" (em porcentagem do peso seco).

\begin{tabular}{ccccccc}
\hline Descrição & \multicolumn{7}{c}{ Amostra } \\
\cline { 2 - 7 } & A1988 & A1995 & A2001 & A2004 & A2007 & A2011 \\
\hline Menor que 4,76mm & 62,6 & 78,9 & 86,6 & 75,0 & 83,4 & 21,2 \\
Plásticos moles, tecidos & 37,4 & 21,0 & 12,0 & 23,4 & 15,8 & 73,2 \\
Pedras, metais, plásticos rígidos & 0,0 & 0,1 & 1,4 & 1,5 & 0,7 & 5,6 \\
\hline
\end{tabular}

A composição gravimétrica do material que foi efetivamente ensaiado, considerando-se o detalhamentos das classes "menor que $19 \mathrm{~mm}$ " e "plásticos moles", é apresentada nas Tabelas 5.18 e 5.19, juntamente com a composição gravimétrica da amostra total, que inclui os componentes maiores que $85 \mathrm{~mm}$. 
Tabela 5.18 - Composição gravimétrica das amostras selecionadas para ensaio (amostras coletadas em trincheiras) (Resultados expressos em porcentagem do peso seco).

\begin{tabular}{ccccccc}
\hline \multirow{2}{*}{ Fração } & \multicolumn{6}{c}{ Amostra } \\
\cline { 2 - 7 } & \multicolumn{2}{c}{ A1988 } & \multicolumn{2}{c}{ A1995 } & \multicolumn{2}{c}{ A2011 } \\
\cline { 2 - 7 } & Campo & Ensaio & Campo & Ensaio & Campo & Ensaio \\
\hline$<19 m m$ & 41,8 & 81,5 & 41,7 & 74,3 & 28,6 & 68,8 \\
Plást. Moles & 19,5 & 0,3 & 13,2 & 0,9 & 17,9 & 3,9 \\
Plást. Duros & 6,6 & 1,8 & 5,3 & 2,3 & 9,4 & 3,3 \\
Madeiras & 9,0 & 2,2 & 2,6 & 0,7 & 8,9 & 2,2 \\
Têxteis & 2,0 & 0,4 & 4,0 & 0,7 & 6,5 & 0,6 \\
Metais & 7,7 & 2,5 & 7,5 & 1,5 & 3,0 & 1,3 \\
Pedras & 6,4 & 7,0 & 13,8 & 14,0 & 8,0 & 6,7 \\
Vidros & 4,4 & 3,3 & 3,4 & 2,7 & 2,1 & 3,1 \\
Papéis & 1,5 & 0,8 & 2,8 & 0,0 & 13,4 & 9,2 \\
Borrachas & 0,7 & 0,1 & 4,5 & 1,2 & 1,7 & 0,2 \\
Outros & 0,4 & 0,1 & 1,2 & 1,7 & 0,5 & 0,7 \\
\hline
\end{tabular}

Tabela 5.19 - Composição gravimétrica das amostras selecionadas para ensaio (amostras coletadas em sondagens) (Resultados expressos em porcentagem do peso seco).

\begin{tabular}{ccccccc}
\hline \multirow{2}{*}{ Fração } & \multicolumn{7}{c}{ Amostra } \\
\cline { 2 - 7 } & \multicolumn{2}{c}{ A2001 } & \multicolumn{2}{c}{ A2004 } & \multicolumn{2}{c}{ A2007 } \\
\cline { 2 - 7 } & Campo & Ensaio & Campo & Ensaio & Campo & Ensaio \\
\hline$<19 m m$ & 46,9 & 78,0 & 43,8 & 69,5 & 56,5 & 79,3 \\
Plást. Moles & 33,8 & 10,1 & 27,3 & 16,1 & 19,0 & 5,8 \\
Plást. Duros & 4,9 & 5,5 & 7,9 & 5,0 & 7,7 & 2,9 \\
Madeiras & 2,1 & 0,2 & 3,9 & 0,4 & 2,8 & 0,6 \\
Têxteis & 5,6 & 0,4 & 7,4 & 0,6 & 5,1 & 0,9 \\
Metais & 2,7 & 1,6 & 4,2 & 1,6 & 2,1 & 1,3 \\
Pedras & 3,4 & 2,9 & 4,2 & 5,4 & 5,7 & 8,4 \\
Vidros & 0,1 & 0,2 & 0,3 & 0,4 & 0,4 & 0,4 \\
Papéis & 0,0 & 0,0 & 0,0 & 0,0 & 0,2 & 0,0 \\
Borrachas & 0,3 & 0,5 & 0,8 & 0,5 & 0,4 & 0,2 \\
Outros & 0,1 & 0,6 & 0,3 & 0,4 & 0,1 & 0,1 \\
\hline
\end{tabular}

Nas Figuras 5.37 e 5.38 estão representadas as composições destas amostras, excluindose os componentes menos significativos (porcentagens menores que 5\%). A Figura 5.37 apresenta a composição das amostras em campo. Nas amostras coletadas em trincheiras ela é mais bem distribuída do que nas amostras coletadas em sondagens. Isto reflete o fato de que as sondagens com trado helicoidal não são capazes de retirar todos os componentes do maciço, como discutido anteriormente. Percebe-se ainda que a amostra A2011 tem composição diferente das demais: ela é mais diversificada, a fração menor que $19 \mathrm{~mm}$ tem menor participação na composição da amostra e os papéis correspondem a $13,4 \%$ do peso total. Estes três aspectos refletem o fato de ela estar menos degradada que as demais amostras. 
Comparando-se a Figura 5.37 e a Figura 5.38 verifica-se que a diversidade de todas as amostras diminuiu, porém nas amostras coletadas por sondagem a trado os plásticos moles continuam sendo uma fração significativa. Isso se explica pelo fato de o trado ser capaz de cortar estes componentes durante a amostragem, como discutido anteriormente.

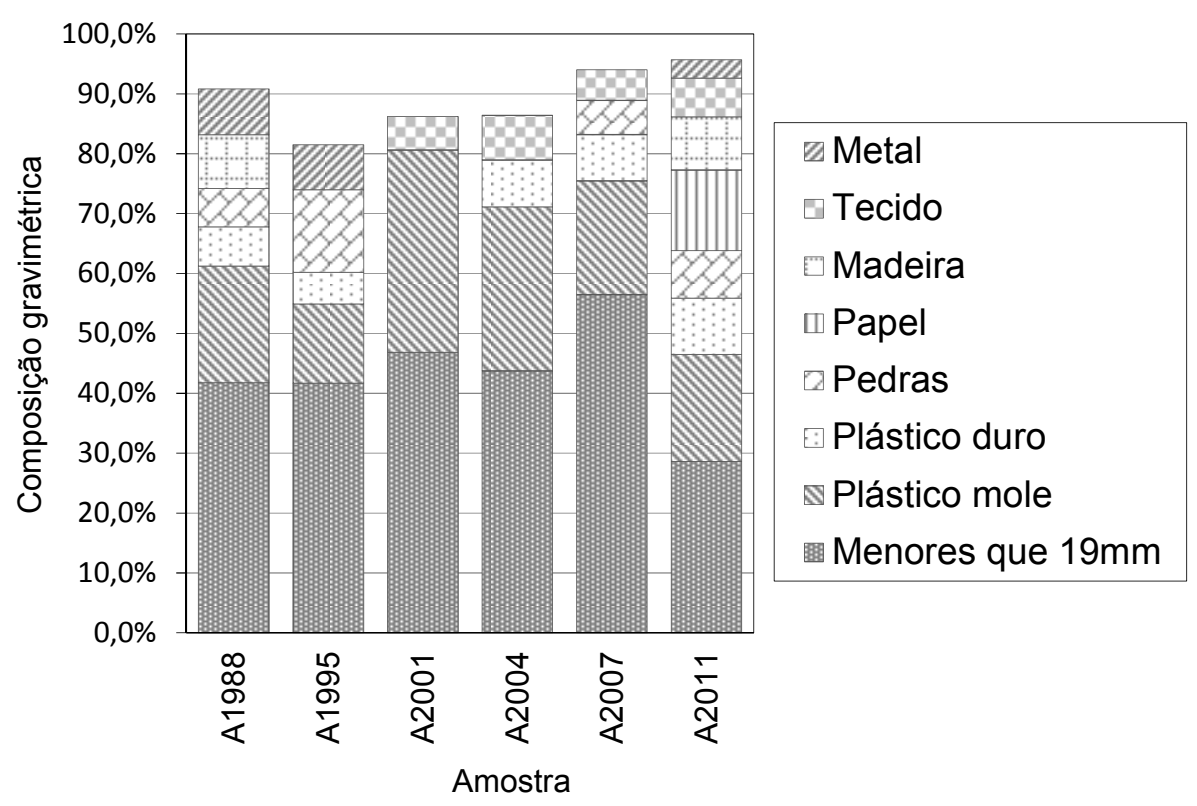

Figura 5.37 - Comparação da composição gravimétrica das amostras em campo (componentes mais significativos apenas, base seca).

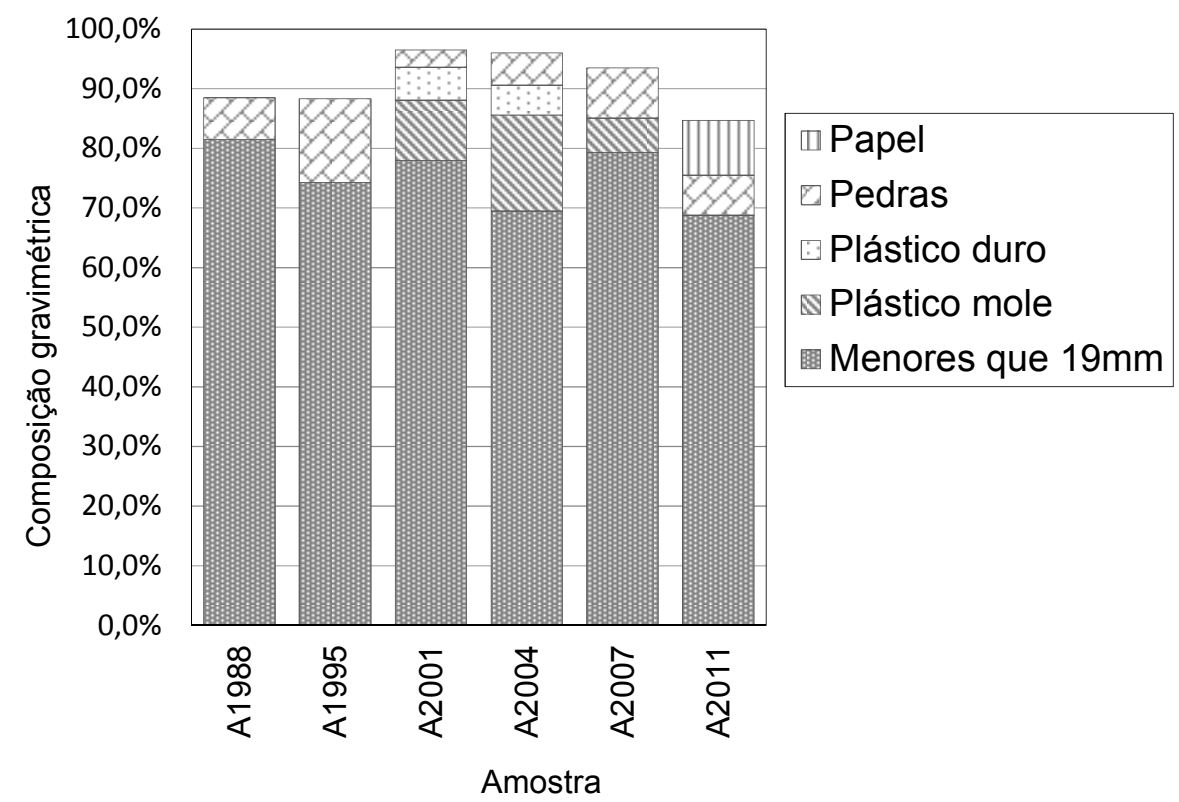

Figura 5.38 - Comparação da composição gravimétrica das amostras ensaiadas (componentes mais significativos apenas, base seca). 
Em todas as amostras as pedras são uma fração importante. Isso se deve ao fato de estes materiais terem massa específica elevada, pois na realidade não são componentes significativos em termos de volume, como se pode observar na Figura 5.39. Na Figura 5.40 apresenta-se um detalhe da composição desta fração. Percebe-se que na amostra A2011 ela é composta predominantemente por fragmentos angulosos, tais como pedaços de rochas ornamentais e cacos cerâmicos (vasos, telhas, azulejos). Na amostra A1995 predominam componentes arredondados, típicos da alteração esferoidal dos basaltos que ocorrem na região de São Carlos. Nas demais amostras a situação é intermediária, havendo fragmentos dos dois tipos. Acredita-se que a incorporação dos fragmentos arredondados ocorra durante o aterramento dos resíduos, pois os solos de alteração de basalto que correm na região são frequentemente utilizados para cascalhar os acessos e a frente de operação dos aterros nas épocas de chuvas.

Observe-se também na Figura 5.39 as proporções em volume dos materiais menores que $19 \mathrm{~mm}$ em relação aos demais componentes em ambas amostras e dos papéis na amostra A2011. A fração menor que $19 \mathrm{~mm}$ das amostras mais degradadas está mais mineralizada do que a da amostra A2011, que é composta principalmente por restos orgânicos (galhos, folhas, etc.) e por papel. Isto justifica o fato de se adotar nesta pesquisa valor de massa específica dos sólidos mais baixo para a mostra A2011 em relação às demais amostras, e também explica a menor participação em peso dessa fração na composição da amostra como um todo.

Dixon e Langer (2006) propõem um sistema de classificação para os componentes dos RSU que contempla suas características de interesse geotécnico. Um dos aspectos considerado neste sistema de classificação é a biodegradabilidade dos componentes do resíduo. Nas amostras ensaiadas inexistem componentes biodegradáveis em curto prazo, tais como restos de comida. Por outro lado, estão sempre presentes componentes ricos em lignina, que sofrem degradação a longo prazo. Esses componentes foram classificados como madeira e são compostos principalmente por madeiras trabalhadas, tais como pedaços de ripas, caibros, sarrafos e brinquedos, e secundariamente por caroços de frutas, sementes e galhos. Eles perfazem entre 2 e $9 \%$ em peso seco nas amostras coletadas em campo e entre 0 e $2 \%$ nas amostras ensaiadas. Na amostra A2011 também estão presentes componentes que sofrem biodegradação a médio prazo, representados por folhas de árvores (classificadas como madeira) e por papéis. Esta composição se reflete também nos resultados dos ensaios físicoquímicos e bioquímicos apresentados no item 5.2.1.1. 


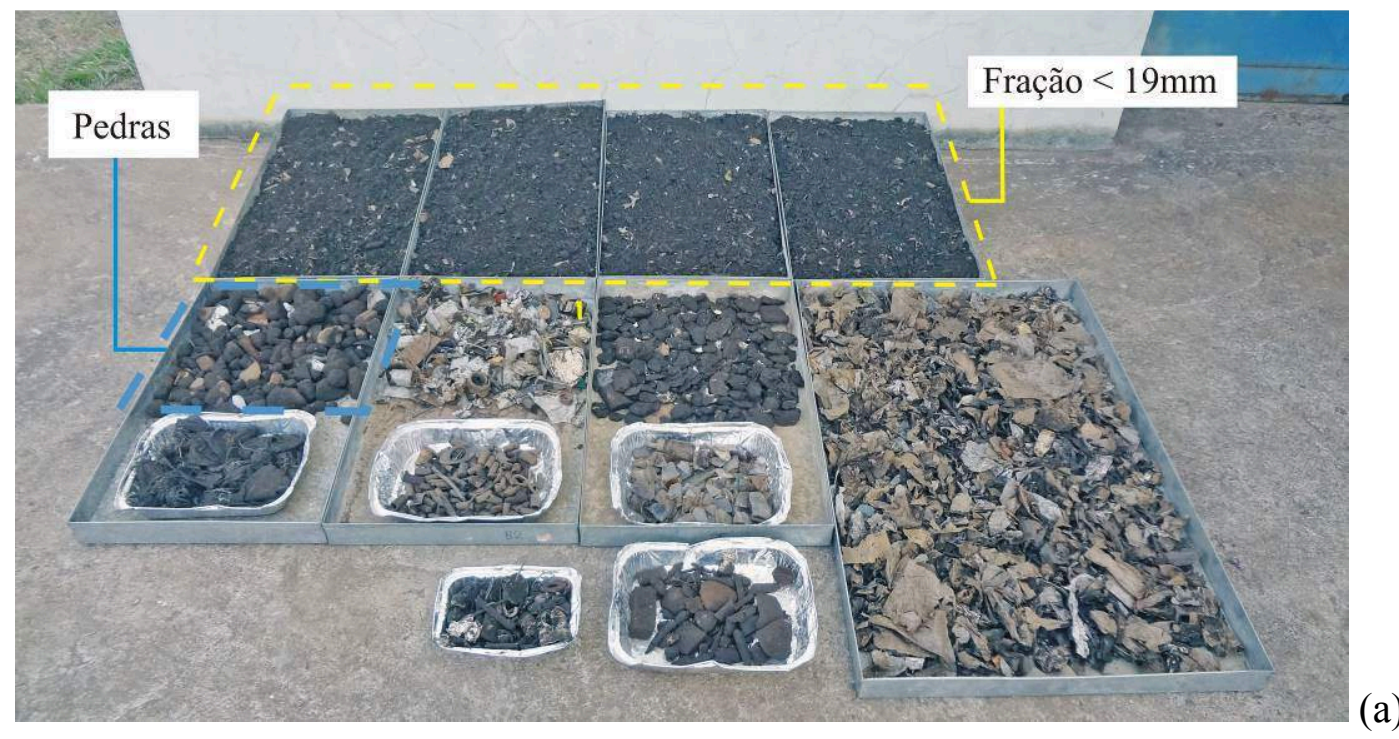

(a)

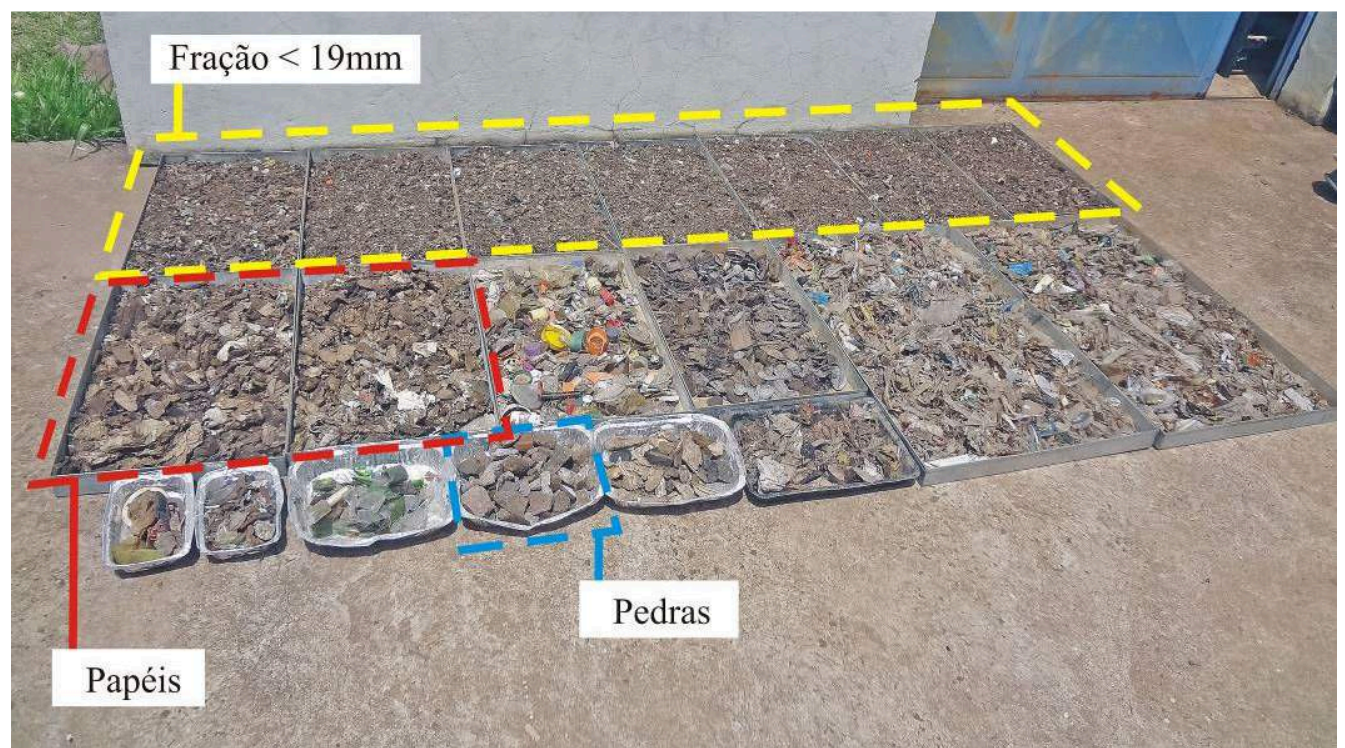

(b)

Figura 5.39 - Proporção dos componentes nas amostras ensaiadas (a) A1995 e (b) A2011.

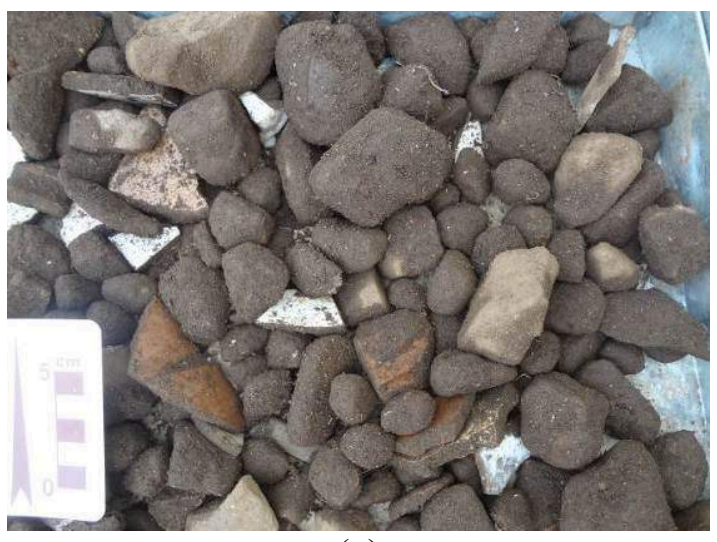

(a)

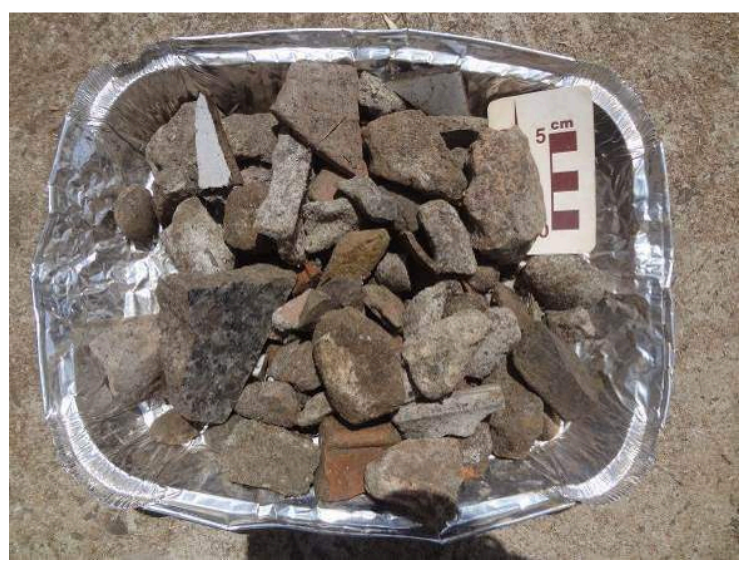

(b)

Figura 5.40 - Aspecto da fração "pedras" nas amostras (a) A1995 e (b) A2011. 
Porém, de maior interesse para a análise dos resultados dos ensaios de cisalhamento direto é a discussão sobre o papel que cada componente exerce quando o RSU é solicitado mecanicamente. Dixon e Langer (2006) propõem que os componentes do RSU sejam classificados em relação à sua forma e às suas propriedades de resistência à tração, à compressão e ao cisalhamento, bem como sua elasticidade e alongamento na ruptura, adotando-se três categorias: "incompressíveis", "compressíveis" e "reforçantes". Os componentes das seis amostras ensaiadas foram agrupados, de acordo com essa classificação. $\mathrm{Na}$ categoria "reforçantes" foram reunidos os plásticos moles, os plásticos duros, os papéis, os têxteis, as madeiras e os metais. Na categoria "compressíveis" estão incluídas as borrachas. $\mathrm{Na}$ categoria "incompressíveis" estão reunidos as pedras, os vidros e os materiais classificados como "outros". A Tabela 5.20 apresenta as porcentagens dos componentes para as seis amostras ensaiadas.

Tabela 5.20 - Porcentagem (em peso seco) dos componentes das amostras, adaptando-se classificação proposta por Dixon e Langer (2006).

\begin{tabular}{ccccccccccccc}
\hline & \multicolumn{10}{c}{ Amostra } \\
\cline { 2 - 13 } Classe & \multicolumn{1}{c}{ A1988 } & \multicolumn{1}{c}{ A1995 } & \multicolumn{1}{c}{ A2001 } & A2004 & A2007 & \multicolumn{2}{c}{ A2011 } \\
\cline { 2 - 13 } & $\mathrm{C}$ & $\mathrm{E}$ & $\mathrm{C}$ & $\mathrm{E}$ & $\mathrm{C}$ & $\mathrm{E}$ & $\mathrm{C}$ & $\mathrm{E}$ & $\mathrm{C}$ & $\mathrm{E}$ & $\mathrm{C}$ & $\mathrm{E}$ \\
\hline Reforçantes & 46,2 & 8,0 & 35,4 & 6,1 & 49,1 & 17,8 & 50,8 & 23,7 & 59,1 & 11,6 & 46,2 & 20,7 \\
compr. & 0,7 & 0,1 & 4,5 & 1,2 & 0,3 & 0,5 & 0,8 & 0,5 & 0,4 & 0,2 & 1,7 & 0,2 \\
incompr. & 53,1 & 91,9 & 60,1 & 92,8 & 50,6 & 81,7 & 48,5 & 75,8 & 39,2 & 88,2 & 52,4 & 79,1 \\
Total & 100,0 & 100,0 & 100,0 & 100,0 & 100,0 & 100,0 & 100,0 & 100,0 & 100,0 & 100,0 & 100,0 & 100,0 \\
\hline $\mathrm{C}=$ campo; E $=$ ensaio & & & & & & & & & & &
\end{tabular}

Comparando-se a composição gravimétrica de campo e a composição gravimétrica do material ensaiado para cada ano de aterramento, como apresentado na Figura 5.41, verifica-se que todas as amostras predominam os componentes incompressíveis em relação aos componentes reforçantes. As porcentagens de componentes compressíveis são pouco significativas para esta análise.

A Figura 5.42 apresenta os resultados das análises granulométricas realizadas com as amostras submetidas aos ensaios de cisalhamento direto, bem como a faixa de granulometria publicada por Jessberger (1994) como sendo típica de RSU e a faixa das granulometrias dos materiais ensaiados por Carvalho (1999). 


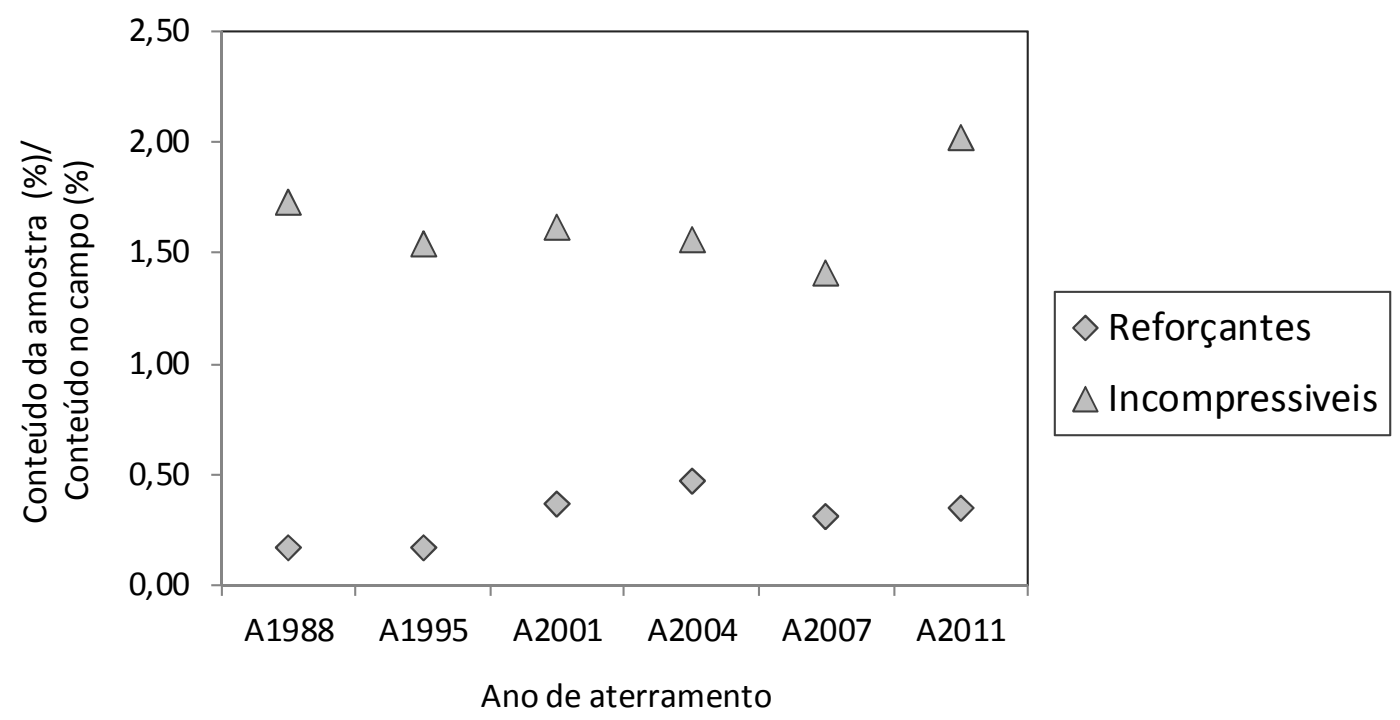

Figura 5.41 - Relação entre a porcentagem de cada classe de componente na composição gravimétrica da amostra coletada em campo e da amostra ensaiada (em peso seco).

Verifica-se que as amostras A1988, A2001, A2004 e A2007 apresentam granulometrias bastante semelhantes entre si, enquanto que as amostras A1995 e A2011 são compostas por partículas maiores. A amostra A2011 tem distribuição granulométrica semelhante à das amostras ensaiadas por Carvalho (1999), porém não se encaixa na faixa proposta por Jessberger (1994). Todas as demais amostras não se encaixam nas faixas de granulometria publicadas por esses autores.

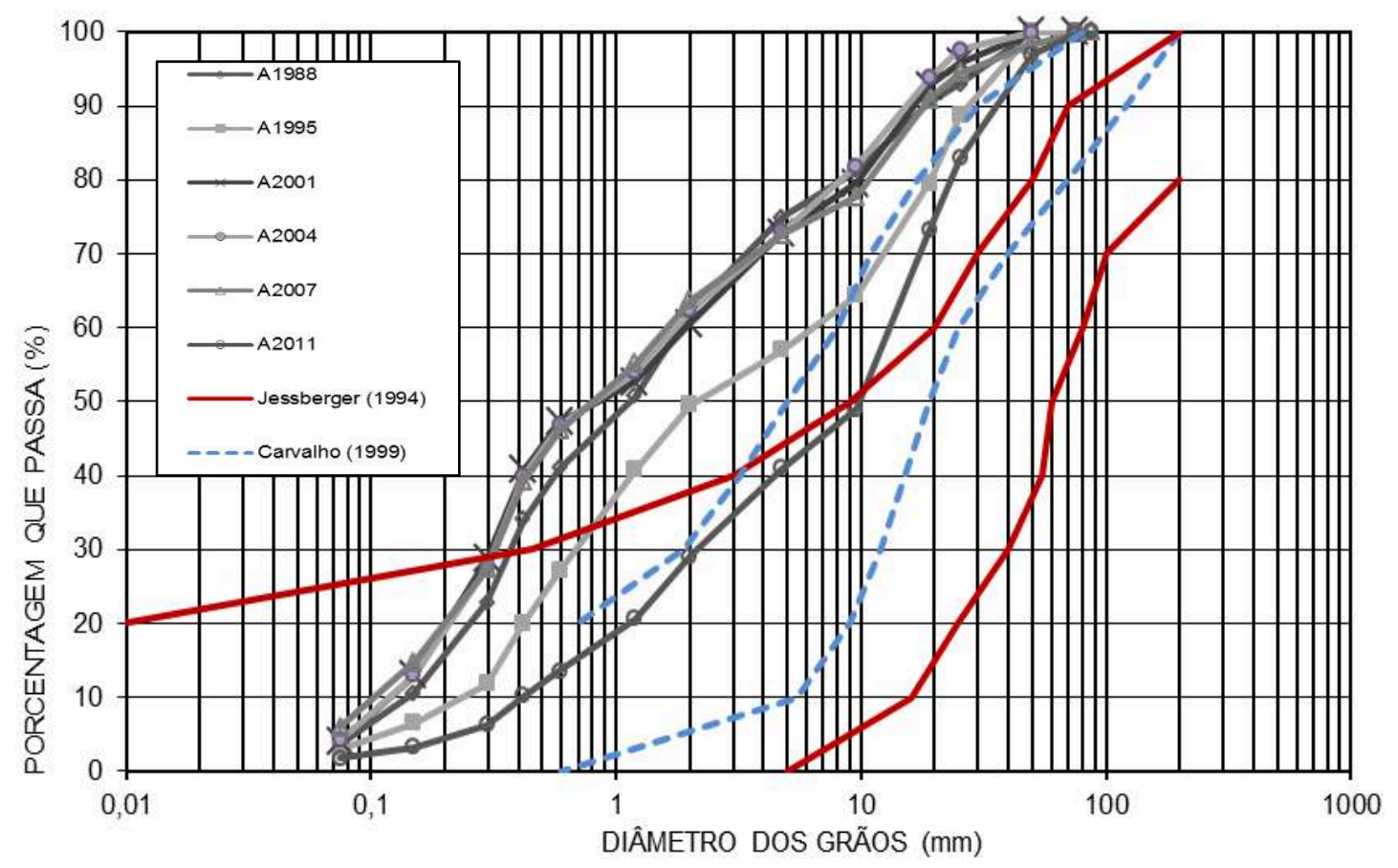

Figura 5.42 - Resultados das análises granulométricas das amostras ensaiadas. 
5.2.2 Resultados dos ensaios de cisalhamento direto

\subsubsection{Fase de adensamento}

$\mathrm{Na}$ fase de adensamento as amostras apresentaram comportamento semelhante. Registrou-se um recalque imediato pronunciado em todas elas, e em poucos minutos foi atingida uma situação de recalques secundários estável, que implicava em diminuição de altura muito pequena (milimétrica) do corpo de prova e que, portanto, pouco alterava os índices físicos do material a ser ensaiado na fase de cisalhamento. As Figuras 5.43 a 5.48 apresentam os resultados da fase de adensamento dos corpos de prova destas amostras.

Apesar do pequeno tempo de ensaio foram calculados coeficientes de adensamento secundário em função da deformação específica (Equação 5.1) para os diversos corpos de prova ensaiados. Os resultados são apresentados na Tabela 5.21 e na Figura 5.49, juntamente com as envoltórias dos resultados obtidos por Carvalho (1999). Verifica-se que há grande dispersão dos resultados, o que pode estar relacionado às variações na composição das amostras e ao pequeno tempo de ensaio.

$$
C \alpha \varepsilon=\frac{\frac{\Delta H}{H o}}{\Delta \log t}
$$

Em que: $\mathrm{C} \alpha \varepsilon=$ coeficiente de adensamento secundário, $\Delta \mathrm{H}=$ variação de altura do corpo de prova, $\mathrm{Ho}=$ altura inicial do corpo de prova e $\mathrm{t}=$ tempo em que ocorreu a variação de altura considerada. 


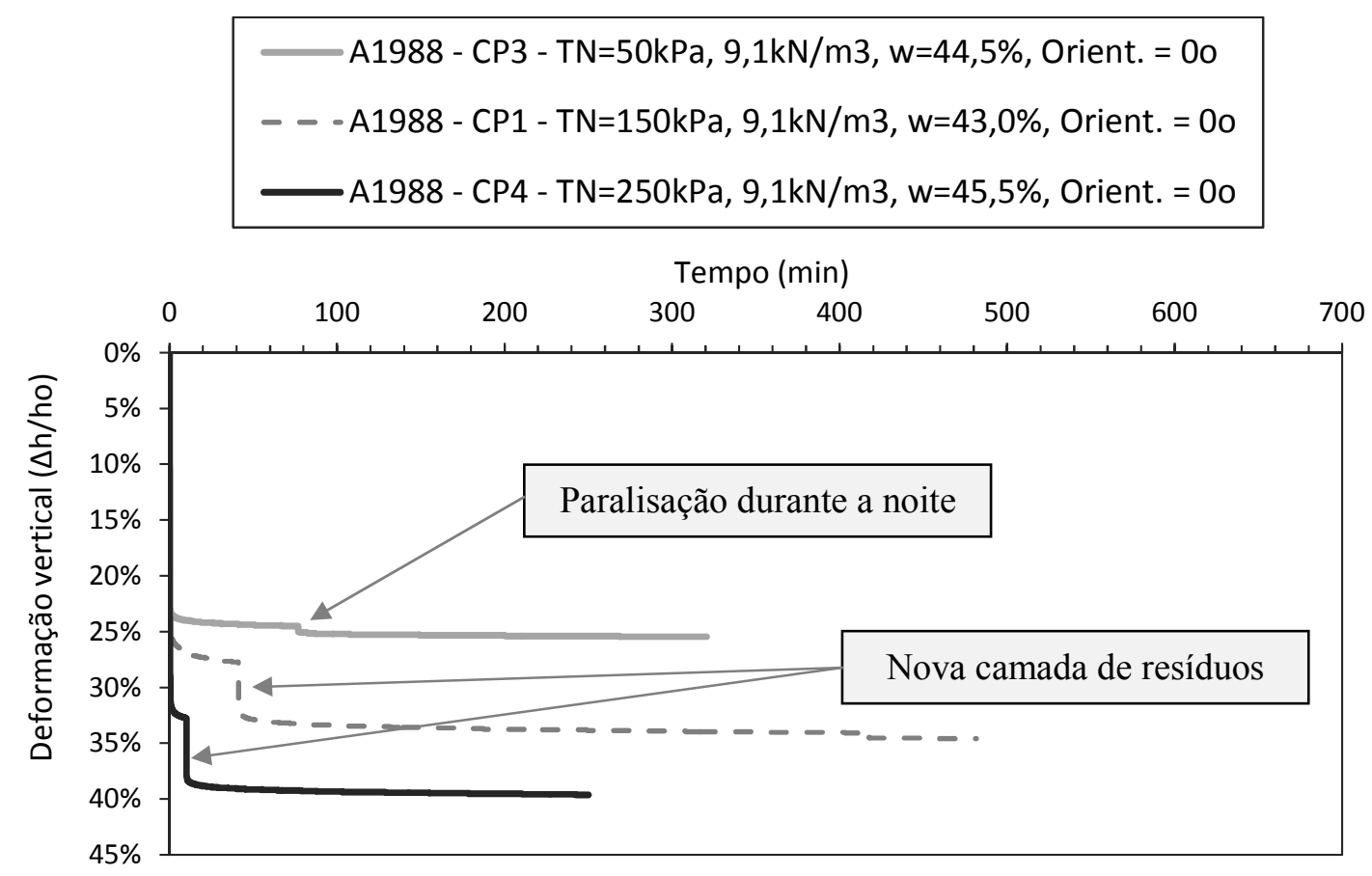

Figura 5.43 - Resultados da fase de adensamento dos corpos de prova da amostra A1988.

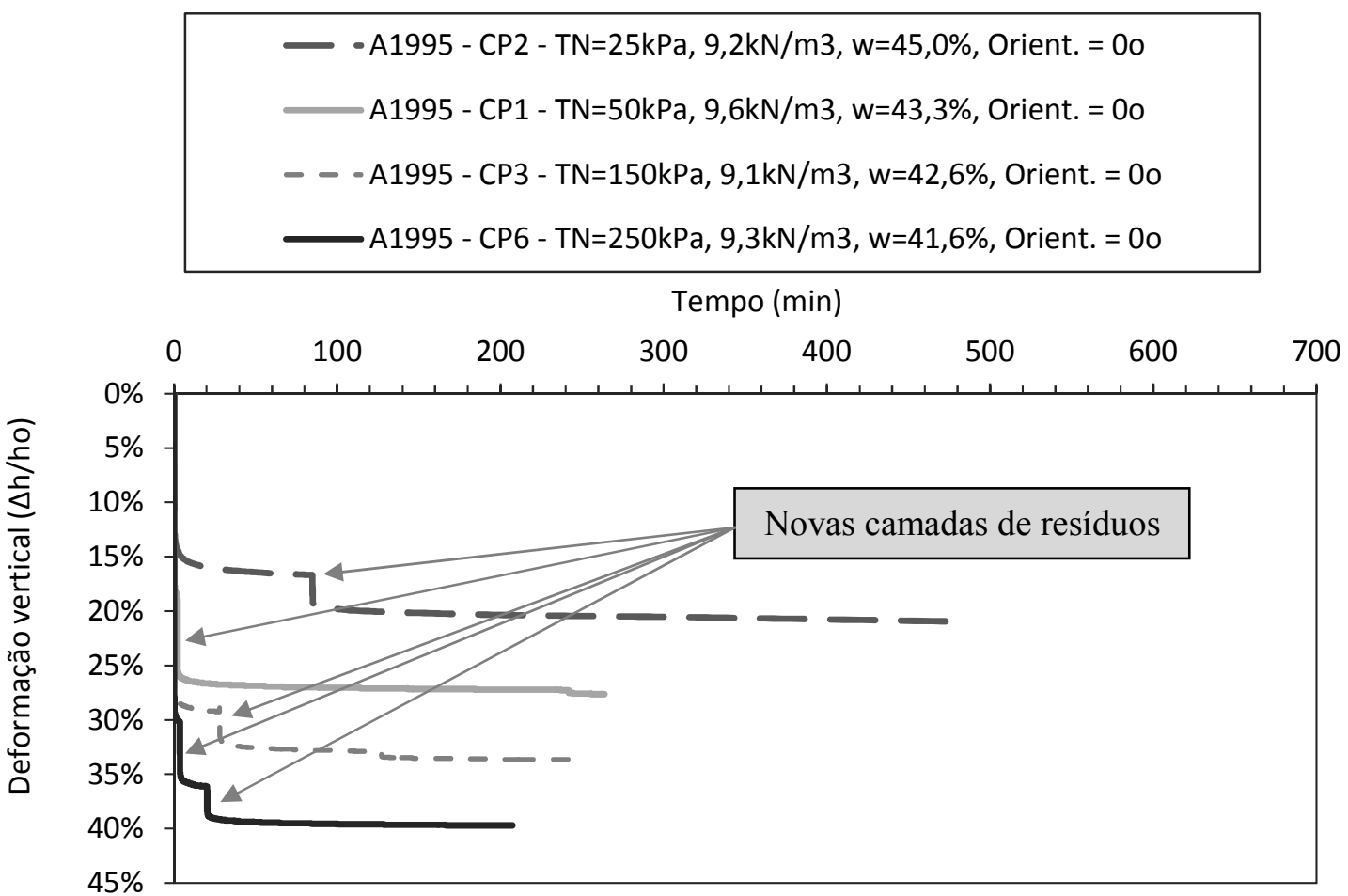

Figura 5.44 - Resultados da fase de adensamento dos corpos de prova da amostra A1995. 


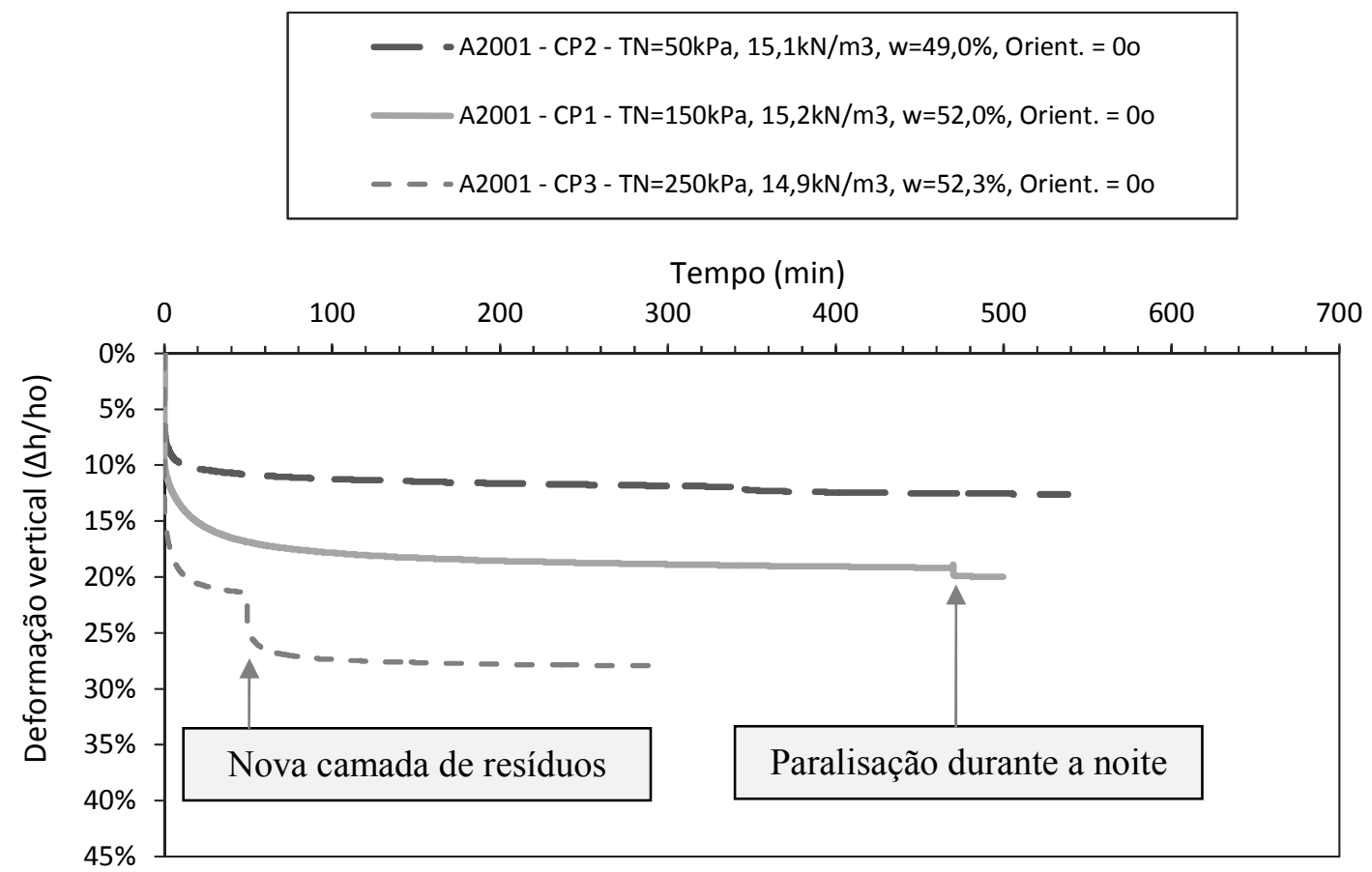

Figura 5.45 - Resultados da fase de adensamento dos corpos de prova da amostra A2001.

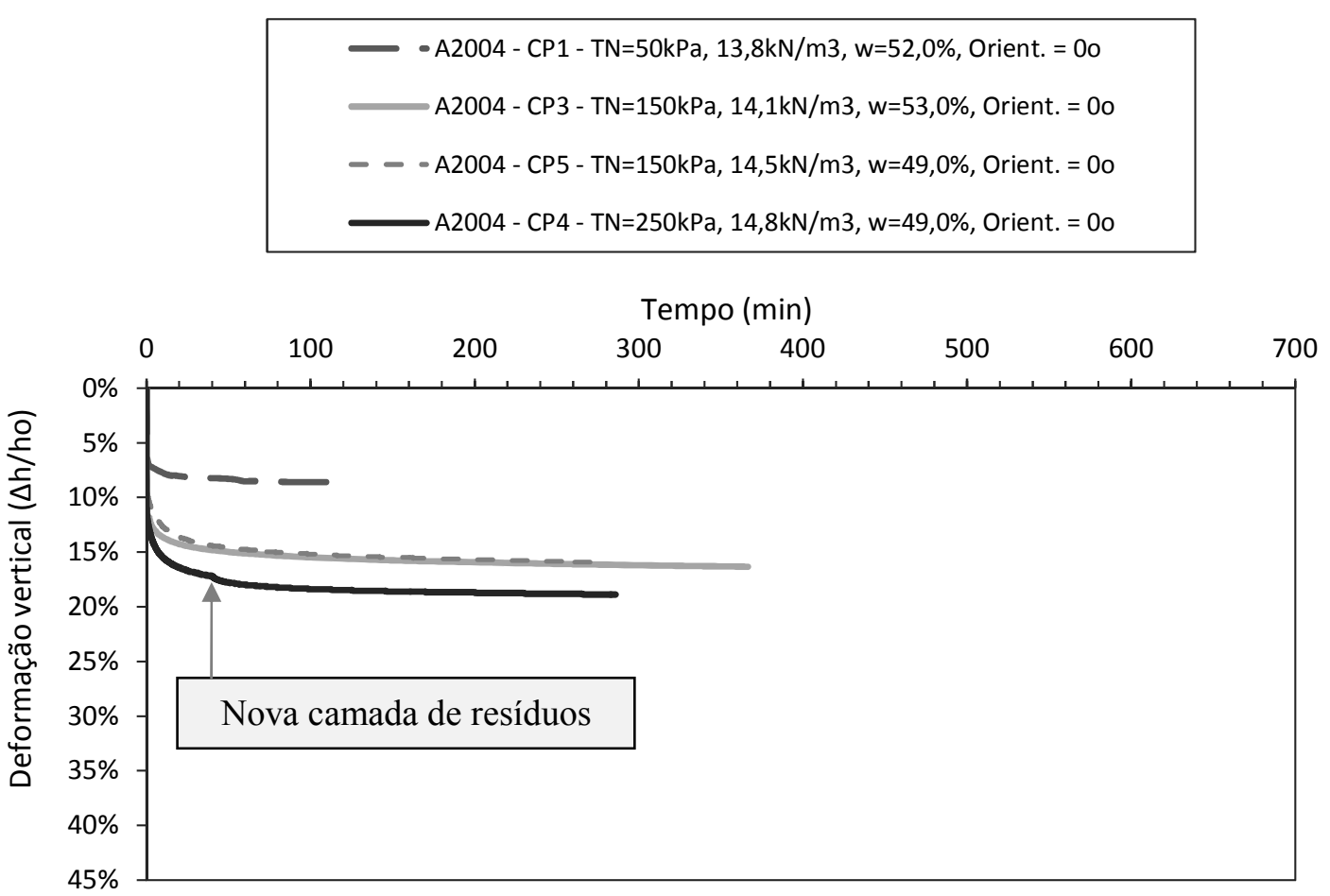

Figura 5.46 - Resultados da fase de adensamento dos corpos de prova da amostra A2004. 


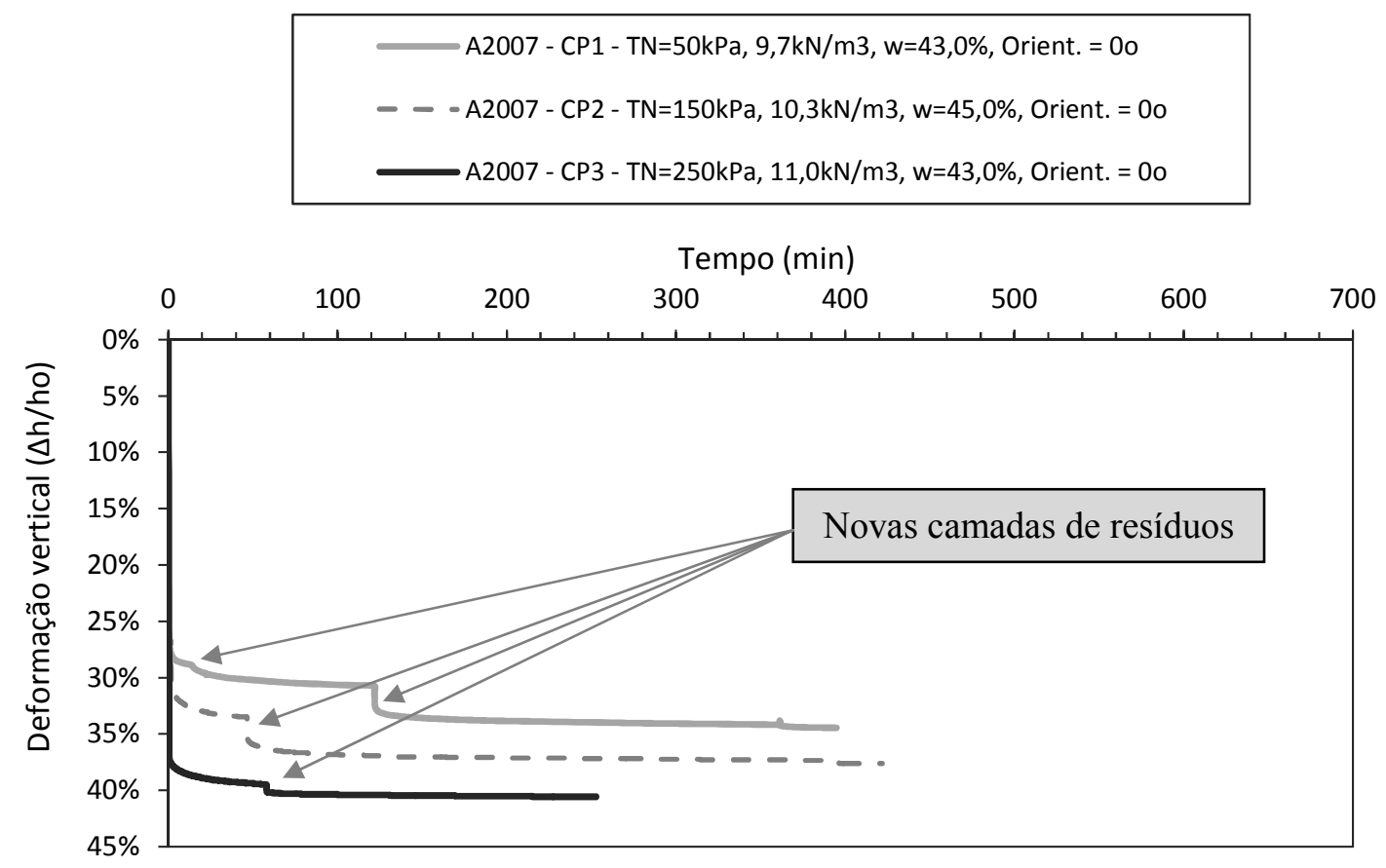

Figura 5.47 - Resultados da fase de adensamento dos corpos de prova da amostra A2007.

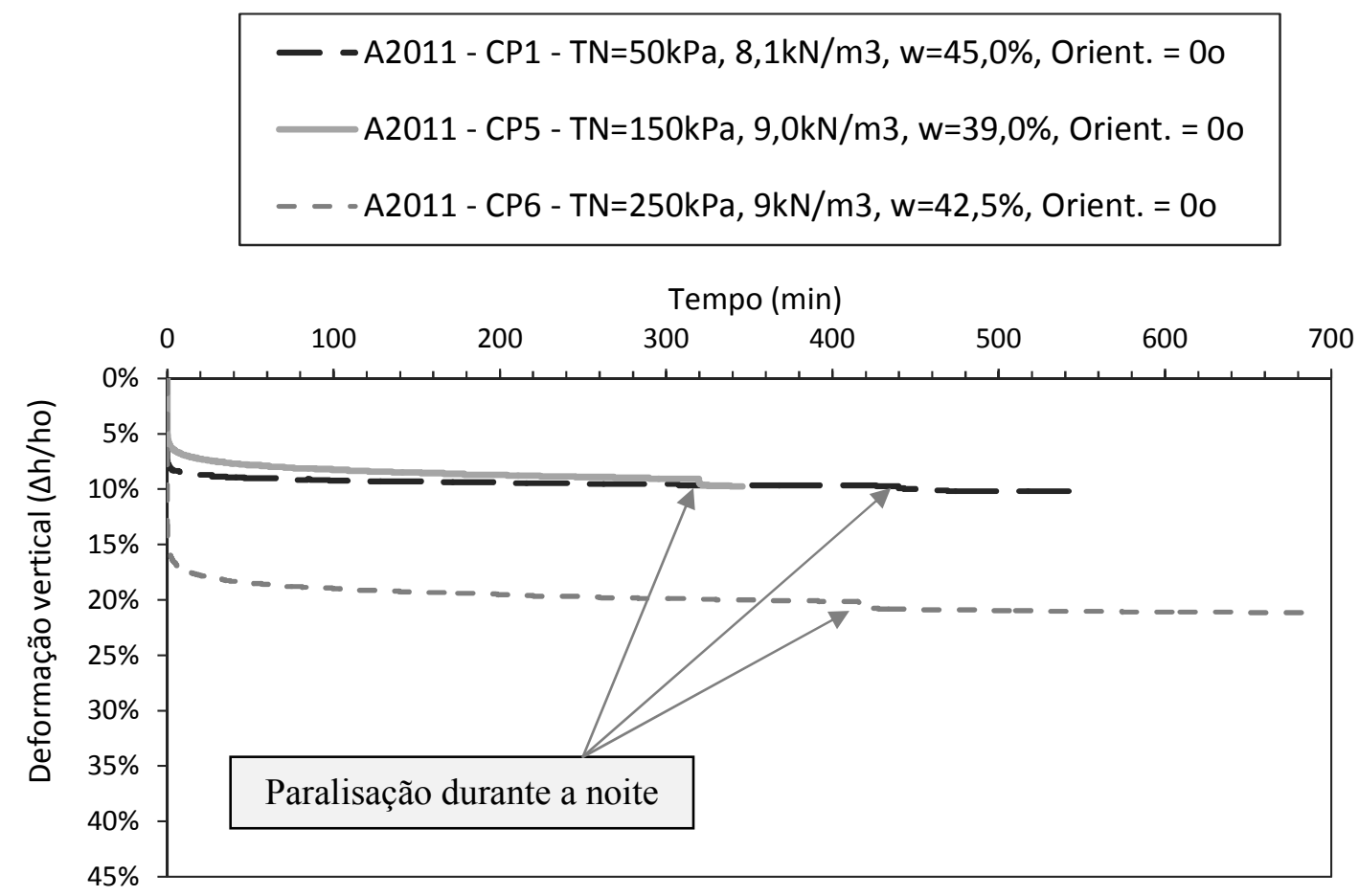


Figura 5.48 - Resultados da fase de adensamento dos corpos de prova da amostra A2011.

Tabela 5.21 - Características dos corpos de prova na moldagem.

\begin{tabular}{ccc} 
Corpo de Prova & Tensão normal $(\mathrm{kPa})$ & $\mathrm{C} \alpha_{(\varepsilon)}$ \\
\hline A1988 CP3 & 50 & 0,0053 \\
A1988 CP1 & 150 & 0,0106 \\
A1988 CP4 & 250 & 0,0070 \\
\hline A1995 CP2 & 25 & 0,0156 \\
A1995 CP1 & 50 & 0,0058 \\
A1995 CP3 & 150 & 0,0104 \\
A1995 CP6 & 250 & 0,0050 \\
\hline A2001 CP2 & 50 & 0,0125 \\
A2001 CP1 & 150 & 0,0186 \\
A2001 CP3 & 250 & 0,0086 \\
\hline A2004 CP1 & 50 & 0,0029 \\
A2004 CP3 & 150 & 0,0144 \\
A2004 CP5 & 150 & 0,0176 \\
A2004 CP4 & 250 & 0,0111 \\
\hline A2007 CP1 & 50 & 0,0131 \\
A2007 CP2 & 150 & 0,0090 \\
A2007 CP3 & 250 & 0,0054 \\
\hline A2011 CP-1 & 50 & 0,0077 \\
A2011 CP-5 & 150 & 0,0165 \\
A2011 CP-6 & 250 & 0,0179 \\
\hline
\end{tabular}

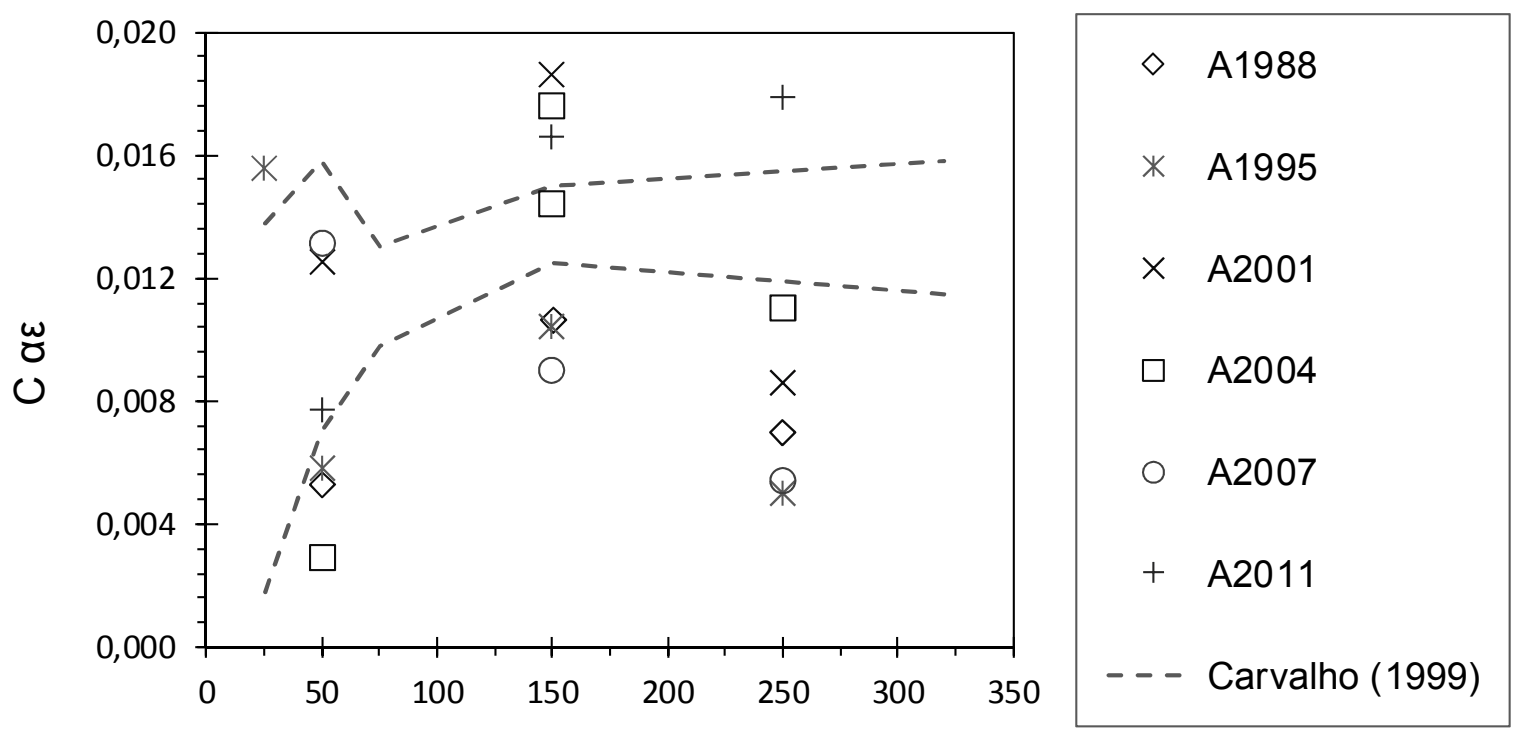

Tensão vertical $(\mathrm{kPa})$

Figura 5.49 - Coeficientes de adensamento secundário calculados para as amostras seis amostras ensaiadas. 
Como consequência das compressões e da expulsão de água ocorridas nas fases de adensamento e de cisalhamento, os pesos específicos e as umidades dos corpos de prova variaram durante os ensaios. As Tabelas 5.22 a 5.24 apresentam as características dos corpos de prova em três momentos dos ensaios: moldagem, início do cisalhamento e término do cisalhamento. As propriedades grau de saturação e índice de vazios foram calculadas considerando-se o peso específico dos sólidos como constante ao longo de todo o ensaio e igual a 2,4 g/cm $\mathrm{cm}^{3}$ para as amostras A1988, A1995, A2001, A2004 e A2007 e igual a 1,6 g/cm para a amostra A2011.

Os volumes de água expulsos em casa fase do ensaio são apresentados na Tabela 5.25.

Tabela 5.22 - Características dos corpos de prova na moldagem.

\begin{tabular}{ccccccc}
\hline $\begin{array}{c}\text { Corpo de } \\
\text { Prova }\end{array}$ & $\begin{array}{c}\text { Tensão } \\
\text { normal } \\
(\mathrm{kPa})\end{array}$ & Umidade $(\%)$ & $\begin{array}{c}\text { Peso } \\
\text { Específico } \\
\left(\mathrm{kN} / \mathrm{m}^{3}\right)\end{array}$ & $\begin{array}{c}\text { Peso Esp. } \\
\text { seco } \\
\left(\mathrm{kN} / \mathrm{m}^{3}\right)\end{array}$ & e & $\mathrm{S}_{\mathrm{R}}$ \\
\hline \multicolumn{7}{c}{ Amostras rasas } \\
\hline A1988 CP3 & 50 & 44,5 & 9,1 & 6,3 & 2,73 & $39 \%$ \\
A1988 CP1 & 150 & 43,0 & 9,1 & 6,4 & 2,70 & $38 \%$ \\
A1988 CP4 & 250 & 45,5 & 9,1 & 6,3 & 2,76 & $40 \%$ \\
A1995 CP2 & 25 & 45,0 & 9,2 & 6,3 & 2,71 & $40 \%$ \\
A1995 CP1 & 50 & 43,3 & 9,6 & 6,7 & 2,51 & $41 \%$ \\
A1995 CP3 & 150 & 42,6 & 9,1 & 6,4 & 2,69 & $38 \%$ \\
A1995 CP6 & 250 & 41,6 & 9,3 & 6,6 & 2,58 & $39 \%$ \\
A2011 CP1 & 50 & 45,0 & 8,1 & 5,6 & 1,81 & $40 \%$ \\
A2011 CP5 & 150 & 39,0 & 9,0 & 6,5 & 1,42 & $44 \%$ \\
A2011 CP6 & 250 & 42,5 & 9,0 & 6,3 & 1,48 & $46 \%$ \\
A2007 CP1 & 50 & 43,0 & 9,7 & 6,8 & 2,47 & $42 \%$ \\
A2007 CP2 & 150 & 45,0 & 10,3 & 7,1 & 2,31 & $47 \%$ \\
A2007 CP3 & 250 & 43,0 & 11,0 & 7,7 & 2,06 & $50 \%$ \\
\hline & \multicolumn{7}{c}{ Amostras profundas } & & & \\
\hline A2004 CP1 & 50 & 52,0 & 13,8 & 9,1 & 1,59 & $78 \%$ \\
A2004 CP3 & 150 & 53,0 & 14,1 & 9,2 & 1,55 & $82 \%$ \\
A2004 CP5 & 150 & 49,0 & 14,5 & 9,7 & 1,42 & $83 \%$ \\
A2004 CP4 & 250 & 49,0 & 14,8 & 9,9 & 1,37 & $86 \%$ \\
A2001 CP2 & 50 & 49,0 & 15,1 & 10,1 & 1,32 & $89 \%$ \\
A2001 CP1 & 150 & 52,0 & 15,2 & 10,0 & 1,35 & $92 \%$ \\
A2001 CP3 & 250 & 52,3 & 14,9 & 9,8 & 1,40 & $89 \%$ \\
\hline
\end{tabular}


Tabela 5.23 - Características dos corpos de prova no início do cisalhamento.

\begin{tabular}{cccccccc}
\hline $\begin{array}{c}\text { Corpo de } \\
\text { Prova }\end{array}$ & $\begin{array}{c}\text { Tensão } \\
\text { normal } \\
(\mathrm{kPa})\end{array}$ & $\begin{array}{c}\text { Altura do } \\
\mathrm{CP}(\mathrm{mm})\end{array}$ & $\begin{array}{c}\text { Umidade } \\
(\%)\end{array}$ & $\begin{array}{c}\text { Peso } \\
\text { Específ. } \\
\left(\mathrm{kN} / \mathrm{m}^{3}\right)\end{array}$ & $\begin{array}{c}\text { Peso esp. } \\
\text { seco } \\
\left(\mathrm{kN} / \mathrm{m}^{3}\right)\end{array}$ & e & $\mathrm{S}_{\mathrm{R}}$ \\
\hline \multicolumn{7}{c}{ Amostras rasas } \\
\hline A1988 CP3 & 50 & 394 & 44,5 & 12,3 & 8,5 & 1,76 & $61 \%$ \\
A1988 CP1 & 150 & 397 & 42,2 & 13,7 & 9,6 & 1,44 & $70 \%$ \\
A1988 CP4 & 250 & 427 & 45,5 & 14,7 & 10,1 & 1,33 & $82 \%$ \\
A1995 CP2 & 25 & 424 & 45,0 & 11,6 & 8,0 & 1,94 & $56 \%$ \\
A1995 CP1 & 50 & 433 & 40,6 & 12,7 & 9,0 & 1,60 & $61 \%$ \\
A1995 CP3 & 150 & 423 & 42,1 & 14,0 & 9,9 & 1,39 & $73 \%$ \\
A1995 CP6 & 250 & 400 & 38,7 & 15,6 & 11,2 & 1,09 & $85 \%$ \\
A2011 CP1 & 50 & 419 & 45,0 & 9,0 & 6,2 & 1,53 & $47 \%$ \\
A2011 CP5 & 150 & 422 & 39,0 & 10,0 & 7,2 & 1,18 & $53 \%$ \\
A2011 CP6 & 250 & 394 & 42,5 & 11,4 & 8,0 & 0,96 & $71 \%$ \\
A2007 CP1 & 50 & 400 & 39,6 & 14,4 & 10,3 & 1,28 & $74 \%$ \\
A2007 CP2 & 150 & 395 & 36,3 & 15,9 & 11,7 & 1,02 & $86 \%$ \\
A2007 CP3 & 250 & 371 & 32,2 & 17,0 & 12,9 & 0,83 & $93 \%$ \\
\hline & \multicolumn{7}{c}{ Amostras profundas } \\
\hline A2004 CP1 & 50 & 375 & 49,7 & 14,9 & 10,0 & 1,36 & $88 \%$ \\
A2004 CP3 & 150 & 374 & 41,8 & 15,7 & 11,1 & 1,12 & $89 \%$ \\
A2004 CP5 & 150 & 465 & 36,2 & 16,0 & 11,7 & 1,00 & $87 \%$ \\
A2004 CP4 & 250 & 404 & 35,1 & 16,0 & 11,8 & 0,99 & $85 \%$ \\
A2001 CP2 & 50 & 392 & 44,7 & 16,3 & 11,3 & 1,09 & $99 \%$ \\
A2001 CP1 & 150 & 378 & 36,8 & 17,0 & 12,4 & 0,89 & $99 \%$ \\
A2001 CP3 & 250 & 385 & 33,0 & 18,1 & 13,6 & 0,73 & $109 \%\left(^{*}\right)$ \\
\hline
\end{tabular}

$(*)$ Ver comentário no texto.

Observa-se nesta tabela valores de grau de saturação superiores a $100 \%$, os quais representam um volume de água maior que o volume de vazios existente no corpo de prova, o que fisicamente não é possível acontecer. Cabe lembrar que este índice físico, assim como o índice de vazios, foi calculado adotando-se um valor de peso específico das partículas considerado razoável, em função do estado de degradação das amostras ensaiadas. A realização de ensaios para determinação deste índice com maior precisão pode resolver esse problema, porém ainda não há um procedimento normatizado para a realização dessa determinação. 
Tabela 5.24 - Características dos corpos de prova no final do cisalhamento.

\begin{tabular}{|c|c|c|c|c|c|c|c|}
\hline $\begin{array}{l}\text { Corpo de } \\
\text { Prova }\end{array}$ & $\begin{array}{c}\text { Tensão } \\
\text { normal } \\
(\mathrm{kPa})\end{array}$ & $\begin{array}{l}\text { Umidade } \\
\text { média } \\
(\%)\end{array}$ & $\begin{array}{l}\text { Umidade no } \\
\text { plano de } \\
\text { cisalham. } \\
(\%)\end{array}$ & $\begin{array}{c}\text { Peso } \\
\text { Específico } \\
\left(\mathrm{kN} / \mathrm{m}^{3}\right)\end{array}$ & $\begin{array}{l}\text { Peso esp. } \\
\text { seco } \\
\left(\mathrm{kN} / \mathrm{m}^{3}\right)\end{array}$ & $\mathrm{e}$ & $\mathrm{S}_{\mathrm{R}}$ \\
\hline
\end{tabular}

\begin{tabular}{cccccccc}
\hline \multicolumn{7}{c}{ Amostras rasas } \\
\hline A1988 CP3 & 50 & 43,5 & 42,7 & 13,1 & 9,1 & 1,58 & $66 \%$ \\
\hline A1988 CP1 & 150 & 40,6 & 38,2 & 14,0 & 10,0 & 1,36 & $72 \%$ \\
\hline A1988 CP4 & 250 & 40,7 & 35,9 & 15,7 & 11,2 & 1,11 & $88 \%$ \\
\hline A1995 CP2 & 25 & 44,9 & 45,2 & 11,8 & 8,1 & 1,89 & $57 \%$ \\
\hline A1995 CP1 & 50 & 38,4 & 36,2 & 12,7 & 9,2 & 1,56 & $59 \%$ \\
\hline A1995 CP3 & 150 & 39,9 & 31,8 & 14,5 & 10,4 & 1,27 & $75 \%$ \\
\hline A1995 CP6 & 250 & 35,1 & 30,1 & 16,3 & 12,1 & 0,95 & $89 \%$ \\
\hline A2011 CP1 & 50 & 45,0 & 46,3 & 9,5 & 6,6 & 1,39 & $52 \%$ \\
\hline A2011 CP5 & 150 & 38,1 & 37,0 & 10,4 & 7,5 & 1,08 & $56 \%$ \\
\hline A2011 CP6 & 250 & 42,5 & 41,6 & 11,8 & 8,3 & 0,89 & $76 \%$ \\
\hline A2007 CP1 & 50 & 37,2 & 33,9 & 15,4 & 11,2 & 1,10 & $82 \%$ \\
\hline A2007 CP2 & 150 & 32,3 & 26,1 & 16,9 & 12,8 & 0,84 & $92 \%$ \\
\hline A2007 CP3 & 250 & 27,4 & 24,8 & 18,0 & 14,1 & 0,66 & $99 \%$ \\
\hline & & & Amostras profundas & & & \\
\hline A2004 CP1 & 50 & 43,6 & 37,7 & 14,7 & 10,2 & 1,30 & $81 \%$ \\
\hline A2004 CP3 & 150 & 37,0 & 30,1 & 15,3 & 11,2 & 1,11 & $80 \%$ \\
\hline A2004 CP5 & 150 & 31,2 & 27,8 & 15,7 & 12,0 & 0,97 & $78 \%$ \\
\hline A2004 CP4 & 250 & 32,3 & 26,6 & 16,6 & 12,5 & 0,87 & $89 \%$ \\
\hline A2001 CP2 & 50 & 35,9 & 32,2 & 16,4 & 12,1 & 0,95 & $91 \%$ \\
\hline A2001 CP1 & 150 & 32,1 & 26,4 & 16,7 & 12,6 & 0,86 & $90 \%$ \\
\hline A2001 CP3 & 250 & 27,8 & 23,0 & 18,0 & 14,1 & 0,67 & $100 \%$ \\
\hline & & & & & & \\
\hline
\end{tabular}


Tabela 5.25 - Volumes de águas expulsos dos corpos de prova durante o ensaio.

\begin{tabular}{cccccc}
\hline \multirow{2}{*}{$\begin{array}{c}\text { Corpo de } \\
\text { Prova }\end{array}$} & $\begin{array}{c}\text { Tensão } \\
\text { normal } \\
(\mathrm{kPa})\end{array}$ & \begin{tabular}{c} 
Volumes de água (ml) \\
\cline { 3 - 6 }
\end{tabular} & \multicolumn{5}{c}{ Moldagem } & Adensamento Cisalhamento & Total \\
\hline A1988 CP3 & 50 & 0 & 0 & 0 & 0 \\
\hline A1988 CP1 & 150 & 0 & 780 & 920 & 1700 \\
\hline A1988 CP4 & 250 & 0 & 0 & 3550 & 3550 \\
\hline A1995 CP2 & 25 & 0 & 0 & 0 & 0 \\
\hline A1995 CP1 & 50 & 0 & 2610 & 1580 & 4190 \\
\hline A1995 CP3 & 150 & 0 & 570 & 1030 & 1600 \\
\hline A1995 CP6 & 250 & 0 & 3250 & 2480 & 5730 \\
\hline A2011 CP1 & 50 & 0 & 0 & 0 & 0 \\
\hline A2011 CP5 & 150 & 0 & 0 & 0 & 0 \\
\hline A2011 CP6 & 250 & 0 & 0 & 0 & 0 \\
\hline A2007 CP1 & 50 & 0 & 3520 & 1320 & 4840 \\
\hline A2007 CP2 & 150 & 0 & 9960 & 1840 & 11800 \\
\hline A2007 CP3 & 250 & 0 & 12890 & 2000 & 14890 \\
\hline & & Amostras profundas & & \\
\hline A2004 CP1 & 50 & 1110 & 1360 & 2360 & 4830 \\
\hline A2004 CP3 & 150 & 3290 & 8230 & 2850 & 14370 \\
\hline A2004 CP5 & 150 & 3200 & 11350 & 2300 & 16850 \\
\hline A2004 CP4 & 250 & 4420 & 12290 & 2550 & 19260 \\
\hline A2001 CP2 & 50 & 3150 & 7980 & 2350 & 13480 \\
\hline A2001 CP1 & 150 & 5200 & 12240 & 2140 & 19580 \\
\hline A2001 CP3 & 250 & 7900 & 17300 & 2550 & 27750 \\
\hline & & & & & \\
\hline
\end{tabular}

Nas Figuras 5.50 e 5.51 são apresentados os pesos específicos e os índices de vazios dos corpos de prova ao final da fase de adensamento. Eles são dependentes da tensão de confinamento aplicada em cada ensaio. O fato de os corpos de prova terem sido moldados com pesos específicos iniciais entorno de 9 e de $15 \mathrm{kN} / \mathrm{m}^{3}$ não foi determinante para definição da condição de adensamento da amostra imediatamente antes do ensaio. Isso fica evidente quando se analisam os pesos específicos das amostras A1988, A1995, A2007 e A2011, cujos corpos de prova foram moldados com 9-10 kN/m³ . A amostra A2011 exibiu sempre os menores valores de peso específico no início do cisalhamento. As amostras A1988 e A1995 podem ser agrupadas numa faixa intermediária de valores, enquanto que a amostra A2007 pode ser agrupada às amostras A2001 e A2004 para compor um último conjunto de resultados, sempre mais elevados que os demais. A composição das amostras parece ter maior 
relação com o seu peso específico imediatamente antes do ensaio, do que as condições iniciais de moldagem do corpo de prova.

Tendência semelhante pode ser verificada para o índice de vazios das amostras no início da fase de cisalhamento (Figura 5.51). Ele diminui, conforme aumenta a tensão confinante. As amostras A1988 e A1995 formam um conjunto que foi ensaiado com índices de vazios mais elevados. As amostras A2001, A2004, A2007 e A2011 podem ser agrupadas em outro conjunto, que foi ensaiado em condição mais adensada.

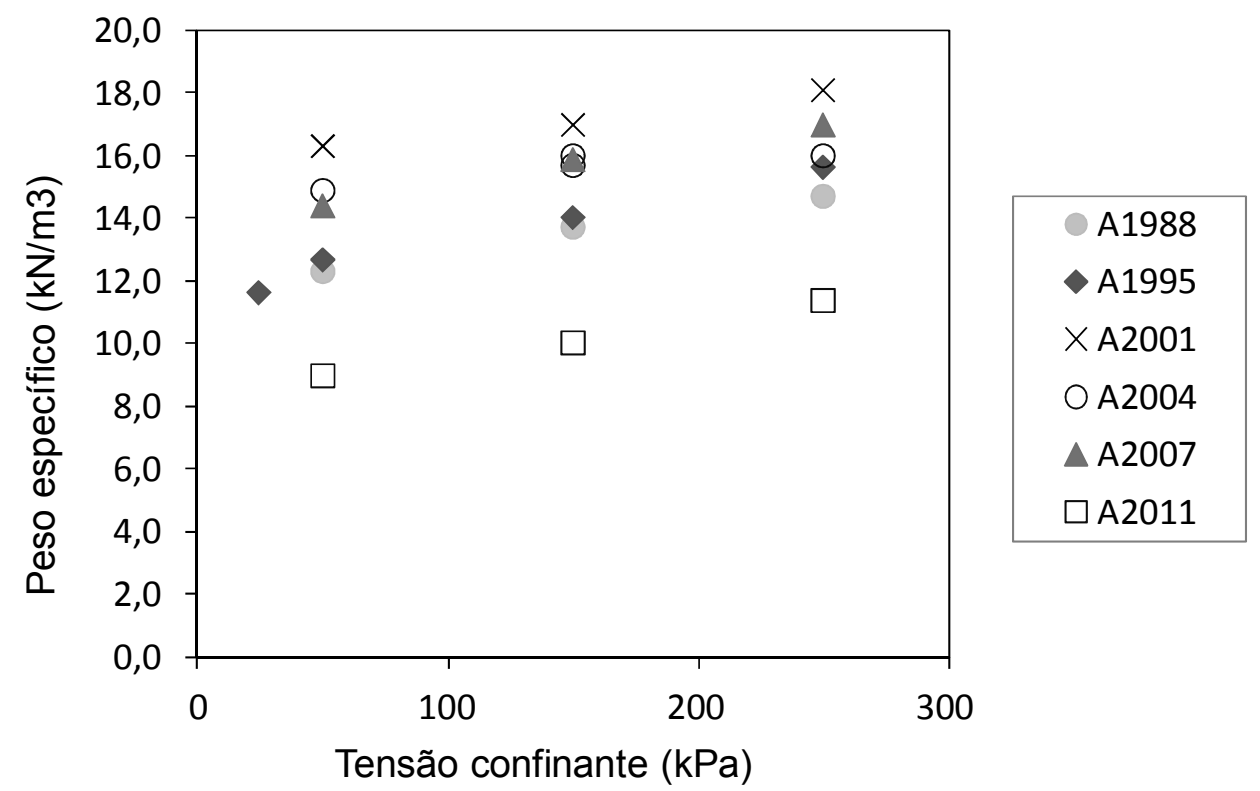

Figura 5.50 - Peso específico dos corpos de prova no início da fase de cisalhamento.

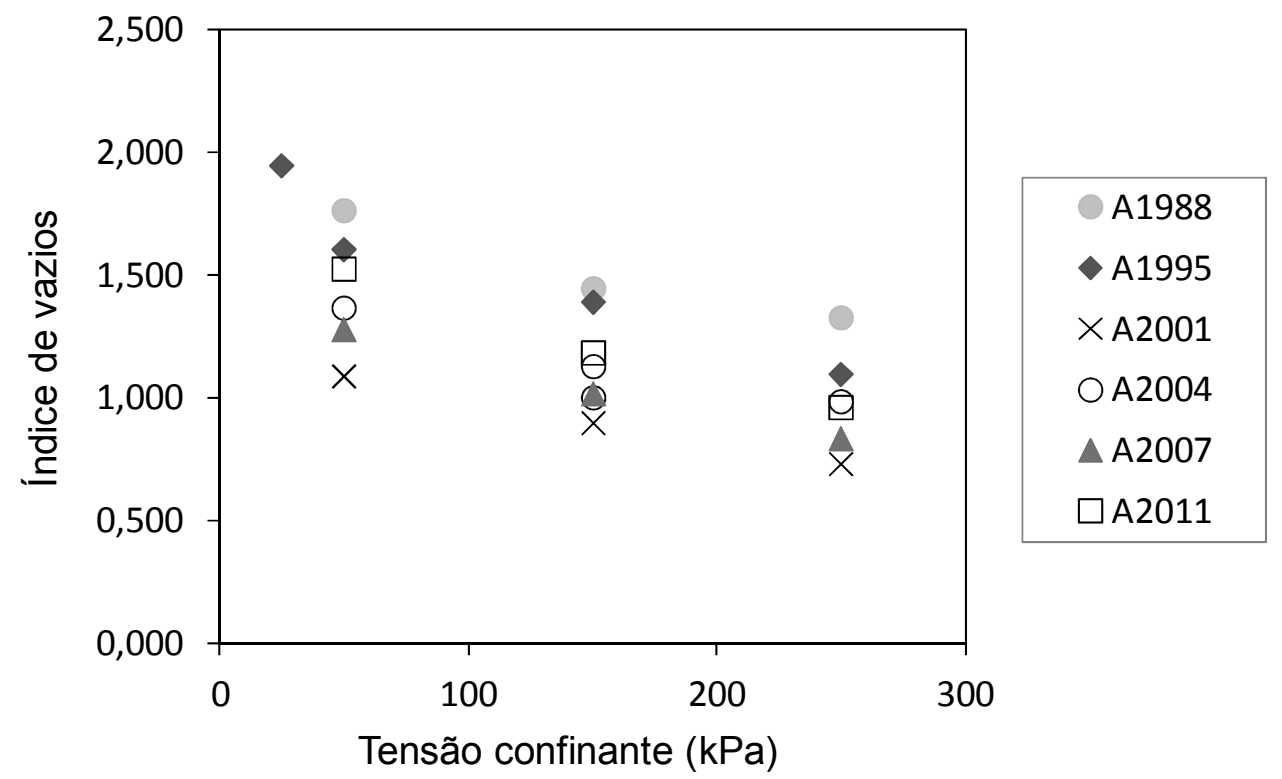

Figura 5.51 - Índice de vazios dos corpos de prova no início da fase de cisalhamento. 
As Figuras 5.52 a 5.57 apresentam as curvas tensão-deslocamento horizontal e as curvas deslocamento vertical - deslocamento horizontal das seis amostras estudadas nesta pesquisa. Todas as amostras ensaiadas na posição horizontal $\left(0^{\circ}\right)$ apresentaram o mesmo comportamento nas curvas tensão-deslocamento: exibem progressivo aumento das tensões conforme progride o deslocamento horizontal (endurecimento). Para todas as tensões normais ensaiadas as curvas exibem concavidade voltada para baixo e em alguns casos, as tensões parecem convergir para um valor assintótico, apresentando forma semelhante a uma hipérbole. O mesmo comportamento foi observado nos resultados apresentados por Zekkos et al. (2010a), Bareither et al. (2012), Fucale (2005), entre outros. Com relação aos deslocamentos verticais, verifica-se constante diminuição de volume conforme progridem os deslocamentos horizontais, o que é típico de materiais ensaiados no estado fofo.

\subsubsection{Parâmetros de resistência}

Para determinação das envoltórias de resistência utilizou-se o critério de MohrCoulomb. Uma vez que as curvas tensão-deslocamento não apresentavam pontos de máximo, adotaram-se deslocamentos horizontais de 25, 50 e $100 \mathrm{~mm}$ para o cálculo das envoltórias. As Figuras 5.58 e 5.59 apresentam estes resultados.

$\mathrm{Na}$ Tabela 5.26 são apresentados os parâmetros de resistência calculados para as seis amostras ensaiadas nesta pesquisa. Verifica-se que tanto a coesão, quanto o ângulo de atrito aumentam com a progressão do deslocamento horizontal, como apresentado nas Figuras 5.60 e 5.61 .

Resultado semelhante foi obtido por Fucale (2005) apenas para resíduos sólidos prétratados pelo método MBT. Para resíduos sólidos antigos, coletados em aterro na Alemanha, a autora não observou aumento da coesão com a progressão do deslocamento horizontal. Martins (2006) observou aumento do ângulo de atrito e da coesão com o progresso dos deslocamentos relativos em amostras compostas a partir de resíduos frescos e antigos da cidade de Belo Horizonte. Nascimento (2007), trabalhando com resíduos coletados no aterro Metropolitano Centro de Salvador, obteve aumento da coesão e do ângulo de atrito para os resíduos novos, porém apenas do ângulo de atrito para os resíduos com quatro anos de aterramento. Carvalho (1999) constatou aumento do ângulo de atrito e da coesão com o aumento das deformações axiais, exceto para uma das amostras, que apresentou redução da coesão para deformações acima de $25 \%$. 

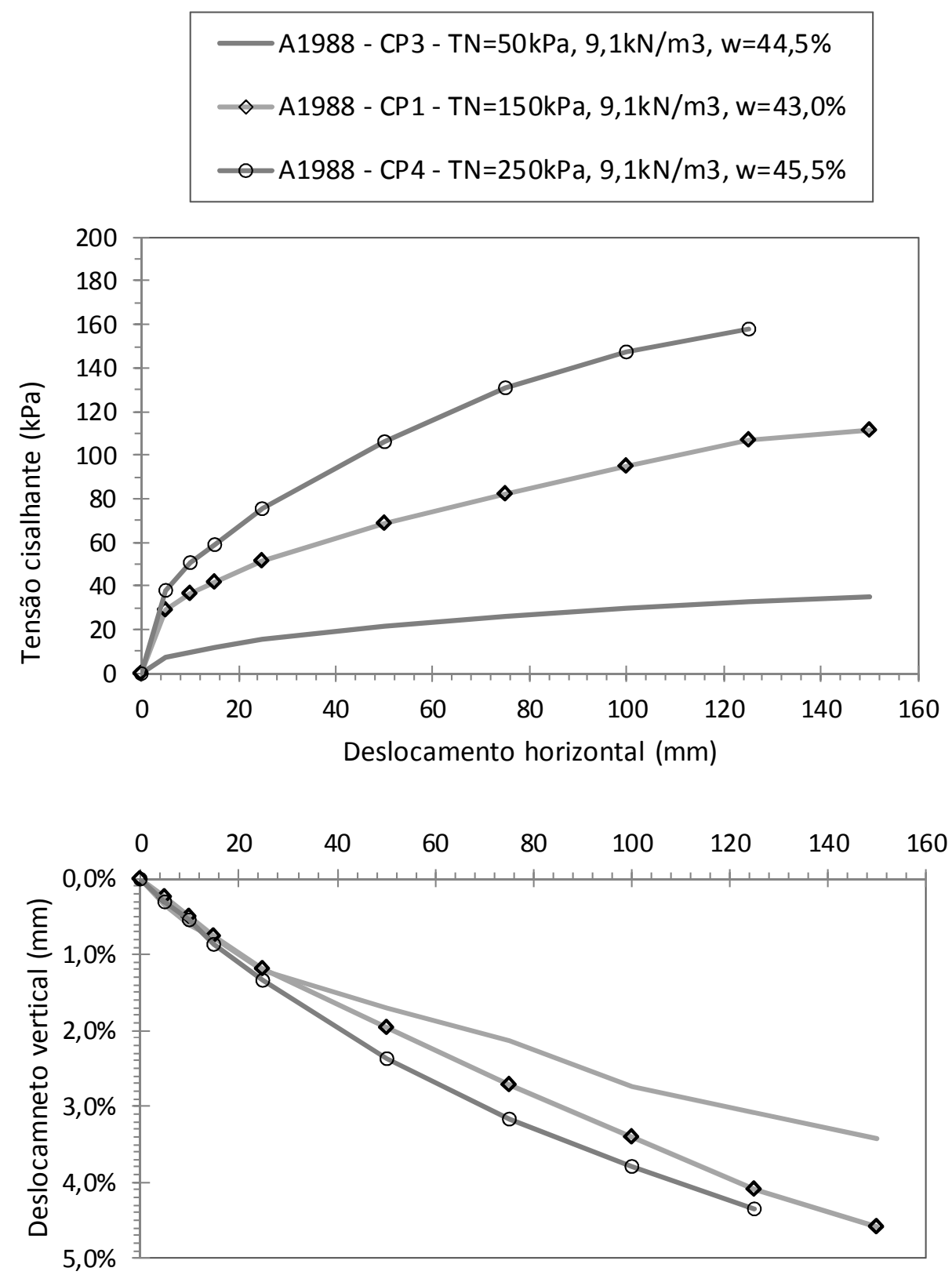

Figura 5.52 - Resultados dos ensaios de cisalhamento direto da amostra A1988 

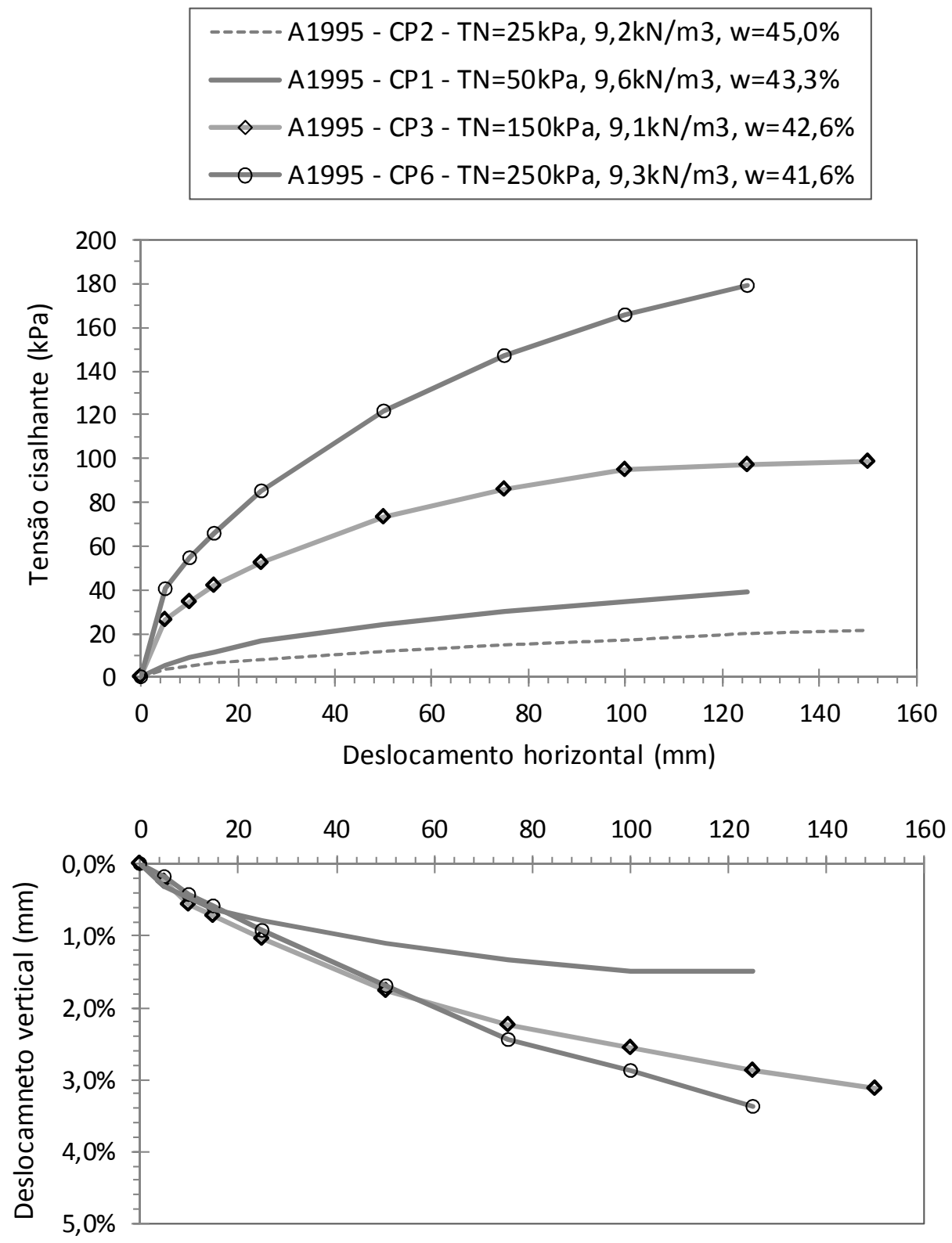

Figura 5.53 - Resultados dos ensaios de cisalhamento direto da amostra A1995 

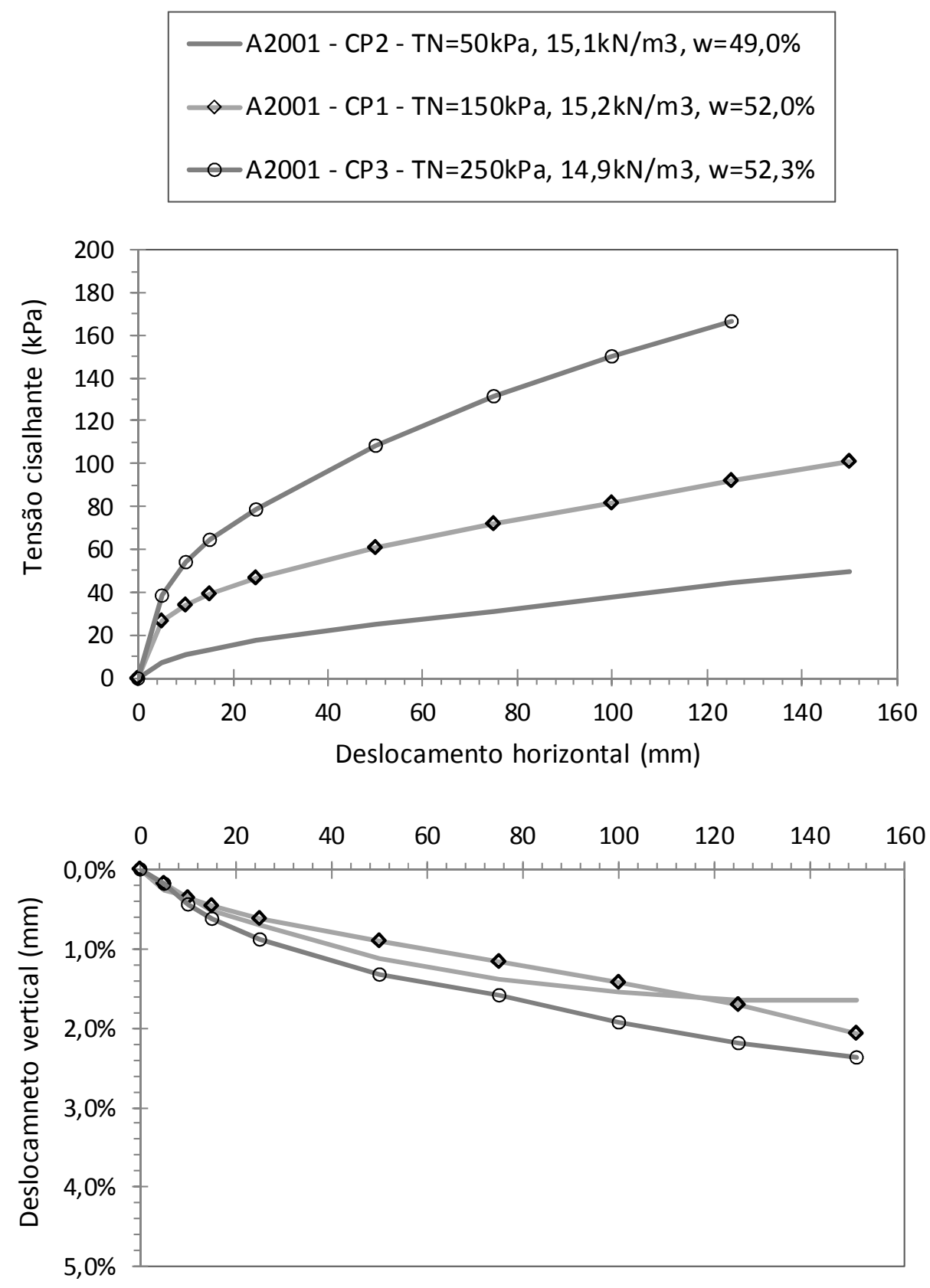

Figura 5.54 - Resultados dos ensaios de cisalhamento direto da amostra A2001 

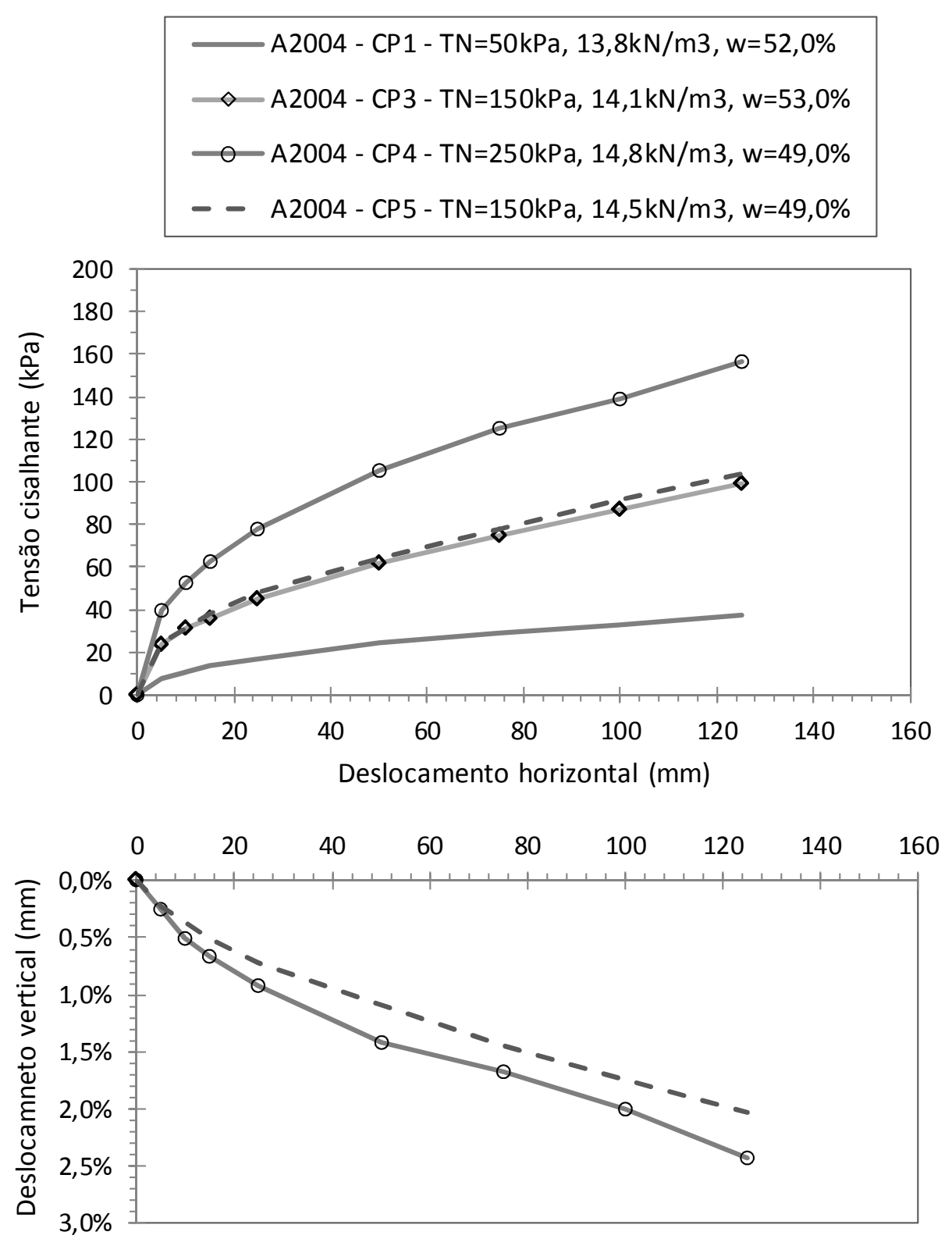

Figura 5.55 - Resultados dos ensaios de cisalhamento direto da amostra A2004 

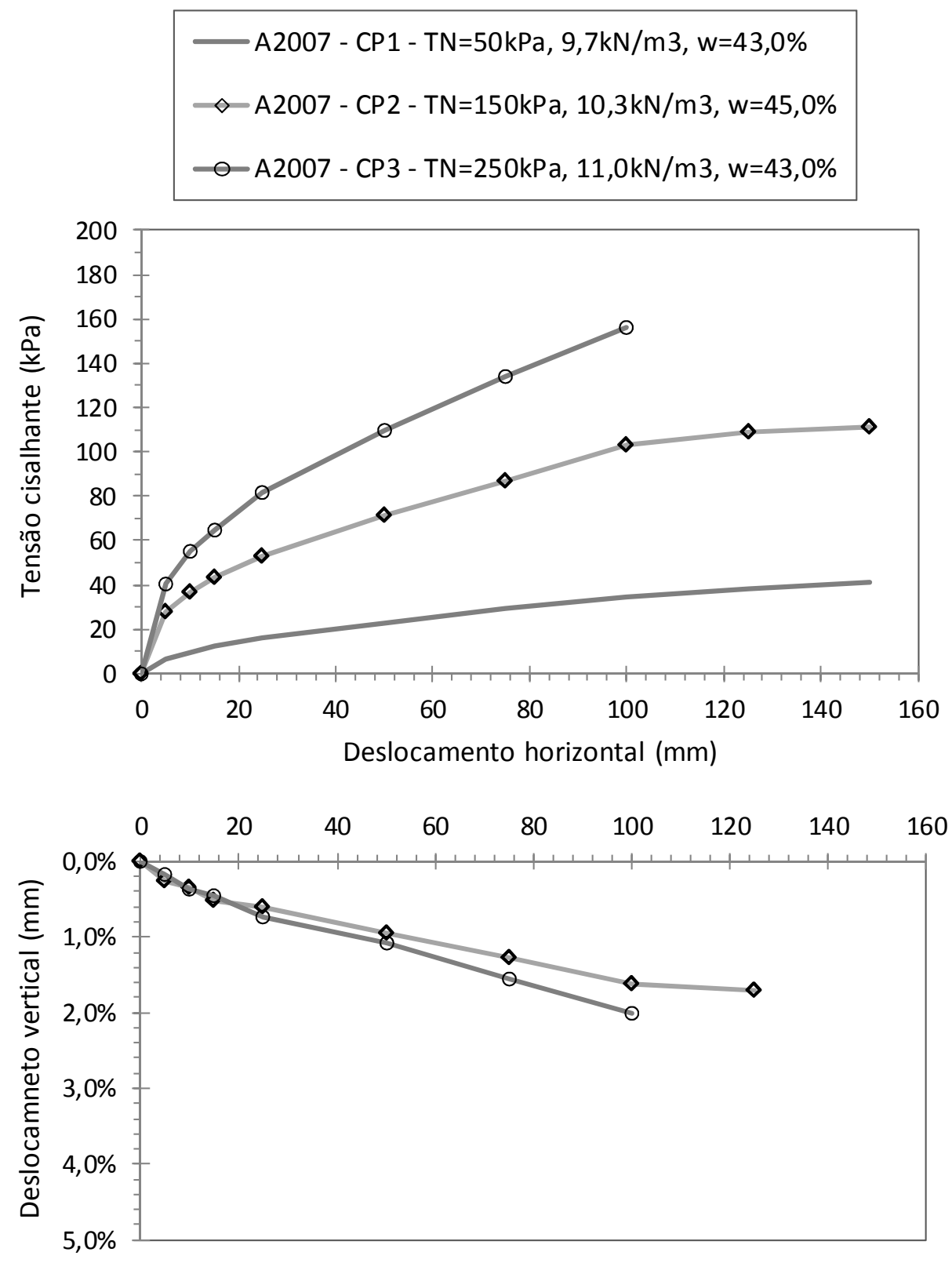

Figura 5.56 - Resultados dos ensaios de cisalhamento direto da amostra A2007 

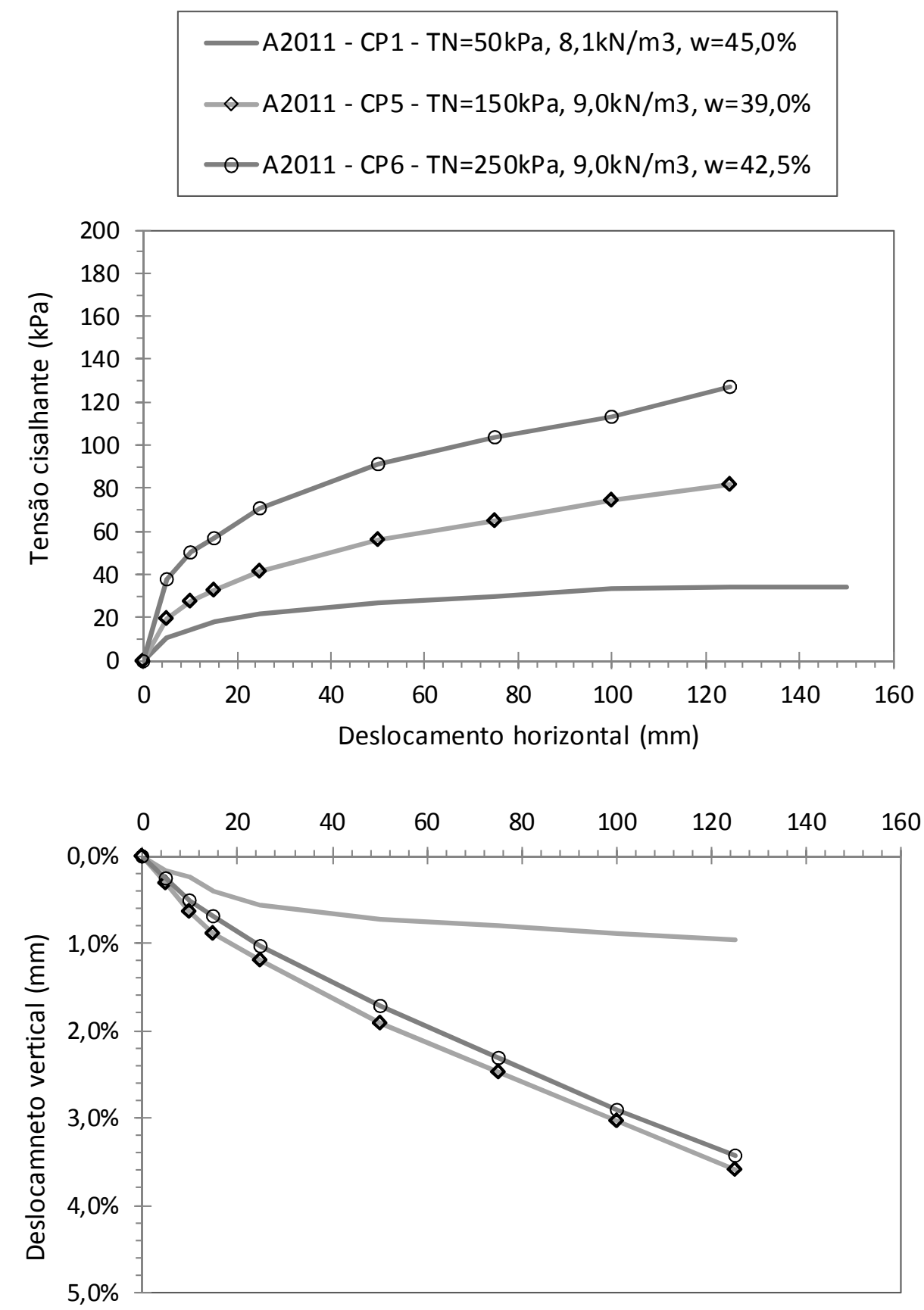

Figura 5.57 - Resultados dos ensaios de cisalhamento direto da amostra A2011 

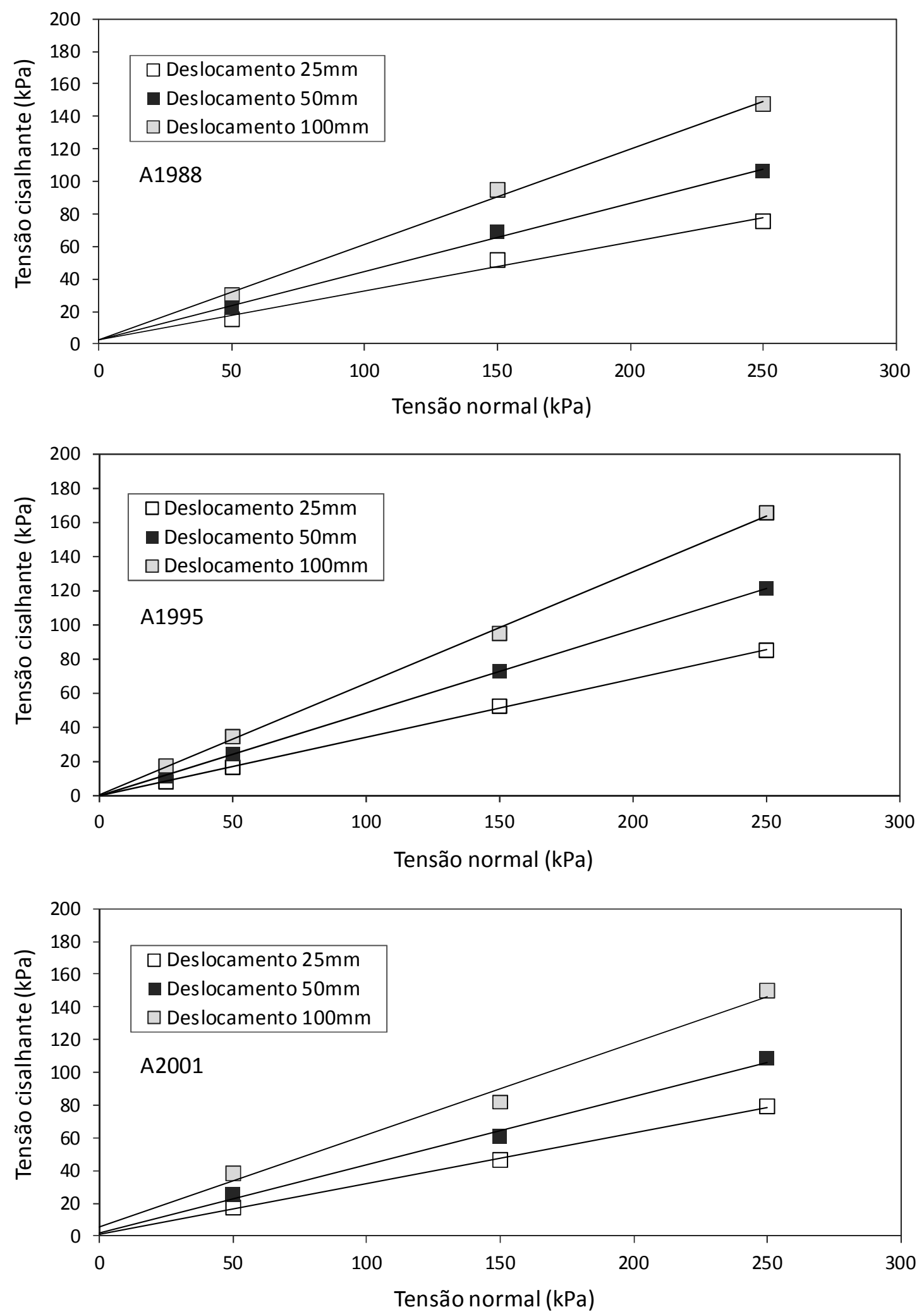

Figura 5.58 - Envoltórias de resistência determinadas para as amostras A1988, A1995 e A2001. 

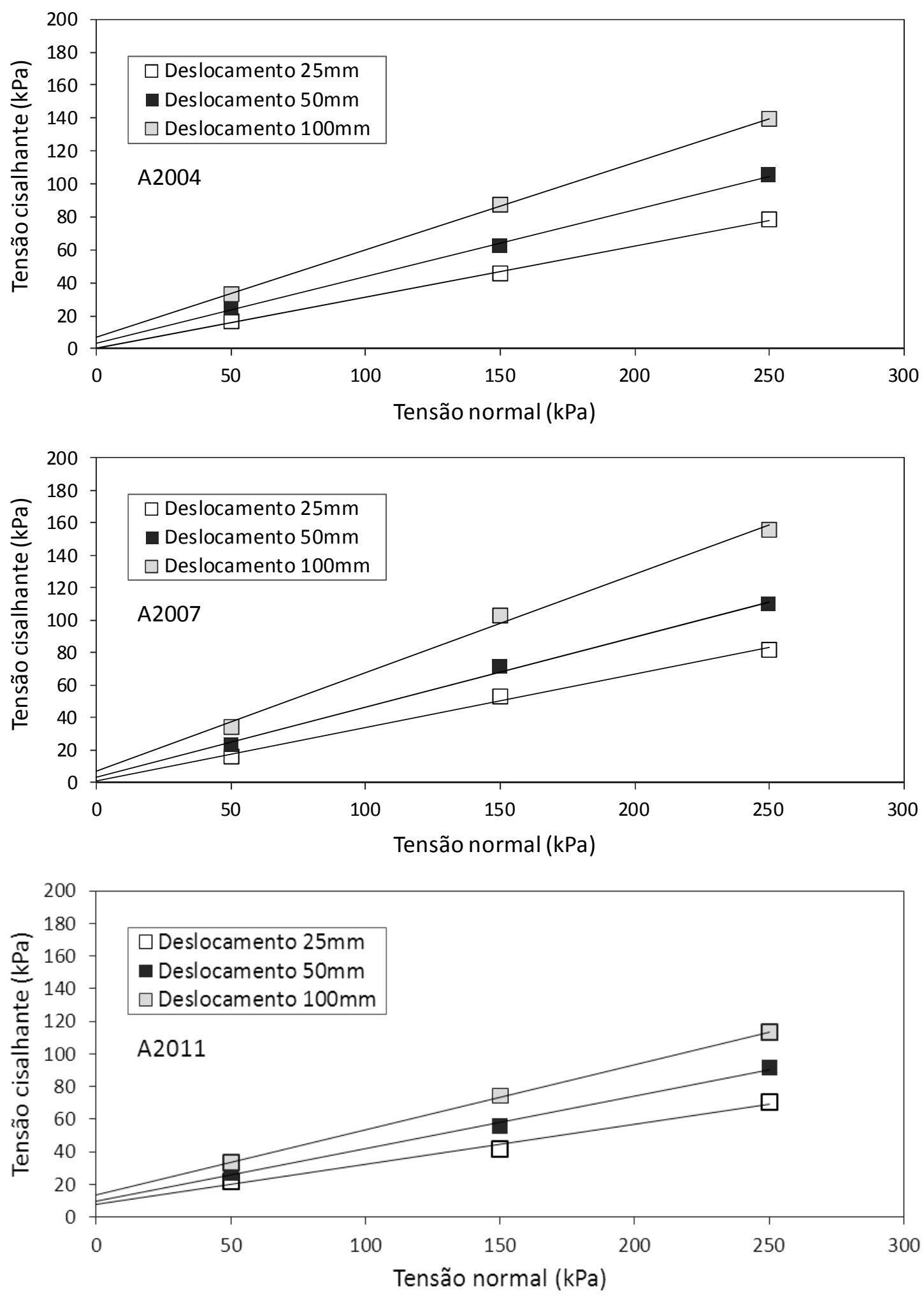

Figura 5.59 - Envoltórias de resistência determinadas para as amostras A2004, A2007 e A2011. 
Tabela 5.26 - Parâmetros de resistência determinados nesta pesquisa

\begin{tabular}{lcc}
\hline \multicolumn{1}{c}{ Amostra } & Coesão (kPa) & $\begin{array}{c}\text { Ângulo de atrito } \\
\text { (graus) }\end{array}$ \\
\hline A1988 & 2,7 & 17 \\
Deslocamento $25 \mathrm{~mm}$ & 2,6 & 23 \\
Deslocamento $50 \mathrm{~mm}$ & 2,7 & 30 \\
Deslocamento $100 \mathrm{~mm}$ & & \\
\hline A1995 & 0,0 & 19 \\
Deslocamento $25 \mathrm{~mm}$ & 0,0 & 26 \\
Deslocamento $50 \mathrm{~mm}$ & 0,5 & 33 \\
Deslocamento $100 \mathrm{~mm}$ & & \\
\hline A2001 & 1,4 & 17 \\
Deslocamento $25 \mathrm{~mm}$ & 1,9 & 23 \\
Deslocamento $50 \mathrm{~mm}$ & 5,8 & 29 \\
Deslocamento $100 \mathrm{~mm}$ & & \\
\hline A2004 & 0,6 & 17 \\
Deslocamento $25 \mathrm{~mm}$ & 3,0 & 22 \\
Deslocamento $50 \mathrm{~mm}$ & 6,7 & 28 \\
Deslocamento $100 \mathrm{~mm}$ & & 18 \\
\hline A2007 & 1,1 & 23 \\
Deslocamento $25 \mathrm{~mm}$ & 2,9 & 31 \\
Deslocamento $50 \mathrm{~mm}$ & 6,8 & 14 \\
Deslocamento $100 \mathrm{~mm}$ & & 22 \\
\hline A2011 & 8,0 & \\
Deslocamento $25 \mathrm{~mm}$ & 9,8 & \\
Deslocamento $50 \mathrm{~mm}$ & 13,7 & \\
Deslocamento $100 \mathrm{~mm}$ & & \\
\hline & & \\
\hline
\end{tabular}

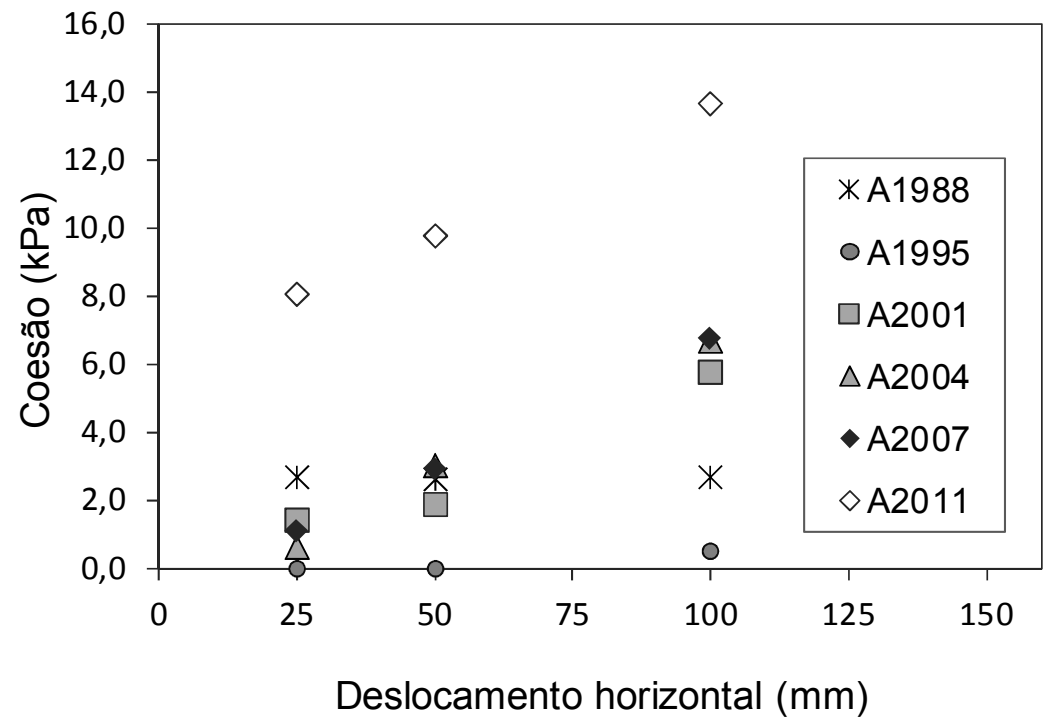

Figura 5.60 - Parâmetro coesão determinado para as envoltórias de resistência considerandose deslocamentos horizontais de 25,50 e $100 \mathrm{~mm}$ como critério de ruptura. 


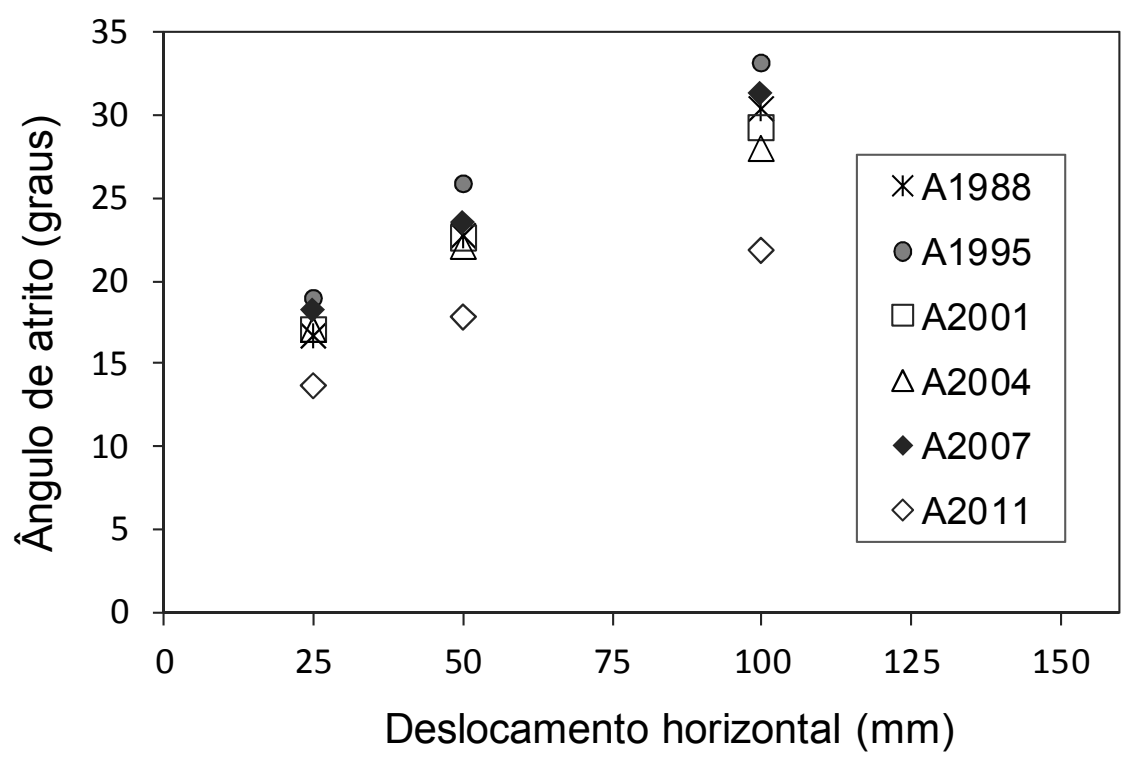

Figura 5.61 - Parâmetro ângulo de atrito determinado para as envoltórias de resistência considerando-se deslocamentos horizontais de 25,50 e $100 \mathrm{~mm}$ como critério de ruptura.

As Figuras 5.60 e 5.61 também permitem a comparação dos valores de coesão (c) e de ângulo de atrito $(\phi)$ das várias amostras. Verifica-se que a amostra A2011, composta por resíduos menos degradados, destaca-se por apresentar parâmetros de coesão maiores que as demais, e parâmetros de ângulo de atrito mais baixos, especialmente para maiores deslocamentos.

No grupo das amostras bastante degradadas a amostra A1995 apresenta os maiores valores de ângulo de atrito, enquanto a amostra A2004 apresenta os menores valores. Entretanto o que se nota é a que tendência geral é semelhante, com o ângulo de atrito aumentando na mesma proporção para todas essas amostras, conforme aumenta o deslocamento relativo adotado para definição da envoltória de resistência.

O mesmo não ocorre com o parâmetro coesão, para o qual podem ser distinguidos dois comportamentos: as amostras A2001, A2004 e A2007 apresentaram coesão crescente com o aumento do deslocamento horizontal, ainda que a razão desse aumento não seja a mesma para as três amostras. As amostras A1988 e A1995 praticamente não apresentaram variação no parâmetro coesão para as várias envoltórias de resistência calculadas. Na literatura discute-se a importância dos plásticos moles como elementos de reforço dos RSU, principalmente com relação ao aparecimento de um efeito de coesão. Essa diferença de comportamento pode ser explicada pelo seu conteúdo de plásticos moles das amostras, que é de 0,3 e 0,9\% para as amostras A1988 e A1995 e de 5,8 a 16,1\% para as amostras A2001, A2004 e A2007 (Tabelas 5.18 e 5.19). Outra possibilidade é que essa diferença seja explicada pelo conteúdo de 
componentes reforçantes, apresentado na Tabela 5.20. As amostras A1988 e A1995 tinham 6 a 8\% em peso seco destes componentes, enquanto as amostras A2001, A2004 e A2007 tinham porcentagens maiores (11 a $24 \%$ ).

As figuras 5.62 e 5.63 apresentam a relação entre a coesão das envoltórias calculadas para $100 \mathrm{~mm}$ de deslocamento e o conteúdo de plásticos moles e de componentes reforçantes das seis amostras ensaiadas nesta pesquisa. O conteúdo de plásticos moles não parece se correlacionar com a coesão das amostras, enquanto o conteúdo de componentes reforçantes se relaciona razoavelmente com a coesão. Na amostra A2011 a coesão aumenta com o aumento da tensão normal, apesar de o conteúdo de plásticos moles desta amostra ser de apenas $0,9 \%$. O conteúdo de componentes reforçantes neste caso é de 20,9\%. Esses fatos sugerem que o conteúdo de componentes reforçantes, e não o de plásticos moles, seja determinante para o aumento da coesão da amostra, conforme aumenta a tensão normal.

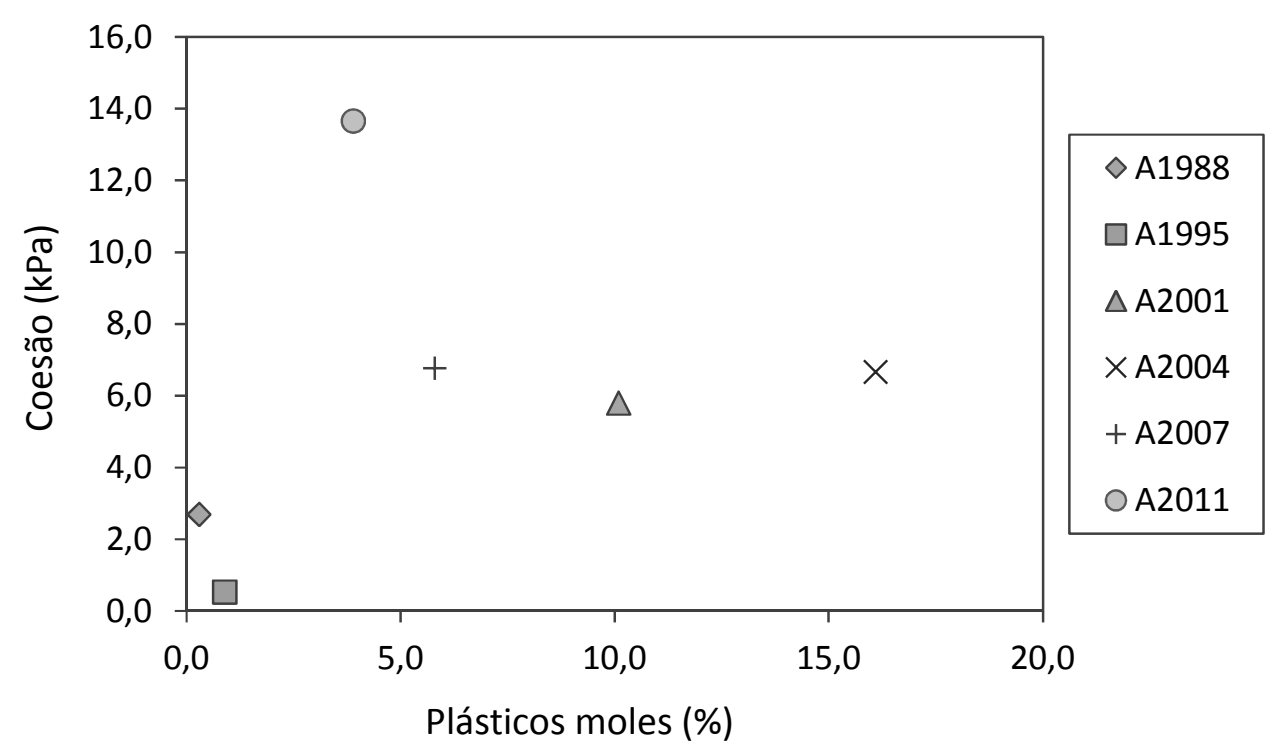

Figura 5.62 - Relação entre o conteúdo de plásticos moles e a coesão calculada para as envoltórias, considerando-se $100 \mathrm{~mm}$ de deslocamento. 


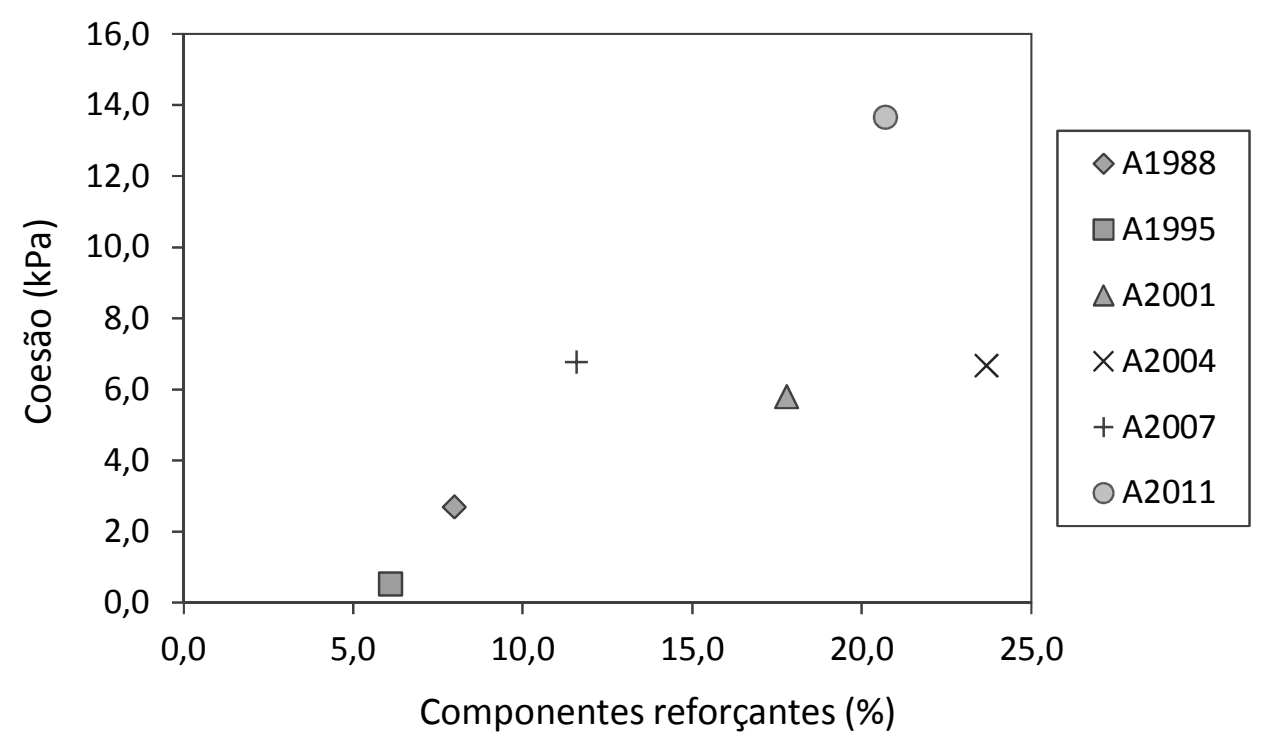

Figura 5.63 - Relação entre o conteúdo de componentes reforçantes e a coesão calculada para as envoltórias, considerando-se $100 \mathrm{~mm}$ de deslocamento.

A definição sobre qual critério é mais adequado para a adoção dos valores de coesão e ângulo de atrito dependerá de cada caso e da avaliação sobre a compatibilidade das deformações envolvidas no projeto. Verificou-se que as envoltórias determinadas nesta pesquisa para deslocamentos de 100mm estão muito próximas de algumas das envoltórias que já foram propostas por outros autores, por exemplo Kavazanjian (2008) e Benvenuto e Cunha (1991). Nas figuras 5.64 e 5.65 apresenta-se esta comparação, considerando-se as amostras ensaiadas com as características típicas do estrato superior do ASSC (amostras A1988, A1995, A2007 e A2011) e as amostras ensaiadas com as características típicas do estrato inferior (amostras A2001 e A2004).

Nos dois casos as envoltórias calculadas para as amostras mais degradadas aproximaram-se da envoltória proposta por Kavazanjian (2008), enquanto que a envoltória relativa à amostra menos degradada coincide com a envoltória proposta por Benvenuto e Cunha (1991). 


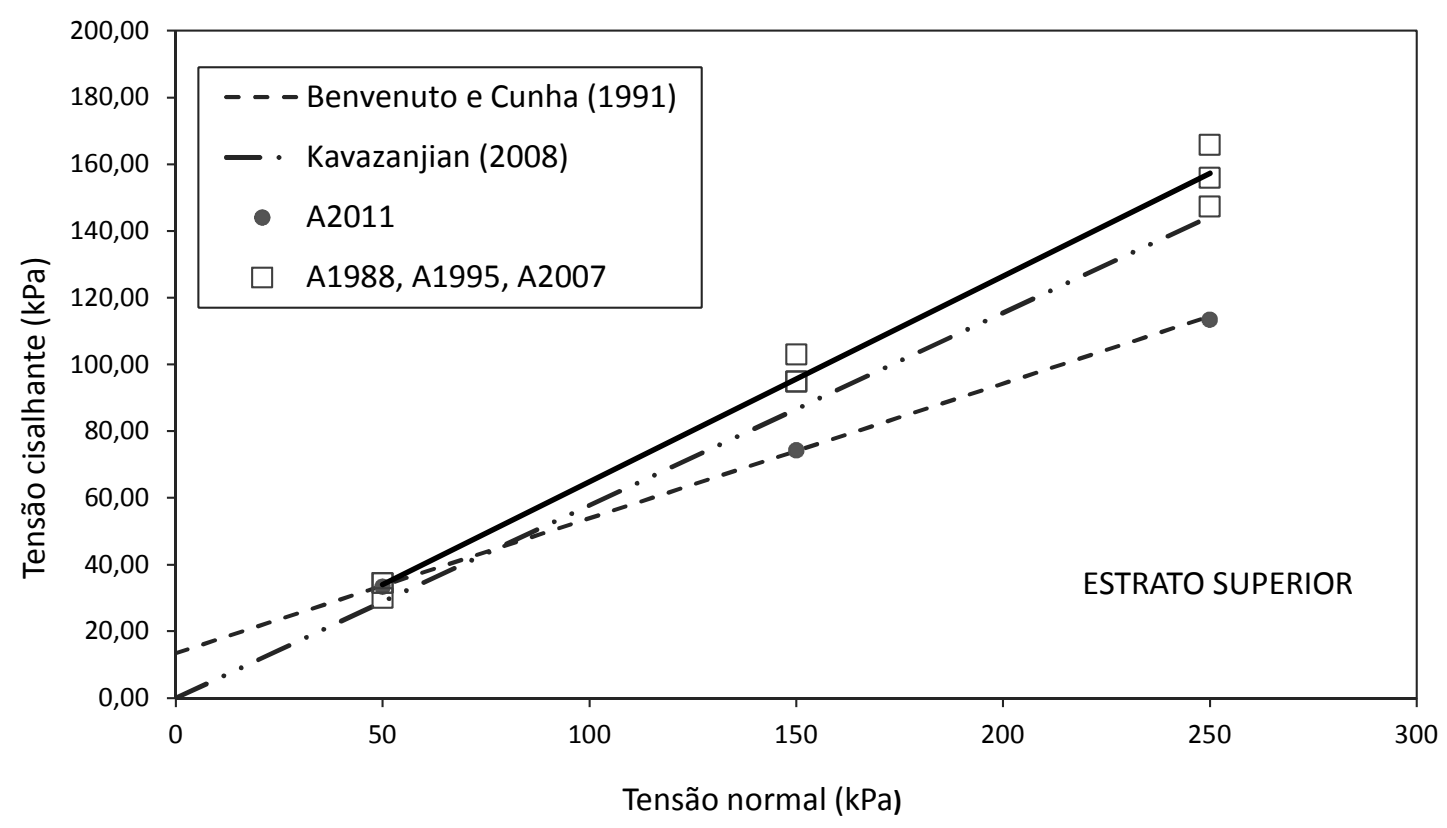

Figura 5.64 - Envoltórias de resistência para o estrato superior e comparação com propostas da literatura.

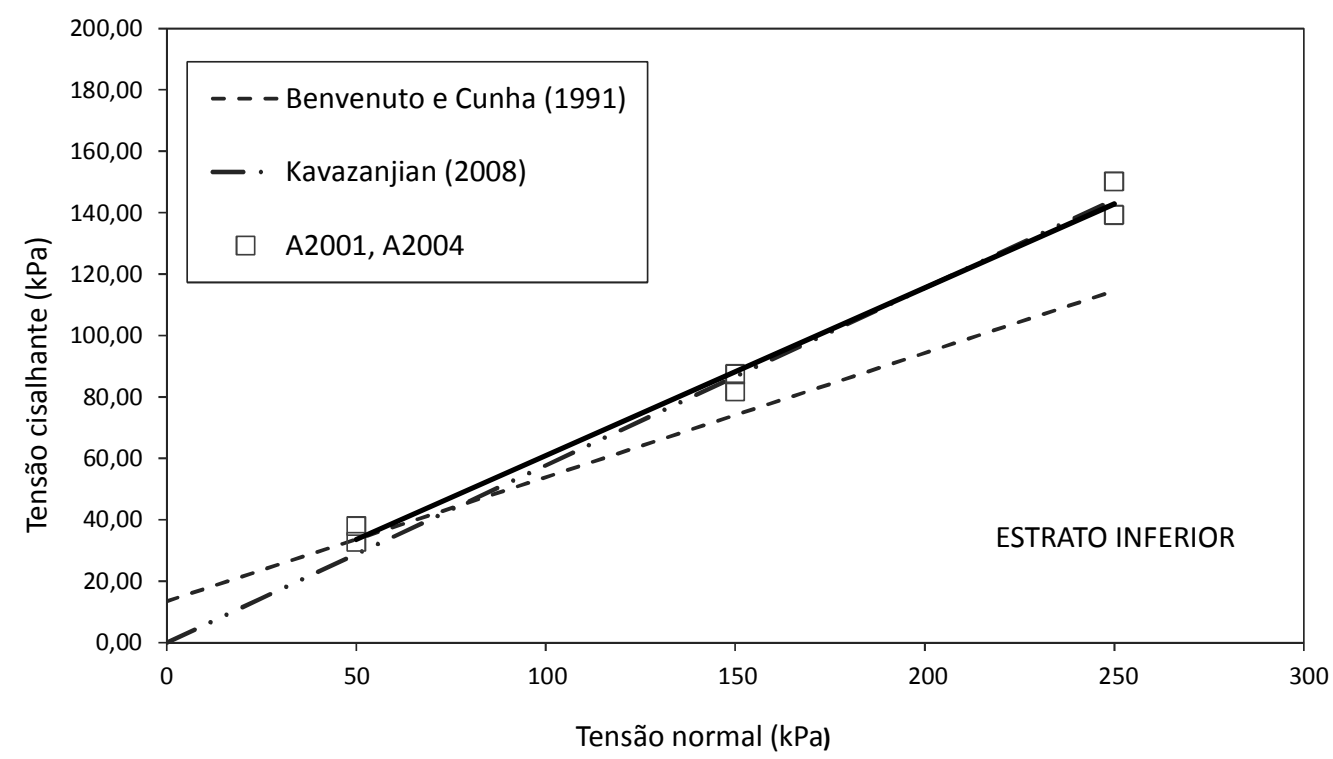

Figura 5.65 - Envoltórias de resistência para o estrato inferior e comparação com propostas da literatura.

Percebe-se ainda que o fato de as amostras terem sido ensaiadas com diferentes umidades e pesos específicos, buscando uma caracterização das diferentes propriedades dos dois estratos identificados no ASSC não implicou em diferença significativa para a definição das envoltórias de ruptura. $\mathrm{Na}$ realidade, se todas as amostras bastante degradadas forem consideradas como integrantes de um só conjunto a envoltória de resistência resultante ainda é 
semelhante àquela proposta por Kavazanjian (2008), como apresentado na Figura 5.66. A Tabela 5.27 resume os parâmetros determinados para estas envoltórias.

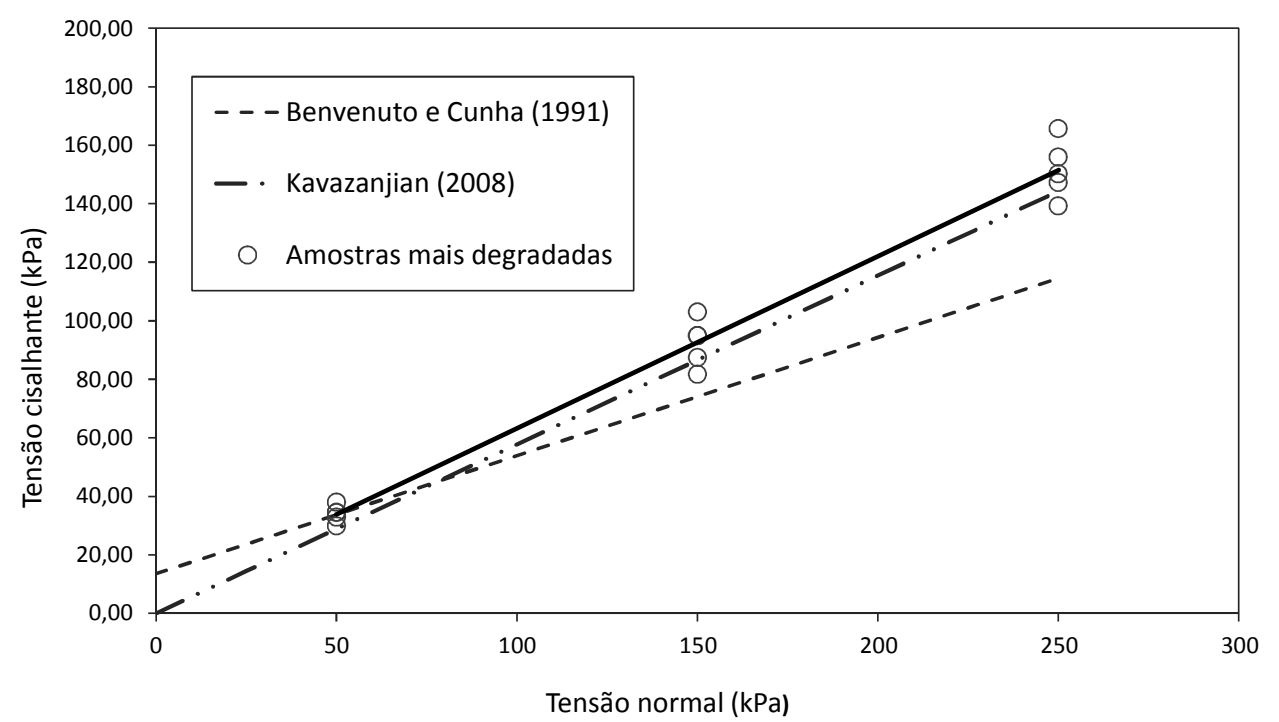

Figura 5.66 - Envoltórias de resistência para as amostras mais degradadas e comparação com propostas da literatura.

Tabela 5.27 - Envoltórias de resistência para o estrato inferior, estrato superior e amostras degradadas - deslocamento de $100 \mathrm{~mm}$.

\begin{tabular}{lccc}
\hline \multicolumn{1}{c}{$\begin{array}{c}\text { Envoltória } \\
\text { (para deslocamento de 100mm) }\end{array}$} & $\begin{array}{c}\text { Coesão } \\
(\mathrm{kPa})\end{array}$ & $\begin{array}{c}\text { Ângulo de atrito } \\
\text { (graus) }\end{array}$ & $\begin{array}{c}\mathrm{R}^{2} \\
(\%)\end{array}$ \\
\hline Amostra A2011 & 13,7 & 22 & 99,5 \\
Amostras mais degradadas (todas) & 4,4 & 30 & 98,0 \\
\hline Estrato superior & 3,2 & 32 & 99,5 \\
Estrato inferior & 6,2 & 29 & 98,9 \\
\hline Literatura: & & & \\
Benvenuto e Cunha (1991) & 13,5 & 22 & - \\
Kavazanjian (2008) & 0,0 & 30 & - \\
\hline
\end{tabular}

O aumento do peso específico, de forma isolada, não parece ser um fator determinante para que a resistência do RSU ao cisalhamento aumente, ao menos para baixas tensões de confinamento. Esta afirmação decorre da observação dos resultados dos ensaios realizados com corpos de prova da amostra A1995 moldados com diferentes pesos específicos, apresentados na Figura 5.67. A resistência ao cisalhamento de ambos para a tensão de $50 \mathrm{kPa}$ é igual e para a tensão de $150 \mathrm{kPa}$ apresenta pouca diferença. Deve-se reconhecer, entretanto, que os pesos específicos dos corpos de prova moldados com 9 e com $12 \mathrm{kN} / \mathrm{m}^{3}$ se aproximam durante a fase de cisalhamento, como apresentado na Figura 5.68.

Calcularam-se os valores da razão entre a coesão e a tangente do ângulo de atrito (c/tg $\phi)$ e do produto da coesão pela tangente do ângulo de atrito $\left(\mathrm{c}^{*} \operatorname{tg} \phi\right)$ para as envoltórias 
calculadas para 25, 50 e $100 \mathrm{~mm}$ de deslocamento horizontal. As Tabelas 5.28 e 5.29 apresentam estes resultados. Nas envoltórias calculadas para deslocamentos de $100 \mathrm{~mm}$ podese diferenciar dois conjuntos de resultados no grupo das amostras mais degradadas: o conjunto das amostras A1988 e A1995, com menores conteúdos de componentes reforçantes, e o conjunto das amostras A2001, A2004 e A2007, com maior conteúdo de componentes reforçantes. Entretanto esta separação não é consistente para as envoltórias calculadas com deslocamentos de 25 e de $50 \mathrm{~mm}$.
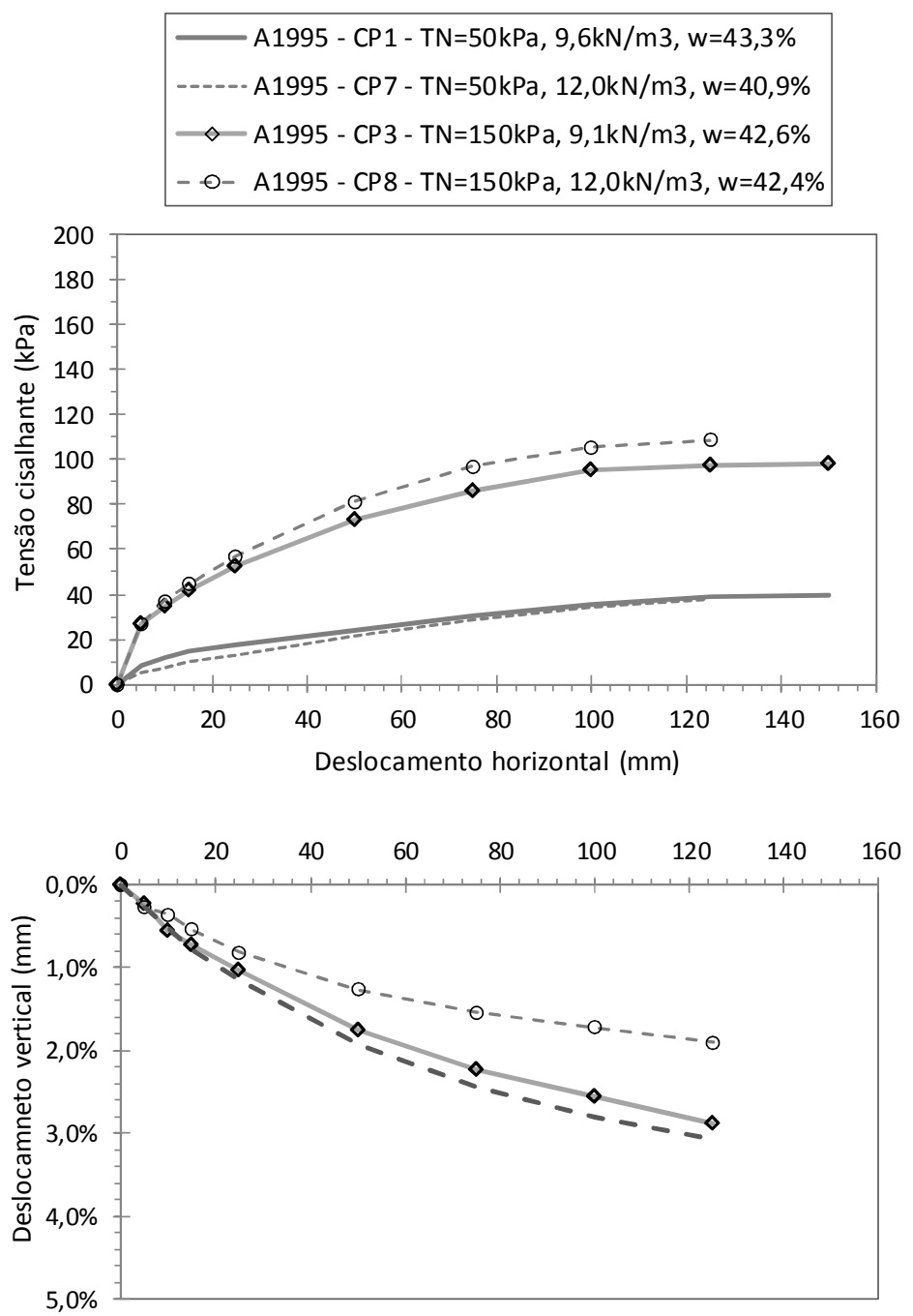

Figura 5.67 - Resultados dos ensaios de cisalhamento direto da amostra A1995 - corpos de prova com diferentes pesos específicos iniciais. 


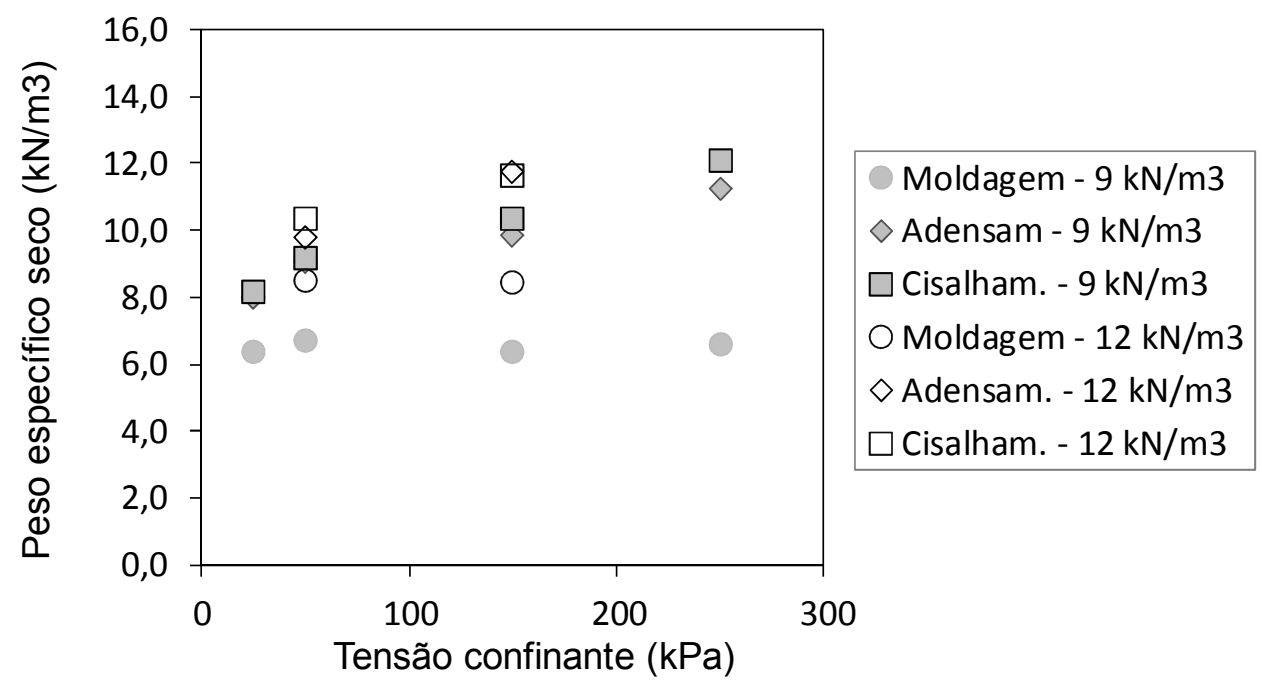

Figura 5.68 - Comparação entre os pesos específicos dos corpos de prova moldados com a amostra A1995.

Tabela 5.28 - Relação c / tg $\phi$ para as envoltórias calculadas nesta pesquisa.

\begin{tabular}{ccccccc}
\hline \multirow{2}{*}{$\begin{array}{c}\text { Deslocamento considerado } \\
\text { para cálculo da envoltória }\end{array}$} & A1988 & A1995 & A2001 & A2004 & A2007 & A2011 \\
\hline $25 \mathrm{~mm}$ & 9,0 & 0,0 & 4,5 & 2,0 & 3,2 & 32,9 \\
$50 \mathrm{~mm}$ & 6,2 & 0,0 & 4,5 & 7,4 & 6,7 & 30,3 \\
$100 \mathrm{~mm}$ & 4,6 & 0,8 & 10,3 & 12,5 & 11,1 & 34,1 \\
\hline
\end{tabular}

Tabela 5.29 - Relação c * tg $\phi$ para as envoltórias calculadas nesta pesquisa.

\begin{tabular}{ccccccc}
\hline Deslocamento considerado & \multicolumn{7}{c}{ Amostra } \\
\cline { 2 - 7 } para cálculo da envoltória & A1988 & A1995 & A2001 & A2004 & A2007 & A2011 \\
\hline $25 \mathrm{~mm}$ & 0,8 & 0,0 & 0,4 & 0,2 & 0,3 & 2,0 \\
$50 \mathrm{~mm}$ & 1,1 & 0,0 & 0,8 & 1,2 & 1,3 & 3,1 \\
$100 \mathrm{~mm}$ & 1,6 & 0,3 & 3,2 & 3,5 & 4,1 & 5,5 \\
\hline
\end{tabular}

Na literatura técnica (Kolsch, 1990, apud Kolsch, 1993) argumenta-se que o efeito da coesão devido à presença de componentes reforçantes se torne mais pronunciado, conforme aumenta o deslocamento horizontal no ensaio de cisalhamento e que este efeito não seja mobilizado para pequenos deslocamentos. Isto pode explicar o fato de os resultados apresentados nas Tabelas 5.28 e 5.29 serem inconsistentes para os menores deslocamentos e se tornarem correlacionáveis com a composição das amostras para os deslocamentos de $100 \mathrm{~mm}$. 


\subsubsection{Efeito da anisotropia}

Nos ensaios realizados para estudo do efeito da anisotropia sobre a resistência dos RSU verificou-se que os corpos de prova ensaiados com as camadas rotacionadas (indicados como $90^{\circ} \mathrm{X}$ e $90^{\circ} \mathrm{Y}$ na Tabela 4.6) apresentaram curvas tensão-deslocamento com tendência de aumento progressivo da resistência, porém o formato da curva não é hiperbólico. As Tabelas 5.30 a 5.33 apresentam as características dos corpos de prova na moldagem, após a fase de adensamento e ao final do cisalhamento, assim como os volumes de água liberados pelo corpo de prova.

A Figura 5.69 apresenta os resultados dos ensaios. A tensão de cisalhamento aumenta continuamente, sendo que para deslocamentos horizontais entre 0 e $5 \mathrm{~mm}$ a rigidez do material é maior do que entre 5 e $100 \mathrm{~mm}$. As variações de volume durante o cisalhamento foram sempre de compressão. Esse comportamento é semelhante ao que foi apresentado por Zekkos et al. (2010a) para amostras de RSU ensaiadas em posições rotacionadas, porém naquele caso as amostras exibiam sempre endurecimento para os maiores deslocamentos, o que não se verificou nos ensaios dessa pesquisa.

Para o par de amostras ensaiadas com confinamento de $150 \mathrm{kPa}$ (CP8 e CP12) o corpo de prova rotacionado apresentou tensões menores que o corpo de prova não rotacionado para deslocamentos até $60 \mathrm{~mm}$ e, a partir deste ponto, essa relação se inverteu. Esse fato também foi registrado por Zekkos et al. (2010a) para tensões de confinamento de 1,8 e de $50 \mathrm{kPa}$. Entretanto, nesta pesquisa, para confinamentos de $50 \mathrm{kPa}$ as tensões desenvolvidas nos corpos de prova rotacionados foram sempre superiores às tensões desenvolvidas no corpo de prova com camadas horizontais, divergindo dos resultados apresentados por aqueles autores. $\mathrm{O}$ comportamento dos corpos de prova com as camadas rotacionadas nas posições $\mathrm{X}$ e $\mathrm{Y}$ é o mesmo.

Deve-se ressaltar, entretanto, que a amostra ensaiada apresenta pequena porcentagem de componentes reforçantes e esses resultados podem não ser representativos para resíduos com maior conteúdo desses materiais. São necessários mais ensaios para que o efeito da anisotropia dos RSU sobre sua resposta ao cisalhamento direto possa ser avaliado de forma mais abrangente. 
Tabela 5.30 - Características dos corpos de prova na moldagem - anisotropia.

\begin{tabular}{cccccccc}
\hline $\begin{array}{c}\text { Corpo de } \\
\text { Prova }\end{array}$ & $\begin{array}{c}\text { Tensao } \\
\text { normal } \\
(\mathrm{kPa})\end{array}$ & $\begin{array}{c}\text { Posição } \\
\text { das } \\
\text { camadas }\end{array}$ & $\begin{array}{c}\text { Umidade } \\
(\%)\end{array}$ & $\begin{array}{c}\text { Peso } \\
\text { Específico } \\
\left(\mathrm{kN} / \mathrm{m}^{3}\right)\end{array}$ & $\begin{array}{c}\text { Peso Esp. } \\
\text { seco } \\
\left(\mathrm{kN} / \mathrm{m}^{3}\right)\end{array}$ & e & $\mathrm{S}_{\mathrm{R}}$ \\
\hline CP7 & 50 & 0o & 40,9 & 12,0 & 8,5 & 1,76 & $56 \%$ \\
CP8 & 150 & 0o & 42,4 & 12,0 & 8,4 & 1,79 & $57 \%$ \\
CP13 & 50 & $90 \mathrm{o}-\mathrm{X}$ & 44,0 & 12,0 & 8,3 & 1,82 & $58 \%$ \\
CP12 & 150 & $90 \mathrm{o}-\mathrm{X}$ & 39,1 & 12,0 & 8,6 & 1,73 & $54 \%$ \\
CP9 & 50 & $90 \mathrm{o}-\mathrm{Y}$ & 41,5 & 12,0 & 8,5 & 1,77 & $56 \%$ \\
CP11 & 165 & $90 \mathrm{o}-\mathrm{Y}$ & 44,0 & 12,0 & 8,3 & 1,82 & $58 \%$ \\
\hline
\end{tabular}

Tabela 5.31 - Características dos corpos de prova no início do cisalhamento - anisotropia

\begin{tabular}{cccccccc}
\hline $\begin{array}{c}\text { Corpo de } \\
\text { Prova }\end{array}$ & $\begin{array}{c}\text { Tensão } \\
\text { normal } \\
(\mathrm{kPa})\end{array}$ & $\begin{array}{c}\text { Altura do } \\
\mathrm{CP}(\mathrm{mm})\end{array}$ & $\begin{array}{c}\text { Umidade } \\
(\%)\end{array}$ & $\begin{array}{c}\text { Peso } \\
\text { Específ. } \\
\left(\mathrm{kN} / \mathrm{m}^{3}\right)\end{array}$ & $\begin{array}{c}\text { Peso esp. } \\
\text { seco } \\
\left(\mathrm{kN} / \mathrm{m}^{3}\right)\end{array}$ & e & $\mathrm{S}_{\mathrm{R}}$ \\
\hline CP7 & 50 & 386 & 40,8 & 13,8 & 9,8 & 1,40 & $70 \%$ \\
CP8 & 150 & 373 & 38,5 & 16,3 & 11,8 & 1,00 & $93 \%$ \\
CP13 & 50 & 414 & 41,0 & 13,5 & 9,6 & 1,46 & $68 \%$ \\
CP12 & 150 & 385 & 36,6 & 14,6 & 10,7 & 1,20 & $73 \%$ \\
CP9 & 50 & 413 & 38,6 & 13,5 & 9,7 & 1,41 & $65 \%$ \\
CP11 & 165 & 376 & 40,7 & 14,7 & 10,4 & 1,25 & $78 \%$ \\
\hline
\end{tabular}

Tabela 5.32 - Características dos corpos de prova no final do cisalhamento - anisotropia.

\begin{tabular}{cccccccc}
\hline $\begin{array}{c}\text { Corpo } \\
\text { de } \\
\text { Prova }\end{array}$ & $\begin{array}{c}\text { Tensão } \\
\text { normal } \\
(\mathrm{kPa})\end{array}$ & $\begin{array}{c}\text { Umidade } \\
\text { média (\%) }\end{array}$ & $\begin{array}{c}\text { Umidade no } \\
\text { plano de } \\
\text { cisalham. }(\%)\end{array}$ & $\begin{array}{c}\text { Peso } \\
\text { Específico } \\
\left(\mathrm{kN} / \mathrm{m}^{3}\right)\end{array}$ & $\begin{array}{c}\text { Peso esp. } \\
\text { seco } \\
\left(\mathrm{kN} / \mathrm{m}^{3}\right)\end{array}$ & e & $\mathrm{S}_{\mathrm{R}}$ \\
\hline CP7 & 50 & 40,3 & 38,9 & 14,5 & 10,3 & 1,28 & $76 \%$ \\
CP8 & 150 & 35,9 & 33,8 & 15,8 & 11,6 & 1,02 & $84 \%$ \\
CP13 & 50 & 37,5 & 34,3 & 13,8 & 10,0 & 1,34 & $67 \%$ \\
CP12 & 150 & 34,0 & 30,5 & 15,5 & 11,6 & 1,03 & $79 \%$ \\
CP9 & 50 & 36,6 & 34,6 & 14,0 & 10,2 & 1,29 & $68 \%$ \\
CP11 & 165 & 35,3 & 30,0 & 15,1 & 11,2 & 1,11 & $76 \%$ \\
\hline
\end{tabular}

Tabela 5.33 - Volumes de águas expulsos dos corpos de prova durante o ensaio - anisotropia.

\begin{tabular}{ccccccc}
\hline Corpo & Tensão & \multirow{2}{*}{$\begin{array}{c}\text { de } \\
\text { normal }\end{array}$} & $\begin{array}{c}\text { Posição das } \\
\text { camadas }\end{array}$ & \multicolumn{4}{c}{ Volumes de água $(\mathrm{ml})$} \\
\cline { 4 - 6 } Prova & $(\mathrm{kPa})$ & & Moldagem & Consolidação & Cisalhamento & Total \\
\hline CP7 & 50 & $0^{\circ}$ & 0 & 110 & 910 & 1020 \\
CP8 & 150 & $0^{\circ}$ & 0 & 4240 & 1900 & 6140 \\
CP13 & 50 & $90^{\circ} \mathrm{X}$ & 0 & 3000 & 1850 & 4850 \\
CP12 & 150 & $90^{\circ} \mathrm{X}$ & 0 & 2550 & 2000 & 4550 \\
CP9 & 50 & $90^{\circ} \mathrm{Y}$ & 0 & 2930 & 1360 & 4290 \\
CP11 & 165 & $90^{\circ} \mathrm{Y}$ & 0 & 3210 & 2020 & 5230 \\
\hline
\end{tabular}



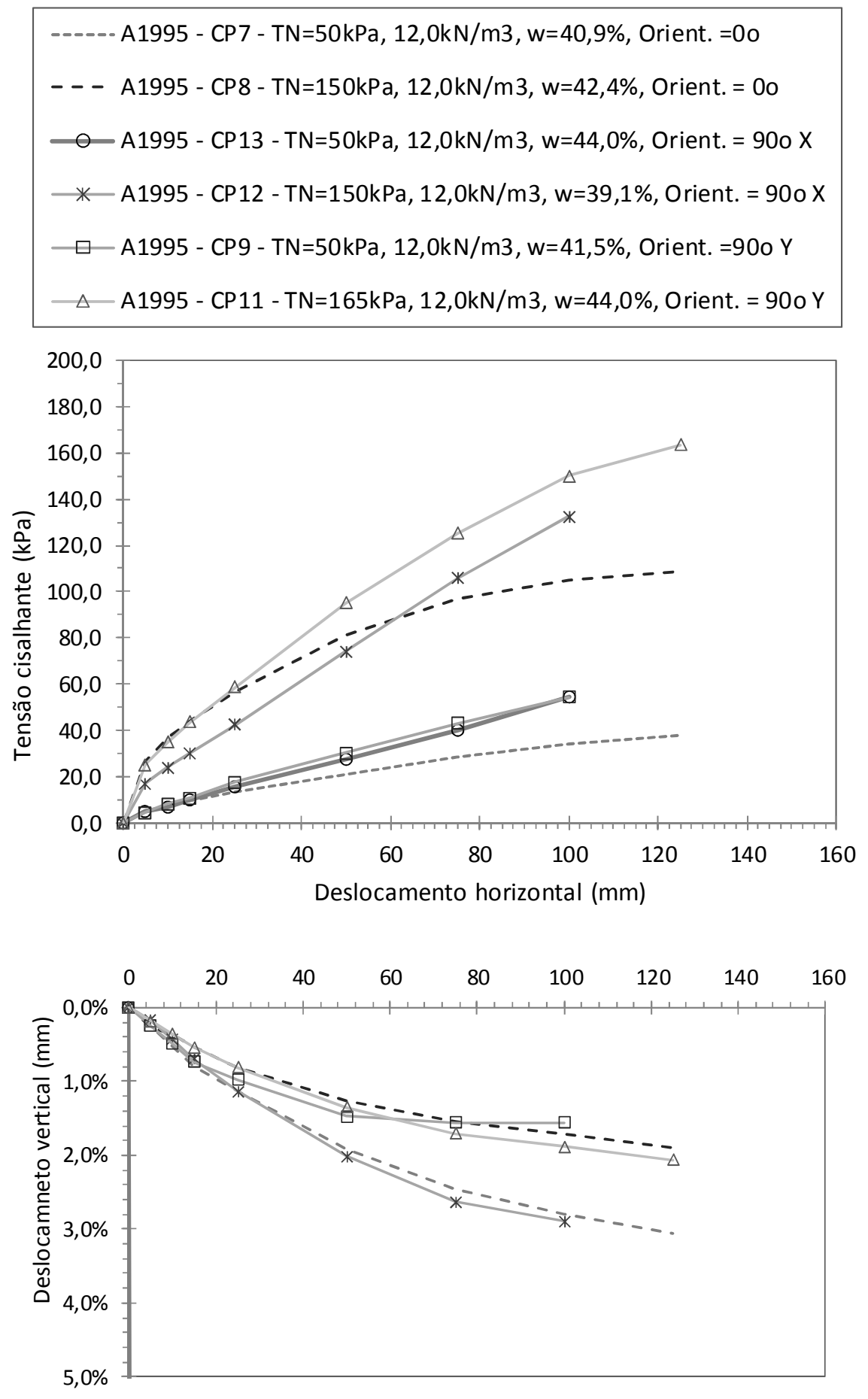

Figura 5.69 - Resultados dos ensaios para estudo da anisotropia em RSU. 


\section{CONCLUSÕES E SUGESTÕES}

\subsection{Caracterização geotécnica do Aterro Sanitário de São Carlos}

As investigações realizadas no Aterro Sanitário de São Carlos revelaram a existência de dois estratos com características geotécnicas diferenciadas, que se evidenciam pelo aumento dos valores médios e da dispersão dos resultados obtidos para temperatura, umidade, peso específico in situ e velocidades de propagação de ondas sísmicas no estrato inferior.

O estrato superior corresponde aos resíduos mais novos, aterrados em 2011 e em 2007, e estende-se até a profundidade de 11 metros. Ele se caracteriza por velocidades de propagação de ondas cisalhantes (Vs) entre 92 e $155 \mathrm{~m} / \mathrm{s}$ e velocidades de propagação de ondas compressionais (Vp) entre 197 e 309 m/s. A umidade média dos resíduos desse estrato é $43 \%$ e o peso específico médio é $9-10 \mathrm{kN} / \mathrm{m}^{3}$. Nesta fase o aterro era operado como um aterro sanitário propriamente dito.

O estrato inferior corresponde aos resíduos mais antigos, aterrados anteriormente a 2004 e localiza-se de 11 metros para baixo. Ele se caracteriza por velocidades de propagação de ondas cisalhantes (Vs) entre 126 e $214 \mathrm{~m} / \mathrm{s}$ e velocidades de propagação de ondas compressionais $(\mathrm{Vp})$ entre 245 e $451 \mathrm{~m} / \mathrm{s}$. Para resíduos relativamente mais secos (umidade média de 30\%) o peso específico médio é $11 \mathrm{kN} / \mathrm{m}^{3}$, enquanto que para resíduos relativamente mais úmidos (umidade média de 52\%) o peso específico médio é de $15 \mathrm{kN} / \mathrm{m}^{3}$. Nesta fase o aterro era operado como um aterro controlado.

Os valores de módulo de cisalhamento calculados para o estrato superior do maciço (resíduos mais recentes) variaram entre 8 e $24 \mathrm{MPa}$, considerando-se peso específico de 9 $\mathrm{kN} / \mathrm{m}^{3}$. Esses valores estão de acordo com aqueles determinados em outras pesquisas em RSU para os mesmos níveis de confinamento.

Para o maciço de resíduos mais antigos, em profundidades situadas entre 11 e 20 metros, os valores de $\mathrm{G}_{\mathrm{o}}$ variaram de 18 a $51 \mathrm{MPa}$, considerando-se peso específico de 11 $\mathrm{kN} / \mathrm{m}^{3}$, e de 24 a $70 \mathrm{MPa}$, considerando-se peso específico de $15 \mathrm{kN} / \mathrm{m}^{3}$.

O conteúdo de STV é a única propriedade que apresenta maiores valores e maior dispersão no estrato superior, pois reflete o estado de degradação destes materiais. Para as amostras recuperadas por sondagens no Aterro Sanitário os teores de STV variaram de 9 a $23 \%$. 
A composição gravimétrica destas amostras não evidenciou tendências claras de diminuição ou de aumento nas porcentagens relativas das frações com a idade de aterramento dos resíduos. Os resultados indicam que no estrato inferior (resíduos mais antigos) a porcentagem de plásticos moles seja maior do que no estrato superior.

\subsubsection{Método adotado para a determinação do peso específico dos RSU in situ}

O método adotado nesta pesquisa mostrou limitações para a determinação de pesos específicos para intervalos de poucos metros de comprimento. Esta inadequação está relacionada à forma de operação do trado helicoidal de haste oca, que realiza um "sobreavanço" no momento da escavação e ao fato de não ter sido possível realizar medidas deste "sobreavanço" nesta pesquisa. Valores de peso específico médios puderam ser calculados, pois para tal consideram-se trechos (ou intervalos de profundidade) com maior comprimento.

Ainda assim, estas determinações estão sujeitas a incertezas, relacionadas principalmente a dois aspectos: primeiramente, ao fato de os trados helicoidais não serem capazes de retirar do maciço os componentes de maiores dimensões e, em segundo lugar, ao fato de não se saber se ocorre sobreescavação (alargamento do diâmetro do furo) por arraste de componentes resistentes à tração, tais como plásticos e tecidos, durante a escavação.

Para tentar quantificar eventuais sobreescavações utilizou-se nesta pesquisa um método de substituição de volume, colocando-se brita com massa específica conhecida dentro do furo de sondagem, na etapa de remoção das hélices. Os resultados desta tentativa revelaram a ocorrência de diminuição do diâmetro do furo de sondagem em $94 \%$ do comprimento total de furos investigados. Esta diminuição do diâmetro ocorreu após a retirada dos trados de dentro do furo de sondagem, pois os mesmos funcionam como revestimento durante a etapa de perfuração. Dificuldades na aplicação do método de substituição de volume já haviam sido relatadas por outros autores, principalmente em condições de acesso de líquidos na escavação. Os resultados sugerem que o método da substituição de volume não seja capaz de identificar eventuais sobreescavações do maciço, quando se realizam determinações de peso específico em maciços com conteúdos de umidade da ordem de 40-50\%, pois os furos tendem a diminuir de diâmetro, assim que o revestimento é removido. 
6.1.2 Aplicação de métodos geofísicos sísmicos a aterros sanitários

As velocidades de propagação de ondas cisalhantes e compressionais foram essenciais para a definição da estratigrafia do maciço de resíduos. Elas ratificaram tendências que estavam sugeridas nos resultados obtidos para outras propriedades (temperatura, STV, umidade e peso específico) e permitiram que se precisasse a profundidade de ocorrência da transição entre os estratos.

Quanto à velocidade de propagação das ondas cisalhantes, os resultados obtidos pelo método crosshole e pelo método MASW apresentaram tendência semelhante de aumento com a profundidade. O método MASW ensaia um volume maior do maciço e fornece um resultado mais geral, enquanto o método crosshole ensaia um volume menor e fornece resultados de maior detalhe.

As velocidades determinadas pelo método crosshole foram sempre superiores àquelas calculadas pelo método MASW. Acredita-se que isto tenha ocorrido porque os dois métodos trabalham com solicitações em frequências diferentes. Resultados de pesquisas para determinação de Vs e $\mathrm{G}_{0}$, em solos e em RSU, descritos na literatura têm mostrado que estas propriedades são dependentes da frequência utilizada nos ensaios.

As velocidades de propagação de ondas S calculadas para o Aterro Sanitário de São Carlos, pelos dois métodos, estão em geral próximas dos limites inferiores de valores relatados na literatura.

\subsection{Resistência ao cisalhamento de RSU de diferentes idades}

\subsubsection{Caracterização das amostras ensaiadas}

Resíduos sólidos urbanos de diferentes idades de disposição foram submetidos a ensaios de cisalhamento direto em equipamento de grandes dimensões $(50 \times 50 \times 50 \mathrm{~cm})$, para avaliação de suas propriedades mecânicas. Estes resíduos foram coletados no Aterro Sanitário de São Carlos, no Lixão Desativado de São Carlos e em Aterro Experimental construído próximo ao lixão. Além de apresentarem idades de aterramento variáveis (entre 2 e 25 anos), esses resíduos refletem condições de aterramento distintas (formas de operação dos depósitos, ambientes de decomposição e condições de confinamento variadas). 
Em vista disso, além da caracterização física dos resíduos, foram realizados ensaios químicos e bioquímicos para avaliação do estado de degradação dos mesmos. Os seguintes ensaios foram realizados sobre o estrato solubilizado dos componentes menores que $19 \mathrm{~mm}$ : $\mathrm{DBO}_{5}, \mathrm{DQO}$, nitrogênio total, nitrogênio amoniacal, COT e determinação do $\mathrm{pH}$. Sobre o extrato lixiviado foi realizado ensaio de DQO e sobre amostras no estado sólido foram realizadas determinações do conteúdo de STV e de COT.

Os resultados destes ensaios revelaram que os resíduos com dois anos de aterramento encontram-se menos degradados que os demais. Os valores de $\mathrm{DQO}, \mathrm{pH}$, razão $\mathrm{DBO}_{5} / \mathrm{DQO}$ e $\mathrm{pH}$ desta amostra sugerem que estes resíduos estavam provavelmente submetidos aos estágios iniciais da fase metanogênica (início da fase 3). As outras cinco amostras estudadas estão bastante degradadas e encontravam-se provavelmente submetidas à fase metanogênica (fases 3 ou 4). Não foi possível estabelecer uma escala de degradação para estas amostras, julgandose mais adequado tratá-las como um conjunto único, que representa resíduos bastante degradados.

Com relação à composição gravimétrica, em todas as amostras predominam os componentes menores que $19 \mathrm{~mm}$. Os plásticos moles estão presentes em porcentagem significativa apenas nas amostras com 5, 8 e 11 anos de aterramento.

\subsubsection{Parâmetros de resistência ao cisalhamento}

Os resultados dos ensaios de cisalhamento direto mostraram comportamento de endurecimento do material, como observado por diversos outros autores para RSU. Para cálculo das envoltórias de resistência pelo critério de Mohr-Coulomb foram adotados critérios de deslocamento (25, 50 e $100 \mathrm{~mm}$ ou 5, 10 e 20\% da dimensão do corpo de prova), uma vez que as curvas tensão-deslocamento horizontal não apresentaram valores de pico.

Os valores de ângulo de atrito assim calculados foram sempre crescentes, conforme progrediu o deslocamento horizontal. O mesmo não se verificou para a coesão, que aumentou continuamente para as amostras com 2, 5, 8 e 11 anos de aterramento, porém manteve-se estável para as amostras com 16 e 25 anos de aterramento. Este fato não se explica pela antiguidade das amostras, mas pelo fato de estas duas apresentarem conteúdo de plásticos moles e/ou de componentes reforçantes inferior às demais. Nesta pesquisa os resultados obtidos para o parâmetro coesão se correlacionam melhor com o conteúdo de componentes reforçantes, do que com o conteúdo de plásticos moles. 
Considerando-se as envoltórias para deslocamentos de $100 \mathrm{~mm}$, o que corresponde à razão de $20 \%$ de deslocamento em relação ao tamanho da amostra, os parâmetros de resistência calculados para o resíduo menos degradado foram coesão de 13,7 kPa e ângulo de atrito de $22^{\circ}$. Estes são parâmetros praticamente iguais àqueles calculados por Benvenuto e Cunha (1991) ao retroanalisarem a ruptura que ocorreu no Aterro Bandeirantes em 1991. Ressalte-se, entretanto, que os parâmetros de resistência obtidos em ensaios de cisalhamento direto representam condições drenadas.

Os resultados desta pesquisa indicam que em poucos anos de aterramento os RSU evoluem para uma situação de resíduo bastante degradado e, considerando o critério de MohrCoulomb, não há diferenças significativas de resistência entre os resíduos aterrados há 5 ou há 25 anos. Para estes resíduos bastante degradados os parâmetros de resistência calculados foram coesão de $4,4 \mathrm{kPa}$ e ângulo de atrito de $30^{\circ}$. Estes parâmetros são semelhantes àqueles propostos por Kavazanjian (2008), que estão baseados principalmente em ensaios de cisalhamento simples de grandes dimensões realizados com amostras provenientes de aterros operados como biorreatores e de forma convencional (ditos “secos"), nos Estados Unidos.

As amostras ensaiadas em posição rotacionada (ensaios para avaliação da anisotropia dos RSU) evidenciaram que, nestas posições, os RSU têm comportamento de endurecimento ainda mais pronunciado que quando ensaiado com os componentes orientados no plano horizontal. Para tensões normais de $50 \mathrm{kPa}$ as tensões de cisalhamento desenvolvidas no corpo de prova foram sempre maiores do que as desenvolvidas nos corpos de prova ensaiados com as camadas na horizontal, enquanto que para tensão normal de $150 \mathrm{kPa}$ as tensões de cisalhamento foram inicialmente menores e, para deslocamentos maiores que $60 \mathrm{~mm}$, tornaram-se maiores. São necessários mais ensaios para que estas relações, assim como os mecanismos de mobilização das resistências nos RSU, sejam melhor compreendidas.

\subsubsection{Representatividade das amostras ensaiadas}

A questão da representatividade das amostras ensaiadas é bastante discutida no estudo da resistência de RSU e ainda não há consenso sobre quais são os procedimentos de ensaio e preparação de amostras mais representativos. Nesta pesquisa constatou-se que alguns dos métodos adotados alteraram as características do material ensaiado. Alguns destes procedimentos foram também adotados nas pesquisas realizadas por outros autores, de tal forma que os resultados, nestes casos, podem ser comparados. Ainda não há dados suficientes 
na literatura técnica para se afirmar quão significativas são estas alterações, em relação à resistência dos resíduos in situ. As alterações relacionadas aos métodos adotados que se pôde constar foram:

a) Para que fossem respeitadas as relações entre o tamanho da caixa de ensaio e o tamanho das partículas que compõem o material ensaiado, os componentes maiores que $8,5 \mathrm{~cm}$ foram removidos da amostra a ser ensaiada. Em massa úmida, as amostras ensaiadas corresponderam a porcentagens entre 47 e $74 \%$ da amostra coletada em campo.

Verificou-se que, para as amostras coletadas em trincheiras, esta porcentagem variou entre 47 e $57 \%$, e, para as amostras coletadas nas sondagens, essa porcentagem variou entre 72 e $74 \%$. Apesar de estas porcentagens sugerirem que a amostragem com trados helicoidais gera amostras mais representativas, o que ocorre é justamente o contrário. Os trados não são capazes de trazer à superfície os componentes rígidos de maiores dimensões, ou seja, as amostras coletadas por sondagens já estão naturalmente “enriquecidas" em componentes de menor dimensão.

b) as amostras coletadas com os trados helicoidais apresentavam maiores porcentagens de plásticos moles, pois os trados eram capazes de rasgar estes componentes e incorporá-los às frações mais finas da amostra.

c) o método adotado para a preparação das amostras, com o escalpelamento dos componentes maiores que $8,5 \mathrm{~cm}$, provocou um enriquecimento em componentes incompressíveis e um empobrecimento das amostras em componentes reforçantes. Isto se aplica tanto às amostras coletadas em trincheiras, quanto às amostras coletadas em sondagens,

\subsection{Sugestões para pesquisas futuras}

Os parâmetros de resistência determinados nesta pesquisa referem-se a solicitações drenadas. As investigações de campo realizadas no Aterro Sanitário de São Carlos evidenciaram que, na região estudada, o maciço é composto por um estrato superior, que foi operado como um aterro sanitário propriamente dito, e por um estrato inferior, formado nos anos em que a operação era do tipo "aterro controlado", onde a eficiência dos sistemas de drenagem é menor. 
Um assunto que deve ser explorado no estudo da resistência ao cisalhamento de maciços sanitários é se as condições que predominam são do tipo drenada ou não drenada. No caso de aterros com diferentes fases de operação, como em São Carlos, pode acontecer de, para uma mesma solicitação, se estabelecerem condições diferentes em cada estrato do maciço.

Além disso, a composição dos RSU parece ser determinante para que se tenha o efeito de coesão aparente na resistência destes materiais. O conteúdo mínimo de componentes reforçantes que deve existir na massa de resíduos para que este efeito de coesão se estabeleça é outro aspecto que deve ser melhor investigado.

Finalmente, a adoção de equipamentos de maiores dimensões permite que se contornem algumas das deficiências relacionados à representatividade das amostras ensaiadas, porém impõe mais dificuldades à execução dos ensaios, devido aos volumes de material a serem manuseados e à magnitude das forças que têm que ser aplicadas, para que se mantenham as mesmas tensões de ensaio. As oportunidades de se calcular parâmetros de resistência para RSU com base em retroanálises de escorregamentos devem ser valorizadas. 


\section{REFERÊNCIAS BIBLIOGRÁFICAS.}

Abbiss, C. P. (2001) Deformation of landfill from measurements of shear wave velocity and damping. Geotechnique, Vol.51 (6), p. 482-492.

ABNT - Associação Brasileira de Normas Técnicas (1984) NBR 7181: Solo - Análise granulométrica. Rio de Janeiro, RJ. 13p.

ABNT - Associação Brasileira de Normas Técnicas (1990) NBR 12.004: Solo Determinação do índice de vazios máximo de solos não coesivos - Método de ensaio. Rio de Janeiro, RJ. 6p.

ABNT - Associação Brasileira de Normas Técnicas (2004a) NBR 10.004: Resíduos sólidos classificação. Rio de Janeiro, RJ. 77p.

ABNT - Associação Brasileira de Normas Técnicas (2004b) NBR 10.006: Procedimento para obtenção de estrato solubilizado de resíduos sólidos. Rio de Janeiro, RJ. 6p.

Agostini, F.; Sundberg, C.; Navia, R. (2012) Is biodegradable waste a porous environment ? A review. Waste Management \& Research. Vol. 30 (10) p.1001-1015. DOI: $10.1177 / 0734242 \times 12452444$

Akunna, J.C.; Hasan, K.; Kerr, K. (2009) Methodology for estimating the methane potential of a closed landfill. Journal of solid waste technology and management. Vol. 35, n. $3,10 \mathrm{p}$.

Almeida, S. (2007) Estudo Térmico e Caracterização Química de Amostras de Resíduos Sólidos de Aterro Sanitário. Tese de doutorado. Instituto de Química. Unesp Araraquara. $107 \mathrm{p}$.

Angelidaki,I.; Alves, M.; Bolzonella, D.; Borzacconi, L.; Campos, J.L.; Guwy, A.J. Kalyuzhnyi, S.; Jenicek, P. and Van Lier, J.B. (2009) Defining the biomethane potential (BMP) of solid organic wastes and energy crops: a proposed protocol for batch assays. Water Science and Technology. Vol. 59 (5), p. 927-934.

ASTM - American Society for Testing and Materials (2007) D4428/D4428M-07: Standard Test Methods for Crosshole Seismic Testing. ASTM International, West Conshohocken, PA, 11p.

ASTM - American Society for Testing and Materials (2011) D3080/D3080M-11: Standard Test Method for Direct Shear Test of Soils Under Consolidated Drained Conditions. ASTM International, West Conshohocken, PA, 9p. 
Athanasopoulos, G. (2011) Laboratory Testing of Municipal Solid Waste In: Zekkos, D. (ed.) Geotechnical Characterization, Field Measurement, and Laboratory Testing of Municipal Solid Waste. ASCE Geotechnical Special Publication 209. p.195-205.

Athanasopoulos, G., Grizi, A., Zekkos, D., Founta, P., and Zisimatou, E. (2008) Municipal solid waste as a reinforced soil: Investigation using synthetic waste. Proc., ASCEGeo-Institute Geocongress 2008, The Challenge of Sustainability in the Geoenvironment, Geotech.Spec. Pub. No. 177, p.168-175.

Attal, A.; Akunna, J.; Camacho, P.; Salmon, P.; Paris, I. (1992) Anaerobic degradation of municipal wastes in landfill. Water Sci. Technol. 25(7):243-253.

Babu, G.L.S.; Reddy, K.R.; Srivastava, A. (2014) Influence of Spatially Variable Geotechnical Properties of MSW on Stability of Landfill Slopes. Journal of Hazardous, Toxic, and Radioactive Waste, Vol. 18 (1), p. 27-37.

Bareither, C.A.; Benson, C.H.; Edil, T.B. (2012) Effects of Waste Composition and Decomposition on the Shear Strength of Municipal Solid Waste. Journal of Geotechnical and Geoenvironmental Engineering, Vol. 138 (6), p. 1161-1174.

Barlaz, M. A. (2006) Forest products decomposition in municipal solid waste landfills.” Waste Managment, Vol.26, issue 4, p.321-333.

Barlaz, M.A.; Bareither, C.A.; Hossain, A.; Saquing, J.; Mezzari, I; Benson, C.H.; Tolaymat, T.M.; Yazdani, R (2010) Performance of North American Bioreactor Landfills. II: Chemical and Biological Characteristics. Journal of Environmental Engineering, Vol. 136, No. 8, p.839-853.

Bauer, J.; Munnich, K.; Fricke, K. (2007) Influence of hydraulic properties on the stability of landfills. Proceedings Sardinia 2007, Eleventh International Waste Management and Landfill Symposium. Cagliari, Italy. CD-room.

Bauer, J.; Munnich, K.; Fricke, K. (2009) Response of MBT residues in large scale triaxial compression tests. Proceedings Sardinia 2009, Twelveth International Waste Management and Landfill Symposiu. Cagliari, Italy. 9p. CD-room.

Benvenuto, C.; Cunha. M.A. (1991) Escorregamento em massa de lixo no Aterro Sanitário Bandeirantes em São Paulo, SP. Anais, Simpósio sobre barragens de rejeitos e disposição de resíduos - REGEO 91 - Rio de Janeiro, 1991 - p. 55-61 
Berto Neto, J. (2009) Medidas da emissão de gases em oito aterros de resíduos sólidos urbanos do estado de São Paulo - Brasil. Tese de Doutorado. Escola de Engenharia de São Carlos da Universidade de São Paulo. São Carlos, 530p.

Bhandari, A.R.; Powrie, W. (2013) Behavior of an MBT waste in monotonic triaxial shear tests. Waste Management. Vol. 33, p. 881-891.

Blight, G. (2008) Slope failures in municipal solid waste dumps and landfills: a review. Waste Management \& Research, Vol. 26, No. 5, 448-463.

Boda, B. (2002) Evaluation of stability parameters for landfills. Dissertação de Mestrado. Virginia Polytechnic Institute and State Univ., Blacksburg, Va. Disponível em: http://scholar.lib.vt.edu/theses/available/etd-08072002120127/unrestricted/ Thesis.pdf. Acessado em 10 de maio de 2012. 49p.

Bookter, T.J.; Ham, R.K. (1982) stabilization of solid waste in landfills. In: proc. Journal of the environmental engineering division, ASCE, v.108 (6), dec. 1982, p.1089-1100.

Borges de Castilhos, A.; Medeiros, P.A.; Firta, I.N.; Lupatini, G.; Silva, J.D. (2003) Principais processo de degradação de Resíduos Sólidos urbanos. In: Borges, A.C., et al. (Org.). Resíduos Sólidos Urbanos: Aterro Sustentável para Municípios de Pequeno Porte. 1 ed. Sao Carlos SP: Rima Artes e Textos, v.1, p.19-49.

Bouazza, A.; Van Impe, W.F.; Haegeman, W. (1996) Quality control of dynamic compaction in municipal solid waste fills. In: Kamon, (editor), Environmental Geotechnics, Balkema, Rotterdam, The Netherlands, p. 635-640.

Bouazza, A.; Wojnarowicz, M. (1999) Geotechnical properties of municipal solid waste and their implications on slope stability analysis of waste piles. $11^{\text {th }}$ panamerican Conference on Soil Mechanics and Geotechinical Engineering. Anales... Foz do Iguaçu. p. 489-495.

Bouazza, A.; Kavazanjian, E. (2000). Characterization of municipal solid waste sites using the continuous surface wave method. Proceedings. GeoEng 2000, Melbourne, CDRoom.

Bouazza, A.; Kavazanjian Jr, E.; Avsar, S.; Kodikara, S. (2003) Application of a geostatistical model to map spatial distribution of shear wave velocities of solid wastes. Proceedings Sardinia 2003, Ninth International Waste Management and Landfill Symposium. Cagliari, Italy. CD-Room. 
Bray, J.D.; Zekkos, D.; Kavazanjian, E.; Athanasopoulos, G.A.; Riemer, M.F. (2009) Shear strength of municipal solid waste. Journal of Geotechnical and Geoenvironmental Engineering, ASCE, New York, v.135, n.6, p. 709-722.

Britto, M.L.C.P.S. (2006) Taxa de emissão de biogás e parâmetros de biodegradação de residuos sólidos urbanos no aterro metropolitano centro. Dissertação de mestrado. Universidade Federal da Bahia. Salvador, 185p.

Burlingame, M.J.; Egin, D.; Armstrong, W.B. (2007) Unit weight determination of landfill waste using sonic drilling methods. Journal of Geotechnical and Geoenvironmental Engineering, Vol.133 (5), p. 609-612.

Caicedo, B., Giraldo, E.; Yamin, L. and Soler, N. (2002a) The landslide of Dona Juana landfill in Bogota. A case study. $4^{\text {th }}$ International Congress on Environmental Geotechnics, Proceedings..., Rio de Janeiro, Brazil, Vol. 1, p. 171-175.

Caicedo, B., Yamin, L., Giraldo, E.; Coronado, O. (2002b) Geomechanical properties of municipal solid waste in Dona Juana sanitary landfill. $4^{\text {th }}$ International Congress on Environmental Geotechnics, Proceedings..., Rio de Janeiro, Brazil, Vol. 1, p. 177182.

Calle, J.A.C. (2007) Comportamento Geomecânico de Resíduos Sólidos Urbanos. Tese de Doutorado - Universidade Federal do Rio de Janeiro, COPPE. Rio de Janeiro. 160 p.

Campi, T.M.O.; Boscov, M.E.G. (2011) Determination of Shear Strength Parameters of Municipal Solid Waste (MSW) by Means of Static Plate Load Tests. Proc. GeoFrontiers 2011. Geotechnical Special Publication 211. ASCE. Dallas. p.1227-1236.

Cardim, R.D. (2008) Estudo da resistência de resíduos sólidos urbanos por meio de ensaio de cisalhamento direto de grandes dimensões. Dissertação de Mestrado - Universidade de Brasília, Brasília-DF. 91p.

Carpenter, P.J.; Reddy, K.R.; Thompson, M.D. (2013) Seismic Imaging of a LeachateRecirculation Landfill: Spatial Changes in Dynamic Properties of Municipal Solid Waste. Journal of Hazardous, Toxic, and Radioactive Waste, Vol. 17 (4), p. 331-341.

Cartier, G; Baldit, R. (1983) Comportment géotechnique des discharges de résidus urbains. Bull. De Liason des laboratories des Ponts et Chaussées, n.128, p.55-64.

Carvalho, M.F. (1999). Comportamento Mecânico de Resíduos Sólidos Urbanos. Tese de Doutorado. Escola de Engenharia de São Carlos da Universidade de São Paulo. São Carlos, 300p. 
Castelli, F.; Maugeri, M. (2014) Mechanical properties of Municipal Solid Waste by SDMT. Waste Management. Vol. 34. p. 256-265.

Chen, Y.M.; Tony L.T. Zhan, H.Y. Wei and H. Ke (2009) Aging and compressibility of municipal solid wastes. Waste Management. Vol. 29 (1). P. 86-95.

Choudhury, D.; Savoikar, P. (2009) Simplified method to characterize municipal solid waste properties under seismic conditions. Waste Management, Vol. 29 (2). p.924-933

Clayton, C.R.I. (2011) Stiffness at small strain: research and practice. Géotechnique Vol. 61, No. 1, p.5-37 [doi: 10.1680/geot.2011.61.1.5].

Cossu, R.; Di Maio, R.; Raga, R. (2001) An integrated geophysical survey of an old landfill site with use of explosive as energy source for the seismic methods. Proc. Sardinia 2001, Eight International Landfill Symposium. Cagliari, Italy, p.425-433.

Cossu, R.; Di Maio, R.; Fais, S.; Fraghí, S.; Ligas, P.; Menghini, A. (2005) Physical and structural characterization of an old landfill site by a multimethodological geophysical approach. Proceedings Sardinia 2005, Tenth International Landfill Symposium. Cagliari, Italy, 8 p. - CD-Room.

Cossu, R.; Lai, T.; Sandon, A. (2012) Standardization of $\mathrm{BOD}_{5} / \mathrm{COD}$ ratio as a biological stability index for MSW. Waste Management Vol. 32. p.1503-1508

Coumoulos, D.G.; Koryalios, T.P.; Metaxas, I.L.; Gioka, D.A. (1995) Geotechnical Investigation at the Main Landfill of Athens. Proceedings Sardinia 95, Fifth International Landfill Symposium. Cagliari, Italy. p.885-895.

Cowland, J.W.; Tang, K.Y.; Gabay, J. (1993) Density and strength properties of Hong Kong refuse. Proceedings 4th International Landfill Symposium Sardinia. Cagliari, Italy, p. 1421-1432.

Cox, S.E.; Beaven, R.P.; Powrie, W.; Cole, D.J. (2006) Installation of Horizontal Wells in Landfilled Waste Using Directional Drilling. Journal of Geotechnical and Geoenvironmental Engineering, Vol. 132 (7). p. 869-878.

De Lamare Neto, A. (2004) Resistência ao Cisalhamento de Resíduos Sólidos Urbanos e de Materiais Granulares. Tese de Doutorado - Universidade Federal do Rio de Janeiro, COPPE. Rio de Janeiro -190 p.

Del Greco, O.; Fassino, A; Godio, A. (2007) Seismic investigation for the assessment of the elastic settlement in MSW landfill. Proceedings Sardinia 2007. International Waste Management Landfill Symposium, $11^{\text {th }}$. Cagliari, Italy. 9 p. CD-Room. 
Dixon, N., Langer, U. (2006) Development of a MSW classification system for the evaluation of mechanical properties. Waste Management. Vol. 26, p.220-232.

Dixon, N.; Langer, U.; Gotteland, P. (2008) Classification and Mechanical Behavior Relationships for Municipal Solid Waste: Study Using Synthetic Wastes. Journal of Geotechnical and Geoenvironmental Engineering, Vol. 134 (1), p. 79-90.

Eid, H.T.; Stark, T.D.; Evans, W.D.; Sherry,P.E. (2000) Municipal solid waste slope failure I: waste and foundation soil properties. Journal of Geotechnical and Geoenvironmental Engineering, Vol. 126 (5). p. 397-407.

El-Fadel, M. (1999) Simulating temperature variations in landfills. Journal of solid waste technology and management. Vol. 26 (2), p. 78-86.

El-Fadel, M.; Al-Rashed, H. (1998) Settlement in municipal solid waste landfills I: field scale experiments. Journal of solid waste technology and management. Vol. 25 (2), p. 8998.

Ferreira, A.G. (2010) Estudo dos lixiviados das frações do aterro sanitário de São Carlos-SP por meio da caracterização físico-química. Dissertação de Mestrado. Escola de Engenharia de São Carlos da Universidade de São Paulo. São Carlos, 134p.

Finno, R.; Jung, Y.H.; Kavazanjian, E.; Seo, B. (2007) Interpretation of MSW Shear Strenght from simple shear tests. Proceedings Sardinia 2007, Eleventh International Waste Management and Landfill Symposium. Cagliari, Italy. CD-room.

FIPAI - Fundação para o incremento da pesquisa e do aperfeiçoamento industrial (2009) Aterro saniário para disposição final de resíduos sólidos domiciliares do município de São Carlos/SP - Estudo de Impacto Ambiental. 2 Volumes. 536p.

Frésca, F.R.C. (2007) Estudo da geração de resíduos sólidos domiciliares no município de São Carlos, SP, a partir da caracterização física. Dissertação de mestrado. Escola de Engenharia de São Carlos da Universidade de São Paulo. São Carlos, 133p.

Fucale, S.P. (2005). Influência dos Componentes de Reforço na Resistência de Resíduos Sólidos Urbanos. Tese de Doutorado, Programa de Pós-Graduação em Engenharia Civil, Departamento de Engenharia Civil, Universidade Federal de Pernambuco, 219 p.

Fucale, S.P.; Juca, J.F.T. (2002) Estudo da resistência à penetração dinâmica (SPT) em aterros de resíduos sólidos urbanos. XXVIII Congreso Interamenicano de Ingenieria Sanitaria y Ambiental. Cancun, México. 
Gabr, M. A., Valero, S. N. (1995) Geotechnical properties of municipal solid waste. Geotechnical Testing Journal, Vol. 18 (2), p.241-251.

Gabr, M.A.; Hossain, M.S.; Barlaz, M.A. (2007a) Shear Strength Parameters of Municipal Solid Waste with Leachate Recirculation. Journal of Geotechnical and Geoenvironmental Engineering, Vol. 133 (4), p.478-484.

Gabr, M.A.; Hossain, M.S.; Barlaz, M.A. (2007b) Erratum for "Shear Strength Parameters of Municipal Solid Waste with Leachate Recirculation”. Journal of Geotechnical and Geoenvironmental Engineering, Vol. 133 (9), p.1181.

Gachet, C.; Lemaréchal, D.; Gotteland, P.; Prudhomme, B. (1998) In situ household refuse density measurement protocol. In: International Congress on Environmental Geotechnics, 3., Proceedings... Lisbon, 1998. p.849-854.

Gadotti, R.F. (1997) Avaliação da contaminação das águas superficiais e subterrâneas adjacentes ao "lixão" da cidade de São Carlos. Dissertação de Mestrado. Escola de Engenharia de São Carlos da Universidade de São Paulo. São Carlos, 150p.

Godley, A.; Lewin, K.; Graham, A.; Barker, H.; Smith, R. (2004) Biodegradability determination of municipal waste: an evaluation of methods. Proc. Waste 2004 Conf. Integrated Waste Management and Pollution Control: Policy and Practice, Research and Solutions. Stratford-upon-Avon, Grã-Bretanha, p.40-49.

Gomes, L.P. (1989) Estudo da caracterização física e da biodegradabilidade dos resíduos sólidos urbanos em aterros sanitários. Dissertação de mestrado. Escola de Engenharia de São Carlos da Universidade de São Paulo. São Carlos, 167p.

Gomes, C., Ernesto, A., Lopes, M.L., Moura, C. (2002). .Sanitary Landfill of San Tirso. Municipal Waste Physical, Chemical and Mechanical Properties. Proc. 4th ICEG (International Congress on Environmental Geotechnics), Rio de Janeiro, Brazil. Netherlands, Balkema.

Gomes, C.C.; Lopes, M.L. (2006) Contribuição para a Caracterizacao do comportamento de Aterros Sanitarios atraves de Monitorizacao. XIII Congresso Brasileiro de Mecânica dos Solos e Engenharia de Fundações (COBRAMSEF). CD-Room.

Gomes, C.C.; Lopes, M.L. (2012) Characterisation of municipal solid waste physical properties and their evolution with age. Proceedings of the Institution of Civil Engineers - Geotechnical Engineering. Vol. 165 Issue GE1 Pages 23-34 doi: http://dx.doi.org/10.1680/geng.10.00016. 
Gotteland, P.; Lemaréchal, D.; Richard, P. (1995) Analysis and Monitoring of the stability of a domestic waste landfill. Proc. Sardinia 95, Fifth International Landfill Symposium. Cagliari, Italy, p.777-787.

Gotteland, P., Gourc, J.P., Alboura, A., Thomas, S. (2000) On site determination of geomechanical characteristics of waste. Proceedings GeoEng 2000, The Institute of Engineers, Australia, CD-Room.

Gotteland, P., Gachet, C., Vuillemin, M., (2001) Mechanical study of a municipal solid waste landfill. Proc. Sardinia 2001, Eight International Landfill Symposium. Cagliari, Italy, p.425-433.

Grisolia, M.; Napoleoni, Q.; Tancredi, G. (1995). Contribution to a Technical Classification of MSW. Proceedings Sardinia 95, Fifth International Landfill Symposium. Cagliari, Italy, p.703-710.

Hanson, J.L.; Yeşiller, N; Oettle, N.K. (2010) Spatial and Temporal Temperature Distributions in Municipal Solid Waste Landfills. Journal of Environmental Engineering, Vol. 136 (8), p. 804-814.

Harris, JM; Shafer, AL; De Groff, W; Hater, GR; Gabr, M.; Barlaz, MA (2006) Shear Strength of Degraded Reconstituted Municipal Solid Waste. Geotechnical Testing Journal. Volume 29, Issue 2. 8p.

Hossain, M. S., Gabr, M. A., and Barlaz, M. A. (2003) Relationship of compressibility parameters to municipal solid waste decomposition. J. Geotech. Geoenviron. Eng., Vol. 129 (12), p.1151-1158.

Hossain, M.S.; Haque, M.A. (2009) The effects of daily cover soils on shear strength of municipal solid waste in bioreactor landfills. Waste Management, Vol. 29 , p.15681576.

Houston, W.N.; Houston, S.L.; Liu, J.W.; Elsayed, A.; Sandres, C.O. (1995) In-situ testing methods for dynamic properties of MSW landfills. In: Earthquake Design and Performance of Solid Waste Landfills. ASCE Geotechnical Special Publication n. 54, p. $73-82$

Imhoff, P.T.; Reinhart, D.R.; Englund, M.; Guerin, R.; Gawande, N.; Han, B.; Jonnalagadda, S.; Townsend, T.G.; Yazdani, R. (2007) Review of state of the art methods for measuring water in landfills. Waste Management, Vol. 27. p. 729-745. 
Instituto de Pesquisas Tecnológicas do Estado de São Paulo - IPT; Compromisso Empresarial para Reciclagem - CEMPRE (1995) Lixo municipal: manual de gerenciamento integrado. São Paulo: Instituto de Pesquisas Tecnológicas. Publicação IPT n. 2163. $278 \mathrm{p}$.

Jamiolkowski, M. (2012) Role of geophysical testing in geotechnical site characterization. Soils and Rocks, Vol. 35 (2), p. 117-137.

Jang, Y.S.; Kim, Y.I. (2003) Behavior of a municipal landfill from field measurement data during a waste disposal period. Environmental Geology. Vol. 44, n. 5, p. 592-598.

Jensen, V.; Andersen, K.J.; Krysell, M. (2003) Desk study on total organic carbon (TOC). Horizontal 17-2. Disponível em http://www.ecn.nl/docs/society/ horizontal/hor_desk_17_TOC.pdf. Acessado em abril de 2010.

Jessberger, H. L. (1994). Geotechnical Aspects of Landfill Design and Construction - Parts 1 to 3. Proc. Institution of Civil Engineers, Geotechnical Engineering, Vol.107, Apr., p.99-121.

Jessberger, H.L. e Kockel, R. (1995) Determination and assessment of the mechanical properties of waste material. Proc. Symp. on Geotechnics Related to the Environment, Waste Disposal by Landfill, GREEN'93, Bolton, UK, p. 313 - 322.

Jones, D.R.V., Taylor, D.P., Dixon, N. (1997) Shear strength of waste and its use in landfill stability analysis. In: Yong, R.N., Thomas, H.R. (Eds.), Proceedings Geoenvironmental Engineering Conference. Thomas Telford, p. 343-350.

Kaimoto, L.S.A; Cepollina, M. (1996) Considerações sobre alguns condicionantes e critérios geotécnicos de projeto e executivos de aterros sanitários. Anais, Simpósio Internacional de Qualidade Ambiental, Porto Alegre, p. 51-54.

Karimpour-fard, M.; Machado, S.L.; Shariatmadari, N.; Noorzad, A. (2011) A laboratory study on the MSW mechanical behavior in triaxial apparatus. Waste Management, Vol. 31, p. 1807-1819.

Kavazanjian, E. Jr. (1999), Seismic design of solid waste containment facilities, Proceedings of the Eight Canadian Conference on Earthquake Engineering, Vancouver, BC, p. 51- 68.

Kavazanjian, E. Jr. (2001) Mechanical properties of municipal solid waste In: Proceedings Sardinia 2001, Eighth International Waste Management and Landfill Symposium, Cagliari, Italy. CD-Room. 
Kavazanjian Jr., E. (2003) Evaluation of MSW properties using field measurements. Proc. of 17th GSI/GRI Conf.: Hot Topics in Geosynthetics-IV, Las Vagas, USA, p. 74-113.

Kavazanjian, E. Jr. (2006) Waste Mechanics: recent findings and unanswered questions. Advances in Unsaturated soil, seepage, and environmental geotechnics. ASCE Special Geotechnical Publication 148, proceedings of sessions of GeoShangai, Shangai, China, p. 34-54.

Kavazanjian, E, Jr. (2008) The Impact of degradation on MSW shear strength. Proceedings of GeoCongress '08: Geotechnics of Waste Management and Remediation. ASCE Geotechnical Special Publication 177, p. 224-231

Kavazanjian, E., Jr,; Matasovic, N. Bonaparte, R.; Schmertmann, G.R. (1995) Evaluation of MSW Properties for seismic analysis. Proceedings of Geoenvironment 2000, ASCE geotechnical Special Publication No. 46, Vol. 2, p. 1126-1141.

Kavazanjian, E., Jr., Matasovic, N., Stokoe, K.H.II, Bray, J.D. (1996), In situ shear wave velocity of solid waste from surface wave measurements. Kamon, (editor) (1996) Environmental Geotechnics. Balkema, Rotterdam, The Netherlands, Vol. 1, p. 97102.

Kavazanjian, E.,Matasovic, R., Bachus, R.C. (1999) Large-diameter static and cyclic laboratory testing of municipal solid waste. Proceedings Sardinia '99, Seventh International Waste Management and Landfill Symposium, Cagliari, Italy, p.437-444

Kavazanjian, E. Jr.. Hendron, D. and Corcoran, G.T. (2001) Strength and Stability of Bioreactor Landfills. Proc., Annual Landfill Symposium, Solid Waste Association of North America, Silver Springs, Maryland.

Kelly, R.J.; Shearer, B.D.; Kim, J.; Goldsmith, C.D.; Hater, G.R.; Novak, J.T. (2006) Relationships between analytical methods utilized as tools in the evaluation of landfill waste stability. Waste Management, Vol. 26, p.1349-1356.

Kjeldsen, P.I., Barlaz, M.A, Rooker, A.P., Baun, A., Ledin, A. e Christensen, T.H. (2002) Present and Long-Term Composition of MSW Landfill Leachate: A Review. Critical Reviews in Environmental Science and Technology, v. 32, p. 297-336.

Kolsch, F. (1993) The bearing behaviour of domestic waste and related consequences for stability. Proceedings Sardinia 93, 4th International Landfill Symposium. Cagliari, Italy, Vol. 2, p.1393-1410 
Kolsch, F. (1995) Material Values for Some Mechanical Properties of Domestic Waste. Proceedings Sardinia 95, 5th International Landfill Symposium, Cagliari, Italy, Vol. II., p. 711-729.

Kolsch, F. (2009) Shear strenght of waste. 3rd International Workshop "Hydro-PhysicoMechanics of Landfills", Braunschweig, Alemanha. Disponível em: http://www.lwi.tu-bs.de/hpm/docs/paper/25\%20Paper\%20Koelsch.pdf. Acessado em 29 de março de 2010.

Konstantaki, L. A., Ghose, R., Draganov, D., Diaferia G., and Heimovaara, T. (2015) Characterization of a heterogeneous landfill using seismic and electrical resistivity data. Geophysics, Vol.80, No.1, p. EN13 -EN25, DOI: 10.1190/GEO2014-0263.1

Laine-Ylijoki, J.L.; Syrjä, J.J.; Wahlström, M. (2004) Biodegradability testing of the municipal solid waste reject. NordTest Technical Report 560. 21p. Disponível em: http://www.nordicinnovation.net/nordtestfiler/tec560.pdf. Acessado em 24-03-2011.

Landva, A.O.; Clark, J.I.; Weisner, W.R.; Burwash, W.J. (1984) Geotechnical engineering and refuse landfills. $6^{\text {th }}$ National Conf. on Waste Management in Canada, Vancouver, British Columbia.

Landva, A. O.; Clark, J. I. (1990). Geotechnics of Waste Fill. In: Landva, A.O.; Knowles, G.D. (eds) Geotechnics of Waste Fill - Theory and Practice. ASTM STP $n^{\circ} 1070$. American Society for Testing and Materials, Philadelphia, p.86-106.

Lee, J.J. (2007) Dynamic Characteristics of Municipal Solid Waste (MSW) in the Linear and Nonlinear Strain Ranges. Tese de doutorado. The University of Texas at Austin. 446 p.

Leite, W.C.A. (1991) Estudo do comportamento da temperatura, potencial hidrogeniônico e potencial de oxi-redução, na decomposição dos resíduos sólidos urbanos em aterros sanitários. Dissertação de mestrado. EESC-USP. 180p.

Lin, Y.; Rosenblad, B.; Stokoe, II, K.H. (2004) Data Report on Shear Wave Velocity Profiles Determined by SASW Method at: 1. Altamont Landfill, 2. Redwood Landfill, and 3. Tri-Cities Landfill. Geotechnical Engineering Report GR04-3 Geotechnical Engineering Center. Civil Engineering Department. The University of Texas at Austin . 40p.

Lopes, I; Santos, J.A.; Almeida, I.M. (2008) O método das ondas superficiais: aquisição, processamento e inversão. Geotecnia, n. 112. p. 79-109. 
Machado, S. L.; Carvalho, M.F; Vilar, O. M. (2002). Constitutive Model for Municipal Solid Waste. Journal of Geotechnical and Geoenvironmental Engineering, Vol.128 (11), p.940-951.

Machado, S.L.; Carvalho, M. F.; Nascimento, J.C.F.; Dourado, K.A. (2006) Aging efect on MSW mechanical behaviour. In: $V$ ICEG (5th International Congress on Environmental Geotechnics. Cardiff, v.2, p.1439-1446.

Manassero, M.; Van Impe, W.F.; Bouazza, A. (1996). Waste Disposal and Containment. Proceedings of the Second International Congress on Environmental Geotechnics, Preprint of Special Lectures, Osaka, Japan, A.A.Balkema, 1997, p. 1425-1474.

Mantlik, F.; Matias, M.; Louren, J.; Grangeia, C; Tareco, H. (2009) The use of gravity methods in the internal characterization of landfills - a case study. Journal of Geophysics and Engineering, Vol. 6, p.357-364.

Mariano, M.O.H. (1999) Recalques no aterro de resíduos sólidos da Muribeca. Dissertação de mestrado. Universidade Federal de Pernambuco. Recife. 108p.

Martins, H.L. (2006) Avaliação da resistência de resíduos sólidos urbanos por meio de ensaios de cisalhamento direto em equipamento de grandes dimensões. Dissertação de mestrado. Universidade Federal de Minas Gerais. Belo Horizonte. 116p.

Matasovic, N.; Kavazanjian, E., Jr. (1998) Cyclic Characterization of OII Landfill Solid Waste. Journal of Geotechnical and Geoenvironmental Engineering, Vol. 124 (3), p.197-210.

Matos, T.F.L. (2006) Diagnóstico dos resíduos poliméricos presentes nos resíduos sólidos domiciliares gerados em São Carlos, SP. Dissertação de mestrado. Escola de Engenharia de São Carlos da Universidade de São Paulo. São Carlos. 175p.

Mazzucato, N., Simonini, P., Colombo, S. (1999) Analysis of block slide in a MSW landfill. Proceedings Sardinia 1999, Seventh International Waste Management and Landfill Symposium, Cagliari, Italy.

McDougall, J.R. (2008) Landfill modelling challenge; HBM model predictions, Proc. Inst. Civil Engineers, Waste \& Resource Man., WR4, p.147-153.

McDougall, J.R.; Pyrah, I.C. (2003) Modelling load, creep and biodegradation in landfill. Proceedings Sardinia 2003, Ninth International Waste Management and Landfill Symposium. Cagliari, Italy. CD-rom. 
Mehta, R.; Barlaz, M.A.; Yazdani, R.; Augenstein, D.; Bryars, M. ; Sinderson, L. (2002) Refuse Decomposition in the Presence and Absence of Leachate Recirculation. Journal of Environmental Engineering, Vol. 128 (3). p. 228-236.

Melo, M.C. (2003) Uma Análise de Recalques Associada a Biodegradação no Aterro de Resíduos Sólidos da Muribeca. Dissertação de Mestrado. Universidade Federal de Pernambuco (UFPE). Recife, 127p.

Menezes, D.B. (1995) Diagnóstico dos impactos do lixão de São Carlos (SP) no meio físico. Dissertação de Mestrado. Escola de Engenharia de São Carlos da Universidade de São Paulo. São Carlos, 101p.

Mitchell, J.K. (1996) Geotechnics of solid-waste material interactions. Proceedings of the 2nd international congress environmental geotechnics, Osaka, Japan. Balkema. Vol. 3, pp. 1311-1328.

Morochnik, V.; Bardet, J.P.; Husmand, B. (1998) Identification of dynamic properties of OII Landfill. Journal of Geotechnical and Geoenvironmental Engineering, Vol. 124 (3), p.186-196.

Motta, E.Q. (2011) Avaliação da resistência ao cisalhamento de resíduos sólidos urbanos com co-disposiçãa de lodo de tratamento de esgoto através de ensaios de cisalhamento direto de grandes dimensões. Tese de doutoramento. Recife: Universidade Federal de Pernambuco. 190p.

Nascimento, J.C.F. (2007) Comportamento mecânico de residuos sólidos urbanos. Dissertação de Mestrado. Escola de Engenharia de São Carlos da Universidade de São Paulo. São Carlos, 160p.

Nascimento, J.C.F.; Vilar, O.M.; Machado, S.L.; Carvalho, M.F. (2008) Resistência NãoDrenada de Resíduos Sólidos Urbanos do Aterro Metropolitano Centro de Salvador BA. In: Combramseg, Anais... Búzios, 8p. CD-Room.

Oweis, I.S. (1993) Stability of landfill. In: Daniel, D.E. (ed.) Geotechnical Practice for waste disposal. Ed. Chapman \& Hall, London, p. 244-268.

Oweis, I. S., and Khera, R. (1986) "Criteria for geotechnical construction of sanitary landfills.” Inter. Symp. on Environmental Geotechnology, Envo Publishing, Lehigh Valley, Pa., Vol. 1, 205-222.

Oweis, I.S.; Khera, R.P. (1998) Geotechnology of waste management. PWS Publishing Company. $2^{\text {nd }}$ edition. $472 \mathrm{p}$. 
Pereira, A.G.H.; Sopeña, L.; Mateos, M.T.G. (2002) Compressibility of a municipal solid wastefill. Proc. 4th International Congress on Environmental Geotechnics - 4th ICEG, Rio de Janeiro, V. 1, p. $201-206$.

Pelkey, S., Valsangkar, A., Landva, A. (2001) Shear displacement dependent strength of municipal solid waste and its major constituent. Geotechnical Testing Journal, Vol. 24 (4), p.381-390.

Ramaiah, B.J.;,Ramana, G.V.; Kavazanjian, E. (2014) Undrained Response of Municipal Solid Waste Collected from a Waste Site in Delhi, India. In: Reddy, K.R.; Shen, S. (2014) Geoenvironmental Engineering .Proceedings Geo-Shangai 2014. GSP 241. ASCE. http://dx.doi.org/10.1061/9780784413432.

Reddy, K.R., Gangathulasi, J., Parakalla, N.S., Hettiarachchi, H., Bogner, J.E., Lagier, T. (2009a). Compressibility and shear strength of municipal solid waste under shortterm leachate recirculation operations. Waste Management \& Research. Vol. 27 (6). p.578-587.

Reddy, K.R.; Hettiarachchi, H.; Parakalla, N.S.; Gangathulasi, J.; Bogner, J.E. (2009b) Geotechnical properties of fresh municipal solid waste at Orchard Hills Landill, USA. Waste Management, Vol. 29. p.952-959

Reddy, K.R.; Hettiarachchi, H.; Gangathulasi, J.; Bogner, J.E. (2011) Geotechnical properties of municipal solid waste at different phases of biodegradation. Waste Management. Vol. 31.pp.2275-2286

Reinhart, D.R. e Al-Yousfi, A.B. (1996) The impact of leachate recirculation on municipal solid waste landfill operating characteristics. Waste Management and Research, vol. 14, pp. 337-346.

Reinhart, D.R., McCreanor, P.T. e Townsend, T. (2003) Instrumentation for in situ monitoring of municipal solid waste landfill processes. Proceedings Sardinia 2003, Ninth International Waste Management and Landfill Symposium. Cagliari, Italy. 10p. CD-Room.

Richardson, G.; Reynolds, D. (1991) Geosyntetic considerations in a landfill on compressible clays. Proceedings of Geosynthetics'91, Vol. 2, Industrial Fabrics Association International, St Paul, MN. p. 507-516. 
Rix G.J., Lai C.G., Foti S., Zywicki D. (1998), Surface wave tests in landfills and embankments, Geotechnical Earthquake Engineering and Soil Dynamics III, Geothecnical Special Publication No. 75, ASCE, vol. 2, p. 1008-1019.

Rocha, E.F.; Azevedo, R.F. (2008) Determinação da Condutividade Hidráulica e Capacidade de Campo de Resíduos Sólidos Urbanos. In: Cobramseg, Anais... Búzios. 8p. CDRoom.

Sadek, S.; Abou-Ibrahim, A.; Manasseh, C.; El-Fadel, M. (2001) Stability of solid waste sea fills: shear strength determination and sensitivity analysis. International Journal of Environmental Studies, 1029-0400, Volume 58, Issue 2, p. 217 - 234

Sahadewa, A; Zekkos,D.; Lobbestael, A.; Woods, R.D. (2011) Shear Wave Velocity Measurements at Municipal Solid Waste Landfills in Michigan. In: 14th PanAmerican Conference on Soil Mechanics and Geotechnical Engineering. Proceedings. Toronto, Canadá. $8 \mathrm{p}$.

Santos, S.M. (1997) Propriedades geotécnicas de um aterro de resíduos sólidos. Recife. Dissertação de Mestrado. Centro de Tecnologia e Geociências, Depto de Engenharia Civil, Univ. Federal de Pernambuco. 108p.

São Carlos Ambiental (2013) Estudo da Composição Gravimétrica dos Resíduos Sólidos Domiciliares de São Carlos - SP. Relatório Interno. 9p.

Schalch, V. A (1992) Análise comparativa do comportamento de dois aterros sanitários semelhantes e correlações dos parâmetros do processo de digestão anaeróbia. Tese de doutorado. Escola de Engenharia de São Carlos da Universidade de São Paulo. São Carlos, 220p.

Schumacher, B.A. (2002) Methods for the determination of total carbon (TOC) in soils and sediments. United States Environmental protection Agency. Environmental Sciences Division. National Exposure Research Laboratory. 23p. Disponível em: http://www.epa.gov/esd/cmb/research/papers/bs116.pdf. Acessado em abril 2010.

Shariatmadari, N; Machado, S.L.; Noorzad, A. and Karimpour-Fard, M. (2009) Municipal solid waste effective stress analysis. Waste Management. Vol. 29 (12), p. 2918-2930.

Shariatmadari, N; Karimpour-Fard, M.; Keramati, M.; Kolarijani Jafari, H.; Naebi, A. (2011) Fiber content impact on the shear strenght of MSW materials in direct shear tests. Proceedings Sardinia 2009, Thirteenth International Waste Management and Landfill Symposium. Cagliari, Italy. 8p. CD-Room. 
Sharma, H. D.; Dukes, M. T. e Olsen, D. M. (1990) Field measurements of dynamic moduli and Poisson's rations of refuse and underlying soils at a landfill site. In: Landva, A.; Knowles, G.D. (ed) Geotechnics of Waste Fills - Theory and Practice, ASTM STP 1070. p. $57-70$

Shinzato, M.P.B. (2014) Mobilização de poluentes no maciço de resíduos de lixão desativado. Tese de Doutorado. Programa de Pós-graduação em Hidráulica e Saneamento, Escola de Engenharia de São Carlos da Universidade de São Paulo, São Carlos, 196p.

Siegel, R. A., Robertson, R. J., and Anderson, D. G. (1990) Slope stability investigations at a landfill in Southern California. In: Landva, A.; Knowles, G.D. (ed) Geotechnics of Waste Fills - Theory and Practice, ASTM STP 1070, Philadelphia. p. 259-284

Silveira, A.M.M. (2004) Estudo do peso específico de resíduos sólidos urbanos. Dissertação de mestrado. Universidade Federal do Rio de Janeiro-COPPE. Rio de Janeiro, 106p.

Singh, M.K. (2008) Characterization of stress-deformation behavior of municipal solid waste. Doctor of Philosophy Thesis. University of Saskatchewan, Saskatoon, Canada. 177p.

Singh, M.K.; Sharma, J.S.; Fleming, I.R. (2009) Shear strength testing of intact and recompacted samples of municipal solid waste. Canadian Geotechnical Journal, Vol. 46. p.1133-1145.

Singh, S.; Murphy, B. (1990). "Evaluation of the stability of sanitary landfills". In: Landva, A.; Knowles, G.D. (ed) Geotechnics of Waste Fills - Theory and Practice, ASTM STP 1070, Philadelphia. p. 240 - 258.

Souto, G.D.B. (2009) Lixiviado de aterros sanitários brasileiros - estudo de remoção do nitrogênio amoniacal por processo de arraste com ar ("stripping”). Tese de Doutorado. Escola de Engenharia de São Carlos da Universidade de São Paulo. São Carlos, 371p.

Stark, T.D.; Huvaj-Sarihan, N.; Li, G. (2009) Shear strength of municipal solid waste for stability analyses. Environmental geology, Vol. 57 (8), p.1911-1923.

Stokoe, K.H., II; Joh, S.; Woods, R.D. (2004) Some contributions of in situ geophysical measurements to solving geotechnical engineering problems. Proceed. 2nd Intern. Site Characterization ISC'2, Porto, Portugal, Vol 1., p. 97-132.

Stokoe, II, K.H.; Zalachoris, G.; Cox, B.; Park, K. (2011) Field Evaluations of the Effects of Stress State, Strain Amplitude and Pore Pressure Generation on Shear Moduli of 
Geotechnical and MSW Materials. International Symposium on Deformation Characteristics of Geomaterials, Seoul, Korea.

Stoltz, G.; Nousheen Arif, K.; Gourc, J.P.; Olivier, F.; Redon, E. (2009) Hydro-mechanical properties of MSW from laboratory tests following a deep drilling campaign. Proceedings Sardinia 2009, Twelfth International Waste Management and Landfill Symposium. Cagliari, Italy. 10p. CD-Room.

Tchobanoglous, G.; Thiesen, H.; Vigil, S. (1993) Integrated solid waste engineering principles and management issues. Mc-Graw-Hill Inc. 978p.

Turczynski, U. (1988) Geotechnische Aspekte beim Aufbau von Mehrkomponentendeponien. Dissertation an der Bergakademie Freiberg. 96p.

Van Elk, A.G.H.P.; Manas, L.S.; Mateos, T.G. (2007) Deformation behaviour of municipal waste landfill. Proceedings Sardinia 2007. International Waste Management Landfill Symposium, $11^{\text {th }}$. Cagliari, Italy. 10p. CD-Room.

Varga, G.; Imre, E.; Czap, Z.; Firgi,T.; Telekes, G. (2011) Laboratory and in situ tests of a landfill. Fourth International Workshop "Hydro-Physico-Mechanics of Landfills" (HPML4) Santander, Spain. Disponível em: http://www.hpm4. unican.es/proceedings.html. Acessado em 09 de novembro de 2011. 10p.

Velozo, R. (2006) Caracterização geológico-geotécnica do lixão desativado de São Carlos SP, com auxílio de geofísica. Dissertação de Mestrado. Programa de Pós-Graduação em Geotecnica. Escola de Engenharia de São Carlos da Universidade de São Paulo. São Carlos, 177p.

Vilar, O.M.; Carvalho, M.F. (2004). Mechanical Properties of Municipal Solid Waste; Journal of Testing and Evaluation, Vol. 32 (6). Paper ID JTE11945.

Warith, M; Sharma, R. (1998) Technical review of methods to enhance biological degradation in sanitary landfills. Water Quality Research Journal of Canada, Vol. 33 (3), p. 417 37.

Wiemer, K. (1982) Qualitative und quantitative Kriterien zur bestimmung der Dichte von Abfällen in geordneten Deponien. Abfallwirtschaft an der Technischen Universitat Berlin. ISBN 3-922021-50-1.108p.

Withiam, J.L., Tarvin, P.A., Bushell, T.D., Snow, R.E \& Germann, H.W. (1995) Prediction and Perfomance of municipal Landfill Slope. Proc. International Conference the Geoenvironment 2000, ASCE GSP $n^{\circ}$ 46, New York. p. 1005-1019. 
Wu, H.; Wang, H.; Zhao, Y.; Chen, T.; Lu, W. (2012) Evolution of unsaturated hydraulic properties of municipal solid waste with landfill depth and age. Waste Management, Vol. 32, p.463-470.

Yesiller, N; Hanson, J.L.; Cox, J.T.; Noce, D.E. (2014) Determination of specific gravity of municipal solid waste. Waste Management, Vol. 34. p. 848-858.

Yu, L.; Battle, F. (2011) A hybrid method for quasi-three-dimensional slope stability analysis in a municipal solid waste landfill. Waste Management, Vol. 31, p. 2484-2496.

Yu, L.; Battle, F.; Carrera, J. (2011) Variations of waste unit weight during mechanical and degradation processes at landfills. Waste Management \& Research. Vol. 29 (12), p. $1303-1315$

Yuan, P.; Kavazanjian, E.; Chen, W.; Seo, B. (2011) Compositional effects on the dynamic properties of municipal solid waste. Waste Management Vol. 31, p. 2380-2390.

Zalachoris, G. (2010) Field Measurements of Linear and Nonlinear Shear Moduli of Solid Municipal Waste using a Dynamically Loaded Surface Footing. Tese de doutorado. The University of Texas at Austin. 429p.

Zekkos, D.P. (2005) Evaluation of static and dynamic properties of municipal solid waste. Tese de doutorado. Department of civil and environmental engineering, University of California, Berkeley, California. 578p.

Zekkos, D.P.; Jonathan D. Bray, J.D.;Kavazanjian, E., Jr.; Matasovic, N.; Rathje, E.M.; Riemer, M.F.;Stokoe II, K.H. (2006) Unit Weight of Municipal Solid Waste. Journal of Geotechnical and Geoenvironmental Engineering, Vol. 132 (10), p. 1250-1261.

Zekkos, D., Bray, J. D., and Riemer, M. F. (2008) Shear modulus and material damping of municipal solid waste based on large-scale cyclic triaxial testing. Can. Geotech. J., Vol.45 (1), p.45-58.

Zekkos, D.; Athanasopoulos, G.A.; Bray, J.D.; Grizi, A.; Theodoratos, A. (2010a) Large-scale direct shear testing of municipal solid waste. Waste Management, Vol. 30, p.15441555 .

Zekkos, D., Kavazanjian Jr., E., Bray, J.D., Matasovic, N., Reimer, M.R. (2010b) Physical characterization of municipal solid waste for geotechnical purposes. Journal of Geotechnical and Geoenvironmental Engineering. Vol. 136, p.1231-1241.

Zekkos, D.; Matasovic, N.; El-Sherbiny, R.; Athanasopoulos-Zekkos, A.; Towhata, I.; Maugeri, M. (2011) Dynamic Properties of Municipal Solid Waste. In: Zekkos, D. 
(ed.) Geotechnical Characterization, Field Measurement, and Laboratory Testing of Municipal Solid Waste. ASCE Geotechnical Special Publication 209. p.112-134.

Zekkos, D.; Bray, J.D.; Riemer, M.F. (2012) Drained response of municipal solid waste in large-scale triaxial shear testing. Waste Management Vol.32. p. 1873-1885.

Zekkos, D.; Sahadewa, A.; Woods, R.D.; Stokoe II, K.H. (2014) Development of Model for Shear-Wave Velocity of Municipal Solid Waste. Journal of Geotechnical and Geoenvironmental Engineering. Vol. 140, p. DOI:10.1061/(ASCE)GT.19435606.0001017.

Zhan, T.L.T., Chen, Y.M.; Ling, W.A. (2008) Shear strength characterization of municipal solid waste at the Suzhou landfill, China. Engineering Geology, Vol. 97, Issues 3-4, p.97-111.

Ziehmann, G. (1999) Bilinear model for stability calculation of domestic waste landfills. In: Yagi, Yamagami \& Jiang. (eds) Slope stability engineering. Balkema. Rotterdam, ISBN 9058090795. p. 853-858.

Zornberg, J. G., Jernigan, B. L., Sanglerat, T. R., Cooley, B. H. (1999), Retention of free liquids in landfills undergoing vertical expansion. Journal of Geotechnical and Geoenvironmental Engineering, Vol. 125 (7). p. 583-594. 
APÊNDICE A - PERFIS INDIVIDUAIS DAS SONDAGENS 


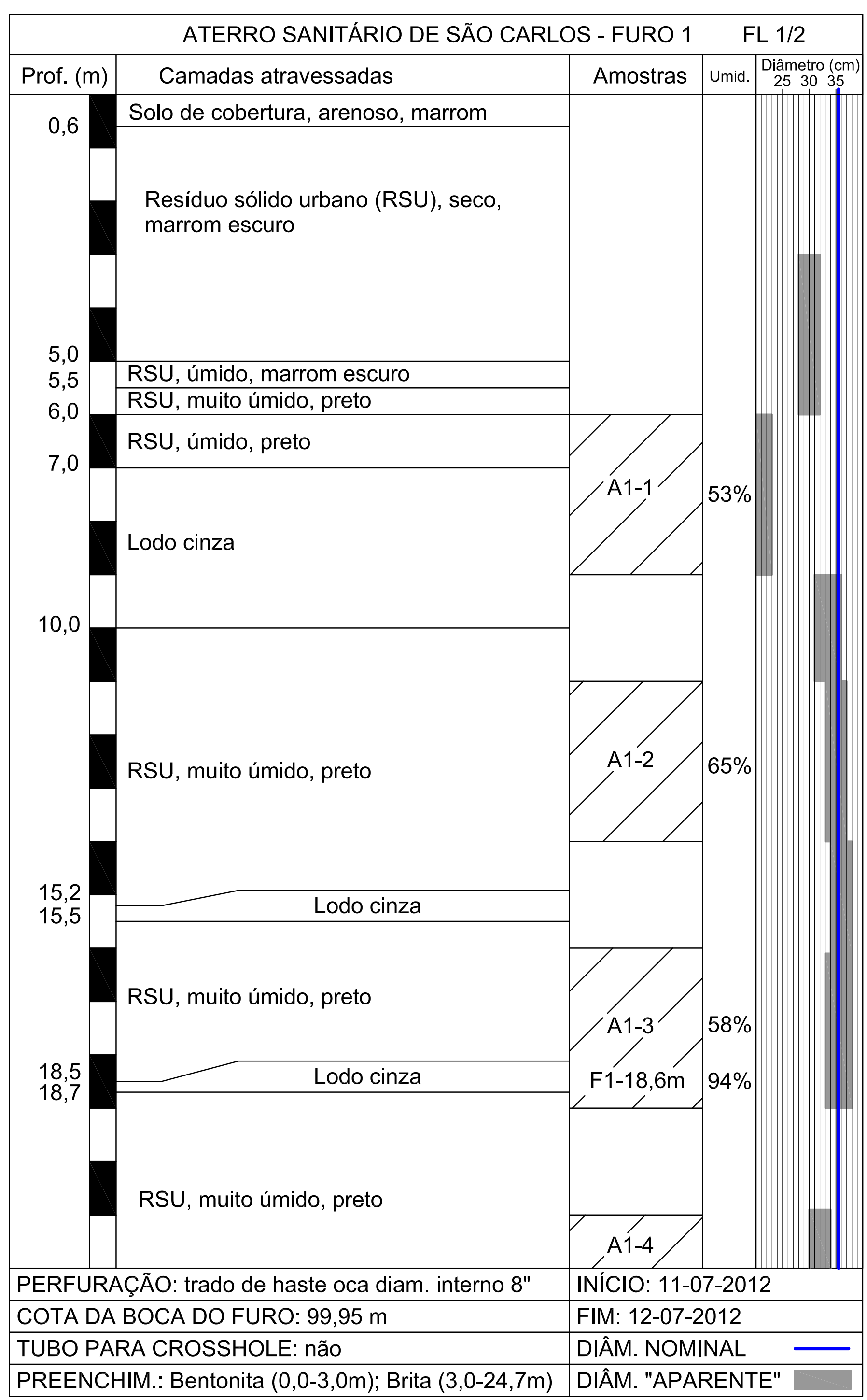




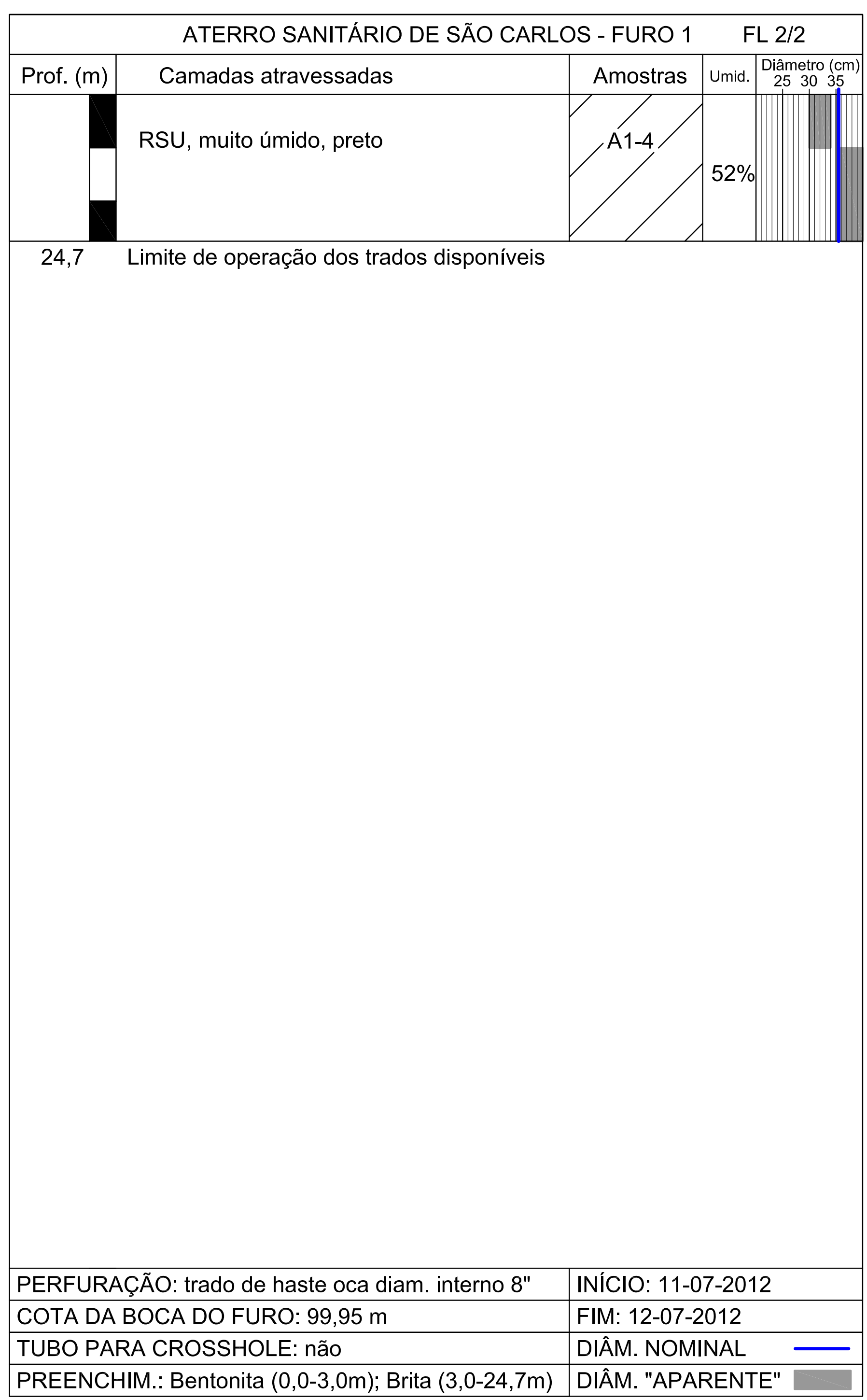




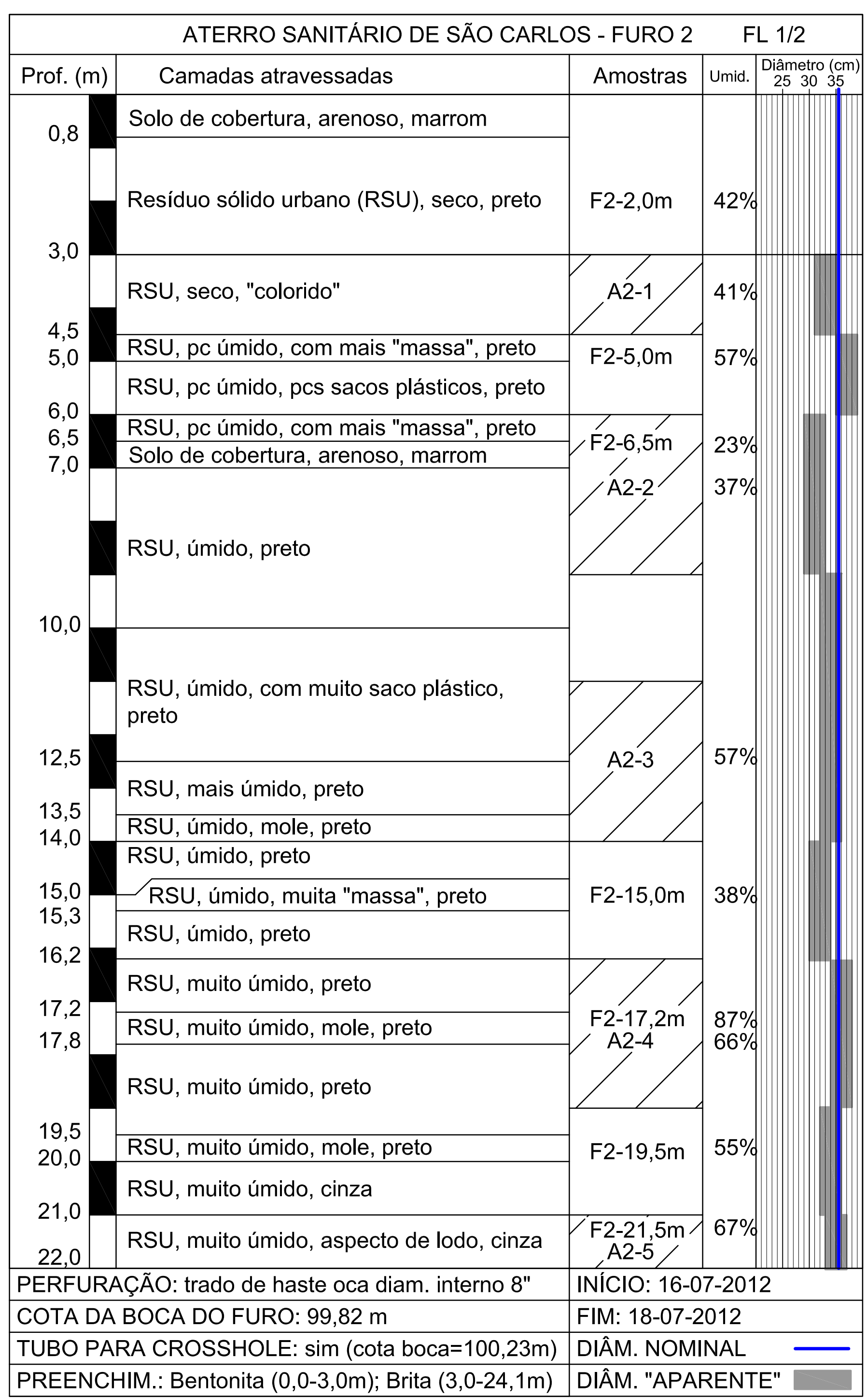




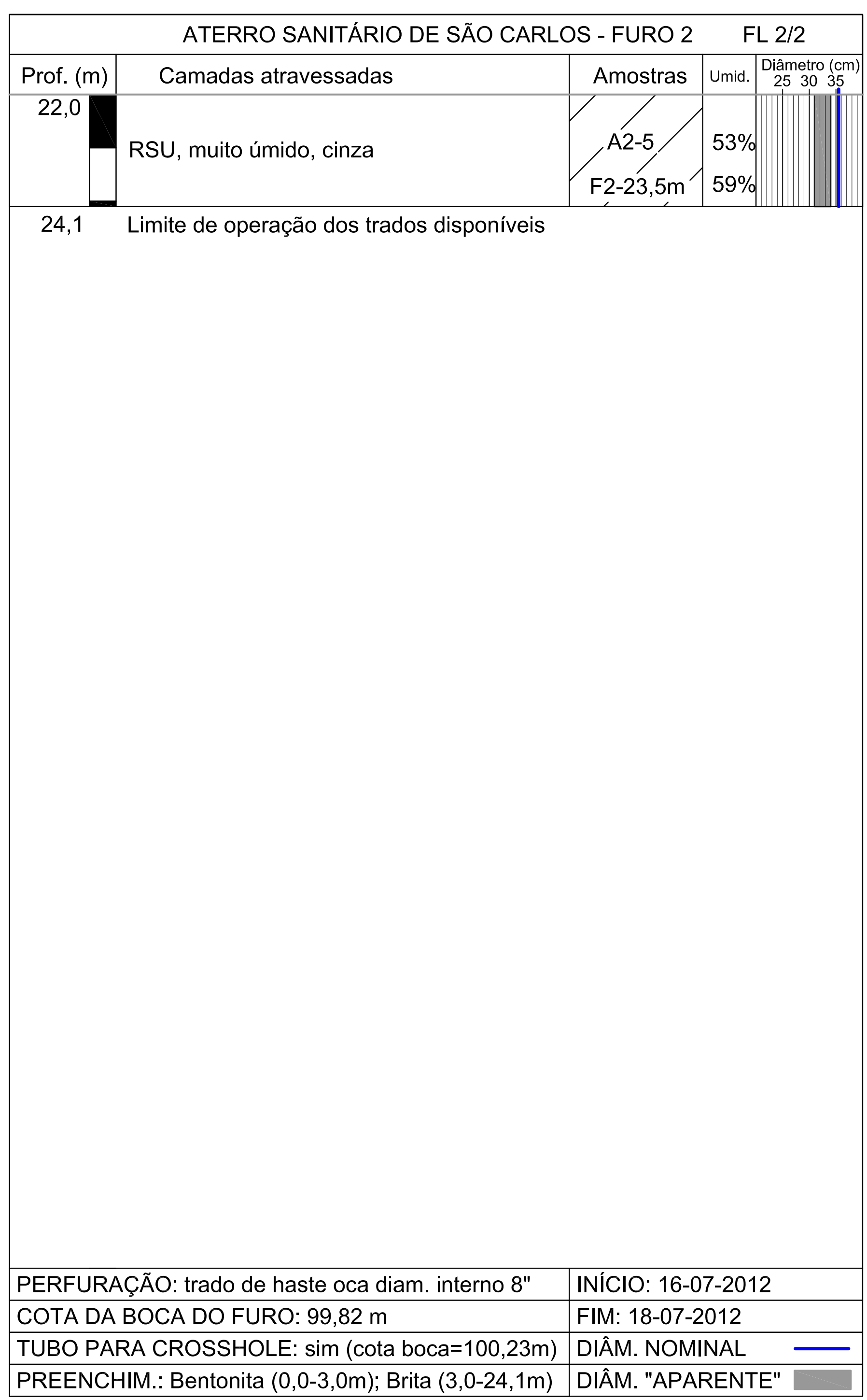




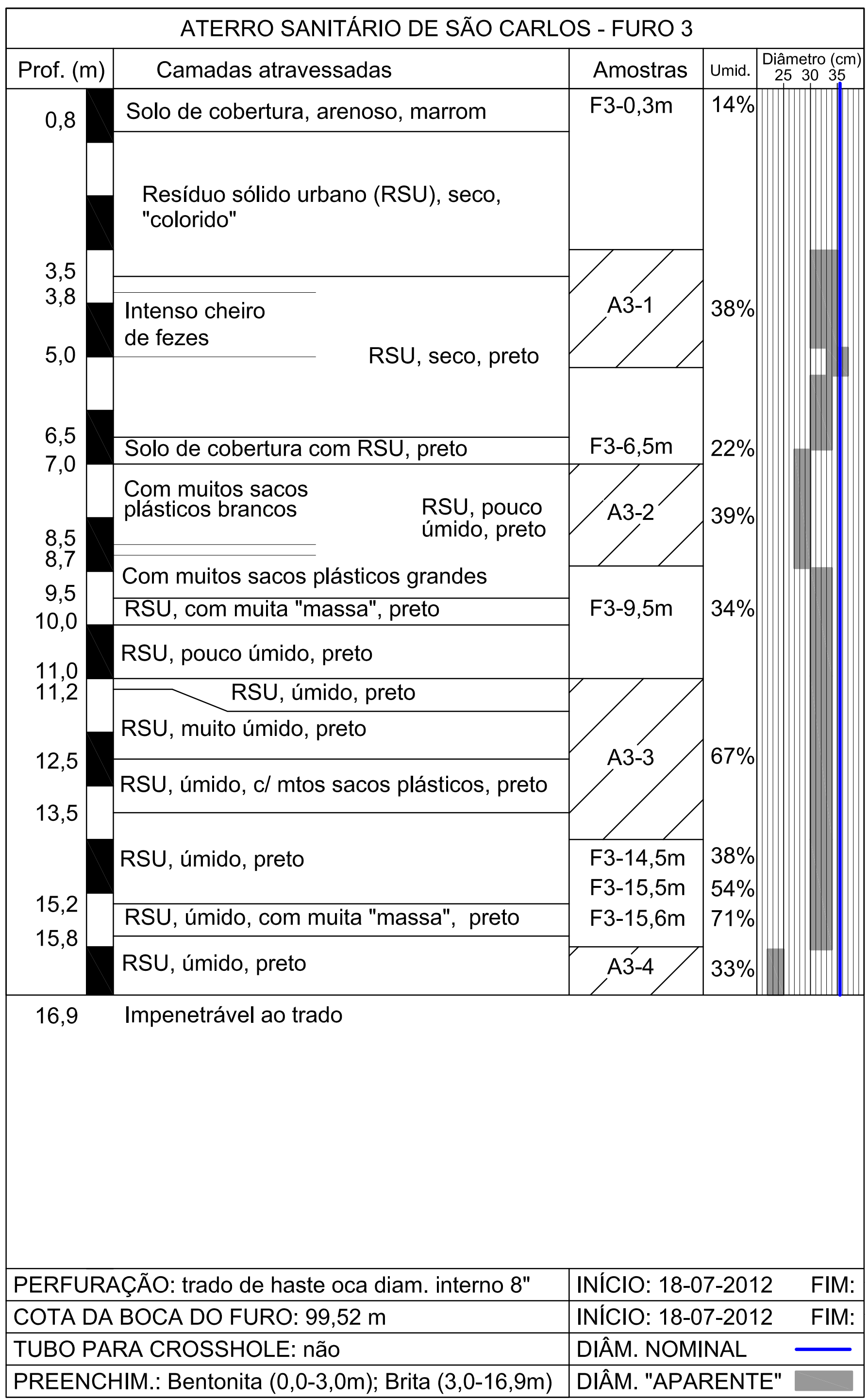




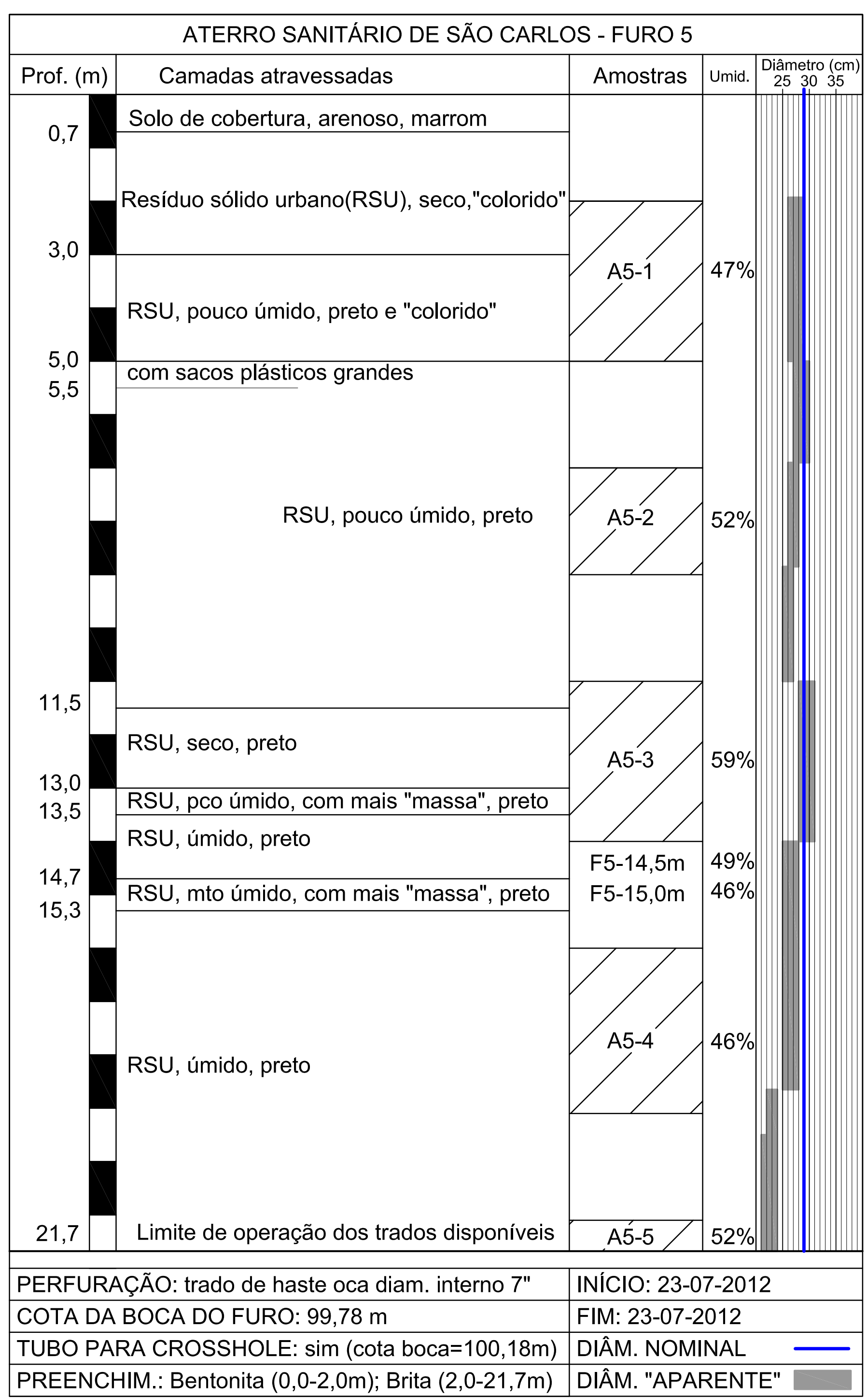




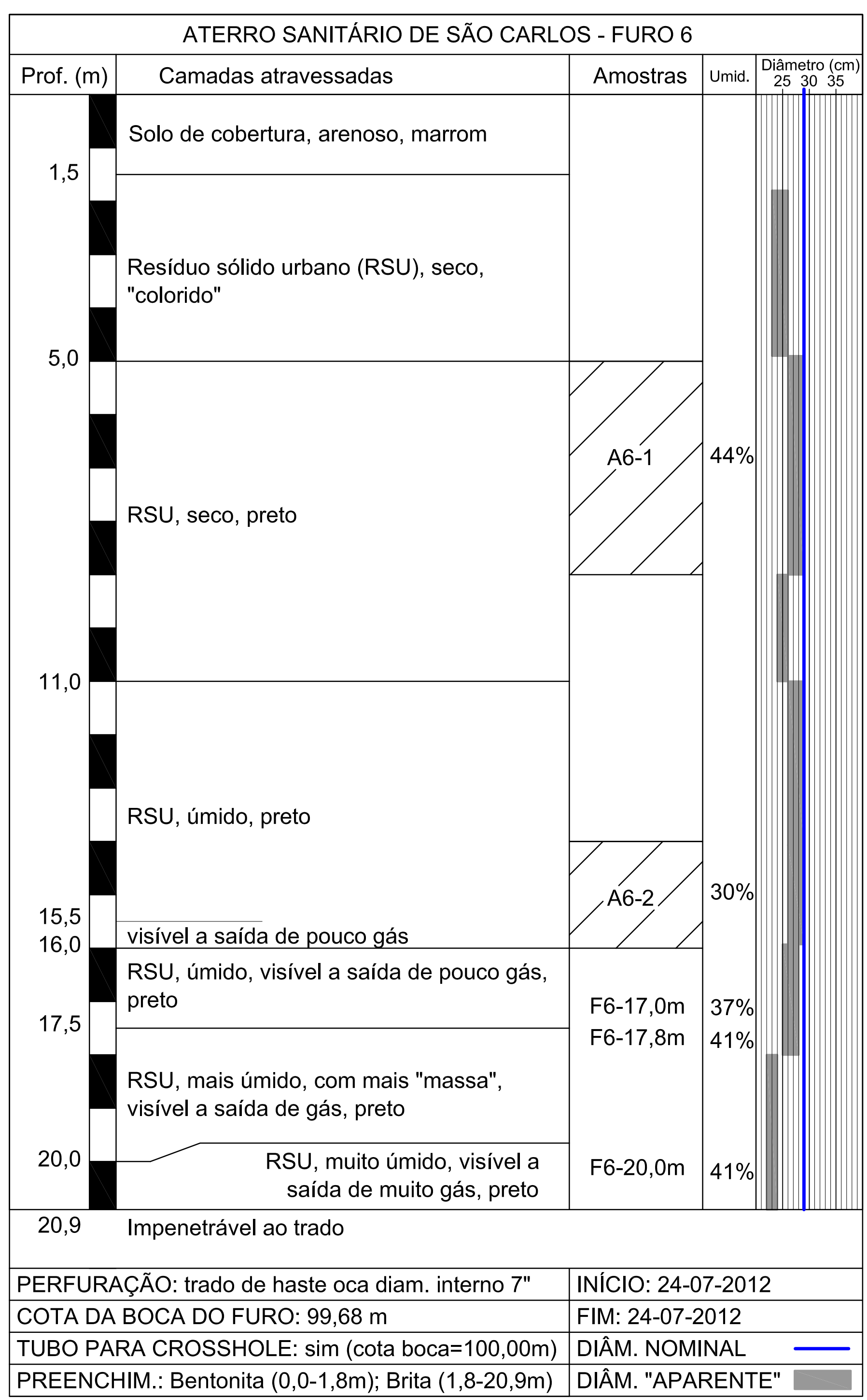


APÊNDICE B - ENSAIOS MASW - RESULTADOS INTERMEDIÁRIOS 


\section{LINHA L-1 (MASW)}

Distance $(m)$

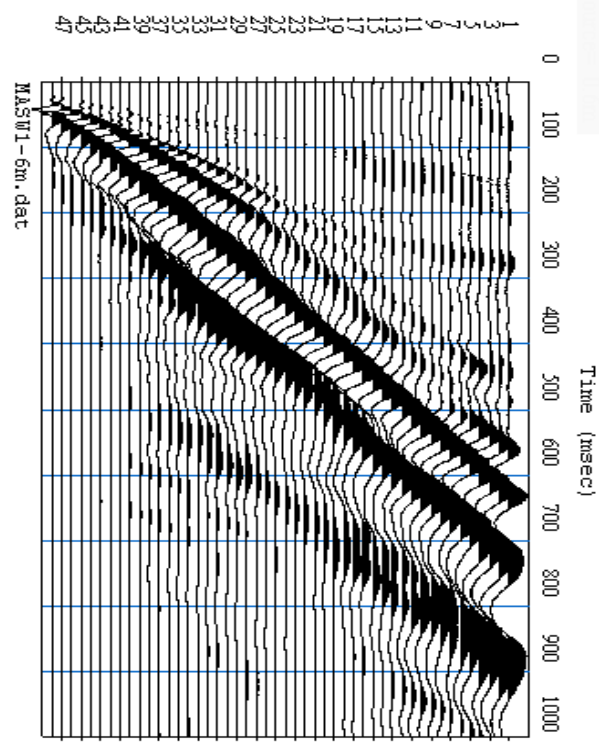

(a)

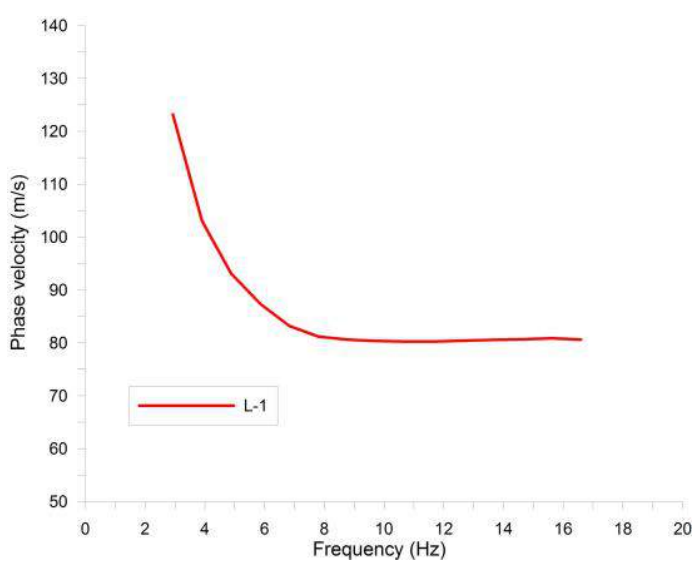

(c)

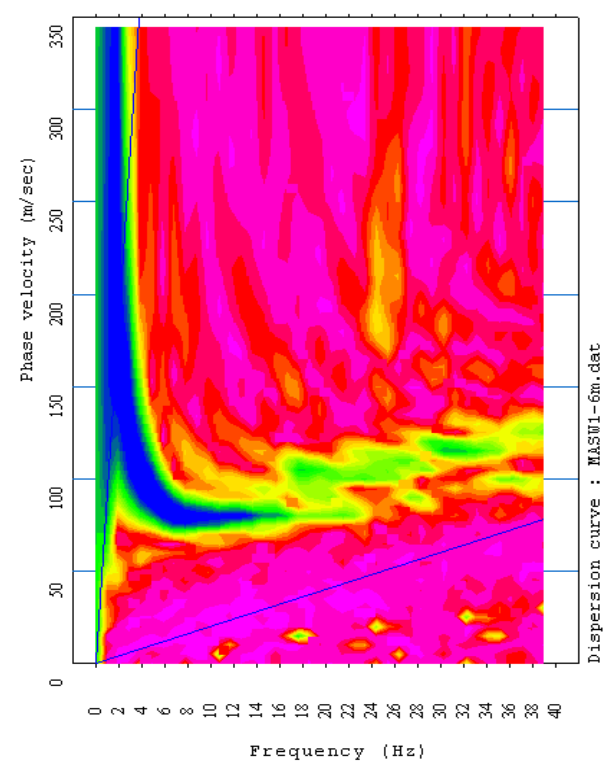

(b)

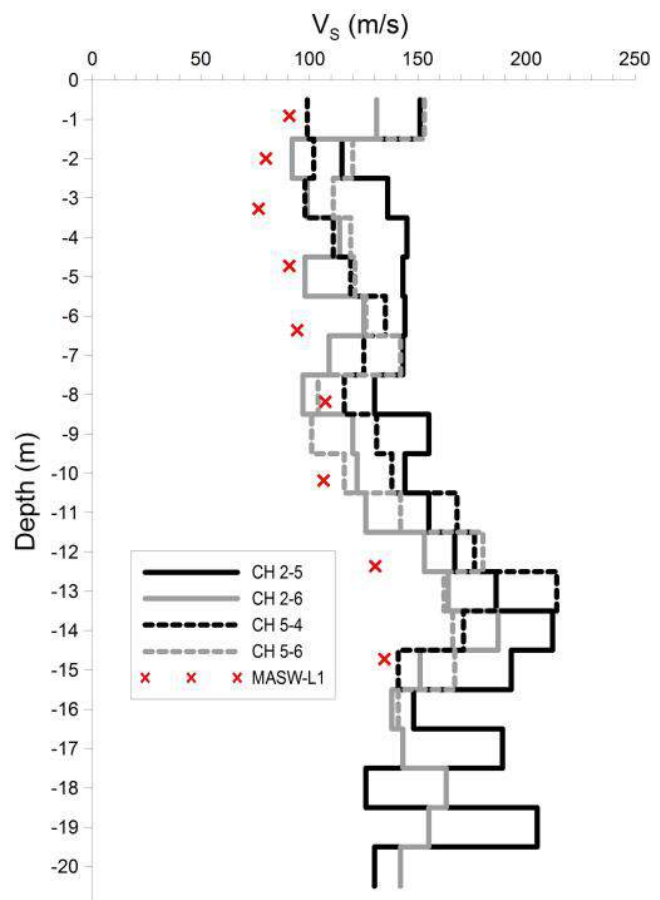

(d)

(a) Sismograma de L-1 com offset igual a $6 \mathrm{~m}$. (b) Imagem de dispersão obtida deste sismograma. (c) Curva de dispersão interpretada (média das curvas de dispersão obtidas com offsets $4 \mathrm{~m}, 6 \mathrm{~m}, 8 \mathrm{~m}, 10 \mathrm{~m}$ e $12 \mathrm{~m}$ ). (d) Modelo de $V_{S} \mathrm{X}$ profundidade de L-1 (MASW) comparado com os resultados do ensaio crosshole $(\mathrm{CH})$. 


\section{LINHA L-2 (MASW)}

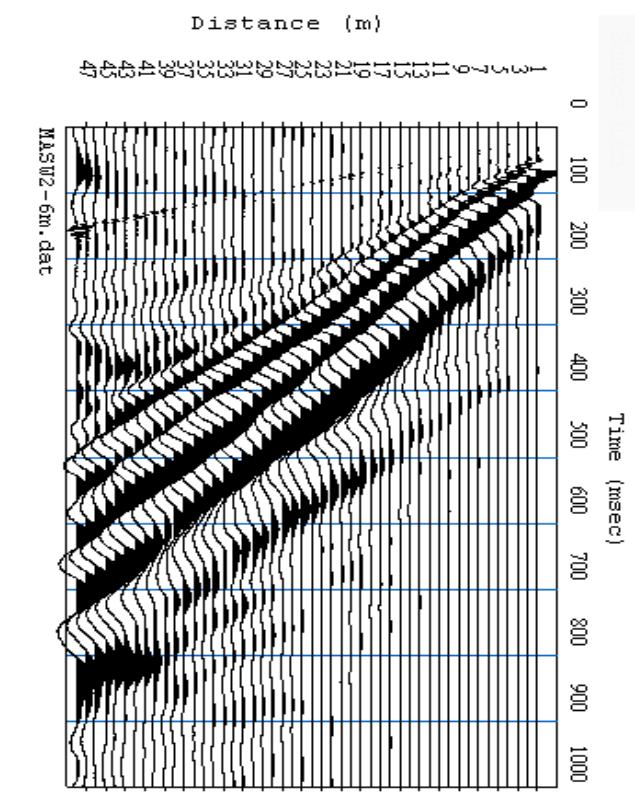

(a)

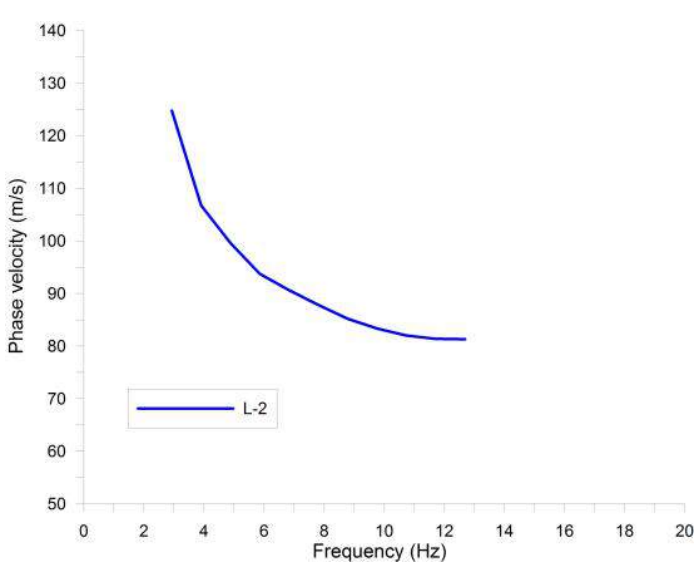

(c)

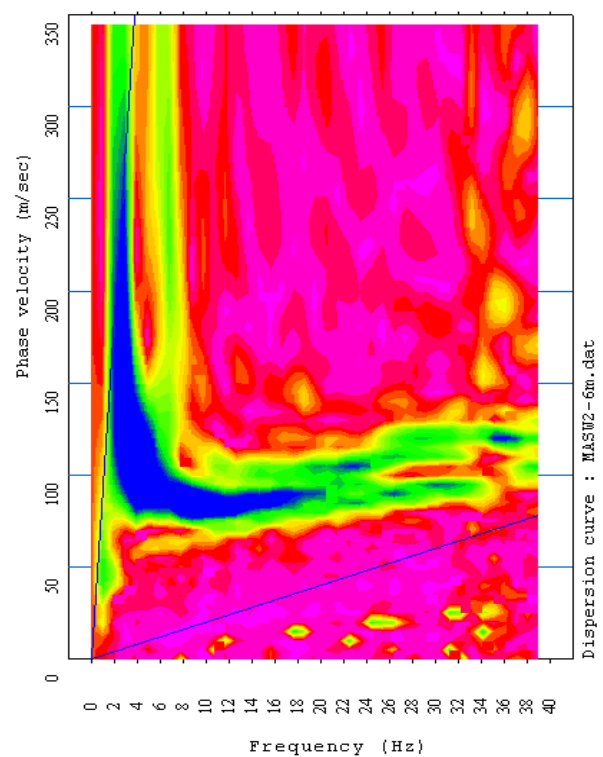

(b)

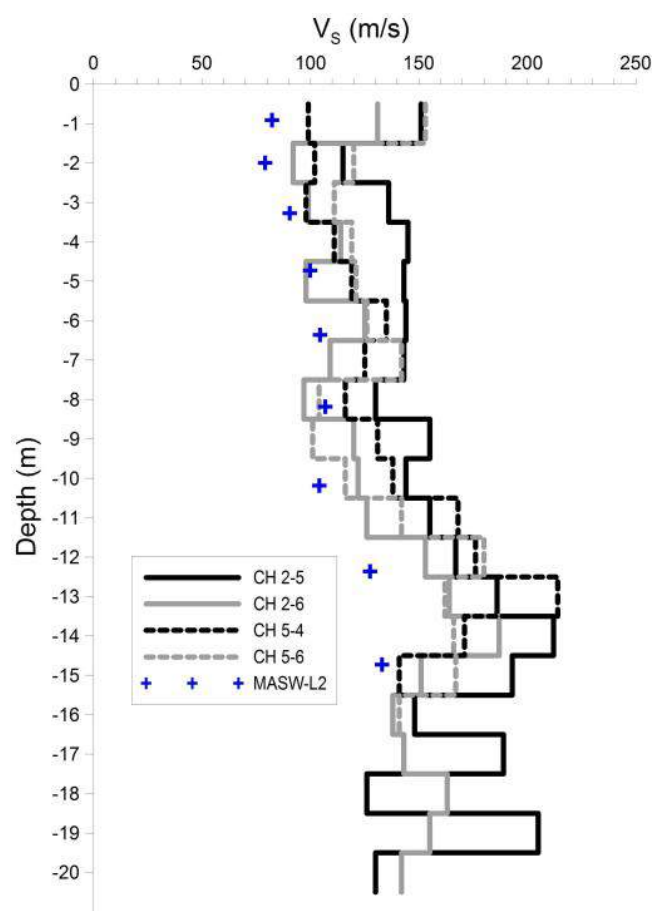

(d)

(a) Sismograma de L-2 com offset igual a $6 \mathrm{~m}$. (b) Imagem de dispersão obtida deste sismograma. (c) Curva de dispersão interpretada (média das curvas de dispersão obtidas com offsets $4 \mathrm{~m}, 6 \mathrm{~m}, 8 \mathrm{~m}, 10 \mathrm{~m}$ e $12 \mathrm{~m}$ ). (d) Modelo de $V_{S} \mathrm{X}$ profundidade de L-2 (MASW) comparado com os resultados do ensaio crosshole $(\mathrm{CH})$. 


\section{LINHA L-3 (MASW)}

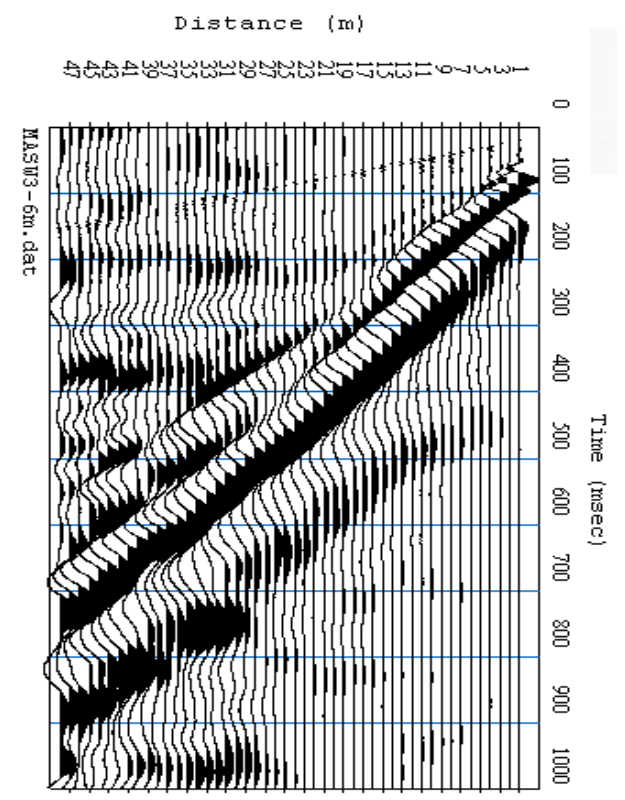

(a)

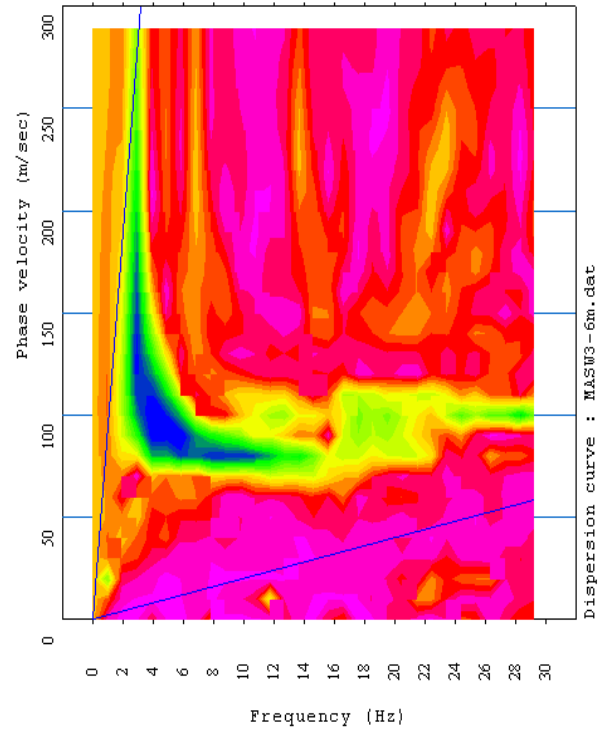

(b)

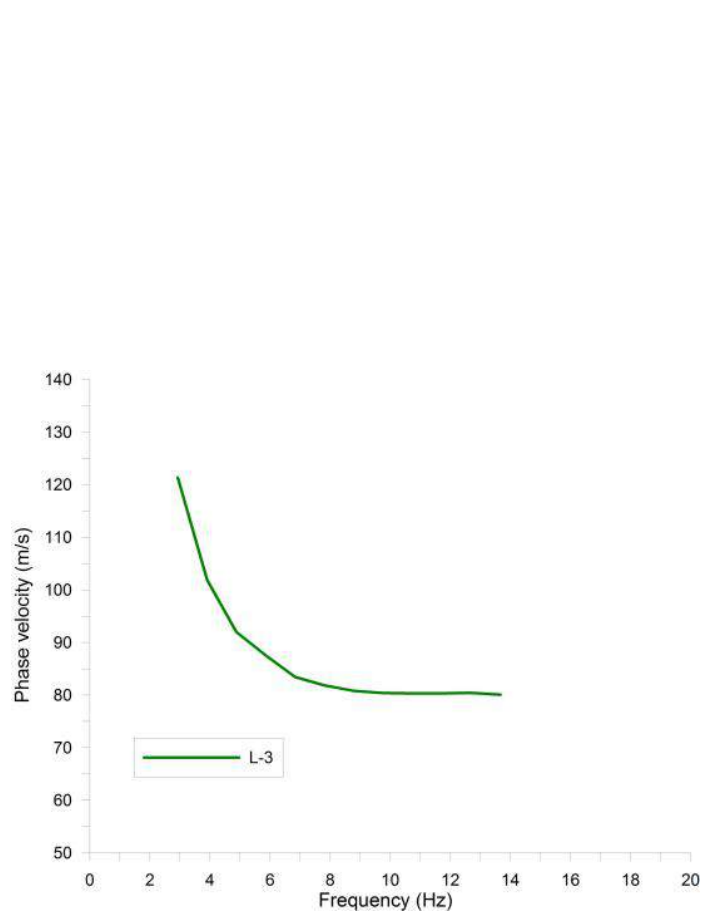

(c)

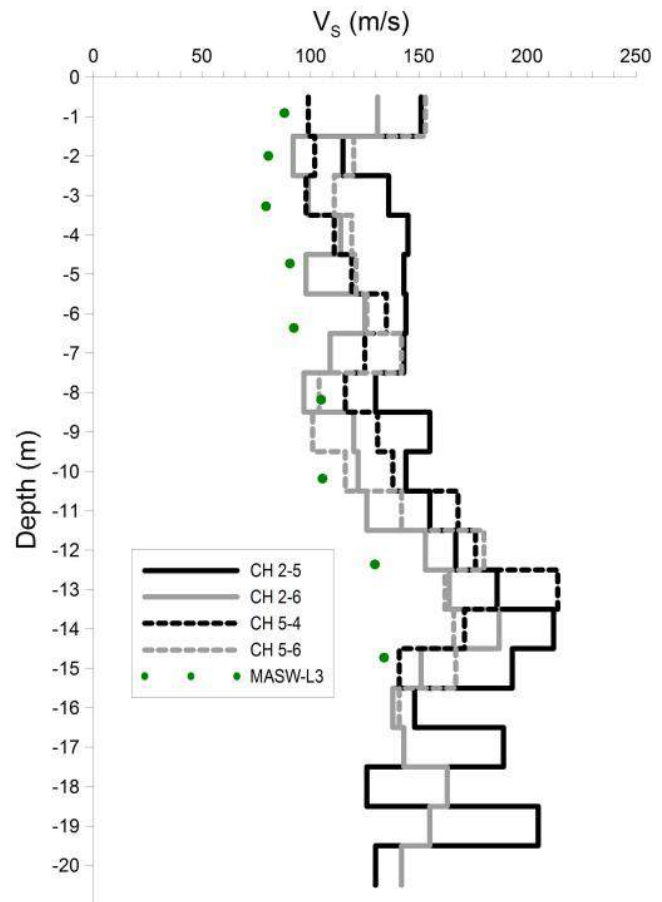

(d)

(a) Sismograma de L-3 com offset igual a $6 \mathrm{~m}$. (b) Imagem de dispersão obtida deste sismograma. (c) Curva de dispersão interpretada (média das curvas de dispersão obtidas com offsets $2 \mathrm{~m}, 4 \mathrm{~m}, 6 \mathrm{~m}, 8 \mathrm{~m}, 10 \mathrm{~m}$ e $12 \mathrm{~m}$ ). (d) Modelo de $V_{S}$ $x$ profundidade de L-3 (MASW) comparado com os resultados do ensaio crosshole $(\mathrm{CH})$. 